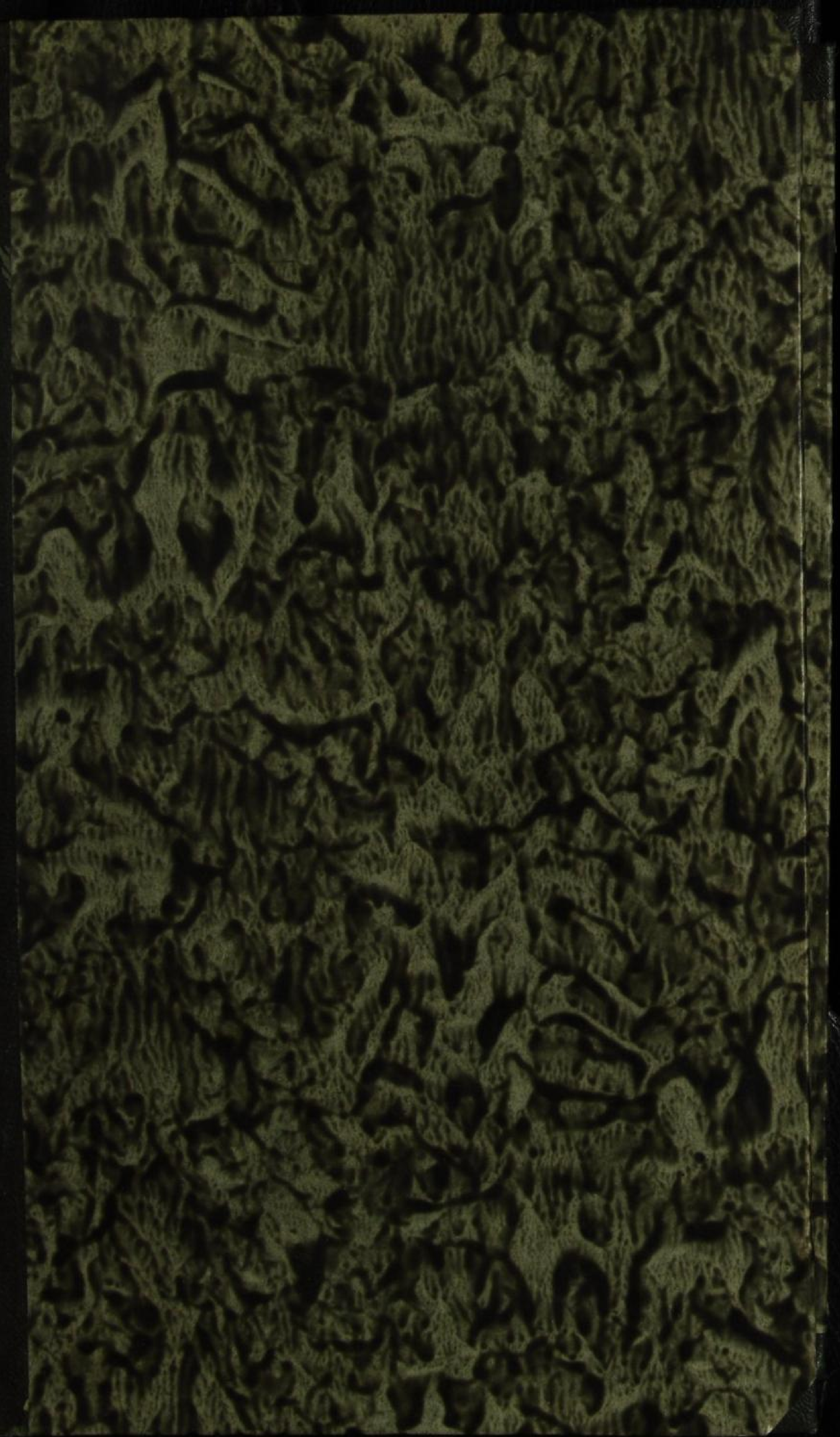




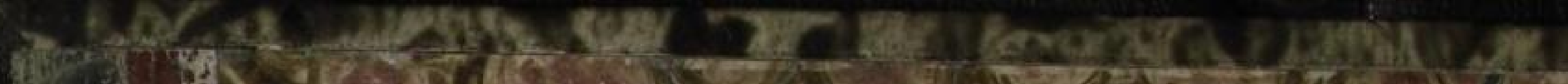

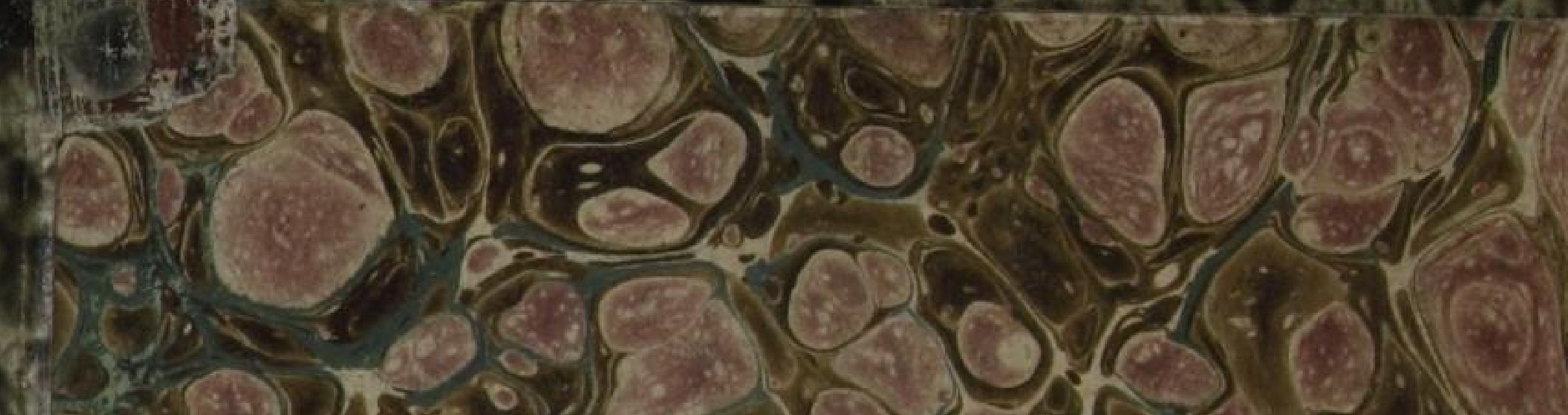

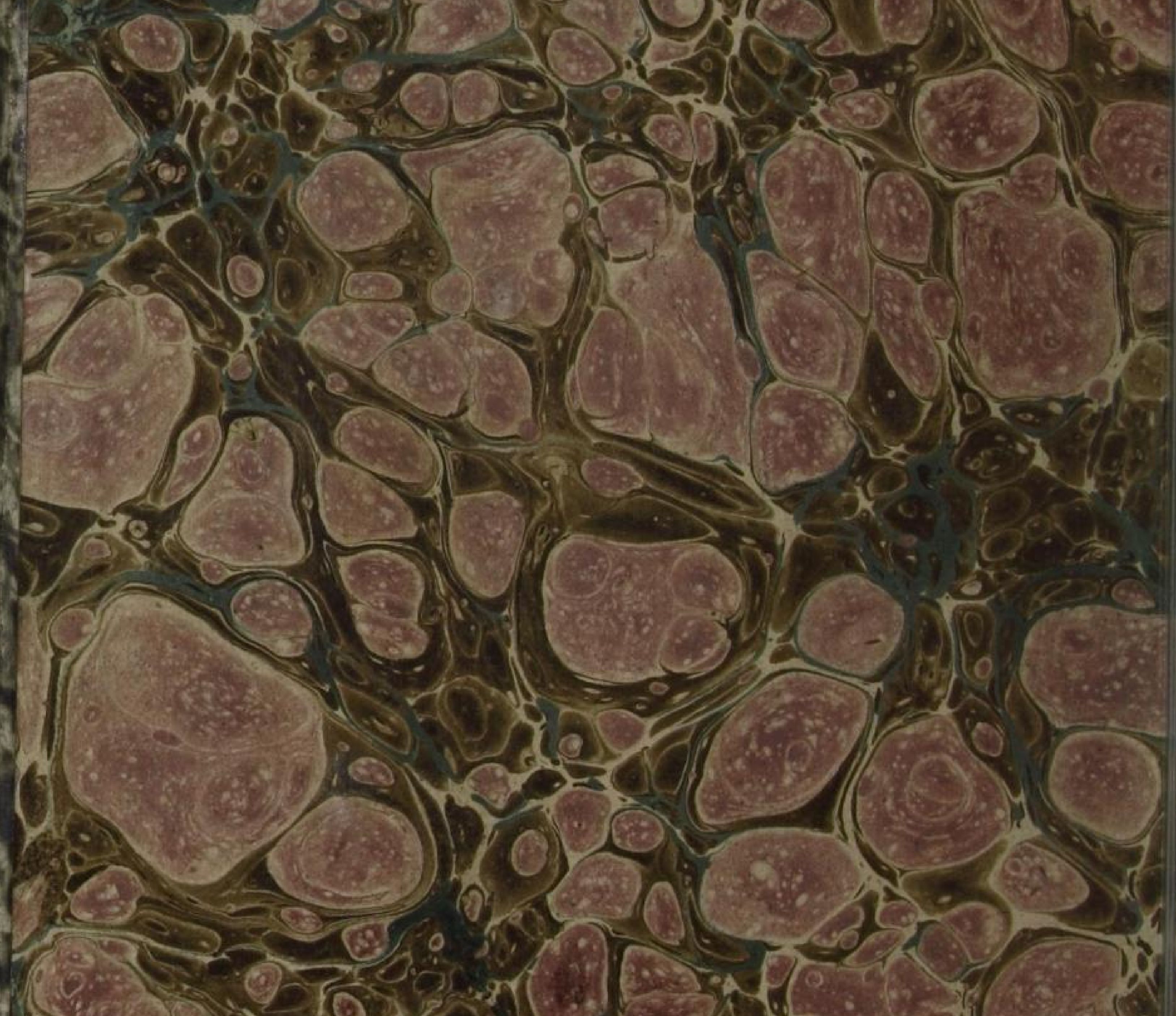

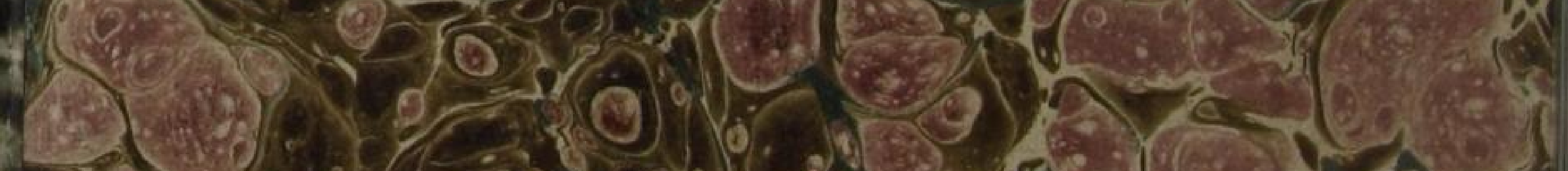
20.) $3(0.2)$ H.

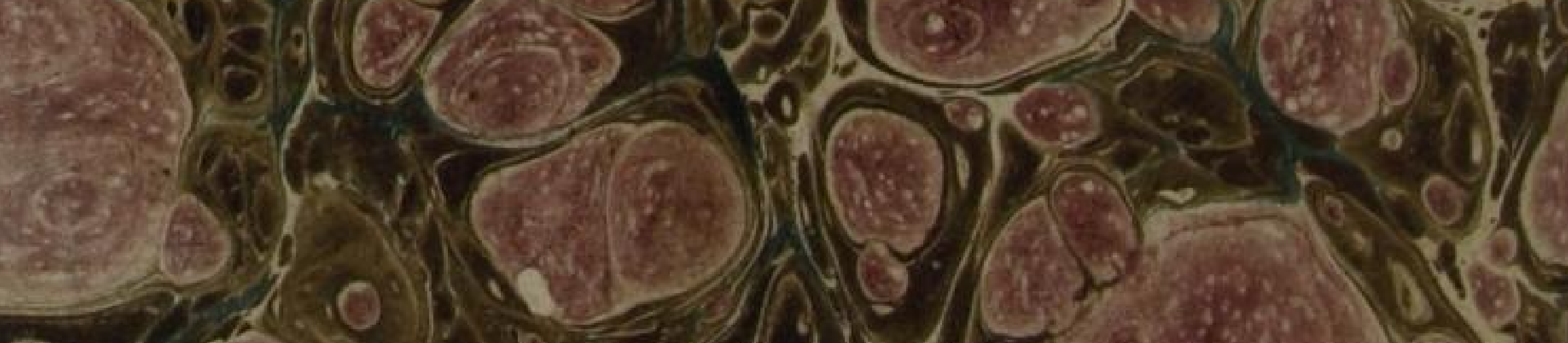

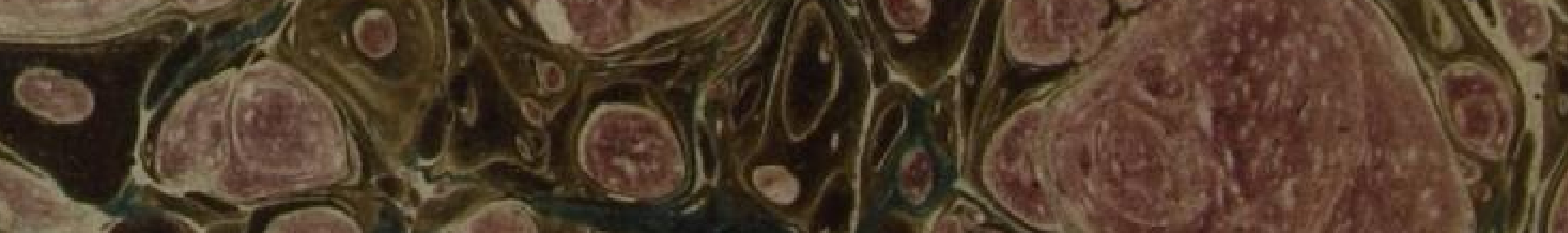

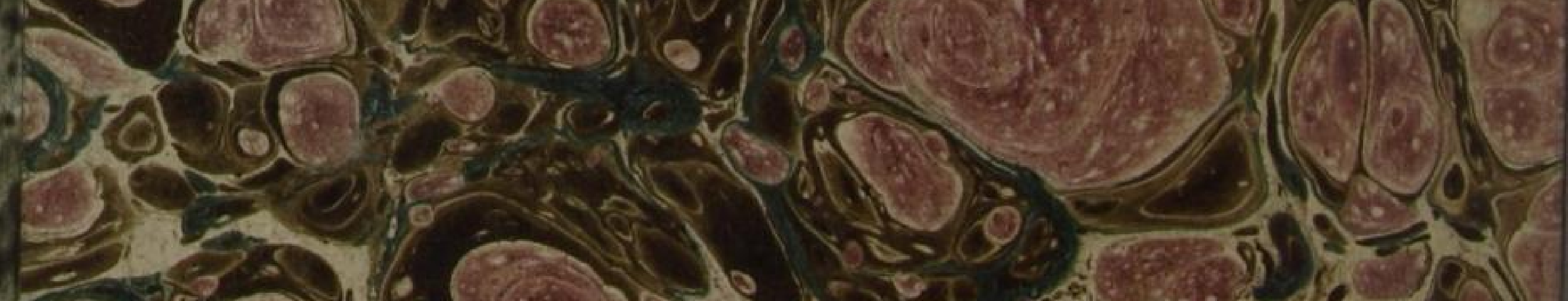

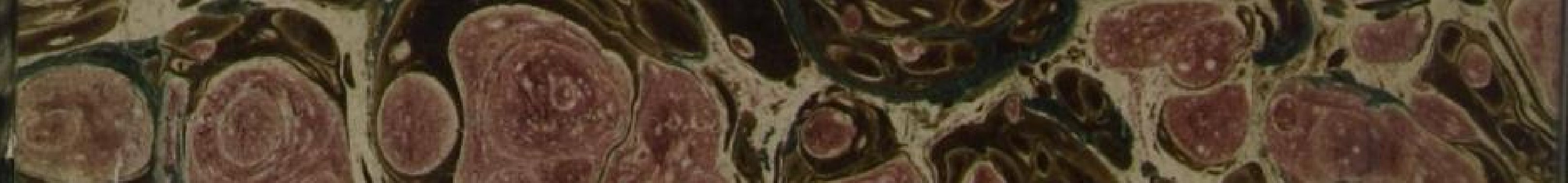

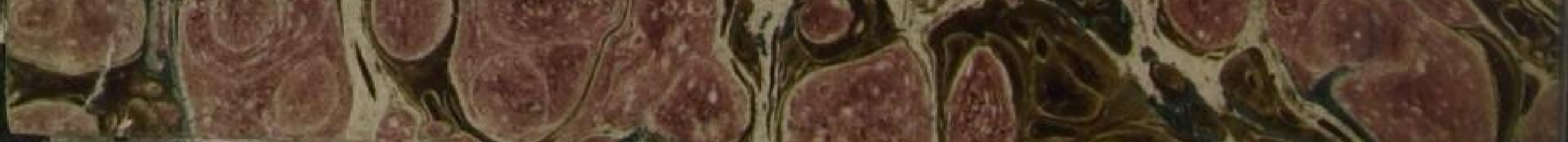
9. 

$2 \times-20 \%$ : - 50063

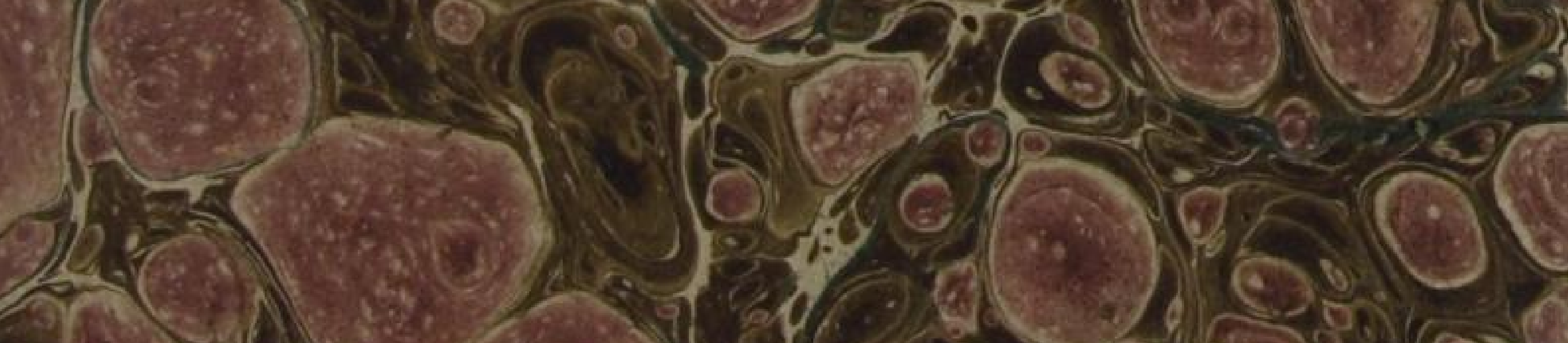

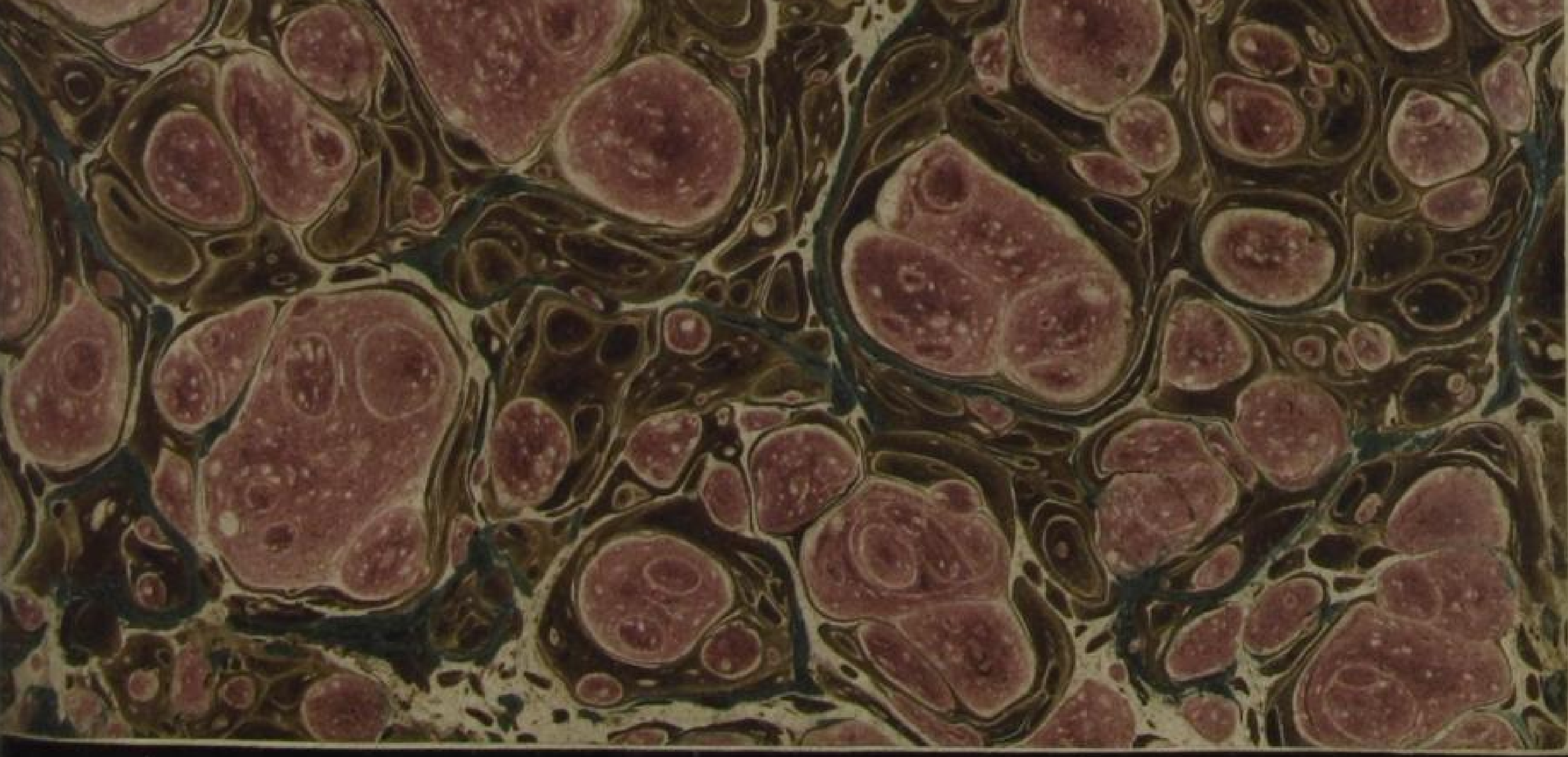




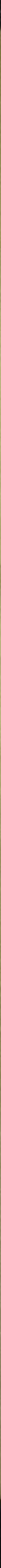




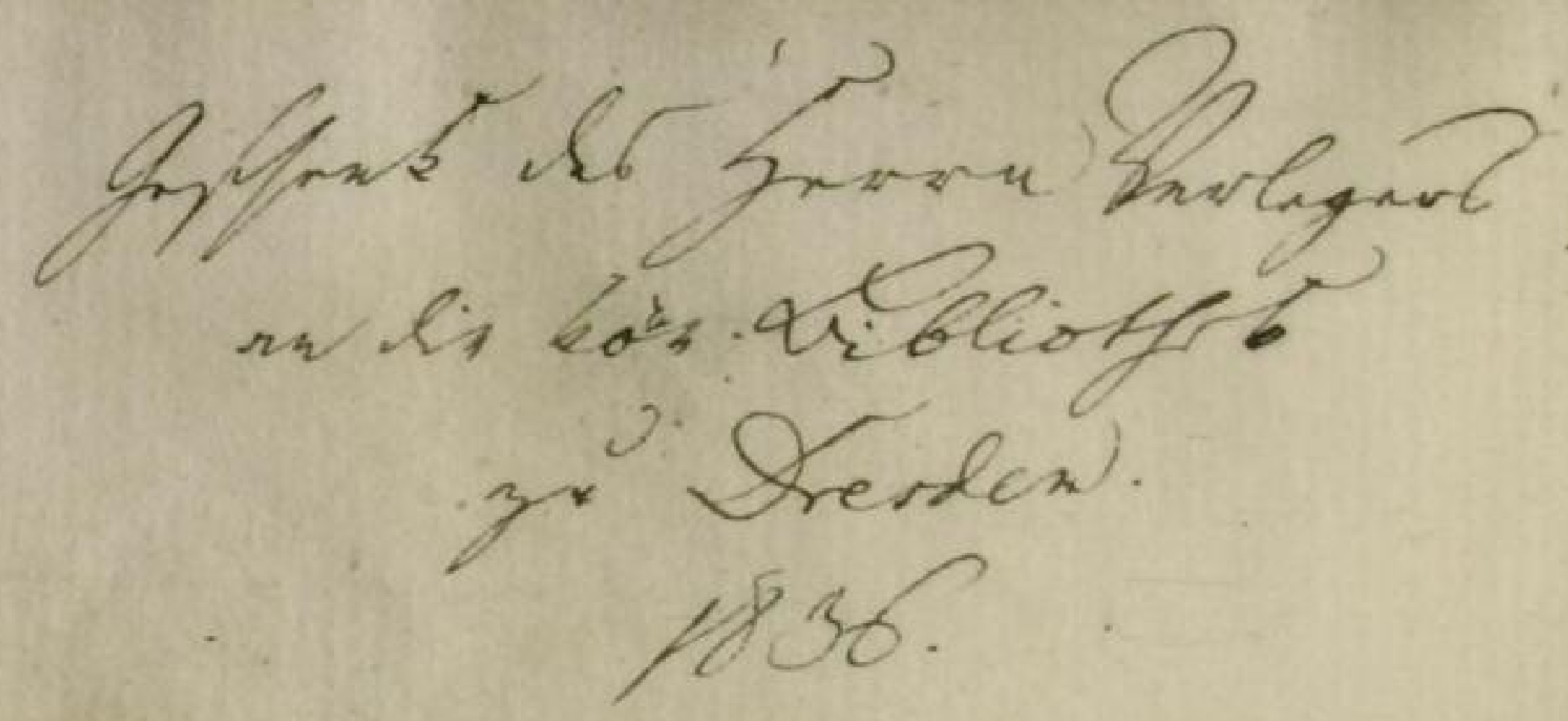




\section{D e $\mathbf{r}$ \\ P r o c e s s \\ d e $\mathbf{r}$ \\ galvanischen Kette}

vo $\mathbf{n}$

Georg Friedrich Pohl.

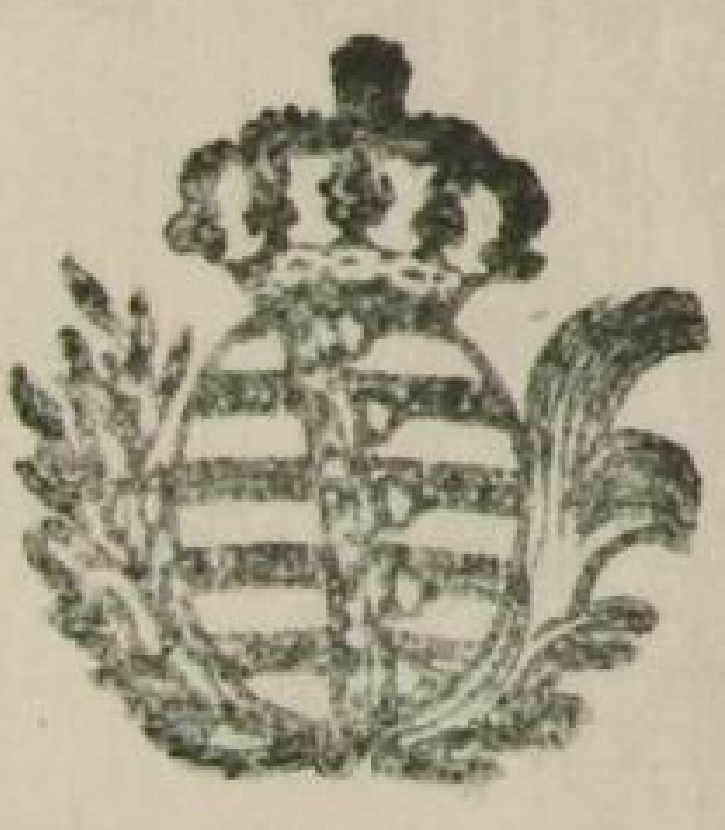

\section{L e i pzig, 1826}

Verlagvon Johann Ambrosius Barth.

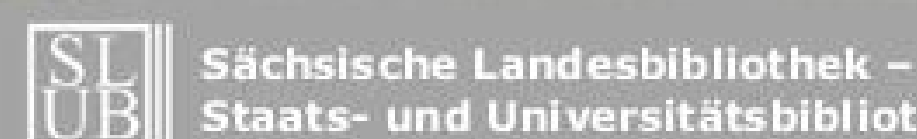




\section{Sachsische}

Landesbibliothek Dresden 


\title{
ALEXANDER VON HUMBOLDT
}

\author{
d e m S t o l z e \\ deutscher Naturforscher
}

gew id met

v o $\mathbf{m}$

$V$ e $r$ f a s s e r. 


\title{
TEIOUHUH nov MHOVAXAIA
}

\author{
$9 \times 10+2$ in o b
}

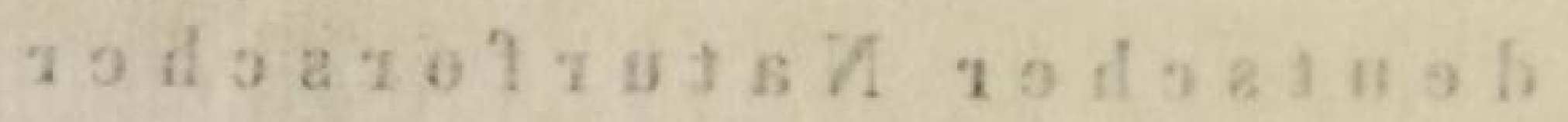

$39 m b i v \circ g$

in $11 ;$

$\begin{array}{lllllllll}-3 & 9 & 8 & 4 & 5 & 7 & 7 & 9 & 7 .\end{array}$ 


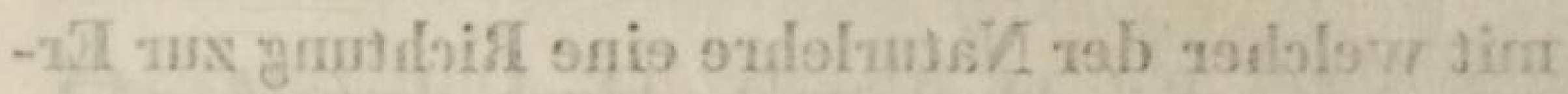

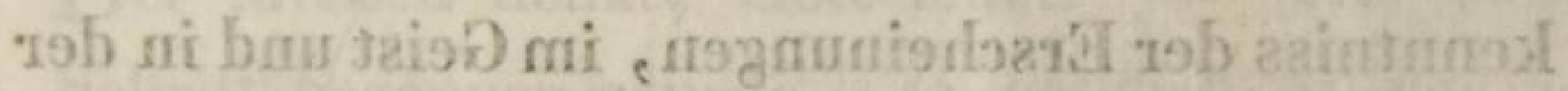

-Wenn es gewiss ist, dass Selbstgefühl und Anspruchfosigkeit beide, falls sie rechter Art sind, aus einer und derselben Quelle, der Selbstkenntniss, hervorgehen, so glaube ich mich nicht scheuen zu dürfen, Ihren grossem und gefeierten Namen dieser Schrift voranzusetzen. Das Bewusstsein, welches mich in den Lichtkreis Ihrer ${ }_{0}$ Nähe treten heisst, indem ich vor den Augen der Welt diese Blätter in I h re Hände lege, würde kein lauteres sein, wenn es nicht zugleich mit der Keberzeugung in mir vereinigt wäre, dass ich nach meinen Bestrebungen und nach dem, was ich Ihnen darbringe, dieses Lichtes nicht unwürdig sei.

Die Thatsachen und Ansichten, welche in dieser Schrift ausgesprochen sind, verdienen es, 
von allen Physikern unserer Zeit beachtet und gewürdigt zu werden und sie werden unfehlbar, falls die Wissenschaft ungestört fortdauert, jetzt oder in Zukunft eine solche Anerkennung finden, mit welcher der Naturlehre eine Richtung zur Erkenntniss der Erscheinungen, im Geist und in der Wahrheit, gesichert sein wird, die ihr gegenwärtig, besonders ausserhalb unsers deutschen Vaterlandes, noch vielfältig mangelt.

Nehmen Sie daher wohlwollend auf, was meine Verehrung I h n e n weiht; die Hand, welche die in anspruchloser Selbstwürdigung dargebotene Pflanze nicht verschmäht, ${ }^{\text {I }}$ kann eben dadurch das segensvolle Werkzeug für die Erhaltung und Verbreitung der Frucht werden, welche in ider jungen, ausserdem vielleicht noch lange verkannten, Blüthe dem Wohl der Wissenschaft entgegen zu reifen trachtet. 


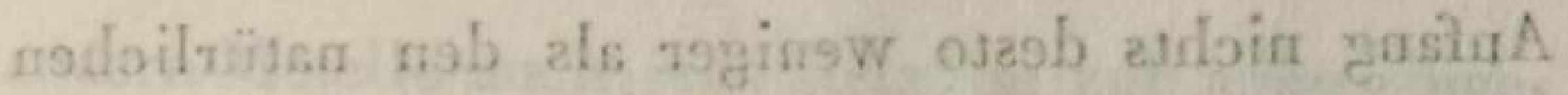
-3ro'

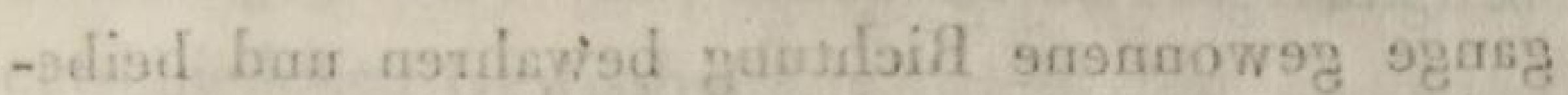

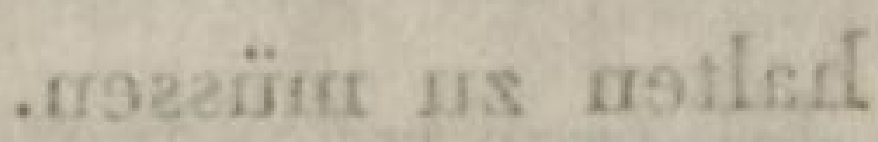

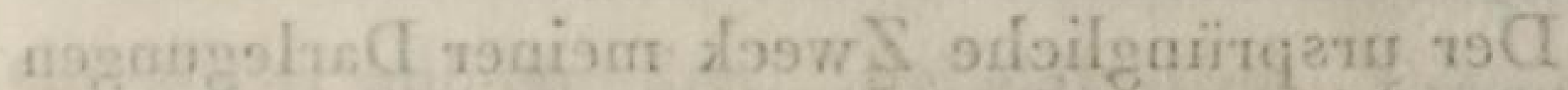

\section{$\mathrm{VORWOR}$ T}

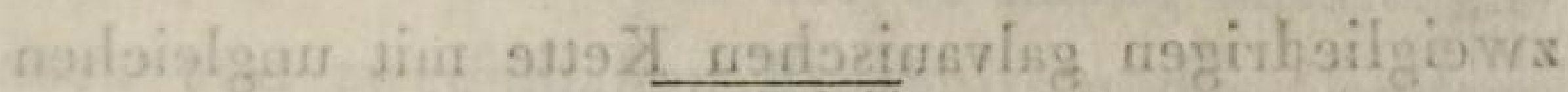

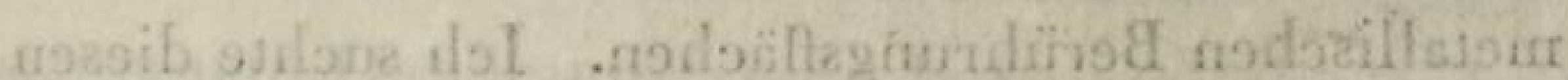

Der Mensch denkt, Gott lenkt. - ${ }^{2}$ Als diese Schrift begonnen wurde, so geschah es nur in der Absicht, ein Princip darzulegen, nach weléhem, aus der Abweichungsrichtung der Magnetnadel durch die elektromagnetiséhe Kette, dié elektrische Relation der Glieder derselben auf eine reelle und klar begrundete Weise zu bestimmen wäre, um die Wissenschaft vor den Irrthümern zu bewahren, denen sie ausgesetzt ist, wenn man in diesem Punkte, so wie es insbesondere bei den Untersuchungen eines ausländischen Pliysikers geschehen ist, nur von leeren Analogieen und blossen Scheiinconsequenzen geleitet wird. - Diese Absicht ist erreicht worden; aber mit ihr noch ungleich mehr, doch so, dass die ersten Bogen des Buches den obigen Ursprung noch deutlich zu erkennen geben. Denn als sich mir während der Arbeit Bedeutung und Umfang derselben unter den Händen, wie von selbst, erweiterten, glaubte ich den 
Anfang nichts desto weniger als den natürlichen und organischen Ausgangspunkt für die im Fortgange gewonnene Richtung bewahren und beibehalten zu müssen.

Der ursprüngliche $Z_{\text {weck }}$ meiner Darlegungen leitete mich, in dem Streben nach möglichst elementarischer Begründung, auf die Betrachtung der zweigliedrigen galvanischen Kette mit ungleichen metallischen Berührungsflächen. Ich suchte diesen Gegenstand um so schärfer ins Auge zu fassen, da seine eigentliche Natur und sein Verhältniss zu den herrschend gewordenen Vorstellungen über den Process der galvanischen dreigliedrigen Kette so lange immer noch etwas völlig Räthselhaftes geblieben waren. Ich faud sehr bald, dass hier von einer Contactelektricität der metallischen Armaturen, wie man sie bis dahin als die eigentliche Triebfeder der Thätigkeit der Kette betrachtet hatte, gar nicht die Riede sein könne; ich sah mich genöthigt, zu schliessen, dass diese Triebfeder nichts anderes, als nur die in der Contactelektricität der Flüssigkeit und des Metalls angedeutete Thätigkeit sein könne und die Erfahrung, welche ich machte, dass die Abweichungsrichtung der Magnetnadel in der geschlossenen zweigliedrigen Kette dieselbe blieb, so lange die elektrische Relation der Flüssigkeit zum Metalle sich nicht änderte und dass sie in die entgegengesetzte überging, sobald mit einem 
andern Metalle auch jene Relation zur entgegengesetzten geworden war, erhob meine Folgerung zur entschiedenen Gewissheit.

Mit dieser Combination war umgekehrt zugleich ein Mittel aufgefunden, die elektrische Erregung zwischen der Flüssigkeit und dem Metalle, deren Kenntniss bis dahin nur den so häufig unzulänglichen und zweifelhaften Ergebnissen des Condensators und Duplicators verdankt wurde, theils dev Art, theils auch der Quautität nach, unzweideutiger versichtbaren und an der magnetischen Boussole ablesen zu können.

Einer Classe vou Physikern, die ihr Augenmerk mehr auf praktische und experimentale Einzelnheiten als auf umfassende speculative Interessen richtet, wird diese Seite meiner Untersuchungen vielleicht beachtungswerther als manche der übrigen sein. Mir war sie es micht. Ich hielt dasjenige, was die zweigliedrige Kette unter dem Charakter unumstösslicher Gewissheit mir anvertraut hatte, vergleichend an die Erscheinungen der dreigliedrigen, und die zur reinsten Evidenz gesteigerte Ueberzeugung, dass auch in der dreigliedrigen Kette die Relation zwischen Flüssigkeit und Metall allein die eigentliche Seele der Thätigkeit sei, während die Contactelektricität der differenten Metalle nur das Reizmittel zur Belebung dieser Thätigkeit bilde, — eiue Ueberzeugung, die ich 
in andern Arbeiten bereits lange vorher, nur nicht unter solchen Documenten als jetzt, ausgesprochen habe, - war die unauslässliche Folge dieser Vergleichung. Ich wurde inne, dass die Physik, in ihrer bisherigen Betrachtungsweise des Processes der galvanischen Kette, nach der Contactelektricität der Metalle nur so, wie ein Kind nach dem, was am meisten in die Augen fällt, gegriffen und die mehr unscheinbaren, aber darum nur um so wesentlicheren, in der geschlossenen Kette nur um so kräftiger sich entwickelnden Qualitäten in der Relation der Flüssigkeiten zu den Metallen, wenn nicht übersehen, dooh fast gänzlich vernachlässigt habe.

Meine seit längerer Zeit gemachten Entdeckungen über die polare Thätigkeit des flüssigen Leiters in der geschlossenen Kette, - ohne dass ich damals ihren Zusammenhang mit den nachfolgenden Untersuchungen bereits so bestinmt als jetzt durchschaute, - bildeten gleichsam, als wären sie die von vorn herein erwarteten Resultate planmässig unternommener Vorarbeiten, die wesentlichen Prämissen zu den späteren Combinationen und als der gemeinsame Mittelpunkt des grossen, alle elektrische Relationen der Flüssigkeiten und Metalle umfassenden, Kreises ergab sich mir eine Norm, die meines Erachtens zu den merkwürdigsten Gesetzen gezählt zu werden verdient, welche die Naturlehre 
kennt, das Gesetz nämlich: dass die elektrische Relation irgend zweier Metalle gegen eine und dieselbe Flüssigkeit jeder Zeit, theils der Quialität, theils der Quantität nach, die entgegengesetzte von der zwischen den Metallen selbst Statt findenden gegenseitigen Relation sei. Die Relationen der Metalle und Flüssigkeiten greifen so, wie aus zwei entgegengesetzten Welten, bedeutungsvoll in einander und die starren, regulinischen Metalle, je mehr sie durch den Drang ihrer gegenseitigen Erregung im Contact mit einander der entgegengesetzt erregenden Einwirkung der Flüssigkeit Widerstand zu leisten trachten, fallen dadurch nur um so gewisser dem regen, unaufhaltsamen Fortschritte der allgemeinen Entwickelungsmetamorphose des grossen, heiligen Naturlebens anheim.

Was bereits seit mehreren Jahren unter einem bloss speculativen Gesichtspunkte von mir ausgesprochen worden ist, bei welchem ich damals allein das Ganze der Erscheinungen vor Augen hatte und die specielleren Thatsachen noch nicht kannte, die sich mir später eben erst nur in Folge dieser Ansicht ergaben, dass nämlich die Polarität, mit welcher die Metalle, als Glieder der geschlossenen Kette, die Zersetzung des Wassers und die Ablenkung der Magnetnadel bewirken helfen, gerade die entgegengesetzte von derjenigen sein müsse, welche sie in der Contactelektricität 
versichtbaren, das ist jetzt nicht nur zur Gewissheit eines Factums erhoben, sondern es ist sogar, was ich damals noch nicht in der Bestimmtheit erkannt hatte, erwiesen, dass selbst schon vor dem Greschlossensein der zusammengesetzten Kette die Contactelektricität der Metalle, durch die Eiuwirkung der Flüssigkeit auf die Metalle, zurück gedrängt und die entgegengesetzte Erregung der letzteren, die mit der Schliessung in voller Intensität als Chemismus hervortritt, bereits entschieden vorbereitet sei. Das in der Einseitigkeit seines Princips schon von Innen heraus verfehlte System der Elektrochemie ist hiemit zugleich auch äusserlich als eine irrige Richtung, vermöge welcher alle Relationen, das Positive und Negative, unaufhörlich mit einander verwechselt werden, auf eine entschiedene Weise bezeichnet.

Die Phänomene der sogenannten elektrischen Ladung, wie sie besonders durch Ritter's Ladungssäule, als ein für ernstliche und tiefere Untersuchung im höchsten Grade geeigneter Gegenstand, sich schon so lange dringend dargeboten haben, gewinnen unter der naturgemässen Auffassung des Processes der galvanischen Kette eine durchgreifende Bedeutung, die einen Reichthum von wichtigen Aufschlüssen für die Elektricitätslehre und die Pliysik überhaupt in sich begreift und mit der insbesondere über Wesen und Bedingung der elek- 
trischen Leitung an sich, so wie namentlich über die Natur der sogenannten unipolaren Leitung ein wirksames Licht verbreitet wird.

Eine Forschung, die einmal, frei von hypothetischen Fesseln, durch die Zusammenstimmung aller Momente der Speculation und der Erfahrung zu dem Bewusstsein gelangt ist, dass sie den wahren Weg zur Erkenntniss ihres Gegenstandes glücklich betreten habe, wird, so wie der innerlich ge, regelte Zug einer begonnenen Curve, auf jedem Punkte der Entwickelung durch ihr eigenes Gesetz zu fernerem Fortschritte immer aufs Neue und unwillkührlich getrieben. So erweiterte sich mir anch der Gesichtspunkt, unter welchem an dem Verständnisse der zweigliedrigen Kette mit ungleichen metallischen Eerührungsflächen zugleich dasjenige der dreigliederigen sich erschlossen hatte, zu einer noch ungleich umfassenderen Aussicht. Ich wurde gewahr, dass jene zweigliederige Kette nur eine besondere Species einer viel allgemeineren, durch die mannichfaltigsten Aeusserungen der $\mathrm{Na}$ turthätigkeit verbreiteten, in den Erscheinungen der gemeinen Elektricität, in den Wirkungen der thermomagnetischen Kette, im Verbrennungsprocesse, in allen Regungen des Chemismus und in den Bildungsprocessen der Krystallisation, nach völlig gleichem Typus der Thätigkeit, sich unaufhörlich wiederholenden Gattung sei. 
Der Typus des Processes der zweigliedrigen galvanischen Kette ist das Grundthema, welches die mechanische, wie die chemische Naturthätigkeit, wenn zunächst noch von der höheren Sphäre ihrer ausschliesslich sogenannten organischen Wirksamkeit abgesehen wird, durch eine unbestimmbare Mannichfaltigkeit der Formen, von der keinsten Regung bis zum kosmischen Rhythmus der Planetenbewegung in zahllosen Variationen darstellt; er ist die allgemeine, auf eine unübersehbare Menge mannichfaltig gestalteter Bewegungen durchgehends bezogene Gleichung, der gemäss, nachdem sie ein für alle $\mathrm{Mal}$ aufgefunden worden, die Aufgabe des Naturforschers in allen jenen Fällen nur auf dieselbe eine Forderung zurückgeführt ist, die Lage der Coordinaten in jeder einzelnen Erscheinung auszumitteln und nachzuweisen, um damit alsbald auch das Gesetz dieser Erscheinung und ihre wahrhafte Bedeutung mit Klarheit und Bestimmtheit zu durchschauen.

Es ist nicht zu berechnen, wie weit dieser Universalschlüssel die Naturlehre noch führen könne, wie viel Geheimnisse durch ihn aufzuschliessen, welche Hieroglyphen durch ihn zu entziffern sein werden. Es kommt vor allem zunächst darauf an, ihn selbst zum Behuf seines erfolgreichen Gebrauches vollständig und gründlich kenneu zu lernen und zu dieser Bekanntschaft 
lade ich die Naturforscher angelegentlich durch die gegenwärtige Schrift ein. Sie hebt, ungeachtet ihres verhältnissmässig kleinen Umfanges, so viel Momente und Belege hervor, als zu einer solchen Würdigung des Gegenstandes fürs erste wenigstens hinreichend sind, sobald diese, wie gesagt, mit Unbefangenheit und, was sie selbst erst als möglich bedingt, nur nach einer yollständigen und gründlichen Auffassung der ganzen DarIegung / vollzogen wird.

Unter dem; was die Critik an dieser Schrift zu rügen finden kann, mag dasjenige, was zur polemischen Seite derselben gehört, durch scheinbare Bitterkeit hie und da vielleicht Veranlassung zum Tadel darbieten. Niemand kann indess mchr als ich von der Ueberzeugung durchdrungen sein, dass alles, was auf selbstständige Gültigkeit Anspruch machen will, dazu überall nur durch seine eigene Entwickelung von innen heraus gelangen müsse, die das bedeutungslos und unhaltbar Gewordene einer früheren Zeit schon durch sich selbst aus der Stelle drängt, welche sie einzunehmen trachtet. Dasjenige, was so durch eine spätere Entwickelung beseitigt wird, hatte, gleich der Blüthe vor der Frucht, früher seine eigene Bedeutung, die, so weit die Tendenz des Ganzen es mit sich bringt, geehrt werden muss und mit ihr ein jeder, der die ältere Form zu erhalten 
und zu pflegen bemüht war, bis die jüngere in mehr vollendeter Reife aus ihr hervorgegangen war. Damit ist indess zugleich klar, dass alles, was einer von innen hervorstrebenden Production als ein Todtes und Geistloses hemmend entgegen drückt, auch mehr oder weniger auf eine äusserliche Weise abgewiesen oder entfernt gehalten werden müsse, wenn der Trieb nicht ersticken soll; andererseits kann zugleich wiederum jede von innen heraus erfolgende Beseitigung demjenigen, welcher dieses Innere so wenig als seinen. Zusammenhang mit dem Beseitigten erkennt, gar leicht als eine äusserlich hervortretende, tadelnswürdige Härte sich darstellen, wie die Natur im Einzelnen unaufhörlich finster und lieblos erscheinen kann, ohne dass sie es im Ganzen weder ist noch sein will. Unter diesen Gesichtspunkten wird, wie ich gewiss zu sein glaube, dasjenige, was in der obigen Beziehung in dieser Schrift hart erscheinen könnte, sicher nicht verkannt werden. Niemand kann die Wissenschaft in allen Formen, unter welchen sie sich von den frühesten Perioden ihrer Entwiekelung an bis auf den heutigen Tag dargestellt hat, höher achten und niemand kann für jeden Naturforscher jeglicher Zeit, der an dieser Entwickelung lebendigen Antheil hat, ein tieferes Gefühl des Danks und der Verehrung in sich tragen, als ich. Meine Aeusserun- 
gen sind daher, fern von Lieblosigkeit, niemals gegen irgend einen früheren Standpunkt der Wissenschaft an sich und das, was mit ihm gegeben ist, gerichtet, sondern nur, so oft die Darstellung es mit sich führte, gegen den widerstrebenden Sinn, der das Bedürfniss höherer Einsicht nicht anerkennen will, gegen das Vorurtheil und die engherzige Verschlossenheit, welche den Standpunkt der früheren oder nächsten Vergangenheit als einen absoluten fest halten, den kleinlichen Maasstab ihrer eigenen oder gar einer fremden Beschränkung noch fortwährend an alles legen, was demselben längst entwachsen ist, und an jedem Streben nach reellem Fortschritte, an jeder Regung einer freieren, lebendigen Entwickelung nichts als den trüben Reflex ihrer eigenen Verkehrtheit zu erblicken vermögen.

Wie unzulänglich und unhaltbar die bisherige Richtung der Physik im Gébiete des Galvanismus gewesen sei, geht am augenscheinlichsten daraus hervor, dass sie länger als ein Vierteljahrhundert hindurch selbst nicht einmal die äusserlichsten Verhältnisse der Polarität der galvanischen Kette richtig und naturgemäss, sondern unter ganz verkehrten Gesichtspunkten aufgefasst hat, so wie dagegen ein solcher Standpunkt der Speculation, von dem aus ein bereits so tief verwachsener und vielfältig übertragener Irrthum mit Bestimmtheit 
erkannt wird, unmöglich so unzuverlässig sein -kann, als viele es sich einbilden. Wo aber eine neue Bahn gebrochen wird, da weiss derjenige, der mit beschränkter, individueller Kraft die Hand zuerst ans Werk legt, in der Regel auch am besten, wie vielen Mängeln seine erste Arbeit noch unterworfen sei, wie viel Punkte des neu gebildeten Weges ungeebnet, ungelichtet, unangedeutet, ja völlig verfehlt sein können. Den Spilitterrichtern kann es in solchem Falle an Einzelnheiten zur Nahrung des Tadels und der Verkleinerungssucht niemals fehlen; aber eben deshalb, weil es sich in Einzelnheiten verliert, ist $\mathrm{ihr} \mathrm{Ur}_{\mathrm{r}}$ theil von keiner Bedeutung.

Was nicht durch äussere Aggregation, sondern aus einer inneren Einheit hervorgegangen ist, kann nicht nach Fragmenten beurtheilt, es will und muss, wie die Natur selbst, nur im Ganzen und unter allseitiger Anschauung erfasst und begriffen werden. In dem Fortschritte der geraden Linie ist keine andere Consequenz, als nur die scheinbare, vermöge welcher sie die wahrhafte immer auf dieselbe einförmige Weise, aber unaufhörlich vergebens, sucht und ein wissenschaftiches Ganze, welches sich eben so auf jedem einzelne Punkte seiner Entwickelung auch sofort vollständig zu begründen trachtet, tödtet, wie dies in der gemeinen mathematischen Lehrmethode so hüufig 
geschieht, sein eigentliches Leben, indem es den natürlichen Zusammenhang seiner edelsten Organe gewaltsam zerreisst. Die wahrhafte wissenschaftliche Begründung besteht, wie die Selbstständigkeit eines jeden organischen Individuums, vielmehr darin, dass das Einzelne nicht durch ein Einzelnes, sondern nur durch das Ganze, wie das Ganze durch das Einzelne getragen werde und dass alle Momente nach dem Schema der lebendig geschlossenen Kreislinie, in Wechselbeziehung auf einander zurückweisen und sich gegenseitig zum Beweise dienen.

Möge diese Schrift recht viel Leser finden, die ans diesem Gesichtspunkte zu sehen gewohnt sind; ihnen wird das eigentliche Verständniss ihres Gehalts gewiss-nicht verschlossen bleiben und nur sie werden es vermögen, ein wahres und reifes Urtheil über Bedeutung und.Werth dessen, was hier niedergelegt worden ist, auszusprechen.

$$
\text { Berlin, am 24sten Februar } 1826 .
$$




\section{Uebersicht des Inhalts.}

\section{Erster Abschnitt.}

Metall und Flüssigkeit als Glieder der galvanischen Kette. Verhalten und Relation derselben im Allgemeinen. S. 1-38.

Specifisch verschiedene Thätigkeit der Leiter erster und zweiter Classe, in elektrischer und chemi.

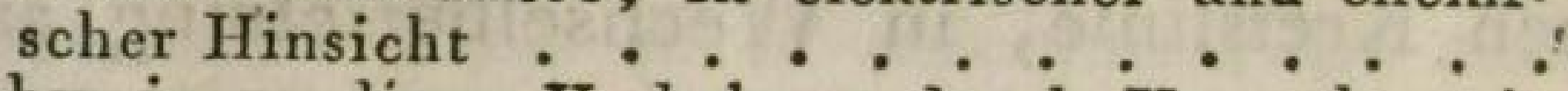

Nachweisung dieses Verhaltens durch Versuche mit der armirten galvanischen Kette ..... .

Desgleichen durch Versuche am Elektroskop . . .

Nothwendigkeit eines Princips bei der Bestimmung der elektrischen Relationen zwischen Leitern erster und zweiter Classe, und Täuschungen, die aus dem bisherigen Mangel dieses Princips hervorgegangen sind .. . . . . . .

Angefügte Bemerkungen über Hypothesen und Ideen

Seite 1.

- 4.

- 11. in der Naturforschung überhaupt und über die Idee der elektrischen und magnetischen Erscheinungen insbesondere . . . . . . .

\section{Zweiter Abschnitt.}

Die dreigliedrige galvanische Kette. S. $39-84$ :

Wesentliche Unterscheidungen bei der Vergleichung der elektrischen Relationen zwischen den drei Gliedern der Kette ........

Der constante Gegensatz zwischen den Relationen der Metalle zu einander und zur Flüssigkeit als Grundgesetz und Träger aller Erscheinungen an der Kette

Die Functionen der Erreger gegen einander und gegen die Flüssigkeit in der Kette bedingen sich wech. selseitig wie Irritabilität und Sensibilität im thierischen Organismus . . .

Die vollendetste Anschauung der Thätigkeit der Kette besteht darin, dass die in der endlichen Vorstellung auseinander gehaltenen Momente coexistirend gesetzt werden . . . . . . .

Die Form der magnetischen Polarität der Kette, die Circularpolarität, ist die Folge des Conflicts beider sich durchdringender Thátigkeitsmomente der Kette . . . . . . . . .

Begründung der bisher entwickelten Ansicht durch $-39$.

$-42$.

$-47$.

- 49.

$-52$.

Versuche, verbunden mit der Darlegung eines 
durchgreifenden Grundgesetzes der elektrischen Erregung . . . . Seite 59.

AllgemeinsterAusdruck des früher entwickelten Grund. gesetzes über die elektrischen Relationen und Anwendung desselben auf alle dreigliedrige galvanische Ketten ohne Ausnahme . - .

Gānzliche Unzulänglichkeit der bisherigen auf die Contactelektricität der Metalle gegründeten Lehre vom Galvanismus : • • • • • • • Anhang über die Bestimmung der Relationen der Metalle in der elektrischen Spannungsreihe aus ihrem Verhalten in der dreigliedrigen galvanischen Kette •. • • • • • • • • •

\section{Dritter Abschnitt.}

Die zweigliedrige galvanische Kette mit ungleichen metallischen Berührungsflächen. S. $85-9^{8}$.

Parallele zwischen der Thätigkeit dieser Kette und der dreigliedrigen.

Nachweisung des eigentlichen Princips der Wirksamkeit dieser Kette aus der im vorhergehenden Abschnitte entwickelten Theorie - . .

Bestimmung der Relationen zwischen Metallen und Flüssigkeiten in der elektrischen Spannungsreihe, aus ihrem Verhalten in der zweigliedrigen Kette mit ungleichen metallischen $\mathrm{Be}$ rührungsflächen $\cdot . \cdot \cdot \cdot \cdot \cdot \cdot \cdot \cdot$

\section{Vierter Abschnitt.}

Die galvanische Säule, als das Vielfache der dreigliedrigen einfachen Kette. S. 99-141.

Erregungszustand der Säule vor der Schliessung der-

Folgerungen in Bezug auf die wahre Polarität $\dot{\mathrm{der}}$ Säule und die davon abhängige Nomenclatur

Die Tendenz zur Thätigkeit der Săule während ihres der Schliessung vorangehenden Zustandes durch Versuche in Vergleich mit früheren Ansichten und Versuchen von Ritter nachgewiesen . .

Das Wesen der Thătigkeit und die wahrhafte Polarität dieser Thätigkeit (Circularpolarität) im geschlossenen Zustande der Săule . . . . . . . .

Berücksichtigung der Säule mit Erregern von gleichartiger Relation gegen die Flüssigkeit . . .

$-108$.

$-313$.

Fünfter Abschnitt.

Die Ritter'sche Ladungssäule. S. 142-248.

Vorausgeschickte Betrachtungen der drei Hauptmomente der galvanischen Thätigkeit nach der drei-

fachen Dimension der Säule . . . . * . - 142. 
Ueber die Maxima der chemischen Functionen der Sänle . . . . . . . . Seite 155.

Entwickelung des wahrhaften Charakters der Thätigkeit in der Ritterschen Ladungssäule . . .

Das Princip dieser Thätigkeit ist eine im Chemismus begründete und bei weitem mehr dem Metalle als der Flüssigkeit zugehörige Reaction . . . .

Bestätigende Versuche durch Reactionserscheinungen

a) an einfachen Ladungselementen . . . .

b) an einzelnen Gliedern der einfachen Primärkette

c) an der Integrität der Wirkung einer und derselben einfachen Kette, (Zwischenkette) . .

d) an einnem merkwürdigen Verhalten der zusammengesetzten Kette . . . . . . .

Das elektrische Leitungsvermögen und die Thätigkeit der Glieder der Kette, vermöge welcher sie bei der Schliessung der letzteren den eigentlichen galvanischen Process vermitteln, sind durchaus von einander verschieden . . . . . .

Bestătigung durch Versuche, welche darthun, dass die Kette durch Flüssigkeiten absolut vollkommner als durch Metalle geschlossen werde $\dot{v} \cdot$

Unzulänglichkeit bisheriger Bestimmungen und Vorstellungen über Leitung und Wirksamkeit der Elektricität . . . . . . . . •

Die Phănomene der sogenannten unipolaren elektrischen Leitung sind nicht Modificationen der elektrischen Leitung, sondern der chemischen Reactionsthätigkeit dèr specifisch differenten Stoffe

Beleuchtung der Erman'schen Argumentation über die

'Polaritat der Metalle in der' galvanischen Säule

Andeutung der höheren Einheit in den Phänomenen der

Reaction und der Polarität überhaupt .. . - -245 .

\section{Sechster Abschnitt.}

Die zweighiedrige galvanische Kette schlechthin, das Urbild jeder galvanischen Kette und die Grundform aller chemischen Naturthätigkeit überhaupt. S. $249-430$.

Betrachtung der zweigliedrigen, aus zwei differenten Flüssigkeiten gebildeten Kette und Bestimmung der elektrischen Relationen der Flüssigkeiten aus ihrem Verhalten in dieser Kette . . . . .

Der natürliehe chemische Process zwischen differenten - Flüssigkeiten erfolgt alle Mal unter dem Typus der geschlossenen galvanischen Kette . . .

Die Thätigkeit desselben aber ist die Vereinigung der Wirksamkeit unzähliger Partialketten, deren jedo von zwei Focalstellen der progressiven und reagirenden Thätigkeit abhängig ist - - i d -

Der Magnetismus einer aus Flüssigkeiten gebildeten, so wie überhaupt jeder natürlichen zweigliedrigen Kette ist nur unter besondern Bedingungen sichtbar ................. - . 275 . 
Betrachtung der zweigliedrigen, aus einem Metall und

einer Flüssigkeit gebildeten Kette . . . . Seite 278 .

Der natürliche chemische Process zwischen einem Metall und einer Flüssigkeit erfolgt alle Mal unter dem Typus der geschlossenen galvanischen Kette vermöge einer, so wie bei zwei Flüssigkeiten, in unzählige Partialketten vertheilten Thätigkeit. . • • • • • • . .

Jeder chemische Erfolg überhaupt wird unter dem Typus einer Thätigkeit vollzogen, die ihrer $\mathrm{Na}$ tur năch keine andere, als die Thătigkeit der geschlossenen galvanischen Kette ist . . .

Durchfülrung dieses Princips an den drei Hauptmomenten des Galvanismus. Wahre Bedeutung des Wortes Galvanismus im Gegensatz der drei subordinirten Momente .........

Elektrismus, als individuelle Tendenz zum Chemismis nur durch Anziehung und Abstossung versichtbart

Chemismus. - Die über die Phänomene der blossen Anziehung und Abstossung hinausgehenden sogenannten elektrischen Erscheinungen sind nicht eigentlich mehr elektrischer, sondern chemischer Natur. - Luftzersetzungsprocesse.

Das sogenannte Ausstromen der Elektricität beruht auf der Thätigkeit einer die Luft zersetzenden zweigliedrigenKette mit ungleichen Berührungsflächen

Theilnahme der atmosphärischen Luft am chemischen Process überhaupt und am Process der galvanischen. Kette insonderheit . . . . . .

Verhältniss des gemeinen unter Flamme oder Glut erfolgenden Verbrennungsprocesses zu dem durch die Elektricität eingeleiteten Zersetzungsprocesse der Luft, mit Rücksicht auf Licht und Farbeder Flamme . . . . . . . . .

Wahre Bedeutung des Gegensatzes zwischen mitgetheilter und vertheilter Elektricität.

Rechenschaft über die eigentliche Natur der Wirksamkeit des Elektrophors, Condensators und der Leidner Flasche . . . . . . . .

Magnetis mus, als universelle Tendenz zum Chemismus wieder nur durch Anziehung und Abstossung versichtbart, aber im Zersetzungsprocesse der Säule in der Form der Circularpolarität nachgeviesen

Parallele $\mathrm{zw}$ ischen Magnetismus und Elektricităt und wahre Bedeutung des Wortes: Elektromagne$\mathrm{t}$ is $\mathrm{mus}$

Das Gesetz der chemischen Aequivalente lediglich die Folge der Polarität des chemischen Processes über-

Die Temperaturveränderung beim chemischen Processe und in der geschlossenen galvanischen Kette als ein und dasselbe Princip der Wärme . . .

Die thermomagnetische Kette als eine den bisher entwickelten Ansichten entsprechende zweigliedrige, 
aus zwei differenten Metallen gebildete, durch Temperaturdifferenz polarisirte galvanische Kette Seite $37 \mathbf{r}$.

Fundamentalversuch des Verfassers über die chemisch. polare Thätigkeit der Flüssigkeit in der galvanischen Kette

Vergleichung der polaren Schichten der Flüssigkeit in diesem Versuche mit dem Durchgange der Blätter im Krystall nebst Folgerungen für die ersten Ausgangspunkte zu einer Theorie der Krystallbildung . . • • . . . . . . .

Die Durchführung chemisch polarer Stoffe an der galvanischen Säule ist nicht mechanische Dislocation, sondern dynamische Metamorphose .

Nähere Betrachtung des Fortschrittes des chemischen Processes in Bezug auf das Produkt desselben.

Jedes chemische Produkt ist nicht das Resultat einer unter örtlich veränderten Verhältnissen Statt findenden Durchdringung, sondern einer rein dynamisch erfolgten Metamorphose . . . . .

Der Kreislauf dieser Metamorphose führt zur Reproduction der Factoren, die bis ins Unendliche gesondert und zugleich in eine höhere Einheit aufgenommen im Krystall wieder erscheinen

In der künstlichen Kette geschieht diese Reproduction nur einseitig, die Säule selbst ist bereits der Krystall ; in der natürlichen Kette aber erfolgt sie, wie die Synthesis, an unzähligen Focalstellen unzähliger Partialketten . . . . . . . •

Die verschiedenen Durchgänge im Krystall entsprechen den chemischpolaren Gegensätzen, deren in jeder Flüssigkeit und in jedem Krystall wenigstens drei sein müssen. - Form des wechselseitigen Gebundenseins und Freiwerdens dieser Gegensātze

Zwillingskrystallisation. - Richtendes Princip bei der Krystallbildung der Magnetismus. - Elektrische Polarität des Krystalls. - Rigidität . .

Schluss. Andeutung einer höheren Trias des Naturlebens aus den drei untergeordneten Sphären der universellen Trias (Licht, Materie und Schwere), der galvanischen (Elektrismus, Chemismus, Magnetismus) und der organischen (Irritabilität, Reproduction, Sensibilität.) . . . . . . - 428 . 


\section{Erster Abschnitt.}

Metall und Flüssigkeit als Glieder der gulvanischen Kette. Verhalten und Relation derselben im Allgemeinen.

Dass wir über das Verhältniss und die Ordnung der Leiter erster und zweiter Classe in der allgemeinen elektrischen Spannungsreihe der Körper fortwährend in Unsicherheit geblieben und zum Theil noch jetzt durch die nevesten Untersuchungen in Gefahr sind, zu ganz entgegengesetzten Vorstellungen von der wahren Beschaffenheit der Sache verleitet zu werden, mag allerdings in den Mängeln der Werkzeuge, in den trugvollen Aussagen des Condensators und in den Unvollkommenheiten der Beobachtungsmethoden begründet seyn; ein Hauptgrund jener Unsicherheit aber liegt in dem tisherigen Mangel an bestimmter Kenntniss des specifischen Unterschiedes, welcher zwischen der Action der Metalle und der Flüssigkeiten Statt findet, so oft sie als Leiter der Elektricität in Wirksamkeit treten.

Wenn Chemismus und Elektricitât dem Wesen nach identische Thätigkeitsüusserungeu der Materie sind, so ist es begreiflich, dass der Unterschied, welchen die Metalle und die flüssigen Leiter in ilirem chemischen Grundverhalten zeigen, auch in der Art,

A 
wie sie die Elektricität leiten, sich wiederhole und versichtbare. Das Wasser als der eigentliche Repräsentant der flüssigen Leiter ist ein höheres, dem Lichte verwandteres Product, als das in den finstern Schooss unentwickelter Lebenskraft noch tief versenkte, von den Fesseln der Schwere eng umschlossene Metall; und so wie letzteres, auch unter den mächtigsten Aufforderungen zur Diremtion, in seiner starren, elementarischen Indifferenz beharrt, da wo das Wasser in beweglicher Erregbarkeit nach beiden Seiten des chemischen Gegensatzes als Oxygen und Hydrogen auseinander tritt, eben so ist auch der Gegensatz der positiv - und negativ-elektrischen Erregung, in deren undulatorischem Wechsel diejenige Thätigkeit besteht, welche man unter dem Namen der elektrischen Leitung begreift, bei der Leitung durch ein Metall noch in einem Zustande embryonischer Unaufgeschlossenheit, während er bei der Leitung durch das Wasser und die Flüssigkeiten in einer für die nähere Prüfung auf das entschiedenste ausgebildeten Sonderung, gleich dem Gegersatze der magnetischen Polarität sich versichtbart.

Diese ungleich grössere Aufgeschlossenheit des elektrischen Gegensatzes bei der Leitung durch das Wasser ist es eben, durch welche, nach den allgemein gangbaren Vorstellungen darüber, die Leiter zweiter Classe schlechtere Leiter der Elektricität darstellen, als die Metalle. Was nach der gewöhnlichen Betrachtungsweise, zumal nach der Vorstellung, welche die elektrischen Erscheinungen an das Phantom eines elektrischen Fluidums knüpft, als die höchste Lebendigkeit in der Elektricitatsleitung durch ein Metall erscheint, das ist in der That nur Folge der trägen Passivität der 
metallischen Masse, welche, indem sie der Erregung widerstrebt, ohne doch das Vermögen, sie absolut zu. rück zu weisen, zu besitzen, den Eindruck von einem Punkt der Masse zum andern leicht und schnell hinweg gleiten lässt, ohne ihn an irgend einer Stelle zu einer lebendig haftenden Entwickelung gelangen zu lassen. In der Flüssigkeit hingegen ist jedem Punkte der Lichtkeim der Empfängniss eingepflanzt, durch den auf eine wahrhaft thätige Weise die zunächst angeregte Stelle den Eindruck in sich aufnimmt, ohne ihn sogleich wieder fahren zu lassen, sondern indem sie ihn fest hält, wird in der ihr unmittelbar benachbarten Masse die ent gegengesetzte Erregung hervorgerufen, diese ruft weiter aus gleichen Gründen abermals die entgegengesetzte, der ersten gleichartige Erregung hervor und so schreitet die Leitung, scheinbar unkräftiger, aber in der That auf eine ungleich innigere Weise und unter einer reellen Aufgeschlossenheit des elektrochemisch-polaren Gegensatzes durch die Masse des flüssigen Leiters von einem Extrem zum andern hindurch. Jedes Quantum elektrisch erregter Flüssigkeit, jede einzelne Schicht des flüssigen Leiters in der galvanischen Kette, ist so als ein Aggregat von abwechselnd positiv - und negativ - elektrisch - polaren unendlich nahen Lamellen zu betrachten, die, so wie die krystallinischen Blätterdurchgänge, durch wechselseitige Erregung hervorgerufen sind und an den Extremen jeder einzelnen Schicht, wie die Pole eines Magneten, stets mit entgegengesetzter Polarität hervortreten. Ein einzelnes, in die Kette versetztes oder von verschiedenen Seiten her entgegengesetzt erregtes Metall, wie z. B. der Schliessungsdrath, wird durch die Energie

$$
\text { A } 2
$$


der Entwickelung des ganzen Processes zwar gezwungen, sich gleichfalls für den polaren Gegensatz aufzuschliessen; aber eben nur durch den Zwang, üfnet es sich ihm und es verschliesst sich demselben wieder, nicht selten mit einer Gewalt der Reaction, 'die auf kürzere oder längere Zeit eine entgegengesetzte Erregung zur Folge hat, so bald der Zwang aufhört, oder so oft es nur einseitig angeregt wird, in welchem Falle es immer nur ganz positiv oder ganz negativ durch seine ganze Masse hindurch erscheint, während jede nur von einer Seite her erregte Flüssigkeit auf der entgegengesetzten Seite jedes $\mathrm{Mal}$ auch auf das bestimmteste die entgegengesetzte Erregung versichtbart und den ein Mal hervorgerufenen Erregungszustand längere Zeit beibehält. Dies wird durch einzelne 'Thatsachen, so wie durch das Ganze der Erscheinungen, von denen im Verfolg dieser Schrift die Rede seyn wird, vollkommen bewährt werden.

Wenn die Erregung in soleher Energie Statt findet, dass die Tendenz zum Chemismus, was die Elektricitït einzig und allein nur ist, durch den wirklichen Uebergang in denselben am Leiter zweiter Classe realisirt wird (wie sie mit jedem elektrischen Funken an der Luft, die man einen Leiter dritter Classe nennen könnte, verwirklicht wird), so ist eben das Zerfallen in Acides und Basisches der unmittelbare Ausdruck der vollkommen gesonderten, an den entgegengesetzten Extremen jeder einzelnen Schicht des flüssigen Leiters Statt findenden, entgegengesetzt elektrisch-polaren Erregung; und dass diese polare Doppelerregung auch da, wo sie nicht in Chemismus übergeht, durch und durch in allen Punkten des Lei- 
ters zweiter Classe Statt finde, das zeigt die ganze Reihe meiner in Kastners Archiv für die Naturlehre beschriebenen Versuche über die polareThätigkeit des flüssigen Leiters in der galvanischen Kette, Versuche, für die ich die Aufmerksamkeit der Naturforscher, denen sie bis jetzt etwa noch nicht bekannt geworden seyn sollten, mit Recht in Anspruch nehmen zu dürfen glaube, und aus denen ich jetzt nur zum an' schaulicheren Verständnisse des zunächst Folgenden, einen besonderen Fall hervorhebe, der unter den Beziehungen, in welchen er hier vorkommt und durch die hinzugefügte Construction vielleicht auch für diejenigen nicht ohne Interesse seyn wird, die aus meinen Darlegungen im Kastnerschen Archiv bereits von der Sache an sich unterrichtet seyn mögen.

Man fülle einen etwa $20 \mathrm{Zoll}$ langen, $14 \mathrm{Zoll}$ breiten und 4 Zoll hohen Kasten $a b c d$, der aus Holz oder irgend einem andern nicht leitenden Stoffe besteht, mit rerdünnter Schwefelsäure bis zum Rande an,

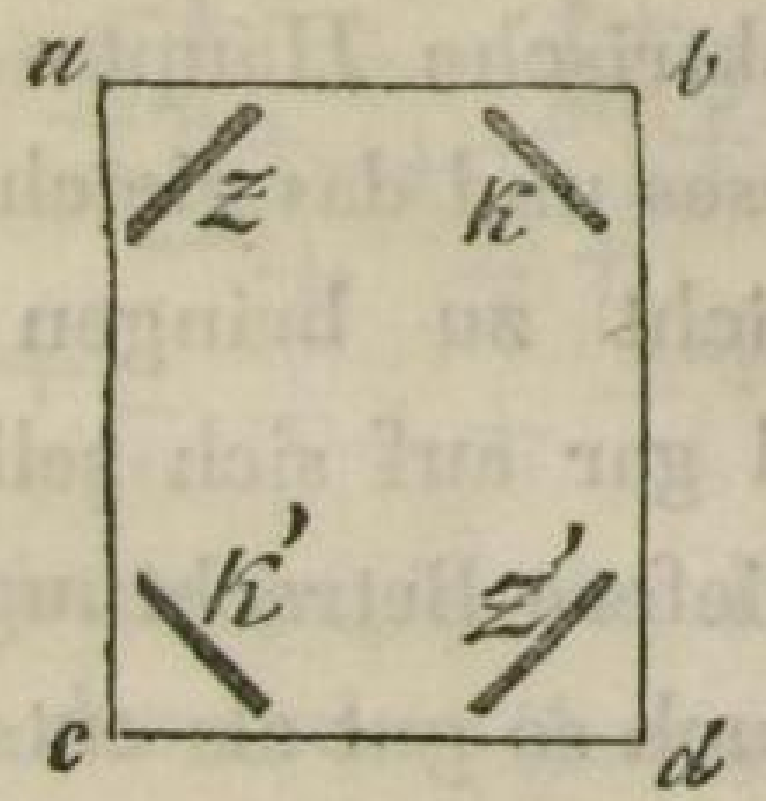

stelle in der Nähe der innern Querwand $a \quad b$ ein Paar unverbundene Erreger $z$ und $k$, aus Zink und Kupfer, und in möglichst grosser Entfernung von ihnen, neben der andern Querwand $c d$ in beliebiger Lage ein Paar Kupferplatten $k^{\prime}$ und $z^{\prime}$ auf; und vorbinde die letzteren durch einen um die Magnetnadel geschlungenen Multiplicator. Sind die Kupferplatten 
$z^{\prime}$ und $k^{\prime}$ von gleicher Grösse und Beschaffenheit und gleichzeitig oder lüngere Zeit hindurch in die Flüssigkeit gètaucht, so erfolgt durch ihre Verbindung mit dem Multiplicator an und für sich keine Ablenkung der Nadel. Man verbinde nun aber die Erreger $z$ und $k$ durch einen besonderen Schliessungsdrath und in demselben Augenblicke wird man die Nadel unter dem Multiplicatordrathe der Armaturen $z^{\prime}$ und $k^{\prime}$, (die auch beide aus Zink, Messing oder jedem andern Metalle bestehen können) auf das entschiedenste abweichen sehen, und zwar so, dass die Richtung, nach welcher sie abweicht, von derjenigen, nach welcher sie durch die Erreger unmittelbar unter sonst gleichen Umständen abgelenkt werden würde, die entgegengesetzte ist; nehmlich die der Kupferplatte $k$ gegenüberliegende Armatur $z^{\prime}$ wirkt wie eine Zinkplatte und die andere der Zinkplatte opponirte Armatur $\ell^{\prime}$ wie eine Kupferplatte.

Ich lasse jede vermeinte Erklärung, mit welcher durch fingirte elektrische Haupt - und Nebenströme ein Factum wie dieses und das gleich folgende unter die gewöhnliche Ansicht zu bringen versucht werden möchte, ganz und gar auf sich selbst beruhen. Für eine ernstere und tiefere Betrachtungsweise ist es schon durch diesen Versuch so gut als entschieden, dass eine wechselseitige polare Erregung zwischen den Metallen und der Flüssigkeit Statt finde, und dass die Erregung in der letzteren, eben weil sie innerlicher und eindringlicher, als in den Metallen ist, nicht bloss unmittelbar auf den Raum zwischen den Metallplatten, in geradliniger Richtung sich erstrecke, sondern durch die ganze Masse der Flüssigkeit bis zu den üussersten Gränzen 
derselben fortgepflanzt werde, wo sie eben wieder in den Armaturen abermals eine entgegengesetzte Erregung hervorruft, in Folge deren die Magnetnadel unter dem Multiplicator so und nicht anders abgelenkt wird.

Die Form unter welcher diese Erregung, parallel irgend einer in der Flüssigkeit beliebig gedachten Ebene, z. B. der Horizontalehene, in ihr fortschreitet und sich ausbreitet, kann in ihren allgemeinsten $\mathrm{Um}$ rissen unter dem Bilde der magnetischen Erregung aufgefasst werden, welche auf einer mit Eisenfeilspänen bedeckten Tafel, durch die beiden Pole eines Magnets, entsprechend den beiden entgegengesetzten polaren Erregern hervorgebracht wird, wie es durch die hier beigefügte Zeichnung veranschaulicht ist.

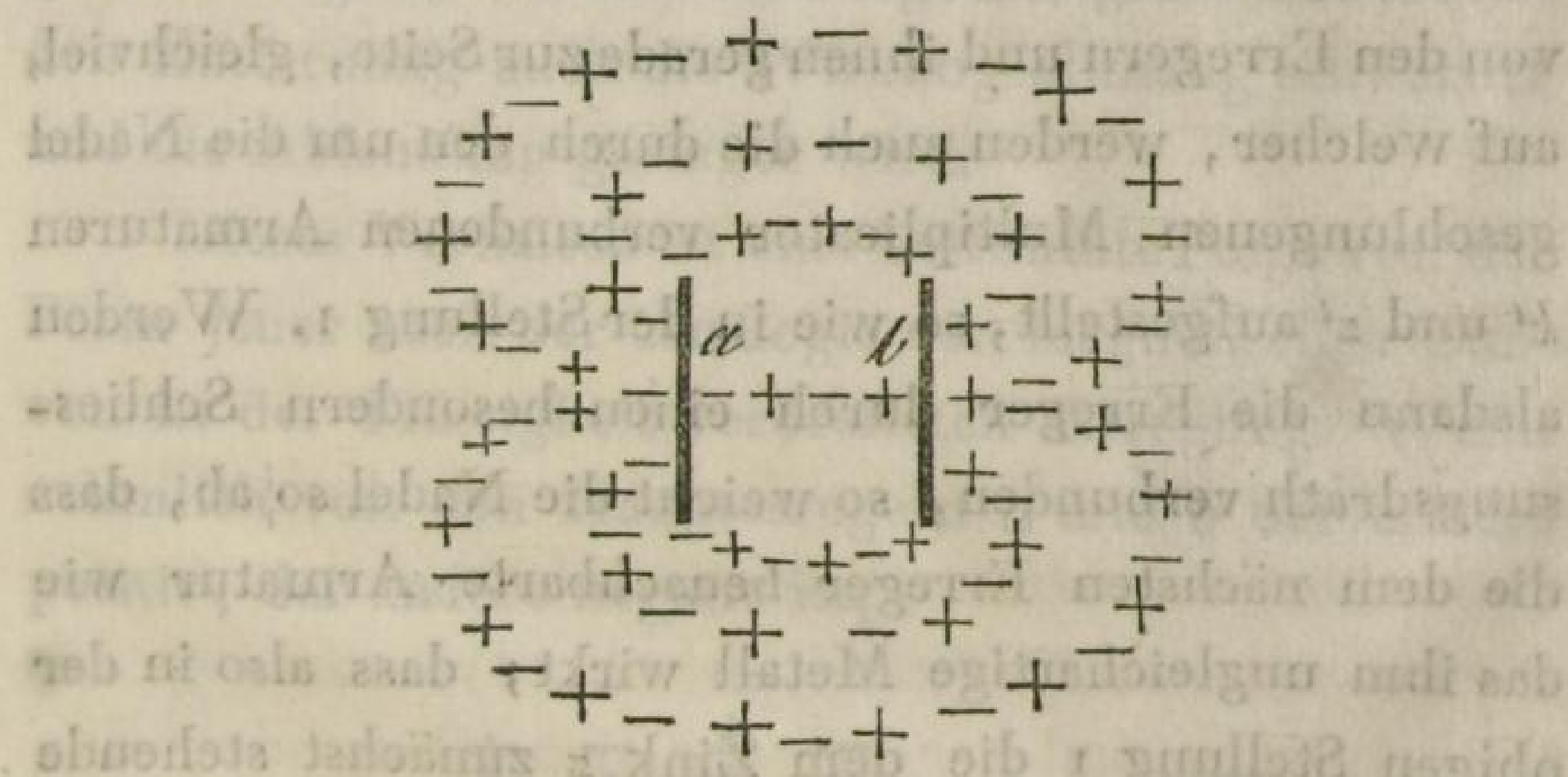

Der eine Erreger in $a$ ist in der Berührung mit der Flüssigkeit positiv, der andere $b$ negativ; gegen jenen ist dalier in allen Punkten der negative, gegen diesen der positive Pol der erregten Flüssigkeit gerichtet und von diesen beiden Extremen aus verbreitet sich zwischen die Erreger und rings um sie herum die Erregung durch das ganze Continuum der Flüssigkeit in Curvenzügen, deren Natur im Einzelnen noch zu untersuchen übrig ist, deren Vorhandenseyn im Ganzen 
aber bestímmt durch den folgenden Versuch verbürgt wird.

Die beiden Erreger $z$ und $k$ mögen, unter sich und den längeren Seitenwänden des obigen mit der Flüssigkeit angefullten Kastens a $b c d$ parallel, in der Mitte desselben aufgestellt seyn.

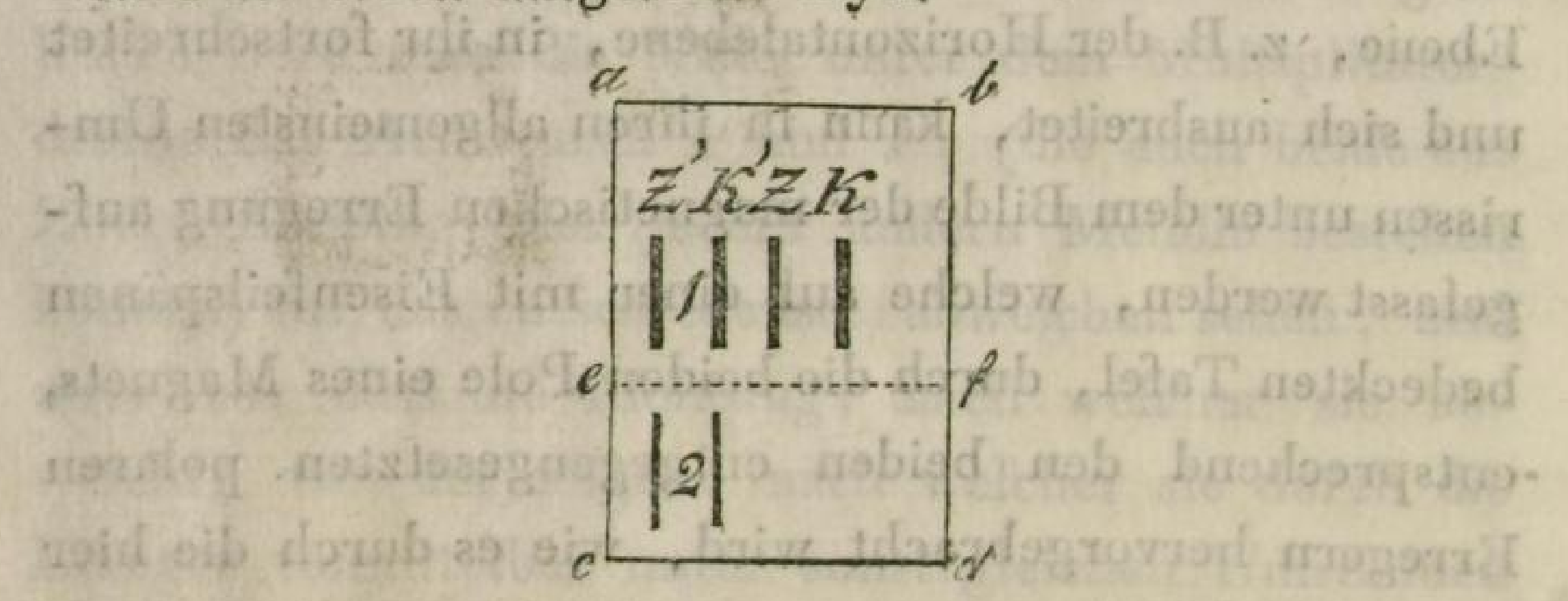

In gleicher Lage unter einer kleinen Entfernung von den Erregern und ihnen gerade zur Seite, gleichviel, auf welcher, werden auch die durch den um die Nadel geschlungenen Multiplicator verbundenen Armaturen $k^{\prime}$ und $z^{\ell}$ aufgestellt, so wie in der Stellung 1 . Werden alsdann die Erreger durch einen besondern Schliessungsdrath verbunden, so weicht die Nadel so ab, dass die dem nächstẹn Erreger benachbarte Armatur wie das ihm ungleichartige Metall wirkt; dass also in der obigen Stellung 1 die dem Zink z zunächst stehende Armatur $k^{*}$ wie Kupfer, die andere $z^{\ell}$ wie Zink sich verhält. Nun lasse man, ohne sonst irgend etwas zu ändern, die beiden Armaturen der längern Seitenwand ao des Kastens parallel, nach der einen Seite, gleichviel, nach welcher, allmälig fortrücken, z. B. nach der Querwand $c d$ hin, so'wird man die Ablenkung der Nadel allmïlig geringer werden sehen, bis sie, wenn lie Mitte der Armaturen eine bestimmte vor den Ränlern der Erreger himlaufendo Linie $e f$ erreicht hat, 
gunzlich Null geworden ist. Von diesem Punkte aus beginnt bei ferner fortgesetzter Bewegung der Armaturen in derselben Lage und Richtung, die Nadel abermals wieder abgelenkt zu werden, aber die Ablenkung ist nun die entgegengesetzte von der vorhergehenden und nimmt zu, bis die Armaturen ganz diesseit der Linie ef, wie z. B. in der Stellung 2 sich befinden. Sie haben also ihre früheren Rollen gänzlich vertauscht; diejenige, welche vorhin wie Kupfer wirkte, verhält sich jetzt wie Zink, und die andere, welche zuerst den Zink repräsentirte, wirkt jetzt wie Kupfer, und in dieser Umkehrung beharren sie, wie weit sie nun auch ferner in derselben Richtung und Lage fortbewegt werden mögen, nur dass in Folge der grösser werdenden Entfernung auch die Wirkung allmälig schwächer und die Ablenkung geringer wird.

Dieses Verhalten ist eine bestimmte Folge von der Form jener nach der Analogie der magnetischen Curven in der Flüssigkeit verbreiteten Erregung. Wenn nehmlich von den Haupterregern $a$ und $b$ der erstere positiv, der andere negativ ist,

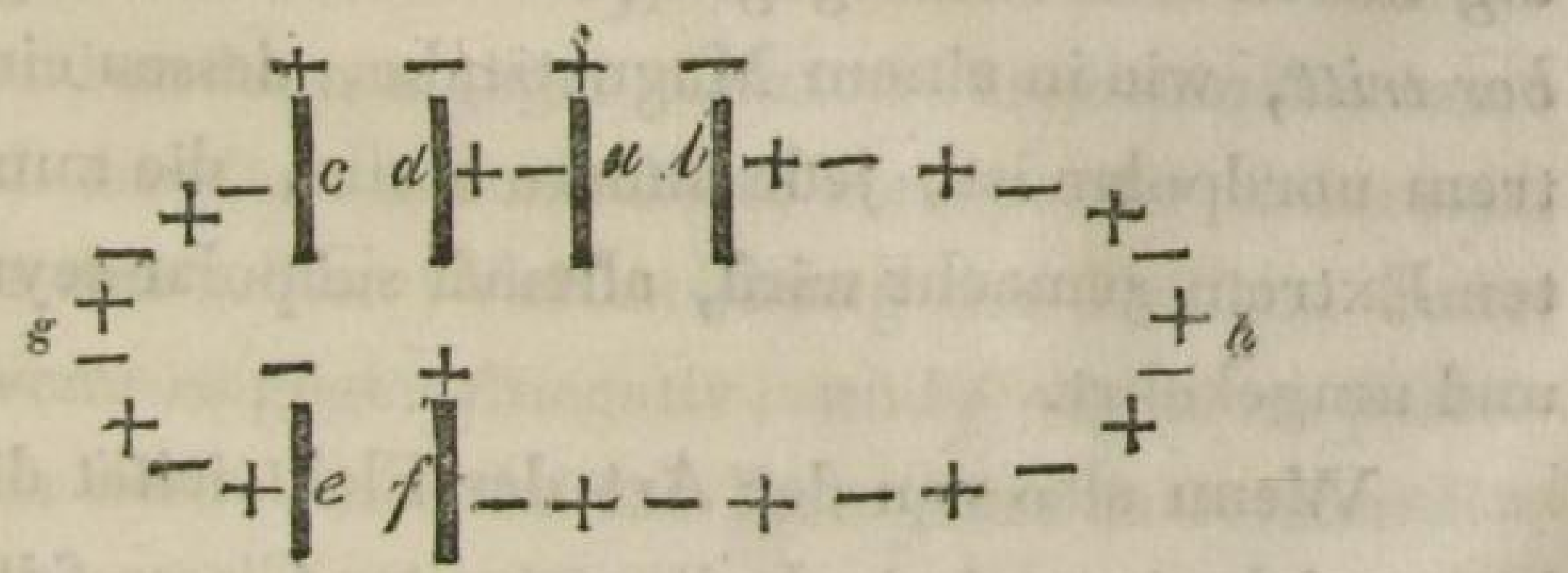

so ist der unmittelbar gegen a geriehtete Pol der Flüssigkeit negativ, und der unmittelbar an $b$ gränzende $\mathrm{Pol}$ derselben positiv, und wenn $g h$ eine solche zwischen beiden Polen befindliche Erregungslinie ist, so richtet 
der Theil derselben, der an a negativ ist, seinen positiven $\mathrm{Pol}$ gegen die Armaturen $d$ und $e$ und diese sind dadurch selbst negativ erregt, während der gegen $b$ positive Theil seinen negativen Pol gegen $f$ und $c$ richtet und dadurch diese Armaturen selbst positiv erregt. Die Armaturen $e$ und $f$ haben also eine der Lage nach entgegengesetzte Polaritat von derjenigen, welche in $c$ und $d$ Statt findet, und zwischen beiden Stellungen liegt nothwendig ein Uebergangspunkt aus dem einen Zustande in den entgegengesetzten, in welchem die Polarität unentschieden und die Ablenkung der Nadel Null ist. Die nähere Beschaffenheit der Linie der Nullpunkte und der Curve selbst muss einer besonderen Untersuchung vorbehalten bleiben; für den Zweck der gegenwärtigen Entwickelung ist zunächst nur das, aus den angeführten Thatsachen hervorgehende, Resultat $\mathrm{zu}$ fixiren, dass die elektrische Erregung in einem flüssigen Leiter stets entschieden polar sey, so dass jedem ursprünglich erregten Punkte eines solchen Leiters jeder andere Punkt desselben, so fern er als ein Extrem in der Masse des Leiters hervorgehoben wird, nothwendig immer mit der entgegengesetsten Polarität gegenüber tritt, wie in einem Magnetstabe, dessen eines Extrem nordpolar ist, jede andere Stelle, die zum zweiten Extrem gemacht wird, allemal südpolar seyn muss, und umgekehrt.

Wenn also von der Art der Elektricität die Redo ist, welche irgend ein Leiter zweiter Classe $f$ im Contact mit einer von der seinigen verschiedenen Masse $m$ erhält, so darf man diese Elektricität nicht als eine und dieselbe durch die ganze Masse des $f$ gleichmässig verbreitete Lrregung betrachten, sonderi es muss darun- 
ter immer nur diejenige Elektricität verstanden werden, welche unmittelbar in der Berührungsfläche an jenem $f$ erzeugt wird, denn in jedem andern Punkte seiner Oberfläche oder seiner Masse überhaupt, der als ein jener Berührungsfläche entgegenstehendes Extrem hervorgehoben wird, wird der Leiter $f$ in der entgegengesetzten elektrischen Erregung sich befinden, welche gleichartig mit derjenigen ist, die $m$ im Contacte mit $f$ erhält.

Es sey z. B. $m$ ein Metall, welches im Contact

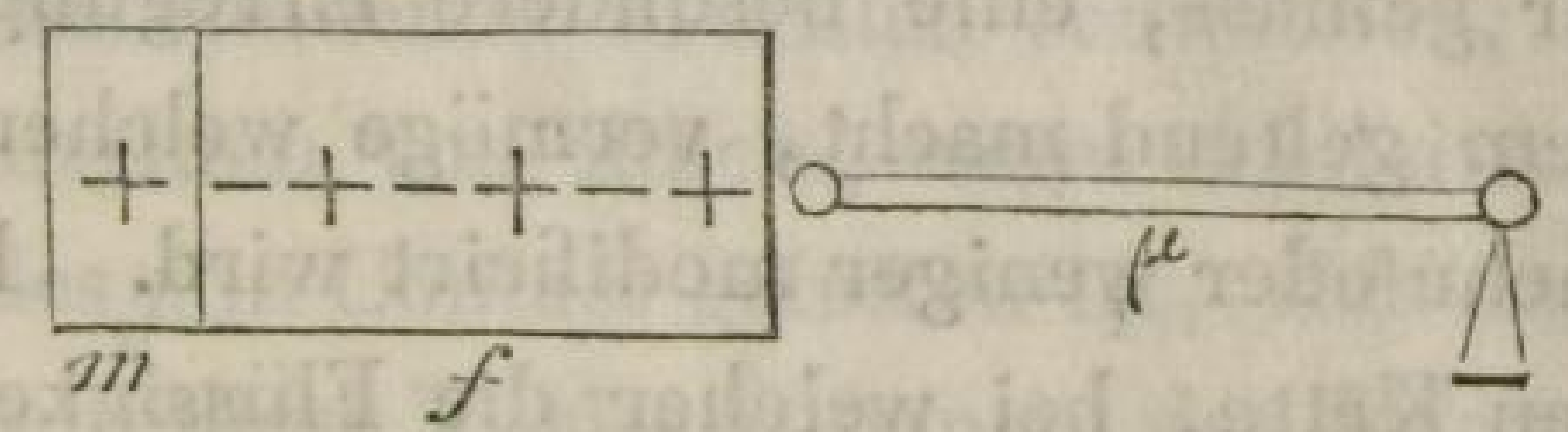

mit dem Leiter $f$ zweiter Classe positiv elektrisch wird, so wird dagegen fim Contact mit $m$ negativ elektrisch; aber diese negative Erregung des $f$ ist nicht etwa so wie die Flüssigkeit in einem Filtrum, durch seine ganze Masse verbreitet, sondern sie findet zunächst am stärksten nur in der Flüche des $f$ Statt, mit der es das $m$ berührt, und an dem entgegengesezten äussersten Extreme zeigt sich das $f$, so wie $m$ selbst, stets positiv elektrisch. Dasselbe nur unter Vertauschung der Zeichen findet Statt, wenn $m$ gegen $f$ negativ, und $f$ gegen $m$ positiv elektrisch wird, in welchem Falle $f$ am üussersten Extreme allemal negativ elektrisch erregt ist.

Ungeachtet dieses polare Verhalten schon durch die oben angegebenen Erfolge, mittelst der Armaturen in der geschlossenen Kette, auf das entschiedenste dargethan ist, so ist dennoch mit den eben angeführten 
Bestimmungen zugleich die Anfforderung sehr nahe gelegt, es auch ausserhalb der Kette durch die unmittelbare Untersuchung des äussersten Extrems der Flüssigkeit zu constatiren. Und in der That ist es möglich, auch auf diesem kürzesten Wege die Ueberzengung von der Richtigkeit des Gesagten sich zu verschaffen, nur ist dabei die experimentale Demonstration nicht so direct, als sie auf den ersten Blick scheinen mag und zwar deshalb, weil das zu prüfende Extrem der Flüssigkeit mittelbar oder unmittelbar immer wieder durch ein Metall untersucht werden muss, das jedes Mal, seiner Natur gemäss, eine besondere Erregung für sich von Neuem geltend macht, vermöge welcher das Ergebniss mehr oder weniger modificirt wird. In der geschlossenen Kette, bei welcher die Flüssigkeit in der Wechselwirkung mit den Haupterregern so kräftig erregt ist, dass dadurch die specifische Erregung zwischen der Flüssigkeit und den Armaturen bei weitem überboten wird, tritt diese Modification nicht so sichtbar hervor.

Es finde der in der obigen Zeichnung versichtbarte Fall Statt: das ursprünglich mit der Flüssigkeit $f$ im Contact begriffene Metall $m$ sey positiv, $f$ also in der Berührungsfläche negativ und am anderen Extreme positiv. Wird nun dieses letztere mit einem zweiten Metalle $\mu$ in Verbindung gesetzt, welches beim Contacte mit demselben an und für sich schon negative Elektricität empfüngt, während $f$ positiv erregt wird, so wird diese Wirkung durch die bereits zwischen $m$ und $f$ Statt findende Thätigkeit erhöht und in gleichem Maasse wird eben dadurch auch die gegenseitige Erregung zwischen $m$ und $f$ selbst verstärkt, so dass nun 
von den beiden auf entgegengesetzten Extremen des $f$ liegenden Metallen das erstere $m$ stärker positiv, das andere $\mu$ stärker negativ hervortritt, als jedes dieser Metalle an und für sich einzeln und allein in der Berührung mit $f$ erregt wird. - Wenn dagegen' $\mu$ ein Metall von der Art ist, dass es in der Berührung mit $f$ an und für sich, eben so wie $m$ positiv, und dass $f$ daher auch am zweiten Extrem, durch welches es mit $\mu$ in Verbindung trilt, negativ wird, so wirken die Thätigkeiten einander entgegen, und die Erregung wird in beiden mit dem $f$ auf entgegengesetzten Seiten zugleich verbundenen Metallen schwächer, als sie in jedem einzelnen von ihnen, wenn es allein mit einem Extrem des $f$ in Contact getreten ist, sich darstellt, ja sie kann auf diese Weise zu einem der Wahrnehmung völlig entzogenen Minimum herabsinken.

$\mathrm{Da}$ die elektrische Erregung zwischen den $\mathrm{Me}$ tallen und Flüssigkeiten so schwach ist, dass schon sehr günstige Umstünde dazu erforderlich sind, wenn sie durch den einfachen Gebrauch des Condensators dargestellt werden soll, so bediene ich mich, um die obigen Erfolge zu versichtbaren, zweier Condensatoren zugleich, deren Platten sechs Zoll im Durchmesser halten und, wie gewöhnlich, auf der Innenseite mit Firnissüberzogen sind. Der eine dieser Condensatoren ist, wie die nachstehende Figur andeutet, sogleich mit dem Goldblattelektrometer verbunden; die untere Scheibe $k$ ist eine Kupferplatte, die obere mit dem isolirenden Handgriffe versehene $z$ ist von Zink. Dagegen ist dic untere Platte $\boldsymbol{z}^{\prime}$ des zweiten Condensators, welche auf einem isolirenden Stative ruht, ton Zink, und die obere $k$ ', welche wieder an einer gläsernen Handhabe getragen 


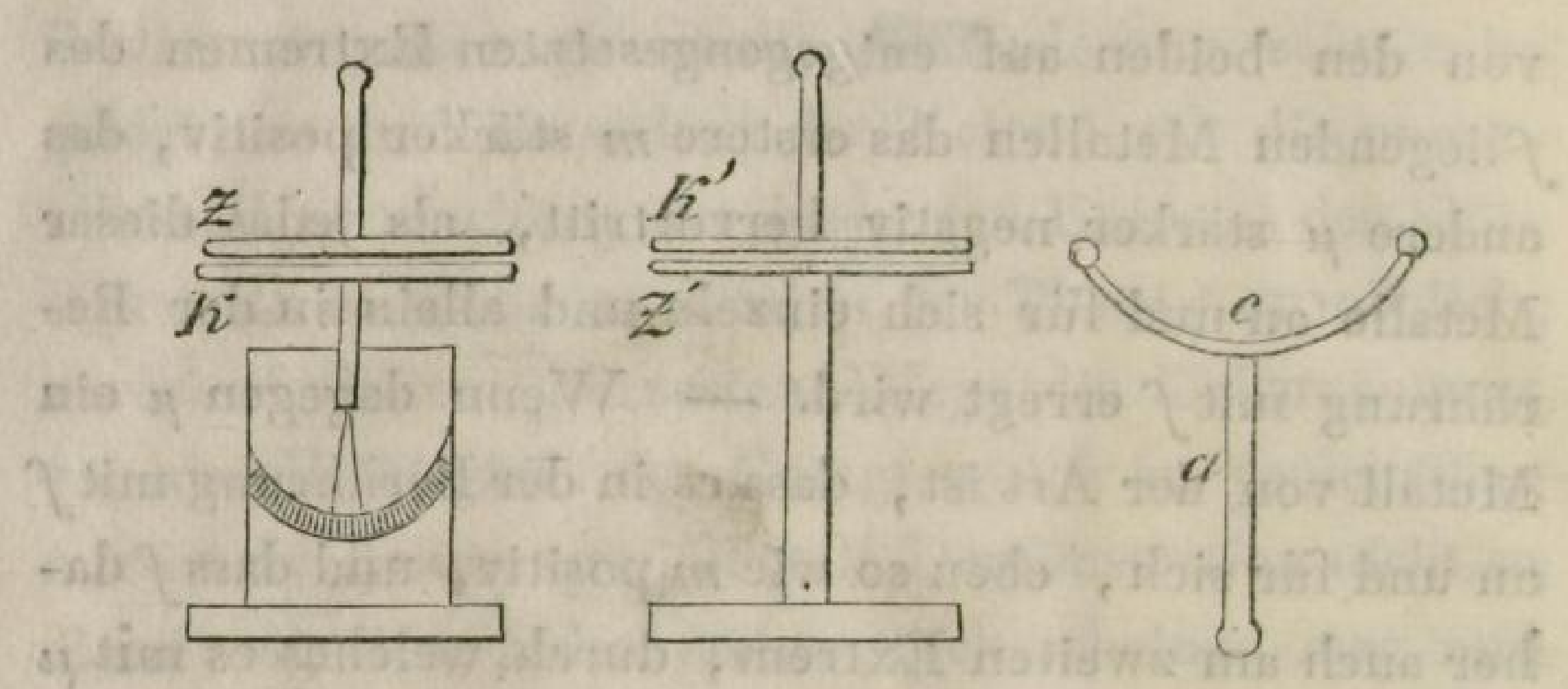

wird, von Kupfer. Zugleich werden zu dem Experimente zwei Hülfsconductoren gebraucht, deren jeder auf einem isolirenden Stiel $a$ einen gebogenen, an den Extremen mit kleinen Knöpfen versehenen Drath $c$ trägt, der eine dieser Conductoren ist von Kupfer, der andere ron Zink.

Man deckt num auf ein Kupferblech von etwa 6 Zoll im Gevierten eine beinahe eben so grosse mit verdünnter Schwefelsäure getränkte, und durch starkes Auspressen von aller frei schwimmenden Flüssigkeit befreite, Pappscheibe, legt das Blech auf die Fläche der linken Hand, und berührt, den kupfernen Conductor in der Rechten haltend, mit dem einen Knopfe desselben die feuchte Pappscheibe, mit dem andern die Platte $k$ etwa 8 Secunden lang, während der Daumen der linken Hand die Platte $z$ ableitend berührt. Nachdem dieses geschehen, wird der Deckel $z$ an dem isolirenden Handgriffe aufgehoben und mit $z^{\prime}$ eben so lange in Berührung gebracht, während $l^{t}$ mit der Hand ableitend berührt wird; darauf wird $z$ wieder auf $k$ gelegt und man setzt nun die an der gläsernen Handhabe abgehobene Platte $k^{\prime}$ mit $k$ in Contact, während die Hand oder der Finger eben so lange ableitend auf $z$ ruht. Nachdem hiernächst $k^{\prime}$ wieder an seinen Ort gebracht und der Finger 
von $z$ abgezogen worden, so zeigen mit dem Anfleben von $\boldsymbol{z}$ die Goldblättchen des Elektroscops in der Regel eine unzweideutige Divergenz von etwa 5 bis 5 Graden, und man findet die Erregung des Kupfers gegen die Flüssigkeit auf diese Weise constant positiv.

Nachdem das Eirektrometer und die Condensatoren von aller Elektricität so vollständig als möglich befreit sind, wird auf ein Zinkblech von der Grösse des vorhin gebrauchten Kupferblechs dieselbe oder eine eben so wie vorhin mit der nehmlichen Flüssigkeit getränkte Pappscheibe gedeckt; man legt das Blech abermals auf die linke Hand, deren Daumen jetzt die untere Platte $k$ ableitend berührt, indem man zugleich die Flüssigkeit und die Platte $z$ durch den mit der Rechten gefassten Conductor von Zink in Verbindung setzt; bringt darauf $z$ mit $z^{\prime}$ in Contact, während $k^{\prime}$ mit dem Finger ableitend berührt wird, setzt darauf wieder $k^{\prime}$ mit $k$ in Contact, während der ableitende Finger auf $z$ ruht und hebt demnächst $\approx$ ab. Die Goldblättchen gehen sodann in' der Regel wieder etwa 3 bis $5 \mathrm{Grad}$, und zwar constant mit $+\boldsymbol{E}$ auseinander, woraus sich also ergiebt, dass' der Zink im Contact mit der Flüssigkeit negative Elektricität empfängt.

Der kupferne Conductor wurde, wie sich gleich zu Anfang ergab, an dem einen Extreme des flüssigen Leiters schwach positiv erregt, wenn das andre Extrem mit einem Kupferbleche armirt ist. Man prüfe nun abermals die Erregung desselben ganz so, wie das erste MaI, nur mit dem Unterschiede, dass man das audere Extrem des Leiters zweiter Classe mit einem Zinkbleche armirt und man wird ihn abermals positiv, aber bei weitem in den meisten Fällen ungleich stärker erregt 
finden; sō dass die Divergenz der Goldblättchen, die anfünglich etwa nur auf 3 bis 5 Grad sich erstreckte, jetzt 10 bis 15 Grade betragen wird.

Eben so untersuche man die Erregung des andern Conductors von Zink gleichfalls völlig so, wie es das erste Mal geschah, aber mit dem Unterschiede, dass die Flüssigkeit auf der andern Seite nicht durch Zink, sondern durch ein Kupferblech armirt wird, und man wird abermals, wie vorhin, eine negative, aber ungleich stärkere Erregung wahrnehmen, bei welcher die Divergenz in der Regel wieder mehr als das Doppelte der anfänglichen zu betragen pflegt.

Man kann den Versuch abändern, indem man die Handhaben aus $z$ oder $k^{\prime}$ ausschraubt und diese Platten selbst, jene auf das Elektroscop, diese auf das Stativ schraubt, und dagegen $k$ und $z^{\prime}$ mit den in sie eingeschraubten Glasrohren zu Deckplatten macht. Wiederholt man das ganze Verfahren alsdann nochmals unter Beobachtung der Regel, dass bei allen Berührungen immer nur das gleiche Metall, Kupfer mit Kupfer, Zink mit Zink, in Contact gebracht wird, so werden die Goldblättchen, welche vorhin in allen Fällen mit $+E$ auseinandergingen, jetzt stets mit $-E$ divergiren und man wird dasselbe Resultat constatirt sehen, dass das Kupfer gegen die Flüssigkeit positiv, der Zink nogativ erregt wird, und zwar jedes $\mathrm{Mal}$ in einem Grade, der, wenn das $f$ auf beiden Seiten mit den verschiedenen Metallen in Berührung sich befindet, ungleich stärker, als bei der Armirung mit einem und demselben Metalle hervortritt.

Bei günsliger Atmosphäre und mit vorzüglichen Apparaten ist es möglich, dasselbe Resultat, wie es 
mir öfter gelungen ist, ohne alles Dupliren, schon durch einfache Condensation unzweideutig darzulegen; zu andern Zeiten reicht man dagegen wieder noch nicht mit dem Dupliren aus und muss, um eine entschiedene Divergenz im Elektroscop hervorzubringen, zu einer mehr als zweimaligen Uebertragung seine Zuflucht nehmen, wodurch allerdings die Reinheit des Experiments gefährdet wird, das überdies eine nur durch Uebung zu erwerbende Bekanntschaft mit den mancherlei Eigenthümlichkeiten in der Wirkungsart des ganzen Apparats voraussetzt, um beim Gebrauche desselben vor leicht möglichen Tüuschungen und Anomalien hinlänglich gesichert zu seyn. Der hier angegebene, durch eine sehr grosse Zahl von Wiederholungen und unter den mannigfaltigsten Abänderungen durchaus verbürgte Erfolg bleibt übrigens im Wesentlichen derselbe, man mag statt der Schwefelsäure eine andere Säure, eine alkalische oder sonst irgend eine salzige Solution nehmen; allemal, wenn die Wirkung sonst nur hinlänglich in die Augen fallend ist, wird man das Kupfer positiv, den Zink negativ erregt finden, schwächer, wenn die Flüssigkeit mit einem und demselbenstärker, wenn sie mit verschiedenen Metallen auf beiden Seiten armirt ist; nur ist zu berücksichtigen, dass manche Solutionen, wie z. B. die der Salpetersäure, des Salmiaks u.s. w. zumal in sehr concentrirtem Zustande, in den ersten Momenten einen verhältnissmässig starken, aber sehr bald mit Schnelligkeit herabsinkenden, Grad der Erregung bewirken, ein Nachtheil, der sich in geringerem Masse überall mehr oder weniger bemerklich macht, den man aber bei diesem Versuche dadurch beträchtlichbeseitigt, dass man der feuchten Pappe alle ihrer

B 
Oberfläche frei adhärirende Flüssigkeit zwischen Fliesspapier entzieht und sie selbst, vor dem Gebrauche, zum gleichmässigeren Abtrocknen noch einige Zeit der Luft ausgesetzt lässt, damit die wirkliche chemische Einwirkung der Flüssigkeit in das Metall so weit als möglich zurückgedrängt und die elektrische Erregung, als die Tendenz zum Chemismus, dafür um so kräftiger und reiner herausgefordert werde.

Das polare Verhalten der Leiter zweiter Classe in der bei ihrem Contact mit den Metallen Statt findenden Erregung und Fortleitung der Elektricität ist also durch das obige von einer neuen Seite und zwar so direct und unmittelbar, als es nur möglich ist, erwiesen. Es ist ein Factum, dass im Contacte mit $\operatorname{dem} f$ das Kupfer (k) an und für sich positiv, also $f$ negativ - und der Zink $(z)$ an und für sich negativ, also $f$ positiv erregt wird; wäre nun das $f$ nichts anders als nur ein in allen Puncten gleichmässig erregtes Medium, welches die Elektricität, etwa nur so wie ein Schwamm das Wasser durch sich hindurch ziehen liesse, so müsste, wenn das $f$ auf entgegengesetzten Seiten mit dem $k$ und z zugleich armirt wird, der Grad der Erregung des $k$ und z durch die Vereinigung der entgegengesetzten Elektricitäten vielmehr herabsinken; da aber gerade das Gegentheil in der faktisch erwiesenen ungleich höher steigenden Erregung der Metalle Statt findet, so ist damit unfehlbar eine höhere Wirksamkeit des Leiters zweiter Classe dargethan, der zu Folge er, wie ein Magnet, auf entgegengesetzten Extremen allemal auch entgegengesetzte Relationen der Thätigkeit bei der elektrischen Erregung nach Aussen richtet und in dem Maasse, in welchem die Intensität dieser Thä- 
tigkeit auf der einen Seite erhöht wird, aush vermöge des von Natur ihm eigenthümlichen Erregungsprincips, eine um so viel höhere Intensität des entgegengesetzten Verhaltens aufder andern Seite aus sich entwickelt.

Dieser Satz ist für die Elektricitätslehre und insbesondere für die Theorie der galvanischen Kette ein Fundamentaltheorem von der grössesten Wichtigkeit, er liegt als ein solches allen folgenden Entwickelungen überall zum Grunde und durch ihn allein gewinnt bereits dieses Gebiet des Wissens, wie es der weitere Verfolg dieser Schrift darthun wird, eine Gestalt und Begründung, in welcher es zwar von den herrschenden Vorstellungen bisheriger Lehrgebäude gänzlich abweicht, aber darum um so sicherer auf Haltbarkeit, Wahrheit und früher oder später allgemein werdende Anerkennung Anspruch zu machen berechtigt ist, weil esvon der Willkühr der gewöhnlichen bloss formalen Betrachtungsweise sich gänzlich gereinigt hat und reelle Thatsachen an die Stelle von hypothetischen Fictionen setzt, durch welche man bisher von der wahren Idee der Wissenschaft ungleich mehr entfernt als derselben näher geführt worden ist.

Das, was oben als der eigentliche Zustand der elektrischen Erregung einer Flüssigkeit bei ihrem Contact mit einem Mctalle nachgewiesen worden ist, findet natürlich auch dann, wenn zwei verschiedene Flüssigkeiten im gemeinsamen Contact sich wechselseitig erregen, bei jeder einzelnen von ihnen Statt. Diejenige von beiden also, welche gegen die andere in der Berührungsfläche positiv erregt wird, ist auf der Aussenseite negativ und die andere, welche in der Berührungsfläche

B 2 
negativ wird, ist auf der Aussenseite positiv elektrisch. Soll nun die elektrische Relation zweier sich berührenden Flüssigkeiten ausgemittelt werden, so scheint dieses zunächst nur dadurch möglich zu seyn, dass die Aussenseiten der Flüssigkeiten mit Metallen armirt werden und dass die Erregungen der letzteren durch den einfachen oder Doppel - Condensator untersucht werden. Weil aber durch die Berührungen der Metalle mit den Flüssigkeiten zugleich wieder eigenthümliche Erregungen zwischen beiden bedingt sind, so könnte diese Prüfung nur alsdann direct entscheidende Resultate geben, wenn die wechselseitige Erregung der Flüssigkeiten so kräftig wäre, dass durch sie die specifischen Erregungen zwischen den Metallen und Flüssigkeiten überboten und verdrängt würden. Da dieses indess entweder gar nicht oder höchstens nur sehr selten unter besonderen Umständen geschieht, so ist schon darum eine andere Prüfungsmethode wünschenswerth, die in allen Fällen die Resultate mit Klarheit und Zuverlässigkeit finden lässt. Und eine solche Methode ist. in der That dargeboten durch den Gebrauch der elektromaguetischen Kette, mit welcher man es in seiner Gewalt hat, der Erregung der Flüssigkeiten über die specifischen Erregungen der Metalle ein solches Uebergewicht zu geben, dass durch sie mittelst der Anwendung des Multiplicators, bei Berührungsflächen von ganz müssiger Grösse, eine der Richtung und Art nach höchst bestimmte Ablenkung der Magnetnadel bewirkt zu werden vermag, die das unfehlbarste Criterium für die elektrische Relation der in Wechselerregung begriffenen Substanzen abzugeben verspricht, sobald nur vor allen Dingen zuvörderst für die zuverlässige Anwen- 
dung dieses Criteriums ein eben so unfehlbares und völlig sicher begründetes Princip festgestellt ist.

Dass aber dieses Princip bis jetzt noch gänzlich fehle und seine Feststellung von der höchsten Nothwendigkeit sey, geht schon aus dem Umstande hervor, dass man durch die zusammengesetzte Kette bekanntlich eine ganz entgegengesetzte Ablenkung als durch die einfache Kette bedingt sieht; es wird noch dringender durch den Umstand, von dem gerade der eben angeführte nur das Corollar ist, nehmlich dass auch bei der einfachen Kette, je nachdem sie dem gewöhnlichen Schema: $z f f k$ oder dem invertirten: $f z k f$ entspricht, unter sonst gleichen Bedingungen völlig entgegengesetzten Ablenkung erfolgt *); und besonders mahnt die Erfahrung sehr fülllbar an diese Nothwendigkeit durch manche bereits vorhandene in der angegebenen Beziehung gänzlich verfehlte Bestimmungen and namentlich 'durch das Beispiel, welches ein $\mathrm{Na}$ -

*) Bei der Anordnung: $z f f k$ liegt der flüssige Leiter in der Mitte der Kette zwischen den beiden Metallen. Gesetzt, eine solche Kette stehe im Norden der magnetischen Boussole und der Drath gehe von der Kupferseite aus über die Nadel fort und unter ihr zum Zink zurück, so ist die Ablenkung östlich. Bei der Anordnung: $f z k f$ liegen hingegen tdie beiden Metalle, sich berührend, in der Mitte der Kette und ihre Aussenflächen sind mit der in Pappscheiben gesammelten Flüssigkeit bedeckt. Wenn nun bei gleicher Stellung wie vorhin der Drath, welcher dort vom Kupfer aus über die Nadel fortging, jetze von der Oberfläche der Flüssigkeit, mit welcher das Kupfer bedeckt ist, über die Nadel fort und unter ihr zur Oberfläche der mit dem Zink in Berührung stehenden Flüssigkeit zurückgeführt wird, so ist die Ablenkung die entgegengesetzte der vorigen. sie ist nicht mehr östlich, sondern westlich. 
turforscher des Auslandes, auf dessen Untersuchungen Gewicht gelegt zu werden scheint, uns vor Augen stellt, indem er eben bei dem gänzlichen Mangel jenes Princips zu völlig naturwidrigen Resultaten gelangt und einem Schiffer gleich geworden ist, der nach Norden zu steuern vermeint, während er, durch eine falsche Signatur seines Compasses verleitet, unaufhörlich nach Süden geführt wird.

Die Hervorhebung eines speciellen Falls der Art wird dieses ausser Zweifel setzen und zu gleicher Zeit einen Ausgangspunct für die Entwickelung des erforderlichen Princips darbieten.

Eine Pappscheibe von 3 Zoll im Gevierten wurde mit einer Solution von kaustischem Kali, die mit dem Dreifachen ihres Volumens an Wasser verdünnt war und eine zweite eben so grosse Pappscheibe wurde mit flüssiger nach demselben Verhältnisse verdünnter Schwefelsäure getränkt. Jede von diesen Scheiben, nachdem sie von der üherflüssigen Feuchtigkeit befreit war, wurde auf beiden Seiten mit eben so grossen Kupferblechen armirt. So brachte ich zuerst die Scheibe, welche die alkalische Solution enthielt, yo Secunden lang mit der Unterplatte $k$ des Condensators (s. d. obige Fig.) in Berührung, wahrend $z$ mit der Hand ableitend berührt wurde; darauf wurde unter der bekannten Behandlung die jetzt noch fast ganz unmerkliche Elektricität vervielfacht, indem $z$ mit $z^{\prime}$, sodann $k^{\prime}$ mit $k$, darauf nochmals $z$ mit $z^{\prime}$ und zuletzt $k^{\prime}$ mit $k$ in Berülrung gesetzt wurde. Hiernächst divergirten, als z aufgehoben wurde, die Goldblättchen des Elektrometers mit $15^{\circ}+E$. Bei nochmaliger Wiederholung des Versuchs, nachdem jedesmal die Condensatoren 
von aller Elektricität so weit befreit waren, dass sie an und für sich bei einer so oftmaligen Berührung der Platten keine Divergenz hervorbrachten, zeigte sich jedesmal, so oft $k$ mit der Armatur der alkalischen Pappe berührt worden war, dieselbe Divergenz von $15^{\circ}+E$ höchst constant. - Ganz auf dieselbe Weise und unter den nehmlichen Umständen bewirkte die Armatur der mit der Säure durchzogenen Pappe eine noch etwas stärkere Divergenz von $16^{\circ}$ bis $17^{\circ}+\boldsymbol{E}$.

Ich nahm nun von jeder Scheibe auf der einen Seite das armirende Kupferblech fort und legte die Pappe mit den entblössten Flächen aufeinander, dass also die Säure und das Alkali sich unmittelbar berührten, während die beiden Aussenseiten mit den beiden übrigen Kupferblechen armirt blieben. In diesem Zustande wurde zuerst die Armatur auf der Seite der Säure 10 Secunden lang mit $k$ in Berührung gesetzt, und jetzt zeigte sich schon beim ersten Aufheben der Deckplatte $z$ eine merkliche Divergenz; nachdem aber die Elektricität durch ein eben so oftmaliges Uebertragen als vorhin vervielfältigt worden war, divergirten die Blättchen mit $28^{\circ}+E$. Da also das Kupfer jetżt im Contact mit der Säure ein um so viel stärkeres $+E$ besass, so musste mithin die Süure auf der Aussenfläche jetzt so viel stärker negativ und auf der Innenfläche in der Berührung mit dem Alkali folglich entsehieden positiv erregt seyn. Das Alkali musste demnach in der Berührung mit der Säure auf der Inmenfläche negativ erregt seyn und es war zu erwarten, dass entweder seine Aussenfläche positiv und die kupferne Armatur derselben negativ seyn müsse oder dass, wenn die letztere ihre eigenthümliche positive Erregung 
noch in einer bestimmten Spannung fortwährend gegen die Flüssigkeit geltend machen sollte, diese wenigstens ungleich schwächer seyn müsse, als sie sich anfänglich an und für sich zeigte. Dieses letztere war in der That der Fall; denn als die Armatur auf der Seite des Alkali 10 Secunden lang mit $k$ in Berührung gesetzt und übrigens eben so wie sonst verfahren worden war, so zeigte sich zuletzt nur eine sehr schwache Divergenz von $3^{\circ}$ bis $4^{\circ}+E$. Eine grosse Zahl von Wiederholungen dieses Versuches unter vielfältigen Abänderungen ergaben im Wesentlichen immer dasselbe Resultat und so ist also, wenn gleich in Folge der Beharrlichkeit, mit welcher die Metalle ihre specifische Erregung gegen die Flüssigkeiten beim einfachen Contact ausser der Kette stets geltend machen, das Kupfer auf der Seite des Alkali niemals entschieden negativ sich zeigte, dennoch die verminderte positive Erregung desselben in Verbindung mit der erhöhten positiven Erregung der Kupferarmatur auf der Seite der Säure ein unzweideutiger faktischer Beweis, dass beim gegenseitigen Contacte einer sauren und alkalischen Lösung die erstere in der Berührungsfläche mit positiver, die letztere mit negativer Elektricilät erregt werde.

Nach dieser ein für allemal gültigen Bestimmung ist es nun von Wichtigkeit, zu sehen, unter welcher Gestalt dieselbe Relation sich durch die Magnetnadel zu erkennen gebe.

Weun eine einfache Kette: $z f k$ im Norden der Boussole steht und der Schliessungsdrath, vom Kupfer $k$ aus, über die Nadel fort und unterhalb derselben von Süden nach Norden hin wieder zum Zink, z zurückgeht, so wird die Nadel nach Osten hin abgelenkt. 
Stellt man nun auch die Kette; welche aus den beiden im Contact begriffenen, auf den Aussenflächen mit Kupferblechen armirten Solutionen besteht, im Norden der Boussole auf und leitet den Schliessungsdrath von der mit der Säure verbundenen Armatur über die Nadel fort und unter ihr wieder zu der mit dem Alkali verbundenen Armatur zurück, so sieht man die Nadel eben so, wie vorhin bei der Kette $z f k$ und zwar sehr lebhaft nach Osten hin abweichen. Die Armatur auf der Seite der Säure verhält sich also offenbar wie das Kupfer oder überhaupt wie das beim Contact negative Metall, und die Armatur auf der Seite des Alkali verhielt sich wie der Zink oder überhaupt so wie das beim Contact positive Metall in der Kette $\boldsymbol{z} f \boldsymbol{k}$; aber schon aus dem, was bereits oben als ein fest begründetes Factum erkannt worden ist, geht hervor, dass man deshalb durchaus auf keine Weise zu dem Schlusse berechtiget sey: jene mit der Säure verbundene Armatur sei negativ, diese mit dem Alkali verbundene positiv und die Säure selbst sey folglich im Contact mit dem Alkali negativ, letzteres hingegen im Contact mit jener positiv. Der Schluss würde nur dann als richtig gelten können, wenn man mit Ueberzeugung wüsste, dass die elektrische Polarität der Metalle beim Contact auch in der That dieselbe sey mit derjenigen, unter welcher sie in der Kette wirksam sind; aber wo sind die Beobachtungen oder die Argumente, aus denen diese Ueberzeugung hervorgehen könte? Alles, was vom Kupfer und Zink im Obersatze jenes Syllogismus auszusagen ist, bezieht sich lediglich nur auf das, was die Metalle an und für sich im Contact, nicht auf das, was sie in der geschlossenen Kette zeigen und wer nicht gegen logische Grundregeln verstossen 
will und, was die Hauptsache ist, die Erscheinungen mit Unbefangenheit und frei von hypothetischen Fesseln betrachtet, der kann nicht nur nicht in Gefahr kommen, jenen Fehlschluss zu machen oder in den Ergebnissen, wie sie sich das eine $\mathrm{Mal}$ am Elektrometer, das andere Mal an der Boussole aussprechen, einen Widerspruch zu erblicken, sondern er wird vielmehr, der wwahren Natur der Sache gemäss, die elektrische Polarität der Metalle im Contact und die Polaritüt derselben, unter welcher sie in der Kette wirksam sind, als zwei ganz von einander verschiedene Momente ansehen und sich im Gegentheil zu dem Schlusse berechtigt halten, den ich bereits, von dem Gesichtspuncte einer umfassenderen Combination aus, schon längst ausgesprochen habe, dass die Polarität der Metalle in der geschlossenen Kette in der That die entgegengesetzte von derjenigen seyn müsse, welche sie in der Contactelectricität versichtbaren. Dies wird sich indess im Verfolg dieser Schrift anf eine ganz unzweifelhafte und faktische Weise ergeben und es kommt hier mehr zunächst noch darauf an, Vorurtheile und falsche Ansichten zu beseitigen, als bereits positive Schlussfolgen zu bilden. Es ist zu dem Ende noch zu bemerken, dass der zuletzt erwähnte Versuch noch in einer andern Form anzustellen sey, wenn man nehmlich, statt die Flüssigkeiten in Pappscheiben zu sammeln, sie gesondert in zwei Gefässe von Glas oder Porzellan giesst, in jedes der letzteren sodann ein Extrem des um die Magnetnadel gewundenen Multiplicators taucht und darauf die Flüssigkeiten durch einen mit reinem Wasser befeuchteten Streifen vonFliesspapier, Amianth oder dergl. verbindet. In dem Augenblicke dieser Verbindung sieht man die 
Nadel 'sehr bestimmt abgelenkt und zwär ganz rollkommen der obigen Regel entsprechend, so dass das mit der Säure verbundene Extrem des Schliessungsdrathes sich wie das`Kupfer, und das andere mit dem Alkali verbundene sich wie der Zink der einfachen Kette $z f k$ verhält. Da nun in diesem letzteren Falle im Augenblicke der Reaction'auf die Nadel noch keine unmittelbare chemische Vereinigung der sauren und alkalischen Flüssigkeit sondern nur ein bloss durch Wasser vermittelter Contact derselben Statt findet und der Erfolg dennoch vollkommen eben so, wie beim unmittelbaren Contact der Flüssigkeiten im vorhergehenden Versuche ausfällt, so ist zugleích gewiss, dass die Erregung der Flüssigkeiten in beiden Fällen nicht verschieden seyn könne und dass man hiernach wenigstens durchaus keinen Grund habe, Zwischen einer elektrischen Erregung bei der mit dem unmittelbaren Contacte vor sich gehenden chemischen Vereinigung und zwischen einer solchen, die bloss mit dem Contacte, ohne eine solche Vereinigung bedingt sey, einen Untertchied zu machen.

Wer die Dialektik der elektromagnetischen Erscheinungen sichern Blickes durchschaut, der sieht alsbald, dass die obigen Erfolge nicht nach der Analogie der Wirkung der gewöhnlichen Kette $z f k$ zu deuten seyen, sondern vielmehr nach derjenigen, welche dem invertirten Schema $f z k f$ entspricht, bei welcher die eigentlichen Erreger, welches hier die Innenflächen der Säure und des Alkali sind, nicht ausserhalb, sondern in der Mitte der Kette liegen und er vermag daher, dem äffenden Scheine zum Trotz, aus dem an und für sich mit völliger Consequenz ausgesprochenen Erfolge das wahrhafte Resultat: dass die 
Säure in der Berührung positiv; das Alkali negativ sey, dennoch mit einer Sicherheit, die noch weiter unten in ihr volles Licht treten wird, eben so entschieden und, wegen der experimentalen Klarheit und Unfehlbarkeit jenes Erfolgs, noch bequemer und zuverlässiger an der Boussole als am Condensationselektrometer abzulesen. Bei letzterem liegt der mögliche Trug viel weniger in der Reflexion als in der unzuverlässigen Reizbarkeit des Condensators, beim Gebrauche der Boussole hingegen ist die Wirkung des Apparats an sich von so gediegener Beständigkeit, dass der Vorwurf der verkehrten Erkenntniss, als ein Document der eigenen dialektischen Nachlässigkeit einzig und allein auf uns selbst zurückfallen würde, wenn wir, so wie jener Physiker, aus dem Hergange das Resultat herauslesen wollten, dass die Säure negativ und das Alkali positiv sey. Aber derselbe Naturforscher bleibt noch nicht bei diesem Irrthume stehen; er steigert ihn durch einen neuen Irrthum im Irrthume vollends bis zur höchsten Verwirrung. Er hat nehmlich die wahre elektrische Relation der Säuren und Alkalien, wie sie beim unmittelbaren Contact Statt findet, durch Ueberlieferung oder eigene Beobachtung am Elektrometer kennen gelernt; ihr Verhalten aber, wenn sie durch einen feuchten Amianthstreifen zwar verbunden, aber von chemischer Vereinigung noch zurückgehalten sind, hat er allein in der Reaction auf die Magnetnadel beobachtet und auf seine Weise durch jenen Trugschluss ganz entgegengesetzt gedeutet und nun zieht er daraus die Folgerung: jene einzig und allein Statt findende Errègung sey nicht die wahre elektrische Relation, sondern sie sey nur durch die beim Contact er- 
folgende chemische Thätigkeit hervorgerufen; diese aber (die gar nicht existirt, sondern allein durch falsche Deutung in die Gegenstände hineingelegt ist), sey die eigentliche und ächte elektrische Relation der Säuren und Alkalien, weil sie einzig und allein beim Contacte derselben ohne zu gleicher Zeit Statt findenden chemischen Effect erzeugt werde.

Es sind indess nicht bloss diejenigen Resultate dem Irrthum unterworfen, weilche derselbe Physiker aus seinen Beobachtungen an der Boussole über die elektrischen Relationen gefolgert hat; dasselbe gilt auch von einem grossen Theile der Ergebnisse, welche in Folge seiner Beobachtungen an einem condensirenden Elektroscop Statt haben sollen, das, seiner Beschreibung gemäss, das non plus ultra aller trügerischen Reizbarkeit darstellt, die bekanntlich selbst, wenu sie nur in dem gewöhnlichen geringern Grade Statt fand, gegen Zuverlässigkeit der Aussage dieses Instruments über die leisesten und zartesten Anklänge der elektrischen Erregung von der Skepsis vielfältig in Anspruch genommen worden ist.

Nach meiner unten entwickelten Bestimmungsmethode, welche die Resultate in einem bisher unerreichten Grade von Schärfe, Zuverlässigkeit und experimentaler Einfachheit darbietet, sieht man auf das Entschiedenste die ganze Reihe der Metalle in zwei Classen zerlegt, von denen die Glieder der einen, welche nächst Silber, Gold und Platin auch Quecksilber und Kupfer in sich begreift, gegen das Wasser, gegen die Säuren, so wie gegen die Alkalien und andere Solutionen durchgehends positiv auftreten und zwar um so positiver, je negativer sio in der Metallreihe sind, 
während die Glieder der andern Classe eben so constant gegen Wasser, Säuren, Alkalien und salzige Flüssigkeiten überhaupt ohne Unterschied negativ erscheinen und wieder um so negativer, je positiver sie sich in der Metallreihe verhalten. Diese constante Relation eines und desselben Metalls gegen alle Flüssigkeiten ohne Unterschied, welche sich mir durch umfassende und unmittelbare Prüfungen auf das Entschiedenste bewährt hat, geht zugleich als eine Folgerung aus dem Umstande hervor, dass die Kette $z f k$ die Magnetnadel unter sonst gleichen Umständen stets auf völlig gleiche Art ablenkt, man mag an der Stelle des $f$ eine Säure oder ein Alkali oder irgend eine andere Solution setzen, sobald nur die Metalle dieselben bleiben; wäre die Relation derselben Metalle gegen Säuren, Alkalien und überhaupt gegen verschiedene Flüssigkeiten verschieden, so müsste auch die Ablenkung der Magnetnadel durch die Kette bei denselben Metallen aber verschiedenen Flüssigkeiten bald diese, bald die entgegengesetzte seyn; aber eine solche Veränderlichkeit findet, wenn man rasch vorübergehende Anomalien von dem, was gesetzlich und constant ist, gehörig sondert, schlechterdings nicht Statt und es wird aus dem weitern Verfolg unserer Entwickelungen hervorgehen, dass diese Unveründerlichkeit in der Abweichungsrichtung der Magnetnadel gerade das zuverlästigste Criterium für jene Unveränderlichkeit der Relation eines Metalls gegen die Flüssigkeiten sey.

Der erwähnte Naturforscher hingegen behauptet, dass im Allgemeinen, beim gegenseitigen Contact der Säuren und Metalle, die letzteren positive Elektricität annehmen und dass bei der Berührung mit alka- 
lischen Flüssigkeiten die Wirkungen entgegengesetzt seyen *).

Es wäre ein unnöthiges Unternehmen, hier in specielle Untersuchungen einzugehen, welche theils die

*) Alle Erfolge dio aus älteren und neuern Versuchen hier gleichfalls als Einsprüche gegen die Richtigkeit der eben behaupteten Unveränderlichkeit der Relationen desselben Metalls gegen alle Flüssigkeiten vorgebracht werden möchten, sind entweder gar keine Facta, sondern nur falsche Resultate aus unrichtigen und principlosen Folgerungen wie z. B. die Relationen, welche aus der elektrischen Spannung an den Polen zusamengesetzter galvanischer Ketten hergeleitet sind, ohne dass man bis 'jetzt weder die richtige Vorstellung von dem elektrischen Zustande des Leiters zweiter Classe in der Kette, noch von dem eigentlichen Lokalverhältnisse ihrer Pole gehabt hat -oder diese Erfolge sind, wenn auch Facta, doch nur anomale und transitorische, nicht aber gesetzmässige und für den Zweck der Beobachtung brauchbare Erscheinungen. Dahin gehören z. B. die beobachteten Relationen gewisser Säurenjund Alkalien in festem Zustande, die schon darum nicht als entscheidend angesehen werden können, weil jene Substanzen in der rigiden Form ohne chemische Thätigkeit sind und nur den Namen, nicht aber die Natur der Säuren und Alkalien haben. - So ist ferner z. B. regulinisches Eisen im Contact mit der Solution des Schwefelkali in Wasser anfänglich positiv, bald aber stellt sich die wahre und bleibende Erregung ein, in welcher es, wie gegen alle übrige Flüssigkeiten, negativ wird. Wer also den ersten, bloss transitorischen Erfolg allein beobachtethat und ihn für den gesetzmässigen nimmt, der sagt gerade das Entgegengesetzte von dem aus, was wirklich gesetzmässig ist. Daher die Angaben, dass Ketten von Eisen, Kupfer und wässerigem Schwefelkali eine der gewöhnlichen entgegengesetzte Polarität zeigen, nur einen vorübergehenden und durchaus nicht den wahren Zustand der Sache bezeichnen. Aehnliche transitorische Zustände, die als blosse Vorspiele und Reactionen der eigentlichen und wahrhaften Erscheinungen weiter unten mit Bestimmtheit werden von uns erkannt werden, zeigen sich fast überall mehr oder weniger deutlich, zum Theil nur in momentaner Depression des Normalzustandes, oft aber auch in sehr hohem Grade und mit grosser Lebhaftigkeit, besonders bei der Anwendung sehr glatter, glänzender Metalloberflächen und können so zu unzähligen Täuschungen und ganz verkehrten Bestimmungen Veranlassung geben. 
Widersprüche, theils die mögliche Art der Entstehung einer solchen Aussage aus der Methode, wie der Beobachter seine Versuche angestellt hat, begreiflich zu machen suchten; es ist schon hinlänglich, zu bemerken, dass derselbe öfter zwischen der Condensatorplatte und dem zu prüfenden Metalle Papierstreifen einzuschieben für gut fand, um, wie er sagt, anomale elektromotorische Actionen zwischen den Metallen, die in unmittelbarem Contact seyn mussten, za verhindern. Wenn man beim Gebrauche eines Instruments, dessen Reizbarkeit so gross ist, dass es schon durch den elektrischen Zustand der Hand oder der Haupthaare seines Beobachters in einer Entfernung von mehreren Fussen irritirt wird, sich vollends noch dergleichen willkürliche Modificationen erlauben will, so wird es allemal möglich seyn, gerade diejenigen Aussagen von demselben zu erhalten, die man, seinen eignen oder fremden Hypothesen gemäss, für die allein richtigen zu nehmen geneigt ist.

Die Hypothesen unserer Physik mit den materiellen Imponderabilien in ihrem Gefolge gleichen den Götzenbildern, welche einerseits den Blick auf ein höheres Verständniss der Erscheinungen hinrichten sollen, während sie ihn andrerseits in den sinnlichen Formen und Beziehungen des gemeinen Bewusstseins noch fortwährend gefesselt erhalten und ihn eben dadurch immer tiefer in endlose Widersprüche und Missverständnisse verstrichen, welche die Erkenntniss, statt sie ihrem Ziele näher zu führen, nur noch immer weiter davon entfernen. Durch die Entdeckung des Elektromagnetismus hat die Wissenschaft eine Weihe erhalten, welche die Fesseln des bisherigen Heidenthums vollends von ihr ablösen und sie zur ungetrübten 
Anschauung der lebendigen Einheit aller Naturerscheinungen im Geist und in der Wahrheit empor richten wird; sie kann fortan, ohne in den bittersten Widerspruch mit sich selbst und den reichen Gaben zu gerathen, die ihr zo Theil warden, nur dadurch als ein selbstständiges Glied der Erkenutniss bestehen, dass sie allein in den Ideen der Erscheinungen ihre wahrhaften Bedeutungen ohne Bezug auf irgend ein kleineres oder grösseres Einzelne, zu erfassen trachtet und es sich zur einzigen Aufgabe macht, alles Besondere der Erscheinung auf diese Ideen zurück zu führen und darzuthun, wie jedes Einzelne nichts anderes ist, als nur das reflectirte Bild dieser Ideen, durch welches sie in dem heitern Spiegel der Naturoffenbarung sich manifestiren. Dies ist es, was die Physik in der That auch von Anbeginn ihrer Entstehung gewollt und wonach sie gestrebt hat; aber sie hat in dem bisherigen Kindesalter der Naturspeculation den Gegenstand verfehlt; statt der Ideen hat sie nur Hypothesen erfasst, sie hat statt des Gottes selber nur Götzenbilder angebetet.

Deutschlands Physiker dürfen vor denen aller andern Nationen stolz darauf seyn, dass ihnen als Deutschen eine Philosophie zugehört, durch welche jedes Erkennen, wemn es redlich und lauter ein höheres zu seyn strebt, wie gross oder gering sonst sein Unfang auch seyn möge, sich von den Schlacken einer Relativität für immer frei zu erhalten vermag, der sonst Alles, selbst das Bewusstseyn in den Formen des gewöhnlichen Erkenneus, anheim fält; - eine Philosophie, durch welche auch die Naturwissenschaft bereits lange vorbereitet ist, zu dem Schritte, mit dem sie im Begriffe ist, in die Reife des Iünglingsalters hinein zu C 
treten und für die Bestrebungen aller übrigen civilisirten Nationen ein allgemeines Vorbild der Nacheiferung zu -werden. Die Physiker desAuslandes, welche schon um der -Schwierigkeit der Sprache willen bis jetzt nicht vermögend gewesen sind, dem Deutschen in die Tiefen seiner Philosophie zu folgen, werden unfehlbar noch längere Zeit hindurch in der Einseitigkeit ihrer Schule beharren, die sie, bei allem Verdienst und selbst bei unbezweifelten Vorzügen, welche ihnen im Einzelnen und in der Entwickelung experimentaler Mittel eingerüumt bleiben müssen, dennoch fortwährend in der Entfernung von einer höhern Naturansicht, so wie in dem Mangel einer eindringlichen dialektischen Kraft für das Besondere des Erkennens erhalten werden; aber wenn sie früher oder später auf den wahrhaften Gehalt, auf den Kern und die reine Ideenfülle deutscher Speculation aufmerksam gemacht, von der verblendeten Idolatrie eines leeren Atomismus zurück zu kommen beginnen werden, so möchte es zu wünschen seyn, dass wenigstens dann nicht mehr irgend einem unter uns durch das Beispiel der Ausländer erst die Augen für die Gediegenheit der eigenen vaterländischen Schule geöffnet würden, die leider jetzt noch von so vielen Deutschen unverantwortlich verkannt, ja zum Theil lieblos und hämisch verschmäht wird.

In den elektromagnetischen Erscheinungen ist die Bedeutung und das Verhältniss der Elektricität und des Magnetismus so bestimmt ausgesprochen wie irgend eine Idee durch die Erscheinung nur offenbart zu werden vermag.

Der Magnetismus ist die allgemeine durch allen Wechsel der Processe hindurch greifende Tendenz der 
Masse zur Individualisation, oder, so fern die letztere auf der untern Stufe des Lebens durch den Chemismus in der bipolaren Form des synthetischen und analytischen Effects vermiltelt wird, er ist zunächst die Tendenz zum analytischen Effect des Chemismus; „ein Körper ist magnetisch" "heisst: er strebt aus der Indifferenz in der Totalität zu einer höhern Stufe der Selbstständigkeit hinauf, seine eine Hälfte, die südpolare d. h. die nach dem tellurischen Süden hin gezogene, (am Planeten selber die nördliche) ist vom vorherrschenden Individualisationstriebe ergriffen, während die andere, die nordpolare, gegen die Totalität zurück gedrängt und von ihr festgehalten wird; nach der einen Richtung will der Körper als ein Acides, Geistigeres aus sich hervor treten, während er nach der andern Richtung eín basisches Substrat, als das körperlichere Residuum an die Totalität der Masse zurück zu lassen genöthiget ist.

Die Elektricität ist die Gegenseite am unaufhörlich oscillirden Hebel der Lebensthätigkeit im Grossen; sie ist die Tendenz zum synthetischen Effect des Chemismus, die Wechselwirkung der Individuen, vermöge deren ein Differentes durch die Gegenthätigkeit eines anderen in das gemeinsame Streben zur Einheit, nach der Seite der Totalität hin, wiederum zurück gezogen wird. Wie der Magnetismus bedingt ist, durch Continuität und Differenz der Masse nach Aussen, so ist die Elektricität bedingt, durch Continuität und Differenz der Masse nach Innen; wie die universelle Tendenz des Magnetismus realisirt wird durch die Diremtion der einen Masse in ein mehr und minder oxydirtes, durch das Auseinandertreten in ein Acides und Basi-

C 2 
sches, d. h. durch den analytischen Effect des Chemismus, so wird die individuelle Tendenz, der Elektricität realisirt durch die Neutralisation der differenten Stoffe, die allemal wie ein acides und basisches sich einander gegen über stehn, d. h. durch den synthetischen Effect des Chemismus. Niemals hat die Elektricität eine andere Bedeutung und einen andern Ursprung, als dass das differente, chemisch Polare mit der Continuität im Contact der Masse alsbald auch die chemisch neutrale Einheit innerlich wieder zu gewinnen strebt; die Ansicht, dass Elektricität auch mit der synthetischen Action des Chemismus selbst als solcher erzeugt werde, gehört zu den gefährlichsten und schädlichsten Täuschungen der empirischen Naturanschauung. Eben so einseitig, wenn auch nicht so schlechthin naturwidrig, ist es aber auch, wenn man mit der Elektrochemie die Elektricität als ein wirkendes Agens, gleichsam als die äusserliche Triebfeder für den chemischen Process betrachtet; đie Elektricität ist vielmehr ein und dasselbe mit der chemischen Synthesis, sie ist mit ihr aus einer und derselben Wurzel entsprungen, sie ist die noch ungeöffnete Knospe des Chemismus, und da, wo die eigenthümliche Natur der chemisch polaren Substanzen die Blüthe nicht zur aufgeschlossenen Reife gelangen lässt, wie z. B. beim Contact zweier Metalle, ist sie wenigstens überall die hervortretende Tendenz zur chemischen Synthesis und zwar ist, wie die elektrische Relation der Säuren und Alkalien auf das unzweideutigste zeigt, die positive Elektricität auf der Seite des Aciden oder auf der Seite der Affinität zu den Basen; die negative auf der Seite des Basischen oder auf der Seite der Affinität zum Aciden; "ein Körper ist positiv elektrisch" heisst : 
in ihm ist der mit der Thätigkeit des Oxygens gleichartige Trieb zur Abstossung des Aciden und zur Anzie. hung des Basischen angeregt; „er ist negativ elektrisch" heisst eben so: er besitzt die mit der Thätigkeit des basischen Princips gleichartigeAnregung zur Abstossung des Basischen und Anzichung des Aciden. In diesen Bestimmungen hat sich die Elektrochemie, abgesehen davon, dass sie schon in der Grundansicht einseitig ist, völlig vergriffen und die Prädicate des elektropositiven und elektronegativen durchaus verwechselt, weil sie die Affinitäten blos nach den Erscheinungen an der geschlossenen galvanischen Kette beurtheilt hat und dabei zugleich von der übereilten Voraussetzung ausgegangen ist, dass die elektrische Polarität der Metalle in der geschlossenen Kette dieselbe sey, welche sie auch ausserhalb der Kette während des gegenseitigen Contacls versichtbaren.

Eine Naturforschung, welche durch nichts weiter als durch die Erscheinungen an und für sich und durch die Reflexionsbestimmungen des gewöhnlichen Bewusstseyns geleitet wird, ist mit jedem Schritte und zwar gerade dann, wemn er mit der grössesten Behutsamkeit geschieht, am ersten, in Gefahr, durch die äfende Dialektik des Scheins der Dinge zu unglaublichen Täuschungen verlockt zu werden, vor welchen die Speculation, welche auf der Basis durchgreifender und umfas. sender Ideen sich bewegt, für immer gesichert ist; ja die letztere durchschaut da den wahrhaften Zusammenhang der Erscheinungen am ersten, wo der Schein derselben nichts als gerade die entgegengesetzte Ansicht darbietet und aufdringt. - Bald nachdem ich durch die Oerstedsche Entdeckung in dem neu aufgeschlosse- 
nen Gebiete der Naturwissenschaft auf das' lebhafteste zu Untersuchungen angeregt worden war, sprach ich von meinem gewonnenen Standpuncte die bestimmte Ueberzeugung aus, dass Magnetismus und Elektricitït als Extreme des Chemismus polare Reactionen seyen, deren Wechselerregung die Thätigkeit der galvanischen Kette bedinge und dass im Zusammenhange damit die Polarität, mit welcher die Metalle in der geschlossenen Kette das Wasser zersetzen und auf die Magnetnadel reagiren, die entgegengesetzte von derjenigen seyn müsse, welche sie ausserhalb der Kette im blossen Contacte zeigen. Durch meine Nachweisungen der polaren Thätigkeit des Leiters zweiter Classe in der geschlossenen Kette sind diese Resultate bereits sehr sichtbar unterstützt worden; durch die Richtung aber, welche meine Untersuchungen über die Bestimmung der elektrischen Relationen mittelst der elektromagnetischen Kette in der gegenwärtigen Arbeit genommen haben, bin ich gerade hin darauf geführt worden, die wahre Polarität der Metalle in der Kette unmittelbar, wie es sich weiter unten ergeben wird, am Experimente zu demonstriren und ich halte mich daher für berechtigt, das Ganze dieser Darlegungen als eine über Skepsis und Polemik hinausgearbeitete Grundlage zu der wahren und für immer gültigen Theorie des Processes der galvanischen Kette zu betrachten. 


\section{Zweiter Abschnitt.}

Die dreigliedrige galvanische Kette.

Jede galvanische einfache Kette, und nur von der einfachen ist hier zunächst äberall die Rede, da das von ihr Gültige seine Anwendung auf die zusammengesetzte ohne grosse Schwierigkeit finden wird, besteht, wenn sie nicht zu den zweigliedrigen gehört, die weiter unten betrachtet werden sollen, allemal aus drei Gliedern, von denen zwei durch die Differenz der Masse, das dritte aber bei homogener Masse durch seine Relation zu. jenen beiden, einen electrochemischen Gegensatz bilden. Die beiden ersteren heissen Erreger, eine Benennung, welche in dem Sinne, den die weitere Entwickelung der Theorie von selbst ergeben wird, allerdings beibehalten werden kann, die aber nach der ursprünglich in sie hinein gelegten Bedeutung die Einseitigkeit bis. heriger Theorien verrüth, welche allein nur die elektrische Relation dieser beiden Glieder in der Ketle hervorheben, während die elektrische, zum Chemismus gesteigerte Thätigkeit zwischen dem dritten Gliedo und den beiden sogenannten Erregern die eigentliche Seele aller Functionen der Kette isl.

Es kann hier nicht darauf ankommen, die möglichen Classificationen der Ketten in Hinsicht der Glieder und ihrer Anordnung zu erschöpfen, indem, was von irgend einer Combinatiou der Art gilt, mit Leich- 
tigkeit auch auf jede' andere zu úbertragen ist ; wir legen daher hier den gewöhnlichen Fall zum Grunde, in welchem die beiden Erreger zwei differente Metalle sind, von denen das im Contact positive mit z, das negative mit $k$ bezeichnet werde, und das dritte Glied als ein Leiter zweiter Classe werde durch $f$ bezeichnet.

Aber nun entsteht eine, bisher nicht beachtete, obgleich höchst wichtige Disjunction: die elektrische Relation der Erreger gegen das $f$ ist nämlich entweder eine und dieselbe, sie werden entweder beide für sich einzeln gegen das f positiv, wie z. B. Silber und Platin, oder beide negativ, wie z. B. Blei und Zinn, oder diese Relation ist verschieden, indem das eine, wie $z$. $B$. Kupfer, gegen das $f$ positiv, das andere, wie z. B. Zink, negativ gegen dasselbe wird.

Es ift schon sehr merkwürdig und beweist im Voraus, dass die elektrische Relation des $f$ gegen die beiden Erreger ein bedeutendes Moment in der Thätigkeit der Kette seyn müsse, dass nehmlich der eigentlich hohe und wahre Grad in der Intensität der Wirkung der galvanischen Ketten nur in dem letztgenannten Falle einer gegen das $f$ wirklich verschiedenen elektrischen Relation der Erreger Statt finde. Wir sprechen daher zunächst nur von diesem Falle; für den zuerst genannten wird sich die Gelegenheit seiner Betrachtung weiter unten darbieten.

Hier macht sich nun abermals logisch eine nene Disjunction geltend, vermöge welcher die verschiedene electrische Relation der beiden Erreger gegen das $f$ entweder gleichartig oder ungleichartig mit derjenigen, welche zwischen ihnen selber Statt findet, 
gesetzt werden kann; das heisst: es muss entweder der Fall Statt finden, dass derjenige Erreger, welcher gegen den andern positiv oder negativ ist, auch positiv oder negativ gegen das $f$ ist; oder der zweite mögliche Fall ist der, dass derjenige Erreger, welcher gegen den andern positiv ist, negativ gegen das $f$ ist, und dieser andere, welcher gegen jenen negativ ist, wiederum positiv gegen $f$ sich verhält.

Aber was fragt die Natur nach unsern logischen Divisionen? Es ist ein Factum von der höchsten Bedeutung, dass dieser angegebene Unterschied eben keine andere als nur eine logische, und durchaus gar keine physikalische Realität hat. Denn da, wie bereits erwähnt ist, die Relation eines und desselben Metalls, der Art nach, gegen alle Flüssigkeiten auch stets eine und dieselbe ift, und gewisse Metalle so gegen alle Flüssigkeiten ausschliesslich positiv, die übrigen hingegen gegen alle Flüssigkeiten eben so ausschliesslich negativ sind, so ist klar, dass nur einer von den beiden eben unterschiedenen Fällen wahrhafte Realität haben könne. - Aber welcher? - Denkt man sich eine geradlinige elektrische Reihe aus den positiven Metallen auf der einen, den negativen auf der andern Seite und den Flüssigkeiten in der Mitte, so hat man die Verhältnisse nach der Weise des gemeinen $\mathrm{Be}$ wusstseyns gefasst, das entweder nur das Endliche festhält oder das Unendliche nicht anders als nur unter dem Schema der geraden äusserlich endlosen Linie anzuschauen vermag. Nach dieser Vorstellungsweise ist der erstere Fall als der ausschliesslich gültige gesetzt, und nach ihr würde die Relation zweier Metalle aus den beiden verschiedenen Seiten gegen irgend eine 
Flüssigkeit aus der Mitte allemal gleichartig seyn, mit der unter den Metallen selbft Statt findenden Relation. Aber gerade dieser Fall ift es, den die Natur, wie durch eine absolute, unendlich tief begründete Negation schlechthin verweigert, und nur dem anderen kommt die alleinige uneingeschränkte Realität zu. Die Flüssigkeiten stehen durch ihre Relation einerseits allerdings in der Mitte zwischen den positiven und negativen Metallen, andererseits aber liegen sie zugleich auch wie ein ganz entgegengesetztes Reich der Erscheinungen völlig ausserhalb der Reihe der Metalle und stehen ihnen nur wie in einem Kreise, dem Bilde der wahrhaften schlechthin innern Unendlichkeit, auf diametral entgegengesetzten Puncten gegenüber, und so findet das in seiner Entschiedenheit und Beständigkeit höchst merkwürdige Verhalten ganz allein Statt, dass so oft die elektrische Relation der beiden Erreger gegen das $f$ nicht gleichartig sondern verschieden ist, sie alsdann nothwendig immer auch die entgegengesetzte von derjenigen ist, welche unter den Erregern selber Statt findet, dass also das gegen $z$ negative $k$ stets positiv gegen $f$ und das gegen $k$ positive z stets negativ gegen $f$ seyn muss, welche Flüssigkeit auch $f$ und was fïr Metalle $z$ und $k$ sonst auch seyn mögen. Und dieser constante Gegensatz der elektrischen Relationen zwischen den Metallen und der Flüssigkeit ist es, welcher den eigentlichen Träger aller Erscheinungen an der Kette bildet, der Conflict dieser entgegengesetzten Elektricitäten oder vielmehr der lebendige, durch die fortdauernde Reaction der Gegensätze immer stärker aufgeregte Kreislauf der Thätigkeiten, welche sich vor der Schliessung der Kette nur mit ihren ersten 
gesonderten Regungen in den leisen Anklängen der elektrischen Relationen, als den Tendenzen dieser Thätigkeiten offenbarten, das ist der alleinige und wahrhafte Mittelpunct, von dem alle Lebensäusserungen der Kette ansgehen, und auf welchen sie einzig und allein sämmtlich zurück bezogen werden müssen.

Wir wollen, um dieses so bestimmt als möglich za erkennen, die beiden entgegengesetzten Relationen, bevor sie in ihrer Wechselwirkung angeschaut werden, noch vorher einmal getrennt, jede besonders für sich betrachten.

Das $z$ an und für sich ist oxydirter als das $k$, es ist bereits mehr in die allgemeine Metamorphose der Richtung zur Iudividualisation hineingezogen', als dieses und seine Oxydabilität, d. h. die universelle Tendenz, diese Richtung zu verfolgen, ist eben deswegen bei ihm auch grösser als bei dem $k$. Wenn also $z$ und $k$ durch den Contact ein Continuum bilden, so sind, wie es scheint, die Bedingungen des Magnetismus: Continuität und Differenz nach Aussen in der Gesammtmasse beider realissirt, das $z$ entspricht der südpolaren, nach Süden gerichteten -, das $k$ der nordpolaren Hälfte eines gemeinen Magneten. Aber das Ganze verhält sich noch keineswegs wie ein Magnet, weil mit der Continuität das Streben der differenten Masse zur Einheit nach Innen hin erwacht, das Metall vergisst gleichsam seine universelle Tendenz und versinkt, eins durch das andere nach entgegengesetzter Richtung gezogen, in die individuelle zum synthetischen Effect des Chemismus, so dass das universell negative $z$ jetzt positiv elektrisch, und $k$ hingegen negativ elektrisch erscheint. Ift es 
möglich, diese elektrische Relation zu beseitigen, ohne dass zu gleicher Zeit weder der Contact und die Continuität aufgehoben, noch die generelle Tendenz zu einer blos specifischen gemacht wird, so muss in der Masse dic Polarität der universellen Tendenz rein hervortreten, und sie muss zum Magneten werden. Eine solche absolute Beseitigung der Contactelektricitätiaber, mit der die sich berührenden Metalle einen vollendeten Longitudinalmagneten darstellen würden, wird indess das Experiment jemals eben so wenig zu bewerkstelligen vermögen, als es universelle Tendenzen in den individuellen Massen hervor zu rufen vermag; aher ein partielles Aufheben dieser Elektricität und damit auch ein particlles, modificirtes Hervortreten des Magnetismus, das ist es, was die grossen Entdeckungen unserer Tage im Thermomagnetismus und Elektromagnetismus dargestellt haben. Bei jenem geschieht die partielle Vernichtung der Contactelektricität durch partielle Temperaturveränderung; die bestimmtere Auseinandersetzung der Art und Weise, wie hier der Erfolg Statt findet, muss künftigen Arbeiten vorbehalten bleiben, wie überhanpt in den gegenwärtigen Darlegungen Beziehungen auf die hervortretende Temperaturveränderung im Process der Kette, um den Gesichtspunct fürs erste noch so einfach und klar als möglich zu erhalten, grossentheils vermieden bleiben. Der Elektromagnetismus hingegen ift das modificirte Hervortreten des Magnetismus in Folge der durch die geschlossene Kette bewirkten partiellen Vernichtung der Contactelektricität und eben dieses, dass alle Thätigkeilsäusserungen der Kette nicht, wie bisher allgemein geglaubt worden, eine direcle Wirkung der 
Contactelektricität der Erreger, sondern vielmelir gerade umgekehrt das Resultat ihrer von Innen heraus erfolgenden Vernichtung unter einer der gemeinen elektrischen Relation gerade entgegengesetżten Polarität der Erreger sey, das ist die eigentliche und bei dem jetzigen Stande der Untersuchung bereits unerschütterlich gewordene Basis meiner Theorie des Processes der galvanischen Kette.

Betrachten wir nun noch ferner das dritte Glied $f$, wenn es sich im Contact mit den beiden Erregern $z$ und $k$ befindet, ohne dass Contact zwischen den letzteren Statt findet, so wird das $f$ mit den differenten Tendenzen der Metalle selbst different; es richtet gegen das ursprünglich mehr oxydable, negative $z$ seinen aciden, positiven Factor, und gegen $k$ den basischen negativen Factor, und indem es so in der Einheit seiner Masse nach entgegengesetzten Richtungen auch unter differenten Tendenzen hervor tritt, so scheinen abermals die Bedingungen eines magnetischen Verhaltens in dem $f$ vorhanden zu seyn; aber sie sind es nur der Form, nicht dem Wesen nach, und das $f$ ist noch kein Magnet, weil es nicht von Innen heraus durch sich selber, sondern nur von Aussen her durch die Erreger zur Diremtion aufgefordert wird; die entgegengesetzten Tendenzen sind keine generellen sondern bloss specifische Tendenzen, welche allein durch die einseitigen Wechselwirkungen zwischen dem $f$ und den gesonderten Erregern bedingt sind, und somit wiederum nur in der Form einer zwiefachen Tendenz zum synthetischen Effect des Chemismus als eine zwiefache elektrische Erregung hervortreten, indem das $z$ gegen $f$ negativ, dieses gegen jenes 
positiv elektrisch wird, während $f$ gegen $k$ negativ und letzteres gegen $f$ wiederum positiv elektrisch erregt wird, wie es im folgenden Schema anschaulich gemacht ist:

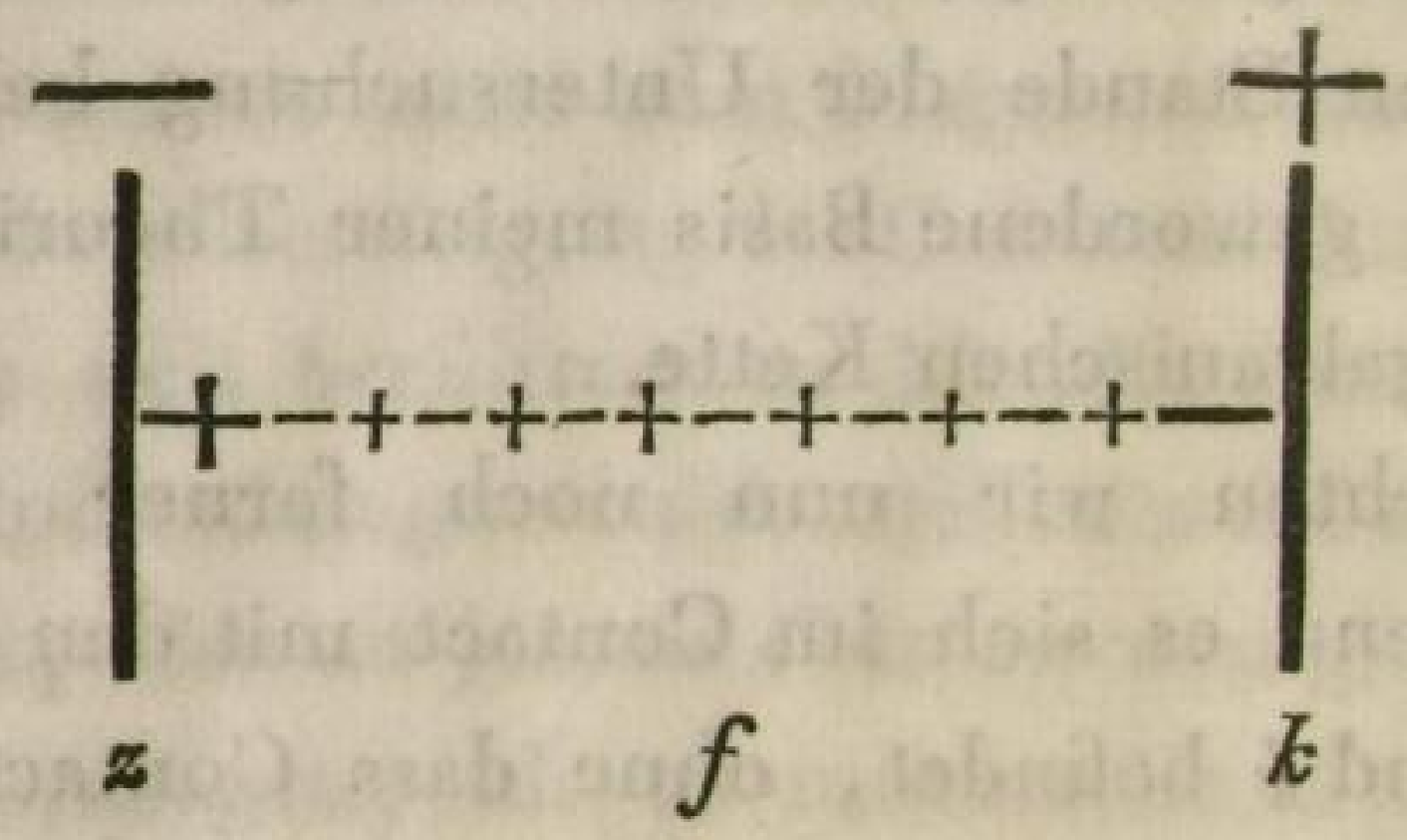

In diesem Zustande lässt sich die Kette mit einer elektrischen Verstärkungstafel vergleichen, bei welcher $f$ die Stelle des Glases einnimmt, $z$ und $k$ die Belege bilden, und die aus eigener innerer Erregungskraft auf der Seite des $z$ negativ auf der andern des $k$ hingegen positiv geladen ift.

Ist man der Untersuchung bis zu diesem völlig gesicherten Gesichtspuncte gefolgt, so muss man von demselben aus auch die Natur des lebendigen Processes, welcher mit der Schliessung der Kette beginnt, vollständig übersehen. In dem Moment der Schliessung wird die geladene Tafel entladen und, wenn man will, entgegengesetzt geladen, aber nur für einen unendlich kleinen Augenblick, nach dessen Verlauf sie abermals, wieder aus eigener innerer Kraft mit einer durch den Impuls der Reaction um so höheren Intensität von neuem geladen wird, um abermals wieder eben so entladen und nach der Entladung wieder mit einer von neuem gesteigerten Intensität geladen zu werden, and so immer, so lange die Kette durch die Verbin- 
dung der Metalle zu einem organischen Ganzen in sich geschlossen ist, und so lange durch die Qualität ihrer Elemente die Bedingungen zur Thätigkeit vorhanden sind, diesen regen Wechselpuls fortzuschlagen, welcher als der gemeinsame Trüger und Regulator ihrer sämmtlichen Lebensäusserungen ạngeschaut werden muss.

Die Relation der Erreger auf der einen, und die Relation des $f$ gegen die Erreger auf der andern Seite stehen hier in der Bedeutung der Functionen der Irritabilität und Sensibilität des thierischen Organismus; die erstere enthält nicht das Princip der Wirksamkeit der Kette selher, welches vielmehr nur in der letzteren gegeben ist, aber durch jene zu dem hohen Grade einer nach Aussen hervortretenden Thätigkeit erregt wird, deren Tendenz vor der Schliessung der Kette sich nur in der kaum bemerkbaren elektrischen Spannung des $f$ gegen die Erreger ankündigte *). In der ungeschlossenen Kette war bereits das $f$ gegen $z$ positiv und $z$ selbst negativ, d. h. in $\operatorname{dem}$ positiven $f$ war die Tendenz, sich gegen $z$ zu desoxydiren, und den nciden Factor gegen dasselbe treten zu lassen, in dem negativen $z$ dagegen war die Tendenz sich zu oxydiren, und den aciden Factor des $f$ an sich zu ziehen, versichtbart; eben so war durch die Relation des negativen $f$ gegen das positive $k$ bei jenem die Tendenz, den basischen Factor abzustossen, bei diesem das Streben, ihn anzuzieherı, offenbart. In der geschlossenen Kette

*) Auf den Parallelismus der Irritabilităt und Sensibilităt mit dem Elektrismus und Magnetismus im Allgemeinen hat bereits Steffens in seiner Anthropologie ganz entschieden hingewiesen. 
sehen wir vollkommen denselben Typus der Thütigkeit ausgesprochen, vollkommen dasselbe Verhältniss der Polarität, nur die anfängliche Tendenz jetzt zur reellen Thätigkeit, den früher fast ganz verborgenen, kaum glimmenden Lebensfunken jetzt zur lodernden Flamme gesteigert; der Elektrismus ist durch die entgegengesetzte Relation in der Contactelektricität der Erreger zum wirklichen Chemismus angefacht, so dass das $f$ gegen $z$ und $k$ im analytischen Effect dirimirt und der acide Factor von dem $z$ als dem negativ polaren, der basische von dem $k$ als dem positiv polaren $\mathrm{Me}-$ talle angezogen wird.

In jedem Moment dieses analytischen Effects ist also die Polarität der Contactelektricität der Erreger verdrängt, und in demselben Moment tritt daher auch der Magnetismus in beiden hervor; aber auch die Diremtion des $f$ nach entgegengesetzten Tendenzen ist in dem jetzt zu einem selbstständig und organisch in sich geschlossenen Ganzen der Kette keine einseitige und von Aussen her erregte mehr, sondern eine überwiegend innere, und auch das $f$ ist daher, so wie die $\mathrm{Me}$ talle, im Momente des analytischen Effects, ein Magnet, nur ist es ungleich schwächer magnetisch als die Metalle, weil der liffect selbst in $\operatorname{dem} f$ durch seine ganze Masse hindurch ungleich mehr Realität als in den Metallen erlangt, und die Tendenz zu diesem Effect, d. h. der Magnetismus eben deshalb um so viel schwächer als in jenen hervortritt. Jeder magnetische Moment wird als von dem zunächst folgenden durch einen elektrischen Moment geschieden gesetzt, in welchem der analytische Effect und mit ihm der Magnetismus aufs neue angeregt werden durch die sich 
geltend machende Contactelektricität, welche auf die polaren Factoren des $f$, zum synthetischen Effect des Chemismus zurückdrängend reagirt, aber dadurch nur für den nächstfolgenden Moment eine um so grössere Spannkraft ihrer Diremtion hervorruft.

Bei der unendlich grossen Geschwindigkeit, mit welcher die Momente auf einander folgen, erscheinen die sie begleitenden Zustände des Magnetismus und Chemismus einzeln als stetig zusammenhängende; man tritt aber der wahrhaften Natur des Processes völlig nahe, wenn man die Momente der Erregung und Thätigkeit nicht absolut aus einander gehalten, sondern vielmehr coexistirend setzt, indem man die Vorstellung festhält, dass der stetig fortschreitende analytische Effect mit dem gleichzeitig sich regenden Magnetismus einerseits es zur vollständigen Ausbildung des Gegensatzes der Contactelektricität der Erreger nicht kommen lasse, während er andererseits durch den gleichzeitig fortbestehenden Drang der Erreger diesen Gegensatz zu entwickeln, in Wirksamkeit erhalten und zu immer höher gesteigerter Thäligkeit gereist wird. Indem man die Zeitmomente unendlich klein setzt, so hat man ohnehin dieselbe Ansicht der Sache, nur unter dem Schema der sondernden, endlichen Auschauung; aber der eben angegebene Gesichtspunkt stellt den Erfolg seiner wahrhaften Natur nach unmittelbar vor Augen und giebt das reine abgeschlossene Integral desselben, nach welchem, in vollkommner Uebereinstimmung mit der Erfahrung, an der gänzlich geschlossenen Kette alle wahrnehmbare Elektricität als solche verschwunden und nur als erregender modificirender Entwickelungsdrang im Processe zurückgebliehen ist, 
während unter dem Uebergetvicht des analytischen Effects die chemisch polare Diremtion der Flüssigkeit in ihrer unmittelbaren Berührung mit den Metallen, und ausserhalb dieser Berührungsstellen in allen übrigen Punkten der Kette die Tendenz zu dieser Diremtion im Magnetismus, als allein noch wahrnehmbare Erscheinungen fort bestehen und das eigentliche $\mathrm{We}$ sen des ganzen Herganges ausmachen.

Mit dieser Ansicht wird zugleich die eigenthümliche Form, unter welcher der Magnetismus der Kette sich darstellt, sehr wohl begreiflich. Das wirkliche Auseinandertreten der Flüssigkeit, nach der einen Seite hin als Acides, nach der andern als Basisches, erfolgt bei der Berührung mit den dargebotenen Metallflächen unter den speciellen, der jedesmaligen Lage und $\mathrm{Be}-$ schaffenheit dieser Flächen angemessenen und daher nach Willkühr abänderlichen Lokalverhältnissen; in jedem andern Punkte der Kette, in welchem diese Diremtion nicht Statt findet, ist dagegen die Tendenz zu einer solchen polaren Sonderung nach entgegengesetzten fest bestimmten Richtungen um so entschiedener vorhanden, d. h. jeder andere Punct der Kette, nach dem, was oben als die wahre Bedeutung des Magnetismus festgestellt worden, ist nach bestimmten entgegengesetzten Richtungen zugleich nordpolar und südpolar magnetisch; nordpolar in der Richtung, nach welcher die in ihm befindliche Flüssigkeit als Basisches, südpolar in derjenigen, nach welcher sie als Acides aus sich heraus zu treten strebt*). Beim gemeinen Magne-

*) Die Nomenclatur ist hier unserm deutschen ganz richtigen Sprachgebrauche gemäss, und so wie sie oben in einzelnen Stellen bereits beobachtet ist, beibehalten worden. Wir 
ten ist vollkommen derselbe Zustand der magnetischen Thätigkeit in jedem einzelnen Punkte vorhanden, aber weil sie hier nicht partiell, sondern frei und unbeschränkt hervortritt, so erscheint die eine Hälfte des Stabes vorherrschend nordpolar, die andere überwiegend südpolar. In der geschlossenen Kette kann dagegen jeder Punkt der Masse, unter dem hemmenden, im metallischen Contact fortbestehenden, Gegendrange des synthetischen Effects, seine Thätigkeit nach beiden entgegengesetzien Seiten hin nur in diagonalen oder Transversalrichtungen entfalten, die gegen die Longitudinalaxe, welche von dem einen metallischen Pol der Kette bis zum andern gezogen wird, unter einem so grossen Winkel geneigt sind, dass sie, wie die Erfahrung zeigt, sich als senkrecht auf dieser Axe betrachten lassen. Wenn durch $k z$ diese Longitudinalaxe bezeichnet wird, so stellt die erste der beiden folgenden Figuren symbolisch für alle Puncte der Masse irgend

nennen am Magnet ,,Südpol“" den nach Süden gerichteten Pol, so wie z. B. Zielschuss ein nach dem Ziel gerichteter Schuss heisst, und ,,südpolar" bezeichnet die magnetische Thătigkeit, welche gleichartig mit derjenigen des Südpols eines Magneten, also auch gleichartig mit der im Norden des Erdkörpers, herrschenden Thätigkeit ist. Die Franzosen können in dem Sinne wie wir gar nicht: „Nordpol, Südpol" sagen, sondern nur: ,nördlicher, südlicher Pol"“ und sie verfahren daher consequent, wenn sie da, wo vom Magnet die Rede ist, die Prädikate umkehren, was wir bei der viel grösseren Freiheit und Zwanglosigkeit unsers Sprachgebrauchs in der Begriffsbezeichnung durch Zusammensetzung gar|nicht nöthig haben, oder, wenn wir unsere eigenen Vortheile nicht kurzsichtiger Weise aufgeben wollen, selbst nicht einmal dürfen. Es ist daher selbst tadelnswerth, wenn bei Uebersetzungen aus dem Französischen ins Deutsche das pole boréal und austral jenes durch Nordpol, dieses durch Südpol übertragen wird.

D 2 
eines Querschnittes der Kette die Richtungen vor, nach welchen die magnetische Thätigkeit derselben, wäre sie nicht im Conflict mit der Contactelektricität der Metalle, sich ungehemmt, wie in einem gemeinen Magneten, parallel der Axe kz manifestiren würde, während die 2 te Figur eben so symboliseher Weise die Richtungen anschaulich macht, nach welchen dieselbe Thätigkeit unter dem fortbestehenden Gegendrange der Reaction überhaupt nur nach der Diagonale unter irgend einem bis jetzt noch nicht gemessenen, aber vielleicht in der Folge noch bestimmbaren Winkel, gegen die Axe $k z$ sich zu entwickeln, vermag.

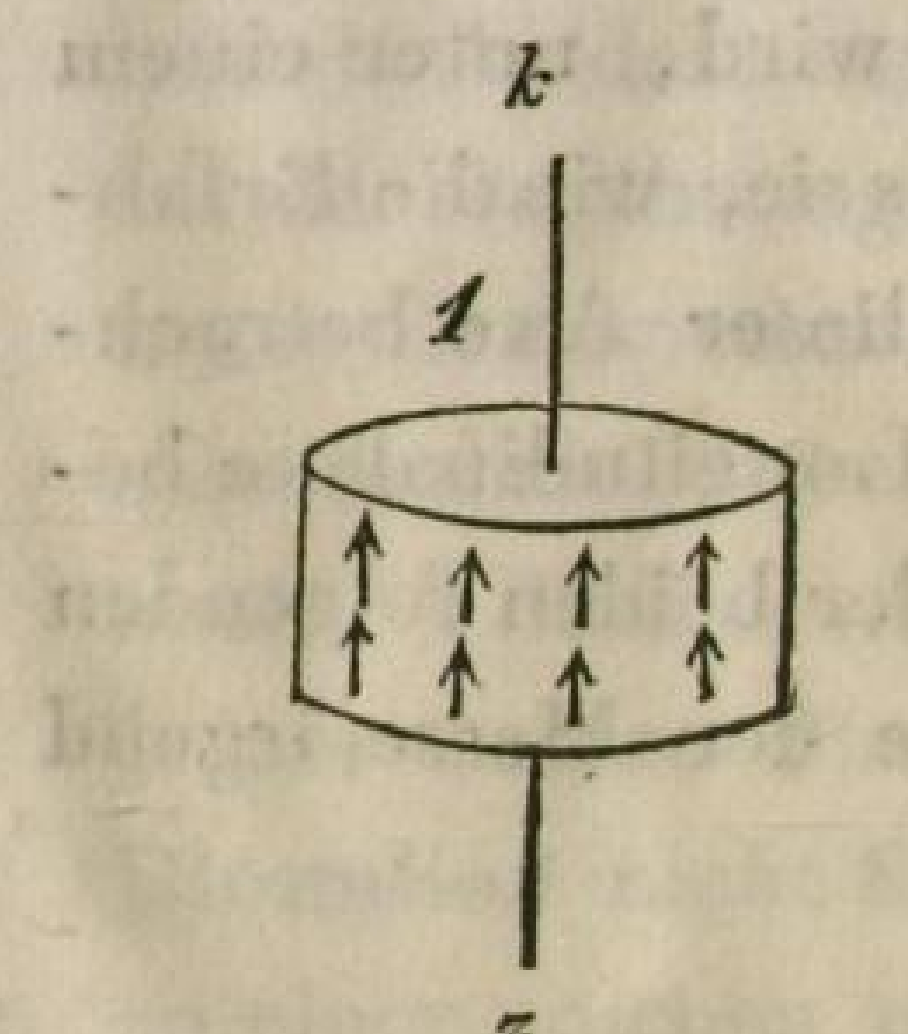

z

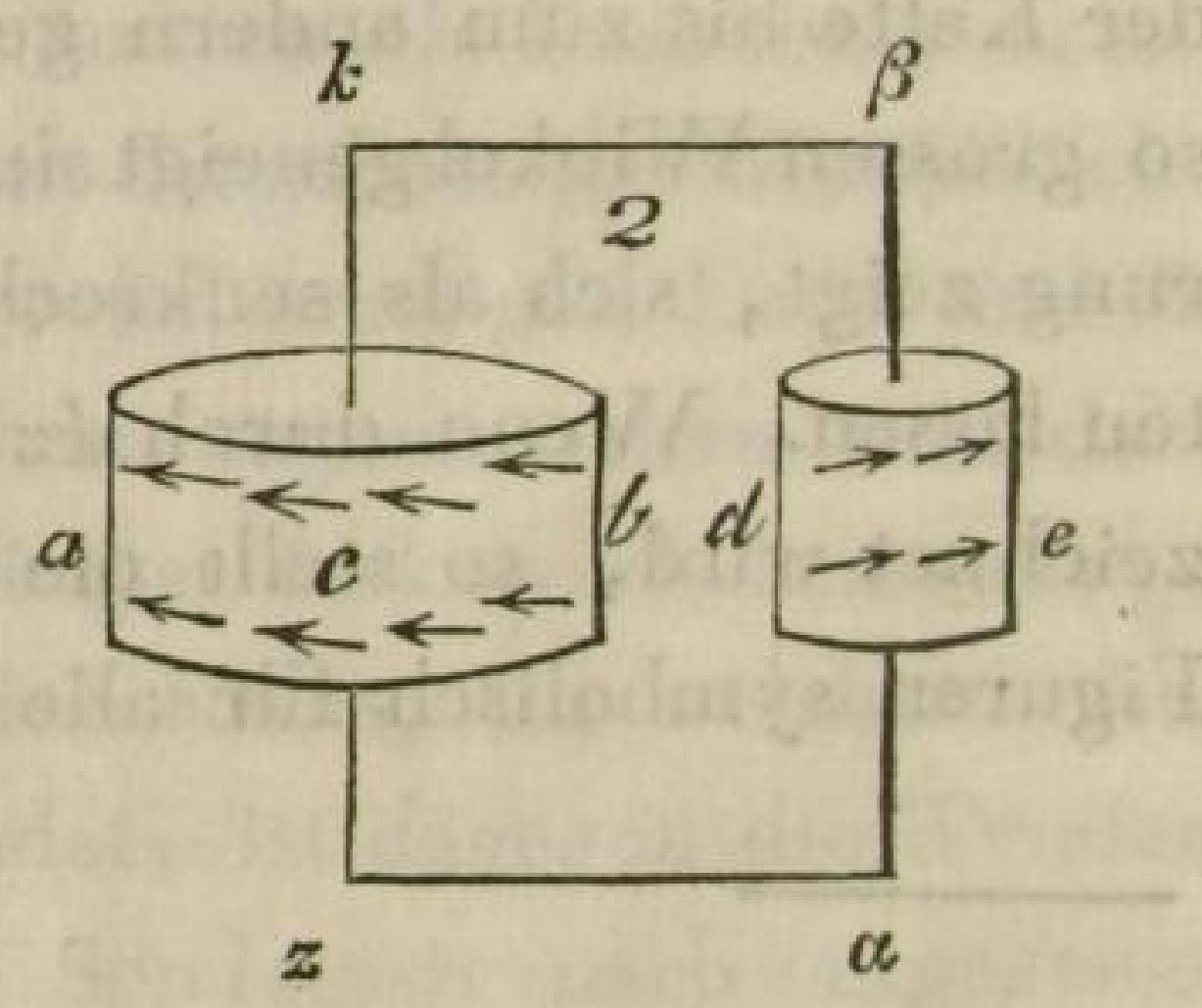

Vermöge dieser Transversalrichtung der magnetischen Polarität wirkt die Kette mit der in Fig. 2 sichtbaren gegen einen andern Magnet oder magnetisch erregbaren Körper gerichteten Fläche, so als wäre sie auf der Seite in $a$ nordpolar, in $b$ südpolar magnetisch, dass z. B. der vorgehaltene Nordpol einer in der Horizontalebene frei beweglichen Magnetnadel von $a$ her abgestossen, nach $b$ hin angezogen wird. Aber jeder andere grössere oder kleinere Theil des Umfangs, mit welchem die Kette in sonst gleicher Lage und unter gleichen Umständen wirkt, muss, z. B. hinsichtlich der Ablenkungsrichtung der Nadel, ganz denselben 
Erfolg hervorbringen, weil die Transversalrichtung der magnetischen Polarität überall dieselbe ist; nirgend, weder in $a$ und $b$ noch sonst irgendwo am Umfange der Kette kann die Thätigkeit der magnetischen Polarität begränzt seyn, nirgend hat die Kette fixirte Pole, wenn nicht jeder Punkt derselben gleich allen übrigen ohne Unterschied nach der einen Richtung als Südpol, nach der andern als Nordpol zugleich gesetzt wird; sondern die südpolare Thatigkeit erstreckt sich am ganzen Umfange der Kette rings herum nach der einen Richtung $a c b$ und die nordpolare in entgegengesetzter Richtung $b c a$, ohme irgend wo anzufangen und anfzuhören und, wie ich zu aller möglichen Sicherung gegen die endlosen Missverständnisse der Empirie und der Hypothesensucht noch ausdrücklich hinzufüge, ohne in irgend einer kreisenden örtlich mechanischen Bewegung irgend eines hypothetisch materiellen Substrats zu bestehen, noch durch eine solche hervorgebracht zu seyn; sie sind einzig und allein die nach den festbestimmten überall gleichen Richtungen sich manifestirenden Tendenzen zur Diremtion der in der Kette befindlichen Masse. Der scheinbare kreisförmige oder spiralförmige Fortschritt der elektromagnetischen Thätigkeit ist keine wirkliche örtliche Bewegung, aber er entsteht aus dem Conflict der entgegengesetzten Tendenzen des synthetischen und analytischen Effects eben so, wie die mechanische Wirbelbewergung irgend eines flüssigen Mediums aus dem ursprünglich geradlinigen Fortschritl desselben im Conflict mit einer perpendiculär entgegenwirkenden Kraft erzeugt wird. Wenn $z$ die Zinkseite, $k$ die Kupfer'seite der einfachen Kette $z k f$ bezeichnet, so sind die Richtungen der magneti- 
schen Polarität in der Flüssigkeit zwischen dem $k$ und $z$, desgleichen ausserhalb derselben in den Metallen und im Schliessungsdrathe, so weit er in der unmittelbaren geradlinigen Verlängerung der Axe $k z$ liegt, gerade so, wie sie in der 2ten Figur unter $a b$ dargestellt sind; in dem Theile $\alpha \beta$ des Schliessungsdrathes hingegen zur Seite des $f$ sind sie so, wie sie unter de angegeben sind; diese letzteren sind jenen nicht wirklich, sondern nur scheinbar entgegengesetzt, indem die Axe $\alpha \beta$ des Verbindungsdrathes als ein Theil der Axe $k z$ der Kette betrachtet und daher in der geraden Verlängerung $z k \cdot \beta c$ oder $k z \alpha \beta$ gedacht werden muss und in beiden Fällen sieht man, dass in der ganzen Kette durchgehends absolut dieselben Richtungen der magnetischen Folarität herrschend sind.

Der Umstand, dass unsere Theorie durch sich selber zugleich das klare Moment zur Nachweisung der Transversalität jener Richtungen hergibt, die ausserdem etwas höchst Räthselhaftes bleiben würden, kann allein schon als eine nicht geringe Bürgschaft ihrer innern Begründung angesehen werden; die Anfschlüsse aber über das Absolute dieser Richtungen, warum gerade immer und unabänderlich die nordpolare Thäligkeit nur in der Richtung $b c a$, die südpolare in der entgegengesetzten $a c b$ Statt finde, können nicht von der Theorie als solcher erwartet werden und die Frage nach höheren Beziehungspunkten für dieses Absolute gehört zu derselben Kategorie, in welcher etwa zu wissen verlangt würde, warum gerade die magnetischen Pole der Erde diese und nicht die entgegenge. setzte Lage haben oder warum die Planeten gerade von 
West nach Ost und nicht in entgegengesetzter Richtung sich um die Sonne bewegen*).

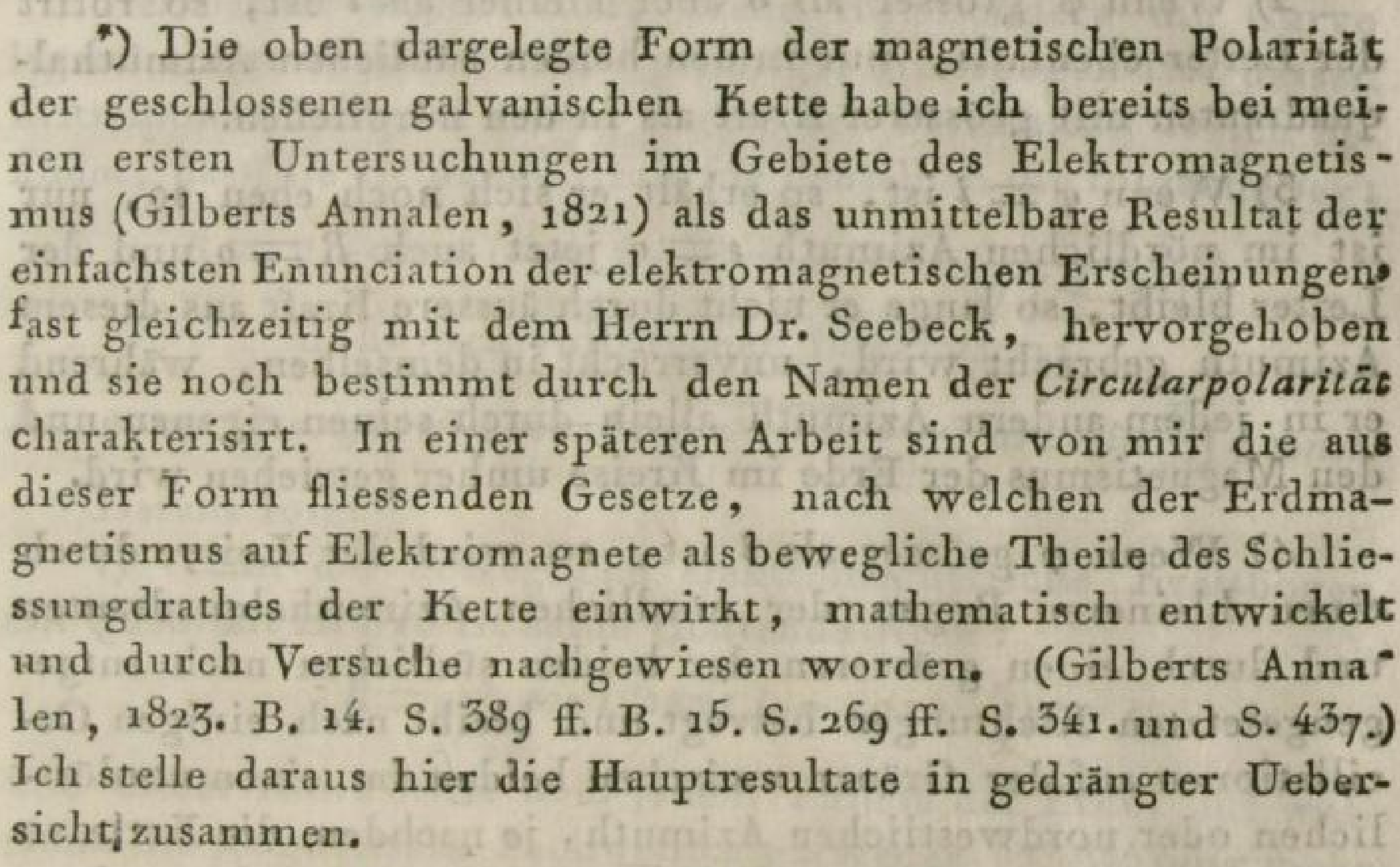
a 12 Wenn ein geradliniger Leiter $a b$ unter irgend einem Winkel $\varphi$ gegen den Horizont geneigt um

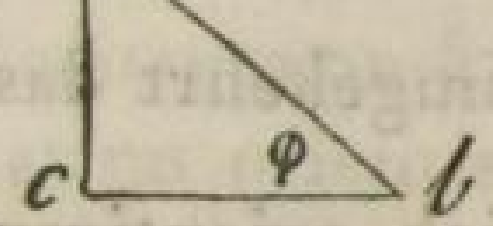
die Vertikalaxe $a c$ beweglich ist und wenn zъgleich der Radius $b c$ durch $r$, der Winkel der magnetischen Inclination für den Ort des Experiments durch $i$ bezeichnet wird, so ist die richtende Kraft, mit welcher der Erdmagnetismus den Leiter sollicitirt, wenł derselbe in irgend einer Ebene $a b c$ sich befindet, die mit der Ebene des magnetischen Meridians den Azimuthalwinkel $\varepsilon$ bildet, durch den Werth

$$
R=q r^{2} \cos i(\operatorname{tang} i-\cos z \operatorname{tang} \varphi) .
$$

ausgedrückt, worin der Coefficient $q$ von der Intensität des Magnetismus der Erde, des Leiters und der Grösse des auf der Länge senkrechten Querdurchschnittes des letzteren, der nicht leicht über $0,05^{\prime \prime}$ betragen wird, abhängig ist. - Hieraus folgt:

1) Wenn $\varphi=0$, der Leiter also in der Horizontalebene liegt, dass derselbe unaufhörlich durch den Erdmagnetismus im Kreise herum getrieben wird, in allen Graden des Azimuth mit unveränderter Kraft, um so stärker, je grösser $i$ ist; also über einem magnetischen Erdpole mit dem Maximum der Kraft, auf dem magnetischen Aequator hingegen gar nicht, dort findet gar keine Rotation des horizontalen Leiters mehr Statt. 
Es scheint fast unmöglich, dass die Evidenz und die innere Begründung der objgen Ansicht über den

2) Wenn $\varphi$ grösser als o aber kleiner als $i$ ist, so rotirt der Leiter ebenfalls, nur in den beiden südlichen Azimuthalquadranten mit grösserer Kraft als in den nördlichen.

5) Wenn $\varphi=i$ ist, so erhält er sich noch eben so, nur ist im nördlichen Azimuth $\varepsilon=0$ jetzt auch $R=0$ und der Leiter bleibt, so lange er nicht durch äussere Kraft aus diesern Azimuth gebracht wird, unverrückt in demselben, während er in jedem andern Azimuth allein durch seinen eigenen und den Magnetismus der Erde im Kreise umher getrieben wird.

4) Wenn $\varphi$ grösser als $i$ ist, so wird der Leiter durch einen kleineren Bogen der nördlichen Azimuthalquadranten und durch einen grösseren der beiden südlichen nach entgegengesetzten Richtungen bewegt und bleibt nach einigen Oscillationen auf der Gränze zwischen beiden im einen nordöstlichen oder nordwestlichen Azimuth, je nachdem die Kette so oder entgegengesetzt geschlossen wird, unverrückt stehen. Das Azimuth dieses Ruhepunctes wird jedesmal durch die Gleichung $\cos \varepsilon=\frac{\operatorname{tang} i}{\operatorname{tang} \varphi}$ bestimmt und wenn umgekehrt das $\varepsilon$ vorher bestimmt ist, in welchem der Leiter sich orientiren soll, so ist der dazu erforderliche Neigungswinkel $\varphi$ desselben durch die Gleichung tang $\varphi=\frac{\operatorname{tang} i}{\cos \varepsilon}$ gegeben. Wenn der Neigungswinkel $\varphi=76^{\circ} 20^{\prime}$, so orientirt sich der Leiter bei einer magnetischen Inclination von $71^{\circ}$ gerade im magnetischen NO oder NW und der vertikale Leiter, bei welchem $\varphi=90^{\circ}$, orientirt sich überall in $O$ oder $W$, auf dem magnetischen Aequator am kräftigsten; nur über einem magnetischen Erdpol ist er indifferent.

Wenn ein Leiter $a b$ die Gestalt irgend einer einfachen

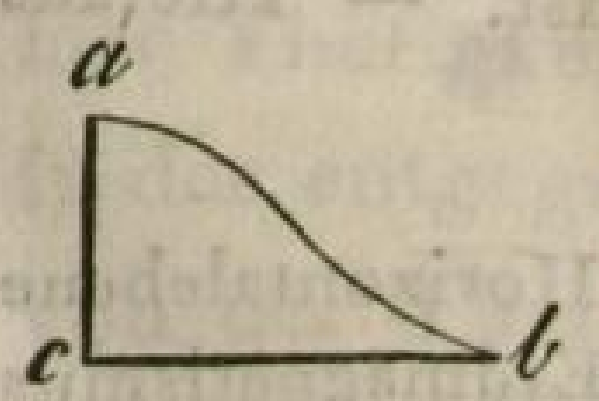

Curve hat, welche um die' in ihrer Ebene liegende Vertikalaxe $a c$ beweglich ist und deren Gesetz durch eine Gleichung zwischen rechtwinkligen Coordinaten $x, y$ ausgedrückt wird,

dergestalt, dass der Nullpunkt der Abscissen in der Axe ac liegt, so ist unter den sonst gültigen, oben angegebenen, Bestimmungen die richtende Kraft, mit welcher ein solcher Curvenbogen durch seine eigene und die Thätigkeit des Erdmagnetismus sollicitirt wird:

$$
R=q \cdot \cos i\left(\text { tang } i \cdot x^{2}-2 \cos \varepsilon \int x d y\right)
$$


Process der Kette überhaupt nicht schom jetzt eine Anerkennung finden sollte, die sie in Zukunft gewiss

Demnächst ergiebt sich, wenn insbesondere die Curve irgend ein zum Halbmesser $r$ gehöriger Kreisbogen ist, dessen Mittelpunkt in irgend einem Puncte der Vertikalaxe $a c$ sich befindet, dass!die richtende Kraft für denselben die folgende sey:

$$
R=q \cdot \cos i\left(\operatorname{tang} i \cdot x^{2}-2 \cos \varepsilon \int \frac{x^{2} d x}{\sqrt{\left(r^{2}-x^{2}\right)}}\right)
$$

d. h. nach vollzogener Integration:

$R=q \cdot \cos i\left[\operatorname{tang} i \cdot x^{2}+\cos \varepsilon\left(x \sqrt{r^{2}-x^{2}}-r^{2} \operatorname{arc} \cdot \sin \frac{x}{r}\right)\right]+$ consi.

Daraus folgt

3) Wenn der bewegliche' elektromagnetische Kreisbogen ein Quadrant ist, so ist seine richtende Kraft :

$$
R=q r^{2} \cos i\left(\operatorname{tang} i-\cos \varepsilon \cdot \frac{\pi}{2}\right)
$$

und dieser rotirt daher über jedem Puncte der Erde, auf welchem die magnetische Inclination entweder $57^{\circ} 32^{\prime}$ oder mehr $a^{l s} 57^{\circ} 32^{\prime}$ beträgt, in den südlichen Azimuthalquadranten mit grösserer, in den nördlichen mit geringerer Kraft. Unter Breiten von $57^{\circ} 3^{\prime}$ und noch geringerer magnetischer Inclination orientirt sich dagegen der. Quadrant eben so, wie oben der geradlinige Leiter bei 4 , in irgend einem nordöstlichen oder nordwestlichen Azimuth $\varepsilon$, welches hier durch die Gleichung $\cos \varepsilon=\frac{2 \text { tang } i}{\pi}$ bestimmt ist. Dieses $\varepsilon$ rückt also um so näher an das magnetische Ost oder West, je kleiner die magnetische Inclination wird; bei einer Inclination von $48^{\circ} 0^{\prime} 9^{\prime \prime}, 9$ orientirt sich bereits der Quadrant gerade in NO oder NW und bei $o^{\circ}$ Inclination, unter dem magnetischen Aequator orientirt er sich vollkommen im magnetischen Ost oder West.

2) Für solche Puncte der Erde, über welchen der elektromagnetische Quadrant noch rotirt, kann das Bogenadditament $\beta$ (in Graden) mit welchem er in irgend einem gegebenen nordöstlichen oder nordwestlichen $\varepsilon$ keine richtende Kraft mehr besitzen, sondern in demselben sich orientiren soll, gefunden werden, indem der Werth von $\beta$ aus der folgenden, der obigen allgemeinen Integrationsformel gemäss construirten Gleichung:

$\cos \varepsilon\left(\pi+\sin \beta \cdot \cos \beta-\operatorname{arc}\left(90^{\circ}-\beta\right)\right)-\operatorname{tang} i \cdot \cos \beta^{2}=o$ hergeleitet wird. Demnächst ergibt sich, dass bei uns unter einer magnetischen Inclination von $71^{\circ}$ 


\section{allgemein finden wird und nothwendig erhalten muss.} Sie ist dem Wesen nach ganz dieselbe, welcho ich

a) der bewegliche elektromagnetische Kreisbogen von $90^{\circ}+25^{\circ}=115^{\circ}$ im nördlichen Azimuth keine richtende Kraft mehr besitzt, sondern dort nach $\mathrm{N}$ gerichtet in Ruhe bleibt, und dass

b) ein solcher Bogen von $9^{\circ}+36^{\circ} 8^{\prime}=126^{\circ} 8^{\prime}$ gerade im nordöstlichen oder nordwestlichen Azimuth ohne richtende Kraft ist, sondern sich im magnetischen NO oder NW nach mehr oder weniger Oscillationen vollkommen orientirt.

c) Der Bogen von $90^{\circ}+90^{\circ}$ d. h. der Halbkreis, dessen Rotationsaxe zugleich sein Durchmesser ist, orientirt sich vollkommen in $\mathrm{O}$ oder W, für jedes $i>o$; auf dem magnetischen Aequator am kräftigsten; über einem magnetischen Erdpol aber ist er völlig indifferent.

Die obigen Folgerungen nächst mehreren aus dem nehmlichen Princip hervorgegangenen sind, so weit sie sich auf ein und dieselbe magnetische Inclination beziehen, durch Versuche auf eine genügende Weise bestätigt und die Circularpolarităt, aus welcher allein alle diese Resultate theoretisch hergeleitet sind, ist durch die Uebereinstimmung derselben mit der Erfahrung von allen Seiten her faktisch nachgewiesen worden. Ihre früheste und unfehlbarste Begründung aber verdankt sie vor allem den Darlegungen des, Herrn Seebeck, der mit sehr kräftigem Apparat es ausser allem Zweifel setzte, dass ein und derselbe Punkt des Schliessungsdrathes nach entgegengesetzten Richtungen als Nordpol und Südpol zugleich wirksam sey.

Ungeachtet im Reiche der Wahrheit die Stärke der Parteien glücklicher Weise nicht so viel gilt, wie in der Politik und ungeachtet an der Zustimmung solcher Physiker, die zu ihrer Ueberzeugung immer erst einer Autorităt vom Auslande her bedürfen, wenig gelegen ist, so kann es doch für denjenigen, der in seiner Ansicht selbstständig ist, nicht anders als eine sehr erfreuliche Genugthuung mit sich führen, dass vom Auslande her mehrere Stimmen sich der Hauptsache nach in entschiedenem Einverständnisse mit der seinigen ausgesprochen haben. Ich glaube mir daher bei dieser Gelegenheit die Erwähnung nicht versagen zu dürfen, dass namentlich einer von Frankreichs ausgezeichnetsten und verdienstvollsten Physikern, Herr Biot in der neuesten Ausgabe seines Précis de Physique, Tom. II. p. $77^{1}$ ff. sich für die Circularpolarität, die er dem Wesen nach, nur mit einem andern Worte, durch das 
schon früher, bald nach der Entdeckung des Elektromagnetismus, ausgesprochen habe, nur erscheint sie hier durch die eigenthümliche Richtung der Betrachtung in der gegenwärtigen Schrift von einer neuen Seite, nehmlich von der Seite der elektrischen Relation der Erreger gegen das dritte Glied der Kette durchgefihrt, eine Seite, die allerdings zur Gewinnung der richtigen Totalanschauung des Gegenstandes die natürlichste und zugänglichste ist, so dass ich bedaure, sie in meinen früheren Darstellungen nicht gleich hervorgehoben zu haben, wenn schon auf der andern Seite das allgemeine Geschick menschlicher Bestrebungen mich trösten kann, nach welchem der angemessenste und kürzeste Weg zum Ziele in der Regel immer erst gefunden wird, nachdem das Ziel bereits selbst auf Umwegen erreicht worden ist.

Ich habe den Gegenstand bis jetzt so dargestellt, wie er an und für sich unter Zusammenstimmung aller

Prädicat der Molecularmagnetisirung als die Grundlage aller elektromagnetischen Erscheinungen bezeichnet, auf das Entschiedenste erklärt hat. Derselbe hat zugleich a. a. O. ein nach allen Beziehungen so treffendes und bestimmtes Urtheil gegen die Zulässigkeit der Ampèreschen Hypothese ausgesprochen, dass es von jedem, der mit dem Streben nach Einheit in der Naturanschauung die totale bis zum Gipfel der Willkühr gesteigerte Abweichung von derselben in jener Fiction erkennt, bereitwillig unterschrieben werden würde, wenn es ander's dessen noch bedürfte. Dass ein horizontaler elektromagnetischer Leiter unter den oben angegebenen Umständen von jedem Azimuth aus rotirt, während er der Ampère'schen Vorstellungsweise gemäss durch die fingirten tellurischen OstWestströme in dem östlichen oder westlichen Azimuth festgehalten werden müsste, ist, wie ich schon lange erinnert habe, ein so reiner absolut unausweichlicher Viderspruch, dass dadurch die Hypothese des Herrn Ampère auf eine äus. serliche Weise eben so bestimmt, als ihrem Innern nach, für mmor von der Wissenschaft zurückgewiesen ist. 
Elemente der Combination in seinem eigenen ursprünglichen Lichte die Ueberzeugung eines jeden ansprechen wird, dem überhaupt die innere Begründung einer Ansicht mehr gilt, als ihre äussere Nachweisung. Das einzelne Experiment kann sich zur Speculation immer nur wie die Probe zu einer aus inneren Gründen so und nicht' anders geführten Rechnung selber verhalten und die letztere muss früher als jene und 'unabhängig von $\mathrm{ihr}$ vorhanden seyn. So war es auch hier. Ich habe die obige Combination unabhängig von irgend einem einzelnen Versuche als solchem durchgeführt, ohne etwas anderes als das Ganze der Erscheinungen in seinem Zusammenhange vor Augen gehabt zu haben, und ich würde von ihrer objectiven Wahrheit auch ohne experimentale Documentirung derselben eben so überzeugt gewesen seyn, wie es möglich ist, dass man der Richtigkeit eines Calculs aus inneren Gründen gewiss seyn kann, auch wenn man nicht Gelegenheit gefunden hat, sie durch die äussere Zusammenstimmung mit einer einzelnen Rechnungsprobe nachzuweissen.

Was indess innere Realitüt hat, das muss sich frïher oder später irgend einmal und auf irgend einem Puncte auch äusserlich nachweisen lassen und so gewiss es ist, dass man die Natur aus dem Experimente allein niemals weder verstanden hat, noch je verstehen wird, so entschieden jst auf der andern Seite die Befugniss, mit welcher die Wissenschaft überall auf die experimentale Constatirung einer jeden aus der Totalität der Erscheinungen hergeleiteten Ansicht dringen muss. Es ist mir daher erfreulich gewesen, dass ich durch meine obige Ansicht über die wahre Natur des Processes der Kette auf experimentale Thatsachen gefihrt worden 
bin, welche meiner Theorie zugleich eine solche äussere Nachiveisung verschaffen, mit der ihre objective Begründung und faktische Gewissheit völlig entschieden wird.

Dass schon vor der Schliessung der Kette $z f k$ das $z$ negativ und $k$ positiv sey, gehört zu den absolut entschiedenen Thatsachen; aber sobald die Kette geschlossen wird, ist nach der gewöhnlichen Meinung an diese schwachen Erregungen gar nicht mehr zu denken, dann tritt, so heisstes, allein die Contactelectricität der Metalle auf und übertönt bei weitem jeden leisen Anklang der elektrischen Erregung, welche sonst im wechselseitigen Contact der Flüssigkeit und des $\mathrm{Me}-$ talls für sich allein noch wahrgenommen $\mathrm{zu}$ werden vermochte. Diese Ansicht hat jedoch nichts weiter fiir sich, als eben nur die völlig vereinzelte Rücksicht, dass die Contactelektricität der Metalle stärker sey, als die der Flüssigkeit mit den Metallen und sie hat, ausserdem, dass sie an der Stelle einer genügenden Rechenschaft über das Wesen und den Zusammenhang der Elektricität mit dem Chemismus nichts weiter als nur hypothetische Fictionen von einem fabelhaften elastischen Fluidum vorzubringen vermag, schon das allein gegen sich, dass sie eine wesentliche, in den Erregungen schon ausserhalb des Geschlossenseyns der Kette sich geltend machende Seite völlig unberücksichtigt lässt. Allerdings ist die Contactelektricität zwischen den Metallen und Flüssigkeiten an und für sich, ausserhalb der Kette, so wie sie durch den Condensator oder Duplicator versichtbart wird, bei weitem schwächer, als die Contactelektricität der Metalle; aber der Grund dieser Unscheinbarkeit ist der nehmliche, aus 
welchem auch die Flüssigkeiten schlechtere Leiter der Elektricität als die Metalle zu seyn scheinen, obgleich sie die eigentliche Wirkung in der That ungleich kräftiger als jene in sich aufnehmen und fortpflanzen Die elektrische Erregung ist die versichtbarte Tendenz zum Chemismus und es ist begreiflich, dass innerhalb gewisser Gränzen an den heterogenen Stoffen diese Tendenz um so lebendiger ausgesprochen seyn könne, je weiter die Stoffe selbst, ihrem Cohäsionszustande zufolge von der Realisirung einer, wirklichen chemischen Vereinigung entfernt sind. Das eben ist der Fall beim gegenseitigen Contact der Metalle; je weniger sie chemisch auf einander einzuwirken vermögen, desto stärker und sichtbarer muss einerseits der mit der gegenseitigen elektrischen Erregung versichtbarte Drang nach einer solchen Einwirkung in ihnen seyn, um so leichter muss andererseits aber auch dieser Drang, weil er auf keine Weise eine reelle Wurzel zu schlagen vermag, an der er sich festhalten und behaupten könnte, durch äussere anderweitige Einwirkungen auf die metallische Substanz, in der Erscheinung geschwächt, aufgehoben und selbst zu völlig entgegengesetzter Form modificirt werden können *). Beim

*) Daher kommt es bei Bestimmungen dieser Art nicht auf einzelne Erfahrungen schlechthin, sondern lediglich nur auf das an, was unter bestimmten Umständen als gesetzlich hervortritt. Alle rigiden Stoffe, die im Contact elektrisch werden, sind noch so weit von dem Punkte der Neutralisation entfernt, zu welcher der Trieb durch jene elektrische Erregung sich offenbart, dass vor der wirklichen Erreichung desselben mannigfaltige Veränderungen der Cohäsionszustände eintreten können, mit welchen zugleich ein eben so oftmaliger VWechsel der elektrischen Relation verbunden seyn kann. Je nachdem z. B. dieser oder jener von beiden Stoffen früher als der andere erweicht, flūssig gemacht oder nur dem Schmelzpuncte näher 
Contact einer Flüssigkeit mit einem Metalle findet dagegen mehr oder,weniger schon ein Anfang von wirklicher chemischer Einwirkung der beiden Stoffe anf einander Statt, und die Aeusserung des Strebens nach chemischer Neutralisation zeigt sich in einer schwächeren elektrischen Grregung, eben darum weil jenes Streben zum Theil bereits Befriedigung findet; die Thätigkeit ist weniger nach Aussen hin sichtbar, weil sie schon ungleich mehr nach Inuen gerichtet und reeller geworden ist; aber sie ist eben darum auch um so unveränderlicher und beständiger. Fine mit einem Metalle in Berührung gesetzte Flüssigkeit behauptet die Thätigkeit, mit der sie einmal das Metall erfasst hat, wie schwach auch die entsprechende elektrische Erregung sich zeigen möge, mit sehr grosser Beharrlichkeit und es gehört ein hoher Grad von Gegenerregung auf der andern Seite der Flüssigkeit dazu, um sie von jenerLinwirkung abzuziehen und ihr das Metall wieder zu entreissen. Daher wird ein Metall, das auf der einen Seite von irgend einer, scheinbar noch so indifferenten Flüssigkeit, z. B. nur von Wasser, und auf der andern Seite von einem entgegengesetzt und zwar scheinbar viel stärker erregenden Metalle berührt wird, nichts desto weniger je-

gebracht wird, kann die elektrische Relation derselben Stoffe das eine Mal diese, ein ander Mal dagegen wieder ganz die entgegengesetzte seyn. Daraus ist zugleich wieder begreiflich, wie unzulässig es sey, wenn aus Beobachtungen der elektrischen Relationen gewisser Säuren und Alkalien im festen $\mathrm{Zu}$ stande gegen einzelne Metalle Schlüsse über das gegenseitige Verhalten dieser Stoffe im Allgemeinen und namentlich über ihre Relationen in Bezug auf die galvanische Kette, bei welcher die Leiter zweiter Classe immer nur als Solutionen wirksam sind, hergeleitet werden. 
der Zeit immer nur durch die Flüssigkeit erregt werden und zwar nun durch polare Reaction um so viel entschiedener und lebhafter, je stärker der durch den metallischen Contact bewirkte Drang zur entgegengesetzten Erregung ist. Es sey z. B. ein Zinkblech (z) auf der einen Seite mit einer durch irgend eine Flüssigkeit $(f)$ getränkten Pappscheibe und auf der andern Seite mit einem Kupferbleche $(k)$ in Berührung, so hat in der Verbindung $f z k$ das $z$ in der Mitte zwischen dem $f$ und $k$ gleichsam die Wahl zwischen zwei entgegengesetzten Erregungen, indem es durch den Contact mit $\operatorname{dem} f$ an und für sich allein schwach negativ elektrisch, durch, den Contact mit $k$ dagegen viel stärker positiv wird und nach der ! gewöhnlichen Art zu urtheilen, glaubt man unbedingt, dass es der letzteren Erregung, eben weil sie so viel stärker erscheint, ganz entschieden folge, also wirklich positiv werde und dass zugleich dieses $+E$ aus dem $z$ sich durch das ganze $f$ verbreite. Aber dem ist nicht so. Die elektrische Erregung zwischen $f$ und $z$ allein ist zwar viel schwächer als die zwischen $k$ und $z$, aber diese Erregung ist nicht die eigentliche vollständige Thätigkeit der gegenseitigen Einwirkung zwischen $\operatorname{dem} f$ und $z ;$ sie ist nur ein durch den Condensator versichtbarter Theil dieser Thütigkeit, welche vielmehr ihrem eigentlichen Gehalte nach schon ein beginnender Chemismus ist, der viel energischer und entschiedener als die gegenseitige Einwirkung zwischen $k$ und $z$ ist und der nur von der Seite eines noch nicht vollständige Befriedigung findenden Strebens, als die blosse Tendenz zu einer tiefer greifenden Vereinigung, gleichsam nur wie der nach Aussen geworfene Abglanz der eigentlichen inneren 
Einwirkung, unter der Gestalt einer leisen elektrischen Spannung durch den Condensator reflectirt wird. Dasjenige, was daher in der Verbindung $f z k$ wirklich geschieht, ist folgendes. Das $z$ wird durch $f$ unbedingt negativ erregt; indem aber $k$ das $z$ positiv zu erregen und es dadurch der Erregung des $f$ zu entreissen strebt, so wird dadurch die Thätigkeit des $f$ gegen das $z$ nur noch gesteigert und das $z$, statt positiv zu werden, wird vielmehr jetzt nur noch um so stärker negativ, während das $f$ in der Berührungsfläche mit $z$ um so viel stärker positiv wird. - Eben so wird in der Verbindung $f k z$ das $k$, welches an und für sich im Contact mit $f$ bereits positiv ist, vermöge des Contacts mit $z$ keineswegs negativ, sondern im Gegentheil nur noch um so viel mehr positiv, indem das $f$ in $\operatorname{der}_{r} \mathrm{Be}$ $x$ ührungsfläche mit $k$ zu einer um so viel stärkeren negativen Erregung gereizt wird. Und so ist es in allen ähnlichen Fällen. Die ursprüngliche Erregung eines Metalls im Contact mit einer Flüssigkeit wird durch die entgegengesetzte Erregung eines zweiten Metalls, mit dem es auf der andern Seite in Contact gesetzt wird, nich̀t nur nicht aufgehoben, sondern im Gegentheil nur noch um so stärker und entschiedener hervorgerufen und es wird vielmehr mit dieser verstärkten Erregung die ausser dem sich geltendmachende Contactelektricität der Metalle, wenigstens an den mit der Flüssigkeit in Berührung stehenden Extremen derselben, gänzlich unterdrückt und vernichtet.

Dies ist ein zweites Fundamental-Theorem deI Elektricitätslehre, durch welches, wenn es erwiesen und gehörig constatirt ist, offenbar, wie man sehen 
muss, die Unzulänglichkeit aller bisherigen Vorstellungen über den Process in der galvanischen Kette dargethan und die obige durchgeführte Ansicht als die allein richtige gerade zu aufgedrungen werden muss. Wohlan, hier sind die Argumente und Thatsachen, welche den klaren Beweis dieses Theorems vollführevi. zurt Wenn man eine mit irgend einer hinlänglich wirksamen Flüssigkeit angefeuchtete Pappscheibe, die etwa 3 Zoll ins Gevierte gross ist, zwisehen zwei Kupferbleche bringt, so wird jedes derselben durch die Flüssigkeit positiv elektrisch, wobei die an sich schon sehr schwache Erregung an jedem einzelnen Bleche durch die gleichartige Gegenwirkung des anderen noch schwächer wird, so dass sie in der Regel nicht anders als nü mit Hülfe des Doppelcondensators sichtbar gemacht werden kann. Wenm man dagegen statt des einen der beiden Kupferbleche ein Zinkblech ( $z$ ) auf die feuchte Pappscheibe deckt, so wird bekanntlich, indem dieses negativ erregt wird, die positive Erregung des anderen Kupferblechs (k) beträchtlich erhöht und kann unter günstigen Umständen schon mittelst einfacher Condensation am Elektrometer durch eine Divergenz von etwa 3 bis 5 Graden sichtbar werden, wenn, wie es sich versteht, die mit dem $k$ berührte Condensatorplatte gleichfalls von Kupfer ist. Gegen das negative $z$ ist nehmlich das fin der Berührungsfläche positiv, auf der entgegengesetzten Fläche ist es folglich negativ und diese negative Erregung vereinigt sich mit derjenigen, welche schon, vermöge des Contacts dieser Fläche mit dem $k$ hervorgerufen ist, um das $k$ noch positiver zu machen, als dasselbe vermöge dieses Contacts bereits an und für sich ist. 
Würde das $z$ in seinem Contact mit dem $f$ noch in einem höheren Grade negativ, so würde auch die positive Erregung des $k$ noch verstärkt werden, und umgekehrt ist klar, dass wenn, bei einer aufs neue von Aussen her Statt findenden Einwirkung auf das $z$, die positive Erregung des $k$ vermelirt wird, diese auch eine durch jene Einwirkung Statt findende Vergrösserung der negativen Erregung des $z$ voraussetze, weil mit eirer Verminderung der letzteren Erregung auch die positive Erregung des $k$ nicht $z u$-sondern abnehmen müsste. Man decke nun unmittelbar auf die Aussenfläche des $\mathrm{z}$ noch ein Kupferblech $k^{\prime}$, so dass mithin in der Verbindung $k f z k^{\prime}$ auf der einen Seite das $k$ mit $\operatorname{dem} f$, auf der andern Seite aber das $z$ mit $\operatorname{dem} f$, und mit $z$ wieder $k^{\prime}$ in Contact sey und untersuche jetzt die Erregung des $k$ am Condensator, indem die kupferne Condensatorplatte mit $k$, und die andere Platte, so wie $k^{\prime}$, ableitend mit der Hand berührt werden, so wird man finden, dass, wenn $k$ in der simpeln Verbindung $k f z$ eine positive Erregung von etwa 3 bis 5 Graden Divergenz besass, dasselbe jetzt in der Verbindung $k f z k^{\prime}$ eine ungleich stärkere positive Erregung von etwa 15 bis 20 Graden zeigen wird. Das $z$ ist also der Erregung des $f$ durch den Contact mit $k^{\prime}$ schlechterdings nicht entrissen, sondern es ist vielmehr dadurch nur noch um so negativer geworden, weil das $k$ sich in seiner Erregung um so viel mehr positiv zeigt.

Wenn eben so in der Verbindung $z f k$ das mit der Zinkplatte des Condensators in Berührung gesetzte $z$, während $k$ und die andere Platte mit der Hand ableitend berührt werden, eine negative Erregung von

E 2 
etwa 5 bis 6 Graden zeigt, so wird in der Verbindung $z \int k z^{\prime}$, bei welcher das $k$ noch mit einer Zinkplatte $z^{\prime}$ in Contact gebracht ist, das z eine viel stürkere negative Erregung von 15 bis 20 und mehreren Graden zu erkennen geben, woraus eben so, wie in dem vorigen Falle folgt, dass das $k$ der Erregung des $f$ durch den Contact mit dem $z^{\prime}$ keineswegs entzogen sondern dadurch nur um so viel mehr positiv erregt worden sey.

Wenn hingegen nach der Verbindung $k f k^{\prime}$, bei welcher ein jedes der beiden Kupferbleche $k$ und $k t$ nur eine sehr schwache positive Erregung zeigt, das eine derselben noch mit einer Zinkplatte $z$ in Contact gesetzt wird, so dass man also die Verbindung $k f k^{\prime} z$ hat, so zeigt jetzt das andere $k$ eine schwache negative Erregung von etwa 5 Graden. Da also hier das $k$ nicht nur nicht positiver, sondern selbst seiner ursprünglichen Erregung im Contact mit $\operatorname{dem} f$ entrissen und schwach negativ geworden ist, so muss das $k^{\prime} \mathrm{ihm}$ gegenüber im Contact mit $\operatorname{dem} f$ und $z$ zugleich keineswegs negativ, sondern nur um so viel krüftiger positiv erregt worden seyn.

Eben so ergibt sich aus der Verbindung $z f z^{\prime} k$ dass das $z^{\prime}$ im Contact mit $f$ und $k$ zugleich, durchaus nicht der Erregung des letzteren folge und positiv werde, sondern nur durch das $f$ in eine um so viel stärkere negative Erregung versetzt werde *).

*) Dem bisherigen Mangel an Kenntniss des eigentlichen hier auseinander gesetzten Zusammenhanges der Erscheinungen ist eine grosse Zahl völlig irriger Angaben über elektrische Relationen zuzuschreiben und sehr viele andere Bestimmungen, die wirklich richtig sind, sind dies gewissermassen nur zufällig, weil bei ihnen zwei auf, einmal begangene Bestimmungsfehler sich wechselseitig aufgehoben und das in der 
Hat man sich einmal von der höchst einseitigen und falschen Vorstellung losgemacht, dass die Fort-

Reflexion an sich verfehlte Resultat dadurch allein als richtig. wieder hergestellt haben. Zu diesen Fehlschlüssen gehört z. B. der überall geläufige, mit welchem man die Relation des Zinks gegen das Kupfer aus den durch eine Flüssigkeit vermittelten Aussagen 'eines Condensators von Kupfer oder Messing herzuleiten pflegt. Man hält das eine Ende eines Kupferstücks in der Hand, an dessen anderes Ende ein Zinkstück befestigt ist und lässt das letztere die kupferno Condensatorplatte berühren, während die andere Hand die zweite Condensatorplatte ableitend berührt: so bleibt der Condensator aus bekannten Gründen ungeladen; wenn man aber eine feuchto Pappscheibe zwischen den Zink und die Condensatorplatte bringt, so wird diese letztere dadurch positiv geladen und man schliesst daraus, dass der Zink in dem Versuche gegen den Condensator hin positiv gewesen sey und leitet daraus überhaupt die Bestimmung, seiner Relation gegen das Kupfer $a b$, indem man mittelst'einer völlig unbegründeten und willkührlichen Vorstellung die Flüssigkeit hier nur als ein Filtrum der $+E$, durch welches diese zum Condensator gelange, betrachtet. Aber der Zink, der im Contact mit dem Kupfer allerdings positiv ist und von da aus auch diese Erregung, falls sie nicht anderweitig gehemmt wird, nach allen Richtungen hin versichtbart, war hier im Contact mit der Flüssigkeit nur um so negativer; die Flüssigkeit in der Berührung mit ihm dagegen war positiv, auf der entgegengesetzten Seite in der $\mathrm{Be}^{-}$ rührung mit dem Condensator war sie hingegen negativ und letzterer wieder dadurch erst positiverregt. Dass man bei der obigen fehlerhaften Art zu sehen und zu schliessen dennoch die richtige Relation herausbringt, rührt von zwei Omissionen her; in solchen Fällen, wo deren nur eine Statt findet, wird daher das Resultat allemal das entgegengesetzte des eigentlich richtigen, und solcher Umkehrungen gibt es viele und mannichfaltige. Wenn man z. B., um die Relation des Zinks gegen eine Säure zu prüfen, die letztere in ein Gefäss von Zink füllt, dieses auf den Condensatordeckel stellt, aber zur Beseitigung der sogenannten elektrometrischen Wirkung zwischen beide ein feuchtes Kartenblatt bringt und sodann dis Säure und die andere Condensatorplatte ableitend berührt, so wird der Deckel positiv geladen. Wer nun diesen Erfolg auf die gewöhnliche Art beurtheilt, der lässt den Zink, welcher in der 
leitung der elektrischen Erregung durch das fetwa nur so wie die Verbreitung einer Flüssigkeit durch einen Schwamm vor sich gehe; weiss man vielmehr, dass sie lediglich durch die lebendige, auf entgegengesetzten Extremen allemal auch entgegengesetzt-polare Thätigkeit des $f$ bewerkstelligt werde, so wie sie in einer grossen Reihe der sprechendsten Thatsachen dargethan und als ein erstes Fundamentaltheorem unserer Theorie ein für allemal von uns aufgestellt worden ist, so ist die Folgerung des oben ausgesprochenen zweiten Fundamentaltheorems aus den eben angeführten höchst bewährten Thatsachen so unfehlbar und nothwendig, dass nichts, was sonst noch der Berücksichtigung werth wäre, ihrer völligen Anerkennung ferner im Wege stehen kann und dass mithin auch die Richtigkeit und Naturgemässheit unserer Darstellung des Processes der galvanischen Kette, so weit sie durch alles obige entwickelt und begründet worden, für immer dadurch bekräftigt und entschieden ist.

Kehren wir nochmals einen Augenblick zur Betrachtung der einfachen Kette $z f k$ zurück. Vor der Schliessung ist bereits $k$ positiv und $z$ negativ; wird ferner bei fortwährend geöffneter Kette das z mit einem zweiten $k^{\prime}$ verbunden, so wird das $k$ der. Kette noch sehr viel positiver und eben so wird, wenn das: $k$ mit einem zweiten $z$ verbunden wird, auch das $z$ der Kette noch sehr viel negativer. - Wohlan, in diesen Erfolgen $\mathbf{i}_{\text {st }}$ eben dasjenige zwar noch unvollkommen und fast

Berührung mit der Säure und jeder andern Flüssigkeit negativ erregt wird, positiv elektrisch werden, und setzt dabei vielleicht selbst noch ein Verdienst in die klügliche Anwendung des feuchten Zwischenmittels, dem allein er die vermeinte Unfehlbarkeit des Resultats verdanken zu müssen glaubt. 
nur symbolisch, aber für jeden, dem es an der rechten Empfänglichkeit nicht mangelt, dennoch höchst verständlich vorgebildet, was bei der wirklichen Schliessung der Kette mit den zum organischen Kreislaufe in einander greifenden Thätigkeiten wahrhaft und selbstständig ins Leben tritt. Wenn die Kette geschlossen, also $k$ mit $z$ und $z$ mit $k$ verbunden wird, so ist ja in der That das $k$ dem $z$ dasjenige, was diêsem früher das $k^{\prime}$, und zugleich $z$ dem $k$ dasjenige, was diesem früher das $z^{\prime}$ war; aber weil jetzt jedes von den beiden Metallen in der Kette dem andern dasjenige ist, was ihm vorher ein fremdes ausser der Kette war und so alle Erregung, welche durch das eine dem andern zu Theil wird, auch die absolute Bedingung zur Erhöhung der eigenen Thätigkeit des letzteren ist, so ist das $k$ in seinem unmittelbaren Contact mit dem $z$ jetzt auch noch in einem ungleich höheren Grade positiv und das $z$ in seinem unmittelbaren Contact mit dem $k$ eben so noch in einem ungleich höheren Gradè negativ, als es vorhin in der ungeschlossenen Kette bei der blossen einseitigen Berührung des $k$ durch das $z^{1}$ und des $z$ durch das $k^{t}$ bereits der Fall war, und zwar ist in dieser lebendig gesteigerten Intensität der Thätigkeiten die Gränze der blossen elektrischen Spannung völlig uberschritten und die Elektricitäl gauz in Chemismus übergegangen, zu dem sie sich vor der Schliessung der Kette nur als die erwachte Tendenz, als das von Aussen her und von vereinzelten Standpuncten nach Innen hin gerichtete Streben zur Gewinnung einer harmonisch abgeschlossenen Einheit ankündigte. In dem Moment der Erreichung dieses Ziels aber, mit welchem der organische Kreislauf gebildet und geschlossen und 
der innere Mittelpunct aller in lebendiger Wechselwirkung sich gegenseitig fördernder und belebender Functionen gefunden ist, tritt umgekehrt wieder von Innen heraus der Magnetismus als das Streben des allseitig angeregten Entfaltungstriebes in jedem Puncte des geschlossenen Kreises hervor und verbürgt so in der kleinen, wie in der grossen kosmischen, Sphäre das kreisende, von dem sicher gewonnenen Mittelpuncte zur erweiterten Peripherie stets lindrängende und unablässig nach immer höherer Selbstständigkeit ringende Leben.

Wenn die einfache Kette $z f k$, wie gewöhnlich, durch einen metallischen Verbindungsdrath geschlossen wird, so ist das mit $k$ in Berührung gebrachte Extrem desselben, so wie $k$ selber, positiv und das an $z$ gelegte, so wie $z$ selber, negativ. Die Magnetnadel weicht dann bekanntlich, wenn die Kette im Norden der Boussole sich befindet, und das mit $k$ verbundene positive Ende über der Nadel, das an z gelegte negative unter ihr fortgeht, nach Osten hin ab. - Bei der einfachen Kette, welche dem invertirten Schema $f z k f$ entspricht, ist dagegen die Ablenkung unter sonst gleichen Bedingungen die entgegengesetzle und es lässt sich jetzt mit Bestimmtheit der Grund angeben, warum es so und nicht anders seyn müsse. Indem nehmlich die Metalle schon vor der Schliessung der Kette sich berühren, zugleich aber in der Mitte zwischen den beiden gesonderten Abtheilungen der Flüssigkeit auch in Contact mit der letzteren sind, so ist dadurch das $k$ nur noch um so mehr positiv und $z$ eben so um so stärker negativ. Befindet sich nun, wie oben, die Kette im Norden der Boussole, während die Aussen- 
fläche eines' jeden $f$ durch ein kleines Metallblech armirt und der Verbindungsdrath von der Armatur des $f$ auf der Seite des $k$ über der Nadel fort und unter ihr zu der Armatur des $f$ auf der Seite des z zurückgeleitet ist: so ist das erstere $f$ in der Berührungsfläche mit dem positiven $k$ negativ, also auf der Aussenfläche positiv und die Armatur dieser Fläche nehst dem mit ihr verbundenen Extrem des Draths wird folglich negativ; dagegen ist die Armatur und als Drathende an der Aussenfläche des zweiten, mit dem negativen z verbundenen, $f$ positiv. Also ist jetzt das Extrem des Schliessungsdrathes über der Nadel negativ, das unter ihr liegende positiv, die Polarität also, bei gleicher Lage und unter sonst gleichen Bedingungen, der obigen, welche bei der Kette $z f k$ Statt fand, entgegengesetzt und daher auch die Ablenkung der'Nadel, welche dort östlich war, jetzt westlich.

Alle bis hieher gemachten Auseinandersetzungen über die einfache Kette sind auf die Kategorie einer gegen das $f$ verschiedenen elektrischen Relation der beiden metallischen Erreger $z$ und $k$ bezogen worden; es ist jetzt aber der Ort, auch die so lange noch beseitigte Kategorie, in welcher den Erregern eine und dieselbe Relation gegen das $f$ zukommt, näher zu betrachten, und es bedarf zur Gewinnung der Ueberzeugung, dass auch unter diesen Bedingungen die Erscheinungen den bisher entwickelten Ansichten vollkommen entsprechen, nur weniger Erörterungen.

Der Satz, dass die elektrische Relation der Metalle gegen die Flüssigkeiten, so oft sie verschieden ist, jeder Zeit die entgegengesetzte von derjenigen sey, welche der blosse Contact der Metalle zeigt, stellt das 
Gesetz über die elektrischen Relationen 'zwischen Flüssigkeiten und Metallen noch nicht in seiner höchsten Allgemeinheit dar, eben weil er es nur in Bezug auf den Fall einer gegen das $f$ verschiedenen Relation der $\mathrm{Me}-$ talle ausspricht. In seiner ganzen Ausdehnung umfasst das Gesetz alle diejenigen Fälle mit, in welchen die Relation der Metalle gegen das $f$ der Qualität nach nicht verselieden ist; denn auch in diesen Fällen ist die Relation der Metalle gegen die Flüssigkeit jeder Zeit die entgegengesetzte von derjenigen, welche sich durch die Contactelektricität der Metalle versichtbart, nur wird dieser Gegensatz alsdann, wie es sich schon so versteht, nicht mehr durch die qualitative, sondern allein durch die quantitative Verschiedenheit der Re- , lationen begründet. Wenn man daher von der ersteren Verschiedenheit beim Ausdrucke des Gesetzes absieht und eine bloss quantitative Bestimmung zum Grunde legt, vermöge welcher das negative dem positiven nur als ein minder positives und eben so das positive dem negativen nur als ein minder negatives gegenübergestellt wird, so lüsst sich der Satz ohne Einschränkung als ein allgemeines Naturgesetz in folgende Worte zusammenfassen:

die elektrische Relation irgend zweier Metalle gegen Wasser und gegen irgend eine Solution ist immer die entgegengesetste von derjenigen Relation, welche beim Conlact derselben Metalle Statt findet. Die demnïchst hervor zu hebenden Kategorien, unter welchen das Gesetz verständlich und anschaulich wird, sind folgende:

1) Die Relation der Metalle gegen das $f$ ist nicht bloss der Quautität, sondern zugleich der Qualität nach 
verschieden. - Unter dieser Kategorie ist alsdann auch dieselbe Relation nicht bloss der Quantität, sondern auch der Qualität nach die entgegengesetzte von der, welche im Contact der Metalle sich darstellt.

Wenn also von den beiden Metallen $z$ (Zink) und $k$ (Kupfer) im gegenseitigen Contact $z$ das positive, $k$ das negative ist, so ist beim Contact mit der Flüssigkeit gerade umgekehrt $z$ das negative und $k$ das positive.

2) Die Relation der Metalle gegen das $f$ ist nicht der Qualität, sondern allein der Quantität nach verschieden; beide sind gegen das $f$ positiv, oder beide negativ, nur das eine mehr, das andere weniger. - Unter dieser Kategorie ist alsdann auch dieselbe Relation jedesmal der Quantitüt nach die entgegengesetzte von der, welche im Contact der Metalle versichtbart wird.

a) Wenn die Metalle $k$ (Kupfer) und $s$ (Silber) beide gegen die Flüssigkeit positiv werden und im gegenseitigen Contact dieser Metalle $k$ das positive, $s$ das negative (das minder positive) ist, so ist im Contact mit der Flüssigkeit: $k$ das minder positive, $s$ das mehr positive.

b) Wenn die Metalle $b$ (Blei) und $z$ (Zink) beide gegen die Flüssigkeit negaliv werden und im gegenseitigen Contact dieser Metalle $b$ das negative, $z$ das positive (das minder negative) ist, so ist im Contact mit der Flüssigkeit: $b$ das minder negative, $z$ das mehr negative.

Wenn nun eine einfache Kette aus irgend einem $f$ und zwei solchen Metallen, deren Relation gegen das $f$ der Qualitat nach nicht verschieden ist, zusammengesetzt wird, so sind vermöge des obigen Gesetzes dieselben 
Bedingungen, die von uns als der wahre Grund der Thätigkeit der Kette in allen Erscheinungen derselben erkannt worden sind, so wie bei der Kette $z f k$, gegeben; nur sind sie in einem quantitativ ungleich geringerem Grade vorhanden, mit dem auch 'eine verhältnissmässig schwache Wirkung der Kette verbunden ist.

Die Kette werde z. B. aus irgend einem $f$, aus Silber $(s)$ und Kupfer $(k)$, die beide gegen das $f$ positiv werden, zusammengesetzt. Tritt also zuerst $s$ mit dem $f$ in Contact, so wird $s$ positiv und das $f$ in der Berührungsfläche mit ihm negativ, am entgegengesetzten Extrem aber positiv. Wird sodann auch $k$ mit diesem letzteren Extrem in Berührung gesetzt, so wirkt $k$ der positiven Erregung desselben entgegen, indem es selbst gleichfalls an $f$ positive Elektricität empfängt während $f$ dagegen in Berührung mit $k$ negativ erregt wird. Diese Erregung kommt auch zu Stande, aber sie ist gehemmt [durch die stärkere, welche von $s$ ausgeht und der Erfolg ist, dass in ider ungeschlossenen Kette $k f s$ beide Metalle, eines durch die Gegenwirkung des anderen, minder positiv als jedes für sich allein in Berührung mit dem $f$ werden. Aber die Erregung des $k$ ist, weil sie an sich die schwächere ist, mehr durch $s$, als die des $s$ durch $k$, gehemmt; $s$ ist stärker, $k$ bei weitem schwächer positiv und steht in so fern dem $s$ (so wie in der Kette $z f k$ das $z$ dem $k$ ) als ein negatives gegenüber. Wird die Kette geschlossen, so soll vermöge des Erregungsdranges beim metallischen Contact das stärker positive $s$ negativ, das schwächer positive $k$ positiv werden; daher wird nach derselben Aetiologie, wie sie oben für die Kette $z f k$ entwickelt worden, das $s$ von dem $f$ in der ursprünglichen Erre- 
gung nur um so energischer fest gehalten; $s$ wird in einem so viel höheren Grade positiv und $f$, welches in der Berührung mit $s$ um so stärker negativ angefacht ist, wird auf der Seite des $k$ dadurch zugleich so viel kräftiger positiv, dass jetzt $k$ entschieden negativ wird. Das im Contact (gegen $k$ ) negative Metall $(s)$ ist also auch hier in der Kette $k f s$ das positive und das im Contact positive (k) ist das negative dieser Kette; an jenem erscheint in der zum Chemismus gesteigerten Thätigkeit der Kette das Hydrogen oder der basische Theil des $f$, an letzterem das Oxygen, und die Metalle $z$ und $s$ in der Kette $k f s$ verhalten sich hinsichtlich ihrer Polarität bei der Zersetzung des $f$ und bei der Ablenkung der Magnetnadel eben so wie respective $z$ und $k$ in der Kette $z f k$.

Bei einer Kette $b f z$, in welcher beide Erreger gegen das $f$ negativ sind, wie z. B. Blei (b) weniger, Zink (z) stärker negativ gegen irgend ein $f$ erregt werden, steht das weniger negative $(b)$ dem andern $(z)$ als ein positives gegenüber, und bei der Schliessung der Kette, mit welcher die Contacterregung der Metalle das Verhältniss umzukehren droht, tritt es durch die lebendige Action des $f$ wieder um so bestimmter hervor, so dass $z$ mit viel stärker negativer und (b) mit vollends entschiedener positiver Polarität wirksam werden und dieser Polarität gemäss auf die chemische Zersetzung des $f$ und auf die Magnetnadel reagiren.

Die metallischen Erreger verhalten sich also der Polarität nach, mit welcher sie in der Kette wirksam sind, im Verhältniss zu ihrer durch den gegenseitigen Contact versichtbarten Relation ausser der Kette unter allen Umständen nach einer und derselben Regel: das 
Metall, welches der Contactelektricität nach das negative ist, wirkt in der geschlossenen Kette auf die Zersetzung des $f$ und auf die Magnetnadel mit der positiven Polarität und so umgekehrt, gleichviel ob die Relation der beiden Erreger gegen das $f$ ungleichartig oder gleichartig ist; nur dass im letzteren Falle mit der ursprünglich sehr geringen Spannungsdifferenz auch nur eine ungleich schwächere Thütigkeit der Kette zusammen hängt.

Mit der Ueberzeugung also, dass auf einem Hauptgebiete der Naturwissenschaft den Erscheinungen die Maske des Scheins endlich entrissen sey, mit welcher sie seit ihrer Entdeckung den Forschenden täuschten und mehr oder weniger, wie der Schein überall, gerade den der Wahrheit entgegengesetzten Charakter heuchelten, können wir jetzt die im Lichte sonnenklarer Thatsachen für immer gültigen und unerschütterlichen Resultate unserer bisherigen Untersuchung durch das Folgende ausprechen:

1) Nicht die Contactelektricität der Metalle an sich, sondern die zum analytischen Effect des Chemismus gesteigerte Elektricität der Flüssigkeit im Contact mit den Metallen ist es, welche die wahrhafte Thätigkeit der galvanischen Kette bedingt und begrïndet.

2) Die Contactelektricität der metallischen Erreger an und für sich macht so wenig die wahrhafte Tlätigkeit der galvanischen Kette aus, dass vielmehr die Polarität, mit welcher die Erreger in der geschlossenen Kette an der chemischen Zersetzung der Flüssigkeit und an der Wirkung auf die Magnetnadel Antheil haben, grerade die entgegengesetzte Polarität von der- 
jenigen ist, welche sie in der Contactelektricität versichtbaren *)

- 3) Die Polarität, mit welcher das der Contactelektricität nach sogenannte negative Metall (Silber, Kupfer etc.) das Hydrogen und die Basen in der geschlossenen Kette anzieht, ist also die positive (nicht die negative) und die Polarität des Hydrogens und der

*) Wenn von Polarität der Thätigkeit der einzelnen Glieder der Kette die Rede ist, so wird darunter nicht einseitiger Weise nur der Gegensatz der positiven und negativen Elektricität verstanden, sondern der Gegensatz der beiden Thätigkeiten überhaupt, die nach der einen Seite, theils als positive Elektricität, theils als oxydirende Selbst-Desoxytation, theils als nordpolarer (tellurisch südpolarer) Magnetismus, nach der andern, theils als negative Elektricität, theils als desoxydirende Selbst - Oxydation, theils als südpolarer (tellurisch nordpolarer) Magnetismus hervortreten. Die Polaritãt eines Körpers ist eine und dieselbe, er mag wirklich Oxygen absetzen und andere Körper ausser sich oxydiren, indem er sich selbst desoxydirt, oder er mag nur die Tendenz zu dieser Oxydation, (der eigenen Desoxydation) auf individuelle Weise im Zustande der positiven Elektricität, auf universelle im Zustande der magnetischen Nordpolarităt (der tellurischen Südpolarität) aussprechen; die Art und Richtung, das heisst, die Polarität der Thätigkeit ist in dieser dreifachen Modification eine und dieselbe, nehmlich die positive, und eben so umfasst dio negativ polare Thätigkeit die Triplicität des Gegensatzes.

Für einen jeden, der in die Entwickelung der obigen Resultate auf die zu ihrem Verständnisse erforderliche grūndliche Weise eingegangen ist, wird diese Bemerkung überflüssig seyn, deren Inhalt durch Form und Wesen unserer ganzen Darstellung längst gegeben ist, da aber im Auslande wie unter den Anhängern der Afterspeculationen bei uns alle Vorstellungen immer nur auf nichts anderes als ein elektrisches Fluidum und auf diefabelhafte Substantialität des courant electrique gerichtet sind, so oft vom Wesen der Thätigkeit der galvanischen Kette nur die Rede ist, so mag diese Anmerkung hier wenigstens ein für allemal daran erinnern, dass die Resultate unserer Untersuchungen mit den zerfliessenden Dunstbildern der Hypothesenmacherei weder vermengt noch nach ihnen beurtheilt werden mögen. 
Basen in ihrer'Wechselthätigkeit mit jenem Metalle ist folglich die negative (nicht die positive). - Desgleichen ist die Polarität, mit welcher das seiner Contactelektricität nach sogenannte positive Metall (Zink) das Oxygen und die Säuren in der geschlossenen Kette an sich zieht, die negative (nicht die positive) und die Polarität des Oxygens und der Säuren in ilhrer Wechselthätigkeit mit jenem Metalle ist folylich die positive (nicht die negative) *)

*) Die Elektrochemie nennt das Hydrogen und die Basen elektropositive, das Oxygen und die Säuren elektronegative Substanzen. Dies ist erstens unter dem einseitigen und unrichtigen Gesichtspunkte des ganzen elektrochemischen Lehrsystems geschehen, indem die Elektricität bei der chemischen Thätigkeit so wenig als sonst wo als Agens auftritt, sondern selbst nur als dienoch unentwickelte Form jener Thätigkeit betrachtet seyn will, bei welcher hier allein die Richtung als Polarität zu fixiren war; aber zweitens sind auch schon bloss in Hinsicht dieser Polaritätsbestimmung die Charaktere verfehlt und gerade hin, als sollten sie aller Wahrheit in der Natur Hohn sprechen, mit einander verwechselt. - Wie sich von jeher in Sprache und Wissenschaft zwischen dem Bezeichneten und dem scheinbar zufällig entstandenen Zeichen nicht selten ein tiefer innerer Zusammenhang erst in der Folge offenbart hat, vermöge dessen, eben wegen seiner nothwendigen über das Einzelne des Erkennens hinausreichenden Begründung, das Einzelne, ohne in einem höheren Zusammenhange bestimmt erkannt zu seyn, durch die lautere, unbefangene und unergründliche Schöpferkraft des Geistes frïherer Zeiten dennoch richtig und harmonisch bezeichnet wurde, wie z. B. die Planeten durch die Zeichen der Metalle; so sind auch die Säuren von Alters her treffend und in bedeutungsvollem Zusammenhange mit einer tiefen Ansicht der Natur und des Lebens durch das Zeichen des Kreuzes, das Symbol des Positiven, des Realen, des Geistigen und Wahrhaften bezeichnet worden. Es ist nur als das Resultat einer Afterspeculation unserer Tage zu betrachten, dass man diesen Einklang eine Zeit lang überhören und verderben konnte; möge er bald seiner rechten Bedeutung nach wieder von Vielen anerkannt und vernommen werden. 
Aus dem Bisherigen ergibt sich endlich noch das Verfahren, nach welchem aus der Einwirkung der Metalle in der einfachen Kette auf die Magnetnadel das System der elektrischen Relationen der ersteren zu bestimmen sey, vermittelst sehr einfacher und ganz directer Folgerungen. Es ist klar, indem, wie gewöhnlich, die Zusammensetzung der Kette dem Schema $z f k$ entspricht, dass ein Metall, wenn es hinsichtlich der Ablenkungsrichtúng der Nadel sich so wie das Kupfer verhält, auch gegen das andere im Contact ausser der Kette negativ elektrisch, und wenn es in dieser Hinsicht wie der Zink wirkt, dass es im Gegentheil gegen das anderre positiv elektrisch seyn müsse. Um also die Relationen eines und desselben Metalls gegen alle übrigen und die Relationen aller unter einander zù bestimmen, werden, bei einem und demselben $f$, bei gleicher Grösse, gleicher Entfernung der wirkenden Flüchen und überhaupt unter sonst gleichen Unständen einem und demselben Metalle der Reihe nach die übrigen in der Kette gegenüber gestellt, und die verschiedenen Abweichungswinkel bei der dureh den Multiplicator bewirkten Ablenkung der Magnetnadel dienen ausser dem, dass durch sie die Relationen der Ait nach angegeben werden, zugleich als Maass für das Quantitative dieser Relationen. In Hinsicht auf die Bestimwung der blossen Reihenfolge, bei welcher es allein nur auf das mehr und minder der elektrischen Spannungen ankommt, ist die Zuverlässigkeit dieses Criteriums ausser Zweifel, da innerhalb der Wirkungsgrünzen der einfachen Kette der Magnetismus der Metalle als eine von der Contactelektricität der letzteren abhängige Function auch stärker oder schwächer seyn F 
muss, je riachdem die Spanmung der Contactelektricität stärker oder schwächer ist, wie es die Erfahrung zugleich in allen Fällen bestätigt. $\mathrm{Um}$ aber aus den an der Boussole abgelesenen Ablenkungswerthen zugleich das Verhältniss dév Intensität in der Contactelektricität der/verschiedenen Mefalle zu beurtheilen, würde man vor allem zuiächst die goniometrischen Ablenkungswerthe anf die eigentlichen Verhältnisswerthe der Intensität dér magnetischen Wirkung der Kette und insonderheit des Verbindungsdrathes reduciren müssen, und diese Réduction beruht, unter der vielfältig bewährten und zugleich a priori erweislichen Annahme, dass die Wirkungsgrösse des einfachen oder mehrfach um die Nadel geschluigenen Verbindungsdrathes umgekehrt wie die iste Potenz der Entfernung sich verhalte, auf dem gleichfalls leicht erweislichen Satze, dass die absoluten Wirkungswerthe sich wie die Producto aus dem Sinus in die Tangente der jedesmaligen Ablenkungswerthe verhalten, vorausgèsetzt, dass der Verbindungsdrath in der Ebene des magnetischen Meridians und dass er zugleich der Nadel so nahe als möglich liege. Hiernach würde z. B. bei zwei verschiedenen Ablenkungen, wenn die $\mathrm{Nadel}$ das eine Mal um $20^{\circ}$, das andere Mal um $60^{\circ}$ abwiche, das Verhältniss der wahren Wirkungsgrösse nicht wio 1 zu 3, sondern das von 1 zu 12, und noch etwas grösser als dieses, seyn. $\mathrm{Ob}$ man aber mit diesen auf das wahre Verhältniss der magnetischen Intensität zurückgeführten Ablenkungswerthen zugleich dasjenige der elektrischen Spannungsintensität beim Contact der $\mathrm{Me}-$ talle habe oder nicht, und nach welchem Gesetze ferner das letztere von dem ersteren abhängig sey, ist eine 
Frage, / deren Antwort nach dem dermaligen Zustande der Wissenschaft nicht anders als nur darch Versuche und zwar nur durch schwierige und mühsame Versuche zu findeu seyn wird. Doch wäre fürs Erste schon mit der Darstellang einer vollständigen Reihe jener auf die wahren Veihältnisse der Intensität reducirten Ablenkungswerthe an und für sich zur Kenntniss der elektrischen Relationen aller oder der meisten Metalle etwàs viel Gediegneres und Zuverlässigeres geleistet, als dásjenige, was bisher nur dem Gebrauche des Condensators und Duplicators seine Entstehung zu verdanken hat, vorausgesetzt, dass die Feststellung dieser Reihe von Zahlenwerthen mit genauen, durch längere Erfahrung und Uebung geleiteten, vielfältig wiederholten und kritischen Versuchen zusammenhänge; denn der Experimentator, welcher es unternimmt, in dieser Hinsicht etwas zu leisten, muss sich besonders erst mit den schon oben erwähnten transitorischen Anomalieen der geschlossenen Kette und überhaupt mit den Lrscheinungen, welche Statt finden, bevor sich der flüssige Leiter in seiner polaren Action durch die ganze wirkende Masse der Kette hindurch in das rechte dauernde Gleichmaass gesetzt hat, durch Erfahrung vollständig bekannt gemacht und sie von dem, was als gesetzmässiges und constantes Resultat der Wirkungen nach kürzerer oder längerer Dauer des Geschlossenseyns der Kette hervorgeht, gehörig unterscheiden gelernt haben, wenn er nicht, wie das so häufig geschehen ist und noch fortwährend zu geschehen pflegt, blosse Beobachtungen, die an sich richtig und redlich gemeint seyn können, aber in keiner Bedeutung und in keinem Verhältnisse zum eigentlichen Zwecke F 2 
der Untersuchung stehen'; an der Stelle der wirklich brauchbaren Data aufzeichnen und mittheilen will.

Die Bestimmung der elektrischen Relationen zwischen den Metallen und Flüssigkeiten, so wie der Flüssigkeiten unter sich, ist nicht mehridurch eine so directe und einfache Methode vermöge der dreigliedrigen Kette zu bewerkstelligen, sondern geht erst aus der näheren, im folgenden Abschnitte Statt findenden, Betrachtung der Natur der zweigliedrigen Kette hervor, eine Betrachtung, welche indess durch die Fruchtbarkeit an Aufschlüssen, die nach allen Seiten hin aus ihr hervorgehen, ein bei weitem grösseres Interesse erlangt, als dasjenige, welches allein an die Bestimmung der elektrischen Relationen geknüpft ist; sie ist zunächst der entschiedenste Probierstein, an welchem die obigen, in Bezug auf die dreigliedrige Kette entwickelten, Theoreme ihre Aechtheit und Gediegenheit auf das Anschaulichste bewähren, und sie fuihrt. ausserdem auf Standpunkte, von denen aus die Gesammtheit aller Erscheinungen auf dem Gebiete der Chemie unter einer gemeinsamen, eigenthümlichen Beleuchtung sich darstellt, welche schon jetzt durchgreifende Verständnisse eröffnet und für die Zukunft in grösserem, unbestimmbar reichlichem Maasse aufzuschliessen verheisst. 


\section{Dritter Abschnitt.}

Die zweigliedrige galvanische Kette mit ungleichen metallischen Berührungsfächen.

Unter zweigliedrigen Ketten versteht man bis jetzt in der Regel solche Ketten, die aus einer Flüssigkeit und einem einzigen homogenen Metalle gebildet werden, welches, statt der beiden differenten Erreger der dreigliedrigen Kelte, die Flüssigkeit auf entgegengesetzten Seiten mit verschiedener Flächengrösse berührt. Wir werden unten diesen Begriff der zweigliedrigen Kette sich bedeutend erweitern sehen, bleiben aber fürs Erste bei ihm in der angegebenen Beschränkung stehen.

Dass eine solche zweigliedrige Kette der Wirkung nach im Wesentlichen so wie die dreigliedrige sich verhalte, ist bekannt und insbesondere anschaulich durch ihre elektromagnetische Thätigkeit, indem der um die Magnetnadel geschlungene Multiplicator, sobald seine Extreme die ungleichen metallischen Armaturen der zweigliedrigen Kette berühren, die Nadel bei mässiger Grösse und hinlänglicher Differenz des Flächeninhalts der beiden sonst qualitativ völlig gleichen Metallbleche beträchtlich abzulenken vermag.

Man hat diese Wirkung und früher die elektrische Spannung an den Polen solcher aus mehreren Elementen zusammengesetzten zweigliedrigen Ketten, eben wegen der Uebereinstimmung mit der Wirkungsart 
der dreigliedrigen, auch aus derselben hypothetischen Quelle mit jener hergeleitet; die Vorstellung, dass die Contactelektricität der Erreger das ursprünglich bedingende Princip der Wirksamkeit der Kette sey, war in solchem Grade die allgemein, unbedingt und ausschliesslich herrschende geworden, dass sie auch hier ihre Stereotypenrechte behauptete, so dass man unbedenklich den Erfolg aus einer elektrischen Erregung hervorgehen lassen zu müssen glaubte, die hier, so wie sonst durch die qualitative Differenz, einzig und allein nur durch die quantitative der metallischen Armaturen mit dem Contact derselben hervorgerufen werde.

Hätte man, statt bei der Unhaltbarkeit und den unverkennbaren Widersprüchen dieser Annahme sich zu beruhigen, durch sie vielmehi Veranlassung zu einer unbefangenen und gründlichen Untersuchung der eigentlichen Quelle der Erscheinungen genommen und sodann, statt von der dreigliedrigen auf die Zweigliedrige zu schliessen, vielmehr von der letzteren auf jene zurückgeschlossen, so würde an der Stelle der ungebührlichen Erweiterung einer falschen Ansicht vielmehr ihre Beschränkung und gänzliche Berichtigung erfolgt seyn. So aber bestätigte sich hier dasselbe, was zu keiner Zeit härter und schneidender hervorgetreten ist, als in unsern Tagen gleich nach der Eutdeckung der unendlich bedeutungsvollen Erscheinungen des Eleklromagnetismus: wenn einmal das Organ der Naturforschung bis zu einem gewissen Grade durch den verwerflichen Gebrauch der Hypothesen verwöhnt und geblendet ist, so ist der höhere Lichtstrahl jeder neuen Offenbarung, welche ausser- 
dem das unbefangene Gemüth des Naturforscher's mit dem warmen Enthusiasmus eines leberidiger eröffneten, tiefer dringenden Verständnisses zu erfüllen vermag, für das kranke Auge nichts als ein Mittel, mit dem der bereits herrschende Grad der Blindheit, statt gehoben $\mathrm{zu}$ werden, nur noch vermehrt wird uind dúrch welches auf dem überall unsichern und finstern Hintergrunde des Erkennens statt der walirhaften Gestalten nur Phantome und Zerrbilder hervorgerufen werden, welche den reinen Resultaten einer gesunden Naturforschung nur noch immer stärker und hämischer Hohn sprechen, als es bereits durch die früheren geschah.

Es bedarf kaum der Erwähnung, dass es an sich unmöglich sey, zwei getrennte Metallmassen in absoluter Homogeneität darzustellen; es ist auf der andern Seite aber auch eben so gewiss, dass man in Bezug auf einen bestimmten Grad der Schärfe der Beobachtung die Homogeneität in solchem Grade darzustellen vermöge, dass die aus den Abweichungen von derselben entspringenden Erregungen der Massen beim Contacte der Beobachtung entzogen bleiben, und dașs man in so fern überhaupt von diesen Erregungen abstrahiren und zwei getrennte, möglichst homogen gemachte, Massen eines und desselben Metalls in so fern als zwei völlig homogene in der Physik eben so wohl und mit noch grösserem Rechte betrachten köine, wie man in der Mathematik zwei Grössen, deren Differenz eine gewisse Gränze nicht überschreitet, als völlig gleiche Grössen behandeln kann.

Dass nun zwei in diesem Sinne homogene und durch nichts als die Quantität der Masse verschiedene 
Metalle beim Contact bloss in Folge dieser rein quantitativen Verschiedenheit sich elektrisch erregen sollten, wäre eine in sich so haltungslose Vorstellung, dass man mit Recht denjenigen verlachen würde, der von dem Vorhaidenseyn oder Nichtvorhandenseyn einer solchen Erregung sich noch erst durch den Condensator unterrichten wollte; in der Annahme derselben an sich ist bereits die vollständigste deductio ad absurdum enthalten, weil nach ihr jede kleine willkürlich begränzte Quantität aus irgend einer Metallmasse mit der letzteren und somit auch die ganze Masse in allen ihren einzelnen Theilen mit sich selber in entgegengesetzter Erregung begriffen seyn müsste, welches, wenn es nicht den Sinn haben soll, dass gar keine Erregung solcher Art möglich sey, völlig ohme Sinn ist. Eben so ungereimt würde es seyn, den Grund der Erregung in einer Ungleichheit der Berührungsflächen der beiden sonst homogenen Metallstiucke suchen zu wollen, weil die Berührungsfläche in beiden natürlich immer ,dieselbe gemeinschaftliche ist, wie verschieden sie auch dem sonstigen Volumen nach seyn mögen.

Vernünftiger Weise kann also in Folge dessen, was die zweigliedrige Kette versichtbart, nur in so fern von einem elehtrischen Gegensatze die Rede seyn, als derselbe aus dem Conflict der homogenen Metalle mit der Flüssigkeit selber unter der Bedingung entspringt, dass die Berührungsflächen zwischen Metall und Flïssigkeit auf verschiedenen Seiten der letzteren verschieden seyen. Aber eben diese aus dem gegenseitigen Conflict des Metalls und der Flüssigkeit hervorgelrende Erregung ist nichts anderes, als die Contactelektricitüt zwischen der Flüssigkeit und dem Metalle, 
welche wir bereits oben bei der dreigliedrigen Kette als das wahre Princip ihrer |Thätigkeit erkannt haben, während die Contactelektricität der Metalle unter sich nur das Reizmittel zur Belebung dieses Thätigkeitsprincips bildete. Ganz dasselbe Princip und mit ihm die allerentschiedenste Bürgschaft für die Richtigkeit jener Ansicht finden wir in der zweigliedrigen Ketto wieder, welche sich von der dreigliedrigen im Ganzen fast nur so unterscheidet, wie insbesondere eine dreigliedrige Kette aus der Kategorie, in welcher die Relation der beiden Erreger gegen das $f$ gleichartig ist, von einer Kette aus der Kategorie, in welcher diese Relation ungleichartig ist, abweicht; die zweigliedrige Kette stellt einen Organismus auf einer niedrigeren Stufe vor, dessen Organe weniger gesondert nur in unbestimmten Umrissen theils bloss angedeutet, theils noch gänzlich ununterscheidbar wechselseitig verschmolzen und in einander versenkt sind.

Es sey $z$ eine Metallfläche, die im Contact mit der Flüssigkeit $f$ negativ elektrisch wird, so wird die letztere in der Berührungsfläche mit $z$ positiv und am entgegengesetzten Extrem negativ', elektrisch. Wird an dieses Extrem eine der Grösse und Beschaffenheit. nach mit z völlig gleiche Metallfläche gelegt, so hebt sie durch dieselbe elektrische Relation gegen $f$ einen Theil der negativen Erregung der ersteren gänzlich auf, eben so wie die ihrige durch die erstere Metallfläche auf der andern Seite zum Theil vernichtet wird, and beide Metalle sind in gleichem aber viel schrächerem Grade negativ elektrisch, als jedes von ihmen in der Berührung mit $f$ an und für sich allein seyn würde. Ist dagegen die berührende Fläche der zweiten Arma- 
tur $z^{f}$ bei sonst völlig gleicher Beschaffenheit betrüchtlich kleiner, als die der ensteren $z$, so ist auch das Integval ihrer gegenwirkenden Erregungsthätigkeit beträchtlich geringer, als bei jener; denn da die Erregungsintensität jedes einzelnen Puncts der Kette nur eine Function der Erregungsintensität der Masse derselben in allen ihren Puncten schlechthin ist, so muss $z^{\prime}$, wenn auch bei seinem Contact mit der Flüssigkeit die eigenthümliche Erregung sich geltend macht, vermöge welcher das $f$ in der Berührungsfläche mit $z^{\prime}$ positiv und $\approx$ selbst negativ wird, von dieser negativen Erregung im Conflict mit der von dem grösseren z ausgehenden Erregung doch viel mehr als z von der seinigen verlieren. $\quad$ Vor der Schliessung der Kette ist also $z$ negativ und die kleinere Armatur $z^{\prime}$, wenn auch ebenfalls, doch in viel schwächerem Grade negativ, als $z$, so dass sie dem $z$ als eine posiliv erregte gegenüber steht und dass es nur noch einer angemessenen Verstärkung der negativen Erregung des z bedarf, damit der Gegensatz völlig entschieden und $z^{t}$, ausser, Vermögen, der kräftigeren Thätigkeit gegenüber seine eigene Erregung noch ferner geltend zu machen, absolut positiv wird. Dieser Erfolg findet nun in der That bei der Schliessung der Kette, eben so wie bei einer Kette aus der zweiten Kategorie der dreigliedrigen, Statt, nur mit dem Unterschiede, dass beim Contact der Armaturen die Erhöhung der Erregung und die eigentliche Thätigkeit der Kette nicht, wie dort, durch den Drang zur Entwickelung der entgegengesetzten Erregung, sondern jetzt nur durch den Drang zur Herstellung des Gleichgewichts herbeigeführt wird. Mit dem Contact bei der Schliessung 
entsteht in dem mehr negativen $z$ und in dem ungleich weniger negativen $z^{\prime}$ der Drang, sich einander zu o $E$ auszugleichen, aber die Flüssigkeit, statt diesem Drange nachzugeben und die Metalle aus der Erregung, mit welcher sie dieselben bereits erfasst hat, fahren zu lassen, tritt dafür nur in desto lebhaftere Thätigkeit gegen sie, sie richtet ihren positiven, aciden Factor, der bis dahin bereils vorzugsweise nach der Seite des mehr negativen $z$ hin beschäftigt war, jetzt nur um so entschiedener gegen $z$, dieses wird daher ungleich stärker negativ, $z^{\prime}$ dagegen absolut positiv und mit der erhöhten Thätigkeit geht die anfängliche elektrische Erregung in entschiedenen Chemismus über, das z wird oxydirt und auf der Seite des $z^{\prime}$ tritt die Base oder das Hydrogen auf; während zugleich in allen Puncten der Kette die lebendig angeregte Tendenz zu derselben Diremtion der Masse, so wie bei der dreigliedrigen, als Magnetismus offenbart wird.

Die Wirkung der zweigliedrigen Kette ist aber ungleich schwächer als die der dreigliedrigen, weil bei jener das Moment des Ausgleichungsdranges im Contact der Armaturen nur auf o $E$ gerichtet ist, während in der dreigliedrigen Kette dieser Drang vermöge der Contactelektricitüt der Metalle noch über den Nullpunct des Gleichgewichts hinüber greift und damit eine um so kräftiger unterhaltene Wirksamkeit der Kette nach der entgegengesetzten Seite hin hervorruft. Gerade deswegen aber, wèil bei der zweigliedrigen Kette eine solche Erregung durch Contactelektricität der metallischen Armaturen an und für sich nicht möglich ist, während dennoch qualitativ vollkommen gleiche Erscheinungen an ihe wio an der dreigliedrigen 
Kette erfolgen, ist man nicht nur berechtigt, sonderu vielmehr gezwungen, das Princip der Thütigkeit in einer andern Quelle als jener Contactelektricität der Metalle an sich zu suchen, und diese Quelle kann allein nur in der elektrischen Relation der Armaturen zur Flüssigkeit enthalten seyn.

Durch die zweigliedrige Kette gewinnen also die Theoreme, welche in dieser Schrift in Bezug'auf die wahre Beschaffenheit der Thätigkeit der dreigliedrigen und der galvanischen Kette überhaupt aufgestellt sind, von Neuem eine durchaus vollendete Evidenz, sobald es entschieden ist, dass die grössere Metallfläche während des Geschlossenseyns der zweigliedrigen Kelte jeder Zeit ganz in derselben Art, wie der Erreger von dem nämlichen Metalle in der dreigliedrigen Kette sich wirksam zeige, und dies letztere wird durch die Erfahrung auf das Unzweideutigste bestätigt. - Man armire eine Flüssigkeit mit einem hinlänglich grossen Zinkbleche, von etwa 36 Quadratzoll Flächeninhalt, tauche gleichzeitig mit demselben auf dem andern Extrem der Flüssigkeit ein Zinkblech von völlig gleicher Beschaffenheit, aber nur von etwa 70 Quadratlinien Flächengrösse, ein und verhinde beide Metalle durch den um die Magnetnadel geführten Schliessungsdrath, so wird die Nadel durch die grosse Zinkfläche gerade eben so wie vom Zink in der einfachen dreigliedrigen Kette, in welcher die Metalle Kupfer und Zink sind, abgelenkt werden; unter denselben Umstïnden, unter welchen die Nadel dort in der Kette $z f k$ über oder unter dem mit dem Zink verbundenen Theil des Multiplicators nach Osten oder West abgelenkt wird, wird sie eben so auch hier in der zweigliedrigen Kette 
über oder unter dem mit der grüsseren Armatur aus Zink verbundenen Theile des Multiplicators nash derselben Richtung abgelenkt werden. Da nun in der zweigliedrigen Kette der Zink mit keiner andern als der negativen Polarität auftreten kamn, indem dieses, wie der Condensator zeigt, die ursprüngliche und eigenthümliche Erregung des Zinks gegen die Flüssigkeit ist, und da in der dreigliedrigen Kette die Nadel durch die Zinkseite nicht anders wie in der zweigliedrigen abgelenkt wird, so muss auch in der dreigliedrigen Kette der Zink mit der negativen Polarität wirksam seyn. - Wendet man statt der grossen und kleinen Zinkflächen eben solche Kupferflächen an und verführt eben so, so sieht man die Nadel durch die grosse Kupferfläche unter denselben Umständen nach der entgegengesetzten Richtung wie durch den Zink abgelenkt, nämlich eben so wie es in der dreigliedrigen Kette $z f k$ auf der Kupferseite geschieht. Da nun das Kupfer gegen die Flüssigkeit überhaupt wie der Condensator zeigt, und also auch gegen die Flüssigkeit in der zweigliedrigen Ketle nicht anders als positiv seyn kann, so muss auch das Kupfer in der dreigliedrigen Kette $z f k$ mit der positiven Polarität wirksam seyn.

Nachdem aber diese Ueberzeugung ein für allemal gewonnen ist, so kann umgekehrt wieder die zweigliedrige Kette als das beste und zuverlässigste Mittel benutzt werden, um die elektrischen Relationen zwischen den Metallen und Flüssigkeiten, so wie die elektrischen Relationen der Metalle untereinander durch die dreigliedrige Kette, zu bestimmen, indem man das sicher begründete Princip dabei zum Grunde legt, 
dass dasjenige Metall, welches mit der grösseren Fläche in der zweigliedrigen Kette auf die Nadel entweder so wie das Kupfer oder so wie der Zink in der drei-und zweigliedrigen Kette einwirke, auch völlig eben so wie das Kupfer oder der Zink gegen die jedesmalige Flüssigkeit respective positiv oder negativ elektrisch werde. Wenn man so die verschiedenen Glieder der ganzen Metallreihe gegen eine und dieselbe Flüssigkeit, oder verschiedene Flüssigkeiten gegen ein und dasselbe Metall unter sonst gleichen Bestimmungen durchprüft, so gehen daraus Resultate hervor, welche die Relationen an sich und das Quantitative derselben mittelst der Ablenkungswerthe der Nadel oder vielmehr mittelst der jenen Ablenkungen entsprechenden Wirkungswerthe in Reihen geben, die etwas ungleich Vollständigeres und Zuverlässigeres darbieten werden, als Alles der Art, was man bisher zu ermitteln bemüht gewesen ist und von den unzuverlässigeren Aussagen des Condensators je zu erwarten gehabt haben würde. Doch versteht es sich, dass, ungeachtet der grösseren Einfachheit und Sicherheit, welche diese Untersuchungsmethode vor den bisherigen voraus hat, dennoch das Verfahren, durch welches auf diese Weise brauchbare und bleibende Resultate für die Wissenschaft gewonnen werden sollen, nur von einer geübten und umsichtigen experimentalen Critik beständig geleitet seyn müsse.

Aus dem hier eröffneten Verständnisse der zweigliedrigen Kette ist klar, dass die Intensität ihrer Thätigkeit nicht, wie man bisher zu glauben geneigt war, von einem möglichst grossen Unterschiede der Flächengrösse der metallischen Armaturen auf beiden Seiten 
der Flüssigkeit abhänge, sondern die Grösse der Wirkung nimmt anfänglich mit der iwachsenden Grösse der kleineren metallischen Berührungsfläche fortwährend zu, bis] sie erst von einer bestimmten Gränze an wieder allmälig abnimmt und gänzlich verschwunden ist, wenn beide Metalfflächen einander völlig gleich geworden sind. Aber in demiselben Maasse, in welehem die zweite Berührungsfläche wächst, wächst auch das Vermögen derselben, eine zufillig etwa zwwischen ihr und der Hauptflüche Statt findende Differenz geltend zu machen, die, wenn sie im Uebergewicht auf der Seite der kleineren Fläche vorhanden ist, das ganze Verhältniss umkehren und gerade das entgegengesetzte Resultat von demjenigen, was eigentlich gesucht wird, hervorbringen muss, wie dieses besonders bei den leichter oxydabeln Metallen zu geschehen pflegt, so dass dem Scheine nach alle Gesetzmüssigkeit in der Wirkung der zweigliedrigen Kette darüber verloren geht. Man muss daher die kleinere Metallflüche so klein als möglich nehmen und den Mangel an stärkerer Wirkung durch grössere Empfindlichkeit der Magnetuadel und möglichst grosse Zahl von Windungen des Multiplicators zu ersetzen suchen, weil eine anomale Gegenerregung der kleinern Fläche, sie sey so krüftig als sie wolle, durch die Wirkung der Hauptfläche um so sicherer unterjocht wird, je kleiner jene ist.

Ich habe nach der hier angegebenen Methode die elektrischen Relationen der edlen Metalle und einer grossen Zahl der übrigen gegen Wasser, gegen stärker und schwächer verdümnte saure, alkalische und andere Solutionen geprüft, und wenn gleich das nu- 
merische Detail der Resultate schon darum, weil ich weder die Metalle in chemisch reinem Zustande anwendete, noch die Concentrationsgrade der Flüssigkeit genau bestimmt hatte, keine Ansprüche darauf machen kann, den wissenschaftlichen Normalbestimmungen der Physik beigezählt zu werden, weshalb auch die Mittheilung desselben in dieser Schrift um so mehr unterbleibt, da der: Zweck derselben über specielle experimentale Darlegungen hinausreicht, so haben meine Untersuchungen dennoch vollkommen entschieden das bereits ausgesprochene, allgemeine Resultat dargeboten und bestätigt : dass die edlen Metalle mit Inbegriff des Quecksilbers, Kupfers und des Wismuthes, oder die Glieder der negatiren Seite der Metallreihe, wie sie in Folge der Contactelektricität der Metalle unter einander bezeichnet werden können, gegen das Wasser und die übrigen Solutionen der Art nach in einer und derselben elektrischen Relation stehen, nämlich sämmtlich in der Berührung mit jenen positiv werden und zwar um so positiver, je näher sie dem Extrem der negativen Seite der Metallreihe stehen, oder je negativer mit einem Worte sie selbst sind; dass hingegen die übrigen Metalle als Glieder der positiven Reihe gegen Wasser und andere Flüssigkeiten sümmtlich negativ werden und wieder um so negativer, je entschiedener sie selbst in der Metallreihe als positive Glieder derselben auftreten.

Da die bisherigen Betrachtungen ein Ganzes ausmachen, durch welches die wahre Beschaffenheit des Processes in der galvanischen Kette, so weit derselbe durch die Erscheinungen an der einfachen Kette offenbart wird, ausser Zweifel gesetzt ist, so wird es dem 
Zwrecke dieser Darlegungèn dm bestèn entsprechen, wenn jetzt auch in Bezug anf den eigentlichen Zustand der Thätigkeit in der zusammengesetzten Kette dio Haúptmomente, welche als eben so viel Corollare aus dei erkainten Nátur /der Wirksamkeit einfacher Ketten entspringen, hier hervorgehoben werden, gavevor wir den Bishér nuriunter einem beschränkten Gésiehtš punkté anfgefassten Begriff der żveigliedrigen Ketté in séinèm iganzen Umfange und in seiner innigen Verbinta dung mit dem des chemischen Processes überhaupt: noch weiter verfolgei. Bis dahin muss hier die'Bemerkung genügen, dass das, was in dem gegentwärtigen Abschinitte über das Wesentliche in der Wirkung dere zweigliedrigen Kette mit ungleichen metallisèhen Berührüngsflächèn zunächst in der Absicht einer noch leben digeren Bekräftigang der im 2 ten Abschinitte entwickel ten Theorie vorgetragen worden, selbst wieder noch in ein volleres Licht durch die umfassenderen Ansichten treten werde, welche erst unten im 6ten Abschnitua uiber die Natur der zweigliedrigen Kette überhaupt sich ergeben werden. Eben da wird sich zugleich die Gele. genheit darbieten, dasjenige, was hier über die Anwendung der zweigliedrigen Kette mit ungleichen metallischen Berührungsflächen zur Bestimmung der Relationen zwischen Metallen und Flüssigkeiten beigebracht worden, noch in vieler Hinsicht zu vervollständigen durch eine specielle Angabe der Umstände, welche dabei noch die oben erwähnten Störungen und regellose, unsern Aussagen scheinbar zuwider laufende, Erfolge zu bewirken vermögen. Die Quellen dieser Anomalien liegen ausserhalb der eigentlichen Gränzen des in diesem Abschnitte behandelten Gegenstandes selbst,

G 
nämlich in den erst im 5ten und 6ten Abschnitte untersuchten Phänomenen der Reaction oder der sogenannten Ladung, in den Ergebnissen des ungleichzeitigen Eintauchens der Metalle in die Flüssigkeit und in den allgemeinen und umfassenderen Wirkungen der zweigliedrigen Kette überhaupt, und sie konnten deshalb, wenn die aus anderweitigen überwiegenden Gründen beobachtete Ordnung in der Abhandlung der Gegenstände nicht geändert werden sollte, hier noch nicht umständlicher erwähnt werden. Um so mehr aber ist, Behufs eines gründlichen Verständnisses und einer gesicherten Anwendung der angegebenen Methode zur Bestimmung der elektrischen Relationen, die sorgfältige Berücksichtigung der in den folgenden Abschinitten vorkommenden Untersuchungen erforderlich, mit denen überhaupt in der Lehre über den Galvanismus und über den Process der galvanischen Kette noch sehr wesentliche, zur wahrhaften und naturgemässen Anschauung des Ganzen völlig unerlässliche Gesichtspuncte sich ergeben werden. 


\section{Vierter Abschnitt.}

\section{Die galvanische Säule, als das Vielfache der dreigliedrigen einfachen Kette.}

Da sich die einfache Kette in zwiefacher Form entweder dem Schema : $z f f k$ oder diesem: $f z k f$ entsprechend darstellen lässt, so lässt sich auch die zusammengesetzte Kette gleichfalls als ein System von Elementen nạch der einen oder nach der andern Form betrachten. Bisher hat man für die einfache Kette allgemein und mit Recht das" erstere Schema: zffk zum Grunde gelegt und die Seite derselben, auf welcher das Kupfer liegt, auch wirklich den Kupferpol, die andere, wo der Zink liegt, den Zinkpol genannt; für die zusammengesetzte Kette hingegen ist mit einer merkwürdigen Inconsequenz die zweite Form: $f z k f$ als Regel der Betrachtung angenommen worden, der gemäss diejenige Seite der Säule, welche mit einer einzelnen Zinkplatte schliesst, ihr Kupferpol, und die entgegengesetzte mit einer Kupferplafte endigende ihr Zinkpol genannt wird. Einzig und allein diesem Zwiespalte gehört es auch an, dass wir die Magnetnadel durch die einfache und zusammengesetzte Kette nach entgegengesetzten Richtungen abgelenkt sehen; die Umkehrung liegt hier nur in der willkürlichen, für beide Fälle völlig umgekehrten, Art zu sehen, schlechterdings aber nicht in der Sache an und für sich.

G 2 
Das eigentliche allgemeine Schema der einfachen dreigliedrigen Kette, welches die beiden obigen verschiedenen Formen derselben zugleich umfasst, ist dieses:

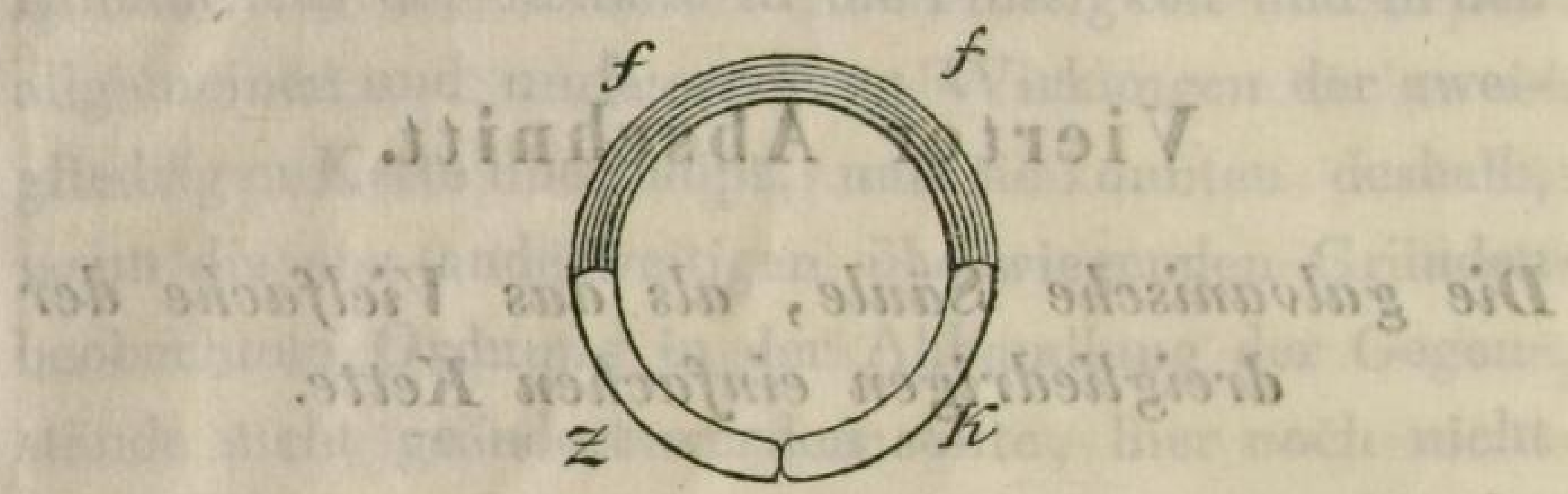

das Schema der in sich zurücklanfenden, organisch in sich abgeschlossenen, Linie, deren eine Hälfte durch die Metalle, die andere durch die Flüssigkeit (durchDuplicität der Factoren den beiden Metallen entsprechend) gegeben ist, und worin einerseits die Metalle eben so wohl zwischen den $f$ als die detzteren zwischen jenen liegen, andern Theils aber auch keins von beiden geschieht, sondern beide Momente zugleich auf diametral auseinander gehaltenen Puncten sich einander direct gegenüber stehen. - Ist der Zusammenhang der Metalle unterbrochen, so findet der durch das parm ticuläre Schema: $z f f k$ angedeutete Fall Statt und die Kette wird geschlossen, wenn die:Lücke wieder darch ein Metall, den Verbindungsdrath, ausgefüllt wird. Ist hingegen der Zusammenhang der Flüssigkeit aufos gehoben, so ist dieses der Fall, auf den allein sich das zweite Schema: $f z$ k f $f$ bezieht, und in welchem daher auch die Kette eigentlich nur wieder durch einen flüst sigen, und nicht, wie es auch hier in der Regel geschieht, durch einen metallischen Verbindungsbogen geschlossen wird. Wenn daher die Frage ist, welche von beiden Formen der einfachen Kette als allgemeine 
Norm für die Betrachtungsweise derzusammengesetzten gelten solle, so ist es gewiss ausser Zwiveifel, dass die durch das erstere Schema $z f f k$ dargestellte, als die natứrlichere und angemessenere, bei weitem den Vorzug verdiene, und wir betrachten dem gemüss die ganze Säule auch unfelilbar aus dem richtigsten Gesichtspuncte, wenn wir sie uns als ein System von Elementen vorstellen, deren jedes einzelne die Form der gewöhnlichen eìnfachen Kette $z f k$ an sich trägt.

+ In jedem einzelnen Elemente der Art fällt, wie bereits fuir immer entschieden ist, sein negativer PoI mit dem Zinkpole und sein positiver mit dem Kupferpole zusammen, oder es liegt ubberhaupt der negative Pol auf der Seile des im Contact positiven, der positive auf der Seite des im Contact negativen Metalls, und dies findet im ungeschlossenen wie im geschlossenen Zustande der Kelte Statt, nur dass im letzteren Falle dieselben, durch den Drang der Contactelektricitut beIebten, Thätigkeiten in ungleich melir erhöliter Intensitüt hervortreten. Ist ein solches Element isolirt, so hat die auf beiden Polen entgegengeselzte Erregung nothwendig an einer Stelle innerhalb des $f$ in der Mitte zwischen beiden ihren Indifferenzpunct, jenseit dessen bis zum Maximum des negativen Pols die entsprechende positive Erregung des $f$ überwiegend hervortritt, während diesseits bis zum Maximum des positiven Pols die negative Erregung des $f$ die vorherrschende ist, und der Indifferenzpunct liegt vermöge eines in ihm Stait findenden Gleichgewichts von positiver und negativer Erregung als ein relatives Null zwischen beiden Extremen mitten inne. Wird aber der eine Pol mit der Hand ableitend berührt, so tritt die Thäligkeit des an- 
dern mit zwiefacher Intensität hervor, aus demselben Grunde, aus dem, wie es oben entwickelt worden ist, in noch höherem Grade die Erregung des Metalls auf dem einen Pol verstärkt wird, wenn man dasjenige des andern Pols mit dem differenten Metalle ableitend berührt, welches, wie sich deutlich gezeigt hat, zugleich der eigentliche Grund der erhöhten Thätigkeit der Kette in ihrem geschlossenen Zustande überhaupt ist.

Betrachten wir nun das System von einer grösseren oder geringeren Anzahl solcher Elemente: $\bar{z} f \vec{k}$ die wir, so wie zwei oder mehrere kleinere Magnete mit den ungleichnamigen Polen zu einem einzigen grösseren und stärkeren über oder neben einander gelegt, zusammen setzen:

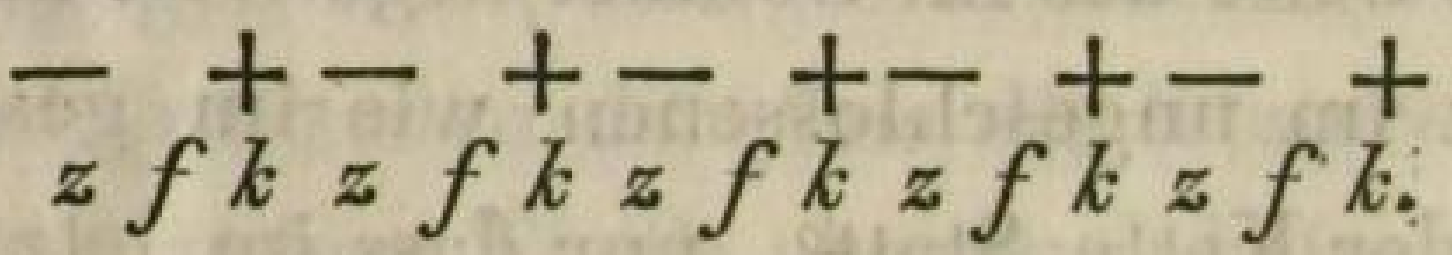

so ist es nicht genug, zu wissen, was bereits erwiesen und mit dem vorstehenden Schema bezeichnet ist, dass nämlich die in den einzelnen Elementen vor ihrer Zusammensetzung bestehende, aus dem Contact der Flüssigkeit mit den Metallen hervorgehende, Elektricität der Art nach in der zusammengesetzten Säule unverändert bleibe und durch den Contact der Metalle nur noch zu beträchtlich höherem Grade verstärkt werde, sondern es ist zugleich in Bezug auf das Quantitative und auf die bewirkte Steigerung und Vertheilung der beiden Elektricitäten von der grössesten Wichtigkeit, zu bemerken, dass sie nach dem nämlichen Typus, nach welchem sie in jedem einzelnen Elemente Statt findet, nothwendig auch in dem ganzen Systeme wiederholt und vollzogen seyn wüsse, so dass das Maximum der 
negativen und positiven Erregung nach entgegengesetzten Richtungen und zwar schlechthin nach denselben Richtungen, welche durch die Pole jedes einzelnen Elements bereits fest und unabänderlich vorgeschrieben sind, aus einander gehalten, und bei stufenweise fortschreitender Zunahme der Intensität der Erregung von einem Pole zum andern, so wie dort, durch einen in der Mitte der Säule liegenden relativen Nullpunct unterschieden sind, so lange das ganze System isolirt ist.

Bezeichnen wir also das Maximum der positiven Erregung, 'wie es bloss aus dem Contact der Flüssigkeit mit dem Metalle hervorgeht, vor der Combination, in jedem einzelnen Elemente durch $+\delta$ und eben so das der negativen durch $-\delta$, so ist zünächst bei zwei combinirten Elementen, ohne fürs Erste noch Rücksicht auf die Contactelektricitat der Metalle zu nehmen, durch die wechselseitige Berührung in der Mitte, eben so als wäre jedes Element ohne eine anderweitige gleichzeitige Erregung für sich dort bloss ableitend berührt, die Intensität der Erregung an den beiden Extremen verdoppelt und der Zustand der zusammengesetzten Säule, in Absicht auf die Vertheilung der elektrischen Erregung, durch das folgende Schema dargestellt :

$$
+2 \delta \frac{0}{-\delta+\delta}-2 \delta
$$

Setzen wir nun nach Maassgabe dessen, was uns durch Thatsachen bekannt und aus dem ganzen Gehalte un serer bisher entwickelten Theorie der galvanischen Kette völlig entschieden und geläufig ist, dass vermöge 
der Spannung durch die Contactelektricität der $\mathrm{Me}-$ talle jedes $\delta$ nicht nur nicht' aufgehoben, sondern vielmehr noch sehr beträchtlich um ein mit ihm gleichartiges $\delta^{\prime}$ vergrössert wird und also, wenn man $\delta+\delta^{\prime}=\varepsilon$ setzt, in dieses $\varepsilon$ übergeht, so haben wir zur Bezeichning der wahren Beschaffenheit der Vertheilung der elektrischen Erregung in der aus zwei/Elementen zusammengesetzten isolirten Kette ein dem obigen röllig entsprechendes Schema, worin nur $\delta$ mit $\varepsilon$ vertauscht ist, nümlich dieses;

$$
+2 \varepsilon f_{k}^{-\varepsilon+\varepsilon} f^{-2 \varepsilon}
$$

Völlig nach demselben Vertheilungsgesetz ist der Zustand einer aus drei Elementen zusammengesetzten Kette, so wie ihn das folgende Schema darstellt: Jtois

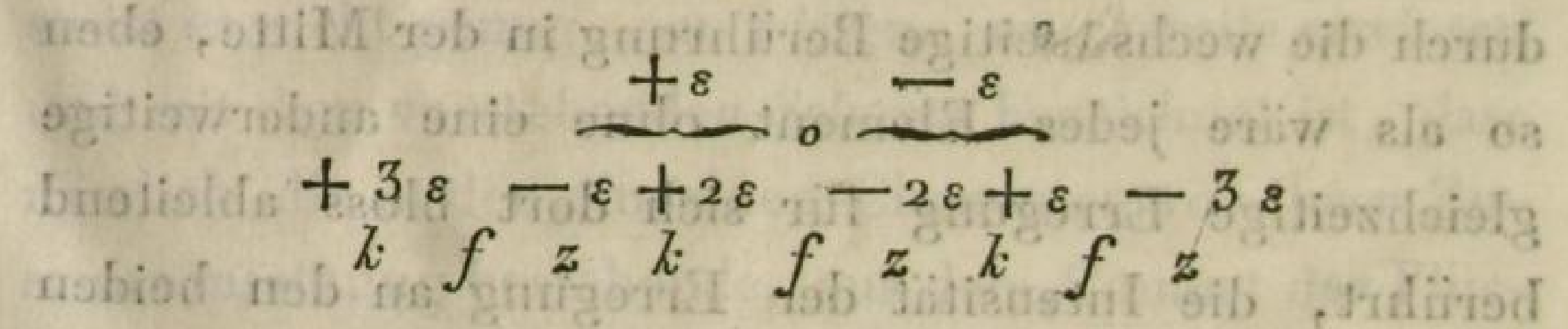

bei welcher, wie bei jeder aus einer ungeraden ZahI von Elementen zusammengesetzten Kette das relative Null in der Mitte des mittleron f liegt.

Eben so der Zustand einer aus vier Elementen bestehenden Kette :

$$
+4 \varepsilon-\frac{+2 \varepsilon}{-\varepsilon+3 \varepsilon-\overbrace{k+2 \varepsilon}} \frac{-2 \varepsilon}{-3 \varepsilon+\varepsilon}-4 \varepsilon
$$

bei weloher, wie immer in einer jeden aus einer geraden Zahl von Elementen zusammengesetzten Kette, das re- 
Jâtive Nüll durch die beiden gleichen entgegengesetzten Erregungen des mittleren Plattenpaars gebildet.wird. 17ici So ist also das Gesetz der Vertheilung der Erregung für einé jede aus noch so viel Elementen zusamnengesetźte Kette bestimmt, indem die letztere der einfachen Kette vollkommen eben so entspricht, wie der grössere Magnet jedem einzelnen der kleineren, aus denen er durch die successive Vereinigung ihrer ungleichnamigen Pole entstanden ist. Von den beiden folgenden Figuren macht die erste den Erregungszustand einer aus fün, überhaupt einer aus einer ungeraden Zahl von Elemęnten bestehenden, die zweite den Erregungszustand einer aus sechs, überhaupt einer aus irgend einer geraden Zahl von Elementen zusammengesetzten isolirten Kette anschaulich:

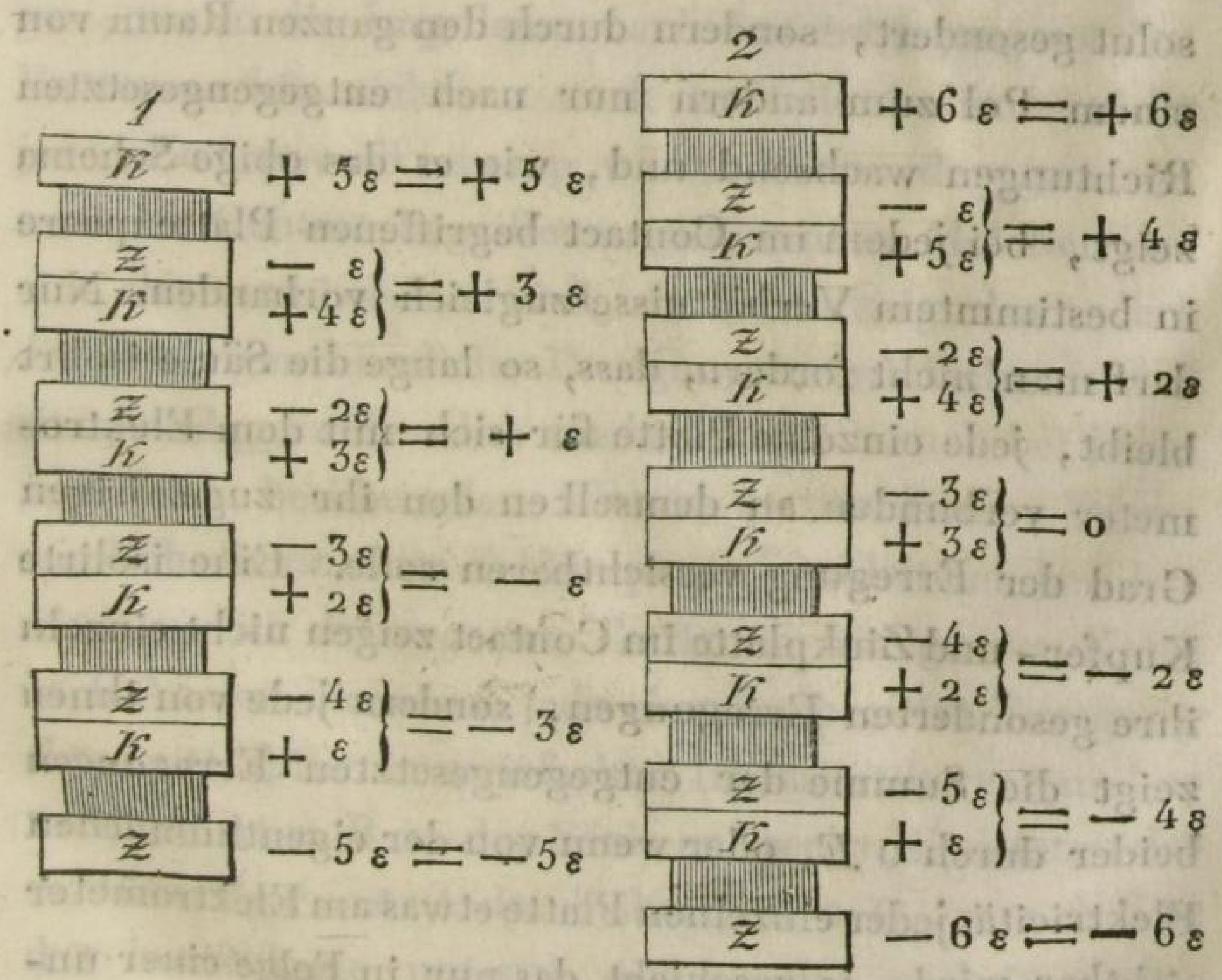

Die Intensität der Spannung an den Polen der zusammengesetzten Kette ist also der Zahl ihrer Ele- 


\section{6}

mente proportional; so weit die Erregung durch die mit der Zahl der Plattenpaare immer grösser werdende Reaction der Gesammtmasse der Säule nicht modificirt und gehemmt wird, wovon weiter unten die Rede seyn wird; die positive Erregung nimmt durch alle Kupferplatten allmälig zu nach dem Extrem der Säule hin, welches mit einer einzelnen Kupferplatte schliesst, und hat in dieser ihr Maximum erreicht, die negative dagegen nimmt durch alle Zinkplatten gegen dasjenige Extrem der Säule hin fortwährend zu, welches mit einer einzelnen Zinkplatte schliesst bis zu ihrem in dem letzteren gegebenen Maximum. Die positive und negative Erregung sind also nicht, wie es sonst höchst irriger und naturwidriger Weise dargestellt worden, durch den Indifferenzpunct in der Mitte der Säule absolut gesondert, sondern durch den ganzen Raum von einem Pol zum andern nur nach entgegengesetzten Richtungen wachsend und, wie es das obige Schema zeigt, bei jedem im Contact begriffenen Plattenpaare in bestimmtem Verhältnisse zugleich vorhanden. Nur darf man nicht fordern, dass, so lange die Säule isolirt bleibt, jede einzelne Platte für sich mit dem Elektrometer verbunden an demselben den ihr zugehörigen Grad der Erregung versichtbaren solle. Eine isolirte Kupfer- und Zinkplatte im Contact zeigen nicht einzeln jhre gesonderten Erregungen, sondern jede von ihnen zeigt die Summe der entgegengesetzten Erregungen beider durch o $E$, oder wenn von der eigenthümlichen Elektricität jeder einzelnen Platte etwas am Elektrometer sichtbar wird, so geschieht das nur in Folge einer unvollkommenen Isolirung der andern und so verhält es sich auch hier. In der obigen, aus sechs Elementen zu- 
sammengesetzten, Säule zeigt so das mittlere Paar stets o $\boldsymbol{E}$, welche von den beiden /Platten auch mit dem Elektrometer in Verbindung gesetzt werden möge, desgleichen von den beiden dem mittleren zunächst benachbarten Plattenpaaren zeigt wieder, ohne Unterschied der einzeln geprüften Platte, das untere eben so ausschliesslich nur negative, das obere positive Elektricität, in einem Grade, welcher der Summe der entgegengesetzten Erregungen beider, die im ersten Falle: $-2 \varepsilon$, im zweiten: $+2 \varepsilon$ beträgt, und der grösseren oder geringeren, aber jeder Zeit Statt findenden, Unvollkommenheit der Isolirung der Säule angemessen ist; und so bei allen übrigen Plattenpaaren. Eigentlich würde jede Platte die Summe der entgegengesetzten Elektricitäten der ganzen isolirten Säule, d. h. völlig o $E$ zeigen, wenn die Impulsion nach den entgegengesetzten Extremen hin nicht zu stark und die Isolirung nicht jeder Zeit unvollkommen wäre. Wenn dagegen von zwei im Contact begriffenen differenten Metallen das eine ableitend berührt wird, dann erst zeigt das andere die ihm eigenthümliche Erregung in zwiefacher Intensität, und ganz dasselbe wiederholt sich auch bei jeden zwei sich berührenden Platten in der Säule. Wenn nämlich die unterste Schlussplatte $z$ ableitend berührt wird, so ist die negative Erregung der ganzen Kette nach Aussen hin $=o$, jede einzelne positive Erregung aber tritt dafür in zwiefacher Intensität hervor und es versichtbart z. B. in der Säule aus sechs Elementen das mittlere Paar, statt des bisherigen o $E$, nun $+6 \varepsilon$; das benachbarte untere: $+4 \varepsilon$, das nächste obere: $+8 \varepsilon$ u.s. f., wenn hingegen die obere Schlussplatte $k$ ableitend berührt wird, so zeigt, während die positive 
Erregung der ganzen' Kette nach Aussen hin unsichtbar geworden ist, das mittlere Paar: $-6 \varepsilon$, das benachbarte obere: $-4 \varepsilon$, das nächste untere: $-8 \varepsilon$

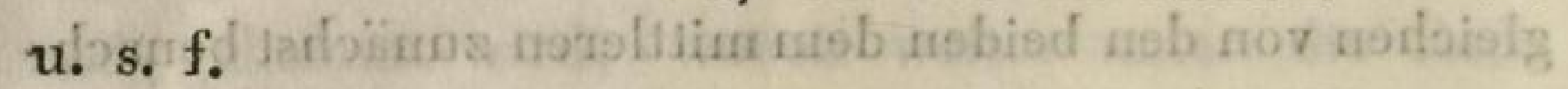

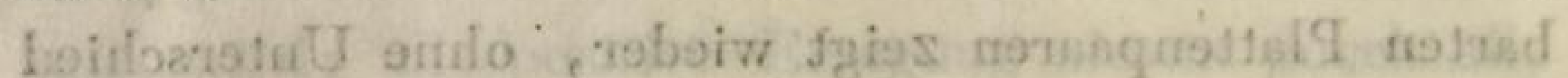

- ana Die zúsammiengesétzte Kelte, wie sie in allen diesen Erscheinungen eine nur mèr zergliedeite und vernehmlichier ausgespróchene, aber sonst mit der. Thätigkeit der einfachen Kette schlechthin unter völlig gleichem Typus stehende; Wirksamkeit offenbart, besitzt also auch, was jetzt noch eine ganz besondere Hervorhebung verdient, eine der der einfachen durchaus analoge Polarität.

Die Seite der zusammengesetzten Kette nämlich, auf welcher die Schlussplatte $z$ liegt, hat dieselbe negative Polarität, wie diejenige, auf welcher auch in der einfachen Kette das $z$ sich befindet und die andere, welche mit der Kupferplatte $k$ schliesst, ist eben so, wie die Kupferseite der einfachen Kette positiv. Hat man durch die einfache Kette $z f k$ die Magnetnadel abgelenki, so war, wenn die Kette im Norden der Boussole stand und der Verbindungsdrath vori $k$ aus über der Nadel von Norden nách Süden und unter ihr von Siiden nach Norden zum z zurückging, die Ablenkung ästlich. Lässt man nui die zusammengésetzte Kette unter denselben Bedingungen auf die Nadel reágiren, also so, dass, während die Kette wieder im Norden der Boussole steht, der Schliessungsdrăth von der obern Schlnssplatte $k$ aus zuerst über der Nadel und sodann unter ilir nach der andern Schlussplatte $z$ zurückgeht, so wird die Nadel eben so wie vorhin bei 
der einfachen Kette nach Osten abgelenkt.1 L Diese Ablenkung aber hat man, so lange sie bekanntiund mit der durch die einfache Kette bewirkten vérglichen ist, dennoch als die entgegengesètzte von jener dereinfachen Kette zugehörigen Ablenkung angesehen. (-C) Weshalb? - Weil man die Seite der zusammenge- 5 setzten Kette, auf welcher die Schlússplatte $\approx$ liegt,' nicht mehr, wie in der einfachen, als deir Zinkpol, sondern als den Kupferpol, und diejenige, welehe nit I dem $k$ endigt, , ebeu so nicht mehr als den Kupferpó,? sondern als den Zinkpol betrachtet. - Und warum das ? - Weil man die Pole der Kette ledighích durchi die Contactelektricilät der beiden Metalle, also durch die gegenseitige Lage der letzteren in der Ketle be-i slimmit glaubt, und so die negative Elektricität der Schlussplatte $z$ nicht als ihre eig enthümliche, sondern nur als die nach dieser Seite hin gerichtete Wirkung von der den Kupferplatten zugehörígen Errégung, und eben só die positive Elektricität der Schlussplatte $k$ nur als die übertragene, ursprünglich den Zinkplatten eigenthümliche, Erregung betrachtet. - Kam es eine Iro-t nie geben, mil der eine irre geleitete Reflexion durch die eigenen Fehltritte und Missgriffe sich selbst treffender, augenscheinlicher tadelt und "widerlegt, als diese? - Es list nicht anders möglich _ die Wis-I senschaft muss nach kürzerer oder lüngerer Zeit einen Irrthum bekemnen, deriso alt ist, als die Entdeckuig der galvanischen Säule; aber an diesen Gestäiduiss hüngt alsdann auch unzertrennlich, die Verpflichtuing; die falschen, zum Theil noch jetzt schwankenden, Benemumgen mit dem bisherigen Irrthum, wie die

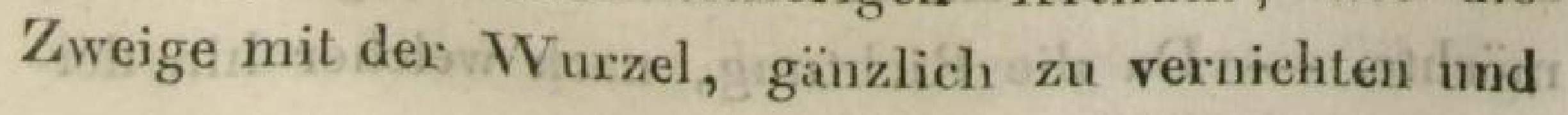


an ihrer Stelle eine feste und geregelte Nomenclatur einzuführen, welche schon die äussere Analogie und noch mehr das innere, gründliche Verständniss der Erscheinungen als die natürliche und allein richtige darbieten und erheischen. Sollte die alte Benennung der Pole der zusammengesetzten Kette beibehalten werden, so ist klar, dass man dafür in der einfachen Kette die allgemein herrschende Nomenclatur auf eine höchst widerstrebende Weise umkehren müsste; wenn es dagegen natürlich und angemessen ist, die Seite der einfachen Kette, welche mit einer Zinkplatte schliesst, ihren Zinkpol und die andere ibren Kupferpol zu nennen, so ist es das allein Consequente und Richtige, auch in der zusammengesetzten Kette, dasjenige Extrem, welches mit einer einzelnen Zinkplatte endigt, ihren Zinkpol, und das entgegengesetzte, in eine einzelne Kupferplatte ausgehende, Extrem ihren Kupferpol zu nennen und zugleich sind alsdann, im vollkommensten Einklange mit den Erscheinungen und ihrem richtigen Verständnisse, für die einfache so wie für die cusammengesetzte Kette, im ungeschlossenen, so wie im geschlossenen Zustande derselben, die Benennungen:

negativer Pol synonym mit Zinkpol und positiver Pol synonym mit Kupferpol.

Höchst wünschenswerth wäre es, dass durch die entschiedene Stimme einzelner vorurtheilsfreier und wahrheitliebender Physiker, wenn sie durch eine aufrichtige öffentliche Erklärung auf die Seite der richtigen Ansicht treten sollten, der von diesem Schritte unzertrennliche Sprachgebrauch zugleich ausdrücklich anerkannt und so ein für allemal befestiget werden möchte. - Da die Richtung, nach welcher hin der 
Zinkpol sich erstreckt, mit der Richtung des bisher sogenannten Kupferpols zusammenfallt, welcher, da man das Kupfer als das in der Kette mit negativ elektrischer Erregung wirksame bis dahin betrachtete, auch der bisherigen Ansicht nach der negative genannt worden ist, und da eben so die Benennung des positiven Pols der Säule im Sinne der bisherigen, so wie der hier entwickelten, Ansicht der sächlichen Localität nach zusammentrifft, so möchte es fürs Erste das Beste seyn, sich der bisherigen Benennungen: „Kupfer-oder Silberpol und Zinkpol", die überdies an und für sich in sprachlich-logischer Hinsicht nicht wohl angemessene Ausdrücke bilden, ganz zu enthalten und allein die Prädicate: negativer und positiver Pol beizubehalten, so dass also der negative $\mathrm{Pol}$ an der einfachen Kette auf der Zinkseite, an der zusammengesetzten ebenfalls auf derselben, also auf der bisher so genannten Kupferseite liegt, nur dass man hier eben von der bisherigen falschen Vorstellung gänzlich zu abstrahiren und diese negative Polarität nicht als dem Kupfer, sondern eben so, wie bei der einfachen Kette, als dem Zink zugehörig, zu betrachten hat, und dass ferner der positive $\mathrm{Pol}$ an der einfachen Kette auf der Kupferseite und an der zusammengesetzten Kette gleichfalls auf derselben, d.h. auf der bisher so genannten Zinkseite liegt, wobei jedoch abermals diese Polarität nicht als die dem Zink, sondern wieder eben so, wie bei der einfachen Kette, als die dem Kupfer zngehörige, verstanden werden muss. Diese Nomenclatur werde ich selbst von jetzt an unabänderlich gebrauchen und mich der Prädicate: negativer und positiver $\mathrm{Pol}$ in dem eben angegebenen Sinne zur Bezeichnung der entgegengesetzten Thätig- 
kéten der Ketto unter Vermeidung sonstiger Synonymen vorzugsweise bedienen *).

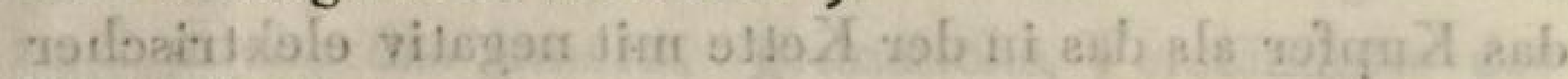

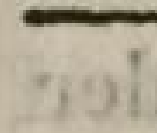

*) Es hat in der ersten Entdeckungsperiode, der galvanischen Sắule niclit an Bemerkungen und Winken gefelilt, durch welche auf das Verhältniss derselben zur einfacheni hette unid auf die erforderliche Berichtigung der bisherigen Terminologie hingedeutet worden ist. Im Sten Bande der Gilbertschen Annalen, Iahrgang 1801, ist sogar an einer Stelle, die ich erst mit der ganzen, daran geknüpften Verhandlung nach der völligen Beendigung dieser Schrift kennen gelernt kabe, auf S. 166 f. f. Iit einer Antmerkung des Herausgebers die einfacho Kette: $f f s$ als das wahre Element der Säule unid die davion abhängige Benennung der Pole nach den. Endigungen derselben als die richtige Terminologie für die Wissenschaft vindicirt worden. Abei es lág dabei mehr nur die äussere Analógié und die ganz vereinzelte, von niemand tiefer verfolgte, Beobachtung, dass in der ungeschlossenen Kette $z f$ s der Zink $z$ negativ und das Silber s positiv sey, allein zum Grunde. Is Bei wirblichr geistreichen Leuten, wénn sie einmal irren, ist auch der Irrthum nicht selten gediegen zunennen, so fern ex nicht als ein Fragment, sondern als ein lebendiges Ganzes an ihnen hervorzutreten pflegt; aber er ist gerade durch diese relative Consequenz für die übrigen : um so gefährlicher. - Ritter, der bei aller Genialitat, die ihn in seiner Ansicht der galvanischen Säule vor so manchem Zeitgenossen auszeichnete, durch und durch in dem Irrthume befargen war, dass allein. die Erregung im Contact der festen Leiter die Elektricität und die Thätigkeit der Batterie unmittelbar bestimme, zeigte in diesem Sinne: und auf seine Weise, mit unverhältnissmässig gehäuften und ermüdenden Mitteln, in einer, so oft es galt, ihm núr zu leicht zu Gebot stelienden Deduction, durch eine lange, im gten Bande der Annalen S. 212. f. fi enthaltene, $A b$. handlung, dass - āussere Analogien in der Sache nichts entschieden - er ahnete nicht, welche ominöse Bedeutung in dên Worten, mit welchen er diese Abhandlung schliesso: „. Kolta's Batterie wird noch manchem Freude machen, aber auch noch manchen zum Besten haben" gerade in der allernächsten und treffendsten Beziehung auf ihn selbst ausgesprochen war. In einem gleich beigefügten Zusatze zu derselber Abhandlung leugnet er theils das Factum, dass in der einfachen Kette $z f s$ vor der Schliessung das $z$ negativ, das $\boldsymbol{s}$ positiv sey, und stells es nur als das Resultat einer verfehlten Deutung dar, theils 
Es ist nun noch die Frage über die specielle Art und Weise der Thätigkeit der zusammengesetzten Kette im geschlossenen Zustande derselben zu beantworten übrig. Im Allgemeinen und nach äusseren Beziehungen ist diese Thätigkeit bereits dadurch bestimmt, dass mit dem Maximum der Steigerung der Erregung an den Extremen der Säulei bei der /Ver-

urgirt er auch im Falle der Gültigkeit desselben, die secundäre geringe Erregung des $f$ in Vergleich der beträchtlichen, die ausgemacht zwischen den festen Leitern Statt habe. Was er weiterhin über die Bestimmung der Pole nach der Localität des Auftretens des Oxygen und Hydrogen beibringt, ist als ein Sophisma zu betrachten, weil er diese Localität nur nach dem Gegensatz zwischen Silber und Zink schlechthin, keineswegs aber, wie es nothwendig ist, nach dem Gegensatze der Innen- und Aussenseite ieder einzelnen Zink- und Silberplatte in Betrachtung zieht, worüber weiter unten noch die Rede seyn wird. - ,Wie wenig wir auch die Erscheinungen an der galvanischen Kette bis jetzt verstehen mögen " sagt er endlich gegen den Schluss dieses Nachtrages auf Seite 260. -

"das.wissen wir ganz'bestimme, dass an allem, was ge. schieht, in Zink-Silber-Batterien z. B., der Zink und das Silber beständig Antheil haben und dass, welches auch die grosse Rolle sey, die Wasser, oder überhaupt, wie es scheint, Feuchtigkeit in ihnen spielt, doch was geschieht und der Gegensatz in dem es geschieht, angestiftet und erhalten wird durch diese beiden verschiedenen festen Leiter. Sie sind die Puncte, an die alles geheftet ist - u. s. w.

Die Folge von dieser Discussion war, dafs der Herausgeber der Annalen in demselben 9ten Bande S. 25g. Ritters Auseinandersetzung der streitigen Materie völlige Gerechtigkeit widerfahren liefs; dass er alle Gründe, welche seinerseits im 8ten] Bande für das Gegentheil aufgestellt waren, dadurch für völlig weggeräumt erklärte und so im Jahre 1801. 2u den anfänglichen Ansichten und Benennungen Volta's, Nicholson's, Cruikshank's, Ritter's u. a., als den ächten, ein für allemal auf den einseitigen falschen Standpunct zu. rückkehrte, der, wie bekannt, der herrschenden Ansicht nach so lange überall als der völlig begründete und unfehlbare in der Lehre vom Galvanismus gegolten hat.

H 
bindung derselben auch 'ein gleicher und nach dem nehmlichen Typus gestalteter Erfolg, wie bei der geschlossenen einfachen Kette, Statt haben muss, nur in einem Grade und unter Modificationen, die allein die Folge von der so viel höher gesteigerten Intensität der Pole der zusammengesetzten Kette sind, wie es bereits bemerkt ist, dass dieselben Pole auf die Magnetnadel eben so, unter einer nach der nehmlichen Richtung, nur mit grösserer Lebhaftigkeit erfolgenden Ablenkung, wie die Pole der einfachen Kette reagiren.' Um aber auch die Thätigkeit der Säule ihrer Natur und innern Organisation nach während des Geschlossenseyns mit grösserer Bestimmtheit zu erkennen, wird es dienlich seyn, noch einige Zeit bei der Betrachtung ihres, der Schliessung vorangehenden, Zustandes, während sie isolirt ist, zu verweilen.

Es muss in dieser Beziehung nochmals auf das ausdrücklichste erinnert werden, dass die beiden entgegengesetzten Erregungen in der Kette durch den Indifferenzpunct nicht absolut, sondern nur ihrem relativen Uebergewichte nach aus einander gehalten sind, so wie, dass der eigentliche Grund der Thätigkeit nicht im Metall, sondern in dem höher ausgebildeten, männlichen Princip der Säule, der Flüssigkeit, enthalten sey. Sie ist es, welche in jedem Puncte als Acides und Basisches zugleich auseinander zu treten strebt, als Acides nach dem Zink, als Basisches nach dem Kupfer hin. Durch alle Schichten der Flüssigkeit von der äussersten kupfernen Schlussplatte auf dem positiven Pol bis zur Schlussplatte von Zink auf dem negativen Pol wächst so die Tendenz, nach derselben Richtung Oxygen zu geben, in der positiven Erregung der Flüs- 
sigkeit und in derselben Richtung, und eins damit, wächst die Tendenz des Zink, das Oxygen zu empfangen, in der zunehmenden negativen Erreguug der Zinkplatten. Eben so wächst in entgegengesetzter Richtung vom negativen Pol zum positiven hin die negative Erregung der Flüssigkeit durch alle Schichten, und die positive des Metalls durch alle Kupferplatten, bei jener als Tendenz, das Hydrogen zu geben, bei diesem als die gleichzeitige entsprechende Tendenz, das Hydrogen zu empfangen.

Diese elektrische Polarität einmal in der aus mehr oder weniger Elementen bestehenden Säule angeregt, pflanzt sich, wie die magnetische durch Eisenmassen, hier durch metallische oder flüssige Fortsätze und Zwischenglieder, die an die Säule angefügt, oder in sie eingeschoben werden, fort, vorausgesetzt, dass die Summe der dadurch möglicher Weise bewirkten Gegenerregungen kleiner als die der ursprünglichen Erregungen der Säule bleibe. Theilt man z. B. in der Mitte eines Elements $z f k$ die Flüssigkeit $f$ zwischen der Kupfer- und Zinkplatte $z, k$ desselben durch eine eingeschobene Platte irgend eines Metalls in zwei Theile, so wird diese durch den polaren Erregungsdrang des Ganzen gezwungen, sich eben so, wie jedes einzelne Plattenpaar, in zwei Zonen zu theilen, indem sie auf der dem Kupfer zugewandten Seite negativ, und auf derjenigen, welche nach $z$ hingerichtet ist, positiv elektrisch wird, und zwar nach Maassgabe ihrer verschiedenen Entfernung von den beiden Polen der Säule in ungleichem Grade der Intensität beider Erregungen, wenn die Stelle der Einschaltung nicht gerade die Mitte ist, in welcher beide Erregungen gleich stark sind. Auf diese Weise erleidet jede einzelne ein. H 2 , 
geschaltete Metallplatte eine Doppelerregung, und wird so ein Nachbild jedes ursprünglichen Plattenpaares; nur in den beiden Schlussplatten findet durchweg eine tungetheilte Erregung Statt; in der Zinkplatte am negativen Pol ist die positive Erregung gänzlich $=0$ und die Platte selbst durchgehends negativ; in der Kupferplatte am positiven $\mathrm{Pol}$ der Säule ist die negative Lrregung völlig $=0$ und sie selbst durchgehends positiv. Wenn man aber auf eine dieser Schlussplatten abermals eine flüssige Schicht legt, so widerfährt nun der Schlussplatte vollkommen dasselbe, was vorhin jeder andern zwischen die Flüssigkeit gebrachten Metallplatte geschah, sie wird nun eben so in zwei elektrische Erregungszonen getheilt, indem sie auf der inmern Seite die frühere Erregung behält, auf der äussern Seite aber entgegengesetzt erregt wird, und eine auf das äussere Extrem der aufgelegten flüssigen Schicht von Neuem gedeckte Metallplatte wird dagegen wieder durchgehends die Erregung der früheren jetzt eingeschalteten Schlussplatte erhalten. Legt man z. B. anf die positive Schlussplatie von Kupfer eine feuchte Schicht, so wird die Flüssigkeit derselben auf dem äussersten Extrem negativ, eben so wie die Flüssigkeit im übrigen Raume der Säule in der Richtung rom Zink zum gegenüberliegenden Kupfer negativ ist; auf dem gegen die Kupferplatte gerichteten Extrem wird sie positiv, wieder eben so, wie die übrige Flüssigkeit der Säule in der Richtung vom Kupfer zum gegenüberliegenden Zink positiv ist; die kupferne Schlussplatte bleibt also auf der innern Seite positiv, auf der äussern aber wird sie negativ, und eine auf das äusserste negative Extrem der angefügten flüssigen Schicht abermals auf- 
gedeckte Metallplatte wird wieder, so wie vorhin die kupferne Schlussplatte, durch und durch positiv angeregt. Legt man auf sie abermals eine feuchte Schicht mit einer einzelnen Endplatte, so wiederholt sich dasselbe Erregungsgesetz, und so fort durch eine unbestimmte Zahl solcher Schichtungeu hindurch, nur dass mit der zunehmenden Menge der letzteren die polare Wirkuig nach Aussen hin im Allgemeinen, so wie die Verbreitung der magnetischen Polarität durch unmagnetisches weiches Eisen abnimmt in einem Verhältnisse, über welches durch specielle Untersuchungen noch erst entschieden werden muss.

Obgleich die chemische Thätigkeit, so lange die Kette; ungeschlossen bleibt, vorzugsweise nur der durch die elektrische Spannung versichtbarten Tendenz nach in derselben herrschend ist, so findet dennoch durch den gesteigerten Drang bereits im ungeschlossenen $\mathrm{Zu}$ stande der isolirten Säule eine starke Oxydation der Metalle in ihr Statt, und da die negative Erregung dér Zinkplatten und gleichzeitig damit die Tendenz zur Oxydation in derselben nach der bekannten Richtung allmälig zunimmt: so ist zu erwarten, dass in der ungeschlossenen isolirten Säule die negativ erregten Zinkplatten um so stärker von der Oxydation angegriffen werden müssen, je näher sie nach dem negativen Pol der Süule hin liegen. Mir sind ausser den von Ritter, und zwar, wie er ausdrücklich sagt, nur beiläufig gemachten Beobachtungen, keine weitern über diesen Gegenstand bekannt. Wie aber auch das Resultat einer in dieser Beziehung absichtlich angestellten umständlicheren Untersuchung ausfallen möchte, so ist im Voraus so viel gewiss, dass es nie- 


\section{8}

mals ein entscheidendes Moment für oder gegen das Ganze unserer Ansicht abzugeben vermöge; denn abgesehen davon, dass besonders bei Apparaten mit angefeuchteten Scheiben, von welcher Art die Ritter'schen Säulen dürchgehends waren, durch Ungleichförmigkeit des Drucks, durch Ungleichheit des Feuchtigkeitsgrades in den verschiedenen Scheiben, insbesondere auch durch weniger vollkommene Isolirung des einen untern Pols der Kette und durch eine grosse Zahl anderweitig möglicher Differenzen beträchtliche Abweichungen und sehr leicht selbst völlig entgegengesetzte Ergebnisse von dem, was man nach den obigen Bemerkungen zu erwarten geneigt seyn kann, entstehen können, so ist es besonders zu beachten, dass mit der nach dem positiven Pol hin erhöhten Tendenz zur Desoxydation und mit der davon abhängigen Entbindung des basischen Theils der Flüssigkeit, vermöge eines gleichzeitigen Freiwerdens des aciden Factors, auch in dieser Gegend der ungeschlossenen isolirten Säule eine nach der Natur und dem individuellen Neutralisationsverhältnisse der Flüssigkeit so beträchtliche Oxydation des Zinks Statt haben könne, durch welche die Entscheidung unsicher gemacht oder unter der Herrschaft eines bereits waltenden Vorurtheils selbst völlig getäuscht zu werden vermöge. Es kann daher durchaus nicht befremden, wenn Ritter, befangen in der irrigen, bis zur gegenwärtigen Zeit herrschend gebliebenen, Vorstellung, dass der Zink das positive Metall in der Kette, und der positive $\mathrm{Pol}$ das eigentliche $\mathrm{Oxydationsextrem}$ derselben sey, aus ganz beiläufig gemachten Beobachtungen das Resultat ziehen zu können glaubte, dass der Zink in der ungeschlossenen isolirten Säule nach 
dem positiven Pol (in Ritters und der herrschenden Sprache: nach der Zinkseite oder dem Zinkpole hin) eine gradweise zunehmende Oxydation erleide.

Ritters Säulen waren, wie man aus gelegentlichen Beschreibungen von ihm erfährt, stets in der Ordnung, wie sie in der obigen Zeichnung auf Seite 100 beobachtet ist, aufgeschichtet, so dass in jedem einzelnen Plattenpaare der Zink oben, das Kupfer unten lag, indem seine Zinkplatten mit erhöhten Rändern gegossen waren, zur Verhütung des Ueberlaufens der Flüssigkeit aus den auf die Zinkplatten aufgelegten, |von jenen Rändern umgebenen', Pappscheiben. Die Platten. seines Apparats hatten daher ein beträchtliches Gewicht und die untern Lagen wurden bei Säulen von 50 Paaren und darüber durch die obern schon so stark gedrückt, dass Ritter, um das trotz der Randplatten Statt findende Ueberfliessen zu beseitigen, die Scheiben der untern Lagen vor dem Aufbauen der Säule entweder schon stärker als die der obern ausgepresst haben musste, oder dass durch den stärkern Druck, welchen der obere Theil der Säule auf den untern ausübte, in dem letzteren mehr Flüssigkeit als in jenem aus den Pappen getrieben wurde, und die Thätigkeit der Säule, wie es ,ohnedies immer der Fall zu seyn pflegt, in dem obern Theile grösser als im untern war, so dass in jenem scheinbar gegen unsere Ansicht, aber ohne dass dadurch in der That etwas gegen sie bewiesen wäre, die Platten stärker als nach unten hin angegriffen seyn konnten.

Um indess in der Sache nach eigenen und directen Erfahrungen zu urtheilen, setzte ich zuvörderst eine Säule aus 5o Paaren dünner Kupferplatten, und leichten, wohl gereinigten Platten von gewalztem Zink- 
blech zusammen; aber in entgegengesetzter'Ordnung als die Ritter'schen Säulen aufgeschichtet waren, so dass in jedem einzelnen Plattenpaare der Zink zu unterst lag. Die wohl isolirte, durch ein schwaches Gewicht mässig gedrückte, Kette, mit möglichst gleichmässig gefeuchteten kochsalznassen Pappen stand un. geschlossen 24 Stunden lang. Nach Verlauf derselben zeigten sich beim Auseinandernehmen die Platten im obern Theile der Säule im Ganzen etwas stärker angegriffen, als im untern, also im Einklange mit unserer Ansicht; aber der Fortschritt der Oxydation vom positiven $\mathrm{Pol}$ zum negativen $\mathrm{Pol}$ hin war unregelmässig und der Unterschied auf beiden Extremen überhaupt so geringe, dass jemand bei nur oberflächlicher Prüfung in seinem Urtheile unentschieden bleiben oder sich wohl selbst zur entgegengesetzten Seite neigen konnte. Ich errichtete darauf eine Säule aus 100:Paaren, in welcher die Zinkplatten ganz neu mit blanker regulinischer Fläche der Flüssigkeit dargeboten wurden, so dass sie aus zwei gleichen, aber entgegengesetzt geschichteten, Schenkeln bestand, die, auf wohl isolirenden Stativen ruhend, an den untern Extremen durch eine Kupferschiene verbunden waren, und deren obere unverbundene Extreme also die Endpole der 24 Stunden lang geöffueten Batterie bildeten. Beim Auseinandernehmen derselben war eine im Ganzen allmälig zunehmende Oxydation der Platten in jedem einzelnen Schenkel von unten nach oben hin sichtbar, dass also nach dem einen Schenkel, dessen Extrem der positive Pol war, Ritters Ansicht, nach dem andern hingegen, der in dem negativen Pol endigte, die unsere bestätigt zu werden schien. Verglich man aber die neben ein- 
ander gelegten Platten beider Schenkel, so war ausserdem ein Uebergewicht der Oxydation in dem letztern Schenkel, dessen Extrem der negative Pol war (der eigentliche Zinkpol, gewöhnlich der Kupferpol 'genannt) nicht zu verkennen, und das Hauptresultat fiel daher in diesem Versuche völlig zu Gunsten unserer Theorie aus, während zugleich durch dasselbe anschaulich wurde, wie leicht aus einzelnen, wenn auch sonst richtigen, Beobachtungen der Art ein scheinbar ganz entgegengesetztes Resultat gefolgert werden könne.

Endlich setzte ich nochmals eine Säule aus den nehmlichen, sorgfältig gereinigten, hundert Plattempaaren zusammen, so dass jetzt die beim vorhergehenden Versuch von der Flüssigkeit unberührt gebliebenen Seiten der Zinkplatten ihr dargeboten wurden, und dass die Säule aus vier verbundenen |Abtheilungen bestand, deren jede von 25 Paaren besonders auf einem guten Isolatorium ruhte. Nachdem sie so 48 Stunden lang ungeschlossen gestanden hatte, ergab sich beim Auseinanderlegen eine zwar nur schwache und durch einzelne Anomalien im regelmässigen Fortschritt hie und da gestörte, aber dennoch bei näherer Prüfung nicht zu verkennende Zunahme der Oxydation der Platten vom positiven nach dem negativen $\mathrm{Pol}$ hin. Ich glaubte schliesslich den Erfolg zu Gunsten der Theorie noch in die Augen fallender zu machen, als ich eine Säule aus 5o Paaren zwar ungeschlossen, aber am positiven Pol mit dem Boden in leitende Berührung gesetzt, 24 Stunden hindurch stehen liess; aber in diesem Versuche fiel zwar die Oxydation stärker als bei den gänzlich isolirten Säulen aus, ein Unterschied in der Grösse der- 
selben nach den Polen hin blieb jedoch hier nur um so zweifelhafter.

Die Resultate dieser Versuche zeigen daher wenigstens auf das Entschiedenste, dass Ritters Folgerungen, welche er zur Bestätigung der herrschenden, aber unrichtigen, Ansicht aus zufälligen Beobachtungen herleitete, auch wenn die Beobachtungen richtig waren, dennoch eben so wenig für jene Ansicht als gegen die unsrige entscheiden; aber Ritter hat noch andere directe Versuche angestellt, aus denen, wie er meint, eine Zunahme der Oxydation nach dem positiven Pol der Säule hin bestimmt hervorging, und die daher hier nicht mit Stillschweigen übergangen werden dürfen. Er hattenehmlich auf jedem Extrem der isolirten Süule einen Messingdrath in horizontaler Lage angebracht, so dass das eine Ende des Draths in unmittelbarer Verbindung mit den Endplatten der Säule sich befand und das andere in eine kleine, durch Korkstöpsel verschlossene, und mit destillirtem Wasser gefüllteRöhre hinein reichle. Eben solche in Wasser geleitete Dräthe waren zugleich noch an andern Stellen in gleichen Entfernungen von den Polen und einer derselben gerade in der Mitte der isolirten Säule, wo sie ihren Indifferenzpunct hatte, in leitender Verbindung mit einzelnen Plattenpaaren zwischen sie eingeschoben. Nach 24 Stunden fand Ritter den letzteren Drath im Wasser eben so stark oxydirt, wie einen gleichen, den er in derselben Zeit ausser Verbindung mit der Batterie dem Einflusse des Wassers eben so ausgesetzt hatte. Đie übrigen mit der Süule verbundenen Dräthe hatten nach dem positiven Pol hin eine stärkere, und der mit dem positiven $\mathrm{Pol}$ selbst verbundene Drath die stärkste, von einer Trü- 
bung des Wassers begleitete Oxydation erlitten; nach dem negativen Pol hin fiel aber;die Oxydation und jene Trübung gradweise weg und am negativen Pol selbst, wo nach unserer Ansicht das Maximum der Oxydation Statt findet, war gar keine Spur von Oxydation mehr an dem Messingdrathe sichtbar, und das umgebende Wasser war hier, wie Ritters eigene Worte lauten, fast noch klarer und durchsichtiger als anderes, das weder mit der Batterie, noch mit Messingdrath in Verbindung gewesen war, und hatte noch überdies ein schwaches aber deutliches gelbgrünliches Ansehen bekommen. (Ritter's phys, chem. Abhandl. 2 r Bd. S. 69.)

Ritter's Andenken und seine grossen Verdienste um die neuere $P$ hysik werden bei allen vorurtheilsfreien Kennern stets in Ehren bleiben, aber es ist nicht zu läugnen, dass er auf dem Gebiete der Wissenschaft, wo nur Wahrheit und nicht die Meinung herrschen soll, zuweilen fast nur so verfuhr, wie die Diplomaten unserer und aller Zeiten auf dem unzuverlässigen Boden der Politik einherzuschreiten pflegen, indem sie den Ereignissen und historischen Momenten nicht den wahrhaften, sondern nur einen solchen Charakter beilegen, wie er dem blossen Interesse ihrer individuellen, unfreien Ansicht entspricht. Ich will die obigen von Ritter angeführten Erfolge nicht geradehin läugnen, da sie nach Abrechnung dessen, was etwa Vorurtheil und Phantasie in sie hinein getragen haben mögen, nicht nur nicht ausser der Ordnung liegen und keineswegs das beweisen, was Ritter durch sie dargethan wissen wollte, sondern vielmehr unsere ganze Ansicht bestätigen; aber ich bin vergebens bemüht ge- 
wesen, ähnliche Erfolge zugleich mit meinen oben erwähnteu Versuchen an den ungeschlossenen Säulen, so dass ich auch nur ein Datum zur Annäherung an irgend eine Entscheidung auf der einen oder andern Seite erhalten hätte, an Messingdräthen hervorzubringen. Ich habe stärkere und schwächere Messingdräthe in ausgekochtem, destillirtem Wasser, wie es Ritter bei seinen Versuchen angewandt zu haben ausdrücklich angiebt, mehrere Táge lang der Oxydation ausgesetzt olme einen so merklichen Grad derselben eintreten zu sehen, der mit irgend einer Trübung des Wassers, mit irgend einer noch so geringen Quantität zu Boden gefallenen Oxyds, wie es Ritter schon nach 24 Stunden deutlich bemerkt haben will, verbunden gewesen wäre, und der so zu Vergleichung mit der angeblichen Oxydation der Messingdräthe in der Batterie, welche in meinen Versuchen ebenfalls ausblieb, hätte dienen können.

Nachdem diese Versuche fruchtlos ausgefallen waren, nahm ich daher zu den folgenden, statt des Messings Dräthe, von vollkommen regulinischem weichen Eisen, und hier war der Erfolg dieser, dass alle Dräthe auf der negativen wie auf der positiven Seite der Batterie nach 24 Stunden angegriffen waren, und das Wasser mit rothbraunem Oxyd mehr oder weniger erfült hatten, und zwar war der Drath in der Mitte der Säule nicht stärker und schwächer als ein eben solcher zur Vergleichung ausser Verbindung mit der Batterie niedergelegter Drath oxydirt; auf dem negativen Pol aber, wo nach unserer Ansicht das Maximum der Tendenz zur Oxydation Statt findet, war die Oxydation des Draths am schwächsten, am positiven Pol hingegen, wo das Minimum der Oxydation Statt findet, war der Drath 
am stärksten angegriffen und das umgebende Wasser am 'meisten durch das losgerissene Oxyd erfüllt und gefärbt.

Wer ohne die Fähigkeit oder den Willen, in den innern Zusammenhang der Erscheinungen einzudringen, nur nach vagen Combinationen und grundlosen Analogien schliesst, der ist hier abermals in Gefahr, von den Erscheinungen geneckt und zu einem ihrer wahrhaften Bedeutung völlig zuwiderlaufenden Urtheile verleitet zu werden. Die Data zur eigentlichen richtigen Würdigung des mit unserer 'Theorie in vollkommenem Einklange stehenden Erfolgs sind übrigens schon oben in früheren Auseinandersetzungen beigebracht worden. Allerdings nimmt die Tendenz zur Oxydation durch alle Plattenpaare nach dem negativen Pole hin zu; aber bekanntlich vorzugsweise nur in den dem positiven Pole zugekehrten negativen Hälften, den Zinkplatten derselben, während die abgewandte Kupferseite derselben, dem positiven Pole entsprechend, selbst vorherrschend positiv und um so positiver ist, je näher das Paar dem positiven Pole liegt. Eben so ist irgend eine einzelne, in die Säule eingeschaltete, Metallplatte, wie es oben bereits bemerkt worden, gleich jedem Plattenpaare der Säule, auf der dem positiven Pol zugewandten Seite negativ, auf der entgegengesetzten hingegen positiv, sie wird bei ungeschlossener und noch mehr bei geschlossener Säule nur vorzugsweise auf jener negativen Seite oxydirt, während auf der andern ein verhältnissmässiges Streben zur Desoxydation sich geltend macht, wie es gleichfalls bekannt ist, dass bei einem, zwischen den Polardräthen der Säule befindlichen, vom Wasser umgebenen Drathe auf sein dem positiven Pol 
'der Säule, d. h. auf |sein 'der innern Seite der kupfernen Schlussplatte zugewandtes Extrem das Oxygen, auf das entgegengesetzte aber das Hydrogen hinströmt. Und ganz dieselbe Vertheilung der Zustände in Absicht auf Oxydations - und Desoxydationstendenz erleidet jeder der in obigem Versuche mit der Batterie in Verbindung gesetzten Dräthe. Ist das eine Ende derselben mit dem negativen $\mathrm{Pol}$ der Säule verbunden und daher selbst negativ, so ist das in das Wasser hineinreichende Ende dagegen positiv und macht dadurch eine Tendenz zurDesoxydation geltend, mit welcher es, wenn auch der Oxydation durch das Wasser im Ganzen unterliegend, hier am negativen Pole, als dem eigentlichen Oxydationsextrem der Säule, dennoch weniger oxydirt wird, als das von Wasser umgebene Ende des am entgegengesetzten Desoxydationsextrem der Säule befindlichen Draths, der eben, weil sein mit der Batterie verbundenes Ende positiv ist, im Wasser negativ und damit zu einer um so höher gesteigerten Oxydabilität erregt wird.

Welche Modificationen also auch die noch ungeschlossene Säule in Absicht auf den in ihr mit der erhöhten elektrischen Spannung bereits angeregten chemischen Process versichtbaren, möge, das durch die vollkommenste Consequenz unserer bisherigen Combinationen und durch die sprechendsten Thatsachen begründete Resultat bleibt unerschütterlich dasselbe: in der ungeschlossenen galvanischen Säule erstreckt sich mit der durch alle Zinkplatten wachsenden, negativ elektrischen Erregung die Tendenz zur Oxydation, zur Anziehung: des Aciden oder Abstossung des Basischen, in der Richtung vom positiven zum negativen Pol, also in der Richtung von jeder einzelnen Kupferplatte nach der 
durch die angränzende Flüssigkieit von ihr getrennten Zinkplatte hin, und eben so erstreckt sich mit der durch alle Kupferplatten wachsenden positiv elektrischen $\mid$ Erregung die Tendenz zur Desoxydation, zur Anziehung. des Basischen oder Abstossung des Aciden, in der Richtung vom negativen zum positiven Pol, also in der Richtung von jeder einzelnen Zinkplatte nach der durch die angränzende Flüssigkeit von ihr getrennten Kupferplatte hin.

Und diese Tendenzen sind es, die zwar schon in der ungeschlossenen Kette zum Theil realisirt, mit dem Momente der wirklichen Schliessung nach denselben Richtungen vollends zur kraftrollsten Thätigkeit des Chemismus selbst entflammt werden. So oft nur ein Pol der isolirten Säule ableitend herührt wird, eben so oft wird auch nur momentan die Tendenz des andern um das Zwiefache gesteigert, während die mit dem berührten Pol zusammengehörige Thätigkeit auf ein von Null nicht zu unterscheidendes Minimum herabgezogen wird. Wird z.B.der negative Pol ableitend berührt, so erhalten alle negativ erregten Zinkplatten o $\boldsymbol{E}$, sie sind vermöge des Dranges der Contactelektricität in diesem Zustande auf dem Uebergange $\mathrm{zu}+E$ begriffen, aber die Kupferplatten reagiren jede mit dem zwiefachen Antheil des $+E$ ihres Erregungswerthes; wird nun aber auch der positive Pol leitend mit dem negativen verbunden, so werden in demselben Moment, mit welchem nun auch alle Kupferplatten o $E$ erhalten, alle Zinkplatten wirklich positiv und gleichzeitig alle Kupferplatten negativ, - der lang verhaltene Blitz der metallischen Contactelektricität durchzuckt urplötzlich die ganze Kette, - aber nur um dadurch für den un- 


\section{8}

mittelbar folgenden Moment den Chemismus, welcher in der Contactelektricität zwischen der Flüssigkeit und den Metallen sich regte, zur heftigsten Gluth zu entflammen; und, wie bei der einfache Kette, so schlagen nun auch bei der zusammengesetzten, nur in bestimmten Gränzen um so voller und mächtiger, je zusammengesetzter sie ist, die wechselnden Pulse der erregenden und erregten Thätigkeit fort, so bedingen und fordern sich gegenseitig'der Moment der zum synthetischen Effect des Chemismus zurückdrüngenden Contactelectricität der Metalle und der vom Magnetismus begleitete Moment des mit immer weiter greifender Gewalt hervortretenden analytischen Effects des Chemismus.

Beide Momente sind der endlichen Vorstellung nach, aber nicht dem Wesen und der innern Anschauung nach, von einander gesondert, sie sind verschieden und dennoch eins, sie verhalten sich nicht wie Rückgang und Fortgang, sondern sie greifen zu einem und demselben progressiven Act in und durch einander, wie die beiden entgegengesetzten elektrischen Erregungen in der ungeschlossenen Kette, so dass mit dem immer grösser werdenden relativen Uebergewicht des analytischen Effects die elektrische Erregung nach Aussen hin zu Null wird, und Chemismus und Magnetismus durch den Entwickelungsdrang der gehemmten Contactelektricität der Metalle um so energischer als stetig fortdauernde Zustände der geschlossenen Kette ins Leben treten. Sie sind das lebendige Integral jener abstracten Differentialmomente 'und die Mathematiker derjenigen Schule, welche den Infinitesimalcalcul in das niedrigere Gebiet der gemeinen endlichen Functionenrechnung hinabgezogen wähnen, kön- 
nen hier an einem Beispiele die wahrhafte und tiefe Bedeutung der bewunderungswürdigsten Disciplin ihrer Wissenschaft noch auf eine lebendigere Weise als auf dem eigenen Grund und Boden vernehmen, wie es überhaupt gewiss ist, dass das höhere Verständniss der Mathematik eben sowohl aus dem lebendigen Verständnisse der Natur, als umgekehrt das Verständniss der Natur aus dem der höhern Mathematik hervorgehen müsse.

Zur gründlichen Erkenntniss der eigentlichen Natur der Thätigkeit der geschlossenen Kette gehört vor Allem eine klare und unbefangene, von den einseitigen Beziehungen der gewöhnlichen endlichen Vorstellungsweise völlig gereinigte, Anschauung ihrer PoIarität. Unter Polarität der Kette schlechthin kann nichts als der Gegensatz der beiden in ihr herrschenden Tendenzen zur Oxydation und Desoxydation verstanden werden und in einer specielleren Bedeutung wird in die Vorstellung zugleich noch das Unterscheidungsmerkmal der bestimmten entgegengesetzten Richtungen mit aufgenommen, nach welchen hin diese Tendenzen sich wirksam zeigen. Ist diesen Tendenzen in zwei entgegengesetzten auseinander gehaltenen Extremen der räumlichen Masse, innerhalb welcher sie wirksam sind, eine Gränze der Thätigkeit gesetzt, so heissen diese Extreme die Pole derselben Thätigkeit, und es ist klar, dass überall, wo sich solche Pole zeigen, auch Polarität Statt finden müsse; aber es ist zugleich eben so gewiss, dass da, wo Polarität herrscht, nicht auch nothwendig immer. Fole vorhanden seyn müssen, weil die Polarität an sich nur einen Gegensatz der Thätigkeit und die entgegengesetzte Rich- 
tung dieser zwiefachen Thätigkeiten umfafst, der Realität nach folglich eine und dieselbe bleibt, die beiden Thätigkeiten mögen irgendwo durch zufällige Gränzen der Masse, innerhalb welcher sie wirken, in ihrer weitern Ausbreitung gehemmt seyn oder nicht; der letztere Fall enthält selbst durch die in ihm Statt findende Beseitigung der hemmenden Schranken vielmehr die Bedingung zu noch lebendigerer Anregung der Thätigkeiten, und die mit der Realisirung dieser Bedingung gegebene Form einer frei und ungehindert im Kreise nach fest bestimmten Richtungen fortwirkenden Polarität wird ohne Zweifel durch das mit der Untersuchung über die elektromagnetische Polarität zuerst von mir aufgenommene Prädicat der Circularpolarität zweckmässig und passend bezeichnet.

Die Polarität der zusammengesetzten galvanischen Kette hat ihre Pole in den Extremen der Säule, so lange diese ungeschlossen ist; im geschlossenen Zustande aber ist die Kette ein Kreis ohne Extreme, kein Glied derselben, oder jedes ist das erste und letzte zugleich; die Kette hat alsdann, so gewiss ihre Thätigkeiten zu einem ungleich höhern Grade gesteigert sind, auch eine um so lebendiger; und kräftiger hervortretende Polarität; aber sie hat keine Pole mehr, oder jedes einzelne Element hat seine Pole schlechthin in demselben Sinne, wie alie übrigen; es ist durchaus falsch und ein grosser Theil bisheriger Irrthïmer ist darin begründet, dass die beiden Extreme der Kette, welche im ungeschlossenen Zustande ihre Pole bildeten, auch während der vollkommenen Schliessung, mit welcher sie aufgehört haben, Extreme zu seyn, demmoch als von Innen nach Aussen hin wirkende Pole der Kette fixirt 
werden. Der Schliessungsdrath, welcher die äussersten Endglieder der Säule verbindet, ist nur als der metallische Fortsatz dieser Extreme und als Aequivalent ihrer in unmittelbare Berührung tretenden Aussenflächen zu betrachten, in der reinen Anschauung der geschlossenen Kette fällt er daher gänzlich aus, die Endglieder selbst berühren sich, durch nichts aus einander gehalten, unmittelbar, und wie das Schema der geschlossenen einfachen Kette (s. oben S. 100.), so ist auch das der zusammengesetzten im Zustande ihrer vollkommenen Schliessung ein schlechthin symmetrisch in sich zurücklaufender Kreis.

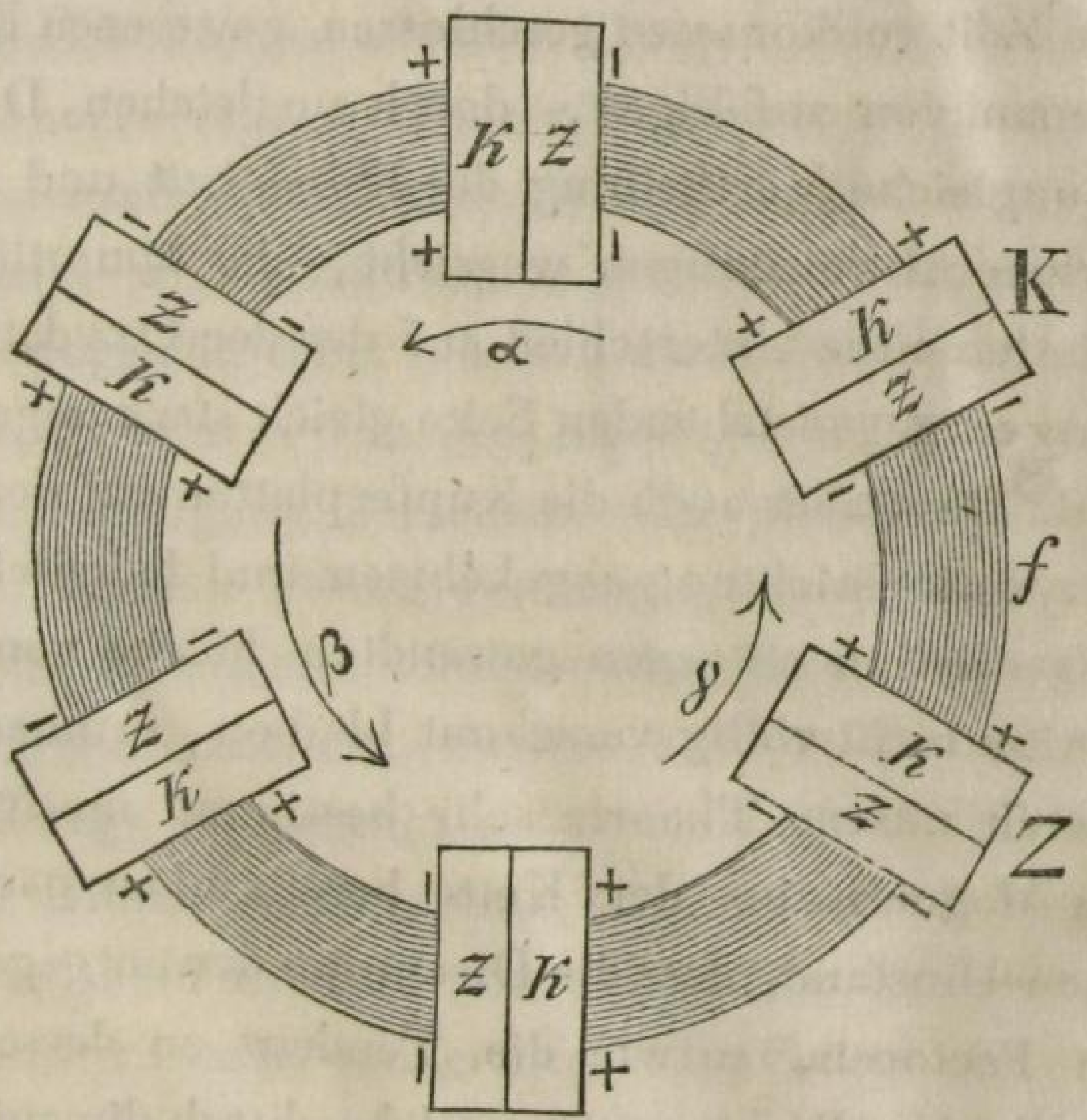

Die Richtungen, nach welchen die beiden polaren Thätigkeiten der Kette hervortreten oder nach denen die Factoren des flüssigen Leiters dirimirt werden, sind auf das entschiedenste bestimmt; durch die ganze Kette erstreckt sich die Tendenz zur Oxydation nach der durch die Pfeilspitzen in der obigen Zeichnung an-

I 2 
gedeuteten Richtung $\alpha \beta \gamma$, und die Tendenz zur Hydrogenisation mach der entgegengesetzten Richtung $\gamma \beta \alpha$; nach allen mit - bezeichneten Metallflächen hin entbindet sich Oxygen, und nach allen durch + unterschiedenen Stellen hin tritt das Hydrogen auf. Aber anch diese Richtungen allein sind es nur, welche in der geschlossenen Kelte, wenn von örtlich betrachteter Polarität derselben die Redo ist, fixirt werden müssen; die Vertheilung und der Grad der Intensität beider Thätigkeiten ist in allen Elementen der Kette ohne Unterschied ein und derselbe, wie es ein entschie-. denes Factum ist, dass beim Auseinandernehmen einer längere Zeit vollkommen geschlossen gewesenen Kette, wenn man von zufülligen, durch ungleichen Druck, durch ungleiche Vertheilung der Flüssigkeit und sonst möglichen Abweichungen wegsieht, die sämmtlichen Zinkplatten ohne Unterschied auf der der Oxydationsrichtung entgegenstehenden Seite gleich stark angegriffen sind. Dass aber auch die Kupferplatten auf der von der Oxydationsrichtung abgekehrten und lediglich der Hydrogenisation entgegen gewandten Fläche von der Oxydation nicht völlig verschont bleiben, erinnert an den durch unsere Theorie sehr bestimmt motivirten und im Magnetismus der Kette bereits oben nachgewiesenen Umstand, dass die Diremtion der entgegengesetzten Factoren, so wie die Tendenz zu derselben, zwar nach den Richtungen, welche durch die auf den verschiedenen Seiten liegenden Metalle entschieden bestimmt sind, aber keineswegs parallel mit der Longitudinalaxe der Kette, sondern unter einem beinahe rechten Winkel gegen dieselbe erfolge, so dass vermöge dieser sehr starken Neigung Erhöhungen und 
Rüinder grösserer und klem̀nerer mikroskopischer Vertiefungen auf den Kupferplatten ron noch tiefer liegenden Puncten aus allerdings in der deprimirten Diagonale der vou der Oxydation beherrschten Richtung liegeu, und ron jener daher sehr wohl ergriffen werden können. In der That wird man bei genauerer Prüfung in der Regel finden, dass die stärker angegriffenen Stellex auf den Zinkplatten Vertiefungen sind, während sie auf den Kupferplatten wall - und hügelförmig erhöhte Theile bilden. Bei den Zinkplatten sind es die weniger oxydirten, bei den Kupferplaiten hingegen die stärker angegriffenen Stellen, welche gleich inselförmigen Erhöhungen aus dem übrigen Theil der Metallfläche hervorragen. Dieser Umstand, weleher ausserdem xäthselhaft erscheinen würde, steht also unserer Theorie, wie es beim ersten Anblick scheinen möchte, keineswegs enlgegen, sondern dient vielmehr durch das Licht, welches er von ihr empfängt, zu einer abermaligen Bestäligung derselben. In gleicher Beziehung ist von den zur Wasserzersetzung dienenden Polardräthen eimes die Kette schliessenden Gasapparats die Bemerkung zu machen, dass es unserer Theorie zufolge keineswegs schlechthin nothwendig sey, dass an dem eixen Drathe durchaus nur das eine, an dem andern eben so ansschliesslich nur das andere der beiden Gase entbunden werde, sondern es ist im Geiste unserer ganzen Ansicht sehr wohl denkbar, dass an dem Oxygendrathe auch ein Minimum von Hydrogen and umgekehrt am Hydrogendrathe auch ein Minimum von Oxygen entbunden werden, oder an letzterem dafür ein entsprechender Oxydationserfolg Statt hahen könne, und zwar ist dieses um so minder unwahrschein- 
lich, je länger der Drath, je rauher seine Oberfläche ist und je zahlreichere und grössere Vertiefungen und Hervorragungen sich folglich auf ihr befinden, zwischen welche die Flüssigkeit zu treten, und auf die, wie auf einander gegenüberliegende mehr oder minder polarisch entgegengesetzte Spitzen, sie einzuwirken vermag.

Es gehört also schlechthin zur klaren Anschauung der Thätigkeit der Kette, dass man den ganzen in sich geschlossenen Kreis derselben in jedem einzelnen Puncte wie in allen übrigen von der durchgehends gleichen, nach den beiden entgegengesetzten Richtungen polarisch wirkenden, Oxydations - und Desoxydationstendenz erfüllt, und das sonst Differente, durchdrungen von dieser Alles durchstrahlenden Gluth, zu einem gemeinsamen und durchaus gleichartigen organischen Ganzen in ihr verschmolzen sieht. Was in diesen Kreis als ein anfänglich ihm Fremdartiges von Aussen hinein versetzt, wird, das wird augenblicklich von dieser in ihm herrschenden Gluth, so weit es derselben nur empfänglich, ergriffen und dem Ganzen assimilirt; theils tritt die Flüssigkeit von entgegengesetzten, durch die Müchtigkeit der Polarität fest und unabänderlich gebotenen, Seiten mit den dirimirten Factoren gegen dasselbe, theils wird'es, gleich ihr, in ein oxydirtes und desoxydirtes dirimirt, oder werigstens zur Tendenz einer solchen Diremtion lebendig angeregt, und so wirkt es zugleich auf das Ganze erregend zurück, und muss so wiederum auch der Totalität des Processes der Kette zum Organ dienen, so wie die Metalle von demselben Leben der Kette, welches sie als ursprüngliche Organe desselben unterhalten und ernähren lielfen, auch gleich allen übrigen Lebensorganeu wiederum verzehrt werden. 
Weil man die Kette gewöhnlich nicht aus diesem allein wahren und naturgemässen Gesichtspuncte betrachtet, sondern sie gleichsam nur wie ein mit elektrischer Materie erfülltes Compressionswerkzeug angesehen hat, das auf einen dritten Körper, sobald er den Extremen der Säule nahe genug gebracht wird, das fabelhafte Fluidum gewaltsam ausströmt und damit auf der einen Seite Oxydation, auf der andern Hydrogenisation oder Desoxydation bewirkt, wobei also, ohne dass über den Zusammenhang dieser fingirten elektrischen Strömung mit den chemischen Erfolgen irgend eine genügende Rechenschaft gegeben würde, die Süule als ein einzelnes, mit fixirten von Innen nach Aussen wirkenden Polen, und der Körper als ein gleichfalls gesondertes äusserliches, sich fremd und mechanisch einander gegenüber stehen, so hat man den einen Pol, welcher nach dieser Art zu sehen der oxydirende ist, weil an ihm das Oxygen erscheint und der Körper durch ihn eine Oxydation erleidet, den Oxygenpol, und deu audern nach einer ähnlichen Argumentation den Hydrogenpol genannt, und in gleichem Sinne pflegt auch von den mit den Polen der Süule verbundenen Gold- oder Platindräthen der eine als der Oxygengebende, der andere als der Hydrogengebende Drath bezeichnet zu werden.

Das Vage oder völlig Verwerfliche in dieser Vorstellung und Bezeichnungsweise springt aber jedem, der selbst nur einige Bekanntschaft mit unsern bisheri-' gen in die innere Natur des Gegenstandes mehr eingehenden Entwickelungen gewonnen hat, unwillkürlich in die Augen. Aus den Metallen geht so wenig da Oxygen und Hydrogen selbst, noch sonst etwas Ma- 
terielles hervor, welches etwa das Oxygen und Hydrogen erzeugte, sondern aus der Flüssigkeit tritt umgekehrt beides nach verschiedenen Seiten zu den Metallen hin, und diese können nur als empfangende, secundäre, nicht als gebende Glieder der Kette bezeichnet werden, und wenn von Polen der Kette nur im ungeschlossenen Zustande derselben oder nur in sofern, als bei einer minder vollkommenen Schliessung die nicht befriedigte Tendenz zum Chemismus sich durch die elektrische Spannung in ihnen zu erkennen gibt, die Rede seyn darf, so kamn nur die directe Beziehung solcher Pole auf den elektrischien Zustand, nicht aber auf die in der geschlossenen Kette eingetretene Thätigkeit des Chemismus eine Bedeutung haben, wenn man nicht jeden Punct der Kette ohne Unterschied als Oxygenpol und Hydrogenpol zugleich, den nach entgegengesetzten Richtungen gemeinschaftlich in ihm Statt findenden Tendenzen gemäss, bezeichnen will. Nur eine indirecte Beziehung der elektrischen Pole der ungeschlossenen Kette auf die chemische Thätigkeit der geschlossenen und eine davon abhängige Nomenclatur würde in sofern einen Sinn haben, dass man den negativen, in eine einzelne Zinkplatte ausgehenden, Pol zugleich den Oxygenpol der Kette nennen könnte, weil durch die negativ elektrische Spannung das Maximum der Tendenz zur Oxydation in ihm ausgesprochen ist, und so wären consequenterWeise gleichbedeutend die Benennungen : negativer Pol, Zinkpol, Oxysenpol, eben so wie auf der andern Seite: positiver Pol, Kupferpol, Hydrogenpol Synonyme wären, die vor den Richterstühlen der Logik und Naturlehre bestehen künnten. Aber der verjährte Irrthum, dass der Zink das positive und das Kupfer das negative Mer 
tall in der Kette sey, hat die Verkehrung der Begriffe durch die Gleichsetzungen: positiver $\mathrm{Pol}=\mathrm{O}$ xygenpol und negativer $\mathrm{Pol}=\mathrm{Hydrogenpol} \mathrm{bis} \mathrm{zum} \mathrm{Gipfel}$ der Verwirrung gesteigert und dadurch dem elektrochemischen System einen desto gewaltsameren Sturz vorbereitet, je grundloser und unhaltharer diese luftige Höhe ist, in welcher es sich übereilter Weise anbauen zu dürfen gewähnt hat.

Es werde die in der obigen Zeichnung S. $13 \mathbf{x}$. als geschlossen dargestellte Kette in dem Zustande des Ungeschlossenseyns gedacht, indem man den Leiter zweiter Classe bei $f$ ausfallen lässt, so ist in der metal lischen Endigung bei $K$ der positive, und in der bei $Z$ der negative Pol der ungeschlossenen Kette. Man mag sich nun die Endigung bei $K$ ganz aus Kupfer, und die bei $Z$ ganz aus Zink bestehend denken, wie es bekannter Massen der wahren Norm der ungeschlossenen Kette entspricht, oder man mag, der zurückgebliebenen Signatur der Zeichnung gemäss, das $K$ in Zink und das $Z$ in Kupfer ausgehend, oder auch das $K$ und $Z$ aus irgend welchen Metallen bestehend annehmen: in jedem Falle wird, bei einer durch eine hinlänglich grosse Zahl von Elementen fest und unabünderlich bestimmten Polarität, das $K$ zunächst auf der einen Seite, uud daher auch, so lange die Kette ungeschlossen bleibt, durch seine ganze Masse hindurch, positiv erregt seyn, und eben so" wird $Z$ ganz durchgehends negativ erregt seyn. Wird nun die Kette geschlossen, dadurch, dass eine metallische Verbindung zwischen $K$ und $Z$ hergestellt wird, so gelten $K$ und $Z$ vereinigt so viel, als jedes andere durch $k$ und $z$ bezeichnete verbundene Metallpaar der Kette, und das ganze $K$ ist gleich jedem an- 
dern $k$ positiv, und das ganze $Z$ eben so gleich jedem andern $z$ der Kette negativ. Wird aber die Schliessung der Kette bewirkt, indem der Leiter zweiter Classe $f$, oder irgend ein Aequivalent desselben, wie z. B. ein Gasentbindungsapparat, oder ein reducirbarer Stoff, wie ein Alkali, zwischen die so lange als Pole geltenden Endigungen $K$ und $Z$ gebracht wird, dann wird das $K$, ausser directer Verbindung mit $Z$, aber in lebendiger Gemeinschaft mit dem Ganzen der geschlossenen Kette, so wie jedes andere $k z$, während es auf der Seite des $k$ positiv bleibt, auf der Seite des $z$ negativ; das $Z$ wird eben so, während es auf der Seite des $z$ negativ bleibt, auf der Seite des $k$ positiv und das $f$, das Alkali etc. tritt nun dem $K$, nicht wie ein negatives dem positiven, sondern umgekehrt wie ein positives dem negativen, oder vielmehr wie ein oxydirendes dem nach Oxydation verlangenden, entgegen, und eben so tritt es dem $Z$, nicht wie ein positives dem negativen, sondern wie ein negatives dem positiven, oder vielmehr wie ein desoxydirendes (reducirtes, regulinisch gewordenes) dem zum Verlangen nach Desoxydation angeregten, entgegen.

Gewiss ist ein jeder, von dem der Sinn unserer früheren Entwickelungen über die wahrhafte Natur der einfachen Kette gründlich gefasst worden, auch ausser Gefahr, von der zusammengesetzten Kette getäuscht zu werden, und für ihn wird die eben gegebene Auseinandersetzung kaum noch erforderlich gewesen seyn. Wer, den Ideen der Naturoffenbarung erschlossen, mit lebenswarmen Sinne sie umfasst, der hält den Faden der Ariadne in Ḧ̈nden, welcher nicht nur ohne Gefahr, sondern selbst zum Siege gegen die monströ- 
sen Missgestaltungen des Trugs durch das verworrene Labyrinth der Erscheinungen hindurch führt; wer aber, den verschlungenen Windungen der Kette folgend, sie nicht mit einem Auge betrachtet, mit dem jeder niedere uud höhere Organismus, wie der ewige und heilige Organismus des grossen allumfassenden Naturlebens selber, um verstanden zu werden, einzig und allein nur angesehen seyn will, als ein absolut in sich geschlossenes, durch sich selbst getragenes und im schrankenlosen Kreislauf durch einander hindurch greifender polarer Lebensthätigkeiten sich offenbarendes, Ganze; wer im Gegentheil das in sich wahrhaft Unendliche aus dem Gebiete der innern Naturanschauung in die engen Schranken des gemeinen Bewusstseyus, der endlichen, bloss formalen Reflexion hinabzieht urd statt des lebendig in sich geschlossenen und fortbewegten Kreises nur die starre gerade Linie als das Schema absolut gesonderter, durch fixirte Pole begränzter und durch Aussenverhältnisse bedingter, Thätigkeiten zur Norm der Betrachtung macht, dem öffnet sich unausweichlich der finstere Abgrund der alten Irrthümer, mit denen alles verkehrt und wie auf den Kopf gestellt erscheint, von denen aber leider eine grosse Zahl unserer heutigen Physiker bereits so gefasst und umklammert seyn werden, dass sie diejenigen, welche die Erscheinungen in ihrem wahren Lichte sehen, Phantasten schelten und es fürs Erste wenigstens gerathener und bequemer finden werden, lieber die Natur noch fortwährend umgekehrt zu sehen, als vor allen Dingen zuerst eine Umkehrung an sich selber vorzunehmen.

In der bisherigen Betrachtung der zusammengesetzten galvanischen Kette sind die beiden Metalle 


\section{0}

$k$ und $z$ als von ursprünglich entgegengeseizter Relation gegen das $f$ vorausgesetzt worden. Er würde aber nur anf Wiederholungen und in unnüthige Weitläufigkeit führen, wenn hier abermals in cine umständlichere Erörterung dessen eingegangen werden soltte; was bei einer zusammengesetzten Ketle in dem Falle Statt findet, wenn die beiden verschiedenen Metalle in ihr zugleich positiv, oder zugleich negativ gegen das $f$ sind. Für denjenigen, welcher der obigen Auseinandersetzung dieses Falls bei der einfachen Kette mit Aufmerksamkeit gefolgt ist, muss das, was in demselben Falle bei der zusammengesetzten Kette vorgeht, ohne weitere Entwickelung bereits hinlänglich klar seyn. Sind beide Metalle gegen das $f$ entweder zugleich positiv oder zugleich negativ, so wird schon bei der Combination von zwei Elementen und bereits vor der Schliessung der Kette, durch den Conflict der entgegengesetzten Lirregung im Contact der Metalle mit der zwischen der Flüssigkeit und den Metallen Statt findenden Erregung, das gegen $f$ minder positive entschieden negativ, oder das gegen $f$ minder negative entschieden positiv, gerade so und vollkommen nach derselben Aetiologie, wie es bei der Schliessung der einfachen Kette geschieht, und dieses Resultat findet bei noch mehr Elementen und bei wirklicher Schliessung der aus ihnen zusammengesetzten Kette nur noch um so bestimmter Statt, so dass die Wirkung derselben einer aus Metallen von entgegengesetzter Relation zusammengesetzten Kette qualitativ durchans identisch und nur quantitativ um so geringer ausfällt, je kleiner der nach dem allgemeinen Gesetze der Relationen stets vor handcue Unterschied der gleichartigen Spannung beider Metalle gegen das $f$ ist. 
Was aber ausserdem noch zum gründlichen Ver* ständniss der Thätigkeit der zusammengesetzten Kette überhaupt, namentlich in Bezug auf das Verhältniss ihrer elektrischen Spannungsintensitüt vor der Schliessung, ihrer Temperaturerhöhung, ihrer chemischen und magnetischen Wirksamkeit während der Schliessung und nach Massgabe der Zahl und Flächengrösse ihrer Elemente für die Betrachtung wichtig und bereits zugänglich ist, das wird sich erst mit oder nach der genauern Untersuchung über die eigentliche Natur der Ritlerschen sogenannten Ladungssäule ergeben, die an merkwürdigen Aufschlüssen über das Wesen des Galvanismus überhaupt um so ergiebiger sich zeigen wird, je weniger sie bisher beachtet und ihrer eigentlichen, ungemein tiefen Bedeutung nach gewürdigt worden ist, weshalb wir bei der Reichhaltigkeit von Gesichtspunkten, welche dieser Gegenstand nach mannichfaltigen Richtungen hin darbietet, ihn, wie er es in aller Absicht verdient, als ein Ganzes für sich behandeln und in dem gleich folgenden Abschnitte besonders einer genauen Betrachtung unterwerfen wollen. 


\section{Fünfter Abschnitt.}

\section{Die L a dungssäule.}

Die drei Hauptmomente in der Gesammtthätigkeit des Galvanismus entsprechen eben so vielen Beziehungen, welche in der räumlichen Dimension der Kette wesentlich von einander unterschieden werden müssen. Die elektrische Spannung, als Tendenz zum synthetischen Effect des Chemismus vor dem Geschlossenseyn der Kette tritt vorzugsweise hervor mit dem Uebergewicht der durch die Zahl der Elemente gebildeten Longitudinaldimension der Kette. Die magnetische Spannung, als Tendeuz zum analytischen Effect nach dem Geschlossenseyn der Kette tritt vorzugsweise hervor mit dem Uebergewicht der durch die geometrischeFlächengrösse der Elemente bewirkten Arealdimension der Kette. Der Chemismus endlich als analytischer und synthetischer Effect zugleich während des Geschlossenseyns der Kette hängt seiner Intensität nach von dem im körperlichen Volumen der Säule beobachteten Verhältnisse beider Dimensionen, der Longitudinal - und Arealdimension zugleich ab, so dass das Maximum desselben gerade da Statt findet, wo keine dieser beiden Dimensionen auf Kosten der andern vorwaltet, und näher oder entfernter ist an dieses Maximum zugleich das stärkste und kräftigste Hervortreten des elektrischen Funkens, als eines der Wasserzersetzung analogen Zer- 
legungsprocesses der Luft, der Temperaturerhöhung und der Verbrennungsphänomene geknüpft. Wir wollen ein jedes dieser drei Momente fürs Erste im Verhältnisse zu den angegebenen Dimensionen sogleich noch einer genaueren Ansicht zu unterwerfen suchen,

1.

Dass die elektrische Tension einer Süule mit der Zahl ihrer Elemente nicht nur wachse, sondern auch ziemlich nahe im geometrischen Verhältnisse dieser Zahl zunehme, gilt als eine durch die Erfahrung bostätigte Thatsache, obgleich directe Versuche von hinlänglicher Genauigkeit und dem erforderlichen Umfange über diesen Gegenstand, so wie in Bezug auf die meisten der übrigen hieher gehörigen Ermittelungen, noch immer fehlen. Es ist zugleich aber auch keinem Zweifel unterworfen, dass die Zunahme der Spannung nicht vollkommen in jenem Verhältnisse Statt finden könne, sondern um so mehr hinter derselben zurückbleihen müsse, je grösser die Zahl der Elemente der Säule werde. Als Ursache dieser Verminderung pflegt der Umstand angeführt zu werden, dass die Leitungsfähigkeit der Flüssigkeit in der Säule nicht absolut, sondern nur mehr oder weniger unvollkommen sey, wobei aber wieder die Willkür und der Widerspruch der gewöhnlichen Vorstellung zum Grunde liegen, dass die Elektricitüt, als ein materielles Flnidum, welches sich in der dichten Masse der Metalle ohne merklichen Widerstand ausbreitet, nach seiner Emission aus den letzteren beim Fortgange durch die Flüssigkeit mehr oder weniger gehemmt und zurückgehalten werde. Nach unserer Ansicht ist dagegen das 
Leitungsvermögen der Flüssigkeit nichts anderes, als die polare Thätigkeit derselben, durch welche die an der Oberfläche im Contact mit dem Metalle erzeugte Erregung zur Tendenz des Chemismus sich durch die Masse des flüssigen Leiters hindurch verbreitet, und es ist damit von selbst klar, dass diese Masse, welche ihre Erregung nicht als Folge des unmittelbaren Contacts, sondern nur als Mittheilung der primitiven Thätigkeit an der Oberfï̈che, empfängt, die Gesammterregung und somit die elektrische Spannung um so mehr schwächen und retardiren müsse, je mehr die Masse theils durch die Zahl der flüssigen Schichten bei gleicher Höhe, theils auch durch die Höhe der einzelnen Schichten bei gleicher Zahl derselben anwächst. - Wenn die Flächengrösse der Elemente in zwei gesonderten Sänlen verschieden, aber die Zahl und Höhe derselben, so wie die anderweitigen Bedingungen in beiden gleich sind, so hat man, ungeachtet das Quantitative der Erregung in der Säule mit den grösseren Platten auch nothwendig grösser als in der andern seyn muss, bis jetzt bekanntlich doch keinen Unterschied der elektrischen Spannung an beiden bemerkt und daraus den überall gelüufig gewordenen Schluss gezogen, dass das Elektrometer nur das Intensive, nicht aber das Quantitative der elektrischen Erregung der Säule anzeige. Dass die Aussage des Instruments in jeder Beziehung nur relativ sey, verstelit sich ohne alle Erwähnung von selbst; aber um so weniger wäre gerade bei dieser Relativität die Möglichkeit zu begreifen, mit welcher, während das aus der innigsten Durchdringung beider Factoren gebildete Product in seiner vollständigenEinheit auf das Instrument einwirkt, letzteres nur im 
Verhältnisse des einen, der Wirklichkeit nach gar nicht getrenrt existirenden, sondern nur der Vorstellung nach gesonderten Factors allein afficirt werden sollte. So wie der mit irgend einer Massenbewegung zusammengehörige Eindruck allemal das vereinigte Resultat der Geschwindigkeit und der bewegten Masse zugleich seyn muss, so kann unmöglich auch in irgend einem einzelnen Falle die Divergenz des Elektrometers für etwas anders als das aus der Intensität und Quantität der Erregung zugleich hervorgegangene Product der Einwirkung auf dasselbe angesehen werden, und der obige Schluss ist nothwendig in jedem Falle unrichtig, während die Umstände, welche zu seiner Entstehung Veranlassung gegeben haben, sich auf zwei Fälle werden zurückführen lassen. Es ist nümlich eines Theils anzunehmen, dass die Beobachtung selbst, nach welcher unter sonst gleichen Umständen bei der variirenden Flüchengrösse der Elemente die Divergenz des Elektrometers constant bleiben soll, sey es in Hinsicht der Schärfe oder in Hiusicht des Umfanges, bis jetzt noch stets mangelhaft gewesen ist und dies wird aus den folgenden Gründen sehr wahrscheinlich. Dass die Quantilät der Erregung zwar mit der erregten Fläche, aber nicht im uumittelbaren Verhältnisse derselben wachse ist a priori gewiss. J eder erregte Punkt strebt den gleichnamig erregten abzustossen und die vereinigte Thätigkeit solcher gleichnamig erregter Puncte ist in Folge dieser gegenseiligen Störung ungleich geringer, als die directe Summe ihrer absoluten 'Thätigkeiten. So hat sich mir durch frühere Untersuchungen als Geselz wahrscheinlich gemacht, dass die elektromagnetische Erregung nur im Verhältnisse der BiquaK 
dratwurzeln der erregten Flächen wachse. (S. Kastner's Archiv, B.III. S. 13 ff.) Nehmen wir nun in Ermangelung bestimmter Ermittelungen über die im Verhältnisse der Flächengrösse erfolgende Zunahme der elektrischen Erregung in der ungeschlossenen Kette einstweilen dasselbe als Gesetz dafür an und setzen zugleich, was ebenfalls noch aus Mangel an Fundamentalversuchen ungewiss aber doch sehr wahrscheinlich ist, dass sich die Chorden der Elongationswinkel in den elektromagnetischen Divergenzen, oder bis zu Winkeln von etwa $30^{\circ}$, diese Winkel selber, nahe wie die Cubikwurzeln aus den wirklichen Erregungswerthen verhalten, so folgt, dass jene Divergenzen nur wie die Wurzeln des 12 ten Grades der elektrisch erregten Flächen, also in einem Verhältnisse zunehmen, bei welchem die Unterschiede der Flächen bereits sehr bedentend seyn und die Unterschiede der elektrometrischen Divergenzen dennoch so klein bleiben können, dass sie bei der Unvollkommenheit unserer Elektrometer theils gar nicht wahrzunehmen sind, theils sehr leicht übersehen werden können. Andererseits aber ist eben so wenig zu vergessen, dass mit der Erweiterung der erregten Fläche eine grössere Annäherung zum chemischen Process und mit dem dadurch gegebenen höheren Grade der Befriedigung eine Abnahme der in der elektrischen Spannung äusserlich erscheinenden Tendenz zu demselben bedingt werde, so dass, selbst wenn jene Beobachtung in der That hinlänglich und genau gewesen seyn sollte, man den Erfolg allein nur aus diesem Gesichtspunkte würde betrachten dürfen, dass, indem mit der Ausbreitung der Thätigkeit durch einen grösseren Flächenraum ihr Fortschritt zum wirklichen Beginn 
des Chemismus realisirt werde, die elektrische Erregung, als die nach Aussen hin sich manifestirende Tendenz zum chemischen Effect, gerade durch jene erhöhte Stufe der Verwirklichung dieses Effects selber um eine solche Grösse herabsinke, vermöge welcher dieser Reflex nach Aussen hin weder vermehrt noch vermindert, oder wenigstens nur um ein so Geringes grösser gemacht werde, dass er der Wahrnehmung innerhalb beträchtlicher Gränzen ganz entzogen bleibe. Dies ist derselbe Grund, nach welchem in der Berührung zwischen zwei Stoffen, die ihrer Natur nach von gegenseitiger chemischer Thätigkeit entfernter sind, als zwei andere, bekanntlich eben deshalb die elektrische Erregung stärker ist, als bei den letzteren; wie darauf zugleich die Möglichkeit und nach Ritter's Versicherung die wirklich durch ihn gemachte Erfahrung beruht, dass von zwei unter gleichen Dimensionsverhältnissen und Bedingungen, aber mit verschiedenen Flüssigkeiten zusammengesetzten Batterien, diejenige, deren Flüssigkeit von schwächerer chemischer Wirkung ist, vor der Schliessung stärkere Elektricität als die andere giebt, eben weil mit der kräftigeren chemischen Action schon vor dem Geschlossenseyn der Kette ein Theil der Thätigkeit, welcher sich ausserdem nur durch das Streben zum Chemismus als elektrische Erregung offenbart, bereits vollständig in den letzteren übergegangen ist.

$$
2 .
$$

Mit der ersten geringeren Zahl der Elemente wachsen alle Functionen der Säule; mit der Steigerung jeder einzelnen Function ist da noch die Erhöhung

K 2 


\section{8}

aller übrigen verbunden und so wächst mit dem durch eine grössere Zahl von Elementen gesteigerten chemischen Effect in den Berührungsflächen der Metalle und der Flüssigkeit bei geschlossener Kette ’anfänglich auch die Tendenz zu gleichem Effecte in allen übrigen Massenpuncten der Kette, d. h. ihr Magnetismus. Nach Massgabe der Flächengrösse der einzelnen Elemente ist aber früher oder später mit einer grösseren oder geringeren Menge derselben eine bestimmte Gränze gegeben, auf welcher die Realisirung des analytisch chemischen Effects bereits in solchem Grade erreicht ist, dass die im Magnetismus ausgesprochene.Tendenz der Masse zu demselben Effect matter zu werden beginnt, und von diesem Puncte an nimmt sie mit der Vermehrung der Elemente immer mehr ab, bis sie sich endlich in der Gesammtthätigkeit aller Elemente der Kette schwächer als in einem einzelnen derselben zeigen kann, wenn es an und für sich geschlossen wird und man sieht deutlich, dass der magnetische Effect einer Säule auf diese Weise mit der Vermehrung der ZahI ihrer Elemente einem immer tiefer herabsinkenden Werthe fortwährend genähert werden könne, ohne das absolute Null vielleicht jemals zu erreichen. Diese Abuahme des magnetischen Effects, welche eine Folge der Vergrösserung des chemischen ist, muss aber noch von derjenigen, welche in der Verminderung der Gesammtthätigkeit der Säule überhaupt begründet ist, unterschieden werden. Wie anfünglich alle Functionen der geschlossenen Kette gemeinschaftlich zunehmen, so nehmen endlich auch, nachdem für jede einzelne Function der Punct ihres Maximums überschritten worden, alle mit der in der Menge der Elemente immer 
mehr überhand nehmenden und vorherrschend werdenden Trägheit dev Masse gemeinschaftlich wiederum ab und werden in ein Minimum zusammenschwinden miüssen, das endlich, wenn zwar nicht absolut, doch für die Wahrnehmung unfehlbar zu Null werden müsste. Nur mit der einzig und allein vergrössertex Arealdimension der geschlossenen Kette scheint die magnetische Thätigkeit eben so fortwährend zu wachsen, wie die elektrische Spannung der ungeschlossenen Kette mit der Longitadinaldimension unaufhörlich za. nehmen zu müssen scheint. Zwar wird diese Zunahme des Magnetismus durch die mit der vergrösserten Fläche auch grösser werdende Masse gleichfalls immer mehr retardirt werden, aber ohne dass der Fortschritt selbst dadurch jemals aufhörte oder noch weniger rückgängig gemacht werden könnte. Ob in Bezug auf diesen Fortschritt meine aus der Erfahrung durch Vergleichungen von der einfachen bis zux 144 fachen Flächengrösse hergeleitete Bestimmung; dass die Zunahme der absoluten Wirkung im Verhältnisse der Biquadratwurzeln der Flächen (abgesehen von den goniometrischen Ablenkungswerthen) erfolge, auch nach Anlegung eines grösseren Massstabes allgemeine Bestätigung finden, ob sie das eigentlich zum Grunde liegende Gesetz oder schon eine durch den Einfluss der Masse erzeugte Modification desselben ausspreche, darüber, so wie über so vieles andere hieher Gehörige, was bis jetzt noch von niemand dem Experimente ernstlich unterworfen worden ist, müssen zukünftige Untersuchungen entscheiden. 
3.

Dass in der geschlossenen einfachen Kette die chemische Thätigkeit mit der Vergrösserung ihrer Flächeudimensionen wachse, ist so wenig in Zweifel zu ziehen, als die mit der vergrösserten Zahl der Elemente erfolgende Zunahme der elektrischen Tension; núr darf von einer einfachen Kette, ihre Oberfläche sey übrigens noch so gross, keine Zersetzung der Flüssigkeit im Gasapparate erwartet werden, weil durch letzteren kein Contact der Metalle und also auch keine reelle Schliessung der einfachen Kette vermittelt wird. Wenn die Kette aber nur aus wenigen und selbst nur aus zwei Elementen zusammengesetzt ist, so zeigt auch der Gassapparat die mit der erweiterten Flächengrösse der Elemente verbundene Zunahme der chemischen Thätigkeit offenbar, indem bei derselben Zahl der Elemente unter sonst gleichen Bedingungen die Gasentwickelung das eine Mal ausbleibt, das andere Mal Statt findet, je nachdem die Fläche der Elemente nur klein ist oder eine entsprechende Grösse hat. An einer Kette, deren Elemente nur von sehr geringem Durchmesser sind, oder in welcher die flüssigen Schichten von den Metallen nur mit sehr kleiner Oberfläche, z. B. nur mit Spitzen, berührt werden, ist dagegen auch bei einer beträchtlichen Anzahl von Elementen und einer elektrischen Spannung, welche der Angabe des Elektrometers zufolge scheinbar nicht geringer ist, als an einer gewöhnlichen unter gleichen Bedingungen zusammengesetzten Säule mit breiten Platten, die chemische Thätigkeit nach der Schliessung noch so schwach, dass keine Spur von Luftentbindung im Gasapparate Statt findet, die sich ausserdem bei viel weniger und 
breiteren Platten und unter einer geringeren elektrischen Spannung schon mit Lebhaftigkeit darzubieten vermag. Nach den gewöhnlichen Vorstellungen soll diese gehemmte chemische Thätigkeit aus der Annahme eines verminderten Zuflusses der fingirten elektrischen Materie begreiflich werden, obgleich es nicht deutlich ist, wie bei einer solchen Verminderung die elektrische Spannung dennoch eben so gross bleiben, noch wie durch das hypothetische Fluidum das Gas überhaupt und insbesondere in solcher Abhängigkeit vom vermehrten oder verminderten Zuflusse erzeugt werde, während das Verständniss des Erfolgs sich mit unserer Ansicht anf eine ungezwangene, Weise und wie von selbst darbietel. Selbst wenn die Spannung bei kleineren Platten nicht geringer als bei einer gleichen Zahl von grösserer Breite wäre, so würde dennoch die Ungleichheit der chemischen Thätigkeit nach unserer Theorie nicht paradox seyn, weil uns die elektrische Spannung nur die Tendenz zum Chemismus ist, die begreiflich sehr wohl in verschiedenen Fällen gleich seyn kanu, ohne dass der letztere selbst deshalb nothwendig in gleichem Grade Statt finden muss, so wie bekanntlich umgekehrt einem gleichen chemischen Verhalten in verschiedenen Fällen ein ungleicher elektrischer Spannungsgrad und selbst der grösseren chemischen Thätigkeit die geringere elektrische Tension vorausgehen kann. Dass aber die elektrische Spannung bei geringerer und grösserer Ausdehnung der Fläche der Elemente unter sonst gleichen Bedingungen nicht absolut als gleich angesehen werden könne, wenn sie auch in der Beobachtung am Elektrometer als gleich erscheinen sollte, davon ist bereits oben die 
Rede gewesen: Was es nun damit auch für eine Bewandniss haben möge, so geht in jedem Falle aus dem dort Gesagten wie überhaupt aus dem Ganzen unserer Ansicht unmittelbar hervor, dass mit der erweiterten Fläche der Elemente die chemische Thätigkeit eben so an Kraft und Erfolg zunehmen müsse, wie sie umgekehrt unter sonst gleichen Umständen mit der verkleinerten Fläche abnehmen und zu einem kaum oder gar nicht wahrnehmbaren Minimum hinabsinken muss. Die elektrische Spannung vor dem Geschlossenseyn der Kette und die chemische Action nach demselben, beide sind einzeln genommen Producte aus den beiden Factoren, deren einer durch die Zahl der Elemente, der andere durch die Flächengrösse derselben gebildet wird. Aber indem das eine Product nur die Tendenz zur Realisirung des andern ist, wächst jencs als elektrische Spannung vorzugsweise nur mit dem steigernden Longitudinalfactor, dieses hingegen nimmt gleichmässiger nach beiden Richtungen mit dem steigernden so wie insbesondere mit dem die eigentliche Realisirung des Processes bedingenden Arealfactor zu. Die Thätigkeit einer aus sehr vielen, aber zugleich sehr schmalen Elementen zusammengesetzten Kette gleicht dem Producte einer Bewegung, die zwar mit grosser Geschwindigkeit vollführt wird, der es jedoch zur rechten Wirkung an Masse fehlt, so wie umgekehrt eine aus einer geringen Zahl breiter Elemente bestehende Kette in ihrer Action durch das Product der Bewegung einer grossen Masse, der es an Geschwindigkeit mangelt, versinnlicht wird, aber nur auf eine schlechthin metaphorische Weise, so dass in diesem Vergleiche die bewegte Masse nur das Relativ-Quantitative in der 
Thätigkeit der Kette, nicht aber ein durchaus fabelhaftes elektrisches Fluidum, noch sonst irgend etwas materielles und am wenigsten die wirkliche sichtbare Masse der Kette repräsentirt, denn diese ist es gerade, welche in ihrer mit der wachsenden Zahl der Elemente immer mehr der Erregung widerstrebenden Trägheit, auch bei einer Säule von noch so grosser Flächendimension, unter dem eintretenden Uebergewichte des Lougitudinalfactors, die chemische Wirksamkeit und alle übrige Functionen während der Schliessung eben so beschränkt und endlich vollends hemmt, wie sie vor der Schliessung auch die elektrische Spannung der Säule beträchtlich retardirt. Die Masse der Säule nimmt zu im vollständigen zusammengesetzten Verhältrisse der longitudinalen und Flächendimension, die Erregung aber in einem zwar gleichfalls durch beide Factoren bestimmtem, aber sehr viel kleinerem Verhältnisse, so dass, nachdem mit der fortwähiend durch eine kleinere oder grössere Zahl von Elementen hindurch gesteigerten Erregung die Masse der Süule bis zu einem gewissen Puncte beherrscht worden ist, diese endlich umgekehrt wieder ein Uebergewicht über die Erregung zu erlangen beginnt und sie von da an eben so fortwährend immer mehr bis zur gänzlichen Verdrängung aller Functionen beherrscht. Mit diesem Wendepuncle fällt also das Maximum der Erregung und der durch sie erzeugten Functionen der Kette zusammen und es ist vermöge des Vorhergehenden von selbst klar, dass diese Maxima in verschiedenen unter sonst gleichen Bedingungen construirten Säulen um so höher hinaufreichen, d. h. erst mit einer um so grösseren Zahl von Elementen eintreten werden, je grösser 


\section{4}

die Fläche der letzteren ist; jedoch wieder so, dass der Fortschritt nicht im eigentlichen geometrischen, sondern nur in einem diesem angenäherten und um so mehr retardirten Verhältnisse Statt findet, je grösser die Arealdimensionen 'selbst sind. Es werden z. B, bei drei unter sonst gleichen Bedingungen zusammengesetzten Säulen, deren Elemente der Flächengrösse nach sich wie die Zahlen 1, 10, 100 verhalten, die respectiven Höhen der Säulen, mit denen die Maxima einer und derselben Function errèicht sind, zwar mit jenen Zahlen wachsen, aber sich doch nur annäherungswèise mit immer zunehmender Retardation wie jene Zahlen selbst verhalten, so dass das Verhältniss díeser Höhen in der 1 sten und 2 ten Säule kleiner als $\}$ das Verhältniss 1: 10, das in der 1 sten und 3 ten kleiner als $1: 100$ und insbesondere wieder das letztere noch mehr als das erstere von (dem Verhältnisse der Flächengrösse entfernt seyn wird. - Es ist aber auch ferner gewiss, dass bei einer und derselben Flächengrösse, aber einem verschiedenen Grade der ursprünglichen Erregungsintensität, Zwischen der Flüssigkeit und den Metallen, die Lirregung gegen die Reaction der Masse sich um so kräftiger behaupten und sie um so länger beherrschen werde, das heisst, dass die Maxima der Functionen erst mit einer um so grösseren Zahl von Elementen eintreten, oder um so höher liegen werden, je höher jener ursprüngliche Erregungsgrad selbst ist. Bei zwei unter denselben Dimensionsverhältnissen, aber mit verschiedenen Flüssigkeiten zusammengesetzten Säulen, von denen die eine z. B. mit Kochsalzlösung, die andere unter verhältnissmässiger Concentration mit Salmiaklösung geschichtet ist, werden die Maxima der Functionen in der mit der chemisch krüf- 
tigeren Flüssigkeit, der Salmiaksolution, construirten Batterie verhältnissmässig höher als in der andern liegen. - Endlich aber ist es keinem Zweifel unterworfen, dass in einer und derselben Säule bei verschiedenen Functionen, wie die des Erschütterungsschlages, der Zersezzung der Flüssigkeiten durch Gasentbindung, der Zersetzung der Luft durch Funkenerzengung, der Temperaturerhöhung des schliessenden Bogens, der Reduction und der mit oder ohne Verbrennung verbundenen Oxydation basischer Stoffe, auch die jedesmalige Höhe des zugehörigen Maximums nicht eine und dieselbe bleiben, sondern für jede einzelne dieser Functionen auch eine verschiedene werden und mannichfaltigen Abänderungen unterworfen seyn müsse. Dies ist nämlich nothwendig, weil bei den verschiedenen Functionen die Kette auch durch verschiedene Bogen geschlossen wird und mit jedem andern schliessenden Bogen auch das Verhältniss der Erregung und der erregten Masse verändert, also die ganze geschlossene Säule selbst nicht eigentlich dieselbe bleibt, sondern jedes Mal eine andere wird, in der mithin, gerade so wie es bei verschiedenen Säulen Statt findet, auch die jedesmalige Höhe des Maximums der Function eine andere werden muss. Eben daher aber hat es sehr grosse Schwierigkeiten, oder es ist vielmehr ohne mannichfaltige Disjunctionen und ohne Berücksichtigung einer Menge sehr complicirter Bedingungen gar nicht möglich, im Allgemeinen zu entscheiden, für welche der verschiedenen Functionen bei einer gegebenen Säule die Maxima höher, für welche sie niedriger und in welchem Verhältnisse der Höhe und Entfernung von einander sie liegen, indem jede einzelne Function selbst 
wieder unter den mannichfaltigsten Bedingungen und in den verschiedensten Graden Statt finden kam, deren jeder einzeln für sich wieder in einer bestimmten Höhe der Säule sein eigenes ihm allein und ausschliesslich zugehöriges Maximum besitzen muss. Gesetzt man findet an einer Säule mit einem Gasapparate das Maximum der Gasentbindung in der Höhe einer bestimmten , Zahl von Elementen. Füllt man nun denselben Gasapparat, unter dersélben Entfernung der Polardräthe, statt der bisherigen Flüssigkeit mit einer andern, die, wie man gewöhnlich sagt, ein besserer Leiter ist, das heisst hier, welche eine grössere Thätigkeit der Säule in Anspruch nimmt, als jene, z. B. statt einer bisher gebrauchten Kochsalzlösung jetzt mit verdünnter Schwefelsüure, so wird die Gasentbindung in allen Graden, welche sie mit der successiven Einwirkung einer immer grösser werdenden Zahl von Elementen durchlänft, und also auch in ihrem Maximum, stärker seyn als vorher; aber dieses Maximum liegt eben deshalb, weil die Flüssigkeit jetzt eine grössere Action der Kette in Anspruch nimmt, ohne selbst Gelegenheit zu unmittelbarer Vermehrung der Erregungssumme zu finden, auch tiefer und tritt bereits mit einer geringeren Zahl von Elementen ein, als das vorige. Dasselbe wird erfolgen, wenn man die Polardrüthe melır als vorher einander nähert; dagegen wird bei einer grösseren Entfernung derselben, oder wenn man die Flüssigkeit mit einer minder chemisch kräftigen vertauscht, z. B. statt Kochsalzlösung nur Brunnenwasser nimmt, die Action zwar im Ganzen schwächer, aber das Maximum derselben dafür höher als anfangs hinauf gerückt werden. - Etwas ganz Aehnliches num, 
wie das, was so eben der Gasapparat gezeigt hat, findet auch Statt in Absicht lauf das Maximum des Erschütterungsschlages, so wie aller übrigen Functionen. Man hat die Commotion, welche unser Körper erführt, wenn er die Säule schliesst, von jeher dem Durchgange einer elektrischen Materie durch denselben zugeschrieben; ; aber abgesehen davon, dass diese Vorstellung auf einer blossen Fiction berulit, so fehlt es dabei durchaus an gehöriger Rechenschaft über den Umstand, dass der Schlag bei der Berührung mit trockenen Ḧ̈nden grossentheils oder ganz ausbleibt, und dass er dagegen um so kräftiger erfolgt, je vollkommner die Uberhaut der zunächst mit der Säule in Verbindung gesetzten Theile des Körpers von Flüssigkeit durchnetzt, je chemisch kräftiger diese Flüssigkeit, je grösser die benetzte Fläche und je vollstündiger sie in allen Puncten mit einem Metalle armirt ist, durch welches zunächst die Kette auf den Extremen berührt und geschlossen wird. Wenn dabei die Nothwendigkeit des Netzens der Oberhaut auf den Mangel an Leitungsfähigkeit der letzteren geschoben wird, so lässt sich dagegen andererseils die Möglichkeit von dem, was eine entschiedene Thatsache ist, nicht begreifen, dass sonst schon ein üusserst schwacher Grad von elektrischer Erregung durch die trockene Hand abgeleitet und dass eben so jeder Pol der isolirten Säule durch die kleinste Berührung mit völlig trockener Fingerspitze augenblicklich entladen werde. Diese Widersprüche sind schon mehr als hinreichend, die völlige Unzulänglichkeit jener Vorstellung ausser Zweifel zu setzen, während es im Simue unserer Ansicht kaum noch einer Auseiuandersetzung zum Beweise 
dessen bedarf, worin die Action 'der galvanischen Kette auf den Körper, wenn er in den geschlossenen Kreis derselben tritt, der ersten Einwirkung nach eigentlich bestehe. So gewiss die elektrische Spannung der ungeschlossenen Säule nur die Tendenz ihrer eigentlichen Thätigkeit im geschlossenen Zustande ist, und so gewiss von einer bloss polaren Fortleitung jenes schwachen bloss äusserlichen Reflexes da nicht eigentlich mehr die Rede seyn kann, wo die innerste, lebendigste Regsamkeit des Chemismus bereits in vollendete Realität übergegangen ist, so entschieden ist auch dasjenige, was im Kreise der Kette dem menschlichen und thierischen Körper widerfährt, die Folge einer in allen Puucten auf den synthetisch analytischen Effect des Chemismus hingerichteten energischen Wechselerregung zwischen der Batterie und dem in ihren geschlossenen Kreis eingetretenen Körper. Der letztere mit der durchnetzten, metallisch armirten Oberhaut empfängt die Erregung und wirkt erregend zurück, wie irgend ein anderes flüssiges, durch Metall armirtes Element der Kette und so wie bei letzterem ist daher auch die Einwirkung auf den Körper um so kräftiger, je entschiedener und inniger die Berührung zwischen Flüssigkeit und Metall und je grösser die Ausdehnung ist, welche den im Contact begriffenen Flächen des Metalls und des Körpers als eines Leiters zweiter Classe gegeben wird. - Das Maximum des Erschütterungsschlages ist daher auch als das Maximum derselben modificirten Function zu betrachten, welche bei der Wechselwirkung zwischen der Säule und einem Gasapparate erfolgt; wie die Action bei letzterem durch Auwendung einer chemisch kräftigern Flüssigkeit, 
oder durch grössere Nähe der Polardräthe erhöht, das Maximum dieser Action aber eben dadurch an der Säule tiefer hinabgerückt wird, indem es schon mit einer geringeren Zahl von Elementen als früher bei nicht so kräftiger Thätigkeit eintritt, so wird auch der Schlag durch das Anfeuchten der Haut an den mit den Extremei der Säule in Berührung tretenden Stellen des Körpers und durch grössere Anuäherung dieser Stellen zu einander, indem die Erschütterung nur durch kleinere Theile des Körpers hindurch geleitet wird, bei weitem kräftiger, während das Maximum desselben zugleich tiefer an der Säule hinabsinkt; wie im Gegentheil die Gasentbindung schwächer wird und ihr Maximum höher hinauf steigt durch Anwendung einer mehr indifferenten Flüssigkeit oder durch grössere Entfernung der Polardräthe im Gasapparate, so wird auch der Erschütterungsschlag schwächer und sein Maximum tritt erst mit einer grösseren Zahl von Elementen ein durch das Netzen der Haut mit chemisch unkräftigerer Flüssigkeit und durch grössere Entfernung der mit den Polen der Säule in Verbindung gesetzten Theile, wenn z. B. die Erschütterung durch den ganzen Körper von einer Hand zur andern oder durch eine Kette von zwei oder mehreren Personen hindurch geleitet wird. $\mathrm{Ob}$ also das Maximum der Gasentbindung an einer und derselben Säule höher oder niedriger liege, als das des Erschütterungsschlages, lässt sich im Allgemeinen nicht bestimmen, weil nach Massgabe der besondern Bedingungen das eine so gut als das andere Statt finden kann, und eine gleiche Relativität gilt in Bezug auf die Bestimmung der Maxima aller übrigen Functionen der geschlossenen Säule; wie über= 
haupt mit dieser ganzen Materie ein bis jetzt nach Ritter leider noch von niemand betretenes Feld zu den mannichfaltigsten Uutersuchungen dargeboten ist, die in theoretischer und praktischer Hinsicht von der grössten Wichtigkeit und ergiebig an Aufschlüssen seyn müssen, denen die Lehre vom Galvanismus überhaupt, so wie ohne Zweifel vieles von dem, was hier nur noch als eine der vollständigeren experimentalen Unterstïtzung ermangelnde Conjectur über den Gegenstand beigebracht ist, Berichtigung und grössere Vollendung zu verdanken haben werden.

Die sämmtlichen Gegenstände, deren Erörterung bis jetzt den Inhalt des gegenwärtigen Abschnittes gebildet hat, stehen in dem innigsten und genauesten Zusammenhange mit den Phänomenen, deren Charakter im Allgemeinen wieder nur nach Massgabe einer einseitigen Vorstellung, unter welcher sie in allen Modificationen, von der Kleistischen Verstürkungsfiasche an bis zui Ritterschen Ladungssäule hinauf betrachtet worden sind, durch das Prädicat der elektrischen Ladung bezeichnet worden ist. Indem man in der Haupthätigkeit der geschlossenen Kette nur ein Ausströmen des fingirten elektrischen Fluidums erblickte, sah man auch die Fühigkeit eines Körpers, vermüge deren er die galvanische Kette zu schliessen, an ihrer Thätigkeit Theil zu nehmen, sie zu unterhalten und selbst in Folge dieser Wechselwirkung mehr oder minder sichtbare Veränderungen im Kreise derselben zu erleiden vermag, lediglich nur als ein Vermögen des Körpers an, die Elektricität fortzuleiten, ungeachtet dieses Fortleiten der Elektricitüt, als einer bloss polarun Teudenz und die. Theilnahme am reellen Processe 
der geschlossenen Kette wenn auch verwandte, doch ganz von einander verschiedene Thätigkeiten sind, und so wie man die vorhin in diesem Abschnitte erörterten Wirkungen, so weit sie beachtet waren, nur als Folge eines unvollkommnen elektrischei Leitungsvermögens nehmen zu können meinte, so betrachtete man bis jetzt auch die Phänomene der sogenannten elektrischen Isadung nur als Resultate einer durch eine solche unvollkommene Leitung bewirkten Anhäufung des hypothetischen Fluidums im Leiter zweiter Classe, den maî sonach als einen mit elektrischier Materie geladener Körper ansah und dabei auf die Thatsache sich berief, dass derselbe auf ent gegengesetzten Seiten die gleichnamigen Elektricitäten der Pole zeige, mit denen er eine Zeit lang in Verbindung gesetzt worden sey. Diese Ansichten bedürfen bei der ein für alle Mal erkannten Nichtigkeit der Quelle, aus der sie mit so vielen anderen ähnlicher Art hervorgegangen sind, keiner besondern Widerlegung mehr; aber die aufmerksame Betrachtung der Thatsachen an sich ist dafür desto wichtiger, uh durch sie zu dem so sehr nöthigen festen Gesichtspunkte zu gelangen, an welchem es bis jetzt hinsichtlich dieser Erscheinungen noch mangelt. Ein Hülfsmittel vom unschätzbarsten Werthe zu diesen Untersuchungen, welche noch ein weites Feld vielleicht mit manchen wichtigen, kaum geahnten Lrnten darbieten, ist dêr Elektromagnetismus. Die leisesten und rorübergehendsten Grade elektrischer Erregungen, die man sonst kaum Zeit hatte, mit dem Condensator zu untersuchen und nur etwa aus täuschenden physiologischen Wahrnehmungen dem Daseyn und der Art nach zu erkennen vermochte, sind jetzt im 


\section{2}

Conflict mit der Magnetnadel Gegenstände der unzweideutigsten Beobachtung und die wesentlichsten Punkte der folgenden Erörterungen verdanken daher auch ihre Bestimmung solchen unzweideutigen, durch die magnetische Boussole vermittelten Untersuchungen.

Wenn man das eine Extrem einer Ritter'schen Ladungssäule, die aus etwa 50 Wechselschichtungen drei bis vierzölliger Kupferplatten und feuchter Pappscheiben besteht, durch metallische Leitung mit dem einen Pol einer kräftigen, aus 100 bis 200 Plattenpaaren zusammengesetzten galvanischen Kette $G$ in Verbindung bringt, so wird die Polarelektricität der letzteren augenblicklich durch das ganze Contiguum dẹr Ladungssäule, welche mit $L$ bezeichnet werde, fortgepflanzt. Das Extrem von $L$, welches mit $G$ verbunden ist, möge durch $\gamma$, das andere durch $\lambda$ bezeichnet werden. Nach den bereits im vorhergehenden $\mathrm{Ab}$ schnitte gemachten Erörterungen darf hierbei die Art, nach welcher die Fortleitung der Elektricität durch $L$ Statt findet, als hinlänglich bekannt und geläufig vorausgesetzt werden. Wenn z. B. $L$ mit dem positiven, in eine Kupferplatte endigenden Pole von $G$ verbunden wird, so verhalten sich die beiden, in directe Verbindung gesetzten Endplatten von $G$ und $L$ wie eine einzige Kupferplatte, die auf ihrer nach $G$ hingerichteten Seite positiv, auf der andern nach $L$ hin liegenden dagegen negativ ist. Die nun folgende flüssige Schicht in $L$ ist auf dem Extrem, mit welchem sie der eben genannten Platte anliegt, positiv, auf dem entgegengesetzten negaliv; die folgende Kupferplatte ist abermals auf der nach $G$ hin gerichteten Seite positiv, auf der entgegengesetzten negatir und so jede der übri- 
gen feuchten Schichten und Kupferplatten in $\boldsymbol{L}$, bis auf die äusserste Schlussplatte $\lambda$, welche nun, so wie vorhin die Endplatte in $G$ vor der Verbindung mit $L$, durch ihre ganze Masse hindurch als in positiver Erregung begriffen gesetzt werden muss, und am Elektrometer eine positive Dirergenz hervorbringt. Eine gleiche positive Divergenz bewirkt aber auch jede der übrigen Kupferplatten in $\boldsymbol{L}$, wenn sie mit dem Elektrometer verbunden wird, indem sie, obgleich auf verschiedenen Seiten in entgegengesetzter Erregung begriffenn, dennoch, so wie jedes Plattenpaar der ursprünglichen Kette, in jedem Falle nur die überwiegende Seite der elektrischen Erregung nach Aussen kehrt und durch das Elektrometer allein sichtbar werden lässt. Wird dagegen von $\boldsymbol{L}$ das eine Extrem $\gamma$ mit dem negativen, in eine Zinkplatte endigenden, Pol von $G$ in vollkommen leitende Verbindung gesetzt, so pflanzt sich eben so in einem Moment die negativ elektrische Erregung von diesem Pole durch die ganze Lünge von $\boldsymbol{L}$ bis $\lambda$ hin fort, die Schlussplatte von Zink in $\boldsymbol{G}$ verbunden mit der kupfernen Endigungsplatte $\gamma$, bilden ein einziges Plattenpaar, das, so wie jedes übrige, nach $G$ hin negativ, nach $L$ hin positiv ist; eben so ist jede flüssige Schicht und jede Kupferplatte in $\boldsymbol{L}$ nach denselben Richtungen negativ und positiv, bis auf die äusserste $\lambda$, Welche als ganz negativ anzusehen ist und eben so das Maximum der negativen Erregung, wie jede der übrigen Platten ein Uebergewicht derselben, am Elektrometer versichtbart.

Sind $G$ und $L$ anfänglich gehörig isolirt, so wird ein Elektromeler, das an dem $m$ it $L$ verbundenen Pole von $G$ angebracht ist, wie gewöhnlich nur L. 2 
schwach afficirt, wird der andere $\mathrm{Pol}$ von $G$ ableitend berührt, dann divergirt, der Regel gemäss, das Elektrometer um vieles staiker und lebhafter; wird nun aber auch von $L$ das Extrem $\lambda$ mit der Erde in leitende Verbindung gesetzt, so fullt in dem nämlichen Augenblicke dasselbe Elektrometer plötzlich zusammen und bleibt, so lange die Verbindung jenes Extrems mit der Erde fortdauert, beständig ohne Divergenz, so als wäre der Pol von $G$, mit dem es zúsammenhängt, unmittelbar selbst mit dem Erdboden verbunden worden. Dies beweist zur Genüge, dass dasjenige, was geschieht, wenn die beiden Extreme von $L$ zugleich mit den beiden Polen von $G$ leitend verbunden werden, nicht auf einen in $L$ Statt findenden Mangel an elektrischer Leitungsfähigkeit geschoben werden kann; wenigstens würde, wenn durch die Annahme eines solchen Mangels wirklich etwas begreiflich zu werden schiene, dēr Widerspruch des solchergestalt Angenommenen gegen dasjenige, was als Thatsache besteht, dafür nun als eine so viel grössere Unbegreifliehkeit herbei gezogen worden seyn. Wir müssen also zum gründlicheren Verständnisse dessen, wàs erfolgt, wenn von $L$ das eine Extrem $\lambda$ mit dem einen, z. B. dem positiven $\mathrm{Pol}$, und das zweite $y$ mit dem negativen $\mathrm{Pol}$ von $G$ in leitende Verbindung gebracht wird, die Phänomene selbst schärfer ins Auge zu fassen suchen.

oiw Zuerst ist es entschieden und mit dem Ganzen unserer Ausicht in vollkommenstem Einklange, dass dadurch in $L$ qualitativ eine eben solche Thätigkeit thervorgerufen werde, als sie in $G$ ursprünglich Statt findet. Jede einzelne Metallplatte in $L$ repräsentirt ein Plattenpaar in $G$, sie ist rach denselben Richtun- 
gen, wie jenes, auf der einen Seite negatiy, anf der andern positiv und nach der negativen Seite hin entbindet sich eben so, wie nach dem negativen Zink in $G$ hin, das Oxygen; nach der positiven eben so, wie nach dem positiven Kupfer in $G$ hin, das Hydrogen. Wenigstens ist die Tendenz zu dieser Thätigkeit durch empfindiiche Reagenzen in der ganzen Kette allemal nachzuweisen und bei hinlänglicher Kräftigkeit des Apparats tritt sie selbst völlig sichtbar hervor, wie dieses auch durch die Erscheinungen in einem zusammengesetzten Gasapparate, der im Grunde nichts anderes als eine Ladungssäule in Form eines Trogapparates darstellt, zur unmittelbarsten Anschauur g gebracht wird; wenn man nümlich die Polardräthe des Gasapparats in einer langen mit der Flüssigkeit angefüllten Glasröhre weit aus einander rückt und in den Zwischenraum mehrere Dräthe in kleinen Entfernungen von einander vertheilt, so sieht man an allen Drathenden, welche der Regel gemäss negativ seyn müssen, das Oxygen als Gas oder durch den Erfolg der Oxydation, und nach den entgegengesetzten Extremen hin, die positiv seyn müssen, das Hydrogen auftreten. Um aber auch an der gewöhnlichen Ladungssäule $L$ die Phänomenologie für alle Perioden ihrer Wirksamkeit, sowohl während ihrer Verbindung mit der primären Kette $G$, als auch ausser derselben, für den Zustand der sogenannten Ladung, anschaulicher und unzweideutiger zu machen, theilen wir die ganze Säule $L$ etwa in drei von einander gehörig abgesonderte gleiche Theile und verbinden den mittleren derselben mit jedem der beiden äusseren durch einen einfachen Gasapparat, so dass ein System ent- 
steht, wie es schematisch in der folgenden Figur dargestellt ist.

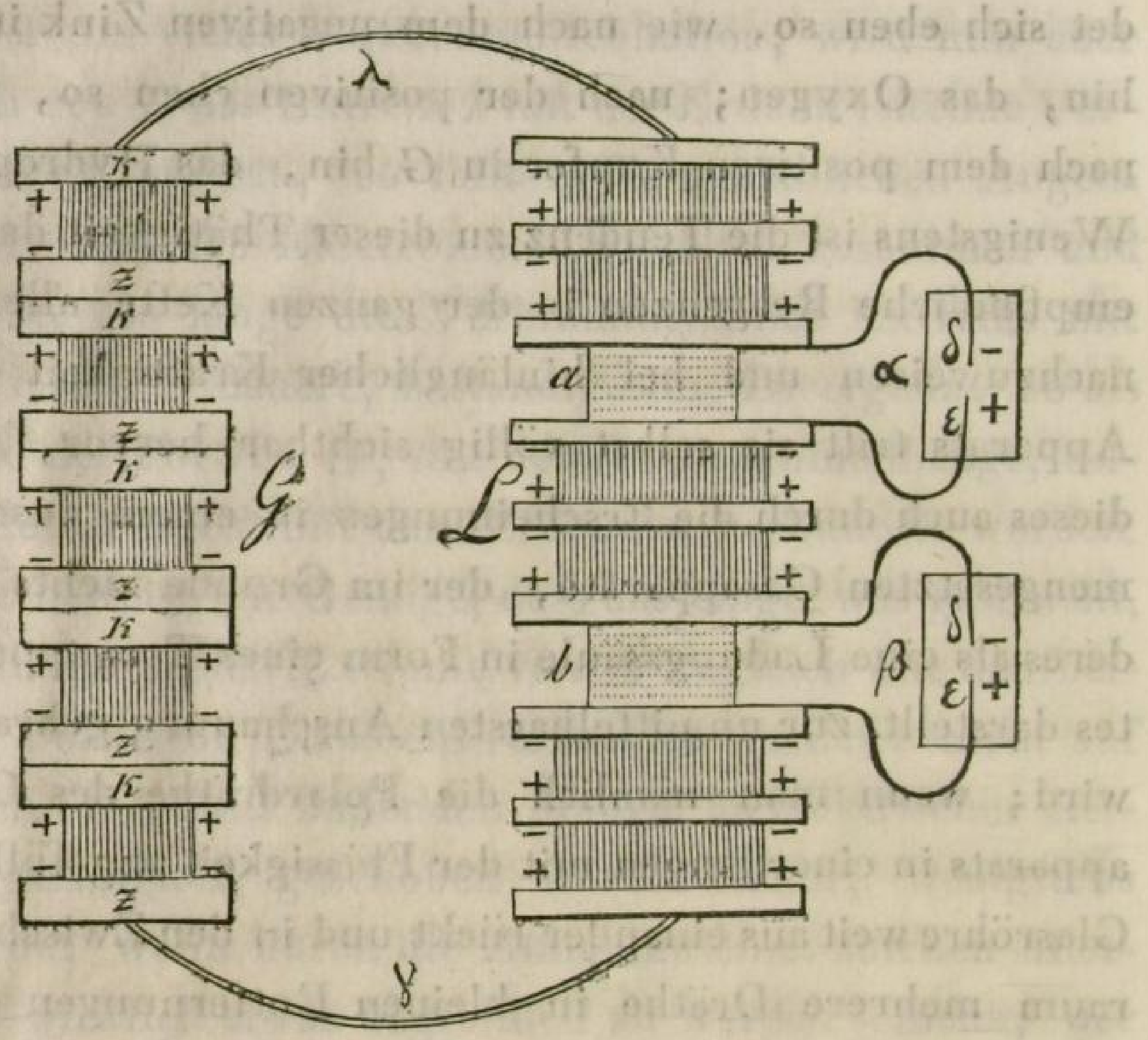

Die Ladungssäule $\boldsymbol{L}$ ist in $\lambda$ mit dem positiven; in $\gamma$ mit dem negativen Pol der primären Kette $G$ verbunden; bei $a$ und $b$ ist sie durch völlig isolirende Zwischenlagen in drei Theile gesondert, die wieder durch die beiden Gasapparate $\alpha$ und $\beta$ mit einander in Verbindung gesetzt sind. Nach allen mit - bezeichneten Stellen hin entbindet sìch nun das Oxygen, nach allen durch + unterschiedenen Stellen hin das Hydrogen; insbesondere sieht man die Entwickelung des Oxygens ader statt seiner den Erfolg der Oxydation deutlich an den Dräthen $\delta, \delta$; das Freiwerden des Hydrogens an $\varepsilon$, $\varepsilon$ und diese zur unmittelbaren Anschauung gestellten Erfolge in den Gasapparaten verbürgen zugleich unwidersprechlich dieselbe nach gleichem Typus und nach den schlechthin homologen Richtun- 
gen im geschlossenen Kreise der ganzen Kette in allen Puncten derselben verbreitete Thätigkeit. Diese qualitative Gleichheit der Simultanaction in der Ladungssäule $L$ wie in der primären Kette $G$, ist daher als das erste Hauptmoment zum Verständnisse der Natur der Ladungssüule wohl zu beachten.

Ein zweites nicht minder wesentliches Móment aber betrifft den quantitativen Unterschied der Thätigkeit in beiden Säulen. Ungeachtet der übereinstimmigen Action, vermöge deren nicht nur $G$ auf $L$, sondern auch $L$ auf $G$ erregend zurück wirkt, zeigt doch $G$ den Charakter des ursprünglich erregenden im Gegensatze zu $L$, als eines bloss erregten und mehr nur der Masse nach vorhandenen um so sichtbarer, je mehr eben die Indifferenz der Masse in den Elementen, aus welchen $L$ zusammengesetzt ist, vorwaltet. Der Unterschied in dem Verhalten beider wird z. B. weniger auffallend seyn, wern die Metallplatten in $L$ nicht aus Kupfer sondern aus Zink bestehen, er wird dagegen bemerkbarer werden, wenn sie durch Bleche von Platin oder Gold vertauscht werden, weil jedes der letztern,Metalle viel weniger, der Zink hingegen viel mehr Antheil an der chemischen Thätigkeit der ganzen Säule nimmt, und sie im ersteren Falle ungleich schwächer, im zweiten bei weitem leichter fortpflanzt als das Kupfer. Aus demselben Grunde wird der Unterschied im Character der Thätigkeit beider Süulen grösser oder geringer seyn, je nachdem eine mehr oder minder indifferente Flüssigkeit die Stelle des Leiters zweiter Classe in $L$ einnimmt; er wird z. B. grösser bei der Anwendung von destillirtem Wasser, als bei der von Brunnenwasser und bei letzterer wieder grösser als beim $\mathrm{Ge-}$ brauch von Kochsalzlösung seyn u. s. w. Man wird 
diesen Unterschied aber nicht sowohl an einer unmittelhar grösseren oder geringeren Thätigkeit in $G$ im Vergleich mit $L$ bemerken, wie etwa daran, dass in einem auch bei $G$ angebrachten Gasapparate mehr Gas als in jedem der an $\boldsymbol{L}$ befindlichen entbunden werde, weil in dem Maasse, in welchem die Thätigkeit in $L$ durch Reaction der Masse gehemmt wird, auch die ursprüngliche in $G$ beschränkt werden muss, sondern er wird vielmehr vermöge des in $G$ Statt findenden Erregungsdranges an einer während der Schliessung der Kette permanent auftretenden elektrischen Spannung erkannt werden, die hier wie überall um so grösser seyn muss, je grösser die Reaction in $L$ und je geringer folglich die Befriedigung der ursprünglichen Tendenz in $G$ ist. Von zwei am isolirten Apparate bei $\lambda$ und $\gamma$ angebrachten Elektrometern divergirt nämlich ersteres positiv, letzteres negativ um so merklicher, je grösser mit dieser Reaction der Gegensatz zwischen der ursprünglich erregenden und der bloss erregten Thätigkeit in $G$ und $L$, und je kleiner in Folge dessen die chemische Thütigkeit in beiden Säulen zugleich ist, Aber diese gefinge chemische Thätigkeit ist nun, so wenig wie die elektrische Spannung selbst, als eine Folge von der geringen elektrischen Leitungsfähigkeit der Ladungssüule $L$ anzusehen; denn dass es derselben nicht an dieser Fähigkeit mangele, hat sich zur Genüge gezeigt; sondern vielmehr ist jene elektrische Spannung eine Folge der geringeren chemischen 'Thätigkeit, welche aụs dem mehr oder minder beschränkten Antheil entspringt, den die Masse in $L$ an der Action nimmt, za welcher in $G$ schon vor der Schliessung die Tendenz durch die elektrische Spannung offenbart und, 
wie hier, auch noch nach der Schliessung fortwährend durch eine eben solche Spannung stärker oder schwä, cher ausgesprochen wird, je nachdem die Befriedigung mehr oder minder hinter der Teudenz zurück bleibt. Wenn das Leitungsvermögen für die Elektricität in der Masse der Ladungssüule $L$ auch noch so gross angenommen wird und dabei zugleich ilıre Reaction gegen die Theilnahme an der chemischen Thätigkeit der Säule $G$ dieselbe bleibt, so wird die Geschwindigkeit, mit welcher in $L$ die bestündige Ausgleichung der Polarelektricitäten von $G$ her vor sich geht, in keinem Falle wenigstens grösser seyn köuneu, als diejenige, mit welcher sie wieder erzengt werden, weil mit der ununterbrochen Statt fiudenden Beschränkung der chemischen Wirksamkeit von $G$ auch die unablässige Tendenz zur Thätigkeit in einer angemessenen elektrischen Spannung coexistirt, die sonach als stehend und permanent erscheinen muss, die Leitung und Ausgleichung in $L$ sey so vollkommen und so schnell als sie wolle. Diese positive und negative Spannung nimmt daher von $\lambda$ und $\gamma$ ans nach der Mitte von $L$ hin, eben so wie in $G$ selbst, ab; jede einzelne Platte in $L$ zeigt am Elektrometer positive oder negative Elektricität, je nachdem sie näher an $\lambda$ oder $\gamma$ liegt und die Mitte zwischen beiden Extremen hat völlig oE; aber diese Elektricität, als ein nur ganz üusserlicher Reflex, steht durchaus in keiner andern Beziehung zu dem, was bereits als wirkliche Thätigkeit und Art derselben in $L$ erkannt ist, als dass nach jhm nur der höhere Grad dieser Thäligkeit abgemessen werden kann, dessen die Masse in $L$ nach Maassgabe des Erregungsdranges in $G$ theilhaftig seyn könnte, wenn sie zugleich 
'durch einen inneren ursprünglich eben so hohen Grad von Erregbarkeit dafür empfänglich wäre. - Dass das Vermögen eines Körpers, mit welchem er die Elektricität als die bloss reflectirte Tendenz einer noch nicht realisirten Thätigkeit fortleitet und dasjenige, mit welchem er an der im Chemismus realisirten Thätigkeit der Kette Antheil nimmt, weder geradehin identificirt, noch in einer so engen und unmittelbaren Causalitätsverknüpfung, wie gewöhnlich, gefasst werden dür fen, sondern dass diese beiden Eigenschaften vielmehr selbst wieder als polare 'Thätigkeitsformen zu betrachten seyen, die zwar den Metallen und Flüssigkeiten gemeinschaftlich zukommen, von denen aber die eine vorzugsweise mehr jenen, die andere mehr den letzteren eigenthümlich ist: das geht, wie es mit dem Ganzen unserer Ansicht, als unmittelbare Enunciation dessen, was die Gesammtheit der Thatsachen zeigt, schon von vorn herein ausgesprochen worden ist, insbesondere aus den eben betrachteten Erscheinungen höchst vernehmlich hervor und wird durch die folgende fortgesetzte Untersuchung derselben von neuen Seiten her immer neue Evidenz gewinnen.

Es ist nun die Frage zu beantworten, welche Bewandniss es mit dem Verhalten der Ladungssäule $L$ habe, wenn dieselbe, nachdem sie eine Zeit lang, etwa 5 bis 10 Minuten hindurch, den Kreis der primären Kette $G$ geschlossen hat, nun ausser aller Verbindung mit derselben an und für sich selbst in Wirksamkeit zu treten beginnt. Wäre dieses Verhalten, wie man allenfalls erwarten möchte, nichts als ein unmittelbar durch den Impuls von $G$ aus bewirkter Beharrungszustand und gleichsam nur ein mit der früheren Thä- 
tigkeit gleichartiger, noch eine gewisse Zeit hindurch fortgeführter, Nachklang derselben, so müssten alle Functionen in der Säule $L$, wenn sie an und für sich geschlossen wird, auch qualitativ eben so, in derselben Ordnung und nach den nämlichen Localitätsbeziehungen, wie die in der anfänglichen Verbindung mit $\boldsymbol{G}$ erfolgen, die Oxydations - und Desoxydationstendenz müsste nach denselben Richtungen hin hervortreten, das Oxygen und Hydrogen müssten an denselben Stellen erscheinen und in den Gasapparaten müsste namentlich jenes an den Drathspitzen $\delta, \delta$, dieses an den Extremen $\varepsilon$, $\varepsilon$ eben so wie vorhin entbunden werden; die Polarität der Säule $L$ müsste mit einem Worte dieselbe geblieben seyn und bei ungeschlossenem Zustande müsste letztere dem zufolge auch in dem Extrem $\lambda$ ihren negativen, in $\gamma$ ihren positiven Pol haben. Aber dem ist keinesweges so, sondern die Erfahrung zeigt vielmehr van allem diesem gerade das Gegentheil. Die elektrische Polarität in $L$ hat dieselbe Form wie in jeder andern ungeschlossenen Primärsäule, ihr Indifferenzpunct liegt in der Mitte und auf beiden Seiten desselben zeigt das Elektrometer entgegengesetzte, nach den Extremen hin zunehmende Elektricitäten, aber der positive $\mathrm{Pol}$ ist nicht auf der Seite von $\gamma$, sondern in $\lambda$ und der negative eben so nicht in $\lambda$ sondern in $\gamma$. Diese elektrische Polarität ist also homolog der elektrischen Spannung, welche sich an beiden Extremen der Säule $L$ während ihrer Verbindung mit $G$ in der Gestalt der beiden entgegengesetzten Elektricitäten versichtbarte; aber sie ist nichts desto weniger die entgegengesetzte von derjenigen Polarität, welche $\boldsymbol{L}$ während jener Verbindung ihrem ganzen 
Verhalten nach zeigte; denn jene Spannung war, wie es ausdrücklich bemerkt worden, nicht wirklich die zu $L$ gehörige, sondern nur die auf $L$ äusserlich reflectirte und in Wahrheit einzig und allein der Säule $G$ zugehörige Polarifät. Dass die Erscheinungen hiev in besonders hohem Grade illusorisch sind, ist nicht zu läugnen, aber um so weniger dürfen wir bei der Oberfïiche derselben stehen bleiben und uns durch sie bestechen lassen. Wäre das, was sich jetzt als elektrische Polarität der Ladungssäule zeigt, nichts als der zurückgebliebene Rest jenes früher an ihx beobachteten elektrischen Gegensatzes, wie küme es, dass sich diese beiden Elektricitälen, bei dem entschiedenen Grade elektrischer Leitungsfähigkeit der Säule $L$, nachdem letztere von $G$ getrennt ist, nicht sogleich zu oE in ihr indifferenzirten, oder dass nicht wenigstens mit der ersten nach dieser Trennung Statt findenden Berührung von $L$ diese zurückgebliebene Elektricität günzlich abgeleitet und alle fernern Wirkungen, die man als Gefolge derselben zu nehmen pflegt, damit völlig aufgehoben würden, und wie wäre es endlich zu verstehen, dass diese nichts desto weniger bei wirklicher vollständiger Schliessung von $L$ eintretenden und eine Zeit lang fortdanernden Functionen in einer der früheren schlechthin und durchgehends entgegengesetzten Richtung erfolgen? Schliesst man

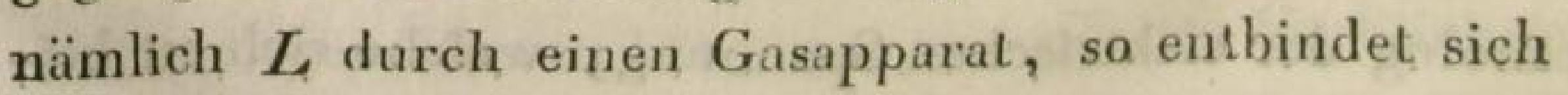
an dem mit $\lambda$ in Verbindung gesetzten Polardrathe das Oxygen, und an dem mit $\gamma$ verbundenen das Hydrogen, und der hiemit für die ganze Säule auf das entschiedenste bezeichneten Thätigkeitsrichtung gemäss entbindet sich eben so in den beiden Gasapparaten nach 
den Drathspitzen $\varepsilon, \varepsilon$ hin, an denen sonst das Hydrogen auftrat, jetzt das Oxygen; desgleichen nach $\delta, \delta$ hin, die sonst das Oxygen anzogen, jetzt das Hydrogen. Die Polarität der ganzen Säule $\boldsymbol{L}$ ist also jetzt in allen Beziehungen ganz offenbar die entgegengesetzte von der, welche während ihrer Verbindung mit $G$ Statt fand; die Zeichen, welche zur Andeutung jenes früheren Zustandes ihrer Wirksamkeit gebraucht sind, müssen zur Bezeichnung des gegenwärtig obwaltenden durchgehends verwechselt werden, die Thätigkeiten der geschlossenen Säule haben sich auf völlig entgegengesetzte Seiten geworfen und mit ihnen auch im ungeschlossenen Zustande der Säule die Tendenzen derselben d. h. ihre elektrische Polarität. Diese ist also keinesweges die Folge einer äusserlich und unmittelbar von $G$ her mitgetheilten Elektricität, sonst müsste sie eben so vorübergehend seyn, und eben so schnell wieder abgeleitet werden können, als alle in eirsem mit hinlänglicher Leitungsfähigkeit begabten Stoffe durch Mittheilung angesammelte Elektricität, sondern sie ist vielmehr ein und dasselbe mit jener, nach der Trennung von $G$, in $L$ hervorgerufenen in den veränderten Richtungen sich offenbarenden Thätigkeit, die bei vollkommener Schliessung von $L$ als reeller Chemismus und im ungeschlossenen Zustande als Tendenz von letzterem in der Form der elektrischen Polarität erscheint und mithin als solche auch so lange dauernd und unerschöpflich ist, so lange die Anregung zu jener innern ursprünglich chemischen Thätigkeit in der Masse von $L$ fortbesteht.

Aber welche Bedeutung hat nun diese nach plötzlich veränderten Richtungen hervorgebrochne Thätig- 
keit, wie ist sie entstanden und in welchem Verhältnisse steht sie zu der früheren während der Verbindung mit $G$ unterhaltenen in $L$ ? - Die Beantwortung dieser Frage, in welche nun also das Hauptmoment der Entscheidung zusammengedrängt ist, kann jetzt unter der in gleichem Maasse gewonnenen Bestimmtheit und Concentrirung des Gesichtspunctes nicht mehr schwer seyn. Es war selbst schon aus der reiflichen Erwägung dessen, was sich während der Verbindung zwischen $G$ und $\boldsymbol{L}$ darbot, die Gestalt und das Wesen des Erfolgs in Absicht auf das Verhalten von $L$ nach der Trennung beider im Voraus zu bestimmen. Es trat uns dabei einerseits als ein wesentliches Moment der $\mathrm{Be}$ trachtung zuvörderst das gleichartige Verhalten in $L$ wie in $G$ entgegen; andererseits aber erkannten wir in der während der Action an $G$ sichtbar gewordenen und auf $L$ hin reflectirten Elektricität eine Beschränkung der Thätigkeit in $G$, und als Ursache davon einen in $\boldsymbol{L}$ geübten Widerstand gegen die Theilnahme an dieser Thätigkeit. Dieser Widerstand war also nur beschränkend, und während er fortdauernd bestand, wurde doch durch das Uebergewicht des Erregungsdranges in $G$ die Masse in $L$ in die gemeinsame reelle, wenn gleich verminderte chemische Thätigkeit mit hineingezogen, vermöge deren alle Metallplatten und alle flüssigen $Z_{\text {wischenschichten in }} L$ auf der einen Seite in positiv-, auf der andern in negativ polare Action versetzt, das heisst, auf der einen Seite ein mehr oxydirtes, auf der andern ein mehr hydrogenisirtes wurden: In demselben Moment aber, in welchem $L$, mit dem Austritt aus dem geschlossenen Kreise von $G$, vom Zwange der aufgedrungenen Thätigkeit befreit wird, 
tritt nun auch seine bisher nur negativ geübte Reaction offen und auf eine positive Weise hervor und so wie das im geschlossenen Kreise einer Kette reducirte, metallisch gewordene Alkali beim Austritt aus demselben augenblicklich wieder nach der entgegengesetzten Seite zum universellen Standpuncte seiner alkalischen Natur zurückstrebt, eben so strebt auch jede, wenn gleich minder sichtbar, doch zuverlässig in einem bestimmten Grade, auf verschiedenen Seiten differenzirte Metallplatte und jede dirimirte Schicht der Flüssigkeit in $L_{4}$ wieder zur Indifferenz zurück; das während der Verbindung mit $G$, in positiv polarer Thätigkeit fortwährend begriffene und dem gemäss veränderte will jetzt, ausser dieser Verbindung, wiederum in den Normalzustand zurückkehren und erscheint eben darum jetzt nach der entgegengesetzten Richtung hin in fortwährend negativ polarer Thätigkeit begriffen und so umgekehrt; und die Summe aller dieser sich wechselseitig unterstützenden, zu einem Ganzen in einander greifenden Thätigkeiten der Säule $L$ bildet so den eigentlichen, sogenannten Ladungszustand derselben, der so lange dauert, bis die wieder erstrebte Indifferenz des Ganzen, schneller durch eine wirkliche Schliessung, langsamer durch eine allmählig erfolgende wechselseitige Ausgleichung in den einzelnen Gliedern vollkommen wieder hergestellt ist.

Es fragt sich nun, ob die beiden Bestandtheile, das Metall und die Flüssigkeit, zu gleicher Zeit, oder ob nur eins von beiden diese Reaction üben, in welcher sonach die Thätigkeit der Säule $L$ an und für sich lediglich besteht; und ob im ersten Falle beide einen gleichen, oder ob etwa vorzugsweise nur das eine und 
welches von beiden Antheil an dieser Reaction haben? Ritter hat bekanntlich durch eine Reihe physiologischer Beobachtungen an einzelnen Dräthen bereits jene Reaction, als eine den Metallen zukommende Eigenschaft nachgewiesen, und er versichert, selbst einmal eine entgegengesetzte Gasentbindung schon an zwei einzelnen Golddräthen eines Gasapparats nach der Trennung aus dem Kreise der Batterie wahrgenommen zu haben, - (Ritter's phys. chem. Abhandl, B. 3. S. 105.) eine Erfahrung, welche dem Wesen nach mit den oben angegebenen Erscheinungen an der zusammengesetzten Ladungssäule und der von uns gefassten Ansicht darüber vollkommen übereinstimmt, ünd in sô fern, da der Gasapparat in der gewöhnlichen Form sich zur Ladungssäule nicht anders wie die einfache zur zusammengesetzten Kette verhält, allerdings nicht für unmöglich gehalten werden darf, die aber, wenigstens eine ausserordentlich kräftige Einwirkung voraussetzt, und sich mir, während der Gasapparat für sich durch den Multiplicator geschlossen, auch nach der schwächsten Einwirkung sehr entschieden auf die Magnetnadel reagirt, bis jetzt noch jedes Mal, so oft ich sie suchte, versagt hat. Ritter wurde dann durch alle jene an einzelnen Metalldräthen zurörderst gemachten Wahrnehmungen ganz consequent auf die Construction seinèr Ladungssüule geführt; aber in der Erörterung und weiteren Verfolgung ihrer Wirkungen lässt er den Zusammenhang zwischen diesen und jenen Erscheinungen wieder gänzlich fallen; man sieht aus seiner Darstellung, dass er das, was er zu suchen veranlasst war, anders gefunden als er es sich vorher gedacht hatte und wenn er gleich seine Entdeckung mit Recht für etwas ungleich 
bedeutungsvolleres nahm, als dasjenige, wozu sie in der Folge, besonders durch französische Lehrbücher und ihre Wiederkäuer gemacht worden ist, so liefs ihn doch die Befangenheit des allgemeinen Vorurtheils von einer den sämmtlichen Erscheinungen der Kette zum Grunde !liegenden radicalen Substantialität des Elektrismus und des elektrischen Stroms nicht zu dem wahren, so einfachen und nahe liegenden Gesichtspuncte gelangen, von dem aus die Erscheinungen erst Einheit und klares Verständnifs gewinnen, und er verlor sich in vage Vorstellungen über den Gegenstand, welche zum Theil mit dazu beigetragen haben mögen, dass derselbe weniger gewürdigt und erfolgloser geblieben ist, als er von Anfang an gesollt hätte.

Zu Ritter's Irrthümern in der Sache gehört insbesondere auch die Vorstellung, dass die Metalle allein und ausschliesslich es seyen, denen die Säule $L$ das, was von ihm zuerst ihre Ladung genannt worden ist, zu verdanken habe; „überall, sagt er (a. a. O: S. 137) ist es nur der Leiter erster Classe, das Metall, welches geladen und entladen wird und Leiter thun hier, was man sonst nur Isolatoren zumuthete." Aber obgleich dieses Urtheil einseitig ist, so enthält es auf der andern Seite doch zugleich etwas sehr Treffendes und steht der Wahrheit unendlich viel näher, als die später allgemein gewordene, entgegengesetzte Vorstel. lung, nach welcher man glanbt, dass nur die unvollkommene Leitungsfähigkeit des Leiters zweiter Classe die eigentliche Bedingung zu den Phänomenen der sogenannten elektrischen Ladung ausmache.

Wird die Kette durch einen Leiter zweiter Klasse von beträchtlicherL Längendimension, wie z.B. durchWas-

M 
ser in einer langen Glasröhre, durch eine feuchte Schnur, ein feuchtes Band u. dgl. geschlossen, so nimmt man an seinen Extremen eine elektrische Spannung wahr, sowohl während der Schliessung als auch einige Zeit nachher, weun er aus dem Kreise herausgetreten ist, eben so, nur in einem verhältnissmässig viel geringeren Grade, wie bei der Ladungssäule $\mathrm{L}$ selber. Dies beweist also, gegen Ritter, dass auch der Leiter zweiter Classe geladen werde; aber seine Ladung ist nicht eine in ihm stecken gebliebene Elektricität, sondern die an ihm wahrgenommene Elektricität ist vielmehr in jedem Falle, eben so wie bei der Ladungssäule, nur Merkmal und Symptom einer von ihm geübten und erst bei seinem Austritt aus der Kette offen hervortretenden Reaction. Dagegen steht Ritters Ausspruch dennoch insofern der Wahrheit sehr nahe, in wie fern diese Ladungsfähigkeit der Leiter zweiter Classe in der That nur eine untergeordnete Seite ihres eigenthümlichen Verhaltens ausmacht und bei ihnen ungleich geringer ist, als bei den regulinischen Metallen, in deren $\mathrm{Na}$ tur im Gegentheil das reagirende, der Entwickelung widerstrebende Princip recht eigentlich vorherrscht and die eben desshalb, wenn auch nicht allein und ausschliesslich, denn alles ist relativ, doch in einem bei weitem überwiegenden Grade die mit der Reaction zusammenhängenden Phänomene der sogenannten elektrischen Ladung versichtbaren.

Wir treten also mit diesem, jetzt zu einer gründlichen Nachweisung hinlänglich vorbereiteten Theorem auf eine, schon von Ritter angedeutete, aber wie gesagt, nicht mit ruhiger Klarheit und Bestimmtheit durch ihn behauptete Stufe der Erkenntniss, von der aus wir 
mithin abermals einer;sehr verbreiteten Meinung zu widersprechen und demjenigen, was in dieser Beziehung zur herrschenden Ansicht geworden, eben so - bestimmt und mit eben so sichern Argumenten, als - den allgemein gangbaren Vorstellungen über die Po- larität der Kette und was an sie geknüpft worden, zu begegnen genöthigt sind. Weil die Phänomene der letzteren nach früheren und späteren Theorien stets einseitig gefasst und, mehr oder weniger, immer nur uaus dem partikulären und ganz unzulänglichen Gesichtsnuncte eines durch einen fabelhaften elektrischen uStrom vorzugsweise vermittelten Processes betrachtet - wiurden, isobei also, wie nicht oft genug bemerkt - werden kann, die Fortpflanzung der eigentlichen - chemischien Thätigkeit und die Fortleitung der Elektricität als eines bloss seitwärts liegenden Symptoms, einer bloss vorlänfigen und nach Aussen hin reflectirten Tendenz dieser Thätigkeit, ohne Unterlass verwechselt und jizu endlosen Verwirrungen beständig durcheinander -geworfen sind, während die höhere und wahrhafte Ein- heit beider noch in keinem System der Physik auf die -rechite, lebendige Weise anerkannt und aufgezeigt worIden: so sah man auch die so merkwürdigen, für o die ganze Elektricitätslehre so höchst wichtigen und aufschlussreichen Phänomene der elektrischen Ladung - nicht nur als die Folge einer unvollkommenen elektrie schen Leitung an, sondern, da die Metalle als die vollmkommensten Leiter der Electricität galten, so wurden -idie[Erscheinungen unbedenklich auch nicht diesen, Jisondern nur den Flüssigkeiten oder vielmehr, in Folge 2. der unvollkomimeneren Leitungsfähigkeit der letzteren, If mư einer noch anabgeführten and in ihnen nach sitzen

$\mathrm{M}_{2}$ 
gebliebenen Elektricität zugeschrieben: Was nun den ersten Punct hinsichtlich der wahren Entstehung und Bedeutung der Ladungsphänomene anbetrifft, so ist darüber durch alles Vorhergehende und mit dem Gan-

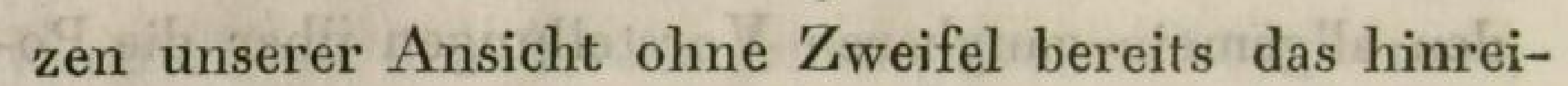
chende Licht zur wahren Erkenntniss desselben verbreitet worden, und! alles Folgende wird zu gleicher Zeit noch fortwährend dazu dienen, die gänzliche Unzulänglichkeit bisheriger Vorstellungen, so wie die

Wahrheit unserer eigenen entwickelten Ansicht über diesen Punct zu bekräftigen; hinsichtlich des zweiten Umstandes aber liegt es uns jetzt besonders ob, den Beweis, dass die Reaction mit den durch sie dargebotenen Ladungsphänomenen vorzugsweise und ursprüng- lich den Metallen angehöre, theils durch directe Argumente, theils durch eine genaue Beleuchtung der Umstände, welche als eben so viel Scheingründe die gewöhnlichen, gänzlich abweichenden Vorstellungen veranlasst haben, zu vollführen, und es werden hiemit - zugleich die bereits mit dem ersten Abschnitte hervorgehobenen Data über den charakteristischen Unterschied der Thätigkeit zwischen Metallen und Flüssigkeiten, wenn sie als Leiter der Gesammtthätigkeit der galvanischen Kette wirksam sind, die vollkommenste Evidenz gewinnen.

Man armire eine feuchte, etwa mit stark verdünn- ter Schwefelsäure durchzogene Pappscheibe von etwa 9 Quadratzollen Flächengrösse auf jeder Seite mit einem eben so grossen Kupferbleche. Sind die Platten gleichzeilig und unter möglichst gleichen Umständen mit der feuchten Pappe lin Contact gebracht, so wird $d_{i s}$ ${ }^{t}$ dadurch gebildete Element einer Ladungssäule, durch ‘ 
einen elektromagnetischen |Multiplicator geschlossen, gar keine oder bei etwaniger zufälliger Differenz, nur eine sehr geringe Ablenkung der [Magnetnadel bewirken, die auch nach einiger Zeit, während welcher die Bleche mit der Flüssigkeit in Berührung geblieben sind, ganz ausbleibt. Das Ladungselement werde nun der Einwirknng einer kräftigen Primärsäule von etwa 3o bis 50 Plattenpaaren ausgesetzt, so dass das eine Kupferblech mit dem positiven, das andere mit dem negativen Pol der Säule leitend verbunden wird. Nach ungefähr 5 Miunten nehme man das Ladungselement aus dem geschlossenen Kreise der Batterie heraus und schliesse es als eine Kette|für sich durch den elektromagnetischen Multiplicator, so wird die Nadel lebhaft abgelenkt werden, zum Beweise, dass das Element geladen sey. Man lasse nun die Lage der beiden Kupferbleche ganz unverändert, wende aber die feuchte Pappe um, so dass jede Seite von ihr mit demjenigen Bleche, welches sie während der Ladung nicht berührte, in Contact kommt und schliesse nach dieser Veränderung /die Ladungskette abermals durch den Multiplicator, so wird die Nadel entweder gar nicht oder sehr viel schwächer als vorher abgelenkt werden. Man kehre die Pappe wieder um, so dass sie und jedes Glied gegen die übrigen die ursprüngliche Lage abermals einnimmt, so hat man auch wieder bei der Schliessung die anfängliche kräftige Ablenkung. Man kann diesen Wechsel, wenn das Umwenden schnell genug vorgenommen wird, sehr vielmal darstellen, nur wird die ursprüngliche Wirkung bei jeder Wiederho. lung immer mehr abnehmen und zuletzt ganz unscheinbar werden. 
(192 Diese Erfahrüng beweist also fürs erste, dass dè Leiter zweiter Classe in der That geladen werde, das, heisst, gégen diel empfangene Einwirking nach der Inidifferenz hinzurück reagire; dènn wäre er gleich, von Anfaüg an indifferent, so müsste natürlich auch die Wirküng in jeder Lage desselben die nämliche bleiben. Derselbe Erfolg aber documentirt zu gleicher Zeit auch schon ganz entschieden einen in den Metallblechen vorhandenen Ládungsźustand; dẹnn wären die Metalle indifferent, so könnte die Ablenkung der Nadel nicht das eine Mal erfolgen und das andere $\mathrm{Mal}$ ausbleiben, sondern sie müsste mit jeder entgegengesetzten Lage des feuchten Leiters gleichfalls entgegengesetzt, übrigens aber dás eine Mal eben so kräftig oder doch beinahe eben so kräftig wie das andere mal seyni Aber diese Ladung oder vielmehr diese reagirende Thätigkeit der Metalle lässt sich eben so direct, wie die des Leiters zweiter Classe, an ihnen selbst nachweisen. -9d Man ladeldaš Ladungselemènt von neuem, indem man es abermals die erforderliche Zeit hindurch mit der Primärkette in die gehörige Verbindung setzt. Beim Herausnehmen desselben aus dem Kreise der Batterie überzeugt man sich zuvörderst von der bewirkten Ládung durch die unter dem schliessenden Multiplicatór erfolgende lebhafte AbIenkung der Nadel. Man lasse nun die Pappscheibe in derselben Lage,! wende aber jedes Metallblech um, so dass zwàr je dieselbe Seito der Pappscheibe von demselben Bleche, aber von einer andern Seite dieses Bleches als vorher berührt wird, und die Ablenkung, wie kräftig sie vor dieser Veränderung auch seyn mochte, ist gänzlich oder beinahe gänzlich vernichtet. Man stelle die ursprüngliche Lage der Ar- 
maturen 'wieder her und sogleich hat man im Moment: der Schliessung die Ablenknng der Nadel in ihrer unverkennbaren anfänglichen Lebendigkeit; mit der wiederholten Umwendung der. Metallbleche ist sie aber máls ganz odẹr höchstens bis auf einen sehr unbedeutenden Uébèrrest verschwunden; sie zeigt sich wieder in der anfänglichen Stärke, sobald die Armaturen ihre eiste Lage wièder eingennommen haben, und so kann man bei rascher Manipulation den Wechsel sehr viel mál erneuerin, bis mit der zur Indifferenz zurïck drän genden Reaetion die Thätigkeit für die Wahrnehmung allmählig zu erlöschen beginnt.

- To5 So vollkommen durch diese Erscheinungen ein in den Metallen vorhandenęr Ladungszustand ausser allen Zweifel gesetzt ist, so entschieden ist durch sie auch die gänzlichè Unzulänglichkeit solcher Vorstellungen, nach welchen diese Ladung michts als eine angehäufte Elektricität ist, dargethan. Wäre diese sogenannte Ládung des Metalls nicht etwas anderes, als ein in ihnen sitzen gebliebenes elektrisches Fluidum, oder, weni auch von dem leeren Phantom einer elektrischen Materie gar nicht miehr die Rede ist, - wäre sie nichts als eine am Metalle zurückgebliebene elektrische Erregung, wio könnte diese Elektricität völlig gegen ihre eigentlichste Natur, trotz aller leitenden Berührung, in dem einzelnen vom feuchten Leiter ganz getrennten Metalle so hartnäckig fest sitzen? Man kann die Metallplatten abwaschen, abtrocknen, sie mit den Händen und mit andern Metallen, in so vielen $\mathrm{Pun}_{7}$ cten als man will berühren und sie verlieren darüber ihre sogenannte Ladung nicht merklich früher, als wenn keine dieser Proceduren während der Zeit mit 
ihnen vorgenommen worden wäre. Es muss also ein zwar vorübergehender, aber in der Masse des Metalls selbst begründeter Zustand seyn, mit dem, unserer vielfältig ausgesprochenen Ansicht gemäss, die Elektricität nur wie ein einzelnes Symptom desselben, als ein bloss secundäres, zusammenhängt und dieser Zustand kann nach Allem, was wir bereits von ihm wissen, nichts anderes seyn, als die Thätigkeit, mit welcher die auf entgegengesetzten Seiten different gewordene Masse des Metalls, so wie der Flüssigkeit die ursprüngliche Indifferenz in der Einheit ihres Verhaltens wieder zu gewinnen strebt. So lange daher dieselben Flächen des Metalls und der Flüssigkeit in derselben Lage erhalten werden, in welcher die Einwirkung auf sie Statt fand, und in welcher nach dieser Einwirkung auch eine gemeinschaftliche, durch das gegenseitige Ineinandergreifen der Thätigkeiten unterstützte und verstärkte Reaction beginnt, treten auch die Symptome derselben in der Wirkung auf die Magnetnadel so wie auf das Elektrometer, wenn es empfindlich genug ist, sichtbar hervor, wenn aber Flächen mit einander in Berührung gesetzt werden, deren reagirende Thätigkeiten nicht zusammen stimmen oder sich gegenseitig hemmen, so muss natürlich die Sichtbarkeit dieser Reaction nach Aussen hin auch ganz fortfallen oder sie muss wenigstens Modificationen oder Verminderung erleiden.

Nach dem; was die obigen Erfahrungen zeigen, scheinen jedoch die Reaction des Metalls und der Flüssigkeit sich einander der Intensität nach ziemlich das Gleichgewicht zu halten und unsere Thesis, dass die Reaction mit den davon'abhängigen Ladungsphänome- 
nen vielméhr den Metallen als den Flüssigkeiten und nur vorzugsweise und ursprünglich den ersteren zukomme, mag vielleicht auf den ersten Blick durch die angegebenen Thatsachen sogar mehr zweifelhaft als bestätigt erscheinen. Aber um so mehr muss dagegen hier sogleich bemerkt werden, dass ein solcher Schluss höchst übereilt und ohne weiteres völlig unzulässig seyn würde. Wenn man den Charakter der Metallität im Allgetreinen nicht aus den Augen verliert, wie er durch das Ganze der Erscheinungen als das Princip des Beharrlichen, Unbeweglichen, aller Veränderung und Fortbildung Widerstrebenden auf die unzweidentigste Weise ausgesprochen ist, so ist damit ein für alle $\mathrm{Mal} \mathrm{der} \mathrm{Ge}$ sichtspunct gegeben, von dem aus unsere Behauptung, selbst wenn uns weiter keine speciellen Thatsachen zu ihrer Bekräftigung als die obigen dargeboten wären, dennoch unerschütterlich bleiben würde. Wenn Metall und Flüssigkeit zugleich einer und derselben durch die Primärkette geïbten Einwirkung ausgesetzt werden, so muss das Metall als solches nothwendiger Weise der eingeleiteten Metamorphose einen ungleich hartnäckigeren Widerstand entgegensetzen, als die Flüssigkeit, und wenn unmittelbar darauf, nachdem die Einwirkung aufgehört hat, die offene Reaction gegen die bereits erlittene Veränderung in dem Metalle dennoch nicht grösser als in der Flüssigkeit zu seyn scheint, so muss dieses eben vielmehr als die Folge des ungleich mächtigeren Reductionsdranges im Metalle betrachtet werden, vermöge dessen es das ganze aus Metall und Flüssigkeit zusammengesetzte Contiguum urplötzlich auf eine durchdringende Weise beherrscht, und es gleich im ersten Augenblicke der nachlassenden Einwirkung mit der 
grossten Schinelligkeit auf einen bestimmten Punct der Indifferénz sogleich wieder zurück drängt, von dema aus sodann die zur Wiedergewinnung des vollkommenen Gleichgewichts noch eine Zeit lang fortbestehender Thätigkeit bloss als das Resultat dieser bereits erfölgten, momentanen, der Wahrnehmung stets vorüber eilenden Ausgleichung, nur noch als ein in beiden Bestandtheilen zienlich gleichmässiger Grad der Reaction für die Beobachtung zurück geblieben' ist. 5 Allein es giebte noch ganze Reihen sprechender Thatsachen, durch welche die ungleich mächtigere Reaction, welche den Metallen als solchen vorzugsweise zugehört, auf das Unverkennbarste vor Augen gelègt wird, und von denen wir daher die wichtigsten/ und überzeugendsten hier sogleich aufführen wollen.

Zuvörderst ist jenes scheinbare Gleichgewicht der Reaction, welches die Flüssigkeit und die beiden metallischen Armaturen des Ladungseléments in den oben angegebenen Versuchen zeigen, nicht ein vollkommeries, soudern eben nur ein scheinbares, und bei genauerer Prüfung unter gehöriger Abänderung des Experiments findet man in der That die Summe der fortbestehenden Reactionsthätigkeit in dem Metalle noch stets um ein Bedeutenđes grösser als in der Flüssigkeit. Mài nelime zu dem Ende zwei dem obigen ähnliche, einander ganz gleiche Ladungselemente, deren jedes für sich geschlos'sen gar keine sichtbare Wirkung auf die Magnietnadel hervorbringt. Man verbinde das eine dieśer Elemente auf die gewöhnliche Art mit der Primärsäüle, damit es eine kräftige Ladung durch sie empfange. Darauf nehme man die beiden kupfernen Armaturen dés ungeladen gebliebenen Elements von der Pappscheibe hinweg, 
und armire dafür die létzere- schnell mit den geladom nen Kúpferplatten, so dass die nämlichen Seiten der-4, selben, welche der Pappscheibe des geladenen Elements anlàgen, aưch jezt mit der des ungeladenen in Berührung kommen. Mit den Platten des nicht geladenen Elements armire man dagegen so geschwind als mö̈glich die entblösste Pappscheibe des geladenen Eleménts, so hat man zwei Elementé, von denen das eine geladenés Metall aber ungeladene flüssigkeit, das andere hingègen geladene Flüssigkeit aber ungeladenes Metall. enthält. Mán schliesse nun das létzere durch den Múltiplicator zuerst, so wird man allerdings eine Ablenkung der Nadel haben, die jedoch nur sehn schwach. zu seyn pflegt, indem sie allein dürch die reagirende Thäligkeit der Flüssigkeit hevorgebracht |wird. Mani schliese darauf auch das erste Element mit den geladenen Armaturen und der Erfolg wird in einer Ablenkung der Nadel bestehen, die alle mal ungleich stärker und um so viel lebendiger als die vorhergehende ist, je schneller man den ganzen. Versuch überhaupt zu Stande gebracht hat.

Noch sehr viel frappanter wird aber die Evidenz welche unsere Ansicht in allen Bezieliungen gewinnt; durch die Ladungsphänomene, welche die Primärketto nach aufgehobener Schliessung an und für sich selber zeigt und diese Erfolge verdienen aus diesem Grunde so wie zugleich deshalb, weil sie eine bis dahin noch unbetrachtet gebliebene Classe von Erscheinungen bilden, eine verdoppelte Aufmerksamkeit. So wie alle Disjunctionen relativ sind und jeder Ggegensatz in einem höher liegenden harmonischen Puncte der Identität seine Auflösung findet, su wird auch der Unter- 
schied zwischen Primä - und Secundärketten durch die erstern unmittelbar selbst aufgehoben; jede ursprünglich selbstthäthige Kette ist zu gleicher Zeit in und durch sich selbst auch eine Ladungskette und muss dieses auch úserer Ansicht zufolge nothwendiger Weise iseyn, sie muss während der Schliessung durch sich selbst um so kräftiger geladen werden, je energischer ihre Wirkung eben an und für sich ist, das heisst, das Metall in ihr muss nach aufgehobener Schliessung die Reaction zum Rückgange in die ursprüngliche Indifferenz gerade durch die Versichtbarung der entgegengesetzten Polarität von derjenigen, mit welcher es im geschlossenen Zustande der Kette thätig war, um so entschiedener und nachdrücklicher üben, je reger und lebendiger diese Thätigkeit während der anfänglichen Schliessung selbst war, und so muss auch die Flüssigkeit nach der aufgehobenen Schliessung der Kette auf beiden Extremen die entgegengesetzten Polaritäten von denjenigen versichtbaren, welche ihr im geschlossenen Zustande der Kette eigenthümlich sind; aber hiebei wird es sich eben zu gleicher Zeit auch zeigen, wie viel mächtiger die Reaction des Metalls als die der Flüssigkeit sey. Wir wollen diese Phänomene im Folgenden sogleich zuvörderst an der einfachen dreigliedrigen Kette kennen lernen; von der sehr merkwürdigen Form, unter welcher sie sich an der zusammengesetzten Kette darstellen, wird weiter unten noch besonders die Rede seyn.

$\mathrm{Zu}$ den Versuchen dient am besten ein grösserer, mit der Flüssigkeit angefüllter Behälter, wie der ersten Abschnitte, S. 5 ff. erwähnte, in welchem man mehrere Metallbleche, mittelst kleiner an ihnen 
befestigter Fussplatten, über jedem Puncte der Bodenfläche vertikal aufstellen, ihre gegenseitige Lage, ohne sie ausser der stetigen Berührung mit der Flüs. sigkeit bringen zu dürfen, sehr schnell abändern und sie dabei, durch Hülfe kleiner, an ihrem obern Theil angelötheter Quecksilbergefässe von Eisen oder Kupfer, mit dem Multiplicator und unter einander in beliebige Verbindung setzen kann.

Es werde zunächst ein Zinkblech und drei gleich grosse Kupferbleche in die Flüssigkeit gesetzt; von den letzteren sey jedes Paar, wenn es durch die in die Quecksilberbehälter getauchten Extreme des Multiplicators verbunden wird, ohne alle sichtbare Wirkung auf die Magnetnadel. Es werde nun das eine Kupferblech (K) parallel der Zinkplatte $(Z)$ etwa in eine Entfernung von zwei Zollen ihr gegenüber gestellt. Die Boussole stehe stets im Süden der Kette und das von Süden nach Norden über der Nadel fortgehende Ende des Multiplicators werde mit jenem Kupferbleche, $\mathrm{K}$, das andere in gleicher Richtung unter der Nadel zur Kette gehende Extrem mit der Zinkplatte, $\mathrm{Z}$, verbunden, so weicht die Nadel sogleich nach $\mathrm{O}$ sten hin ab. Man lasse die Kette so ungefähr 5 bis 10 Minuten lang geschlossen. Dann, öffne man sie, rücke die beiden Platten derselben, fohne die Flüssigkeit zu theilen, durch eine Bewegung in der erweiterten Ebene der Platten von ihren Plätzen, bringe eben so die beiden andern, so lange noch unbenutzt gebliebenen Kupferbleche in ihre leer gewordene Stelle und lege wieder das Multiplicatorende, welches vorhin mit der Kupferplatte K verbunden war, an die kupferne Ar: 
matur, die jetzt deren Stelle einnimmt und eben so das andere vorhin mit der Platte Z verbundene Extrem an die zweite ihre Stelle einnehmende kupferne Armatur: so wird man eine geringe Ablenkung der Nadel nach Westen hin haben, als Beweis einer wirklich in der Flüssigkeit Statt findenden Reaction, die aber nicht selten so schwach ist, dass die Ablenkung nur durch wiederholtes a tempo-Schliessen sichtbar wird, oder auch wohl gänzlich ausbleibt; so oft sie aber Statt findet, ist sie die ent gegengesetzte von derjenigen, welche ganz unter denselben Umständen die Kette selbst hervorbrachte.

Eine ganz andere, ohne Vergleich kräftigere Reaction zeigt dagegen das Kupfer. Man verbinde wieder $\mathbf{Z}$ mit der zuerst benutzten Platte $K$ durch den Multiplicator, so dass die Ablenkung der Nadel abermals östlich ist und erhalte die Kette so wieder mehrere Minuten lang geschlossen. Dann öffne man, während das an die Platte $K$ gelegte Extrem des Multiplicators fortwährend mit ihr in Verbindung gehalten wird, diese zuerst gebildete Kette dadurch, dass man das andere Multiplicatorende von Z fortnimmt; lasse die Nadel so schnell als möglich auf Null einspielen - und hänge sodann das freie Multiplicatorende in irgend eine der beiden andern Kupferplatten, so wird die Nadel sogleich sehr lebhaft we stlich abweichen, und diese Ablenkung erhält sich eine geraume Zeit hindurch, wo man während dessen auch $\mathrm{K}$ und die andere Kupferplatte in den Behälter hinstellen möge. Das- selbe K, welches vorhin in der ersten Kette dem Z mit der dem Kupfer während der Action zugehörigen po- sitiven Polarität gegen über stand, tritt also jetzt in der 
gleich darauf gebildeten zweiten Kette jedem andern Kupferbleche, wie eine Zinkplatte, mit der negativen Polarität entgegen und diese Reaction ist mit der Oeffnung der ersten Kette so unfehlbar und augenblicklich verknüpft, dass man sie stets um so kräftiger sehen wird, je schneller die Manipulation ist, welche den Momenit ihrer Versichtbarung herbei führt. Dass diese Reaction so gut wie allein dem Metalle und nicht der Flüssigkeit angehört, ergiebt sich theils aus dem vorher angeführten Versuche, dessen $Z_{\text {weck }}$ die ausschliessliche Prüfung des Verhaltens der Flüssigkeit war, theils aus dem Umstande, dass die Wirkung der reagirenden Platte $\mathrm{K}$ an jeder Stelle in dem Behälter, wohin sie auch versetzt werden mag, immer dieselbe bleibt; nur nimmt sie natürlich allmählig $\mathrm{ab}$, und ist ausserdem um so schwcäher, je weiter $K$ von der andern Platte entfernt ist. Dass aber K jetzt nicht wie' das geladene Metall in frühern Versuchen (S. 18 2. ff.) nur etwa mit einer bestimmten Seite, sondern in jeder beliehigen Lage gegen die andere Kupferplatte sich wirksam zeigt, das rührt hier daher, weil $K$ in diesen Versuche vom Anfange an auf beiden Seiten mit der Flüssigkeit ganz umgeben, und daher in allen Puncten überall gleichmässig angeregt worden ist. Um jedoch noch die Bedenklichkeit zu beseitigen, dass etwa die nit der reagirenden Platte vom Anfange des Versuchs an in Adhärenz gebliebene Schicht der Flüssigkeit deren Thätigkeit bedingen könne, so kann man $\mathrm{K}$ aus der Flüssigkeit herausnehmen, sie in reinem Wasser abspülen, sorgfältig trocknen und an jedem beliebigen Orte innerhalb des Behälters wiederum aufstellen und wenn hiemit schnell genug verfahren und der sehliessende Mul- 
tiplicator, so wie oben, applicirt worden, so wird man noch dieselbe, nur unter der Zeit etwas schwächer gewordene', we stliche Ablenkung der Nadel sich wiederholen sehen. Zuweilen kann es hiebei wohl geschehen, dass im ersten Moment die Ablenkung östlich ist, wie es bei der angegebenen Application des Multiplicators in der Regel geschieht, wenn einer bereits längere Zeit mit der Flüssigkeit in Berührung gewesenen Kupferplatte eine frisch gereinigte gegenüber tritt; jene repräsentirt sodann die negative Zinkseite, die später nach $\mathrm{ihr}$ in die Flüssigkeit eingetauchte die positiv polare Kupferseite der Kette; aber die Differenz wird, so wie immer, hier besonders, wenn auch wirklich die von ihr abhängende Wirkung in den ersten Momenten 'die Oberhand über die Reaction des Metalls in $\mathrm{K}$ hat, sehr bald ausgeglichen und die durch die letztere bewirkte westliche Ablenkung tritt sodann nur als ein um so anschaulicheres Document von der eigentlichen Natur des Metalls wiederum kräflig hervor.

Die Reaction oder die sogenannte Ladung,', deren der Zink in der dreigliedrigen Kette fähig ist, ist bei weitem geringer als die des Kupfers; sie lässt sich jedoch durch Zuziehung einer zweiten Zinkplatte, die nit der ersten ( $z$ ) von gleicher Grösse und Beschaffenheit und gleichzeitig mit ihr in die Flüssigkeit eingetaucht worden, eben so wie die der Platte k unzweideutig wahrnehmen, wenn man das Experiment mit neuen Platten, und bald nachdem sie in die Flüssigkeit geteucht worden, vornimmt. Wenn aber der Zink längere Zeit in der Flüssigkeit gewesen ist, so gewinnt, wie man schon an der immer stärker werdenden Gasentbindung sehen kann, der Process der zweigliedrigen 
Kette zwischen dem Zink und der' Flüssigkeit an und für sich, von dem weiter unten im folgenden Abschnitte die Rede seyn wird, auf eine von der Thätigkeit der dreigliedrigen Kette unabhängige Weise, ein solches Uebergewicht, dass der Zink, so lange er in der Flüssigkeit bleibt, von der letzteren in der negativ polaren Thätigkeit festgehalten wird, und schlechthin nicht dazu kommen kann, eine Reaction gegen die vorausgegangene Wirkung der dreigliedrigen Kette, als deren integrirendes Organ er zugleich thätig war, offen zu äussern. Wenn man dagegen statt des Zinks Platten von einem andern Metalle nimmt, das zum Kupfer in ähnlicher Relation wie der Zink steht, aber zugleich gegen die Flüssigkeit nicht in so hohem Grade negativ als jener ist, z. B. Platten von Blei oder Zinn, so ist auch bei ihnen unter den angegebenen Umständen das Hervortreten der Reaction zwar ebenfalls beträchtlich schwächer als beim Kupfer, aber dennoch so constant, dass es sich fast niemals verlängnet, während es am Zink 'aus den angegebenen Gründen, wenn gleich vorhanden, doch nur seltener wahrgenommen $\mathrm{zu}_{4}$ werden vermag.

Wir haben bis jetzt die Phänomene der sogenannten Ladung unter mehrfachen Formen und mit jedem Schritte immer entschiedener und zuverlässiger als das, was sie eigentlich sind, als ent gegengesetzte, vorzugsweise dem Metall angehörige Reactionserfolge einer yorausgegangenen chemisch polaren Thätigkeit kennen gelernt; aber wir haben in diesem Gebiet der Erscheinungen noch nicht den Gipfel erreicht, der darin besteht, dass jene ursprüngliche Thätigkeit und nnmittelbar darauf die ihr entgegengesetzte Reaction in der 
Integrität der Wirkung einer und derselben völlig ungeändert gebliebenen Kette dargestellt werde. Dieses scheint auf den ersten Blick, den bisherigen Erfahrungen zufolge, nicht ausführbar zu seyn. Bei der eigentlichen Ladungskette sahen wir zwar die Reaction in der Einheit der Wirkung aller zum Ganzen gehörigen Theile, aber die vorausgegangene Thätigkeit gehört nicht der geladenen, sondern der durch sie geschlossen gewesenen Primärkette. Bei der Primärkette hingegen haben wir zwar zuerst die vollständige, ihr eigenthümliche, Wirkung und unmittelbar darauf die kräfligste Ladung im Metalle, aber diese Reaction ist nur an den einzelnen Gliedern der auseinander genommenen Kette sichtbar, und so lange dieselbe in ihrer Integrität bleibt, zeigt sie begreiflich auch, nach jeder Oeffnung von neuem geschlossen, eine zwar durch die Reaction geschwächte, aber der Richtung und Art nach mit der ursprünglichen völlig gleiche Thätigkeit.

Es giebt aber eine Methode, die Kette za construiren, durch welche die letztere gewissermaassen in der Mitte zwischen die Primär-und Ladungskette gestellt wird, und eine solche Kette gewährt in der That jenen Culminationserfolg, indem man an ihr directe Action und entschiedene Reaction unmittelbar nach einander in der Integrität ihrer Wirkung auf das klarste sich aussprechen sieht. Diese Kette ist dieselbe, mit deren Hervorhebung ich die Reihe meiner Untersuchungen über die polare Thätigkeit der Leiter zweiter Classe eröffnet habe und die, wie es mir scheint, durch das Prädicat: Zwischenkette, dessen ich mich hier, um sie von der Primür- und Ladungkette zu unterscheiden, bedienen werde, am einfachsten und pas- 
sendsten bezeichnet werden kann. Die Beziehung

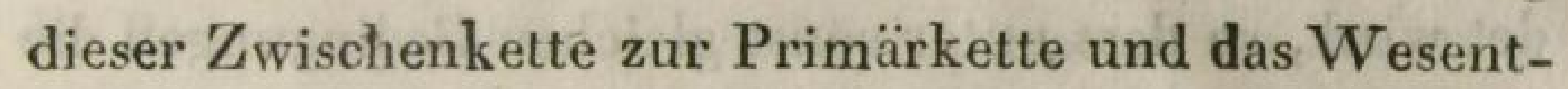
liche ihrer Wirksamkeit können nach dem gegenwärtigen Standpunkte unserer Entwickelung in wenigen $\mathrm{Zü-}$ gen gegeben werden.

Man derıke sich die Flüssigkeit $f$ der einfachen Primärkette $\approx f k$ durch ein eingeschaltetes Kupferblech $k^{\prime}$ in zwei gesonderte Schichten getheilt, dass mithin die Kette in diesem Zustande dem Schema $z f k^{\prime} f k$ entspricht, so weiss man, wie es nach allen bisherigen Deductionen längst geläufig seyn muss, dass das $k^{\prime}$ auf der einen Seite, dem positiven Kupfer $k$ gegenüber, negativ, auf der andern, dem negativen Zink $z$ gegenüber, positiv sey. Statt des einfachen $k \cdot$ werden nun zwei solche von einander gesonderte Kupferbleche $k^{\boldsymbol{t}}$ und $k^{\boldsymbol{t}}$ in die Kette eingeschaltet und durch einen besondern Schliessungsdrath mit einander verbunden, wie es das nachstehende Schema zeigt:

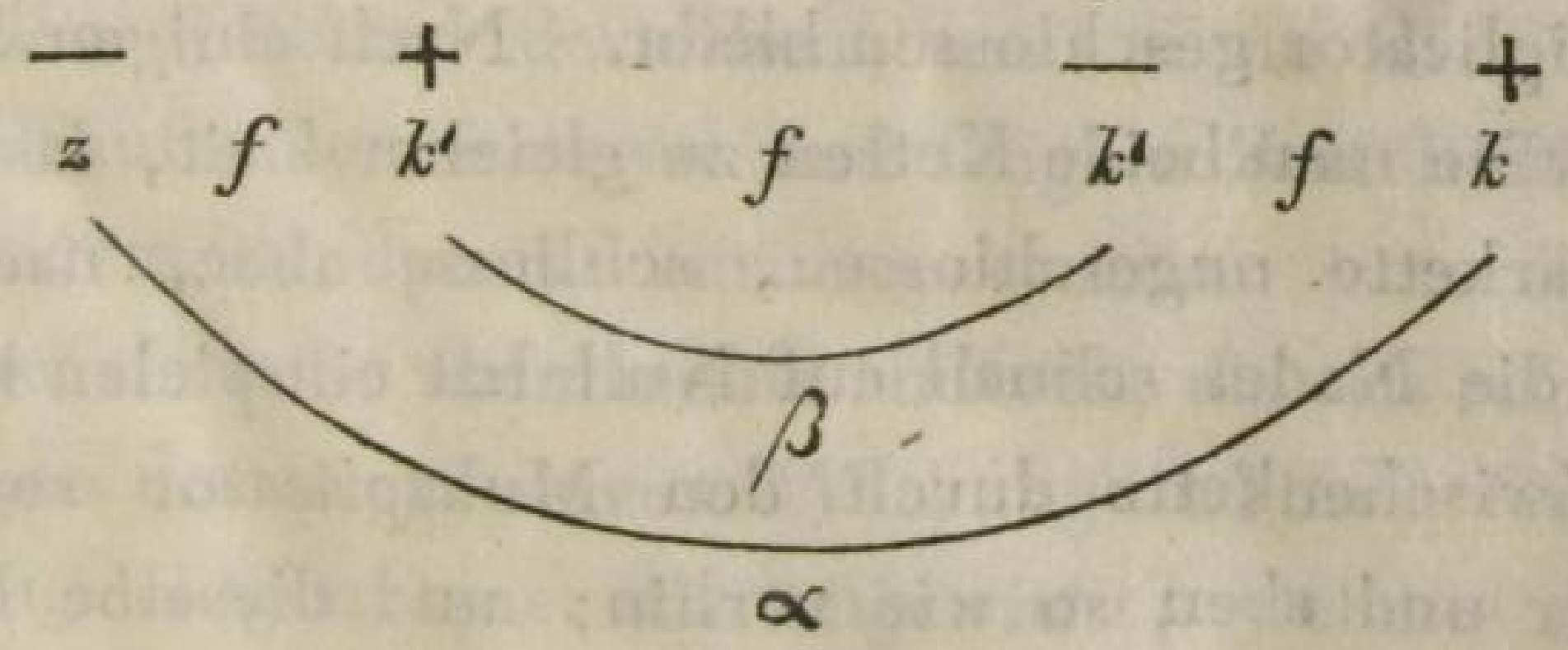

so sind die Armaturen $k^{\prime}$ und $k^{\prime}$ in der durch den Schliessungsdrath $\beta$ hergestellten Continuität gerade so wie vorhin das einzelne $k^{\prime}$ polarisirt: das auf der Seite des $k$ befindliche $k^{\prime}$ ist negativ, das andere auf der Seite des $z$ ist positiv und so bedingen sie, vermöge dieses polaren Gegensatzes, mit der von ihnen armirten Flüs-

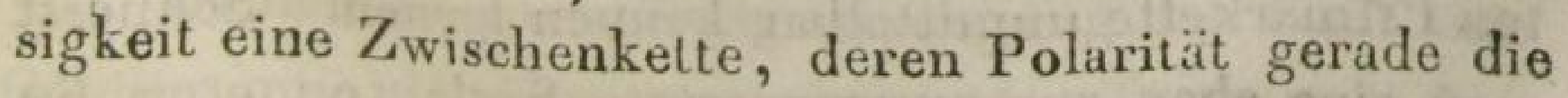
entgegengesetzte von derjenigen ist, die durch das ur- 
sprüngliche $k, z$ ụd ihren Verbindungsdrath $\alpha$ gebildet wird, so dass unter sonst gleichen Bedingungen die Magnetnadel durch $\beta$ gerade nach der ent gegengesetzten Richtung, als durch $\alpha$ abgelenkt wird.

Steht also die vom Multiplicator umschlungene Boussole im Süden des Apparats und man verbindet, statt des Drathes $\alpha$, das über der Nadel von Süden nach Norden zur Kette gehende Ende des Multiplicators mit $k$, das andere mit $z$, so wird die Nadel östlich abgelenkt. Man schliesse die Kette wieder durch den besondern Verbindungsdrath $\alpha$, lege dagegen, statt des Drathes $\beta$, die Multiplicatorenden an $k^{\prime}$ und $k^{\prime}$, so dass das vorhin mit $k$ verbundene Ende jetzt an das benachbarte $k^{\prime}$ (zur Rechten) und das vorhin mit $z$ verbundene jetzt an das dem $z$ zunächst liegende $k^{\prime}$ (zux Linken) gelegt wird, so wird die Nadel westlich abgelenkt und beharrt in dieser. Abweichung, so lange die Primärkette durch $a$ und die Zwischenkette durch den Multiplicator geschlossen bleibt. Nach einigen Minuten öffue man beide Ketten zu gleicher Zeit, lasse die Primärkette ungeschlossen, schliesse aber, nachdem. man die Nadel schnell auf Null hat einspielen lassen, die Zwischenkette durch den Multiplicator sogleich wieder und eben so wie vorhin: und dieselbe Kette, die vorher die Nadel westlich ablenkte, wird sie jetzt unmittelbar darauf gerade durch die entgegengesetzte Reaction östlich ablenken.

Einen eben so kategorisch ausgesprochenen und in vieler Hinsicht noch merkwürdigeren Gegensatz der Thätigkeit wollen wir jetzt auch an der zusammengesetzten Primärkette unmittelbar kennen lernen. Schliesst man eine eben zusammengesetzte Säule von etwa 60 
bis 100 oder noch mehr Plattenpaaren durch den um die Boussole geschlungenen Multiplicator, so hat man in den ersten Momenten eine sehr lebendige und energische Ablenkung der Magnetuadel; lässt man aber die Kette eine Zeit lang geschlossen, so tritt eine anhaltende rückgängige Bewegung der Nadel ein und die Abweichung verändert sich hier fortwährend sehr viel mehir, als es verhältnissmassig bei einer einfachen Kette zu geschehen pflegt.

Die zurückweichende Bewegung der $\mathbf{N a d e l}$ aber kann, so gewiss unsere Ansicht über die Ladungsphänomene überhaupt die wahre und naturgemässe ist, nichts anderes als das Resultat einer mit der fortschreitenden Thätigkeit der Kette gleichmässig bewirkten Ladung derselben seyn; sie ist bei der einfachen, wie bei der zusammengesetzten Kette die Folge einer dem ursprünglichen Effect um so bestimmter, je tiefer derselbe in die Masse einzudringen trachtet, entgegen tretenden Reaction derselben, und wenn die Nadel endlich auf einen festeren und längere Zeit hindurch bleibenden Standpunkt zurückgekommen ist, so bezeichnet derselbe eben nichts anderes, als das relative, zwischen der progressiven Wirkung und ihrer Gegenwirkung eingetretene, Gleichgewicht, welches nach Maassgabe der ursprünglich grösseren oder geringeren Erregunsintensität in verschiedenen Ketten an verschiedene Grade geknïpft ist, die allein, so wie die mechanischen aus zusaminengesetzten Sollicitationen resultirenden Bewegungen, zu sichern Vergleichungspuncten der verschiedenen Wirkungen geeignet sind.

Da nun die rückgängige Bewegung der Nadel im Conflict mit der zusammengesetzten Kette weit be- 
trächtlicher als bei der einfachen Kette ist, so muss auch bei jener die durch ihre eigene Wirkung zu Stande gebrachte Ladung, das heisst ihre reagirende Thätigkeit, bei weitem grösser als bei dieser seyn, nicht anders, wie die Reaction der zusammengesetzten Ladungskette nach Verhältniss ungleich stärker als die eines bloss einfachen Ladungselements ist. So lange die Kette geschlossen ist, kann diese Reaction, wie wir es bisher immer gefunden haben, nur einen hemmenden, negativen Charakter annehmen, bei welchem jedes einzelne Element zwar in geringerer Intensität, als es ohne die Reaction der Fall seyn würde, aber mit einer den Thätigkeitsrichtungen der ganzen Kette durchaus conformen Polarität wirksam ist. In dem Moment aber, in welchem die Kette geöffnet wird, tritt auch die Reaction in mannichfaltiger Form hervor: theils nur noch mit dem bisherigen Gepräge einer blossen Beschränkung des primitiven Erregungsdranges, theils unter einer transitorischen Negirung der ursprünglichen Erregungssymptome; wie man lüngst gefunden hat, dass die isolirte Säule gleich nach der Oeffnung das Elektrometer nicht afficirt und nur allmälig ihre elektrische Tension wieder herstellt, bei grösserer Empfindlichkeit unserer Elektrometer oder bei beharrlicher und vielfältiger angestellten Untersuchungen würde aber ohne Zweifel hierbei öfter schon eine der normalen selbst gerade ent gegengesetzte Polarelektricität bemerkt worden seyn; - endlich aber macht sich die Reaction in einzelnen Theilen der Säule ganz offen und positiv unter Thätigkeitsrichtungen geltend, welche den ursprünglichen vollkommen entgegengesetzt sind, und sie wird in dieser merkwürdigen 
Gestalt am sichersten und leichtesten wieder durch die magnetische Boussole erkannt. Obgleich alle Elemente der Säule gemeinsam die Reaction üben, so behält dennoch in der in einander greifeuden Gesammtthätigkeit des Ganzen die gesetzliche, ursprünglich bedingte Erregungstendenz das Uebergewicht und zeigt sich, obgleich quantitativ beschränkt, der Qualität und dem Wesen nach in der Mehrzahl der Elemente unverändert; in einer geringeren Zahl von Elementen aber sieht man dagegen die widerstrebende Natur der regulinischen Metalle um so unzweideutiger sich hervorthun, sie weisen die von der Flüssigkeit an sie gerichtete Aufforderung zum regen Entwicklungsfortschritte, der sie so lange nur mit Widerstreben sich fügten, jetzt um so gewaltsamer zurück; der Zink, der im Contact mit dem Kupfer nach Aussen gegen die Flüssigkeit positir thätig seyn wollte, aber durch sie gezwungen wurde, sich negativ zu verhalten, wird jetzt in der That positiv, das Kupfer dagegen, welches negativ seyn wollte, aber zur positiven Thätigkeit gezwungen wurde, wird jetzt in der That negativ, und das Stück der Säule, in welchem dieser absolute Rückschritt zur Verwirklichung gelangt ist, verhält sich daher, wenn man seine Wirkung mit der normalen einer progressiv thätigen Kette vergleicht, gerade so, als wenn die Metalle ihre ursprünglichen Rollen vertauscht bätten, so, als wenn die Zinkplatten zu Kupferplatten, die Kupferplatten zu Zinkplatten geworden wären.

Wie gross der durch diese Umkehrung ausgezeichnete Theil im Verhältniss zur ganzen Süule sey, und in welcher Gegend er an ihr gefunden werde, 
darüber lässt sich im Allgemeinen nicht entscheiden, weil zufällige Verschiedenheiten in der'Beschaffenheit der einzelnen Elemente der zusammengesetzten Kette einen grossen Einfluss darauf ausüben, auf welchen und auf einen wie grossen Theil des geschlossenen Kreises nach der Oeffnung desselben diese absolute Reaction sich hinwirft. Nach meinen Erfahrungen ist es die überall durch das Uebergewicht der Reaction charakterisirte, von uns so genannte, Kupferseite, das heisst also das positiv polare Extrem der Säule, welches in der Regel diese Eigenthümlichkeit zeigt, die sich bei einer Säule von 60 bis 100 Paaren oft über 15 bis 3o Elemente erstreckt; doch habe ich dieselbe Reaction auch schon auf der Zinkseite und zwischen den beiden Extremen über eine grössere und geringere Zahl von Elementen verbreitet gefunden. Aber vorhanden ist eine solche total reagirende Stelle in einer zusammengesetzten Säule, wenn sie lange genug geschlossen gewesen ist, jedes Mal und man darf, wenn man die magnetische Boussole mit dem Multiplicator anwendet, nicht lange suchen, um sie zu finden.

Die Boussole stehe im Süden der Säule und vom positiven Extrem oder der Kupferseite der letzteren gehe der Multiplicatordrath über die Nadel fort, und unter ihr von Süden nach Norden wieder zum negativen Pol oder der Zinkseite zurück, so wird die Nadel nach Osten hin abgelenkt. Ist die Kette lange genug geschlossen oder überhaupt schon längere Zeit thätig gewesen, dass die Ablenkung der Nadel, wenn sie anfänglich auch sehr gross war, auf eine geringe Zahl von Graden zurück gekommen ist, so öffnet man die Kette dadurch, dass man das Multiplicatorende vom 
negativen Pol fortnimmt; 'das andere bleibt mit 'dem positiven Pol verbunden und nachdem die Nadel über dem Nullpunct der Boussole wieder zur Ruhe gekommen, so führt man das freie Multiplicatorende, die Metallplatten der Reihe nach mit demselben berührend und vom positiven Pol ausgehend, die Säule entlang, um zu sehen, ob und in wie viel Elementen jene Reaction vorhanden sey, in Folge deren die Nadel unter der nämlichen Application des Multiplicators, bei welcher die Normalablenkung östlich ist, eine westliche Ablenkung erleidet. Ist auf diese oder eine ähnliche Weise die Stelle der totalen Reaction gefunden, so wird man, wenn sie sich, wie gewöhnlich, über mehrere Elemente erstreckt, sie nicht/selten so kräftig finden, dass in einem mit ihren Extremen leitend verbundenen Gasapparate eine wirkliche Wasserzersezzung Statt findet, die in der entgegengesetzten Ordnung von derjenigen vor sich geht, welche durch die Schliessung eines grösseren Theils der Kette oder der ganzen Säule bewirkt wird.

So lange die Reaction dauert, ist die Thätigkeit der ganzen Säule, wie sie sich in der Ablenkung der Nadel nicht nur, sondern auch in der Gasentbindung und den übrigen Functionen zu erkennen giebt, ungleich schwächer als früher; überlässt man aber die Säule im ungeschlossenen Zustande wieder eine Zeit lang sich selbst, so findet man nach Verlauf derselben die Wirkung in der Gegend der totalen Reaction schwächer und die Gesammtwirkung der ganzen Säule in demselben Maasse stürker als vorhin; endlich ist jede Spur von Reaction verschwunden, alle Elemente sind unter einander und mit dem Ganzen wieder in ein har- 
monisches Gleichgewicht der Thätigkeit getreten, die ganze Säule ist wieder von einer in stetiger Progression verbreiteten Polarität durchdrungen und mit dem Momente der Schliessung sprechen alle Functionen abermals in frischer Regsamkeit an, bis die von Nenem geweckte und mit jedem Moment immer nachdrücklicher auftretende Reaclion dem Fortgange des Processes hemmend und endlich völlig negirend sich entgegen stellt. Man sieht olne Erinnerung, dass mit diesen Nachweisungen zugleich dasjenige auf deutliche und bestimmte Merkmale zurückgeführt sey, was man sonst nur unter mehr oder minder schwankenden Vorstellungen durch Phrasen, in denen von einer Erschöpfung, von Erholung und wieder gesammelten Kräften der Säule u. dergl. die Rede ist, zu bezeichnen pflegt.

Wir werden jetzt dasjenige, was noch zur ferneren Behandlung unserer gegenwärtigen Aufgabe gehört, am zweckmässigsten mit einer Frage verknüpfen, durch deren richtige Beantwortung eine Täuschung vollends fortgerüumt werden muss, um derentwillen in unserer bisherigen Physik Thatsachen von der grössesten Wichtigkeit vernachlässigt und fast gänzlich unbeachtet geblieben sind. Wenn nämlich das Metall, nach allem, was wir gesehen haben, unläugbar eine bei weitem grössere Reaction gegen die Fortleitung der eigentlichen chemischen Thätigkeit der galvanischen Kette ausübt, als die Flüssigkeit; wie geht es dern $z u$, so fragt man im Namen des bisherigen Lehrsystems, dass durch irgend eine metallische Verbindung die Säule dennoch viel vollkommner als durch irgend eine Flüssigkeit geschlossen wird? - 
Eine Untersuchung, welche das wahrhafte Verstandniss der Natur eröffnen soll, darf die Thatsachen nicht nur nicht unbeachtet lassen, sie kann vielmehr keinen Schritt vorwärts thun, ohne zuvor die innigste Harmonie zwischen den Resultaten ihrer Forschung und dem, was faktisch ist, gesichert zu haben; aber eben darum kann ohne die in der Tiefe des Gemüths begründete Anschauung der Ideen der Erscheinungen, auch die gewissenhafteste Induction der Thatsachen nicht nur nichts anderes als ein ewig unverstandenes Chaos durcheinander geworfener, widerstreitender Elemente erzeugen, sondern sie weiss selbst gar nicht einmal das, was wahrhafte Thatsache ist, von den Trugbildern, welche die einseitige, von der Wurzel alles lebendigen Erkennens losgerissene Reflexion ihr nur in der lügenhaften Gestalt von Thatsachen vorspiegelt, zu unterscheiden, und sie ist so, in $\operatorname{dem} A b$ fall vom Glauben an ein höheres Wissen, allen Täuschungen Preis gegeben, unter welchen sie nicht selten in den Abgrund des Irrthums gerade da am tiefsten versunken liegt, wo sie sich auf lichter, fest begründeter Höhe der Erkenntniss zu befinden glaubt.

So wie der Beweis hiervon einem jeden, der in das Innere unserer Darlegungen in der gegenwärtigen Schrift eingegangen ist, bereits in vielfacher Gestalt in die Augen geleuchtet haben muss, so finden wir besonders auch Veranlassung, ihn in der Voraussezzung, welche der obigen Frage als ein unbedenklich sicheres Fundament zum Grunde gelegt ist, wiederholt zu sehen. - Ist denin dasjenige, was und wie es eben als eine schlechthin faktische Grundlage ausgesprochen ist, — dass nämlich die galvanische Säule durch Metall 
vollkommner als durchifFlüssigkeit |geschlossen werde, dass jenes ein besserer Leiter der Action der Kette sey als diese - in der That eine solche absolut gültige Thatsache? Allerdings giebt es Erscheinungen von solcher Art, dass da, wo nar sie und die gewöhnliche Reflexion gelten, die Versuchung zu einer entschiedenen Bejahung dieser Frage kaum grösser seyn kann; aber nach unserer, so leicht weder befriedigten noch bestochenen, Betrachtungsweise und von dem sichern, durch sie bereits uns ein für alle $\mathrm{Mal}$ gewordenen Standpunkte aus ist das Resultat ein anderes.

Wenn eine galvanische Säule durch einen metallischen Bogen von beträchtlicher Länge geschlossen wird, so sieht man in demselben Moment die chemische Thätigkeit in allen Puncten der Kette allerdings auf das lebendigste angeregt und von zWei mit den einzelnen Polen der ungeschlossenen isolirten Säule verbundenen divergirenden Elektrometern fallt mit der Schliessung jedes einzelne sogleich auf Null zusammen, ;ohne weiter, so lange die Kette durch den Metallbogen geschlossen bleibt, irgend ein Zeichen von elektrischer Erregung zu geben. - Wird dagegen die Kette durch eine Flüssigkeit von beträchtlicher Längendimension, z. B. durch Wasser, in einer mehrere Fuss langen Glasröhre geschlossen, so ist die chemische Thätigkeit der Säule sehr viel geringer oder sie kann selbst auf ein für die Wahrnehmung von Null nicht verschiedenes Minimum deprimirt seyn, und von den beiden mit den Polen der Säule verbundenen Elektrometern behält ein jedes seine Dirergenz grossentheils oder ganz so wie vor der Schliessung.

Das ist die verführerische Erfahrung, die unbe= 
denklich als völlig gleichbedeutend mit der faktischen Enunciation: „Das Metall ist ein ungleich besserer Leiter der galvanischen Thätigkeit als die Flüssigkeit“ angesehen worden ist, und der gegenüber man so viel andere der sprechendsten Erscheinungen, von denen bald bestimmt die Rede seyn wird und die gerade das Gegentheil aussagen, unbeachtet gelassen, oder als blosse räthselhafte Ausnahmen betrachtet oder höchstens durch die willkührlichsten, herbeigezogensten Suppositionen allenfalls im Vorübergehn so viel als möglich widersprnchlos zu machen versucht hat. Wir wollen nun dasjenige, was in der obigen Erfahrung wirklich als Thatsache enthalten ist, von demjenigen, was als solche nur aus Uebereilung und durch schlechte Dialektik in sie hinein gelegt worden, bestimmt zu unterscheiden suchen.

In welchem Verhältnisse die Länge des metallischen Bogens und der Grad der Thätigkeit in der durch ihn geschlossenen Süule zu einander stehen, darüber fehlt es bis jetzt fast noch gänzlich an Versuchen. Ohne Zweifel wird man aus künftigen experimentalen Untersuchungen finden, wie es sich zum Theil bereits aus elektromagnetischen Beobachtungen ergeben hat, dass die Thäligkeit der Säule mit der zunehmenden Länge des schliessenden Bogens abnehme und zwar bei den minder vollkommnen Metallen in einem grösseren Verhältnisse als bei denen, welche dem negativen Extrem der Metallreihe näher stehen. Im Allgemeinen aber gilt es von allen Metallen, dass wenigstens die Lünge des schliessenden Bogens von so geringem Einflusse auf die eigentliche chemische Thätigkeit der Süule sey, dass man ihn bis jetzt in Bezug auf 
diese chemischen Functionen noch gar nicht wahrgenommen hat. Und dieses Resultat steht im innigsten Zusammenhange mit unserer gleich anfangs über die Natur der Metalle und ihr Verhältniss zum Process der galvanischen Kette ausgesprochenen Ansicht. Das Metall geht nur mit seinen äussersten, der Thätigkeit der Kette dargebotenen, Extremen auf eine reelle Weise in diese Thätigkeit selbst ein, die Veränderung, welche es in Folge dieser Thätigkeit erleidet, sucht es, wie es während der ganzen Dauer des Processes sich fortwïhrend gegen sie strüubt, wenn es sich selbst überlassen ist, so weit ihm die Macht dazu geblieben, augenblicklich wieder aufzuheben und diese Veränderuug greift nicht tiefer in das Innere seiner Masse hinein, sondern sie haftet nur unmittelbar auf der mit der Flüssigkeit in Berührung gewesenen Oberfläche, sie reicht nur so weit, als die Flüssigkeit in der unmittelbaren Berührung mit dem Metalle zu wirken vermochte. Man erkennt dies z. B. darin, dass der Schliessungsdrath einer Säule, wenn er die Endplatten derselben verbunden hat, nach der Oeffnung der Kette keine merkliche Spur von Ladung zeigt, während die Endplatten selbst sehr stark geladen sind, dass er hingegen selbst beträchtlich geladen wird, wenn er mit seinen Extremen an der Stelle der Endplatten die äussersten Schichten der Flüssigkeit der Kette selbst berührt und in Verbindung gesetzt hat. Die ganze übrige Masse zwischen den Extremen des in den Process der Kette hineingezogenen Metalls übt also während dessen durchaus gar keine solche Thätigkeit, welche der an den Extremen Statt findenden gleichartig wäre, sie kann eine Gemeiuschaft mit derselben und eine ihr ent- 
sprechende Erregung nicht zurückweisen; aber in keinem Punéte kommt es zu einer lebendig haftenden Entwickelung, sondern die Masse lässt den empfangenen Eindruck, gleichsam um sich dessen so schnell als möglich zu entledigen, nur von Extrem zu Extrem mil der grössesten Geschwindigkeit und auf dem kürzesten Wege ohme Erfolg fortgleiten. Die eigentliche Wirkung ist daher an den Extremen wie ahgeschnitten, was zwischen ihnen liegt, vermittelt jene Wirkung nur durch eine bloss polare Reflexion in der Form einer schlechthin innern, nach Aussen hin völlig unsiclithar bleibenden Leitung und weil die Geschwindigkeit dieser Leitung, eben in Folge der bedeutenden Reaction der metallischen Masse, an sich so ausserordentlich gross ist, so hat auch die zwischen den Extremen befindliche Masse nur einen unbeträchtlichen Einfluss auf die Grösse der Thätigkeit und diese kann wenigstens innerhalb sehr weiter Gränzen als eine und dieselbe angesehen werden, der schliessende Metallbogen sey kurz oder lang, die ganze Masse desselben ist, wie schon früher bemerkt worden, als nicht vorhanden, nur wie ein Aequivalent der in unmittelbare Berührung getretenen Aussenflächen des Endplattenpaars selbst anzusehen und so wenig irgend ein anderes Plattenpaar während der Schliessung das Elektrometer afficirt, so wenig zeigt auch ein sehr langer Schliessungsdrath irgend eine Spur von elektrischer Erregung, weil er mit den Schlussplatten zusammen nicht ander's wirkt und thätig ist, als jedes andere Platterpaar der ganzen Kette. Daraus, dass auch ein sehr langer metallischer Verbindungsbogen der Säule nicht, so wie ein flässiger, das Elektrome- 
ter afficirt, folgt also keinesweges, dass er die Thätigkeit der Kette besser leite als die Flüssigkeit; er reagirt vielmehr mit seinen Extremen, den Schlussplatten, so wie jedes Metall, ungleich stärker gegen diese Thätigkeit als die Flüssigkeit und nur sein Leitungsvermögen für die Elektricität, welche nicht diese Thätigkeit selber, sondern nur, als Tendenz zu ihr, einen blossen Reflex derselben darstellt, ist grösser, und zwar gerade in Folge jener viel stärkeren Reaction grösser, als bei der Flüssigkeit.

Suchen wir dagegen die Flüssigkeit, ihrer eigenthümlichen Entwickelung getreu, nach ihrem Verhalten im Kreise der galvanischen Batterie aufzufassen, so tritt uns als das wesentlichste Merkmal zu dieser Charakteristik, gerade im Gegensatz mit dem, was das Metall'zeigt, zunächst eine reellere, in allen ihren Puncten Statt findende Theilnahme der Flüssigkeit am Process der Kette entgegen. Man lasse eine Wassersäule von beträchtlicher Länge eine kräftige Batterie mehrere Minuten lang schliessen und bei ihrem Austreten aus dem geschlossenen Kreise derselben wird man sie nicht nur, wie ein Metall, auf den äussersten Extremen geladen findeu, sondern, wenn man irgend zwei zwischen den Extremen liegende Stellen derselben mit indifferenten Metallen armirt und diese mit dem um eine hinlänglich empfindliche Magnetnadel geschlungenen Multiplicator verbindet, so wird man, durch die erfolgende Abrenkung der Nadel, von einer Ladung und der zufolge von einer überall vorgegangenen chemischen Veränderung in der Flüssigkeit überzeugt werden, die wieder nur das Resultat von einer in allen Puncten der letzteren vorhanden gewesenen 
reellen Theilnahme am Processe der Kette seyn kann. Jeder erregte Punct der Flüssigkeit drängt also den empfangenen Eindruck nicht'so spurlos, wie es beim Metalle geschieht, an sich vorüber, seiner Nachbarschaft zu, ex nimmt ilın vielmehr bereitwillig auf, hält ihn fest und an dieser ihm bleibenden Erregung wird - jeder Punct seiner Umgebung wieder eben so erregt, um abermals in der nächstfolgenden Umgebung eine gleiche Erregung hervorzurufen und so fort, Aber je weiter von der ursprünglichen Erregungsquelle, welche in der Berührungsfläche des Metalls mit der 'Flüssigkeit liegt, die so erregten Puncte der letzteren entfernt sind, um so schwächer wird begreiflich diese in die Masse mehr und mehr sich verlierende Erregung und sie muss früher oder später endlich, wenu die Quantität der Masse gross genug ist, so gering werden, dass die Reaction, welche der Flüssigkeit zwar in viel geringerm Grade als dem Metalle, aber ihr dennoch als Masse zugehört, gleichfalls der weitern Verbreitung der Erregung mit Erfolg mehr oder weniger hemmend entgegen wirkt, Bei der Flüssigkeit ist also die Längendimension und ihre, nach Maassgabe der letzteren, angehäufte Masse gerade darum nicht gleichgültig für den Erfolg, mit welchem die Thätigkeit der Kette durch die Flüssigkeit fortgeleitet wird, weil die Flüssigkeit von Natur ein so guter und viel besserey Leiter dieser Thätigkeit als das Metall ist, indem sie mit allen Puncten, selbst noch in beträchtlicher Ent= fernung von den ursprünglichen Erregungsflächen, an dieser Thätigkeit reellen Antheil nimmt, während bejm Metalle die Masse zwischen den Erregungsflächen darum fast gleichgültig ist, weil es ausschliesslich nur 
mit den in diesen Extremen befindlichen Puncten seiner Masse die Thätigkeit der ganzen Kette auf eine wahrhafte Weise theilt.

Wir können demnach den Gegensatz in der $\mathrm{Na}-$ tur des Metalls und der Flüssigkeit, wie sie ihn in ihrem Verhalten als Glieder der galvanischen Kette zu erkennen geben, sehr bestimmt in der folgenden $\mathrm{Par}$ allele zusammenfassen:

Das Princip der Reaction gegen die Thätigkeit der galvanischen Kette ist im Allgemeinen im Metalle das vorherrschende; darum ist das Metall ein schlechter Leiter der eigentlichen chemischen Thätigkeit der Kette und ein guter Leiter der Elektricität, als des blossen Reflexes dieser Thätigkeit.

Das Princip der Reaction ist dagegen im Allgemeinen in der Flüssigkeit schon ein untergeordnetes; darum ist die Flüssigkeit ein ungleich besserer Leiter der chemischen Thätigkeit der Kette und ein unvollkommnerer Leiter, des blossen elektrischen Reflexes dieser Thätigkeit.

Und aus diesem Gesichtspuncte spricht uns sogleich, weil er der wahre und naturgemässe ist, eine Harmonie der Erscheinungen an, die in der chaotischen Verworrenheit der gewöhnlichen Ansicht ganz verloren gegangen ist. Wir erkennen in dem Gegensatze des Verhaltens, welches Metall und Flüssigkeit hinsichtlich des Galvanismus zeigen, die treue Analogie dessen, was sie zugleich in Bezug auf das Licht sind. Das Metall strebt die galvanische Thätigkeit von sich abzuweisen, wie es sich dem Lichte unzugänglich erhält; aber es leitet die Elektricität, als den blossen Reflex dieser chemischen Thätigkeit in Folge 
jener Reaction um so viel besser, eben so, wie es vermöge jener Verschlossenheit gegen das Licht unter allen übrigen Sloffen am geeignetsten dazu ist, dasselbe zu reflectiren, und die quantitative Masse des Metalls erscheint, während es als Leiter der Elektricität sich wirksam zeigt, fast eben so gleichgültig und bedeutungslos, wie sie es bei der Reflexion des Lichts ist. Die Flüssigkeit hingegen leitet die galvanische Thätigkeit, wie das Licht, durch ihre in allen Puncten thätig empfängliche Masse, sie ist aus demselben Grunde eben so ein scltlechter Leiter der Elektricität, wie sie ein unwirksamerer Reflector des Lichtes ist, und der Erfolg ihrer Leitung der galvanischen Thätigkeit ist eben so wie der beim Durchgange des Lichts abhängig von der Quantität und Form der leitenden Masse.

Die gangbaren Benennungen: Leiter erster und zweiter Classe behalten wir, wie es bisher geschehen, als blosse. Synonyme von Metall und Flüssigkeit bei (das letztere Wort, wie sich fast überall in dieser Schrift von selbst versteht, in der gehörigen Beschränkung genommen, in welcher z. B. Quecksilber im gewöhnlichen Zustande und geschmolzene Metalle ganz ausgeschlossen bleiben); obgleich durch die obige Charakteristik die wahre Bedeutung dieser Unterscheidung erst klar geworden ist, so dass eigentlich die entgegengesetzte Nomenclatur von derjenigen, die einmal durch den Sprachgebrauch befestigt worden ist, die richtige wäre.

Wir können jetzt ohne Schwierigkeit die wahre und falsche Seite des obigen Satzes von einander sondern, der so lange höchst irriger Weise als eine rein faktische Enunciation in der Physik unbedingt gegol-

$\mathrm{O}_{2}$ 
ten hat. Setzen wir irgend eine Flüssigkeit, deren ILeitungsvermögen für die Thätigkeit der galvanischen a Süule nochiso vollkommen sey, es wird den vorausgegavgenen Betrachtungen zufolge alle $\mathrm{Mal}$, wenu sie rals leitender Verbindungsbogen zwischen den Extre-men einer Säule thätig seyn soll, eine Länge dieses .Bogens auszumittelu seyn, mit welcher und über welche hinaus die Säale unvölkommner durch denselben geschlossen wird, als durch ingend einen metallischen Bogen, so wvie die Durchsichtigkeit eines Mittels, durch cine hiṇänglich grosse Anliaufung seiner Masse am Ende zu jedem Grade der Uuvollkommenheit zurückgefübrt werden kann. In so fern kann also allerdings gesagt werden, dass die Kette durch jede Flüssigkeit unvollkommner als durch irgend ein Melall geschlossen werde; aber die Täuschung, welche auf eine kaum glaubliche Weise so lange in der W issenschaft obgewaltet hat, liegt gerade darin, dass man dieses: in so fern, ganz übersehen und dasjevige, was nur bedingungsweise richtig ist, sogleich zu einer absolut gültigen Wahrbeit erhoben hat; denn es ist eben so gewiss, dass bei weitem die meisten, wemn nicht alle Tlüssigkeiten, sofern sie in hinlänglich dünnen Schichten zwischen die Pole der galvanischen Süule gebracht werden, eine grössere Thäligkeit der Kette und folglich eine vollkommnere Schliessung derselben, als irgend ein metallischer Verbiudungsbogen bewirken. Wir sagen: hei weitem die meisten, wenn nicht alle Flüssigkeiten, sofern das Behauptete durch das Experiment nachgewiesen werden soll; denn ohne diese Rücksicht, wenn die Bedingung: hinlänglich dünne Schichten der Flüssigkeit anzuwenden, in einem Sinne genommen wird, 
der an die empirische Beschiränkung der experimentålen Leistung nicht gebunden bleibt, ist der Satz, dass die Flüssigkeit, als solche, die Kette vollkommner alsı das Metall schliesse, zuverlässig füir alle eigentlichen Flüssigkeiten ohne Ausnahme richtig. Die einfachste: Methode seiner experimentalen Constatirung beruht wieder auf der Anwendung des Muliplicators mit ders magnetischen Boussole.

Man setze eine einfache Kette aus einem Kupferund Zinkblech und mehreren zwischen diesen befind-; lichen feuchten Pappscheiben zusammen und merke dier Abweichung $(A)$, in welcher die Nadel unter dem schliessenden Multiplicator einen bleibenden Stand er-j langt. Es darf nicht noch er'st ausführlich bemerkt werden, dass die Kette durch jeden ihrer Theile, welcher getrennte Seiten vereinigt, eben so wohl, alsa dı̧rch den Verlbindungsdrath geschlossen wird, sie ist? ein Kreis, den irgend ein Theil seiner Periphevie so gut wie jeder andere zu einem in sich zurüicklaufenden' Ganzen abschliesst. In der obigen Kette kann daher/ auch, während der Multiplicator als ein integrirender Theil derselben in seiner Verbindung mit den Metallblechen unverändert erhalten wird, das Contigunm ders feuchten Pappscheiben zwischen den beiden änssersten, welche den Metallblechen anliegen, als eiu schliessen-3 des Glied der Kelte betrachtet werden. Nimmt man von diesen Pappscheiben eine nach der andern aus der Ketle heraus, so sieht man die Ablenkung der Nadelb fortwährend grösser werden, zum Beweise, dass wit der Verminderang der Längendimension (der Dicke) der schliessenden Flüssigkeit die Thätigkeil der Kelle beständig zunehme. Maumerke zulotzt die steheide, 
Abweichung $(B)$ der Nadel, welche Statt findet, wenn nur noch drei Pappscheiben zwischen den $\mathrm{Me}-$ tallen sich befinden, und die Kette mithin nur noch durch die eine dieser Scheiben, welche in der Mitte zwischen den beiden andern liegt, geschlossen wird. Wird darauf auch diese aus der Kette weg genommen und an ihrer Stelle eine Kupferplatte als schliessendes Glied eingeschoben, so kann die Abweichung grösser seyn, als die anfängliche unter $A$, wenn bei dieser eine hinlänglich grosse Zahl von Pappscheiben genommen war; aber sie wird, so oft die Flüssigkeit eine saure oder elektrische Solution oder auch nur destillirtes Wasser ist, stets 'geringer als die letztere unter $B$ seyn, welches unmöglich wäre, wenn die Kette durch eine Schicht der Flüssigkeit von der Stärke einer Pappscheibe nicht vollkommner als durch das Kupfer geschlossen würde.

Werden statt des Kupfers Platten von verschiedenen andern Metallen genommen, so zeigen alle im Wesentlichen dasselbe Resultat, dass darch die Flüssigkeit, wenn sie in hinlänglich dünner Schicht genommen worden, die Kette vollkommner als durch das Metall geschlossen werde, oder, welches dasselbe ist, dass das letztere gegen' die Thätigkeit der Kette stärker als die Flüssigkeit reagire und daher, der Wahrheit nach, ein schlechterer Leiter dieser Thätigkeit als die Flüssigkeit sey. Hierbei werden zugleich in den verschiedenen Metallen verschiedene Grade der Reaction wahrgenommen, und es findet sich so z. B., dass die Kette durch Zink in Vergleich mit derselben Schicht des flüssigen Leiters bei weitem minder unvollkommen als durch Kupfer geschlossen werde, dass 
also der Zink gegen die Thätigkeit der Kette ungleich weniger reagire oder für diese Thätigkeit ein sehr viel besserer Leiter sey, als das Kupfer, und wenn man ein Gold - oder Platinblech oder statt dessen nur eine ächt vergoldete Messingplatte zwischen die feuchten Pappscheiben bringt, so wird die Ablenkung der $\mathrm{Na}-$ del noch geringer als durch die eingeschobene Kupferplatte, indem Gold und Platin unter den Metallen gerade die schlechtesten Leiter der galvanischen Thätigkeit darstellen.

Ein grosser Theil der Erscheinungen, welche die Ritter'sche Ladungssäule zeigt, ist nur eine Wiederholung der eben angegebenen Erfolge in grösserem Umfange und dient zur vollständigen Bestätigung unserer darüber eröffneten Ansicht.

Man theile eine kräftige galvanische Batterie in zwei gesonderte Theile und setze diese Theile an den innern Seiten durch einen Gasapparat in leitende Verbindung, der, sobald die Süule an ihren äussersten Extremen in gehöriger Vollkommenheit geschlossen wird, augenblicklich in lebhafte 'Thätigkeit geräth. Man schliesse nun die Batterie zuerst durch eine Flüssigkeitssäule, die etwa aus 60 übereinander aufgeschichteten, mit verdünnter Schwefelsäure angefeuchteten, Pappscheiben besteht, deren Extreme mit Kupferplatten armirt sind, von denen Leitungsdräthe zu den Polen der Batterie geführt sind, und beobachte den Grad der Wirksamkeit im Verhalten des Gasapparats.

Man nehme darauf aus der Mitte der schliessenden Säule etwa 30 unmittelbar übereinander liegende Pappscheiben hinweg und schiebe an ihrer Stelle eben so viel mit regulinischen Flächen unmittelbar über- 
einander gelegte Kupferplatten ein. Bei genauer $\mathrm{Ver}=$ gleichung wird man jetzt schon eine Abnahme der Thätigkeit im Gasapparate bemerken, die indess, weil sie nur die Folge der Reaction der beiden metallischen Endflächen des eingeschobenen Kupfercontiguums ist, im Verhältnisse der lebendigen Thätigkeit der Batterie überhaupt hier noch so geringe seyn kann, dass sie nicht auffallend ist. Werden aber die 30 Metallplatten nur in 5 Lagen gesondert und unter die feuchten Pappscheiben vertheilt, so dass Lagen von Kupfer und feuchter Pappe, jede aus 6 einzelnen Scheiben bestehend, abwechselnd auf einander folgen, so wird die Verminderung in der Thätigkeit des Gasapparats und der Batterie schon nicht mehr zu verkennen seyn. Theilt man jede Lage aufs Neue in zwei Theile und ordnet die getrennten Theile abermals zu abwechselnden Schichten von Metall und Flüssigkeit, jede zu 3 Scheiben, so ist die Wirkung der Ketle wieder um ein Beträchtliches geringer geworden und sinkt so durch fortgeselzte Vermehrung der Abwechselungen immer weiter bis zu dem Minimum herah, welches mit dem, durch die einzelnen alternirenden Scheiben gebildeten, Maximum der Abwechselungen eintritt.

Nach den gewöhnlichen Vorstellungen über die Leitung der galvanischen Thärigkeit, denen zufolge diese Leitung nichts anderes als ein uuunterbrochener elektrischer Strom ist, der durch das Metall am leichtesten und schmellsten circulirt, ist es eines Theils nicht zu begreifen, wie in dem obigen Versuche durch das an die Stelle der sonach schlechter leitenden Flüssigkeit eingeschobene Metall die Leitung üherhanpt unvollkomıner werden könne; ja die Erfolge widerspre- 
chen vielmehr geradehin der Zulässigkeit jener Ansichten auf das Entschiedenste; andern Theils bleibt es zugleich nach denselben Vorstellungen noch eben so räthselhaft, wie mit der Vermehrung der Abwechselungen olıne alle Vergrösserung der Masse und der übrigen räumlichen Dimensionen dennoch auch die Leitung und die nach der herrschenden Ansicht davon abhängige Thätigkeit. der Kette veründert werden könne. Man hat sich indess mit einem: "peut-être cette resistance est-elle produite par la couche imperceptible d'air non cunducteur qui adhère aux surfaces de tous les corps" zu beruhigen gewusst und es hequemer gefunden, stalt einen durch die sprechendsten Thatsachen als durchaus einseitig und völlig ungenügend bezeichneten Gesichtspunct aufzugeben, denselben vielmehr unter noch einseitigeren, ganz willkuihrlich herbeigezogenen Suppositionen heizubehalten.

Ritter, der die ron dem vielfältigen Wechsel der Lagen in der Ladungssäule ahhüngige Verminderung der Thätigkeit der Batterie zwar auch noch, mit der in der Lehre vom Galvanismus stets herrschend gewesenen Befangenheit, als die Folge einer retardirten elektrischen Leitung betrachtete, legte denuoch gerade auf diese Seite der Phänomenologie der Ladungssäule ein besonderes Gewicht und sah sie, so wie das Ganze, mit einem ernstlicher forschenden und tiefer blickenden Auge an, als dass es ihm möglich geweseu seyn sollte, zu solchen, aus dem Winkel hergenommenen, Vorstellungen seine Zuflucht zu nehmen, mit. denen später diese Resultate seiner Entdeckungen in Schatten gestellt. wurden, ron denen der geistrolle unvergessliche Mann schon damals eibe gänzliche Refurm der bisherigen An- 
sichten von Volta's Batterie, ihren Phänomenen, von Elektricität, ihrer Erregung, Leitung, Ladung und aller ihrer Wirkungen sich versprochen hatte. (S. Ritter's phys. chem. Abhandl. B. 3. S. 144.)

Aber dasselbe Princip der Reaction, welches in der physischen Welt vorzugsweise durch die regulinische Masse des Metalls geübt wird, die mit dem erlogenen Schein einer edleren Qualität gerade im Gegentheil nur um so mehr auf der Stufe der starrsten Versunkenheit und Unaufgeschlossenheit lastet, dieses Princip der Finsterniss, welches eben so in der Geschichte und in der Welt der geistigen Entwickelung den Fortschritten zum Licht und zur Freiheit von jeher eine dämonische Opposition entgegen gehalten hat, dasselbe Princip hat auch da, wo es am wenigsten oder gar nicht hätte herrschend werden sollen, im unmittelbaren Gebiete der Wahrheit und Wissenschaft sich stets geltend gemacht und nicht selten Reformen, deren Nothwendigkeit durch die reinsten, sonnenklarsten Motive unumgänglich geboten wurden, so lange unterdrückt oder rückgängig gemacht, ja als Thorheit und Frevel gegen die Wissenschaft bezeichnet, bis der von Ewigkeit her entschiedene Sieg des Lichtes und der Wahrheit, der allen Gegenwirkungen aus dem Reiche der Finsterniss doch früher oder später irgend einmal ein Ziel setzt. und sie am Ende selbst durch ihre eigenen ohnmächtigen Bestrebungen unterjocht, auch hier die von Unwissenheit, Irrthum oder bösem Willen geschmiedeten Fesseln zerbrach und den Ideen ihre ursprünglichen Rechte wieder zu Theil werden liess.

Ritter's Scharfblick konnte der gänzliche Mangel an Zusammenhang zwischen jenen Erscheinungen sei- 
ner Ladungssäule und der herrschenden Theorie über die galvanische Thätigkeit nicht verborgen bleiben, aber indem er selbst noch mehr oder weniger von den Vorurtheilen und Irrthümern dieser Theorie gefesselt blieb, so vermochte er es auch nicht, ohne sich zu solchen' durch sein Talent beseitigten Winkelzügen in der Beweisführung zu verstehen, über jene Erscheinungen Rechenschaft zu geben, sondern er rechnete sie noch mit zu den Geheimnissen, die ihm in der Leitungsart der Körper zweiter Classe noch verborgen zu liegen schienen und die er, seinem ausdrücklichen Geständnisse zufolge, bei weitem noch nicht zu enträthseln sich anmafsen konnte. (a. a. O.S. 135.)

Hat man aber einmal von den beengenden Vorstellungen sich völlig frei gemacht, welche lediglich durch die Tyrannei einer aus der Einheit der Naturanschauung ganz herausgetretenen Hypothese aufgedrungen werden, so fältt auch das Räthselhafte, welches die Erscheinungen nur so lange zeigen, als sie in dem falschen Lichte dieser Hypothese gesehen werden, von selbst von ihnen ab. Unserer entwickelten Ansicht gemüss wirken die 3o Kupferplatten in dem obigen zuletzt angeführten Versuche, so lange sie, unmittelbar über einander liegend, nur ein einziges metallisches Contiguum bilden, nicht anders wie ein einziges Metallblech, das allein mit seinen beiden Aussenflüchen an der 'Thätigkeit der Kette reellen Antheil nimmt urd zugleich allein mit diesen Aussenflächen gegen dieselbe Thätigkeit ungleich kräftiger als irgend ein Leiter zweiter Classe reagirt, während die zwischen diesen Aussenflächen befindliche Masse für den Process im Ganzen mehr oder weniger gleichgültig ist, indem sie ihn, sie 
sey gross oder klein, anf eine und dieselbe, wenigstens für die Wahrnehmung um so weniger verschiedene, Weise vermittelt, je näher das Metall dem negativen Extrem der ganzen Metallreihe steht. Wird dagegen dieselbe Metalimasse durch mehrere flüssige Zwischenschichten unterbrochen, so wird mit der vermehrteu Zahl der thätigen reagirenden Flächen auch die Summe der Reactionen grösser und die Thätigkeit der gauzen Kelte muss offenbar in demselben Maasse geringer werden, in welchem mit der vermehrten Zahl der abwechselnden Lagen des Metalls und der Flüssigkeit anch die Summe der reagirenden Thätigkeit mit der Verviclfäligang der reagirenden Flächen vermehrt wird.

Dies wird noch anschaulicher, wenn die reagirenden Metallbleche in der galvanischen Batterie unmittelbar eingeschaltet werden. Die leiztere sey aus 30 Elementen von der Form kfz zusammengeselzt und jedes $f$ bestehe ans zwei fenchten üher einander liegenden Pappscheiben. Werden nun in die Säule 30 Ziukbleche so eingeschaltet, dass in jedem Llemente die beiden Pappen durch ein Zinkblech vollkommen gesondert werden, so wird die chemische Thäligkeil der durch einen Gasapparat geschlossenen Batterje dadureh allerdings um etwas, aber verhältnissmüssig nur wenig vermindert, weil die Reaction des Zinks an sich geringe ist und weil seine Theilnahme an der Action der Batte-s rie noch durch die lehendige Wechselwirkung vermehrt. wird, in welche er unter dem Typus der. Thätigkeit der zweigliedrigen Kette schon an und für sich mit der Flüssigkeit tritt. Werden aber statt des Zinks eben so viel Bleche von Kupfer auf dieselbe Weise in die 
Batterie eingeschaltet, so dass die beiden feuchten Pappscheiben eines jeden Elements durch eine nit ganz trockenen Ründern über sie hervorragende Kupferplatte völlig aus eiuander gehalten werden, so wird darch die vereinigte Reaction der 60 Kupferflachen die chemische Thäligkeit der geschlossenen Säule sehr bedeutend geschwächt, und wenn endlich statt der Kupferbleche eben so viel Gold-oder Platinbleche oder nur ächt vergoldete Messingplatten auf die nämliche Weise interpolirt werden, so kann, wie dieser Erfolg durch die bekannte Jäger'sche Säule längst constatirt ist, die Summe der Reactionen so gross werden, dass die chemische Thätigkeit der ganzen Batterie dadurch völlig aufgehoben und zum Schweigen gebracht wird. Wenn diese Hemmung ron den couches imperceptibles d'air non conducteur abhängen sollte, warum findet sie, worauf doch Ritter gleich mit der ersten Mittheilung seiner Entdeckung besonders aufmerksam gemacht hatte, bei eingeschalteten Platten von andern Metallen in verschiedenem Grade Statt und warum bringen diese couches, die doch auch den Erregerplatten adhäriren, in kleinen schwach wirkenden Säulen an und für sich keine solche Unterbrechung der chemiscisen 'Thäligkeit hervor?

Eine Batterie, deren chemische Action durch metallische Zwischenbleche auf die angegebene $W$ eise vermindert oder gänzlich gehemmt ist, zeigt übrigens in ungeschlossenen Zustande die elektrische Spannung an ihren Polen noch so, als es vor der Einschaltung jener Bleche geschieht, wodurch also die Verschiedenheit zwischen der Fortleitung der elektrischen Erregung und der Fortleitung der eigentlichen chemiscben 'Thätigkeit 
der Kette abermals und zwar auf das unmittelbarste vor Augen gestellt ist. Aber diese Anerkennung der Verschiedenheit berechtigt auf der andern Seite keinesweges dazu, beide Thätigkeiten in der Vorstellung wieder, gänzlich aus einander zu reissen und sie nach der Weise des gemeinen Bewusstseyns, das sich zur vernunftmässigen Anschauung der realen Einheit der Erscheinungen nicht erhebt, indem es beständig nur zwischen den formalen Disjunctionen des gänzlichen Einerlei-und des gänzlichen Verschiedenseyns hin und her schwankt, als absolut getrennte und ohne allen innern Zusammenhang völlig auseinander gehaltene Momente zu betrachten; sondern die elektrische Erregung ist von der chemischen Thätigkeit eben so verschieden und dennoch eben so identisch mit ihr, wie die Knospe und die geöffnete Blüthe oder wie die Blüthe und die Frucht verschieden und dennoch eins sind; die elektrische Spannung ist nur die nach Aussen reflectirte, noch nicht zur innern That ausgebildete, Erscheinung des Chemismus, sie ist nur, wie wir das Verhältniss von Anfang an bezeichnet haben, und wie es durch alle Erscheinungen auf das unverkennbarste manifestirt wird, die offenbarte Tendenz zur Realisirung des letzteren, und dem gemäss kann begreiflich die galvanische Kette, deren chemische Wirksamkeit durch die Reaction der eingeschalteten Metallplatten in dem Grade gehemmt wird, dass sie selbst nicht mehr zur reellen Thätigkeit zu gelangen vermag, dennoch die Tendenz zu derselben in der Form der elektrischen Erregung gerade um so bestimmter und kräftiger hervortreten lassen, je entschiedener jene Hemmung an und für sich ist. 
Der Grad der Vollkommenheit, mit dem eine galvanische Kette geschlossen wird und der daraus herzuleitende Grad des Leitungsvermögens in dem schliessenden Gliede hängt also nicht sowohl von der Fähigkeit des letzteren, die elektrische Erregung fortzuleiten, sondern vielmehr von seiner Eigenschaft $a b$, vermöge deren es einerseits gegen die chemische Thätigkeit weniger oder mehr reagirt, andererseits einen grösseren oder geringeren Antheil an ihr zu nehmen und sie fortzupflanzen vermag. Daher sind alle Bestimmungen und Reihenfolgen über das sogenannte Leitungsvermögen, die man aus verschiedenen Graden der chemischen oder magnetischen Thätigkeit einer und derselben galvanischen Kette für verschiedene zu Verbindungsgliedern genommene Stoffe oder für verschiedene Massen eines und desselben schliessenden Stoffes bis jetzt hat herleiten wollen, fast ohne Ausnahme verfehlt, sie sind ohne Basis, indem sie zunächst nicht reine Thatsachen geben, sondern nur aus übereilten, blos nach einer Hypothese gemachten, Schlüssen hervorgehen und die solchergestalt gewonnenen Resultate gelten vielmehr für das chemische als für das elektrische Leitungsvermögen, ungeachtet sie auf letzteres fälschlich einzig und allein bezogen worden sind. Aber auch die naturgemässe Abstufung in dem chemischen Leitungsvermögen der verschiedenen Stoffe ist durch jene Reihen noch keinesweges vollkommen gegeben: denn der Grad der Vollkommenheit, mit dem eine Kette durch irgend einen Stoff geschlossen wird, ist eine Function von dem chemischen und elektrischen Leitungsvermögen dieses Stoffes zugleich, wie der Grad der Durchsichtigkeit eines durchsichtigen Mittels von 
- seiner fortleitenden und reflectirenden Eigenschaft gegen das Licht zu gleicher Zeit abhängt.

Vermöge dieses Satzes wird zugleich die Möglich-

keit der Vereinbarung einer tiefen Gesetzmässigkeit mit einer scheinbar regellosen Willkühr in der Vertheilung individuefler Eigenthümlichkeiten der verschiedenen Stoffe sehr anschaulich. Ueberall, wo eine Fortleitung der elektrischen Erregung Stalt findet, da existirt auch eine partiell, mehroder weniger unvollkommen geschlossene galvanische Kette, wie dies besonders mit dem folgenden Abschnitte über die zweigliedrige Kelte ins Licht treten wird und die bewirkte Fortleitung der elektrischen Erregung hängt allemal mit einer in irgend einem deprimirten Grade vorhanderien, zwar nicht schlechthin realisirten, -aber auch nicht absolut unterdrückten chemischen Thätigkeit zusammen. Jeder Erfolg einer elektrischen Fortleitung ist also zugleich der Erfolg einer gleichzeitigen Fortleitung einer chemischenThätigkeit, und umgekehrt, er ist das Product beider auf eine lebendige Weise verbundener, sich innig durchdringender Factoren, die wohl in der Vorstellung, aber nicht in der Natur getrennt sind. Die gewöhnliche Classification der Körper in Leiter und Isolatoren der Elektricität ist hiernach zwar als Enunciation einer zum Grunde licgenden Thatsache allerdings richtig; aber wenn derselbe Unterschied dep Körper einzig und allein nur als das absolute Resultat der ihnen, ihrer individuellen Natur nach, ursprünglich zugehörigen verschiedenen Grade des elektrischen Leitungsvermögens betrachtet wird, so ist er einseitig und wirft auf die Natur den falschen Wiederschein einer Gesetzlosigkeit, die nur in der starren Arischauungsweise des einseitig Reflectirenden yorhanden ist. Jede 
Thätigkeit eines Körpers; die wir als eine besondere betrachten, ist in der That keine besondere, sondern sie ist seine ganze Thätigkeit, nur in irgend einem durch blosse Abstraction als besonders geselzten Moment; sie ist nicht das Resultat irgend eines einzelnen Vermögens, sondern aller Vermögen des Körpers zugleich, das heisst, seiner ganzen Natur und Daseynsweise. Wenn daher von dem elektrischen Leitungsvermögen irgend eines Körpers die Rede ist, so müssen wir von demjenigen elektrischen Leitungsvermögen, was.nach seiner natürlichen Stellung in der Reihe der z̈̈brigen Körper auf eine abstracte Weise, ohne Berücksichtigung seiner übrigen Qualitäten dem Körper ursprüng-

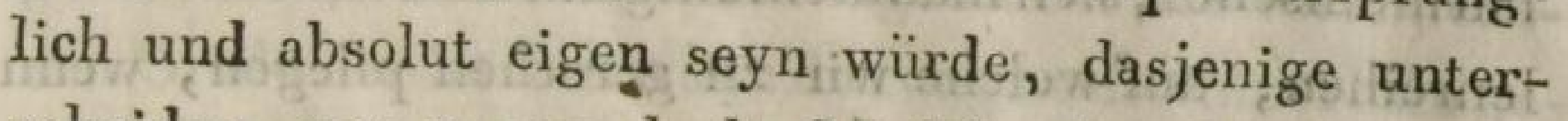
scheiden, was er nur als die Modification dieses primitiven Vermögens unter dem gleichzeitigen Einflusse aller übrigen Vermögen und namentlich in Verbindung mit seinem Fortpflanzungsvermögen der chemischen Thätigkeit in der Erfahrung wirklich zeigt. Daher werden z. B. die empirisch aufgefundenen Grade des elektrischen Leitungsvermögens der Metalle selten oder gar nicht so ausfallen, wie sie der Stellung der Metalle in der elektrischen Spannungsreihe der Körper gemäss wären: das negativste Metall dieser Reihe, welches dieser Stellung zufolge die stärkste Reaction gegen die chemische Thätigkeit ausübt, oder der schlechteste Leiter dieser Thätigkeit ist und folglich, unserer eben entwickelten Ansicht gemäss, das beste Medium zur Fortpflanzung der blossen Tendenz dieser Thätigkeit, das heisst, der beste Leiter der Elektricität seyn sollte, wird sich in der Erfahrung dennoch nicht als dieser beste Elektricitätsleiter zeigen, weil sein Leitungsver- 
mögen der Elektricität durch den Mangel an Leitungsfühigkeit der chemischen Thätigkeit in dem Maasse geschwäclit ist, dass es dem wirklichen Totalerfolg nach nur eine viel tiefere Stelle als Elektricitätsleiter einnimmt. Eben so ist ohne Zwweifel das elektrische Leitungsvermögen der Isolatoren der Elekrioität ursprünglich grösser, als dasjenige von vielen andern Körpern, welche, wie z. B. das Wasser, keine Isola. toren sind, die sich aber in der Erfahrung nur in Folge ihrer sehr viel grösseren Leitungsfähigkeit der chemischen Thätigkeit scheinbar auch als bessere Leiter der Elektricität darstellen. So rühren eines Theils die disharmonischen, sich mannichfaltig durchkreuzenden Zahlenreihen, auf welche wir zu gerathen pflegen, wenn irgend eine einzelne aus dem Zusammenhange herausgerissene Naturthätigkeit nach ihren verschiedenen Graden in verschiedenen Körpern bestimmt werden soll, von dém Mangel an Einheit und umfassendem Blicke in unserer Anschauung der Naturthätigkeit im Ganzen her; wir sondern bei solchen Untersuchungen alles dasjenige ab, wovon wir glauben, dass es durch seinen Einfluss die Resultate ungleichmässig machen könne; aber wir übersehen eine ungleich grössere Menge von Beziehungen, die mit der individuellen Natur der Körper unzertrennlich verbunden und von viel grösserem Einflusse sind: andererseits sind die gewöhnlichen verstandesmässigen, ohne innere Anschanung unterhaltenen Vorstellungen von Ordnung und Regelmässigkeit in der Natur eben so naturwidrig, wie jene disharmonischen Reihen gerade die tiefste und heiligste Gesetzmässigkeit in dem unendlich mannichfaltigen Regungen des grossen Naturlebens verkündigen. 
Jene Bestimmungen der verschiedenen Grade des elektrischen Leitungsvermögens können also höchstens, dem gemäss, was eigentlich einzig und allein Thatsache bei den zum Gruude liegenden Beobachtungen ist, nur als Angaben der verschiedenen Grade angesehen werden, nit welchen die galvanische Kette durch verschiedene Stoffe oder durch verschiedene Massen eines und desselben Stoffes mehr oder minder vollkommen oder unvollkommen geschlossen wird, sie stellen einzig und allein, wenn man so sagen darf, nur Grade des Schliessungsvermögens, nicht aber des Leitungsvermögens, weder des elektrischen noch des chemischen, dar, obgleich sie mit den Bestimmungen über die verschiedenen Grade des letzteren annäherungsweise innerhalb gewisser Gränzen noch am meisten zusammen treffen können. Aber dieses Schliessungsvermögen ist nun wieder nicht allein von dem Stoffe des schliessenden Gliedes, sondern auch von seiner Masse, so wie von der quantitativen und qualitativen Beschaffenheit der Substanzen, aus welchen die jedesmalige Kette zusammengesetzt ist und von dem grösseren oder geringeren Grade der Thätigkeit der letzteren abhängig, die zugleich wieder durch die, der Wirksamkeit der dreigliedrigen stets parallel gehende, Action der weiter unten noch zu betrachtenden zweigliedrigen Kette bedeutend modificirt werden kann, so dass unter dem Zusammenwirken aller dieser Umstände, deren genaue Berücksichtigung an sich sehr schwierig und bis dahin gänzlich ausser Acht geblieben ist, die Resultate bald so, bald anders und zum Theil, wie es die Erfahrung gelehrt hat, ganz abweichend oder völlig widersprechend ausfallen können. 
Wir werden in der Folge noch durch die Betrachtung der zweigliedrigen Kette zu bestimmteren Unterscheidungen veranlasst werden in Absicht auf die $\mathrm{Be}-$ dingungen und die Form, unter welchen dasjenige, was man unter elektrischer Leitung eigentlich verstehen nuss, Statt findet; aber schon nach den bisjetzt festgestellten Resultaten unserer Entwickelung muss sich uns die Bemerkung aufdringen, dass der so lange in der Lehre vom Galvanismus herrschend gewesene Begriff der sogenannten elektrischen Leitung vorzüglich mit zu denjenigen gehört, deren unklare, übereilte und principlose Anwendung in der Wissenschaft es aufs anschaulichste bestätigt, dass, so oft uns die Wirkungen der Natur unzusammenhängend und regellos erscheinen, die Quelle des scheinbaren Mangels an Uebereinstimmung und Gesetzlichkeit nicht ihr, sondern einzig und allein nur der Sichtungslosigkeit unserer eigenen Vorstellungen und dem Widerstreite des Aberwitzes gegen die ewig klare harmonische Gesetzmässigkeit der Naturoffenbarungen beizumesæen sey.

Unter den im Gebiete des Erkennens zu einer transitorischen Herrschaft gelangten Traumidolen, die mit dem erlogenen Schein einer regelnden Leitung nichts als Verwirrung und Widerspruch erzeugt haben, giebt es keines, durch welches die Wissenschaft härter und unverantwortlicher despotisirt worden wäre, als das Phantom der materiellen Substantialität eines elektrischen Fluidums. Die mannichfaltigsten und vielseitigsten Aeusserungen der Naturthätigkeit sind nur als die Erzeugnisse der Allgegenwart und Machtvollkommenheit dieses gigantischen Gespenstes betrachtet worden, ja fast alle übrige Imponderabilien haben die Ent- 
stehung und Anerkennung ihrer Herrschaft mehr oder weniger nur dem Vorbilde der Tyrannei dieses Urgötzen der neuern Physik zu verdanken, und unter der grösseren Mehrzahl der Naturforscher haben selbst die ausgezeichnetsten und verdienstvollsten dem Wahne und der Verblendung dieser allgemein verbreiteten Idolatrie ganz unbedingt gehuldigt. Nicht nur derjenige Theil der Erscheinungen, welcher, besonders ausgezeichnet durch das sogenannte elektrische Lieht, vorzugsweise und recht eigentlich für den Inbegriff der elektrischen Phänomene gilt, ungeachtet er gar nicht mehr der Elektricität, sondern schon dem Chemismus angehört, ist als das Werk des strömenden elektrischen Fluidums betrachtet worden, sondern in allen Erscheinungen der galvanischen Säule, in den Ritter'sehen Ladungsphänomenen, im ganzen Gebiete des Galvanismus überhaupt, in allen Formen des chemischen Processes, in allen Aeusserungen der magnetischen Wirksamkeit, ja selbst auf dem Felde der Krystallisationsthätigkeit und fast überall in der Naturlehre, wo nur zu dunkeln und vagen Vorstellungen Raum vorhanden war, hat man dieses Gespenst nicht nur walten sehen, sondern von seiner Universalherrschaft auch fast alles Besondere der Erscheinungen abhängig machen wollen:

Es ist daher kein Wunder, dass man auch eine Classe von Erscheinungen, deren in unsern bisherigen Đarlegungen noch nicht gedacht worden ist und die nach dem Ganzen unserer Ansicht, eben so wie die Phänomene der sogenannten elektrischen Ladung, denen sie sich enge anschliessen, auf nichts weniger als einer elektrischen Erregung, geschweige auf einer modificirten Strömung der eingebildeten elektrischen 
Materie beruhen, dennoch, wie es sogleich schon die gangbar gewordene Benennung zejgt, ebenfalls nur in dem allgemein herrschenden Sinne vom ersten Augenblicke ihrer Entdeckung an aufgefasst hat, nämlich die Plü̈nomene der sogenannten unipolaren' elektrischen Leitung. Die hieher gehörigen Thatsachen, welche der gewöhnlichen Weise zu sehen ganz unerwartet kommen und die räthselhafteste Willkühr der Naturthätigkeit auszusprechen scheinen, verlieren, von unserm Standpunkte aus betrachtet, nicht nur alle scheinbare Anomalie, sondern sie werden selhst sehr bald als die wesentliche Aeusserung einer allen Körpern ohne Ausnahme zukommenden Eigenschaft erkannt, von solcher Nothwendigkeit, dass man, wären sie nicht durch den Zufall entdeckt worden, sie im Geiste unserer Ansicht hätte voraussagen und aufsuchen können, und von solcher Allgemeinheit, dass sich behaupten lässt, jeder Körper müsse unter den gehörigen Umständen diese Phänomene zeigen, vermöge deren er nach der gewöhnlichen Ansicht als ein unipolarer Leiter der Elektricität bezeichnet wird, so dass dasjenige, was bis jetzt von diesen Erscheinungen wahrgenommen und bekannt geworden ist, nur ein hoher, durch das Zusammentreffén günstiger Umstände besonders hervorgehobener Grad eines Verhaltens sey, welches, wenn unsere Sinne feiner oder unsere plysikalischen Werkzeuge empfindlicher wären, sich an allen Körpern ohne Ausnahme versichtbaren würde.

So wie nämlich die Phänomene der elektrischen Ladung nicht durch eine retardirte elektrische Leitung, sonderu durch die der Masse als solcher überhaupt eigenthïmliche Reaction schlechthin bewirkt werden, so 
werden atich die Phänomene der sogenảnnten tunipolaren Leitung nicht durch eine einseitige elektrische Leitung, sondern vielmehr durch eine einseitige Reaction erzeugt ; sie sind nichts als modificirte Reactionserfolge, die durch die individuelle Natur des reagirenden Stoffs vorzugsweise bedingt werder.

Die sogenannten unipolaren Leiter leiten die eine Elektricität eben so wohl als die andere, wovon man die Ueberzeugung durch die Erfahrung auf dieselbe Weise erlangt, wie wir uns von der hinlänglichen Leitungsfähigkeit der Ladungssäule in Bezug auf beide Polarelektricitäten überzeugt haben, und so verwerflich schon darum die gewöhnlichen Vorstellungen über das Ursachliche der Ladungsphänomene sind, eben so unzulässig ist die Grundansicht und eben so widersprechend die nach dieser von vorn herein verfehlten Basis gewählte, Bezeichnung der in Rede stehenden Phänomene. Wie kann ein Körper, der ganz offenbar die eine Elektricität eben so wohl als die andere leitet, dessen ungeachtet nur in $\mathrm{Bezu}_{\mathcal{o}}$ auf eine von beiden als leitungsfähig angesehen und benannt werden? Nimmermehr würde diese gewaltsame contradictio in adjecto begangen worden seyn, wenn man den Widerspruch nicht als ein unmittelbares Factum in der Natur selbst begründet zu finden geglaubt hätte: Dieses vermeintliche Factum ist jedoch von derselben Beschaffenheit, wie so manches andere, das zu den unantastbaren Dogmen der orthodoxen Physik gezählt wird, obgleich es nicht wirklich im heiligen Codex der Naturoffenbarung befindlich, sondern nur durch falsche Interpretation hineingelegt worden ist; es ist kein reelles, sondern nur ein gemachtes, welches lediglich an der $\mathrm{Hy}$ - 
pothese hängt, dass in der geschlossenen galranischen Kette ein wirklicher Kreislauf eines elektrischen Stroms bestehe, welcher die Thätigkeit derselben vorzugsweise bedinge; es hat mit demselben Momente aufgehört, Thatsache zu seyn, mit welchem man diese leidige Hypothese hat fallen lassen. Aber so gross ist auch hier die Tyrannei derselben gewesen, dass man durch sie lieber sich und der Natur die widersinnigste Contradiction hat aufdringen lassen, ehe man nur auf die entfernteste Weise daran gedacht hätte, dass vor allem nur dieses verwirrende Hirngespinst verscheucht werden müsse.

Die Grundthätigkeit der geschlossenen galvanischen Kette ist, wie es auf dem von uns betretenen Standpunkte längst entschieden worden, nicht in einer elektrischen Erregung und Leitung derselben, sondern lediglich im Chemismus selber gegehen. Ein Körper schliesst die galvanische Kette nicht in so fern er die elektrische Erregung, welche vor der Schliessung Statt findet, fortleitet, sondern dadurch, dass er den Kreis der chemischen Thätigkeit durch einen reellen Antheil an demselben mit seinen beiden Extremen vollendet, und wénn in der solchergestalt geschlossenen Kette noch eine elektrische Erregung forldauert, so findet sie nicht Statt aus Mangel an Leitungsfühigkeit des Körpers für dieselbe, sondern vermöge einer von ihm gegen die chemischen Einwirkungen geübten Reaction, die mit einer permanenten Hemmung der chemischen Thätigkeit verbunden ist und sonach auch eine permanente elektrische Erregung in der Säule, als Ausdruck des nicht befriedigten Erregungsdranges nach chemischer Thätigkeit zur Folge hat; wie wir dieses alles im 
gegenwärtigen Abschnitte gleich oben bei der ersten Betrachtung der Ladungssäule ausführlich auseinander gesetzt haben.

Diese Reaction muss nun aber fïr verschiedene Körper nicht allein, wie wir sie bis jetzt lediglich betrachtet haben, quantitativ verschieden - sondern sie muss zugleich, dem jedesmaligen individuellen Standpunkte des Körpers gemüss, den er in der Reihe der übrigen und im Verhältnisse der Wechselthätigkeit mit der Totalität der Körperwelt überhaupt einnimmt, auch qualitativ verschieden seyn. Je indifferenter der Körper an sich und je verschlossener er als Repräsentant der Masse schlechthin gegen beide Richtungen der chemischen Thätigkeit ist, um so gleichgültiger ist im Processe der Kette selbst die bestimmle Quantität seiner. Masse und um so kräftiger wird nicht allein seine Reaction seyn, sondern um so gleichmässiger wird sie auch nach beiden Richtungen hin erfolgen; er wird der Aufforderung zur Oxydationsthätigkeit, so wie der zur Desoxydationsthätigkeit im geschlossenen Kreise der Kette mit gleichen, wenigstens für die Wahrnehmung als gleich geltenden, Kräften entgegen wirken. Je weiter hingegen ein Körper von dieser untersten Stufe der Individualisation bereits sich entfernt hat, je mehr specifische Eigenthümlichkeiten in ihm entwickelt sind und je differenter sein Verhalten überhaupt ist, um so mehr wird der Grad seiner Thätigkeit in der geschlossenen Kette auch von der bestimmten Quantität seiner Masse, in der Dimension der Axe der Kette, abhängen, um so geringer wird mit Rücksicht auf diese Quantität der Masse auch seine Reaction in der Kelte seyn, aber um so differenter wird auch diese Reaction 
ausfallen müssen und er wird; je nachdem er gerade durch sein Verhältniss zur Totalität und durch den Grad der Bestimmtheit, mit welchem er die seiner Individualität entsprechende Stufe der specifischen Entwickelung bereits hetreten hat, entweder mehr zur entschiedenen Verfolgung der einen oder zum Zurückschlagen nach der andern von den beiden polaren Thätigkeitsrichtumgen_des Chemismus disponirt ist, im Conflict mit der Wechselwirkung der Kette und der Totalität zugleich auch entweder dem Desoxydationsoder dem Oxydationsprocesse stärker und mit einem sichtbaren Uebergewichte der Reaction gegen die eine oder die andere Seite entgegen wirken.

Wir sagen, er wird dieses thun, wenn er sich im Conflict der wechselseitigen Einwirkung der Kette und der Totalität zugleich befindet; denn in dem geschlossenen Kreise der Kette an und für sich allein, wenn die ganze Kette mit dem in ihr befindlichen Körper hinlänglich isolirt ist, findet ein Gleichgewicht der Action Statt, in welchem der Grad des Antheils an der allgemeinen Thätigkeit des Ganzen nach beiden sich wechselseitig fordernden und ergänzenden Seiten hin der Quantität nach nothwendig überall derselbe ist. Wenu aber diese Isolirung durch eine Berührung des Körpers anfgehoben wird, welche ihn nit der Gesammtmasse der Umgebung in leitende Verbindung setzt, so tritt in dem Körper, welcher dadurch der ausschliesslichen bisherigen Einwirkung der Kette eines Theils entzogen worden, seine Reaction, die er bekanntlich beim völligen Austritte aus dem Kreise der Kette ganz offen und uneingeschränkt äussert, jetzt auch wenigstens zum Theil mit mehr Kraft und auf eine mehr positive Weise hervor. 
Der Körper, dessen Thätigkeit bis dahin nur allein derjenigen der Batterie entsprach, genügt jetzt den vereinigten Ansprüchen der Kette und der Totalitüt zugleich gleichsam durch eine diagonale Action, vermöge deren sein Verhalten, wenn es auf die Kette allein bezogen wird, auf entgegengesetzten Seiten derselben als ein ungleichmässiges erscheint. Auf derjenigen Seite nämlich, auf welcher die Wirkung in der Kette mit derselben Thätigkeitsrichtung gleichartig ist, zu welcher der Körpev schon durch seine individuelle Stellung in der Totalität aller übrigen Körper angewiesen ist, wird die Action der Kette grösser, der Chemismus findet auf ihr mehr Befriedigung als vorher und das auf dieser Seite der Kette befindliche, mit ihr zugleich in Verbindung gesetzte, Elektrometer, welches so lange divergirte, fällt auf Null. Auf der entgegengesetzten Seite tritt dafür die eigentliche Reaction des Körpers gegen die seiner individuellen Natur zunächst entgegenlaufende Einwirkung der Kette um so überwiegender hervor, diese Einwirkung wird daher auf derselben Seite noch mehr als vorher beschränkt und die elektrische Spannung, als Ausdruck der Tendenz zur chemischen Thätigkeit, tritt in dem Maasse, in welchem diese selbst eine grössere Hemmung erleidet, noch in höherem Grade als vorhin hervor, wie es die zunehmende Divergenz des auf dieser Seite mit der Kette verbundenen Elektrometers zu erkennen giebt.

Dies ist kürzlich unsere Grundansicht des Phänomens der sogenannten unipolaren Leitung, die wir bei der ohnedies schon so sehr angewachsenen Länge des gegenwärtigen Abschnittes hier um so weniger in einer auseinandergesetzteren und vielseitiger motivirten 
Entwickelung zu geben uns veranlasst halten, da es uns bis jetzt noch nicht vergönnt gewesen ist, den interessanten Gegenstand durch eigene, mannichfach abgeänderte Versuche weiter nach Wunsch zu verfolgen. Wir haben hierbei das Phänomen selbst, so weit es bis jetzt durch experimentale Facta constatirt worden, als bekannt vorausgesetzt und verweisen für diejenigen, welche von dem Detail der hieher gehörigen Erscheinungen umstänálicher, als es etwa bisher geschehen, sich noch zu unterrichten wünschen möchten, auf die reiche, von dem würdigen Entdecker derselben herrührende, in Gilbert's Annalen B. XXII. S. 14. befindliche Originalabhandlung. Unsere hier entwickelte Ansicht, die wir freilich für nicht mehr als die allererste Eröffnung und Begründung einer von neuem vorzunehmenden, umfassenderen Untersuchung des wichtigen Gegenstandes ausgeben, kann allerdings wohl, wie wir weit entfernt sind zu läugnen, in Folge einer solchen Untersuchung selbst weiter hin vielleicht noch mehr oder weniger Modificationen erleiden; aber sie hängt mit unserer ganzen, auf einer unerschütterlichen Basis ruhenden, Lehre über den Galvanismus so innig zusammen und geht insbesondere aus unserer, durch die mannichfaltigsten Thatsachen von allen Seiten her befestigten, Theorie der sogenannten elektrischen Ladungsphänomene so unmittelbar hervor, dass über ihre Haltbarkeit und Naturangemessenheit im Allgemeinen bei unbefangenen Naturforschern, unserm Ermessen nach, nicht leicht ein Zweifel mehr obwalten kann.

Es wäre daher zu wünschen, dass im Einverstïndnisse mit dieser Ansicht. auch eine andere Nomenclatur sich bilden möchte, in welcher, statt der bisheri- 
gen, aus irrigen Gesichtspuncton entlehnten Terminologien, angemessenere Ausdrücke zur wissenschaftlichen Bezeichnung der hier betrachteten Erscheinungen gebraucht würden. Dasjenige, was so lange durch das Prädicat einer elektrischen Ladung bezeichnet worden; ist, wie wir gesehen haben, nichts weniger als etwas mitgetheiltes, inserirtes, sondern im Gegentheil die ursprüngliche Thätigkeit der Masse, welche vielmehr der theils beginmenden, theils wirklich erfolgten Mittheilung einer chemisch polaren Veränderung geradehin entgegen wirkt und da dieser reagirende, eben so wie der progressive Effect des Galvanismus, sich voll-; ständig in den drei Momenten desselben, der Elektricitüt, des Chemismus und Magnetismus, offenbart, so scheint der Inbegriff der Phänomene, die bisher durch die einseitige Benennung der elektrischen Ladung bezeichnet worden sind, auf eine angemessene Weise durch' den Namen der galvanischen Reaction charakterisirt werden zu können. So wie num die in der vorher erwähnten Abhandlung von ihrem Verfasser hervorgehobene Kategorie der sogenannten bipolaren elektrischen Leitung keinesweges auf den Erfolg einer gehemmten elektrischen Leitungsfähigkeit begründet ist, sondern nichts anderes als der Erfolg der nämlichen galvanischen Reaction schlechthin ist, nur so fern sie sich bloss noch im Kreise der galvanischen Batterie äussert, so sind auch die Phänomene der sogenannten unipolaren elektrischen Leitung vielmehr einzig und allein nur Erfolge einer unipolaren galvanischen Re. action und würden folglich durch diese Benennung an sich, so wie im Gegensatze der Phänomene der bipolaren, d. h. der galvanischen Reaction schlechthin, 
gleichfalls auf eine angemessene Weise bezeichnet werden.

Mit dieser Nomenclatur wäre zugleich die factische Realität der in jener Abhandlung geltend gemachten Classification der Körper nach einem fünffach verschiedenen elektrischen Leitungsvermögen so bestimmt verneint, wie ihr überhaupt von unserm Standpuncte aus die Anerkennung verweigert werden muss, da die Phünomene, auf welchen jerre Eintheilung beruht, wie gesagt, durchaus riicht der elektrischen Leitung, sondern lediglich derihrer Natur nach ursprünglich im Chemismus begründeten Reaction angehören, wie denm auch der achtbare Autor jener Abhandlung auf eine solche Ansicht, obgleich er von der herrscherden sich nicht frei gemacht hat, mehrmals hindeutet und insbesondere seine Darstellung mit der treffenden Bemerkung schliesst, dass die Ursache der von ihm entdeckten Thatsachen noch tief im Chemischen verborgen liegen müsse.

Wir müssen übrigens, schon um den Schein einer geflissentlichen Uebergehung von uns zu entfernen, hiermit noch die Erwähnung verbinden, dass die in derselben Abhandlung (a. a. O. S. 4 1. u. 42.) vorkommende Argumentation, vermöge welcher die allgemein herrschend gewordene, von uns widerlegte Lehre, dass in der galvanischen Kette dem Zink der positive, dem Kupfer, Silber u. s. w. der negative Effect angehöre, von einer neuen Seite nachgewiesen werden soll, in der That gänzlich ohne beweisende Kraft für diese Thesis sey. Der Ausspruch einer Autorität, wie die des Herrn Erman, dass diese seine Demonstration es auf immer mit der grössesten faktischen Evidenz darthue, dass in der Säule der Zink und nicht das Silber der positive 
Factor sey, legt uns die Verpfiichtung einer bestimmten Auseinandersetzung seiner Beweismittel auf, deren wir uns sonst, mit Hinweisung auf unsere ganze bisherige Darlegung, in welcher zugleich mit den Quellen der in der ganzen Lehre vom Galvanismus verbreiteten Irrthümer auch die Methoden, sie zu durchschauen und zu vermeiden aufgezeigt worden sind, wohl überhoben halten dürften.

- Bringt man zwischen die Polardräthe einer isolirten, mit ihren Polarelektrometern versehenen galvanischen Säule ein Stück völlig trockene, gleichfalls isolirte Seife, so zeigt die sich gleich bleibende Divergenz in den Elektrometern eine unvollkommene Schliessung der Kette an und mit ihr also zugleich eine starke Reaction der Seifensubstanz gegen die galvanische Thätigkeit. Aber diese Reaction ist unipolar; denn wenn die Seife ableitend berührt wird, so fällt nnr das negative Elektrometer auf Null, während die Divergenz des positiven lebhaft verstärkt wird. Die galvanische Reaction der Seife zeigt sich hiermit also positiv unipolar (die Seife ist nach Herrn Erman ein negativ unipolarer Leiter der Elektricität); der positive, d. h. der desoxydirende Effect der Säule ist vorzugsweise durch die alkalische Substanz der Seife gehemmt, während der negative, oxydirende Effect durch sie hinlängliche Befriedigung findet. Wird der isolirte $\mathrm{Zu}$ stand wieder hergestellt, so divergiren auch wieder beide Elektrometer, wie vorhin, gleich stark; nicht, weil eine gleich grosse Reaction nach beiden Seiten hin Statt findet, sondern, weil mit der gehemmten Thätigkeit von der einen, auch diejenige von der andern Seite unterbrochen ist. Dies wird besonders durch das folgende Factum bestätigt. 
Wenn man' zwischen die Fläche des negativen Polardrathes und der Seife ein mit Wasser befeuchtetes Tuchläppchen anbringt, so bleibt der Effect nach beiden Richtungen hin gehemmt, wie zuvor; sobald aber der feuchte Leiter zwischen den positiven Drath und die Substanz der Seife gebracht wird, so wird durch die Erregbarkeit der Flüssigkeit und durch ihren lebendigen Zersetzungsprocess die vorzugsweise nur auf dieser Seite herrschende Reaction überwältigt; die ausserdem reagirende Seite derSubstanz der Seife wird durch die jetzt unmittelbar mit ihr in Berührung getretene Flüssigkeit in die Action der Kette unwiderstehlich hineingezogen und die verminderte Divergenz beider Polarelektrometer, oder die plötzlich eingetretene Wirkung eines bis dahin unthätigen, in dem geschlossenen Kreise befindlichen, Gasapparats beweist, so lange zersetzbare Flüssigkeit zwischen der Seife und dem positiven Polardrathe vorhanden ist, die nach beiden Richtungen in regem Fortschritte begriffene chemische Thätigkeit der ganzen Kette.

Dieses Factum ist Herrn Erman zugleich das Fundament seiner Argumentation. Er schaltet an der Stelle einer feuchten Pappscheibe zwischen irgend eine völlig trockene Silber - und Zinkplatte eine Scheibe von ebenfalls vollkommen trockener Seife in die galvanische Säule ein, welche letztere sodann durch einen Gasapparat von Pol zu Pol geschlossen wird: so findet keine Gasentbindung Statt, auch dann nicht, wenn die mit dem Silber oder Kupfer in Berührung befindliche Fläche der Seife benetzt wird; sobald aber die andere Fläche der Seife, welche den Zink berührt, befeuchtet wird, tritt sogleich die chemische Thätigkeit der Kette in 
vollei:Regsamkeit nach beiden Richtungen hin hervor. Dei Effect ist höchst constant und wird schon durch kleine Säulen von etwa nur lo bis 15 Plattenpaaren, sehíd deutlich ausgesprochen. L Wir wollen nun sehen, welche Folgerungen aus ihm zu ziehen sind.

anc Die Säule werde durch folgenides Schema dar-

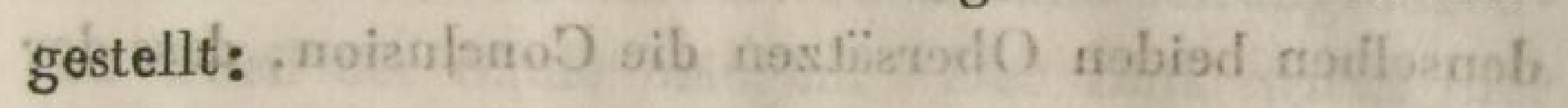

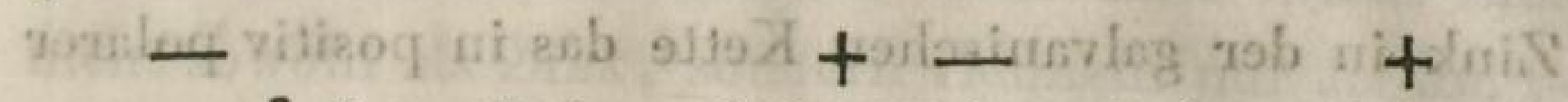

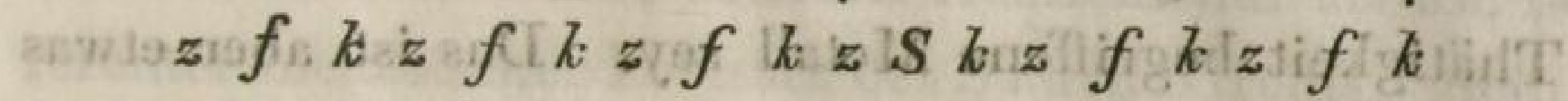
in welchem $S$ die an der Stelle eines $f$ zwischen $z$ und $k$ eingeschaltete Séifenschieibe bezeichnet, so ist auf deni äussiersten Extrem zur linkén, bei z, der négative, zur rechten, bei $k$, dér positive Pol dieser Säule. Wenn man sich aber dièses äusserste $z$ und $k$, indem sie durch den Schliessungsdrath terbunden sind, als env im unmiltelbaren Contact stehendes $P$ aar und dage'gen däs $z$ und $k$, welche durch $S$ getrennt sind und demselben unmittelbar anliegen, lals die Polarextreme der Säule vorstellt, so ist klàr, dass alsidann auf der Seite des ¿q, zur Linken von $S$, der positive, ủñ aúf der Seite des $k$, zuir Rechten von $S$, dér negative Pol der Säule sich befinde. Nun hat das obige Fundamentalfactum gezeigt, dass die vèrmittelıde Fenchtigkeit auf derjénigen Seite der Seifensubstanz angebracht werden musstè, welcho mit demi positiven Pol dèr Säule in Verbindung gesetzt war, und wir können folglich aus dem Umstande, dass auch jetzt an $\operatorname{dem} S$ zwischen dem $z$ und $k$, die linke Seite, neben $z$ befeuchtet werden múss, um den chemischen Effect der Säule in vollex Stärke hervorzurufen, mit Fug und Recht/schliessen, dass auf derselben Seite, wo das $z$ ueben $\boldsymbol{S}$ liegt, das positiv polare Extrem der Säule sich befinde. Mehr 
aber, als, dieses, was wir freilich auch ohne die Zuziehung der Seife eben vorher schon gesehen haben, können wir, ohne uns über ein logisches veto hinwegzusetzen, aus den beiden Obersätzen schlechterdings nicht herleiten.

Was thut dagegen Herr Erman? Er zieht aus denselben beiden Obersätzen die Conclusion, dass der Zink in der galvanischen Kette das in positiv polarer Thätigkeit begriffene Metall sey. Das ist aber etwas ganz anderes als alles, was jemals aus den Prämissen hervorgehen kann. Ob das Extrem einer Säule, welches eben so wohl mit einer Kupfer-als mit einer Zinkplatte schliessen kann, das positiv polare der Säule sey — und ob der Zink in der Säule überhaupt das positiv polare Metall sey: das sind zwei ganz verschiedene Fragen, von denen allein die erstere durch die obigen Vordersätze entschieden wird, während die letztere ein von jedem Bestandtheile des Obersatzes völlig verschiedenes und seinem Inhalte ganz fremdartiges Moment enthält. Der Obersatz sagt nichts anderes aus, als dass diejenige Seite der Seifensubstanz, welche, befeuchtet, den chemischen Effect hervorbringt, mit dem positiven $\mathrm{Pol}$ der Sáule verbunden sey, während die Bestimmung der Art des Metalls, durch welches dieselbe Seite mit demselben $\mathrm{Pol}$ in leitende Verbindung gesetzt ist, der Natur der Sache nach, dabei ganz frei gelassen wird; es kann Platin, Silber, Zink oder irgend ein anderes, ganz beliebiges Metall seyn. Daher kann auch die Conclusion nichts in Bezug auf ein bestimmtes Metall Gültiges, sondern einzig und allein nur die Bestimmung der Polarität des mit der befeuchteten Seite der Seife verbundenen Extrems der Säule aus- 
sprechen, ohne allen Unterschied des verbindenden Metalls, wie es im Experimente auch in der That gleichgültig ist und in dem obigen Erfolge nichts ändert, man mag an der Stelle der Zinkplatte eine andere von Silber, Kupfer oder irgend einem beliebigen Metalle zwischen die befeuchtete Seife und den angränzenden Theil der Säule bringen. Der Zink wirkt hier nicht sowohl als Zink, sondern vielmehr nur als indifferenter metallischer Fortsatz des Säulenextrems, nicht mit der eigenen, sondern vielmehr nur mit der durch das letztere bestimmten Polarität. Man lasse in jedem der beiden Plattenpaare, zur rechten und línken des $S$, die einzelnen Platten ihre Stellen vertauschen, so dass die ganze Anordnung folgende ist :

- $f k z f k z f=k z k f k z f k$ Ist sodann wieder das üusserste $z$ zur Linken mit dem $k$ auf der Rechten gehörig verbunden, so erfolgt wieder, wie sich an einem irgendwo in den Kreis eingeschalteten Gasapparate wahrnehmen lässt, durch die Befeuchtung der rechten Seite des $S$, gar kein Effect, und es findet ebenfalls nur so wie vorhin Statt, wenn abermals die linke Seite, welche jetzt mit dem $k$ verbunden ist, befeuchtet wird. Demnach könnte man jetzt, wenn es erlaubt wäre, den Grund der Wirkung auf das einzelne, an $S$ gränzende Metall zu übertragen, mit demselben Rechte, wie vorhin Herr Erman, auch schliessen: das $k$ sey das positiv, und $z$ das negativ polare Metall der Säule; während man wieder nur, so wie oben, zu der alleinigen Folgerung berechtigt ist, dass auf der linken Seite des $S$ ein positiv polares, auf der rechten ein negativ polares Extrem der Säule liege, ab-

Q 2 
gesehen ron den Metallen und der Art ihrer polaren Thätigkeit in der Süule. Man schalte die Seife in der Säule ein an welcher Stelle man wolle', stets wird man immer nur eine und dieselbe, (nach der Zeichnung die linke) Seite derselben, gleich viel welchem, Gliede der Kette sie anliegt, zur Herrorrufung des Effects be+ feuchten müssen und so dient das Verhalten zwar wohl von einer neuen Seite her zur Bestätigung der Realität derjenigen Form der Thätigkeit, die von uns die Cirt cularpolarität genannt worden ist, indem dadurch jede Stelle der Säule in positiver und negativer Polarität zugleich, nur nach entgegengesetzten, fest bestimmten Richtungen hin, thätig erscheint; aber die hievon ganz und gar verschiedene Frage, welchem von den beiden heterogenen Metallen ursprünglich der eine oder der andere Effect in der Kette angehöre, wird damit durchaus auf keine Weise beantwortet.

Unsere Theoreme über die wahre Polarität der Thätigkeit der Metalle in der galvanischen Kette, die auf einer zu sicher begründeten Basis ruhen, als dass wir ihre Erschütterung durch irgend eine fremde Argumentation jemals fürchten dürften, werden also auch keinesweges durch die angeführten Resultate des Herrn Erman aufgehoben; aber wir glaubten es, wie gesagt, der Autorität eines so ausgezeichneten Physikers schuldig zu seyn, uns durch das Obige, über den Widerspruch der Resultate unserer Untersuchungen gegen frühere, in unbedingt assertorischer Form von ihm ausgesprochene Folgerungen, zu rechtfertigen und so eine disharmonische Stelle in dem grossen Buche der naturwissenschaftlichen Verhandlungen zu tilgen, die ausserdem nur uns zum Vorwurfe gereicht haben wïrde 
155) Wir haben mit dem Inhalte des gegenwärtigen Abschnittes die Phänomene der galvanischen Reaction unter dem mannichfaltigsten Wechsel der Form in einer Einheit und Beständigkeit kennen gelernt, welche über die wahre Bedeutung, unter welcher dieselben in einem höheren Zusammenhange mit dem Naturleben im Grossen überhaupt aufzufassen sind, nicht nur keinen Ziweifel mehr übrig lassen, sondern die dadurch selbst auch auf emen Urtypus der Erscheinungen in dem weitesten Umfange aller Naturoffenbarung wiederum ein Licht zurückwerfen, das unserer Anschauung am Schlusse dieser Betrachtungen nicht unvernommen bleiben darf.

Alle galvanische Thätigkeit ist ursprünglich progressiv; aber jeder seiner Intensität nach noch so geringe Act dieser progressiven Thätigkeit ist, wie es alle Ergebnisse unserer bisherigen Betrachtungen auf das bestimmteste darthun, nicht ohne einen angemessenen Grad von Reaction denkbar und diese regressive Thätigkeit äussert sich, wie wir gesehen haben, durch dieselben Momente, wie die progressive. Der progressive Act ist auf die weitere Entwickelung der $\mathrm{Ma}$ terie gerichtet, das Indifferentere wird durch ihn differenter, es wird auf eine höher liegende Stufe der Individualisation hinaufgehoben und der Grundton dieser individualisirenden Thätigkeit ist der Chemismus; in ihm wird der Fortschritt durch die That realisirt, das starre, regulinische Metall wird zum empfänglichen, fruchtbaren Oxyd, die liquide Flüssigkeit wird zum beweglichen und eindringlichen pneumatischen Stoffe umgeschaffen. In dieser VeredInngsmetamorphose sind der Magnetismus und die Elektricität immanente 
Regungen, doch nur als polare Extreme unter der Form einer blossen Tendenz im Gegensatze des reellen Erfolgs; beide aber stehen einander gegenüber als die Momente der progressiven und jener von ihr unzertrennlichen reagirenden Thätigkeit.

Der Magnetismus erscheint nur mit dem wirklichen Beginn des Processes, nur wenn die Kelte geschlossen, wenn die Functionen mit reeller Thätigkeit im organischen Kreislaufe sich durchdringen und die Glieder der lebendigen Wechselwirkung einen festen, in sich begründeten Mittelpunct ihrer gemeinsamen identischen Thätigkeitssphäre gefunden haben. Der Magnetismus ist der Verkündiger des bereits bestehenden, geordueten, in weiterer oder engerer Sphäre selbstständig gewordenen Lebens, er ist der Wiederhall des Grundtons der Thätigkeit, der vom Focus ihres Hauptsitzes aus alle Glieder des regen Kreises durchdringt und durch den sie sämmtlich als immanente $\mathrm{Or}_{\mathrm{r}}$ gane desselben sich manifestiren, die zur Tendenz der Theilnahme an dem universellen Process um so kräftiger angeregt werden, je weiter sie ihrer individuellen Natur nach noch von demselben entfernt sind. - Die Elektricität dagegen ist die Tendenz des Differenten, nach der Seite der Totalität hin wiederum durch die chemische Synthesis zur Einheit zurück zu kehren und sie erscheirit nur, so lange der Kreis der lebendigen Wechselwirkung noch gar nicht, oder vielmehr nur unvollkommen geschlossen, so lange das Leben noch nicht oder nicht mehr befriedigt, die Thätigkeit nicht der Anregung entsprechend ist. Aber gerade durch dieses Moment der Reaction wird der progressire Effect der individualisirenden Thäligkeit angefacht und wenn 
einmal der Mittelpunct der gemeinsamen. Wirkung gefunden, um so lebendiger unterhalten.

So wie nun in der Einheit jedes progessiven Acts des galvanischen Processes dem Magnetismus die Elektricität als die polare Reaction gegenüber steht; so ist in jedem einzelnen Momente der Thätigkeit der Fortschritt durch eine gleichzeitige Reaction bedingt, und von dem Reiz der Gegenwirkung abhängig gemacht. Der negativ polaren Elektricität steht als Reaction gegenüber die positiv polare, eben so dem südpolaren der nordpolare Magnetismus, der Oxydation die Desoxydation, und der universelle Typus der Bipolarität im Ganzen der Naturoffenbarung überhaupt gewinnt so ein lebendigeres Verständniss und tritt uns als ein in seiner Nothwendigkeit angeschautes entgegen, indem wir in der einen Seite desselben nichts anderes als nur die Reaction, das negirende Princip des beharrlichen Zurücksinkens zur gefesselten Masse gegen den affirmativen Fortschritt der geistigen Entwickelung nach der Seite des Lichts und der Freiheit hin erkennen. Das ist die wahrhafte Bedeutung des durch alle Glieder im grossen und heiligen Organismus der Natur überall ausgesprochenen polaren Verhaltens, dass jegliche, irgend eine, wenn auch noch so niedrige, Stufe der Selbstständigkeit bezeichnende Erscheinung, während sie von der Totalität mit jedem Momente bedroht wird, in die finstere Tiefe des allgemeinen und unterschiedlosen Seyns zurückgezogen zu werden, um so kräftiger und siegreicher dem heiteren Jenseits einer immer freier und selbstständiger sich gestaltenden Individualisirung entgegen geht, je höher der Standpunct der Entwickelung liegt, der von ihr bereits errungen worden. 
Wie es in der sittlichen Welt nur eine Freiheit giebt, so giebt es im Leben der Natur auch nur ein Ziel, welches wieder kein anderes ist, als die Verklärung'der Materie zum Geist, das ist die Verklärung des Geistes selber, - m und nur einen Fortschritt zur Erreichung dier ses Ziels. - Elektricität und Magnetismus, Hydrogenisation und Oxydation, Schwere und Licht sind ein und dasselbe; aber nur die eine Richtung von beiden ist die wahrhafte und ursprüngliche, die entgegengesetzte trägt nur den Schein der Realität und dient allein durch die blosse Negation nur zurFörderung und Bekräftigung der absoluten, von Ewigkeit her entschiedenen Affirmation. - Der Körper ist nur der in Fesseln geschlagene Geist selber; aber so gewiss diese Fesseln zerbrochen werden, so gewiss haben sie auch keine andere Bedeutung, als dass der Geist durch den Kampł mit sich selbst für ein geläutertes Daseyn gekräftigt und veredelt werde. - Wohl dem, der die dämonischen Illusionen der erlogenen Realität, die nur für den Moment eine relative Bedeutung habenkönnen, festen Blickes durchschant und dessen $\mathrm{Be}-$ strebungen nicht mit den momentanen Rückschritten der nach der Seite der Finsterniss inclinirenden Masse zusammen fallen, sondern der eingedenk des ursprünglichen Adels eines unsterblichen Geistes und unbestechlich gegen die glänzende tausendfältige Nichtigkeit des Scheins mit freiem Bewusstseyn nur für das Licht und die Freiheit die Fülle seiner Thätigkeit zu entfalten bemüht ist. 


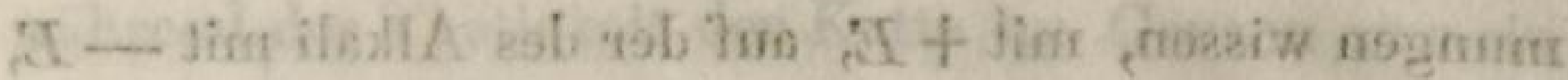

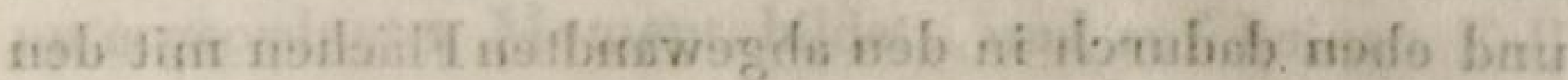

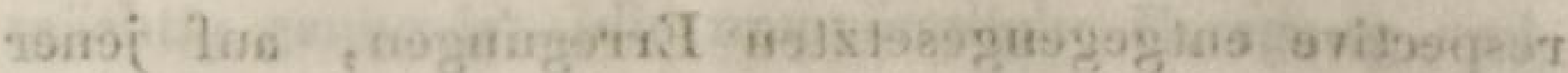

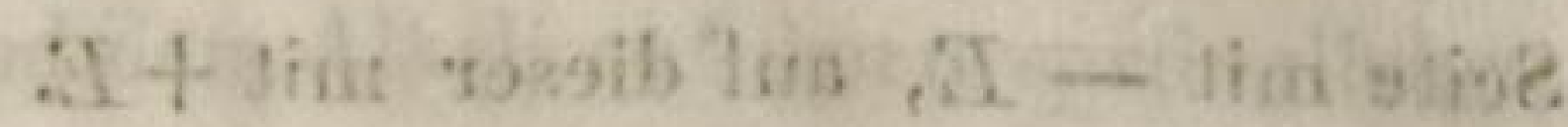
Sechster Abschnit t.

Diel zoveigliedrige galvanische Kette schlechthin das Urbild jeder galvanischen Kette und die Grundform aller chemischen Naturthä-

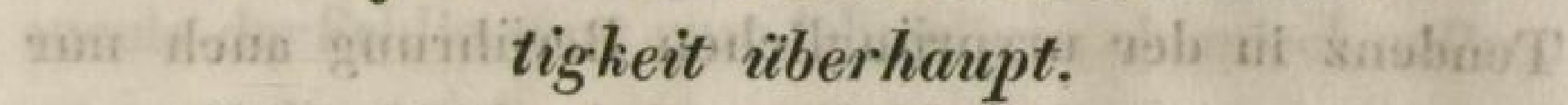

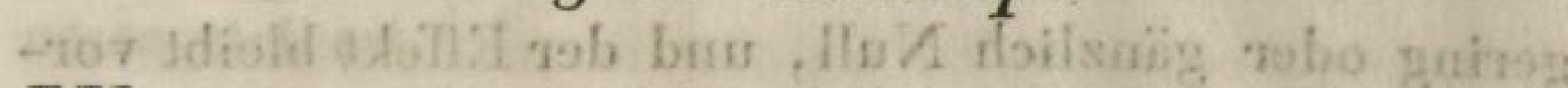
$W_{\text {ir eröffnen die Untersuchungen des gegenwärtigen }}$ Abschnittes am zwreckmüssigsten soggleich mit der Betrachtung eines bestimmten Falles, von dem bereits oben S. 22 ff. die Rede gewesen ist, und der jetzt nach allen während dessen gewonnenen Resultaten zu einer befviedigenden Entscheidung úber den fraglichen Punkt, voin dem wir dort bei demselben ausgegangen sind, geführt zu werden vermag.

Unsere Aufgabe besteht nämlich zuvörderst darin, die elektrische Relation zwischen einer sauern und alkatischen Lösung mit Sicherheit aus der Einwirkung zu bestimmen, die sie/als erregende Hauptglieder einer galvanischen Kette auf die Magnetnadel ausüben. Werden zu dem Ende beide Solutionen etwa in zwei mit ihnen getränkten Pappscheiben in Contact gebracht, so dass sie in hinlänglich grossen Oberflächen sich berühren, während sie an den übrigen Stellen gänzlich aus einander gehalten sind, so offenbart sich die Tendenz zur chemischen Neutralisation beider in den Berührungsflächen auf der Seite der Säure, wie wir schon aus anderweitigen, S. 24., angegebenen Bestim- 
mungen wissen, mit $+E$, auf der des Alkali mit $-\boldsymbol{E}$, und eben dadurch in den abgewandten Flächen mit den respective entgegengesetzten Erregungen, auf jener Seite mit $-\boldsymbol{E}$, auf dieser mit $+\boldsymbol{E}$.

So lange diese letzteren entgegengesetzt erregten Extreme, die wir die äussern nennen wollen, keine Gemeinschaft weiter mit eiuander haben, so lange ist, wie bei einer jeden ungeschlossenen Kette, die Realisirung der durch die Elektricität ausgesprochenen Tendenz in der ursprünglichen Berührung auch nur gering oder gänzlich Null, und der Effekt bleibt vorzugsweise allein bei der elektrischen Spannung stehen. Die Kette kann nun aber entweder dadurch geschlossen werden, dass die äussern Extreme unmittelbar mit einander verbunden werden, oder dadurch, dass sie nur durch einen dritten leitenden Bogen, welcher in unserer Untersuchung durch den metallischen um die Magnetnadel geschlungenen Multiplicatordrath gebildet wird, mit einander in mittelbare Verbindung gesetzt werden. Wir ziehen zuvörderst nur den letztern Fall in Betrachtung, und werden auf den zuerst genannten, welcher die Bedingungen zur Thätigkeit einer zweigliederigen Kette schlechthin enthält, weiter unten zurück kommen.

Die metallische Berührungsfläche, durch welche jedes Ende des Multiplicators mit der Aussenfläche einer der beiden Solutionen in Verbindung gesetzt wird, lässt sich, wie uns dies aus den obigen Betrachtungen des dritten Abschnittes schon bekannt und gelüufig ist, im Verhälıniss zur Grösse jener Aussenfläche allemal so klein nehmen, dass die specifische Exregung zwischen dem Metall und der Flüssigkeit 
während der Thätigkeit der Ketle im Ganzen nur ein untergeordnetes Moment bildet, und auf keinen Fall mächtig genug ist, die ursprüngliche Erregung zwischen der Säure und dem Alkali auf den ursprünglichen innern Berührungsflächen bei geschlossener Kette auf. zuheben. Aber der Conflict dieser beiden Erregungen ist es gerade, welcher hier, so wie bei jeder andern Kette, die eigentliche Thätigkeit derselben üherhaupt bedingt, und die ursprüngliche Erregung mit dem Momente der Schliessung zum lebendigen chemischen Pro. cesse steigert.

Es sey $s$ die Solution der Säure und $a$ die des $\mathrm{Al}$ kali, die sich in einer etwa 9 Quadratzoll grossen Fläche berühren, und auf ihren Aussenseiten eben so grosse Flächen darbieten mögen:

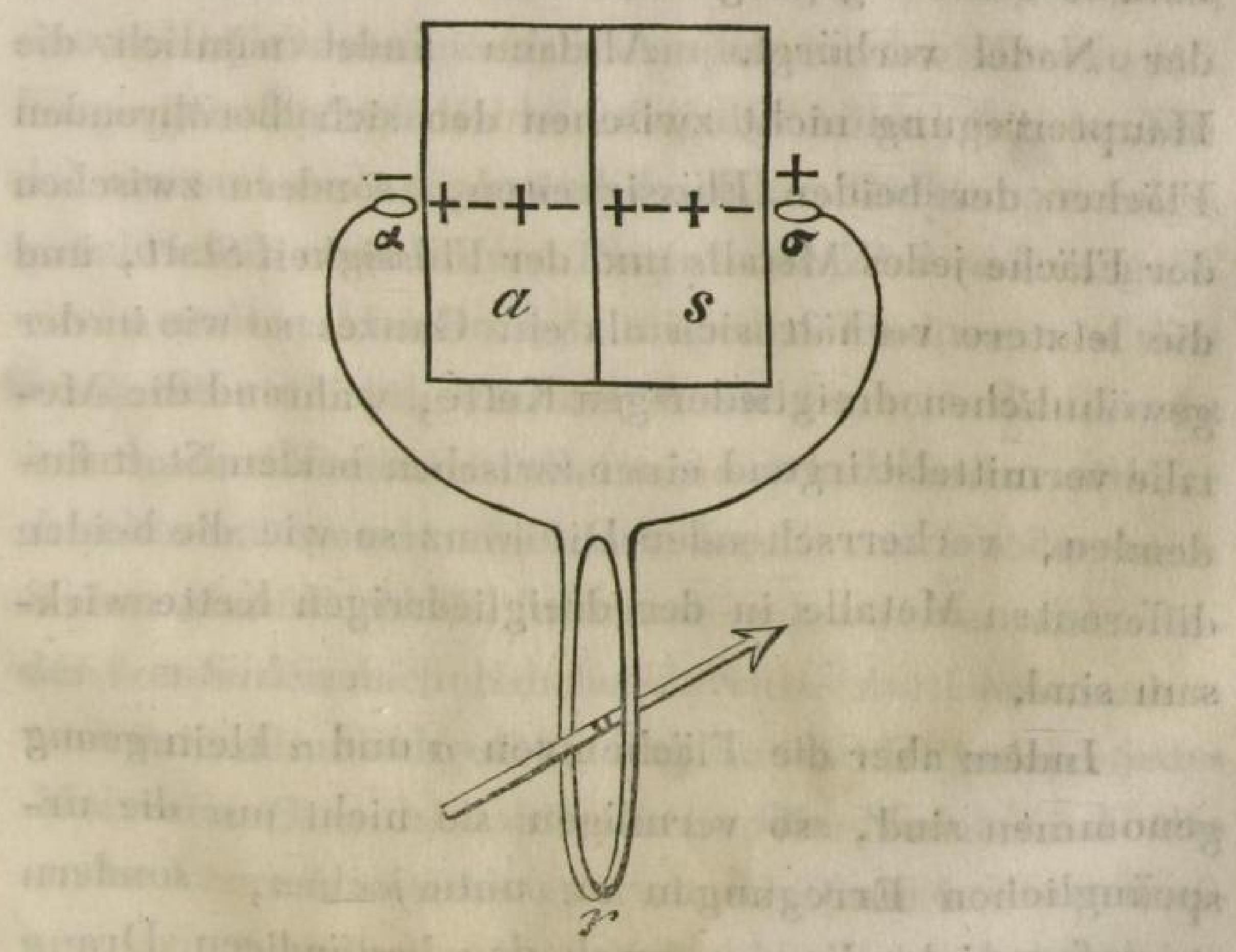

Werden nun 'diese Aussenflächen mit kleinen Metallblechen $\sigma$ und $\alpha$ vonPlatin oder irgend einem andern 
Metalle, die nư went g Linien im Durchmesser haben und mit den Extremen des Multipticators verburiden sind, armirt," so wìrd $\sigma$ an dem negativen Extrem des $s$ positiv, und $a$ an 'dem positiven Extrem des a nègativ ér-

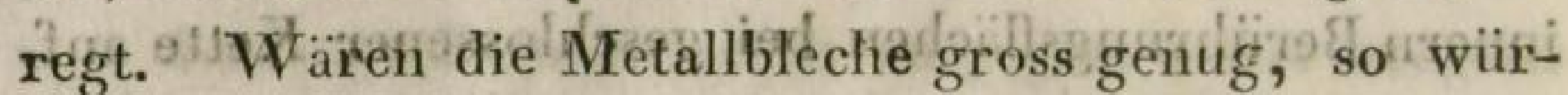
den sie treser Erregung ${ }^{3}$ wicht nachgeben, sondern jedes würde für sich," seiner Natur gemäss, eine eigenthümlìche Eiregung in der Berührung mit der FlüssigKeit bedingen, die sich bis zu den innern Contaetflächen fortpflanzen urid dort die ürsprüngliche Eiregung zwischen $s$ und $a$ aufheben oder schwächen and modificiren witrde. Und in der That sieht man, wenn man breitere Metallflächen in hìłänglicher Grösse an der Stelle von $\sigma$ und $\alpha$ anwendet, unter verschiedenen Umständen auch ganz entgegengesetzte Erfolge durch die bald so bald entgegengesetzt Statt findende Ablenkung der Nadel verbürgt. Alsdann findet nümlich die Haupterregung nicht zwischen den sich berührenden Flächen der beiden Flüssigkeiten, sondern zwischen der Fläche jedes Metalls und der Flüssigkeit Statt, und die letztere verhält sich als ein Ganzes so wie in der gewöhnlichen dreigliederigen Kette, während die Metalle vermittelst irgend einer zwischen beiden Statt findenden, vorherrschenden Differenz so wie die beiden differenten Metalle in der dreigliederigen Kette wirksanı sind,

Indem aber die Flächen von $\sigma$ und $\alpha$ klein genug genommen sind, so vermögen sie nicht nur die ursprünglichen Erregungen zu unterjochen, sondern sie rufen vielmehr nur durch den beständigen Drang dieser Opposition eine um so höhere Thätigkeit hervor, die Säure und das Alkali, statt ihre ursprüngliche, 
gegenseitige Eríegung àuf́ugebon oder żu modificiren, trèten dafür nux um so krüftiger in chemischer: Wechiselwirkung einander ent gegeni, und der Kreislauf der reellen polaren Functionen, li die 'in ihrem istetigen Duxcheinàndergrèifen dàs Lueben dẹ geschlossenen Kette bildën, ist ₹ollkommín lentschiedent und allein ibestimmit durieh die gegenseitige linvegung der Flüssigkeiten, so dass diurch geherids in ider gánźn Kette nach deri Richtung sảàr gesétztén Richțing a

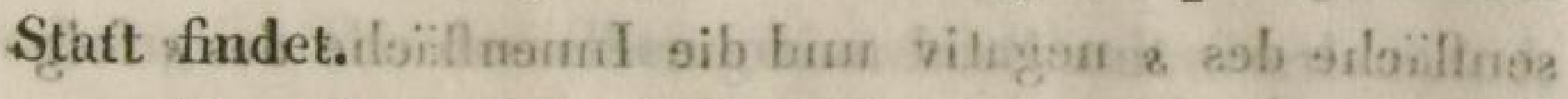
tai ziDeraBeweis udafür berkellt durch die Thatsache, dass alśdánn bei einevıund derselben Application des Multiplicátors, und, wie sich ohnehin versteht, bei Vermeidunglałler sonștigen cübermässigen Differenzén, die

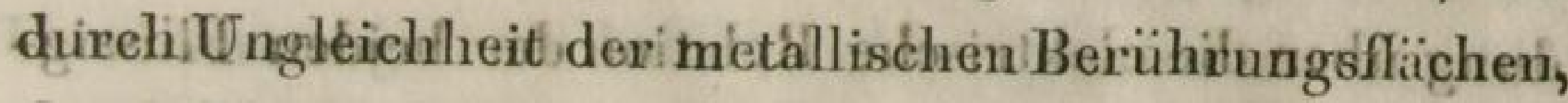
durch: Ungleichlieit iiv der Tèmperatur der Metalle etc. herryorgerufen' werden könnén, die Ablenküng der $\mathrm{Na}$ del constaut nach einer und derselben Richtung erfolgt, gleich fieh ob $\sigma$ und $\alpha$ von Plațin oder ZZink oder irgend einem andern Metalle seyn mögen. Und zwar ist diesér conśtánte Erfölg von der Beschaffenheit, dasś, wenn $s$ und a im Norden dé Boussole sich befinden und dér durch $\sigma$ /mit is communicirende Drath von Norden nach Süden über die Nadel fortiund unter iłır zurück wieder, von Süden nach Norden durch ce zur Comminnication mit $a$ zurückgeführt ist, die $\mathrm{Nadel}_{\text {sodann jedes }}$ Mal nach Osten hin abweicht. Die Nadel wird also unter diesen Umständen gerade so, I! wie in einer dreigliederigen einfachen Kette $z / k$ abgelenkt; bei welcher auf der Seite des $\sigma$ das Kupfer $(k)$ und auf der Seite des $r$ der Ziuk (z) sich befindet. 
Hieraus ist daher auf den Grund der von uns festgestellten Theoreme die Art derErregung zwischen den Flüssigkeiten $s$ und $a$ mit völliger Sicherheit zu bestimmen. Da uämlich die Polarität des Kupfers während der Thäligkeit der Kette $z f k$ die positive, die des Zinks die negative ist, so muss auch die Polarität, vermöge welcher $\sigma$ und $\alpha$ im Zusammenhange mit den zu beiden gehörigen Hälften des Multiplicators in der vorliegenden Kette die Nadel ablenken, bei $\sigma$ die positive, bei $a$ die negative seyn, Ist aber $\sigma$ positiv, so ist die Aussenflüche des $s$ negativ und die Innenfläche des $s$ folglich positiv; eben so folgt, dass, indem a negativ ist, die Aussenflüche von $a$ positiv und die Innenfläche mithin negativ seyn müsse, und so fallt also auch die mittelst der mágnetischen Boussole vollzogene Entscheidung über die elektrische Relation der beiden Flüssigkeiten, und zwar durch ein viel einfächeres und zuverlässigeres Verfahren, als das durch die Anwendung des Condensators vermittelte, dahin aus: dass die Süure im Contact mit dem Alkali positiv, letzteres im Contact mit jener negativ sey.

Es ist klar, dass auf gleiche Weise die elektrische Relation aller Flüssigkeiten mit Bestimmtheit ausgemittelt werden könne, und zwar nicht bloss der Art nach, sondern auch quantitativ, durch die Vergleichung dergoniometrischen Ablenkungswerthe, welche eine und die selbe Flüssigkeit unter sonst gleichen Umständen gegen eine Reihe anderer durch die Wirkung auf die Magnetnadel unter dem Multiplicator hervorbringt.

Dass eine solche Arbeit, der grössern Leichtigkeit und Sicherheit der Methode ungeachtet, dennoch nicht olne Erfahrung und Kritik vorgenommen werden 
dürfe; wenn sie umfassende und brauchbare Resultate geben soll, versteht sich hier, so wie in Beziehung auf die oben besprochene Bestimmúng der Relationen zwischen Metallen und Flüssigkeiten, von selbst, und es darf kaum erwähnt werden, dass die Zahlenwerthe bei diesen Ermittelungen, abgesehen von so manchen noch problematischen Beziehungen, nur in so fern eine $\mathrm{Be}-$ deutung finden können, als die geprüften Substanzen in möglichst vollkommenem Grade chemischer Reinheit angewandt und die Concentrationsgrade, oder die $\mathrm{Mi}$ schungswerthe derselben genau bestimmt worden sind. Aus diesen Gründen unterbleibt auch hier die Mittheilung des Details von den experimentalen Untersuchungen, welche wir bis jetzt nur zur Constatirung der Gesetze der elektrischen Relation in ihren allgemeinsten Umrissen angestellt haben. Aber gewiss ist es, und für jeden, der auf eine grüudliche und umbefangene Weise unserer Deduction gefolgt ist, fast unnöthig zu bemerken, dass Alles, was von ausländischen und deutschen Physikern zur Bestimmung der elektrischen Relationen der Flüssigkeiten aus der Beobachtuhng ihrèr Einwirkung auf die Magnetnadel in der geschlossenen Kette bis jetzt vorgebracht worden, theils ganz unbrauchbar, theils wenigstens gänzlich verfehlt sey und noch erst einer berichtigenden, fast überall zu völlig entgegengesetzten Resultaten führenden Interpretation bedürfe. Eines Theils ist unter Anwendung zu grosser metallischer Berührungsflächen experimentirt worden, wodurch bei aller sonstigen Genanigkeit die Ergebnisse falsch oder unzuverlässig geworden sind, andern Theils hat es, auch bei an sich richtigem experimentalen Erfolg, doch an allen gründlichen Fundamentalprämissen 
gefehlt, fund die Schlüsse, nach welchen die Reșultate gebildet wierden, sind von soivager und unlogischer $\mathrm{Be}$ schaffenheit bdèr gèradehinauf só falsçue, wênn gleich gemeinhị (bls richtig ranerkainnte Vordersâtzel gegriù-

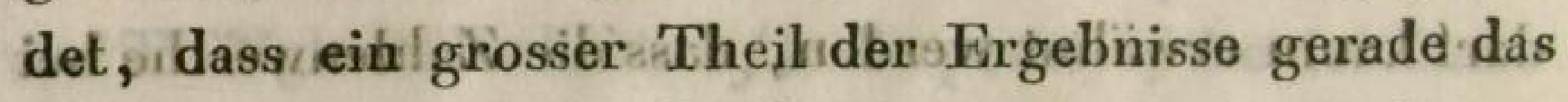
Entgegengesetzte von denajenigen aussagt, , was eigeritgéntlich das Riehtige und Naturgemësse iśt. i tumoldosq nesu:DieErregüng des rëinen Wassers gegen differente Flüssigkeiteh ástsso ungémein ischwach, dasś isie nur, wehn è in sệ grossen Bexührángsfläche gegen ein Minimúm in den Grösse der metallischen / Berühungsfläche iangéwandt /wird, mit/ Sicherheit ërkannt worerden kann.w Doch glauben wir unsern. Untersuchungen zu

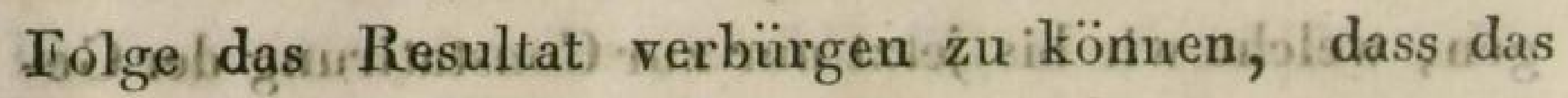
Wasser gégen stark concèntrirte Säuren swie ein Alkali, also negativ; gegen alkblische Flüssigkeiten dagegen wie eira Säure, lalso positiv sich verhạlte.

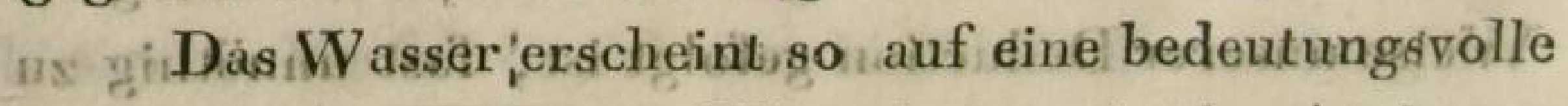
Weise in der Reihe der Flüssigkeiten als, das Analogon der magnetischen Metalle in der Metallreihe, und werin duroh die Metalle und Flüssigkèiten, im Urgegensatze des Festen und Flüssigen, der/Fortschritt von der Schwere zum Licht, von der Totalität der Masse zur Individualisation bezeichnet wird, so wird die Physik erst etwas Ganzes und Umfassendes geleistet haben, ja etwas, ohne welches, so lange es unerfüllt bleibt, an kein gründliches Verständniss der organischen Naturerscheinungen zu denken ist, die jenseit des Wassers wie eine mit den tiefsten,W Wrzeln noch fortwährend in dasselbe hineinreichende, aus ihm hervorgegangene Welt sich uns darstellen, wenn es ihr gelungen ist, den Kreislauf in der grossen Metamorphose, deren 
beide Richtungen durch das Metall und das Wasser, gleich den Polen in der galvanischen Kette, bezeichnet sind, in seinem Grundtypus mit Klarheit zu durchschauen und in der schrankenlosen Mannichfaltigkeit alle seine Productionen mit Sicherheit nach jeder Seite hin überall $\mathrm{zu}$ verfolgen.

Selbst dann, wenn diese Aufgabe nur den Umriss eines nie erreichbaren Ideals vorzeichnen sollte, wäre dennoch durch die Einheit und Bedeutsamkeit des Gesichtspunktes eine stets reichere und fruchtbarere Entfaltung der Wissenschaft für immer gesichert. Denn etwas anderes ist es, mit klarem Bewusstseyn des Ziels einen bestimmt vorgezeichneten Weg, im Lichte eines, wenn auch aus unzugänglicher Ferne, dennoch nur um so untrüglicher leitenden Gestirns zy verfolgen, als in der Dunkelheit der Nacht, ohne eigentliche Kunde des Woher und Wohin, nur richtungslos den Irrlichtern des blossen Scheins und den Dunstgebilden der Hypothesen nachzugehen und nach einzelnen, kleinlichen Zielpunkten sich abzumühen, die, wenn sie mit den unverhältnissmässigsten Opfern erreicht sind, dennoch nichts als die trüben Documente undankbarer Anstrengungen oder höchstens eine schale Ausbeute für den Vortheil des gemeinen, sogenannten praktischen Lebens darzubieten vermögen.

Aber wie weit auch unsere heutige Physik von einer selbst nurannäherungsweise Statt findenden Lösung jener Aufgabe entfernt seyn mag, wir dürfen sie dennoch nicht mehr für absolut unerreichbar halten. Jene Aufgabe ist ihrem Wesen nach eins mit der Anforderung an die wissenschaftliche Speculation, dass sie den bisherigen Gegensatz zwischen Physik und Chemie besei- 


\section{8}

ligen und statt seiner eine umfassende Erkenntnissstufé herstellen möge, welche das tiefere Verständniss des Chemismus in seinen innersten, zurückgezogensten Verhältuissen aufzuschliessen und aus ihm die Bedeutung und Entstehung dèr Erscheinungen der Gegenwart wie der Vergangenheit im weiten Gebiete des Waltens tellurisch kosmischer Naturkräfte zu entwikkeln und darzustellen vermag. Und ein bedeutender Schritt zur Erreichung dieses Ziels ist gethan, theils dadurch, dass Elektricität und Magnetismus, modificirte Seiten des Lichts und der Schwere, entschieden als die Extreme des Chemismus selbst erkannt sind, theils und ganz vorzüglich durch die uns jetzt obliegende Feststellung des Gesichtspunktes, von dem aus der durchgreifende Typus des chemischen Processes in der Einheit der Functionen der zweigliederigen galvanischen Kette angeschaut und als die Seele der chemischen Naturthätigkeit überhaupt in allen ihren zahllosen Formen von der leisesten Regung an bis zur mächtigsten Action hinauf mit Bestimmtheit erkannt wird, ja, mil Gewissheit können wir es aussprechen, das Licht, das von diesem Standpunkte aus bereits manche tief in das Innere der Erscheinungen zurückgezogene Seiten erleuchtet, beginnt zugleich die Scheidewand zu durchdringen, hinter welcher bis jetzt die Krystallisation, als das tiefste und verborgenste Geheimniss des Chemismus, unsern Blicken gänzlich entzogen zu seyn schien.

Wir wenden uns, mit der Ueberzeugung, durch unsere ferneren Entwickelungen diese Aussprüche noch hinlänglich begründet zu sehen, zur Betrachtung der obigen rorzugsweise aus zwei differenten Flüssigkeiten 
bestehenden einfachen Kette zurück. Der Drath, durch welchen diese Kette geschlossen wird, um aus der durch ihn bewirkten Ablenkung der Nadel die elektrische Relation der Flüssigkeiten kennen zu lernen, ist', wie überhaupt der Schliessungsdrath einer jeden Kette, kein wesentliches Glied derselben; seine Polarität ist lediglich durch diejenige bestimmt, welche den Extremen der beiden Flüssigkeiten angehört, die durch ihn verbunden werden, und er ist nurder Stellvertreter dieser unmittelbar verbundenen Extreme selbex. Die Kette und ihre Functionen bleiben daher im Wesentlichen nicht nur dieselben, sondern das eigentliche chemische Moment derselben tritt noch reiner und stärker hervor, wenn man die Extreme nicht bloss mittelbar nur in wenig Punkten, wie es durch den Schliessungsdrath geschah, sondern unmittelbar sich berïhren lässt. Die Kette aber ist alsdani im eigentlichsten und unmittelbarsten Sinne des Worts eine zweigliederige Kette schlechthin, und es ist für uns von der grössesten Wiehtigkeit, ihre 'Thätigkeit in dieser Form insonderheit so bestimmt und vollständig als möglich zu zergliedern.

Auf den ursprünglich in Contact gesetzten innern Extremen ist also die Säure positiv, das Alkali negativ, und auf den entgegengesetzten äussern Extremen ist eben daher jene negativ, dieses positiv erregt. So wie nun auch die letztern Extreme, etwa durch einen mit der sauern oder alkalischen Solution getrünkten Streifen von Pappe oder dergleichen in Verbindung gesetzt werden, findet die Säure ein positiv erregtes Alkali, letzteres eine negativ erregte Säure vor. Diese Erregungen aber sind im Widerspruche mit der Tendenz, welche die Natur der Flïssigkeiten bei ihrem Contacte

$\mathrm{R}_{2}$ 
sofort bedingt, und ihrer ursprünglichen Relation gemäss entsteht daher der lebendige Impuls zur gegenseitigen Verdrängung dieser dem individuellen Verhältnisse widersprechenden Erregungen und zur Entwikkelung der entgegengesetzten. Aber der bereits auf der Seite des anfänglichen Contacts vollständig ausgebildete Gegensatz, der demnächst ebenfalls aufgehoben und in den entgegengesetzten übergehen müsste, lässt es dahin nicht kommen, sondern tritt vielmehr nur um so energischer hervor. Eben dadurch wird aber auch wiederum die Opposition auf den äussern Extremen nur um so lebhafter gesteigert, und indem so die ursprüngliche auf den synthetischen Effect gerichtete Tendenz der äusseren Extreme unaufhörlich aufgehoben wird, während sie sich dennoch fortwährend nur um so nachdrücklicher geltend macht, oder, welches dasselbe ist, indem der Trieb/ihrer Entwickelung um so heftiger angeregt wird, je weniger sie selbst zur vollendeten Ausbildung zu gelangen vermag, so wird durch diesenEnt wickelungsdrang zugleich die Tendenz auf der Seite des ursprünglichen Contacts? ungleich kräftiger angefacht, durch diese wird rückwirkend wieder jener Entwickelungsdrang gesteigert und wieder durch ihn nur um so lebendiger der ursprünglich schwache, anfänglich nur in der leisesten elektrischen Spannung versichtbarte Erregungsfunke zur hellen Flamme der chemischen Thätigkeit gefördert, und so wird durch den in sich unendlichen, organisch abgeschlossenen Kreislauf polarer Functionen der lebendige Process verwirklicht, mit welchem auf der Seite der anfänglichen elektrischen Relation zwar die ursprüngliche Polarität der Thätigkeit dieselbe bleibt, aber die primitive elektrische Spannung unendlich 
gesteigert in den entschieden reellen Effect des Chemismus übergeht, dessen]Tendenz sie einzig und allein war.

Diese Thätigkeit ist nun also keine einseitige mehr, wie sie es vor der Schliessung der Kette nur noch bloss der Teudenz nach war, da die Säare allein von der Seite des Alkali, und dieses wieder lediglich von der Seite der Säure her, auf eine bloss äusserliche und gesonderte Weise zur Wirksamkeit aufgefordert war; sondern mit dem Momente der Schliessung, in welchem Wirkung und Gegenwirkung mit blitzesschneller Wechselerregung den ganzen Kreis erfüllen und in jedem Puncte desselben auf gleiche Weise zugleich thätig sind, findet auch in jedem Atom der Masse der so belebten Sphäre die lebendigste und innigste Durchdringung der polaren Functionen Statt, und es ist jetzt nicht allein die Säure, welche desoxydirt, und das Alkali, welches oxydirt seyn will; sondern jedes Atom der Säure, so wie jedes Atom des Alkali und jeder Punct der ganzen Kette überhaupt ist in der Wechselthätigkeit des progressiven und reagirenden Effects zugleich begriffen, er ist zur Oxydations- und Desoxydationsthätigkeit zugleich angeregt, er ist negativ und positiv auf einmal, in einer und derselben Zeit, in einem und demselben Raume zugleich, nur nach direct einander entgegengesetzten Richtungen, deren jede in der ganzen Kette durchgehends eine und dieselbe, schlechthin und unabänderlich bestimmte ist.

Die Richtung der Oxydationsthätigkeit auf der Seite der Säure ist daher an der Stelle des ursprünglichen Contacts dem Alkali zugewandt, an der Stelle der Verbindung, auf den äusseren Extremen, wo die Kette geschlossen worden, ist sie dagegen von dem $\mathrm{Al}$ - 
kali abgewandt; während eben so die Richtung der Desoxydationsthätigkeit des Alkali an jener Stelle der Säure zugewandt, an der letztern dagegen von ihr abgewandt ist. An jener Stelle erfolgt mithin die unmittelbare Realisirung der ursprünglichen, auf den progressiven Effect gerichteten Tendenz: das Alkali wird dort in der That durch die Säure oxydirt, während diese durch jenes desoxydirt wird; auf den entgegengesetzten Extremen, durch deren Contact die Schliessung der Kette vollzogen worden, ist dagegen die Tendenz und Richtung der Thätigkeiten von der Art, dass die Säure hier vielmehr durch das Alkali noch stärker oxydirt, dieses durch jene noch stärker desoxydirt werden würde, wenn nicht der progressive Effect. der überwiegende wäre, dem der eben genannte nur als polare erregende Tendenz, reagirend gegenüber steht.

Diese beiden Stellen der Kette sind daher, gleichsam wie Gehirnund Herz, als die beiden ent gegengesetzt polaren Brennpuncte des ganzen Systems zu betrachten: die eine als der positive Centralpunct für das Maximum des realen progressiven, die andere als der negative Focus für das Maximum der Tendenz des regressiven, reagirenden Effects. Alle übrigen Puncte der Kette sind auf eine untergeordnete, wiewohl lebendig sympathetische Weise von den nämlichen Functionen ergriffen und durchdrungen; aber indem die Tendenz und Richtung der Thätigkeit aller eine und dieselbe in sich zurückkehrende ist, so dass die Action jedes einzelnen Atoms, nicht so wie bei der Elekıricität, nur synthetisch von aussen her durch die eines andern, als ein einzelnes dem einzelnen gegenüber getretenen, sondern analytisch durch die universelle Gesammtthätig- 
keit aller schlechthin von Innen heraus bestimmt ist: so ist auch die Kette in allen Puncten magnetisch, und die Richtungen der magnetischen Polarität, welche keine andern sind, als die aus dem Conflict der progressiven undreagirenden Thätigkeit resultirenden Richtungen dieser Thätigkeit selber, haben gegen die zum Kreise geschlossene Longitudinalaxe der Kette ${ }^{*}$ ) die bekannte transversale Lage, die bereils im 2 ten $\mathrm{Ab}$ schnitte, S. 50 ff., bei der dreigliederigen Kette als eine Folge der Reaction betrachtet worden ist, welche dort der Tendenz zum bloss synthetischen Effect in der Contactelektricität der Metalle und hier in noch umfassenderer Beziehung dem Entwickelungsdrange des ursprünglichen elektrischen Gegensatzes an den Schlussextremen der Kette entspricht.

Der Magnetismus, als diese Offenbarung der allseitigen, in jedem Puncte des geschlossenen Kreises der Kette angeregten 'Tendenz zur Theilnahme an der Lebensthätigkeit der ganzen Sphäre, ist daher in jedem einzelnen Puncte der Kette bis zu einem bestimmten Grade auch um so kräftiger, je weiter dieser Punct seiner individuellen Natur nach von der Befriedigung derselben Tendenz noch entfernt, und je grösser der Conflict zwischen ihm an und für sich und dem durch das Leben des Ganzen in ihm hervorgerufenen Streben ist; je entschiedener die Masse hingegen schon in eine bestimmte Rich-

*) Wenn man sich die ungeschlossene Kette unter dem Bilde eines Cylinders vorstellt, so ist die zwischen den Mittelpuncten seiner Grundflächen liegende Axe zugleich die Axe der Kette, und wie alsdann das Bild der geschlossenen Kette durch denselben zum Ringe zusammen gebogenen Cylinder dargestellt wird, so ist auch ihre Axe nun jene anfänglich gerade, jetzt zum Kreise geschlossene Linie. 
tung der allgemeinen Metamorphose hineingezogen und je differenter sie ihrer individuellen Natur' nach bereits ist, um so leichter vermag sie diese Richtung noch weiter zu verfolgen, um so innerlicher wird daher auch ihre Theilnahme an der Thätigkeit des Ganzen, um so geringer wird der Conflict zwischen der Tendenz und ihrer Befriedigung seyn, und um so schwächer wird sich folglich auch in dieser Masse der Magnetismus nach Aussen hin versichtbaren. Daher tritt der Magnetismus, wie überall, so auch in der geschlossenen Kette vorzugsweise nur im Metalle auf; aber er ist, wenn auch in ungleich geringerem Grade, dennoch, wie Versuche schon seit längerer Zeit gezeigt haben, auch in den flüssigen Bestandtheilen der Kette bestimmt vorhanden. Daher ist es auch keinem Zweifel unterworfen, dass er in einer Kette, wie die eben betrachtete $z$ weigliederige, welche einzig und allein nur aus zwei differenten Flüssigkeiten, unter gänzlicher Abwesenheit alles Metalls, gebildet wird, eben so unfehlbar, wie in jeder andern durch Metall vermittelten Kette, vorhanden sey; aber, wie sich zum voraus erwarten lässt, nur in einer so geringen Intensität, dass seine Wahrnehmung dadurch ausserordentlich erschwert und nur unter günstigen Umständen durch eigenthümliche, besonders vortheilhaft gewählte experimentale Bedingungen möglich zu machen seyn wird.

Es ist mir gelungen, die Nachweisung des Vorhandenseyns der magnetischen Erregung in einer solchen, bloss aus zwei differenten Flüssigkeiten bestehenden Kette, wenn gleich nicht in der absolutesten Form, doch auf eine Art möglich zu machen, die noch frappanter ist, als diejenige, nach welcher bis 
dahin die in der Flüssigkeit vorhandene, magnetische Erregung nur an dreigliedrigen Ketten aufgezeigt worden ist. Auf eine mit alkalischer Lauge getränkte, anderthalb Quadratfuss grosse Pappscheibe wurde eine gleiche mit verdünnter Schwefelsäure durchnässte Scheibe gedeckt, und beide wurden durch einen handbreiten, bügelförmigen, mit derselben sauern Solution getränkten Pappstreifen verbunden, zwischen dessen beiden, enge anliegenden Schenkeln das sehr flache, noch nicht $\frac{1}{4}$ Zoll hohe Glaskästchen stand, in welchem die kleine, 1 Zoll lange, sehr empfindliche Magnetnadel an einem Spinuwebenfaden aufgehangen war, der aus|l einer aufgekitteten, ohen verschlossenen Glasröhre in das Innere der Boussole hineinreichte. Die Nadel, deren Bewegung unter dem obern Schenkel des breiten Pappstreifen unmittelbar nicht wahrgenommen werden konnte, trug einen sehr leichten, 4 Zoll langen Seitenzeiger von Strohhalm, dessen sichtbar hervorstehendes Ende über einem Limbus von einigen Graden im Glaskästchen schwebte. Als nach dieser Vorrichtung die Kette geschlossen wurde, blieb die Nadel noch ohne alle wahrnehmbare Bewegung. Ich armirte darauf die Stellen, an welchen die Kette von dem schliessenden Pappstreifen berührt wurde, mit «wei vollkommen gleichen, ächt vergoldeten Messingblechen, von der Breite des letzteren, und jetzt fand bei jedesmaliger Schliessung eine entschiedene, durchans unzweideutige Ablenkung von einem halben Grade Statt, die durch wiederholtes Schliessen so verstärkt werden konnte, dass die Oscillationen des Zeigers über dem'Limbus einen Raum von mehr als $\frac{\pi}{8}$ Zoll Länge umfassten. Diese Ablenkung war erstens durchaus der 
Regel gemäss, nämlich östlich. (Die Kette stand im Norden der Boussole, und die Säure lag, wie gesagt, oben über dem Alkali.) Wurde ferner die Kette, während alles übrige unverändert blieb, durch einen gleichen genetzten Pappstreifen, und selbst durch einen Metalldrath, der nicht unter und über die Nadel fortgeführt war, von Armatur zu Armatur geschlossen, so blieb die Nadel durchaus bewegungslos; ein Beweis, dass nicht etwa nur die magnetischen Armaturbleche aus der Ferne die Ablenkung zufällig erzeugten, sondern dass diese durch die magnetische Flüssigkeit des Streifens selbst hervorgebracht wurde. Endlich wurden theils die Berührungsflächen zwischen der Kette, dem Streifen und den Armaturendurch Umwendung der letztern verändert, theils wurden die $\mathrm{Ar}$ maturen selbst, nachdem sie jedesmal vorher sorgfältig getrocknet waren, an ihren Plätzen mit einander verwechselt, und in allen möglichen Combinationen der Art und unter vielfachen Wiederholungen blieb die Ablenkung stets, wie sie von Anfang gewesen war und sich zeigen musste, östlich. Hierdurch wurde es also zugleich ausser $\mathrm{Zweifel}$ gesetzt, dass die bewirkte $\mathrm{Ab}$ lenkung nicht etwa einer Kette, welche nur durch das Metall und die Flüssigkeit, oder durch zufällige Erregungsdifferenzen der Armaturen gebildet seyn konnte, sondern dass sie lediglich der zweigliederigen, durch die beiden Flüssigkeiten selbst bedingten Kette angehörte. Es wäre freilich allerdings interessant, diese Wirkung unmittelbar ohne alle Dazwischenkunft irgend eines Metalls hervorzubringen, und es ist denkbar, dass dieses unter günstigen Bedingungen, zumal wenn die Empfindlichkeit der Nadel durch die Beseiti- 
gung der hemmenden Einwirkung des Erdmagnetismus erhöht wird, in der Folge vielleicht noch einmal gelingen kann; allein eines Theils ist schon durch das Obige das reine Vorhandenseyn des Magnetismus in einer zweigliederigen, aus differenten Flüssigkeiten zusammengesetzten Kette, als solcher, ungeachtet der Zuziehung der metallischen Armaturen, ausser Zweifel gesetzt; andern Theils werden wir durch die nähere Betrachtung der eigentlichen Natur der Wirksamkeit dieser Kette weiter unten sehr bald noch auf bestimmtere Ansichten geführt werden, aus denen es klar werden wird, warum selbst mit den vollkommensten und enipfindlichsten Apparaten der in ihnen vorhandene $\mathrm{Ma}$ gnetismus auf eine unmittelbare Weise in der Regel gar nicht, sondern höchstens nur momentan unter günstigen und ganz speciellen Bedingungen sichthar zu machen seyn werde.

Es darf kaum noch gesagt werden, dass die obigen Betrachtungen über die aus zwei differenten Flüssigkeiten, und insbesondere durch eine saure und alkalische Solution gebildete zweigliederige Kette für alle mögliche Fälle gelten, in welchen irgend zwei, mehr oder minder chemisch verwandte Flüssigkeiterr mit einander in Gemeinschaft treten, indem die Berührung beider, wenn z. B. eine in die andere hinein gegossen wird, jedesmal nur so Statt finden kann, dass sie an gewissen Stellen früher oder inniger, oder in irgend einer Beziehung intensiv oder extensiv vollkommner als an andern erfolgt. Alsdann ruft die mit jenem Uebergewichte entschiedene, der ursprünglichen Natur der Flüssigkeiten entsprechende Polarität überall, wo sie zuerst hervorgetreten, an eben so viel entgegenge- 
setzten, durch spätern Contact oder anderweitige Bedingungen minder begünstigten Stellen die entgegengesetzte Polarität hervor, gemäss dem allgemeinen Erregungsgesetze der|Flüssigkeiten (S. 18 ff.); aber indem auch hier nichts desto weniger die Tendenz zu derselben ursprünglichen Polarität sich geltend macht, und mit jener in Conflict tritt, so beginnt das oben betrachtete Spiel wechselseitig gesteigerter Anregung und Thätigkeit. Die Elementarglieder einer galvanischen Kette haben sich gefunden, so oft jener Gegensatz der ursprünglichen Anregung und Opposition hervorgetreten, sie sind zu lebendiger Wechselwirkung in ein Ganzes vereint, und in dem geschlossenen Kreise derselben bewegt sich mit organischer Selbsiständigkeit ein individuelles, in und durch sich selbst genährtes Leben, mit welchem erst der Act der chemischen Synthesis, nothwendig vermittelt durch den über die ganze Sphäre gleichmässig ergossenen analytischen Effect, seine wahre Realität gewinnt, und die chemische Action zwischen den beiden Flüssigkeiten, welche $\mathrm{Ge}-$ stalt von der geräuschlosesten Vereinigung bis zu einer unter der heftigsten Effervescenz erfolgenden Neutralisation hinauf sie auch haben möge, ist nicht das Resultat einer blossen einseitigen Affinität, sondern ein allseitiger, in sich unendlicher, durch und durch polarer, einzig und allein nach dem Gesetze und unter dem ein für allemal erfassten Typus der Thätigkeit der geschlossenen galvanischen Kette ins Leben getretener Process.

Setzt man, dass der Contact zwischen zwei chemisch verwandten Flüssigkeiten in allen Puncten, in welchen er zu Stande kommt, auf einmal, völlig 
gleichreitig, lückenlos und unter schlechthin gleichen Bedingungen vollzogen werde, so ist auch in allen Berührungspuncten der einen Flüssigkeit nur dieselbe eine, und in denen der andern nur dieselbe entgegengesetzte ursprüngliche Polarität möglich, und indem alle übrigen entgegengesetzt erregten Puncte nicht im Contact sind, so bleibt auch die Kette ungeschlossen, und die chemische Vereinigung, als die aisschliessliche Wirkung der geschlossenen Kette, kann nicht erfolgen. Ein experimentales Factum, welches den obigen Forderungen vollkommen entspräche und die Behauptung durch den Erfolg oder vielmehr durch das gänzliche Ausbleiben der chemischen Thätigkeit in aller Schärfe bestätigte, ist begreiflich nicht möglich, weil keine absolute Gleichzeitigkeit, und noch weniger eine absolute Gleichheit aller Bedingungen bei der Berührung aller Puncte zwischen zwei noch so kleinen Flächen verschiedener Flüssigkeiten in der Erfahrung jemals Statt finden kann. Aber es ist nicht schwer, durch das Experiment, welches ja ohnehin überall für jede Thesis nur eine unvollkommene Bürgschaft leistet, die Wahrheit unserer Aussage wenigstens annäherungsweise zu bestätigen. Deckt man z. B. eine mit einer alkalisehen Solution durchzogene Pappscheibe mit möglichst glatter und ebener Oberfläche flach auf eine solche mit flüssiger Säure getränkte Scheibe und verbindet ihre Aussenflächen durch einen hinlänglich breiten, mit einer von beiden Flüssigkeiten vollständig durchzogenen Streifen solcher Pappe, oder auch durch ein Paar zusammenhängende metallische Armaturen, so erfolgt in verhältnissmässiger Zeit eine Neutralisation zu beiden 
Seiten der Berührungsflächen in das Innere beider Scheiben hinein; bleiben hingegen die Aussenflächen ohne jene Verbindung, so können die Scheiben eine ungleich längere Zeit in ihrer Lage über einander beharren, bevor dieselbe Neatralisation in gleicher Ansdehnung bis in das Innere der Scheibe hinein zu Stande gekommen ist. Dass sie am Ende dennoch wirklich Statt findet, ist nur die Folge der praktischen Unmöglichkeit eines schlechthin lückenfreien, absolut gleichzeitigen und gleichmässigen Contacts; die unvermeidlichen Differenzen in der Berührung bedingen jedesmal auch eine Differenz des gegenseitigen Verhaltens beider Flüssigkeiten an verschiedenen Stellen, mit welchem hier der eine, dort der andere Focus einer galvanischen Thätigkeitssphäre sich za bilden beginnen, deren Resultat das neutrale Product der chemischen Synthesis ist. Aber die Erfahrung lehrt schon durch diese Approximation, dass, wenn ein Contact, der in aller Strenge jenen Forderungen entspräche, zu bewerkstelligen wäre, sodann auch keine chemische Thätigkeit zwischen den beiden flüssigen Substanzen erfolgen würde, welches nach der gewöhnlichen Vorstellung, die den chemischen Process lediglich als das Resultat einer einseitigen chemischen oder elektrochemischenAffinität betrachtet, schlechterdings nicht begriffen zu werden vermag.

Wir sind daher durch die Erfahrung nicht nur berechtigt, sondern selbst, um sie nur zu begreifen, dazu gezwungen, den folgenden Satz, welcher für die Lehre vom Galvanismus, und für die Chemie und $\mathrm{Na}$ turwissenschaft überhaupt von der höchsten Bedeutung ist, anzuerkeunen und bei dem fernern Fortgange unserer Untersuchungen zum 'Grunde zu legen. 
Ueberall, so oft zwei differente Flüssigkeiten sich chemisch verbinden, ist diese Vereinigung nur als das Product eines durch und durch polaren Processes zu betrachten, welcher schlechthin nur unter dem Typus einer Thätigkeit vollzogen wird, die ihrem innersten Wesen nach keine andere ist, als die 7\%ätigkieit der geschlossenen galvanischen Kette.

Aber hierbei müssen wir uns jetzt zugleich auf das bestimmteste gegen eine Einseitigkeit der Vorstellung verwahren, deren Beseitigung wir in der unmittelbar vorhergegangnen Auseinandersetzung, um dem Gesichtspuncte fürs erste möglichste Einfachheit zu erhalten, nuv noch mehr andeuten, als bereits ganz positiv aussprechen durften. Es würde nämlich eine völlig willkührliche und schon eben deshalb ganz verwerfliche Betrachtungsweise seyn, wenn wir uns zwei in chemischer Vereinigung begriffene Flüssigkeiten lediglich nur als Glieder einer einzigen Kette, und den Vereinigungspiocess derselben eben so nur als die Action einer einzigen Kettevorstellen wollten, so dass es in der ganzen Sphäre der Thätigheit nicht mehr als zwei Focalstellen in dem eben entwickelten Sinne gäbe, oder mit andern Worten so, dass es nur eine einzige über irgend einen Theil der gemeinsamen Berührungsfläche ausgedehnte Stelle der ursprünglichen Erregung, und eine zweite, ihr gegenüber liegende, eben so continuirliche Stelle der Opposition gäbe, zwischen denen und um welche die Thätigkeit aller übrigen Puncte der Masse sich bewegte und auf die allein sie sich bezöge. Allerdings sind in künstlichen einfachen Ketten, von denen die Betrachtung ausgehen muss, zwei Hauptstellen der ursprünglichen Wirkung und Gegenwirkung zu fixiren, zumal 
dann, wenin durch Metallflächen eine continuirliche Gleichnamigkeit der Erregung in der Berührung mit ihnen gesetzt und festgehalten wird, obgleich auch diese starie Polarität des Metalls nur relativ ist, so dass es selbst nicht schwer hält, an einem dünnen $\mathrm{Me}-$ tallbleche unter gehörigen experimentalen Bedingungen auf einer und derselben Seite desselben in einer und derselben Ebene unmittelbar neben einander entgegengesetzt erregte Stellen unzweideutig nachzuweisen; aber in einer Flüssigkeit, deren Charakter im Gegensatze des Metalls gerade in dieser Erregungsbeweglichkeit, in dieser Empfänglichkeit und Aufgeschlossenheit für beide entgegengesétzte Richtungen der Erregung zugleich besteht, vermöge welcher jeder erregte Punct schon an und für sich die entgegengesetzte Erregung in seiner unmittelbaren Nachbarschaft immer von Neuem hervorruft, ist die Gleichnamigkeit der Erregung keineswegs durch die Einheit und Continuität der in irgend einem Puncte erregten Fläche auch für einen grössern oder kleinern Theil derselben Fläche zugleich mit bedingt, und zwei in chemische Wechselthätigkeit tretende Flüssigkeiten wirken daher nicht etwa nur mit zwei in ursprünglicher, und mit zwei andern in entgegengesetzter Erregung begriffenen Flächen, sondern vielmehr mit unzähligen so und entgegengesetzt erregten Puncten auf einander; der Process ist ein vollkommen galvanischer, welcher schlechthin nach dem Typus der Thätigkeit der galvanischen Kette gestaltet wird: aber er ist nicht der Process einer einzigen, sondern vieler in einander verschlungener Ketten, von denen jede einzelne allerdings eine Function aller übrigen ist, und die mithin sämmtlich eine gemein- 
same Sphäre der Thätigkeit bilden ,und in ihrem äusserlichen Nebeneinanderseyn auch nicht willkührliche, sondern bestimmte und geselzlich geregelte Formen befolgen müssen, in denen, wie sich weiter unten näher zeigen wird, eine ursprüngliche Andeutung der spätern Krystallisationserscheinungen zu erfassen ist ; aber eben wie jedes Kryslallindividuum eine aus unzühligen $\mathrm{Ab}$ sonderungen zusammengefügte Einheit bildet, so muss der chemische Vereinigungsprocess zweier Flüssigkeiten auch als eine Zusammensetzung unzähliger wirksamer galvanischer Ketten angesehen werden, in welcher nicht zwei Focalstellen, sondern unzählige Paare derselben die Träger und Erreger der gemeinsamen Thätigkeit bilden.

Es seyen z. B. $s$ und $a$ eine Säure und ein Alkali, oder irgend zwei andere sich neutralisirende Flüssigkeiten,

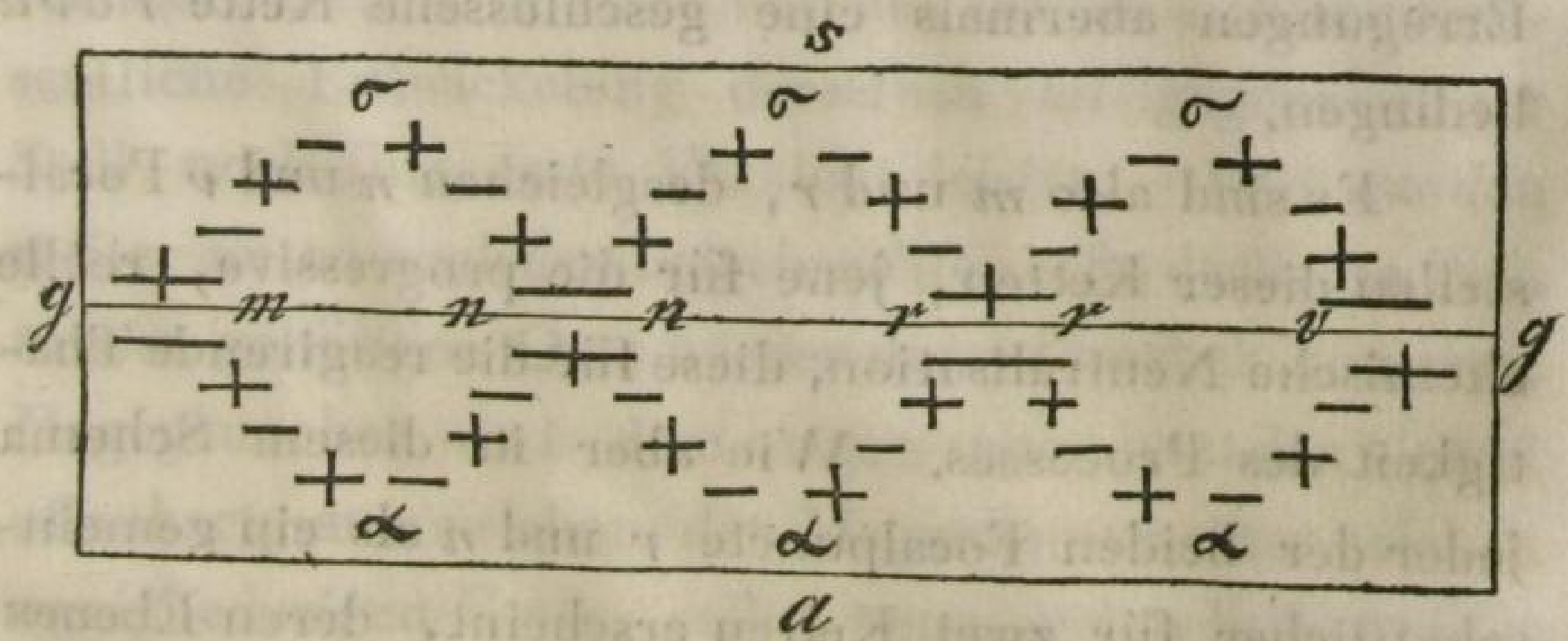

die sich in der durch $g g$ angedeuteten Scheidegränze berühren und sonst keinen Berührungspunct weiter mit einander gemein haben. Die Berührung sey in $m$ früher als an andern Stellen erfolgt, oder es mögen hier grössere Annäherung, innigere Berührung, oder 
andere günstige Umstände ein Uehergéwicht, eine grössere Entschiedenheit der in $s$ positiven, in a negativen Erregang erzeugt haben, so ruft das positive $m$ in $s$ eine negative Erregung, neben sich, dieses wieder eine positive u. s. f., das negative $m$ in $a$ hingegen eine positive, dieses eine negative Erregung u. s. w. nach allen Richtungen um sich hervor, bis sich die fortschreitenden Erregungen nach einem für die Beháuptung der ursprünglichen Polarität minder begünstigten Puncte $n$ hinziehen, sich in $\mathrm{ihm}$ begegnen und damit bereits die geschlossene Kette $m \sigma n a$ erzeugen. Von $\boldsymbol{n}$ aus verbreiten sich aber, eben so, wie ursprünglich von $m$, nach allen Seiten durch $s$ und $a$, abermals fortschreitende Erregungen, die mit andern, von einer ursprüngliich dafür geeigneten Stelle $r$ ausgehenden Erregungen zusammenstossen und so von neuem die Thätigkeit einer geschlossenen Kette $r \sigma n \alpha$, so wie ferner von $r$ nach $v$ fortschreitende und sich begeguende Erregungen abermals eine geschlossene Kette $r \sigma \nu \alpha$ bedingen.

Es sind also $m$ und $r$, desgleichen $n$ und $v$ Focalstellen dieser Ketten, jene für die progressive, reelle chemische Neutralisation, diese für die reagirende Thätigkeit des Processes. Wie aber in diesem Schema jeder der beiden Focalpuncte $r$ und $n$ als ein gemeinschaftlicher für zwei Ketten erscheint, deren Ebenen allein in derjenigen der Zeichnung gedacht werden, so ist er zugleich ein gemeinschaftlicher für unzählige Ketten, deren Ebenen sämmtlich durch denselben Focalpunct hindurch gehen und sich in verschiedenen geraden Linien durchschneiden, die als eben so viel $\mathrm{Ra}-$ dien ron dem gemeinsamen Focus aus nach mannichfal- 
tigen Richtungen hin sich erstrecken. Und wie wir in der Dimension $g g$ nur vier solcher Focalpuncte symbolisch bezeichnet haben, so können deren unbestimmt viele in der gemeinsamen Berührungsfläche zwischen $s$ und $a$, und mit jedem wieder, der eben ausgesprochenen Vorstellung gemäss, eine unbestimmbare Zahl zusammengehöriger Ketten gesetzt werden, deren jede als eine geschlossene Totalität für sich zu betrachten, während andererseits zugleich alle mit allen Focalstellen zusammengehörige Ketten eine gemeinsame Thätigkeit unterhalten, indem begreiflich jede einzelne Kette mit allen übrigen im innigsten Zusammenhange steht, so dass die Action in einer jeden von der in allen übrigen, und die Action aller nicht minder von der in jeder einzelnen Kette abhängig seyn muss.

Was die Vorstellung über die bestimmte Art und Weise anbetrifft, nach welcher der so eingeleitete Process der Neutralisation unablässig bis zu seinem Ende fortschreitet, so müssen wir auf die an sich sehr wesentliche Entwickelung derselben an gegenwärtiger Stelle noch fürs erste Verzicht leisten. Wir werden weiter unten nach den beigebrachten erforderlichen Prämissen gehörigen Orts wieder darauf zurück kommen. Dagegen sehen wir in dem obigen schon jetzt den Grund offenbart, aus welchem der Magnetismus einer solchen zweigliederigen Kette, selbst wenn er von bedeutender Intensität wäre, durch die Wirkung auf eine Magnet-s nadel nach Aussen hin nicht so leicht versichtbart. zu werden vermag. Eine Nadel, deren Länge etwa dem Durchmesser einer jeden von den in dem obigen Schema angedeuteten Ketten gleich wäre, würde, wenn sie über der Kette $m \sigma n \alpha$ nach Osten declinirte, unter

$$
\mathrm{S}_{2}
$$


denselben Umständen über der Kette n $\sigma$ ra nach Westen und über der Kette $r \sigma \nu \alpha$ wiederum nach Osten abweichen. Da aber die einzelnen Durchmesser der sämmtlichen Partialketten, deren Action die Gesammtthätigkeit eines chemischen Neutralisationsprocesses ausmacht, in der Wirklichkeit stets so klein sind, dass auch die kürzeste Nadel jedes Mal der Einwirkung von einer unbéstimmten Anzahl solcher Partialketten zugleich auf einmal ausgesetzt ist, so werden die entgegengesetzten Sollicitationen in der Nadel sich aufheben, und es wird selbst bei einer kräftigen Einwirkung dennoch keine Ablenkung derselben erfolgen. Verbindet man entgegengesetzte Stellen einer zweigliederigen Kette unmittelbar darauf, nachdem die heiden Glieder s und $a$ derselben in einer gemeinsamen Fläche $g g$ in Contact getreten sind, durch einen feuchten Bogen, so kann durch diese plötżliche Verbindung vielleicht tine momentan überwiegende, gemeinsame Erregung, die an der innern Berührungsfläche in $s$ positiv, in $a$ negativ und über ein grösseres Stück dieser Fläche $g \mathrm{~g}$. ausgebreitet ist, begünstigt und ausgebildet werden, n Folge deren eine hinlänglich empfindliche Magnetnadel durch den feuchten Bogen in der That eine Zeit lang eine Ablenkung zu erleiden vermöchte; wenn aber die Berührung zwischen $s$ und $\boldsymbol{a}$ schon so lange Zeit Statt gefunden hat, oder wenn auch die Beschaffenheit der sich berührenden Flächen, oder die Umstände, un_ ter welchen sie überhaupt mit einander in Contact treten, gleich Anfangs von der Art sind, dass damit bereits überwiegende Bedingungen zur Bildung von Partialketten gegeben sind, in deren Action der Process alsbald unter bestimmten und entschiedenen Richtungen 
Leben und Fortgang gewinnt, so ist der Kreis der Gesammtthätigkeit in der blossen Berührung der Glieder $s$ und $a$ schon an und für sich allein geschlossen; und die Nadel wird alsdann unter dem feuchten Verbindungsbogen, wenn dieser auch nach einiger Zeit in die allgemeine Thätigkeit mehr oder weniger mit hinein gezogen wird, doch eben so wenig als über oder unter der eigentlichen Kelte selbst abgelenkt werden.

Ganz anders ist dagegen das Verhalten, wenn entgegengesetzte Stellen der Kette durch Metallflächen armirt werden. Die Unaufgeschlossenheit des Metalls und das starre Versunkenseyn desselben in die äusserliche Einheit seiner Masse macht die Erregung irgend eines Punctes desselben auch sogleich zu einer gemeinsamen Erregung seiner ganzen Masse. Nur durch den Process der Kette im geschlossenen Zustande wird es gezwungen, auf entgegengesetzten Seiten sich auch in eine entgegengesetzte Erregung zu theilen; aber auf einer und derselben Seite in der gemeinsamen Berührungsfläche mit der Flüssigkeit tritt es, mit Ausnahmen, von denen bald weiter unten die Rede seyn wird, der Flüssigkeit in allen Puncten mit gleicher Polarität entgegen, und nöthigt damit auch die Flüssigkeit, einen und denselben Erregungsfactor gegen das Metall in allen Puncten zu richten, während sie nach der entgegengesetzten Seite eben deshalb wieder in allen Puncten die entgegengesetzte Erregung hervortreten lässt. Durch die Armaturen wird daher in der durch die Flüssigkeiten $s$ und $a$ gebildeten zweigliederigen Ketle die Entstehung der Partialketten unterdrückt, den Ar- 
maturen gegenüber wird in allen Puncten'der'gemeinsamen Berührungstlïche $g g$ das $s$ gegen $a$ 'überwiegend positiv, das a gegen $s$ überwiegend negativ, und vermöge dieser zusammengehaltenen, continuirlichen Erregungen äussert die geschlossene Kette, als eine einzige, sowohl an sich, wie durch den feuchten Verbindungsbogen auf die Magnetnadel eine Wirkung, welche ausserdem, wenn die Kette ohne die Armaturen in unzählige Partialketten zerfällt, aus den oben angegebenen Gründen nicht Statt findet.

Wir schreiten demnächst zur Betrachtung solcher zweigliederigen Ketten, deren Glieder nicht mehr beide zugleich Flüssigkeiten sind, sondern von denen nur das eine eine Flüssigkeit, das andere hingegen ein Metall ist. Es wird hierbei dasselbe obige in Bezug auf zwei Flüssigkeiten ausgesprochene Theorem auch für den Process zwischen einer Flüssigkeit und einem Metalle, welches mit jener eine chemische Verbindung einzugehen genöthigt wird, sich ergeben; aber die Erscheinungen sind hierbei Modificationen unterworfen, von denen sogleich im Voraus bemerkt werden muss, dass sie in jener eigenthümlichen, bereits am Eingange dieser Schrift charakterisirten und noch kurz zuvor erwähnten Natur des Metalls begründet sind, vermöge deren das Metall nicht, so wie die Flüssigkeit, schon durch eine einseitige Erregung von Aussen, auf entgegengesetzten Seiten auch sogleich entgegengesetzt erregt wird, sondern die Erregung, die es nicht absolut von sich zu weisen vermag, vermöge seiner starren und unaufgeschlossenen Masse, in allen Puncten seiner Oberfläche entweder andauernd oder wenigstens so lange als möglich gleichförmig $\mathrm{zu}$ erhalten 
trachtet, bis es endlich von'der lebendig andringlichen Wirksamkeit der Flüssigkeit überwältigt und in entgegengesetzten Stellen wirklich auch entgegengesetzt erregt wird, womit dann erst die Kette geschlossen und ihre galvanische Thätigkeit als reeller Chemismus oder wenigstens als die durch den ganzen Kreis ergossene Tendenz zum analytischen Effect desselben in der Form des Elektromagnetismus eingeleitet ist.

Das Metall und die Flüssigkeit, welche mit einander in Berührung treten, mögen aber ihrer individuellen Natur und ihrem gegenseitigen Verhälnisse nach entweder wirklich eine Verbindung eingehen, oder auch gar keinen fortschreitenden chemischen Process bedingen, dass also im letztern Falle das Metall von der Flüssigkeit an und für sich gar nicht angegriffen werden oder höchstens nur an seiner Oberfläche eine leise und durch äussere Merkmale kaum wahrnehmbare reelle chemische Veränderung erleiden möge, so wird dennoch in jedem Falle, wenigstens als Ausdruck der vorzüglich in der Flüssigkeit herrschenden Tendenz zum chemischen Processe, eine elektrische Erregung zwischen beiden Statt finden, die in allen Puncten der Oberfläche der metallischen Masse eine und dieselbe ist, während sie in der Flüssigkeit die bekannten Gesetze der Polarität befolgt.

Allein jetzt, nachdem wir im vorhergehenden $\mathrm{Ab}$ schnitte die Phänomene der Reaction vollständiger kennen gelernt haben, wird hier die schon vorläufig in einer Note zuSeite 31 und 62 . berührte Erwähnung an ihrem Orte seyn, dass diese Erregung keinesweges immer die eigentliche normale sey, welche der wahren elektrischen Relation der beiden Substanzen entspricht, son- 
dern dass sie nicht selten gerade als die entgegengesetzte von dieser letztern kürzere oder längere Zeit hindurch sich darstellen könne. Denn in der That ist es bereits ein bald nach der Entdeckung der Voltaschen Säule durch unmittelbare elektrometrische Beobachtungen bekannt gewordenes Factum, dass bei einigen Metallen in der Berührung mit gewissen Flüssigkeiten ihre anfängliche elektrische Spannung durch o $E$ nach kürzerer oder längerer Zeit in die entgegengesetzte übergeht, und dieser Wechsel kann allein dadurch, dass er als das Symptom einer in den ersten Momenten entweder überwiegend hervortretenden Einwirkung der Flüssigkeit auf das Metall oder einer von Seiten des Metalls gegen jene Einwirkung gleich von Anfang an überwiegend geübten Reaction erfasst wird, Bedeutung und Verständniss gewinnen.

Ursprünglich ist das Verhältniss einer jeden Flüssigkeit gegen jedes Metall ein solches, dass die erstere das Metall zu oxydiren und ihren positiven Factor gegen dasselbe treten $\mathrm{zu}$ lassen, mithin es zuvörderst negativ zu erregen trachtet. Bei einer bestimmten Anzahl von Metallen kommt es aber während des bloss eirıseitigen Contacts mit bestimmten Flüssigkeiten dahin niemals; die Metalle halten durch eine beständige positive Erregung die Flüssigkeit von sich entfernt und zwingen ihr in der Berührungsfläche eine negative Erregung auf. Bei andern erreichen in den ersten Momenten einer lebhaften Einwirkung einige Flüssigkeiten den Vortheil einer negativen Erregung des Metalls; aher nach einiger Zeit tritt das lelztere gleichsam in sich gesammelt der Flïssigkeit wieder, nachdem es durch den Zustand des o E hindurchgegangen, mit einer 
normalen positiven Erregung 'entgegen' und weist sie selbst abermals auf die negative Erregung in der Berührungsfläche zurück. Häufiger scheint der umgekehrte Fall eintreten zu müssen, in welchem die Flüssigkeit zuletzt die Oberhand behält, und nur eine Zeit lang früher der anfänglich stärkeren Reaction des Metalls nachzugeben genöthigt wird. Indem sie das Metall zu oxydiren und mithin zuvörderst negativ zu erregen strebt, tritt dieses dem beabsichtigten Effect mit Erfolg durch die entgegengesetzte positive Erregung in den Weg, während die Flüssigkeit zur negativen Erregung zurückgedrängt wird, bis sie endlich wieder vorschreitend durch ein hergestelltes o $E$ den Uebergang zum Siege gewinnt, mit welchem, während sie selbst in der Berührungsfläche positiv hervortritt, das Metall in der normalen negativen Erregung fortwährend erhalten wird. Noch andere Metalle sind vielleicht in keinem Moment gegen irgend eine Flüssigkeit im Stande, sich in positiver Erregung zu erhalten; aber dennoch ist es selbst bei den oxydabelsten nicht schwer, sich von einer ursprünglich geübten Reaction derselben gegen die negative Erregung, dadurch, dass man die letztere/nur successiv zunehmende Grade ihrer Ausbildung deutlich durchlaufen sehen kann, zu überzeugen. Diese Reactionserfolge sind begreiflich dann, wenn die Metalle der Flüssigkeit mit vollkommen regulinischer, möglichst gleichmässiger, polirter Oberfläche entgegen treten, am stärksten, und es ist sogar nicht unwahrscheinlich, dass selbst die Form der Berührungsfläche, je nachdem sie convex, concav oder eben ist, auf den Grad der Stärke der Reaction nicht ohne Einfluss sey; dabei ist das Verhalten am bequemsten in der Wir- 
kung der dreigliederigen einfachen Kette auf die Magnetnadel zu beobachten.

Wenn man z. B. eine solche aus Kupfer, stark verdünnter Schwefelsäure und Zink zusammengesetzte Kette, in welcher die Metallbleche mit glänzender, polirter Fläche die Flüssigkeit berühren, durch den Multiplicator schliesst, so erfolgt die Ablenkung der Magnetnadel unter dem letztern gewöhnlich nicht so plötzlich, wie es sonst zu geschehen pflegt, sondern viel langsamer und allmälig, so dass die Bewegung der Nadel derjenigen eines stetig fortrückenden Secundenzeigers über dem Zifferblatte einer Uhr zu gleichen scheint. Die polirte Fläche des Zinks gibt alsdann der Einwirking der Flüssigkeit nur allmälig nach, bis die letztere nach einiger Zeit das Maximum der Erregung gewonnen hat, das ihr abermals durch eine Reaction, die wieder mit einer rückgängigen Bewegung der $\mathrm{Nadel}$ verbunden ist, streitig gemacht und entrissen wird. Unter diesen Umständen ist also die Reaction des oxydabeln Metalls gegen die normale Erregung desselben gleich vom ersten Momente der Schliessung der Kette an sichtbar, nur ist sie hloss hemmend und ohne eine vorübergehende entgegengesetzte Erregung, welche dagegen z. B. vorzüglich sichtbar wird und auch am längsten, wenn gleich nicht als eine transitorische bemerkt worden ist, bei einer aus Eisen, Schwefellebersolution und Kupfer zusammengesetzten Kette. Schliesst man eine solche Kette durch einen Multiplicator, so weicht die Magnetnadel unter dem letzteren so $\mathrm{ab}$, als wenn das Kupfer das oxydablere und das Eisen das minder oxydable Glied der Kette wäre. Die Reaction des Eisens gegen die von der Elüssigkeit ausgehende 
Erregung ist nämlich zuvörderst so stark, dass es den positiven Factor der letzteren völlig zurück stösst, und statt negativ erregt zu werden, mit der positiven Thätigkeit auftritt, während das Kupfer durch den gegen dasselbe geworfenen positiven Factor negativ wird. Aber diese Erscheinung ist keinesweges, wie man grösstentheils seit der Bekanntschaft mit ihr geglaubt hat, und eben so wenig, als viele andere Erfolge derselben Art, constant, sondern sie ist nur eine transitorische; denn wenn man die Kette lange genug geschlossen lässt, so sieht man nach einiger Zeit die Nadel auf Null zurïck, und darauf bald zur entgegengesetzten Abweichung übergehen und sich darin erhalten, so dass nun erst die normale Erregung an dem mehr oxydabeln Gliede der Kette als die negative, an dem minder oxydabeln dagegen als die positive hergestellt ist.

Wenn also dergleichen anomale Erfolge selbst noch in der geschlossenen dreigliederigen Kette eine Zeit lang fort bestehen können, so müssen sie ausserhalb derselben, bei der blossen gegenseitigen elektrischen Erregung zwischen differenten Substanzen offenbar noch viel häufiger und dauernder und wohl selbst unter dem hartnäckigen Schein einer constanten Norm auftreten, so dass es das misslichste, undankbarste, nur, zu Verwirrungen und zahllosen Widersprüchen führende Unternehmen seyn würde, wenn allein aus Beobachtung elektrischer Erregungen zwischen differenten Stoffen, namentlich zwischen Metallen und Flüssigkeiten, nur so weit das Elektrometer und der Condensator darüber zu entscheiden oder Bürgschaft zu leisten vermöchten, Normalbestimmun- 
gen über elektrische Relationen in Bezug 'auf ein allgemeines elektrisches System der Körper überhaupt abstrahirt und Folgerungen für ein beabsichtigtes durchgreifenderes Verständniss chemischer, galvanischer und elektromagnetischerErscheinungen daraus hergeleitet werden sollten. Die blosse elektrischeErregung zwischen zwei nur durch gegenseitigen Contact auf einander wirkenden Stoffen ist bei weitem in den meisten Fällen ein so bewegliches, veränderliches Symptom, eben weil es nur momentane chemische Tendenz ausspricht, die von der reellen Action noch unendlich weit entfernt seyn und bis zu ihr mehr als einmal eine veränderte und völlig entgegengesetzte Gestalt gewinnen kann, dass man diesen Gegenstand bisher im Ganzen viel zu positiv und schwerfällig behandelt hat und dass der Gedanke, ein wissenschaftliches System der Chemie, wie das elektrochemische, zu Stande zu bringen, worin die Elektricität als Causalṕrincip betrachtet und die chemischen Erscheinungen mit jenen elektrischen Gegensätzen in Einklang gebracht werden sollen, die allein beim wechselseitigen Contact differenter Stoffe durch das Elektrometer und den Condensator wahrgenommen werden, in seiner Art eben so widerspruchsreich und noch minder ausführbar ist, als es die ältesten ebenfalls nur durch die rohen Täuschungen des sinnlichen Scheins erzeugten Hypothesen der Astronomie waren, die statt der Sonne nur die Erde zum wahren Mittelpunkte aller Bewegungen des Planetensystems machen wollten.

Was wir die elektrische Relation verschiedener Körper und das elektrische System oder die elektrische Spannungsreihe derselben nennen, sollte in der That 
eigentlich nichts anderes, als ihr chemisches Verhältniss zu einander seyn, sofern damit entschieden würde, welcher von irgend $z$ wei in der Richtung zum chemischen Processe gegen einander begriffenen Körpern mit dem positiven oxydirenden, und weleher von ihnen mit dem negativen desoxydirenden Effect gegen den andern auftritt. Aber dieser Effect kann vermöge der obigen Gründe nicht geradehin aus der elektrischen Spannung, welche die Körper beim blossen Contact mit einander zeigen, hergeleitet, geschweige als eine direkte Folge von derselben angesehen werden, weil die Körper bis zu dem Momente, wo entweder dieser Effect unmittelbar als chemische Action oder wenigstens als eine lebendig erhöhte Tendenz zu demselben im Kreise einer geschlossenen galvanischen Kette hervortritt, durch den Erfolg der Reaction häufig gerade die entgegengesetzte elektrische Eiregung festhalten können, sondern er ist vielmehr nur aus dem constanten und normalen Erfolge der geschlossenen Kette selbst entweder unmittelbar oder nach den von uns mit Sicherheit entworfenen Kritorien, vermöge der durch die Kette bewirkten Ablenkung der Magnetnadel, so weit diese Einwirkung auf letztere wirklich Statt findet, $\mathrm{zu}$ beurtheilen, und selbst da kann, wie wir wissen, die Reaction mit einem anfänglichen Uebergewichte noch eine Zeit lang in den Effect der geschlossenen Kette eingreifen, und eben so und im Wesentlichen aus denselben Gründen, wie sie es in so vielen im vorhergehenden Abschnitte betrachteten Fällen thut, noch entgegengesetzte transitorische Wirkungen von kürzerer oder längerer Dauer herroxbringen. 
Nach diesen Bemerkungen kehren wir nun zur Untersuchung der Thätigkeit der zweigliedrigen, aus einem Metall und einer Flüssigkeit zusammengesetzten Kette zurück. Die beiden Flächen, die am Metall und der Flüssigkeit zusammen die gemeinsame ursprüngliche Berührungsfläche in einer solchen Kette bilden, nennen wir, so wie soust, die innern, und die beiden andern von diesen ahgewandten oder ihnen gegenüber liegenden, die äussern Flächen oder Extreme der Kette. Setzen wir nun, dass die Flüssigkeit auf der innern Fläche positiv erregt werde, so ist sie auf der äussern negativ; das Metall hingegen ist auf der innern so wie auf seiner äussern Fläche in allen Puncten negativ. Es wird dagegen eben so, wenn die entgegengesetzte Voraussetzung Statt findet, auf beiden Seiten in allen Puncten positiv erregt seyn. So lange dieser Zustand bleibt, ist keine galvanische Thätigkeit vorhanden; es findet allein die elektrische Spannung Statt. Dieser Zustand kann aber aufgehoben und der Erfolg der reellen Thätigkeit der geschlossenen galvanischen Kette herbeigeführt werden: entweder a) durch künstliche, experimentale Veranlassung, oder b) auf natürlichem Wege vermöge des durch die Natur der beiden Glieder der Kette schon von selbst bedingten wechselseitigen chemischen Processes.

a) Die künstliche Veranlassung der Thätigkeit der Kette besteht nun eben darin, dass auch die bejden äussern Extreme des Metalls und der Flüssigkeit entweder unmittelbar durch eine kreisartige, geschlossene Form des Ganzen oder durch einen bogenförmigen Fortsatz des Metalls, der am äussersten Extrem der Flüssigkeit in sie eingetaucht wird, mit einander 
ebenfalls in Verbindung gesetzt werden, Das Metall und die Flüssigkeit begegnen sich in diesen Extremen alsdann unter gleichnamigen Erregungen, während die Natur ihres wechselseitigen Verhaltens an und für sich verschiedenartige Erregung in beiden eben so, wie auf den innern Extremen erheischt und der Conflict zwischen dem Bestreben, den Widerspruch auf dieser Seite durch Herstellung der ursprünglichen polaren Erregung $\mathrm{zu}$ heben, und zwischen der Beharrlichkeit der dadurch auf gleiche Weise gefährdeten Erregung auf den beiden andern innern Extremen der ursprünglichen Berührung erzeugt vollkommen auf die mehrfältig von uns entwickelte und ein für allemal erfasste Weise die Thäligkeit der geschlossenen Kette. Nur sind hierbei mannichfaltige Disjunctionen in den Bedingungen, unter welchen der Erfolg verschiedentlich modificirt und in seiner progressiven Thätigkeis vermöge des geringen Ausfalls, bald jener, bald dieser Seite der Kette zugewandt werden kann, möglieh oder denkhar; für das Verständniss im Ganzen, da sie in der Wirklichkeit doch niemals so getrennt, als in der logischen Zergliederung vorkommen, wird es indess vollkommen hinreichend seyn, sie auf die folgenden Kategorien zurückzuführen.

a) Die gemeinsame Berührungsfläche zwischen dem Metall und der Flüssigkeit ist auf den äussern Extremen eben so gross, wie auf den innern. Unter dieser Bedingung ist entweder das äussere, der, Flüssigkeit dargebotene Extrem des Metalls noch qualitativ von dem innern verschieden, und bedingt an und für sich eine stärkere oder schwächere Erregung als jenes; oder wenn auch beide Metallflächen ur- 
sprünglich qualitativ so wenig als quantitativ verschioden sind, so bedingt schon die Priorität der Erregung des innern Extrems in seiner frühern Berührung mit der Flüssigkeit einen qualitativen Unterschied, dem zu Folge das eine Extrem in stärkerer, das andere in schwächerer Erregungsintensität gegen die Flüssigkeit tritt und die Thätigkeit der Kette, mit deren Beginn die eine Seite entschieden positiv, die andere entschieden negativ , wirksam wird, findet num im Wesentlichen ganz so und unter denselben Motiven Statt, aus welchen, unsern bisherigen und oben S. $76 \mathrm{ff}$. besonders auseinander gesetzten Gründen zu Folge, zwischen zwei differenten Metallen und einer Flüssigkeit, gegen welche jene der Art nach ursprünglich eine und dieselbe, aber dem Grade nach verschiedene Erregung annehmen, die Wirkung einer dreigliederigen Kette za. Stande kommt, während welcher das eine Metall mit positiver, das andere mit negativer Thätigkeit auftritt, ungeachtet beide einzeln für sich, wie gesagt, gleichartig, bloss in verschiedenem Grade durch die Flüssigkeit erregt werden. Nur ist hier in dieser Art der zweigliederigen Kette das die Thätigkeit unterhaltende Moment des Ausgleichungsdranges der beiden [metallischen Seiten nicht, so wie bei der dreigliederigen Kette, den beiderseitigen Erregungen zwischen der Flüssigkeit und den metallischen Armaturen entgegengesetzt, sondern nur auf oE gerichtet, weshalb im Ganzen auch die Intensität der Wirkung, wenn sie nicht etwa zufälig durch bedeutende qualitative Differenzen der beiden Seiten des Metalls erhöht wird, auch noch viel geringer und von kürzerer Dauer ist, als die jener dreigliederigen Kette. 
Die Wirkung der Kette schweigt nach einiger Zeit, in welcher die Differenz gehoben und die Ausgleichung, auf beiden Seiten vollkommen erfolgt ist, gänzlich, weil sie nicht, so wie bei der dreigliederigen Kette, durch den fortwährend bestehenden Gegensatz der Erregung im Contact zweier differenter Metalle immer von neuem gereizt und im Gange erhalten wird; und wenn auch zwischen der Flüssigkeit und dem Metalle längere Zeit hindurch noch eine fortwährende chemische Wirkung Statt findet, so ist diese doch allmählig gegen beide Seiten des Metalls in ein Gleichgewicht getreten, unter welchem sodann zwar noch eine galvanische Thätigkeit fortbesteht, aber eine solche, die gar nicht mehr der anfänglichen Kette, welche durch den metallischen Verbindungsbogen zwischen den beiden metallischen Extremen geschlossen wurde, sondern umzählig vielen, nach allseitiger Richtung geschlossenen Partialketten angehört, wie wir sie oben (S. 273 ff.) in dem Process zwischen zwei chemisch auf einander einwirkenden Flüssigkeiten kennen gelernt haben, und wie wir weiterhin unter b), sofern sie sich ebenfalls in dem chemischen Process zwischen einem Metall und einer Flüssigkeit wiederholt, das Nähere darüber erwähnen werden.

Wenn beide Extreme des Metalls in einem und demselben Momente mit der Flüssigkeit in Berührung gesetzt werden und dabei alle anderweitigen qualitativen Differenzen wenigstens in dem Grade vermieden sind, dass die Folgen ihrer Wirksamkeit äusserlich unsichtbar bleihen, so ist eben damit gleich vom Anfang an die Wirkung, von der wir bisher hier gesprochen, nicht vorhanden. Welche von beiden Seiten aber, 
wenn jene anfängliche, in dieser Kategorie $(\alpha)$ allein betrachtete Art der Thätigkeit zweigliederiger Ketten wirklich Statt findet, ob das zuerst oder das später mit der Flüssigkeit in Berührung gesetzte Extrem des $\mathrm{Me}-$ talls, positiv oder negativ wirksam werde, das hängt bei gleicher Flüssigkeit theils von dem jedesmaligen Metall und seiner normalen Erregung gegen die Flüssigkeit, theils von den zufälligen qualitativen Differenzen der beiden mit der Flüssigkeit in Contact getretenen Seiten desselben und von eigenthümlichen Reactionserfoigen ab, so dass darüber im Allgemeinen durchaus gar nichts zu entscheiden ist; wie man in der That schon durch eine geringe Anzahl von Versuchen, welche in dieser Absicht angestellt werden, zu der Ueber'zeugung geführt werden kann, dass bei einem und demselhen Metalle und einer und derselben Flüssigkeit die früher eingetauchte Seite von jenem einmal positiv, ein ander Mal wieder negativ thätig seyn kann. Ja nicht selten wird man die Richtung des Erfolgs wechseln sehen, und nachdem die Magnetnadel durch den |schliessenden Bogen eine Zeit lang nach einer Seite hin abgelenkt worden, sie auf Null zurück kommen und dann in die entgegengesetzte Ablenkung übergehen sehen. Es ist sogar nach dem Ganzen unserer Ansicht sehr wohl denkbar, dass bis zur gänzlichen Ausgleichung mehr als eine Oscillation der Art Statt finden und nit Apparaten von der erforderlichen Vollkommenheit und bei sorgfältiger Beobachtung noch bemerkbar werden können. Die Unbeständigkeit und der Wechsel eines solchen Verhaltens liegen begreiflich in dem bloss zufälligen, relativen Gegensatze und dem Mangel an reeller und absoluter Verschieden- 
heit der beiden Seiten des Metalls; sie sind für einen jeden, der mit unserer Theorie des Processes der galvanischen Kette einverstanden, und mit allem, was wir bis dahin zum Verständnisse des Gegenstandes beigebracht haben, gehörig bekannt geworden ist, um so weniger befremdend, da selbst bei solchen dreigliederigen Ketten, deren beide differente Metalle in der elektrischen Spannungsreihe nicht weit von einander entfernt stehen und nur einen so schwachen Gegensatz bilden, dass derselbe durch zufällige qualitative Unterschiede und lebhafte mit der Priorität der Berührung gegebene Reactionserfolge überboten werden kann, abnormale Erfolge nicht ungewöhnlich sind, die über die eigentliche Relation der Stoffe und über die Natur der Thätigkeit galvanischer Ketten überhaupt, wenn man den gewöhnlichen Ansichten folgt, die täuschendsten, räthselhaftesten, verwirrendsten oder unentschiedensten Vorstellungen veranlassen können, während sie in dem Ganzen unserer Darstellung nicht nur als sehr begreifliche, sondern selbst als schlechthin nothwendige Erscheinungen sich auf die ungezwungenste und natürlichste Weise zu erkennen geben. Uebrigens bedarf es kaum der Erwähnung, dass so wie die hier betrachtete zweigliederige Kette mit gleichen metallischen Berührungsflächen nur durch die transitorische Differenz der beiden Metallextreme bedingt, und, so lange diese und ihre Wirkung währt, als eine dreigliederige mit zwei transitorisch differenten Metallgliedern betrachtet werden kann, so umgekehrt auch jede dreigliederige unter dem Gesichtspunkt einer solchen zweigliederigen Kette aufgefasst werden könne, in welcher neben der Flüssigkeit die beiden differenten Metalle als ein einzi-

$\mathbf{T}_{2}$ 
ges auf den Extremen constant differentes Glied gesetzt werden.

$\beta$ ) Die Berührungsfläche zwischen dem Metall und der Flüssigkeit ist auf den äussern Extremen kleiner oder grösser als auf den innern. - Dieses ist nun die specielle Form der zweigliederigen Kette, unter welcher wir sie zuerst oben im 3ten Abschnitte besonders betrachtet und zugleich zur Bestimmung der elektrischen Relationen zwischen Metallen und Flüssigkeiten benutzen gelernt haben. In letzterer Hinsicht bietet sich nun, nach allem, was wir bis dahin und so eben noch kurz vorher in Betrachtung gezogen haben, die Bemerkung von selbst dar, dass die Wirkung einer solchen Kefte begreiflich nicht bloss durch die quantitativen, sondern zugleich durch mannichfaltige qualitative Differenzen der metallischen Berührungsflüchen, durch die Priorität der Berührung auf der einen oder andern Seite, und durch mögliche Reactionserfolge bestimmt und in solchem Grade modificirt werden könne, dass das Ergebniss allerdings völlig anomalisch, und dem wahrhaften, in der eigentlichen Natur der Glieder der Kette begründeten Verhältuisse derselben gerade entgegengesetzt ausfallen könne. Daraus folgt indess keinesweges die Unbrauchbarkeit dieser zweigliederigen Kette mit ungleichen metallischen Berührungsflächen zu dem erwähnten Zwecke, so wenig die täuschende Reizbarkeit des Condensators und Duplicators diese Instrumente zum Behuf der Beobachtung sehr schwacher Grade elektrischer Erregungen schlechthin untauglich macht, sondern es hat damit jetzt nur die Nothwendigkeit der bereits oben von urs zur Bedinging gemachten Vorsicht und Umsichtigkeit bei der 
Bestimmnng elektrischer Relationen durch diese Art der zweigliederigen Kette nach den angegebenen Regeln erst die erforderliche Nachweisung und Anschaulichkeit erhalten. Wenn man die metallischen'Extreme mit der Flüssigkeit gleichzeitig in Berührung setzt, für die Entfernung aller zufälligen, durch Temperatur und anderweitige Bestimmungen bewirkten qualitativen Differenzen das Möglichste anwendet und sie, so weit ihre gänzliche Beseitigung ausser der Gewalt des Experimentators liegt, bei hinlänglicher Empfindlichkeit und Zuverlässigheit des Apparats durch die möglichst grösseste quantitative Differenz der Berührungsflächen zu überbieten trachtet; dabei nicht nach einzelnen Erfolgen urtheilt, sondern die Versuche oft genug wiederholt, und mit Uebung, Sachkenntniss und umfassender Kritik die nöthigen Folgerungen aus jhnen herleitet, so wird diese zweigliederige Kette mit ungleichen metallischen Berührungfflächen in Verbindung mit dem elektromaguetischen Multiplicator und der magnetischen Boussole zur Bestimmung der elektrischen Relationen zwischen Metallen und Flüssigkeiten als das brauchbarste, zuverlässigste und natürlichste Instrument vor den zu gleichem Behuf bis jetzt angewandten übrigen Mitteln sich gewiss selır wesentlich bewähren.

Wir kommen nun zur Betrachtung der Thätigkeit der zweigliederigen, aus einem Metall und einer Flüssigkeit gebildeten Kette, welche

b) auf natürlichem Wege schon vermöge eines durch die beiden Glieder der Kette von selbst bedingten wechselseitigen chemischen Processes Statt findet. Es bedarf hier keiner künstlichen Schliessung und keiner an gegenüberliegenden Punkten mit der Flüssigkeit 
in Contact tretenden metallischen Extreme; durch deren leitende Verbindung sonst erst die Schliessung der Kette bewirkt wird, sondern die letztere erfolgt hier allseitig schon durch die Berührung des Metalls und der Flüssigkeit in unzähligen Punkten und mit einer zwar gemeinsamen, aber in unzählige Partialketten vertheilten Thätigkeit, so wie wir sie oben (S. 273 ff.) in der schon mit der gegenseitigen Berührung zweier sich neutralisirenden Flüssigkeiten erfolgenden Wirksamkeit aufgefasst und erkannt haben, nur dass hier das Metall durch das seiner Natur gemässe Bestreben, der Flüssigkeit in allen Punkten mit einer und derselben Polarität entgegen zu treten und durch Reactionen die Einleitung des Processes in den meisten Fällen mehr oder weniger modificirt, und bei weitem mehr, als es zwischen Flüssigkeiten der Fall ist, erschwert, während andrerseits vermöge der damit verknüpften Erscheinungen die Wahrheit und Angemessenheit unserer Ansicht eben damit um so evidenter hervortritt.

Wird eine Metallmasse von einer auf allen Punkten ihrer Oberfläche möglichst gleichen Qualität unmittelbar in eine Flüssigkeit getaucht, so dass sie von letzterer auf allen Seiten umgeben und berührt wird, so ist der anfängliche Zustand der gegenseitigen Thätigkeit allemal von der Art, dass das Metall in allen Punkten ohne Ausnahme nur die eine, entweder positive oder negative Polarität, der erregenden FJüssigkeit ent gegen richtet, und diese eben damit nöthigt, nur mit der entgegengesetzten polaren Erregung in allen Punkten der Berührungsfläche sich gegen das Metall zu kehren. So lange aber dieser Zustand dauert, kann schlechthin keine chemische Action erfolgen, die nur unter dem Typus 
der Thätigkeit der geschlossenen galvanischen Kette möglich ist, zu welcher die Bedingung entgegengesetzt polarer Erregung an verschiedenen Stellen eben mit jenem Zustande gänzlich mangelt. In allen hieher gehörigen Fällen, in welchen das Metall starr und verschlossen genug ist, die gleiche Polarität in allen Punkten fest zu halten oder in denen die Flüssigkeit nicht kräftig und beweglich genug ist, dieselbe zu durchbrechen und zu überwältigen, bleibt es fortwährend allein bei der elektrischen Spannung, und die Stoffe sind ihrer Natur nach keines gegenseitigen chemischen Processes fähig. Aber selbst da, wo dieser erfolgt, sieht man dennoch sehr häufig das Metall kürzere Zeit hindurch die gleiche Polarität in allen Punkten seiner Oberfläche behaupten und dadurch der Einwirkung der Flüssigkeit eine Zeit lang Widerstand leisten, wie die Erfahrung durch die in den ersten Momenten nicht selten gänzlich schweigende und nur später in successiv zunehmendem Grade hervortretende Thätigkeit des chemischen Processes zwischen beiden Stoffen deutlich zeigt, auf eine Weise, die vollkommen unverständlich seyn würde, wenn die Wirkung nichts weiter als nur die Folge einer bloss äusserlichen, einseitigen, chemischen Affinität wäre. Je gleichmässiger die Beschaffenheit des Metalls auf seiner Oberfläche in Beziehung auf chemische Qualität und äussere Form, je höher der Grad der Glätte und Politur dieser Fläche ist, desto länger hält es die Einwirkung der Flüssiggkeit von sich $a b$, bis diese endlich dennoch ihm in mehr oder weniger Punkten die schwachen Seiten abgewonnen hat, ge. gen welche sie eine der ursprünglichen entgegengesetzte Erregung geltend machen kann, und in demsel- 
ben Moment, in welchem dieses gelingt, sind eben so viel besondere und zugleich durch gemeinsame Thätigkeit geschlossene Partialketten gebildet, der reelle chemische Process beginnt auf die ein für allemal von uns erkannte Weise, und greift in jedem folgenden Moment mit immer grösserer Sicherheit und Kraft weiter um sich. Jener Sieg der Flüssigkeit über das widerstrebende Metall gelingt aber bei übrigens noch so vollkommener Gleichmässigkeit der chemischen Qualität der metallischen Oberfläche andrerseits um so leichter und geschwinder, je rauher die letztere ist, je mehr Vertiefungen und Erhöhungen sie darbietet, die als grössere und kleinere Berührungsflächen einer unzählbaren Menge zweigliederiger Partialketten zu gemeinsamen Stütz - und Focalpunkten dienen, so dass nun die anfangs über die ganze Fläche des Metalls continuirlich verbreitete gemeinsame Polarität desselben von der Flüssigkeit an unzähligen Punkten durchbrochen und die metallische Fläche nicht mehr ausschliesslich positiv oder ausschliesslich negativ, sondern an unbestimmt vielen Punkten positiv und an eben so viel andern zugleich negativ thätig ist.

Setzen wir z. B. in der oben auf S, 273 . befindlichen symbolischen Zeichnung $g g$ als gemeinsame Berührungsfläche zwischen einer Säure $s$ und einem durch sie auflösbaren Metalle $a$, von denen ursprünglich letzteres in allen Punkten von $g g$ gegen s positiv, die Flüssigkeit s dagegen eben so in allen Punkten der gemeinsamen Berührungsfläche gegen $a$ negativ erregt sey, so ruft jeder negativ erregte Punkt der letzteren in seiner Nachbarschaft nach allen Richtungen eine positive Erregung, diese wieder eine 
negative, diese wieder eine positive hervor, und so fort; und die ursprünglich negativ erregte Flüssigkeit strebt zugleich vermöge eines allseitigen Erregungsdranges jene positiven Erregungen auch in der Richtung gegen das Metall geltend zu machen, und sie auf seine Oberfläche zu repliciren, während das starre, für den beweglichen Gegensatz unempfängliche Metall die Realisirurg jener Tendenz durch die eng geschlossene, in allen Punkten gleichmässige Erregung, mit welcher es der Flüssigkeit entgegentritt, so lange als möglich zu vereiteln trachtet. Setzen wir nun etwa, die Punkte $m$ und $r$ in der metallischen Berührungsfläche $g g$ seien mikroskopische, sehr spitze, mit einem verhältnissmässigen Minimum von Flächeninhalt hervorragende Erhöhungen, während $n$ und $v$ breitere Versenkungen oder Ebenen ohne dergleichen einzelne Hervorragungen in derselben Metallfläche bilden mögen: so ist der Widerstand des Metalls gegen den Erregungsdrang der Flüssigkeit in $m$ und $r$ unkräftiger und weniger gesammelt als in $n$ und $v$, und wie in einer zweigliederigen Kette mit ungleichen metallischen Berührungsflächen die kleinere Metallfläche durch die Flüssigkeit in eine der grössern entschieden entgegengesetzte Erregungsthätigkeit versetzt, und durch seine Opposition, eben weil diese die lebendige Action der Kette anregt, um so bestimmter darin erhalten wird, so werden nún auch $m$ und $r$ dem positiv hervortretenden $s$ gegenüber negativ, während $n$ und $v$ dem negativen $s$ gegenüber sich positiv thütig erhalten, die geschlossenen Partialketten $m \sigma n \alpha, r \sigma n \alpha, r \sigma \nu \alpha$, sind realisirt und das Melall wird in $m$ und $r$, so wie 
in unzähligen andern negativen Focalpuncten eben so vieler auf gleiche Weise in Thätigkeit gesetzten Partialketten oxydirt und mit der Flüssigkeit neutralisirt, während es in $n$ und $v$ und in eben so viel andern opponirenden Focalpunkten eben so vieler Partialketten mit der positiven Thätigkeit zu reagiren fortfährt. Im übrigen gilt nun alles, was bereits oben über den Process der natürlichen zweigliederigen Kette, welche zwischen zwei chemisch auf einander wirkende Flüssigkeiten durch ihre gegenseitige Berührung an und für sich allein zu Stande kommt, von uns beigebracht worden, begreiflich eben so auch von diesem natürlichen Neutralisationsprocesse zwischen einem Metalle und einer Flüssigkeit, und in demselben Sinne, wie wir als Resultat unserer bisherigen und als Grundtheorem für alle folgende Untersuchungen den auf S. 271. hervorgehobenen Satz ausgesprochen haben, dürfen wir uns berechtigt halten, hiermit eben so den folgenden aufzustellen:

Ueberall, so oft eine Flüssigkeit und ein Metall sich chemisch verbinden, ist diese Vereinigung nur als das Product eines durch und durch polaren Processes zu betrachten, welcher schlechthin nur unter dem Typus einer Thätigkeit vollzogen wird, die ihrem innersten Wesen nach keine andere ist, als die Thätigkeit der geschlossenen galvanischen Ketle.

Es liegt unmittelbar in dor obigen Darstellung, die uns zu diesem Resultate geführt hat, dass der Erfolg, in wolchem ein Metall durch eine Flüssigkeit bezwungen und von ihr aufgelöst wird, nicht bloss mit derjenigen chemischen Relation der letzteren, welche man die Oxydationsmächtigkeit der Flüssigkeit in 
Beziehung auf das Metall nennen könnte, gegeben sey, sondern dass er seine Entstehung und Realisirung ganz besonders zugleich der polaren Erregungsbeweglichkeit der Flüssigkeit zu verdanken habe, mit welcher sie, in lebendiger Aufgeschlossenheit für beide polare Seiten des chemischen Gegensatzes, mit irgend einer Erregung auch alsbald die Gegenerregung nach allen Richtungen hin durch ihre ganze Masse geltend zu machen strebt. Die bloss einseitige Erregung, nach welcher das eine Glied allein positiv, das andere allein negativ in allen gemeinsamen Berührungspunkten erregt bleibt, bildet nur die elektrische Spannung, in der allein die Tendenz zum Processe ausgesprochen, aber seine Realisirung noch keinesweges gegeben ist, und nur dadurch, dass jedes Glied an verschiedenen Stellen der Berührung positiv und negativ zugleich erregt wird, ist die geschlossene galvanische Kette, und mit ihr einzig und allein der reelle chemische Process, welcher nichts anderes ist, als die Thätigkeit dieser Kette, verwirklicht. Wührend der rigide Körper und namentlich das Metall in der starren Daseynsweise seiner Masse nur die eine Erregung in allen Punkten derselben festzuhalten trachtet, ist es allein die aus der entgegengesetzten Natur der Flüssigkeit hervorgehende Thal derselben, welche jene entgegengesetzten Erregungen an verschiedenen Punkten, mit ihnen die geschlossene galvanische Kette und mit dieser den chemischen Process bewerkstelligt und das alte chemische Grundgesetz: „corpora non agunt, nisi fluida"6 wäre hiermit auf einen höher liegenden Beziehungspunkt, nämlich auf den vom Anfange unserer Untersuchung an durch uns aufgefassten und fest gehaltenen charak- 
teristischen Unterschied zwischen der Erregungsthätigkeit der Metalle und Flüssigkeiten zurückgeführt.

Aber so wie die Metalle und die festen Körper überhaupt verschiedene Grade jener Einseitigkeit und Hartnäckigkeit ihres Verhaltens befolgen, mit welchem sie vorzugsweise nur einer vou beiden Erregungen auf einmal ursprünglich zugänglich erscheinen, so ist jene Aufgeschlossenheit und Beweglichkeit nach beiden Seiten des Gegensatzes zugleich in verschiedenen Flüssigkeiten ebenfalls in verschiedenem Grade vorhanden, und es ist a priori zu erwarten, wie es durch die Erfahrung bestätigt wird, dass diese chemisch polare Regsamkeit in keiner Flüssigkeit grösser seyn könne, als in derjenigen, die nach ihren chemischen Relationen zu den festen und flüssigen Körpern als die indifferenteste unter allen, als der vollkommenste Repräsentant alles Flüssigen schlechthin erscheint, nämlich im Wasser. Indem also der chemische Process zwischen einer Säure und einem Metall einerseits von der absoluten Mächtigkeit, anderer Seits aber zugleich von der polaren Erregungsbeweglichkeit der letzteren abhängig ist, so ist es begreiflich, woher die Wirkung überhaupt und das Maximum ihrer Intensität in sehr vielen Fällen nur bei einem bestimmten Grade der Verdünnung der Säure durch Wasser eintritt. Eben daher aber ist es auch unrichtig, hiebei in der Vorstellung das Wasser noch fortwährend von der Säure getrennt zu halten, ihm in der Art und Weise, wie man den ganzen Hergang betrachtet, noch eine von der Säure verschiedene Function beizulegen, und den Erfolg etwa nter die Kategorie derThätigkeit einer dreigliederigen Kette zu bringen; die verdünnte Säure wirkt hier vielmehr als eine 
in sich schlechthin homogene durch Dilution nur galvanisch beweglicher gewordene Flüssigkeit, und der ganze Hergang gehört ausschliesslich in das Gebiet der Thätigkeit der natürlichen zweigliederigen Kette.

Dieser Process der natürlichen zweigliederigen Kette aber macht sich, wie wir es an einzelnen Stellen oben vorläufig schon $\mathrm{zu}$ bemerken veranlasst waren, mehr oder weniger geltend in jeder andern zweigliederigen oder dreigliederigen künstlichen Kette, in welcher eine Flüssigkeit und ein metallisches Glied mit einander in Berührung kommen, die schon an und für sich einen chemischen Process, das heisst die Thätigkeit der natürlichen zweigliederigen Kette, bedingen. In der zweigliederigen Kette mit gleichen oder ungleichen metallischen Berührungsflächen aus den oben (S. 287.292 ff.) unter $\alpha$ ) und $\beta$ ) angeführte Kategorien hebt er nach kürzerer oder längerer Zeit die frühere Differenz zwischen den Extremen, und damit eine jede der dort in Betrachtung gezogenen Wirkungen grossentheils oder gänzlich auf; denn der dorlige Effect beruhte nur darauf, dass jedes metallische Extrem für sich mit einer und derselben auf seiner ganzen Fläche überwiegend verbreiteten gleichmässigen Erregung thätig war, während mit dem Effect der natürlichen zweigliederigen Kette eben diese Einseitigkeit der Erregung und die aus ihr entspringendeThätigkeit völlig, oder mehr oder weniger aufgehohen wird. In der dreigliederigen einfachen Kette wird eben daher der ihr zugehörige Process durch den gleichzeitigen der natürlichen zweigliederigen Kette, wenn, wie sich versteht, ein metallisches Glied derselben oder beide mit 
der Flüssigkeit an und für sich chemische Verbindungen eingehen, mehr oder ! weniger modificirt ja es können dadurch, zumal wenn die Neigung zu jenen! Verbindungen sehr gross und verbältnissmässig der Gegensatz zwischen den beiden metallischen Gliedern der Kettenur gering ist, ganz anomale und für Momente sehr überraschende Erscheinungen hervorgebracht werden. Dagegen wird begreiflich eben so auch die Thätigkeit der natürlichen zweigliederigen Kette in der dreigliederigen durch den Process der letzteren wiederum mehr oder weniger beschränkt, und sie wird in der zusammengesetzten dreigliederigen Kette, in welcher die Polarität der Action an Mächtigkeit und Entschiedenheit mit der Zahl der einfachen Elemente zunimmt, am Ende gänzlich unterjocht, so dass einzelne Zinkplatten, z.B. die man etwa absichtlich an dieStelle von Kupferplatten gelegt hat, eben so wenig oder mindestens nicht anders, als es den Kupferplatten selbst geschieht, von der Flüssigkeit angegriffen werden.

Wir können nun dasjenige, was durch das Verhalten der Flüssigkeiten und Metalle auf das 'entschiedenste'ausgesprochen und vorgebildet, was durch den unverkennbaren Charakter des Chemismus selbst längst ausser Zweifel gesetzt] und nur in seiner bestimmten Gestalt, so weit unsere Untersuchungen bis jetzt geführt haben, von uns im Zusammenhange mit einer unbefangenen Totalanschauung der Erscheinungen erfasst worden ist, als ein allgemeingültiges, durchgreifendes Gesetz feststellen:

Jeder chemische Erfolg, unter welchen Bedingungen, in welcher Form, zwischen was fur Stoffen er sich auch darstellen und entwickeln möge, ist mehr als 
eine bloss von Aussen her durch einseitige Affinität in Gang gebrachte und unterhaltene Action; er ist ein schlechthin innerer, organisch in sich geschlossener, im schrankenlosen Kreislauf durch einander greifender, sich wechselseitig durchdringender polarer Thätigkeiten tief begründeter Process; jede noch so leise oder unter noch so gewaltsamer Aufregung Statt findende chemische Bewegung, jede Mischung, jede Auflösung, jede Zersetzung, jede Verdunstung, jeder Verbrennungserfolg ist ein bis ins innerste durch und durch lebendig polarer Process, welcher eben so wie der chemische Process zwischen Flüssigkeiten und Metallen, schlechthin nur unter dem Typus einer Thätigkeit vollsogen wird, dieihrer wahrhaften Natur und Bedeutung. nach keine andere ist, als die Thätigkeit der geschlossenen galvanischen Kette.

Dieser Satz, welcher der Chemie das Gepräge einer Bestimmtheit und Consequenz verheisst, wie man es bisher noch beständig an ihr vermisst hat, ist im Grunde nichts anderes, als die Correction der verfehlten Richtung, die sie unter dem Streben nach einer tieferen Begründung in dem elektrochemischen System zu nehmen beabsichtigte. Der Naturforschung ist vielleicht niemals für keine Art von Erscheinungen der Schlüssel ihres Verständnisses in vollkommnerer und unmittelbarerer Gestalt dargeboten worden, als er ihr zu Aufschlüssen über eine unabsehbare Reihe der wichtigsten Probleme aus der Physik, Chemie und Physiologie in der galvanischen Kette zu Theil geworden ist; auch hat es, wie wir alle wissen, an Anerkennung dafür und an Hoffnung zu ausserordentlichen Enthüllungen gerade in der früheren Zeit der Entdeckung der 
Säule nicht gefehlt; aber zumTheil haben diejenigen, welche diese Hoffnung auf die lebendigste Weise nährten, am meisten zu ihrer Vereitlung dadurch mit beigetragen, dass sie das dargebotene Instrument nicht natürlich und unbefangen in der Einheit seiner Wirksamkeit betrachteten, sondern bald diese bald jene Einzelnheit desselben abgesondert, ausser dem lebendigenZusammenhange des Ganzen in's Auge fassten und besonders durch die einseitige Causalitätshypothese eines allgegenwärtigen, allwirksamen elektrischen Fluidums jede Richtung, welche ausserdem zu einem tieferen und innern Verständnisse der Erscheinungen längst eröffnet gewesen wäre, gänzlich verfehlten oder verkehrten.

Dem elektrochemischen System liegt offenbar die Anerkennung einer durchgreifenden Normalbedeutung der galvanischen Kette für das ganze Gebiet des Chemismus, und das Bestreben, sie als solche geltend zu machen, zum Grunde; aber indem die Kette gleichsam zu einem maschinenartigen, nur durch wunderbare und unbegreifliche elektrische Wirbel in Bewegung gesetzten Automate reducirt war, so mussten natürlich auch alle chemische Phänomene nur durch diesen mechanischen Stempel des elektrischen Materiahismus gezeichnet und cursiv gemacht werden, und die herrschende Entfernung von einer höheren und würdigern Naturansicht ist so gross, dass selbst bei vielen, welche wenigstens die gänzliche Relativität dieses widernatürlichen Gepräges zugestehen, dasselbe doch nur als ein unschädliches und unschuldiges Umsatzmittel gilt, zum Behuf einer bequemen, gemächlichen und behaglichen allgemeinen Verständigung. Wie schwer und beengend aber eine solche Form dem Erkenntnissfortschritte 
in den Weg treten, wie gewaltsam sie dem Blicke des $\mathrm{Na}$ turforschers seine Kraft und Unbefangenheit entziehen wie unbeschränkt sie seine Ansichten und sein Urtheil despotisiren könne, das ist besonders in unsern Tagen dadurch am deutlichsten hervorgetreten, dass selbst die Oersted'sche Entdeckung es noch nicht sobald vermoeht hat, so vielen die Fesseln, denen sie sich bisher so willig hingaben, bemerkbar zu machen, ja dass sie selbst für sie dazu hat dienen müssen und vielleicht noch längere Zeit dazu dienen wird, dieselben Fesseln noch enger und drückender um sich zusammen zu ziehen. In der Verblendung, mit welcher man hereits alle chemischen Phänomene zu elektrischen gestempelt hatte, wollte man nun auch die bis dahin noch immer wenigstens mit einer Art von Achtung oder Schen behandelten Erscheinungen aus dem stillen, geheimnissvollen Gebiete des Magnetismus unter dieselbe Presse zwängen, und man erfreute sich dabei noch, ohne jede Ahnung oder Anerkennung einer höheren, metaphysischen Identität der Erscheinungeu, der vortrefflichen äusserlichen Uniform, zu welcher sich unter einem solchen Universalregimente der Elektricität alles gestaltete. Die Gedankenlosigkeit hierbei ist bei Einzelnen so weit gegangen, dass man die Ablenkung der Magnetnadel durch die galvanische Kette ganz unmittelbar und direct mit einer elektrischen Erregung ihrer Aussenglieder identificirt hat (der verkehrten völlig principlosen Folgerungen, die hierbei über elektrische Relationen geltend gemacht sind, nicht $\mathrm{zn}$ gedenken (s, oben S. 255 ff.), und dass man daraus, dass zwei differente Metalle im Contact an und für sich ohne ein flüssiges Zwischenglied nicht auf die Magnet-

U 
nadel wirke, auch das Vorhandenseyn der elektrischen Erregung in ihnen und somit die Zuverlässigkeit der Volta'schen Fundamentalversuche überhaupt hat zweifelhaft machen wollen.

Es ist gewiss, dass unsere Nachkommen Mühe haben werden, wie an so viele andere Widersprüche der gegenwärtigen Zeit, so insonderheit auch an den faktischen Contrast zwischen unserer heutigen Physik und Philosophie zu glauben; aber es ist nicht minder gewiss, dass selbst unsere Zeitgenossen im Auslande, wenn ihnen die Zugänge zur deutschen Philosophie so, wie allen zu uns gehörigen Naturforschern, geöffnet wären, und wenn sie mit ihrer Regsamkeit nicht eher geruht hätten, als bis sie sich in den Besitz eines Wissens gesetzt und für ein höheres Erkenuen ein Organ sich angeeignet hätten, das ihnen, nicht wie so vielen unter uns, aus Mangel an eigenem guten Willen, sondern vornehmlich nur aus Mangel an Kenntniss der deutschen Sprache bis jetzt entzogen geblieben ist, dass sie kopfschüttelnd auf uns blicken und fragen würden: wie ist es möglich gewesen, dass ihr an solchen hypothetischen Dunstgebilden, an solchen atomistischen Chimären, an solchen einseitigen, spielenden und kindischen Vorstellungen, von denen eure Lehrsysteme der Physik noch grossentheils eben so, wie die unsrigen, und was noch schlimmer ist, nach dem Muster der unsrigen erfüllt sind, noch so lange habt festhalten können, nachdem euch seit mehrern Decennien schon in den Tiefen eurer Philosophie, von denen die unsrige sich nichts träumen liess, solche Standpunkte eröffnet, solche Richtungen angewiesen, solche Blicke aufgeschlossen worden sind, die ein reelleres Streben, eine 
gründlichere Speculation erheischen, und ein höheres, vollendeteres Erkennen im Geist und in der Wahrheit unwiderruflich bedingen müssen? - - -

Wenn unsere Physik, oder, welches dasselbe ist, unsere Chemie die galvanische Kette nicht mehr als ein Etwas betrachten wird, zu welchem sie allein durch die willkührlichsten, von der Wahrheit und Einheit der Naturanschauung schon in sich selbst gänzlich abgewandten hypothetischen Fictionen gemacht worden ist, sondern als ein mit unbefangen geöffnetem Wahrheitssinne in der Totalität seiner Erscheinungen allseitig erfasstes Ganze, wie wir in dieser Schrift bemüht sind, eine solche möglichst reine, unverkümmerte und naturgemäșse Anschauung dieses Ganzen von den wesentlichsten und unerlüsslichsten Gesichtspunkten aus durchzuführen, wenn sie diese, nach ihrer Gesammtwirksamkeit lebendig erfasste Einheit in dem oben ausgesprochenen Sinne als Norm und Vorbild für das Verständniss aller auf ihrem Gebiete unter dem Charakter der chemischen Naturthätigkeit sich darstellender Phünomene zum Grunde legen und die durch diesen Schlüssel eröffneten Ansichten vorurtheilsfrei aufnehmen und ernstlich verfolgen wird, so ist es nicht zu berechnen, zu welchen bis jetzt noch ungeahneten Entdeckungen sie gelangen, zu welchen nach ihrem bisherigen Zustande kaum glaublichen und für unmöglich gehaltenen Aufschlüssen sie auf den eigenen, so wie auf den Feldern aller übrigen speculativen Naturwissenschaften sie dadurch noch geführt werden könne. Wir wollen hier zuvörderst die wichtigsten unter den Momenten in der Kürze hervorheben, welche schon jetzt als eben so viel leben-

$\mathrm{U}_{2}$ 
digere Verständnisse der Erscheinungen mit der Anerkennung der galvanischen Kette als Grundtypus des chemischen Processes unmittelbar verknüpft sind, und die sich uns als die ersten und nächsten Ergebnisse der Entzifferung einer grossen und ausgebreiteten Hieroglypherischrift der Natur, zu welcher wir den aufgefundenen Schlüssel in seiner wahren Gestalt und auf die rechte Weise anwenden, gleichsam von selbst darbieten.

Zuvor nur noch eine Bemerkung in sprachlicher Beziehung. Das Wort: Galvanismus bezeichnete, von der ersten Zeit der Entdeckung an, den Inbegriff der Wirksamkeit der Kette als eine eigenthümliche, von Elektricitüt und Chemismus verschiedene Thätigkeit, so lange und so fern man es nicht für ausgemacht ansah, dass diese Wirkung nur eine elektrische sey. Nachdem die letztere Ansicht ein solches Uebergewicht und eine solche Allgemeinheit erlangt hatte, dass sie als eine für immer entschiedene und absolute zu gelten anfing, schien jenes Wort nicht nur überflüssig, sondern durch die abweichende Richtung des Begriffs, der sich damit gebildet hatte, sogar störend in der wissenschaftlichen Terminologie da zu stehen, so dass man sich selbst Mühø gab, es wieder vergessen zu machen und zu unterdrücken. Aber vergebens; das Wort blieb und mit ihm der Begriff, der, von der ersten Wahrnehmung galvanischer Erscheinungen her, auf einen zwar nur dunkel geahneten und durch kein entschiedenes Merkmal begründeten, aber doch mit einem sehr richtigen Takt fortwährend festgehaltenen Unterschied zwischen dem, was in der Kette und in andern als gesondert betrachteten elektrischen und che- 
mischen Erscheinungen angeschant wurde, unverkennbar hindeutet. Diesem ursprünglichen Sinne des Sprachgebrauchs vollkommen getreu unter seiner Autorität und im Zusammenhange mit dem Ganzen unserer bisherigen Darlegungen, glauben wir hier das Wort Galvanismus in seine eigentlichen wohl begründeten Rechte wieder einsetzen zu müssen, indem wir deuselben, ihm bis dahin durch die äussere Begränzung rechtmässig angewiesenen, aber noch nicht bestimmt erfüllten, Raum des Begriffs jetzt zugleich seinem lebendigen Inhalte nach entschieden angeben. Galvanismus ist, wie gesagt, der Inbegriff der Wirksamkeit der galvanischen Kette als solcher. Aber als die bestimmten und vollzähligen Momente dieser Wirksamkeit haben wir den Elektrismus, Chemismus und Magnetismus kennen gelernt; alle übrigen Phänomene, welche die Kette zeigt, namentlich selbst die Temperaturerhöhung, von der unten noch besonders die Rede seyn wird, sind eben so wenig, wie etwa die Schwere, eigenthümliche, die Kette als solche charakterisirende Momente ihrer Thätigkeit, sondern diese letztere ist allein in jener Trias vollständig erschöpft. Das Wort : Galvanismus ist also keinesweges etwa synonym mit Elektricität oder Chemismus, sondern es bezeichnet den sehrwesentlichen Inhalt der Gesammtheit der elektrischen, chemischen und magnetischen Erscheinungen, so fern sie als Momente einev und derselben gemeinsamen Thätigkeit an einer und derselben Kette durch wechselseitigen, nothwendigen Zusammenhang mit und durch einander bedingt sind. Die galvanische Kette kann eine magnetische oder chemische, eben so wohl wie eine elektrische Kette genannt werden, so 
fern sie die entsprechenden Erscheinungen, einzeln an und für sich, ausser dem Zusammenhange betrachtet, darstellt; aber eine galvani sche Kette heisst sie, so fern mit jeder einzelnen dieser Erscheinungen auch die beiden übrigen wesentlich und nothwendig zusammenhangen und in dieser Einheit durch die Kette insgesammt reprüsentirt werden.

Indem nun jeder chemische Process schlechthin und unter allen Umständen in der Bedeutung der Action einer geschlossenen Kette steht, so ist er also zugleich immer auch ein galvanischer, das heisst, er muss zugleich von elektrischen und magnetischen Functionen begleitet seyn, oder seine Thätigkeit ist vielmehr die Einheit der absolut unzertrennlichen und nur in der Reflexion getrennt gesetzten Momente des Elektrismus, Chemismus und Magnetiswus. Wo überhaupt irgend eins dieser drei Momente sich vereinzelt darstellt, da ist jedesmal auch ein galvanischer Process mehr oder minder vollständig mit einem mehr oder weniger zur Realität gelangenden chemischen Fffecte nebst den poIaren Tendenzen desselben, dem Elektrismus und Magnetismus, eingeleitet; das Hervortreten der einzelnen Thätigkeit ist entweder eine bloss momentane, oder durch überwiegende Intensität nur scheinbar gewordene Isolirung; wo sich das eine dieser Momente zeigt, da sind nothwendig auch, wenn auch in einem der Wahrnehmung entzogenen Grade, die beiden andern vorhanden, da ist jedesmal die vollständige Trias beisammen. Es wird von besonderer Wichtigkeit seyn und theils zu noch grösserer Beleuchtung vieler bisher schon mehrfältig entwickelter Ansichten, theils zur Gewinnung neuer und wesentlicher Gesichtspunkte dienen, wenu 
wir in eine nähere Betrachtung des oben Gesagten eingehen. .

So wie bei jeder galvanischen Kette ihrer chemischen Thätigkeit ein Zustand der blossen überwiegenden Tendenz zu dieser Thätigkeit, ehe die Schliessung der Kette erfolgt, vorausgeht, so setzt jeder chemische Process einen gleichen Erregungszustand seiner Glieder voraus, in welchem sie vor der reellen Action, vor dem wirklichen und vollständigen Geschlossenseyn der natürlichen galvanischen Kette nur noch erst die überwiegende Tendenz zu dieser Action längere oder kürzere Zeit, mehr oder weniger sichtbar, oft aller Wahrnehmung entzogen, aber darum nicht minder vorhanden, gegenseitig unterhalten, und diese Tendenz, oder vielmehr die chemische Action, sofern sie noch nicht in ihrer eigentlichen, vollständig ausgebildeten Gestalt, sondern nur zuvörderst dieser Tendenz nach auftritt, ist, wie wir wissen, die Elebtricitë̈t. Und zwar ist in dem oxydableren Gliede der Kette, da wo die Ten. denz, oxydirt zu werden und das andere Glied'zu desoxydiren, angeregt wird, die positive Elektricität, in dem andern Gliede dagegen, wo die Tendenz, desoxydirt zu werden und jenes erstere Glied wiederum zu oxydiren, hervorgerufen ist, die negative Elektricität herrschend, und überall, wo Elektricität sichtbar wird, da hat sie einzig und allein nur diese Bedeutung, da strebt eine noch gar nicht oder noch nicht vollkommen geschlossene galvanische Kette nach reeller, durch vollendete Schliessung des Kreises bedingter chemischer Thätigkeit, und wo dieses völlige Geschlossenseyn des galvanischen Kreises erreicht ist, da ist wiederum die Elektricität als solche nicht mehr, sondern lediglich 
als chemischer Process vorhanden, da ist die Tendenz zur That, die Blüthe zur Frucht geworden.

Die Form aber, in welcher die Elektricität, su lange sie nicht in Chemismus übergegangen, als solche sich darstellt, ist einzig und allein nur die der Anziehung und Abstossung. Jeder elektrisch erregte Massenpunkt stösst, so weit die Kraft seiner Erregung dazu hinreicht, jeden andern eben so erregten und ihm folglich hemmend und feindlich gegenüber tretenden Punkt von sich zurück, wie er gegenseitig durch diesen abgestossen wird; beide, sie mögen positiv oder negativ elektrisch, also mit der gleichnamigen Tendenz, zu oxydiren oder zu desoxydiren, erfüllt seyn, entfernen sich von einander, oder streben sich zu entfernen, weil jeder einzelne in seiner Thätigkeit nur durch Beeinträchtigung derjenigen des andern sich geltend machen kann; während dagegen ungleichmässig erregte sich suchen und anziehen, da sie in der Annäherung oder im Beisammenseyn wechselseitige Befriedigung ihrer differenten Tendenzen durch einander gewinnen. Jenes elektrische $\mathrm{Ab}$ stossen, so wie dieses Anziehen ist nichts als eine und dieselbe versichtbarte Tendenz der ungeschlossenen oder noch unvolikommen geschlossenen Kette, sich vollständig zu schliessen; was aber mit und nach dieser Schliessung erfolgt, es möge in der Gestalt des sogenannten elektrischen Funkens oder unter irgend einer andern Form sich darstellen, das ist nicht sowohl mehr Elektricität, sondern der chemische Process; die Thätigkeit der geschlossenen Kette selbst und die Offeubarungsform der Elektricität als solcher, wenn wir hier, wie billig, physiologische Wahr- 
nehmungen, die durch das Gefühl und den Geruch vermittelt werden, ganz beseitigt lassen, ist und bleibt, wie gesagt, einzig und allein nur auf die Phänomene der Anziehung und Abstossung beschränkt, worüber durch das Folgende bald die bestimmtere Nachweisurg gegeben werden wird,

Der chemische Process als solcher beginnt also mit der Schliessung der Kette, das heisst mit dem Momente, in welchem die Erregung eine einseitige $\mathbf{z u}$ seyn aufgehört hat, wenn die Oxydations - und Desoxydalionstendenz nicht mehr durch aus einander gehaltene Extreme in beiden Gliedern der Kette verein. zelt, sondern wenn jedes Glied mit positiv und negativ zugleich erregten Punkten eben so vielen entgegengesetzt negativ urid positiv zugleich erregten Punkten des andern begegnet, wenn beide so zu einem organisch in sich geschlossenen Ganzen zusammen getreten sind und die polaren Tendenzen, durch nichts als die Richtung aus einander gehalten, im schrankenlosen Kreislauf durch einander hindurch greifend sich in beiden Gliedern in allen Punkten ohne Unterschied nach gleichem Gesetze offenbaren und wirksam erweisen. Der Process an sich aber möge Statt finden unter welcher von den mannichfaltigen möglichen Formen er wolle, so ist er jeden Falls immer nur entweder einer künstlichen oder einer natürlich geschlossenen galvanischen Kette zugehörig. Der Unterschied dieser beiden Kategorien, in der gegenwärtigen übersichtlichen Darstellung nach den Resultaten unserer obigen Betrachtungen kürzlich angegeben, besteht darin, dass in der künstlichen Kette jedes Extrem jedes Gliedes mit einer und derselben über seine ganze Fläche ausschliesslich oder 
wénigstens überwiegend verbreiteten polaren Erregung thätig ist, während in der natürlichen Kette jedes Extrem jedes Gliedes in unzühlig vielen Punkten positiv und zugleich in eben so viel andern negativ wirksam sich verhält. Die künstliche zweigliederige Kette, sie sey durch zwei differente Flüssigkeiten oder durch eine Flüssigkeit und ein Metall mit gleichen oder ungleichen Berührungsflächen gebildet, hat nur zwei Focalstellen; die künstliche dreigliederige hat, ausser den beiden Berührungsflächen des Leiters zweiter Klasse nit den beiden differenten Metallen, in der Berührungsflüche dieser beiden letzteren selbst noch eine dritte Focalstelle; (unter dem oben S. 292. zuletzt bei a) angegebenen Gesichtspunkte, nach welchen auch die dreigliederige als eine zweigliederige künstliche Kette zu betrachten ist, hat sie jedoch gleichfalls auch nur zwei Focalstellen) aber die natürliche Ketle hat unzäh_lig viele Focalstellen und zerfällt zwischen ihnen in unzählig viele nach allen Richtungen hin gelagerte und sich schliessende, wenn gleich zu einer gemeinsamen Thätigkeit verbundene, Partialketten. So fern jede einzelne der zahllosen Partialketten, aus denen die ganze natürliche Kette zusammengesetzt ist, als ein Differential der letztern angesehen werden kann, kann man füglich auch die künstliche zweigliederige Kette mit gleichen Berührungsflächen als ein für sich bestehendes, isolirt dargestelltes Differential irgend einer natürlichen betrachten.

Ueber den chemischen Process in der künstlichen und natürlichen Kette, so weit der leztere zwischen zwei tropfbaren Flüssigkeiten, oder zwischen einem Metall and einer liquiden Flüssigkeit Statt findet, ist das 
Erforderliche oben gesagt. Eine umständliche Parallele des chemischen Processes unter andern Bedingungen und in seinen mannichfaltigen übrigen Formen mit der galvanischen Kette würde hier zu umfassend werden und uns von dem nächsten $Z_{w}$ wecke dieser Schrift zu weit abführen; wir wollen jedoch in dieser summarischen Uebersicht jetzt noch einige der wesentlichsten Gesichtspunkte in Beziehung auf den Verbrennungsprocess und den durch die gemeine oder sogenannte Maschinenelektricität bedingten chemischen Process hervorhehen.

Die Elektrisirmaschine kann als eine künstliche galvanische Kette betrachtet werden, in welcher der idioelektrische Körper dem Leiter zweiter Klasse, das Reibzeug mit seinem Conductor, und der erste Leiter den beiden differenten metallischen Armaturen entsprèchen, während die Erregung im Contact durch die Vervielfältigung der Berührung mittelst des Reibens in sehr hohem Grade verstärkt wird; und zwar bildet, wenn der idioelektrische Körper von Glas ist, wie wir diese Voraussetzung für die Folge überall gelten lassen wollen, das Reibzeug mit seinem Conductor die negative, der Hauptleiter dagegen die positive Armatur.

Wird nun rom Hauptleiter und eben so vom Reibzenge ein Drath in Wasser geleitet, so dass beide Dräthe mit ihren Spitzen, wie im Gasapparate, einander gegenüber stehen, so erfolgt, wenn die Maschine in Bewegung gesetzt wird und für gehörige Zweckmässigkeit des Apparats gesorgt ist, so wie durch die galvanische Säule, eine Zerlegung des Wassers; ein Beweis, dass der Process, welcher mit derSchliessung der durch die Elektrisirmaschine dargestellten 
Kette eintritt, so wie der einer jeden andern Kette von eigentlich chemischer Natur sey; - und zwar wird das Extrem des mit dem positiven Hauptleiter verbundenen Drathes nach demselben Gesetze, dem gemäss ein Leiter erster Klasse zwischen zwei Leitern zweiter Klasse in der geschlossenen Kette auf entgegengesetzten Seiten jedesmal auch entgegengesetzt erregt seyn muss, im Wasser negativ, dasjenige des vom negativen Reibzenge aus ins Wasser geleiteten Drathes wird dagegen positiv, und gegen jenes tritt daher das Oxygen, gegen dieses das Hydrogen aus dem Wasser hervor. - Man hat diesen Versuch als ein Hauptglied unter den Documenten mit hervorgehoben, durch welche die Identität der Thätigkeit der Säule und der Elektrisirmaschine dargethan werden sollte, und als ein solches höchst entscheidendes Beweismittel führen wir ihn hier ebenfalls unf, aber mit der Bemerkung, dass die Identität, deren Nachweisung beabsichtigt wird, nicht in einem völlig fingirten Strome eines fabelhaften elektrischen Fluidums, sondern in der gleichen, unmittelbar vor Augen liegenden chemischen Thätigkeit beider Instrumente begründet ist. Es ist indess durchaus nicht zu übersehen, dass der erzwungene und den Körpern grossentheils gewaltsam anfgedrungeneZustand der Erregung die mit der gemeinen Elektricität zusammenhängenden Phänomene durch einen eigenthümlichen Charakter auszeichne, dessen wesentlichstes Merkmal eben darin liegt, dass der blosse Zustand dev Tendenz zur chemischen Thätigkeit über diese Thäligkeit selbst bei weitem vorwalte. Gewaltsame, elektrische Spannungen können sich daher mit der Schliessung der Kette zwar unter entschiedener Richtung zum 
Chemismus und sehr geräuschroll, aber dennoch ohne merklichen reellen Erfolg auflösen, weil die bis zu übermässigen Graden gesteigerte Tendenz zum chemischen Process in demselben Maasse nothwendig auch den Charakter einer Tendenz zur Abwerfung des aufgedrungenen Erregungszustandes und zur blossen Wiederherstellung des ursprünglichen Gleichgewichtes ohne alle weitere Veränderung annehmen muss; daher gewisse durch Maschinenelektricitüt eingeleitete chemische Erfolge auch nư unter günstigen und zweckmässigen Vorkehrungen, wie z. B. der oben angegebene Versuch nur mit besonders guten Apparaten und nach dem bekannten von Wollaston angegebenen Verfahren, zu gelingen pflegen.

Wenn zwischen den Extremen des Reibzeuges und des Hauptleiters der Elektrisirmaschine, bei der gewöhnlichen Entfernung derselben von einander, kein anderes Medium, als die atmosphärische Luft sich befiudet, so bewirkt diese die Schliessung der Kette eben so wenig, oder nur verhältnissmässig eben so unvollkommen, wie es durch die Wassersäule eines Gasapparats geschieht, wenn die in sie getauchten Polardräthe der galvanischen Säule weit genug aus einander gerückt sind. Werden aber die Extreme durch leitende Fortsätze oder auf irgend eine andere Weise einander so weit genähert, dass die $\mathrm{Z}$ wischen beiden befindliche Luftschicht dünn genug ist, so findet eine Schliessung der Kette Statt, und der chemische Process, welcher, wenn die Schliessung durch eine Wasserschicht vermittelt wird, in der Form einer Wasserzersetzung vor sich geht, ist jetzt eine Zersetzung der Luft. Das Extrem des positiven Conductors wird gegen die Luft negativ, 
und das Extrem der negativen Armatur dagegen positiv thätig; gegen jenes tritt daher der acide Factor der Luft als Oxygen, oder als ein Oxyd des Azots, mit dem kleireren Quantum des letztern, gegen dieses hingegen tritt der basische Factor der Luft als Azot, oder als ein Oxyd des Azots, mit dem grösseren Quanlum des letzteren. Dieser Erfolg, der, wie fast ein jeder die Luft zersetzende Verbrennungsprocess, mit Lichtentbindung verknüpft ist, stellt seiner äusserlichen Erscheinung nach dasjenige dar, was man uneigentlicher Weise den elektrischen Funkten genannt, und worin man besonders von jeher, durch eine zu lebhafte Phantasie verleitet, auf eine nicht wissenschaftliche Weise, eine von einem Extrem zum andern überspringende, leuchtende elektrische Materie hat sehen wollen. Das ganze Phänomen aber gehört nicht mehr dem Elektrismus, sondern allein dem Chemismus an, zu welchem die vor der Schliessung der Kette erregte Elektricität nur die Tendenz war; während des Phänomens aber ist die Elektricität, eben weil sie zur chemischen Action geworden, nicht mehr vorhanden, oder sofern noch gleichzeitig mit dem Phänomen eine elektrische Erregung in irgend einem höheren oder niedrigeren Grade fortbesteht, so findet sie nur in Folge einer unvollkommenen Schliessung der Kette Statt und hat alsdann dieselbe Bedeutung, wie die bei unvollkommener Schliessung der galvanischen Säule gleichfalls noch versichtbarte elektrische Erregung, von der oben S. I68 ff. die Rede gewesen.

Die namentlich von Cavendish und van Marum angestellten Versuche, welche die Zersetzung der atmosphärischen Luft durch die Elektrisirmaschine fak= 
tisch bewiesen, sind von gewöhnlichen Standpunkten aus immer nur so angesehen worden, als wenn die Elektricität und der elektrische Funke ein eigenthümliches, von jener Zersetzung ganz verschiedenes, selbstständiges Agens wäre, durch welches diese letztere vielmehr erst, auf eine Weise freilich, über weiche weiter gar keine Rechenschaft gegeben wird, bewirkt werde; ganz so, wie man sich den mächtigen Chemismus der galvanischen Säule als ein räthselhaftes Erzeugniss des noch räthselhafteren elektrisch materiellen Stroms gemeinhin vorzustellen pflegt. In dieser unsichern und unrichtigen Ansicht des ganzen Herganges liegt ohne Zweifel wohl auch der vornehmste Grund, aus welchem man einen so nahe liegenden, in jenem Versuche von Cavendish so bedeutúngsvoll bezeichneten Weg zur Auffindung nener chemischer Thatsachen bis jetzt noch so gut als gänzlich unbetreten gelassen hat. Zwar ist namentlich vom Oxygen- und Azotgas gesagt worden, dass sie an und für sich auf ähnliche Weise, wie in dem obigen Versuche die atmosphärische Luft, mittelst der Elektrisirmaschine behandelt, keine Veründerung erlitten; aber dieser Ausspruch ist nicht das Resultat einer umfassenden und sorgfältigen Untersuchung, welche nach Beendigung des Experiments mit der Gasart selbst vorgenommen wäre, sondern sie stützt sich allein auf die Bemerkung, dass die alkalische Flüssigkeit, welche während des Versuchs den Recipienten der Luft gesperrt hatte, unverändert geblieben sey. Gesetzt aber, dass auch wirklich eine oder mehrere Gasarten, ausser der atmosphärischen Luft, keine Veränderung bei einer ähnlichen Behandlung erleiden sollten, so würde daraus so wenig als aus 
dem Umstande, dass bei starken elektrischen Entladungen durch Wasser und andere Flüssigkeiten hindurch noch Funken wahrgenommen werden, ein nachtheiliger Schluss für die Angemessenheit unserer eben entwickelten Ansicht herzuleiten seyn, da schon, wie die verschiedenartigsten Erfahrungen anderer Art beweisen, die lebendige, momentan hervorgerufene Richtung und Bewegung zu einer Zersetzung mit Lichtentbindung und momentaner Glut vergesellschaftet seyn kann. Auf jeden Fall müsste eine umfassende und umsichtige Prüfung des Verhaltens einer grössern Reihe von Gasarten in derselben Beziehung mit genauer Bemerkung der jedesmaligen Farbe und Beschaffenheit des Lichts, der Schlagweite, Temperaturerhöhung u, s. w. von wichtigen und lehrreichen Resultaten begleitet seyn. - Noch könnte der specielle Fall, in welchem ein Gemisch aus Oxygen- und Hydrogengas durch den elektrischen Funken zur synthetischen Reproduction des Wassers bestimmt wird, unserer Ansicht, welche den elektrischen Funken vielmehr nur als das durch Lichtentbindung sichtbare Phänomen einer vorgehenden Zersetzung der Luft betrachtet, entgegen gehalten werden; aber es leuchtet dagegen sehr bald ein, dass diese Reproduction nicht die directe Folge von der primitiven Einwirkung, sondern nur eine secundäre, zufällige von der durch jene ursprüngliche Zersetzung veranlasste Inflammation des Hydrogengases sey.

Den positiven Conductor umgiebt die atmosphïrische Luft in allen Punkten negativ erregt, wie ein überall gleich erregtes Metall von der in allen Punkten entgegengesetzt erregten Säure umfangen wird. Wie in jener Flüssigkeit, so ruft nun auch in der Luft 
die ursprüngliche Erregung der Berührungsfläche eine nach allen Richtungen fortschreitende polare Wechselerregung hervor, die sich eben daher auch auf den Conductor zu repliciren trachtet, aber durch die Bestimmtheit, mit welcher dieser in allen Punkten eine und dieselbe Erregung darbietet und nur die entgegengesetzte in der umgebenden Luft überall hervorruft, um so entschiedener daran verhindert wird, je gleichförmiger und glatter die Fläche des Conductors ist. Wenn aber eckige oder spitzige Hervorragungen auf ihm sich befinden, so tritt er einerseits in diesen, andererseits in dem übrigen glatten Theil seiner Oberfläche der Luft mit ungleichen Berührungsflächen entgegen; zwischen diesem und jenem Extreme urd der yon einem zunı andern reichenden benachbarten Luft bildet sich eine für sich bestehende zweigliederige Kette mit ungleichen metallischen Berührungsflächen, in welcher die grössere Berührungsfläche des Conductors die ursprüngliche positive Erregung gegen die umgebende negativ thätige Luft beibehält, während die Ecken oder Spitzen als kleinere Berührungsflüche der mit der positiven Erregung andringenden Luft gegenüber zur negativen Thätigkeit gezwungen werden, und während der durch das Vorhandenseyn hinlänglich kräftiger Erregung bestimmten Dauer dieser Action erscheint da, wo der Zersetzungsprocess der Luft am krüftigsten und concentrirtesten Statt findet, der Spitze, Schärfe u, dergl. gegenüber, das mit ihm verbundene Licht, worin man immer eine in die Spitze einströmende oder von ihr ausströmende elektrische Materie hat sehen wollen. Diese Ansicht ist aber ausserdem, dass ihr Grundstandpunkt ein durchaus unrichtiger $\mathrm{X}$ 
ist, noch besonders darin fehlerhaft, dass sie in den Spitzen die gleichartige Thätigkeit mit derjenigen des ganzen Conductors aunimmt, während das wahre Verhältniss keirı anderes seyn kann, als immer nur dieses: wenn der Körper im Ganzen positiv erregt ist, so werden im Process der für sich geschlossenen zweigliederigen Kette die scharfen oder spitzen Hervorragungen an ihm negativ thätig, sie werden durch die ihnen gegenüber positiv thätige, sich desoxydirende Luft oxydirt; wenigstens ist die Richtung, die Tendenz der Thätigkeit keine andere als diese; wenn dagegen der Körper im Ganzen negativ erregt ist, so sind die Spitzen an ihm positiv thätig, sie werden durch die ihnen gegenüber oxydirte Luft desoxydirt, oder von beiden Seiten findet wenigstens die lebendige Richtung der Thätigkeit zu einem solchen Erfolg Statt.

Dieser Process, welcher, wie gesagt, am Hauptleiter der Maschine an und für sich, als ein in sich geschlossener, mehr oder weniger unabhängig von der im Reibzeuge vorhandenen Erregung, und so umgekehrt wieder auch am Conductor des Reibzeuges ohne directen Zusammenhang mit der Erregung im Hauptleiter Statt findet, schweigt niemals gänzlich und macht sich, vermöge der von der Kugelfläche mehroder weniger abweichenden Gestalt der Conductoren, so wie besonders an Suturen und mikroskopischen Ungleichmässigkeiten auf ihrer Oberfläche zum Nachtheil der mit der Maschine im Ganzen beabsichtigten Wirkung, wenn gleich ohne besonders sichtbare Lichtentbindung um so mehr geltend, je mehr durch den jedesmaligen innerlich qualitativen Zustand der chemischen Beschaffenheit der Luft eine solche allmälig und 
im Stillen Statt findende Zersetzung, oder wenigstens eine solche aufZersetzung hingerichtete Thätigkeit derselben, in welcher die elektrische Erregung der Conductoren zum grossen Theil immer wieder erlischt, begünstigt ist. Auch ist bei einem solchen Zustande der Luft die Bildung einer Kette zwischen ihr und dem Hauptleiter und Reibzeuge, im kürzesten Bogen von einem zum andern sehr bald vollendet, durch deren, wenn auch schwache, doch ununterbrochene Thätigkeit die Wirkung der Maschine im Ganzen beträchtlich geschwächt zu werden vermag. Die geringere Wirksamkeit der Elektrisirmaschine oder die kürzere Dauer künstlich erzeugter elektrischer Erregungen ist also, so oft sie Statt findet, nicht gerade immer nur an der Skale des Hygrometers abzulesen, wenigstens kann Feuchtigkeit, im gewöhnlichen Zustande ihres Vorhandenseyns in der Luft, weniger direct wie ein Leiter der Elektricität, als vielmehr, so fern sie ein das Azotoxyd absorbirendes Beförderungsmittel für die chemische Zersetzharkeit der L_uft ist, der künstlichen Erregung der Elektricität hemmend entgegen wirken.

Die atmosphärische Luft muss schon nach dem bis jetzt Angeführten überhaupt einen mehr oder weniger wesentlichen Antheil haben an allen in ihr vorgehenden chemischen, d. i. galvanischen Processen; sie erregt die thätigen Substanzen, wird von ihnen erregt und wirkt unaufhörlich erregend wiederum fördernd oder hemmend auf das Ganze zurück. Die atmosphärische Luft wird namentlich von der galvanischen Säule, die in Berührung mit ihr von Element zu Elementin allen Punkten durch sie geschlossen wird, begreiflich vermöge der höchst förderlichen Mitwirkung der absorbirenden

$\mathrm{X} 2$ 
Flüssigkeit der Sänle ungleîch schneller und bestimmter als durch die Elektrisirmaschine zersetzt und die Action der ausserdem durch einen Drath oder Gasapparat u. dergl, geschlossenen Kette wird dabei vermöge des durch diese Zersetzung gebildeten und von den feuchten Schichten absorbirten Oxygens oder Azotoxyds bis zu einem bestimmten Grade noch beträchtlich erhöht, obgleich die Thätigkeit der Süule nicht nothwendig von der Gegenwart der sie umgebenden atmosphärischen Luft oder irgend einer andern Gasart abhängig ist, wie über alles dieses, was mit dem Ganzen unserer Ansicht in so vollkommnem Einklange steht, dass es daraus im Voraus hätte hergeleitet werden können, während es nach den elektrochemischen und andern früheren Hypothesen völlig räthselhaft erscheint, durch längst bekannte Versuche bereits hinlänglich entschieden worden ist.

Wenn also der sogenannte elektrische Funke und die an spitzen Hervorragungen des Conductors unter continuirlicher Lichtentbindung Statt findenden Phänomene eben so viel mit partialer Verbremnung verknüpfte chemische Zersetzungsprocesse der Luft sind, so fragt sich: in welchem Verhültnisse sie zu den übrigen die Luft zersetzenden Verbrennungsprocessen stehen, und wie sie davon unterschieden sind. Wir können aber diese Frage nach den gewonnenen Resultaten unserer bisherigen Untersuchungen auf eine sehr bündige und doch zugleich für einen jeden, der dem Gange der Entwickelung vollständig gefolgt ist, auf eine ohne Zweifel befriedigende Weise beantworten. Die Verbrennungsprocesse nämlich, welche durch die Elektrisirmaschine, oder überhaupt durch die gemeine 
Elektricität eingeleitet 'sind, gehören jedesmal der Thätigkeit einer künstlichen galvanischen Ketto an: jeder andere Verbrennungsprocess ist dagegen zwar im Wesentlichen ganz derselbe Luft zersetzende Process; aber er findet Statt als Action einer natürlichen geschlossenen galvanischen Kette, weshalb auch eine rauhe, ungleichmässige Oberfläche und eine zertheilte Masse des verbrennlichen Körpers zur Beförderung und schnelleren Einleitung des Verbrennungsprocesses eben so und aus denselben Gründen, wie bei der Auflösung fester Substanzen in flüssige, sich vortheilhaft und wisksam erweisen. Wenn man aber an dem Prädikat: kü̈stlich hier in so fern Anstoss nehmen möchte, weil die Natur selbst die Wirkungen geschlossener mächtiger Ketten durch die gemeine elektrische Spannung oft genug einleitet, so können wir die Disjunction vielmehr durch die Hervorhebung der ursprünglichen Unterschiedsmerkmale zwischen den beiden Arten von Ketten, die von uns bisher als künstliche und natürliche bezeichnet worden sind, ausdrücken, indem wir sagen, die durch die gemeine Elektricität eingeleiteten Verbrennungsprocesse der Luft gehören jedesmal einer geschlossenen galvanischen Kette an, in welcher jedes Extrem jedes Gliedes mit einer und derselben über seine ganze Fläche ausschliesslich oder wenigstens überwiegend verbreiteten polaren Erregung thätig ist, in der daher nur zwei oder höchstens drei Focalstellen zu unterscheiden sind; jeder andere Verbrennungsprocess ist dagegen die Wirkung einer solchen galvanischen Kette, in welcher jedes Extrem jedes Gliedes in unzählig vielen Punkten positiv und zugleich in 
eben so viel andern negativ thälig ist, die also unzählig viel Focalstellen hat und aus unzählig vielen Partialketten besteht. Der natürliche Verbrennungsprocess ist das Integral desjenigen, welcher durch die gemeine Elektricität eingeleitet ist und von jenem als wiederum nur das Differential darstellt.

Wenn schon der Lichtbüschel an einer hervorragenden Spitze eines in positiv elektrischer Erregung erhaltenen Conductors sich als eíne Art von Flamme betrachten lässt, so hat man eine noch bei weitem getreuere Approximation, wenn man sich einen metallischen, etwa kugelförmigen Körper mit einer sehr grossen Anzahl so nahe als möglich neben einander stehender Spitzen besetzt und den Körper in einer so starken positiv elektrischen Erregung begriffen vorstellt, dass die Luft an allen diesen ihr negativ entgegen tretenden Spitzen mit höher oder tiefer gefärbtem rothen, aus allen gleichsam zu einer einzigen hellen Flamme zusammen schlagenden Lichte oxydirend, sich selbst desoxydirend, beschäftigt ist, während sie in den durch die Stacheln gesonderten positiven Vertiefungen unter violettem Lichte, das aus allen enge an einander gränzenden Räumen gleichsam wieder zu einer einzigen dunklern, niedrigeren, von jener umgebenen Flamme zusammenfliesst, in der desoxydirenden, sie selbst oxydirenden, Thätigkeit begriffen ist. Bei einer jeden natürlichen mit Flamme erfolgenden Verbrennung bricht so, wie es dieses Bild, freilich auf eine fast noch eben so unvollkommene Weise darstellt, wie wenn man das Verhältniss eines Integrals und Differentials durch das eines Berges und Sandkorns versinnlicht, aus 
tausend und aber tausend Punkten des verbrennemden Körpers und der ihn umgebenden gleichfalls verbrennenden Luft die eine, und eben so aus unzähligen andern Punkten die entgegengesetzte polare Thätigkeit in dem lebendigen Processe der natürlichen geschlossenen galvanischen Kette hervor, und wie jede künstliche Kette melir oder weniger auch immer den Typus einer natürlichen dadurch in sich enthält, dass die Erregung an den Focalstellen zwar überwiegend, aber nicht absolut in allen Punkten gleichartig ist, so ist umgekehrt in der natürlichen wiederum auch eine Hindeutung auf die Norm der künstlichen Kette darin gegeben, dass in der gemeinsamen Berührungsfläche allemal an einer Stelle die eine, an einer andern die entgegengesetzte Seite der Thätigkeiten, keinesweges unter gänzlicher Ausschliessung der andern, aber doch vorherrschend auftritt, und so sehen wir jedesmal auch, während des unter einer Flamme erfolgenden Verbrennungsprocesses, diese beiden Richtungen der Thätigkeit des Pro-cesses durch den einerseits überwiegend hervortretenden gerötheten oder heller gefärbten Theil, und den andererseits mit violettem oder dunklerem Lichte von jenem relativ gesonderten Theil der Flamme deutlich versichtbart.

Wir haben in der obigen bildlichen Darstellung die ursprüngliche Erregung des Körpers positiv, also die Spitzen auf ihm negativ thätig gesetzt; denken wir uns hingegen die ursprüngliche Erregung desselben negativ, so werden die Spitzen positiv thätig, und alsdann ist nicht mehr der violette Theil der Flamme von dem gerötheten, sondern umgekehrt dieser von jenem umgeben. So bezeichnet unfehlbar auch der bei ver- 
schiedenen verbrennlichen Substanzen bald durch überwiegend helleres, kräftiges, bald durch dunkleres, violettes Licht unterschiedene Charakter der Flamme ein ursprünglich verschiedenes Erregungsverhältniss zwischen der Luft und den verbrennlichen Stoffen.

Abweichend gefärbte Flammen, welche unter einer ungewöhnlichen, besonders vorherrschenden Farbe dennoch stets denselben Gegensatz eines dunkler und heller gefärbten Theils versichtbaren, deuten, gleich dem unter verschiedenen Bedingungen ebenfalls verschiedentlich gefärbten Lichte bei den durch die gemeine Elektricität eingeleiteten Processen, auf bestimmte Stufen und Combinationen in den chemischen Relationen der Glieder der Kette und auf eine davon abhängige Modification des Processes selbst hin, wie die verschiedenen Farben des Lichts an und für sich schlechterdings keine constant gefärbten Bestandtheile desselben, selbst nicht einmal nach der vor der Newton'schen so unendlich weit vorgeschrittenen, aber doch noch nicht vollkommen freien Ansicht von Goethe Erzeugnisse des Zusammentretens von Licht und Finsterniss unter bestimmten Verhältnissen, sondern schlechthin auf das absoluteste nur Relationen und Modificationen des in sich durchaus einfachen Lichtes, gleich den Vorstellungen im Vorstellungsvermögen, darbieten.

Verbrennungsprocesse ohne Flamme bezeichnen eine stärkere Reaction des einen in den Process hineingezogenen Gliedes und an Substanzen, die, wie die edlen Metalle, aus einer müchtigen Glut unverändert wieder hervorgehen können, wiederholt sich in der Sphäre des natürlichen Verbrennungsprocesses dieselbe Erscheinung, die bei den durch die künstliche Elektri- 
cität eingeleiteten Processen sich in der momentanen Glut und Lichtentbindung bei einer möglicher Weise völlig unverändert bleibenden Beschaffenheit der die Kette schliessenden Luft oder liquiden Flüssigkeit zu erkennen giebt.

In den bisherigen Lehrsystemen über die Elektricität ist der Gegensatz zwischen einer mitgetheilten- und einer bloss vertheilten Elektricität als ein sehr wesentlicher, jedoch in einer Beziehung, die nicht anders als verfehlt zu nennen ist, hervorgehoben worden. Es versteht sich, dass von einem Sinne, der die Ausdrücke in der Voraussetzung einer oder zwei entgegengesetzter wirklich existirender elektrischer Materien nimmt, bei uns nicht die Rede seyn darf, wiewohl die Begriffe dadurch, dass sie ursprünglich mit dieser festgehaltenen hypothetischen Seitenvorstellung gebildet worden sind, schon an und für sich ein für alle Mal etwas Schielendes erhalten haben, weshalb wir die Ausdrücke für sie als eigene wissenschaftliche Terminologieen auch niemals benutzen werden; aber es wird zur Vermeidung von Missverständnissen und zu grösserer Deutlichkeit des Folgenden dienen, wenn wir hier die eigentliche Bedeutung des durch sie bezeichneten Gegensatzes zuvörderst bemerklich machen, - eine Entwickelung, mit welcher auch die Entbehrlichkeit der Ausdrücke füir uns von selbst klar werden wird.

Mittheilung und Vertheilung der Elektricität kann von unserm Standpuncte aus nichts anderes heissen, als: Mittheilung und Vertheilung der' elektrischen Erregung. Was sollen wir uns aber bei diesen Bezeichnungen denken? Was sagt zuerst der Ausdruck: Mittheilung 
der elektrischen Erregung, oder in wiefern kann er nur in einem richligen Sinne gebraucht werden? - Wenn in irgend einer noch so grossen Masse irgend ein noch so kleiner Theil elektrisch erregt wird und diese Erregung sich durch das ganze Continuum der Masse gleichmässig fortpflanzt, wie es vorzugsweise bei den Metallen geschieht, so ist durch alle Erfolge solcher Art allerdings eine bestimmte Sphäre für die Realität des durch jenen Ausdruck bezeichneten Begriffes gegeben. Diese Sphäre gewinnt im Grunde keine wirkliche, sondern nur eine scheinbare Erweiterung, wenn wir noch den Fall als möglich setzen, in dem eine Masse einer andern mit ihr gleichartigen bis zum unmittelbaren Contact beider genähert wird, und vor diesem Contact eine gegenseitige Einwirkung, in Folge einer sehr schwachen in der einen oder in beiden Massen vorhandenen elektrischen Erregung nicht Statt findet, sondern wobei erst mit und nach dem Contact die elektrische Erregung durch beide Massen gleichmässig verbreitet wird. Auch in diesem Falle haben wir eine Mittheilung der Elektricität einzig und allein sofern sie in der Continuität und Gleichartigkeit der Masse begründet ist und dieses: sofern ist in der That auch überhaupt die bestimmte, entschiedene Gränze für den Begriff, über welche hinaus seine Sphäre durchaus nicht erweitert werden darf. Jeder Fall, in welchem zwischen zwei genäherten Körpern schon vor dem Ċontact eine gegenseitige Wirkung in Folge einer elektrischen Erregung, welche in einem von ihnen oder in beiden zugleich Stalt findet, vor sich geht, gehört schlechterdings nicht mehr za derselben Sphäre; er ist das Re- 
sultat einer bereits erfolgten vollkommenen oder unvollkommenen Schliessung einer Kette und erzeugt ohne alle Ausnahme Veränderungen, die entweder in einer blossen Wiederherstellung des Gleichgewichts oder in abermaligen neuen elektrischen Erregungen und Differenzen bestehen körnen, aber schlechterdings nicht, wie dieses in unsern bisherigen Lehrsystemen so vielfältig geschieht, als das Resultat einer blossen einfachen Mittheilung der Erregung zwischen beiden Körpern angesehen werden dürfen. Dies wird, wie es bereits durch die vorangehenden Darlegungen nachgewiesen worden, auch noch mehr deutlich werden, durch die Betrachtung der.Kehrseite des Gegenstandes.

Vertheilung der Elektricität, das ist: Vertheilung der elektrischen Erregung, bezeichnet einen getheilten Zustand der Erregung in einem und demselben Körper, dem zu Folge er auf entgegengesetzten Extremen auch entgegengesetzte Erregungen zeigt, wie dies bei Leitern zweiter Classe die allgemeine Form der Erregung ist, sofern sie aus dem einfachen Contact hervorgeht und nicht durch gewaltsame Wirkungen der gemeinen Maschinenelektricität bloss äusserlich aufgedrungen ist. Bei Metallen hingegen gehört eine solche Doppelerregung, sie sey durch die Wirkungen der Contactelektricität oder der gemeinen erzeugt, ohne Ausnahme einer geschlossenen, in jedem Augenblicke in fortschreitender Thätigkeit begriffenen Kette an, welches bis dahin fast überall übersehen worden ist und unsre bisherigen Theorien über den Elektrophor, die elektrische Batterie, den Condensator, so wie die Ansichten über alle ähnliche zu ihnen gehörige Lr- 
scheinungen einseitig und fehlerhaft gemacht hat, wie wir bald weiter unten bei der Auseinandersetzung der Hauptmomente des thätigen Verhaltens dieser Instrumente am deutlichsten erkennen werden.

Wenn $A$ ein metallischer isolirter Conductor mit thätigem $+E$ und $B$ ein eben solcher mit $o E$ ist und beide so weit genähert sind, dass eine Einwirkung von $A$ auf $B$, aber noch ausser der Schlagweite des elektrischen Funkens, Statt findet, so ist diese Wirkung nach den bisherigen Ansichten so dargestellt worden, dass $A$ nit seinem $+E$ das $-E$ des $B$ anziehe, das $+E$ desselben dagegen abstosse, dass mithin $B$ gegen $A$ zu negativ, auf der entgegengesetzten Seite aber positiv werde, wenn aber $A$ ausserhalb dieses Wirkungskreises wieder zurück trete, so kehren das $+E$ und $-E$ in $B$ gleichfalls wieder, sich neutralisirend, von beiden Seiten zurück und der Zustand von $B$ sey jetzt wieder, wie vorhin, $o E$. So müsste es freilich seyn, wenn in dem $B$ und in den Körpern überhaupt ein solches fertig vorhandenes $-E$ und $+E$ sich befürude, was aus der Ferne her angezogen und abgestossen werden könnte; aber so ist es nicht. Die Behauptung, dass der Zustand des $B$ nach jener Einwirkung und nachdem $A$ völlig wieder entfernt worden,' ein $o E$ sey, ist in der That völlig erfahrungswidrig; man prüfe den Körper $B$, wenn das einfache Elektrometer dazu noch nicht hinreicht, durch einen Condensator von hinlänglicher Capacität, und man wird nicht $o E$, sondern ein thätiges $-\boldsymbol{E}$ in ihm finden. Dies ist kein zufälliges, sondern ein durchaus nothwendiges Moment des ganzen Herganges, die Einwirkung von $A$ aus sey so gering gewesen, als sie wolle, und wenn $A$ bei einer 
solchen Einwirkung ursprünglich mit $-E$ thätig ist, so zeigt nachher wieder $B$ ein freies $+E$.

Aus Vorliebe für eine so bequeme Theorie wie diejenige des elektrischen Dualismus und der Wirkungskreise ist, kann man entgegnen, das freie $-E$ des $B$, nach der Einwirkung des mit $+E$ thätigen $A$, sey die Folge eines Verlustes an $+E$, den $B$ durch die abstossende Thätigkeit von $A$ aus und vermöge der Anziehung und leitenden Eigenschaft der umgebenden Luft erlitten habe. Aber diese Anziehung und Leitung der Luft ist für das supponirte $-E$ des $B$ eben so thätig, wie für sein $+E$; sie kann also auf keiner Seite entscheiden; was hingegen den Verlust an $+E$ durch $\mathrm{Ab}$ stossung von $A$ aus betrifft, so müsste nothwendigerweise ihm gegenüber ein noch grösserer auf der Seite des dem $A$ näher liegenden $-E$ durch Anziehung desselben von $A$ aus bewirkt worden seyn. Warum findet ein solcher Verlust aber nicht Statt? Wer hat überhaupt den Versuch schon jemals im luftleeren Raum, im eigentlichen Vacuum ausgeführt? Eben die Luft oder irgend ein gasförmiges Medium ist es, welches zu seiner Darstellung durchaus unentbehrlich ist, indem es als ein Leiter zweiter Classe den Wirkungskreis zwischen $A$ und $B$, als Leitern erster Classe; einzig und allein vermittelt und alle Erscheinungen, in denen wir eine solche sogenannte Vertheilung der Elektricität gewahr werden, beruhen in jedem einzelnen Falle lediglich auf der Wirkung einer unvollkommen geschlossenen galvanischen Kette, welche eben durch die gemeinsame gleichzeitige Wirkung der Conductoren und der Luft als Leiter erster und zweiter Clasșe zugleich gebildet wird. 
Wenu das obige $A$ und $B$ ein Paar metallische Scheiben von etwa 6 Zoll im Durchmesser sind und $A$ nur die mässige positive Erregung einer etwa viertelzölligen Schlagweite besitzt, so wird $B$, mit seiner Ebene der von $A$ parallel und möglichst nahe, aber, wie sich versteht, noch vollkommen ausser der Schlagweite gehalten, in wenig Secunden gewöhnlich schon so stark negativ erregt, dass es darauf für sich allein nach der Entfernung des $A$ das Goldblattelektrometer nicht selten schon vor der unmittelbaren Berührung zum Anschlagen zu bringen vermag. Der Versuch in dieser Gestalt führt besonders leicht zu der Ansicht, dass überall in demselben, auch bei jeder andern Form der Conductoren $A$ und $B$, jener die Unterscheibe, dieser den Deckel eines Elektrophors vertrete, bei welchem die zwischen $A$ und $B$ befindliche Luft die Function der idioelektrischen, in Berührung mit dem positiven $A$, negativ - und auf der Seite von $B$ positiv erregten Substanz verrichtet, während die umgebende Luft ein unvollkommen leitendes Medium von $A$ nach $B$ hin bildet, vermöge dessen, wenn $A$ sich entfernt, $\boldsymbol{B}$ eben so wie der von der positiven Basis abgehobene Elektrophordeckel, nur wegen der unvollkommenen Verbindung verhältnissmässig schwach, negativ erregt ist. Und in der That ist dies die richtige Ansicht der Sache, nur muss hier ihre Enunciation von aller Beziehung auf den Elektrophor befreit und allein auf den höheren Gesichtspunkt der Thätigkeit der galvanischen Kette, unter welchem auch die Wirkung des Elektrophors als ein specieller Fall enthalten ist, zurückgeführt werden; denn ausserdem würde man in einem ogischen Cirkel über die Erscheinungen der soge- 
nannten vertheilten Elektricität durch den Elektrophor, und über die Wirkungen des Elektrophors wiederum aus jenen Erscheinungen der vertheilten ETektricität Rechenschaft geben.

Die angemessene Art und Weise, den Gegenstand zu fassen, wird daher folgende seyn: $A$ sey positir erregt, so ist die zwischen $A$ und dem ursprünglich indifferenten $B$ befindliche Luft in der Berührung mit $A$ negativ, auf dem entgegengesetzten Extrem in Berührung mit $B$ posiliv und dieses letztere folglich dadurch wieder negativ erregt. Hierdurch allein schon würde also $B$ auch nach der Entfernung von $A$, so wie während der Einwirkung, sich negativ erregt zeigen, jedoch nur in Folge der Thätigkeitstendenz einer gänzlich ungeschlossen gebliebenen Kette. Durch die äussere umgebende Luft wird aber die Ketle jedes Mal und gleichzeitig mit jener Wirkung auf eine zwar unvollkommene aber dennoch ihre Thätigkeit bedeutend erhöhende Weise geschlossen und die äusseren Extreme von $A$ und $B$, welche ausserdem den innern gleichartig erregt geblieben wären, werden ihnen, dem allgemeinen Typus der 'Thätigkeit der geschlossenen Kette gemäss, entgegengesetzt erregt, so dass $A$ nach innen positiv, aber zugleich nach aussen, wiewohl schwächer, negativ, und $B$, welches auf der innern Seite negativ erregt ist, nach aussen gleichfalls schwächer positiv erregt wird, während die Luft von $A$ nach $B$ zu, innerhalb der Kette negativ-positiv, ausserhalb derselben aber in engeren und weiteren Bogen positiv - negativ erregt ist. Wird die Thätigkeit der Kette durch hinlängliche Entfernung von $A$ und $B$ aufgehoben, so zeigt sich $B$ wegen des Uebergewichts der von innen 
Statt gefundenen Action negativ und $A$ vermöge der schwächenden Wirkung von aussen auch verhältnissmässig minder positiv erregt, als es vor dem Beginn der Thätigkeit der Kette der Fall war. - Die Gestalt des Herganges für den Fall, wenn $A$ ursprünglich negativ erregt ist, bedarf keiner Erwähnung.

Das Obige zeigt, dass die wahre Bedeutung des Gegensatzes zwischen mit getheilter und vertheilter Elektricität wesentlich allein darin bestehe, dass der Unterschied in dem Fortschritte der elektrischen Erregung aufgefasst werde, sofern er entweder einzig und allein nur vermöge der Continuität und Gleichartigkeit einer in irgend einer Stelle erregten Masse besteht, oder sofern er durch die Action einer mehr oder minder unvollkommen geschlossenen Kette in verschiedenen Leitern erster Classe, welche durch Leiter zweiter Classe gesondert sind, Statt findet. Aber diese Disjunction ist bisher so unvollkommen gefasst und die beiden Seiten des Gegensatzes sind so vielfältig mit einander verwechselt worden, dass um der schwankenden und einseitigen Begriffe willen, die sich auf diese Weise mit den Ausdrücken zur Bezeichnung dieses Gegensatzes verbunden haben, die letzteren an füglichsten ganz vermieden werden, was um so leichter'geschehen kann, da von unserm Standpunkte aus für die Darstellung des Zusammenhanges der dahin gehörigen Erscheinungen das Bedürfniss jenes Gebrauchs theils nicht vorhanden, theils durch andere bestimmte Ausdrücke $\mathrm{zu}$ befriedigen ist. Namentlich könmen wir es hier zugleich auf das bestimmteste noch ein für alle Mal hervorheben, dass dasjenige, was wir unter elektrischer Leitung zu verstehen, haben, niemals 
etwas anderes sey, als eben nur jener Fortschritt der elektrischen Erregung in der Gleichartigkeit und Continuität einer und derselben Masse, dessen verschiedene Form auf eine so charakteristische Weise die Leiter erster und zweiter Classe von einander sondert. Wir haben in diesem Sinne die Metalle gute, die Flüssigkeiten schlechtere Leiter der Elektricität genannt, weil in der Masse der erstern der Fortschritt der elektrischen Erregung, eben weil sie für die chemische Thätigkeit viel weniger aufgeschlossen sind, als die Flüssigkeiten, so viel gleichartiger und scheinbar schneller und kräftiger als in den letztern erfolgt. Aber von dieser elektrischen Leitungsfähigkeit, wie wir hier gleichfalls unter Zurückweisung auf alles hierüber im vorigen Abschnitte Gesagte erinnern, durchaus verschieden und nur zum Theil von ihr abhängig, ist das Vermögen der Körper, die galvanische Kette in geringerem oder höherem Grade der Vollkommenheit zu schliessen, das ist ihr Leitungsvermögen der chemischen Thätigkeit. Die besten Leiter der Elektricität sind, wie wir oben gesehen haben, in hinlänglicher Zahl mit einer hinreichenden Menge thätiger Flächen angewandt, im Stande, die chemische Action einer galvanischen Kette zu hemmen, während diese Thütigkeit durch schlechtere Leiter der Elektricität, wenn sie nur in hinlänglich dünnen Schichten angewandt werden, ungleich mehr befördert wird und dies findet bekanntlich selbst bei den durch gemeine Elektricität eingeleiteten galvanischen Ketten seine Bestätigung, wenn man durch ihre Schliessung chemische Erfolge, wie Entzündungen, Zersetzungen u. dergl. hervorbringen will und zur Erreichung des $\hat{\mathbf{Y}}$ 
Zwecks die metallische Leitung mit Vortheil durch schlechtere Leiter der Elektricität, d. i. durch bessere Leiter der chemischen Thätigkeit, (s. oben S. 210 ff.) an einer oder mehreren Stellen unterbricht.

Es wird uns demnächst nicht schwer fallen, über alle wesentlichen Erscheinungen der wichtigsten elektrischen Geräthschaften, nämlich des Elektrophors, des Condensators und der Verstärkungsflasche, Instrumente, deren Theorie nach dem bisherigen System, wie gesagt, schon darum theils unbefriedigend, theils verfehlt ausfallen musste, weil sie auf den mangelhaften Vorstellungen beruhte, unter welchen die unter der Kategorie der sogenannten Vertheilung der Elektricität begriffenen Phänomene so lange aufgefasst wurden, jetzt kürzlich noch eine genügende und mit unsern bisherigen Darstellungen in der innigsten Verbindung stehende Rechenschaft zu geben.

Der idioelektrische Bestandtheil des isolirten Elektrophors sey eine Glastafel, die auf ihrer obern Seite positiv und daher auf der untern negativ elektrisch ist, so ist absolut, ohne Rücksicht auf die durch die Luft vermittelte Wirkung, die untere Armatur durchgehends positiv, die obere, der Deckel, durchgehends negativ erregt, und diese Erregungen binden sich an und für sich zuvörderst noch auf keine Weise, weil sie durch die ursprüngliche Erregung des idioelektrischen Körpers hervorgerufen werden und so wie diese nach Aussen hin frei hervortreten. Nach der üblichen Darstellung des bisherigen Systems heisst es: durch das $-E$ der untern Fläche des Glases werde das $+E$ der untern Armatur angezogen oder gebunden und das $-E$ derselben werde frei; desgleichen werde durch das $+\boldsymbol{E}$ 
der obern Fläche des Glases das $-\boldsymbol{E}$ des Deckels gebunden und sein $+E$ werde frei, dass mithin die Unterlage sich negativ, der Deckel hingegen positiv elektrisch zeigt. Aber dies ist nicht richtig. Die genannten Erregungen der Armaturen sind zwar vorhanden; aber sie sind keinesweges die absolute Folge der in dem Elektrophor an und für sich gegebenen Bedingungen, sondern sie sind bereits Symptome der Thätigkeit in der schon vermöge der Luft auf unvollkornmene Weise begonnenen Schliessung der Kette. Im eigentlichen Vacuum würde durchgehends die Unterlage nur entschieden positiv, der Deckel nur entschieden negativ erregt sich zeigen, und nur in Folge der durch die umgebende Luft bewirkten unvollkommenen Schliessung der Kette ist hier eine jede Armatur des Elektrophors, so wie oben ein jeder von den Conductoren $A$ und $B$, auf der äussern Seite gegen die innere in entgegengesetzter Erregung begriffen, weshalb auch jedesmal der Deckel, schon vor aller Berührung von der Basis abgehoben, bereits negativ, so wie alsdann die untere Armatur positiv befunden werden wird. Wird die Kette aber vollkommen durch eine gleichzeitige Berührung des Deckels und der Unterlage mit einem angemessenen Leiter geschlossen, so wird dadurch die erregende Thätigkeit der idioelektrischen Substanz, aus denselben Gründen wie die chemische Action des Leiters zweiter Classe in der gewöhnlichen geschlossenen galvanischen Kette, sehr bedeutend erhöht. Die Ausgleichung der Differenz und die Herstellung des natürlichen Gleichgewichts zwischen den beiden Armaturen würde nur dann möglich seyn, wenn das Glas nicht erregt wäre, oder wenn seine entgegengesetzten Erregungen auf beiden Seiten Y 2 
durch die gleichzeitige Berührung eben so leicht indifferenzirt zu werden vermöchte, wie im Metall. Aber gerade durch diese Indifferenzirung der Erregung des Metalls wird die Differenz der Erregung des Glases vergrössert; das Glas hält, so wie jeder idioelektrische Körper, seine durch Reibung hervorgerufene Erregung nicht nur mit Beharrlichkeit fest, sondern es tritt selbst, gleich der Flüssigkeit, einem jeden Körper, den es erregt hat, mit dem es noch fortwährend in Wechselerregung steht und der sich dieser Erregung entziehen will, bis zu einem gewissen Grade mit um so viel mehr erhöhter Erregung entgegen, um ihn darin fest zu halten. Zwar kann es, vermöge seiner Natur, nicht so wie die Flüssigkeit, diese gesteigerte Tendenz durch eine reelle chemische Action weiter verfolgen und es vermag daher auch nicht die momentane Herstellung des Gleichgewichts zu hindern, da die Thätigkeit, mit welcher es im Momente der Schliessung, durch eine lebhafte Steigerung seiner Erregung dem, drohenden Drange der Indifferenz sich zu widersetzen trachtet, nur bis zu einem bestimmten Grade der Kraft reicht, über welchen es nicht mehr hinaus kann; aher es bewirkt damit jedes $\mathrm{Mal}$ auf der Seite der untern Armatur durch seine eigene erhöhte negative Erregung eine so viel stärkere positive, und eben so in dem Dekkel, durch seine eigene gesteigerte positive Erregung eine so viel stärkere negative Erregung. Auf diesem äussersten Punkte der Steigerung halten sich nun auf jeder Seite der Basis beide Erregungen im Glase und im Metall gegenseitig fest und gebunden, nach Innen mit grosser, gewaltsamer Anstrengung, nach Aussen mit dem Schein der Ruhe und Unthätigkeit. Die In- 
differenz ist nicht die natürliche, das Gleichgewicht ist nicht das eigene der Waage, sondern nur das der Belastung. Wird der Deckel abgehoben, so tritt seine negative Erregung offen und ungebunden hervor; das Glas kehrt mit dem beseitigten Reiz auf den ursprünglichen und eigentlichen Standpunkt seiner wahren Erregung zurück, und die überschüssige positive Erregung der untern Armatur tritt nun eben desshalb, so lange die Basis isolirt bleibt, gleichfalls frei und ungehemmt hervor. - Die Art des ganzen Herganges, wenn der idioelektrische Körper des Elektrophors, wie gewöhnlich, ein Harzkuchen ist, bedarf nach dem Obigen kaum der Erwähnung, geschweige einer besondern Auseinandersetzung.

Die Wirkung des Condensators ist nach den bisherigen Ansichten über die sogenannte vertheilte Elektricität immer nur als die Folge einer erhöhten, wiewohl gänzlich passiven Receptivität der Collectorplatte für die elektrische Erregung, aufgefasst worden. Diese Vorstellung der Sache hat aber schon darum etwas Unbefriedigendes, weil bei vorurtheilsfreier Anschauung die Erscheinungen unverkennbar eine entschiedene Thätigkeit und so zu sagen ein die dargebotene Erregung gleichsam absorbirendes Verhalten des Collectors zu erkermen geben und in der That lässt sich die Thätigkeit des Condensators als eine solche, für jeden, der die Action der galvanischen Kette überhaupt und insbesondere die Wirkung des Elektrophors nach unserer obigen Entwickelung auf eine lebendige Weise erfasst hat, jetzt in wenig Zügen auf eine befriedigende Weise entwerfen.

Wird die Collectorplatte, in der Gemeinschaft 
mit einem durchgehends auf gleiche Weise; z. B. positiv elektrisch erregten Körper, diesem selbst gleichartig erregt, so wird die angränzende dünne Schicht der idioelektrischen Substanz in der Berührungsfläche negativ, auf der entgegengesetzten Seite positiv und durch diese wieder der von ihr berührte Leiter, die zweite Condensatorplatte, negativ erregt. In diesem Zustande wird bereits, auch wenn die letztere isolirt bleibt, die Kette durch die umgebende Luft zwar noch sehr unrollkommen, aber doch schon in solchem Grade geschlossen, dass dadurch die Erregungsthätigkeit der Zwischenschicht, auf eine ähnliche Weise wie die des idioelektrischen Bestandtheils beim Elektrophor, erhöht und damit in der Collectorplatte eine stärkere Erregung bedingt wird, die sich auch an einem hinlänglich empfindlichen Elektrometer sogleich durch verstärkte Divergenz zu erkennen giebt, wenn die beiden Platten von einander getrennt werden. Gewöhnlich ist aber die Erregung des mit der Collectorplatte verbundenen Körpers und die gleichartige der Collectorplatte selbst nur so schwach, dass die blosse Schliessung der Kette durch die Luft noch zu unvollkommen und unwirksam ist, um eine merklich erhöhte Thätigkeit einzuleiten. Wird alsdann aber noch die zweite Condensatorplatte ableitend berührt und so mit der Aufhebung ihrer Isolirung eine nach allen Richtingen mit überaus grosser Vermehrung des Berührungspunkte erweiterte, durch die Luft vermittelte Communication zwischen der Collectorplatte und der leitenden Totalität hergestellt, so wird die Thätigkeit der Kette ungleich grösser, die Collectorplatte wird so viel stärker positiv erregt, während der elektrische Körper auf dem abgewandten Extrem 
negativ oder wenigstens minder positiv wird, ehen so wie die zweite Platte nach dem Innern zu so viel stürker negativ ist, während die ganze, mit ihr verbundene, leitende Umgebung wie ein zweites Extrem gegen die Luft als ein positiv thätiges auftritt. Wird alsdann der ursprünglich positiv elektrische Körper von der Collectorplatte abgezogen und darauf die Isolirung wieder hergestellt, so binden sich noch die entgegengesetzten Erregungen in der Zwischenschicht und den Platten auf beiden Seiten so wie beim Elektrophor; aber sobald die Platten gehörig von einander entfernt werden, so tritt in der Collectorplatte die positive, in der andern die negative Erregung frei und in erhöhter Intensität hervor. - Die Art des ganzen Herganges, wenn der mit der Collectorplatte in Verbindung gesetzte Körper ursprünglich negativ ist, versteht sich von selbst, In beiden Fällen aber ist, wie wir vorausgesetzt haben, jener Körper an und für sich durchgehends so oder entgegengesetzt erregt; wenn aber der Condensator wie ein Ladungselement in den Kreis einer schon früher gebildeten Kette tritt, deren Polarität mithin bereits völlig entschieden und der Richtung nach fest und unabänderlich bestimmt ist, wie wenn z. B. die Collectorplatte mit dem positiven, die andere mit dem negativen Pol einer Zambonischen Säule verbunden wird, danı ist seine Wirkung, wenn er diesen Kreis wiederum verlüsst, eine wahre Reaction und erfolgt im Wesentlichen auf dieselbe Weise wie die der geladenen Verstärkungsflasche, zu deren Betrachtung wir uns jetzt noch besonders wenden wollen.

Wenn der positive Hauptleiter der thätigen Elektriirmaschine mit dem einen, etwa dem innern Beleg 
einer Verstärkungsflasche oder Batterie in leitende Verbindung gesetzt ist, während das andere, äussere, Beleg mit dem Reibzeuge unmittelbar oder durch den Erdboden im Zusammenhange steht, so ist der Erfolg zunächst wesentlich von derselben Art, als wenn eine Ritter'sche Ladungssäule oder vielmehr ein Ladungselement in eine geschlossene galvanische Säule eingeschaltet wird. Der Hanptleiter theilt sich zwischen dem geriebenen Glase der Elektrisirmaschine und dem Glase der Verstärkungsflasche oder Batterie, so wie eine zwischen zwei flüssigen Schichten in der Säule liegende Metallplatte, in zwei Erregungszonen: er bleibt nach der Maschine hin positiv, wird aber nach der Batterie hin negativ; in gleicher Art ist die Leitung zwischen dem äussern Beleg und dem Reibzeuge nach jenem hin positiv, nach diesem hin negativ thätig und zwischen beiden ist das Glas in der Berührung mit dem innern Beleg positiv, mit dem äussern negativ erregt. Je mehr die Spannung in der Erregung beider Belege wächst und sich reagirend zum drohenden Ueberschlagen nach der entgegengesetzten Seite hin neigt, um so beharrlicher tritt ihr die bindende Erregung des Glases auf seinen heiden Seiten entgegen. So wie aber die Batterie den geschlossenen Kreis der Kette verlässt, tritt die Macht der Reaction des Metalls gewaltsam hervor und das Glas vermag es nicht mehr, sie vollständig zu fesseln. Es behauptet sich zwar gegen das innere Beleg zu in der positiven Erregung und hält dieses auf der innern, ihm zugewandten Seite in der negativen Erregung fest; aber nach Aussen hin ist jetzt dasselbe Beleg durch Reaction überwiegend positiv. Eben so ist das Glas nach dem äussern Beleg zu negativ und dieses auf 
seiner innern, dem Glase zugekehrten Fläche positiv; aber nach Aussen hin ist dasselbe Beleg durch Reaction überwiegend negativ thätig.

Wird in diesem Zustande das eine von beiden Belegen, etwa das innere, isolirt vom Glase abgehoben, so zeigt es durchgehends eine positive Erregung, die aber bei weitem nicht mehr so stark erscheint, als sie vorhin während der Verbindung mit dem Glase war, weil der grössere Theil der überwiegend reagirenden positiven Thätigkeit in der frei gewordenen negativen Erregung, die so lange durch die positive Erregung des Glases gebunden wurde, erloschen ist. Bleiben aber beide Belege mit dem Glase vereinigt und man schliesst diese durch den sogenannten Ladungszustand, das ist durch Reaction, gebildete Kette mit einem angemessenen Leiter von Beleg zu Beleg, so wird der so lange bestehende Drang zur Ausgleichung auf die bekannte gewaltsame Weise realisirt. Diese Indifferenzirung ist num aber begreiflich keine vollkommene Entladung, sondern die Schliessung kann auf jeden Fall mindestens nur das Erlöschen der überwiegenden positiven Erregung des innern Belegs in der entgegengesetzten reagirenden Thätigkeit des äussern zur Folge haben, während die negative Erregung des innern Belegs durch die positive des Glases, so wie die positive Erregung des äussern Belegs durch die negative des Glases gebunden bleiben. Nach dieser Schliessung ist also das Ganze vollkommen in dem 'Zustande eines von Beleg zu Beleg geschlossenen Elektrophors und dem gemäss zeigt sodann auch das innere Beleg, für sich isolirt vom Glase abgehoben, negative, das äussere positive Erregung und diese Erregungen gestatten als- 
dann eine so vielmalige wechselseitige Vernichtung und Wiedererneuerung, wie es beim Elektrophor möglich ist.

Aber mit der ursprünglichen Schliessung der geladenen Flasche oder Batterie geschieht unmittelbar an ihr selber noch mehr, als eine blosse Indifferenzirung der überwiegenden reagirenden Thätigkeiten beider Belege. Während der unmittelbaren Verbindung derselben tritt nämlich das Glas, vollkommen nach demselben Thätigkeitsprincip, wie wir es oben beim Elektrophor und im Charakter der Wirkung des Leiters zweiter Classe in der geschlassenen galvanischen Kette überhaupt kennen gelernt haben, abermals mit aufs Neue gereizter Kraft, in gesteigerter eigener Erregung, der Erregung der beiden Belege entgegen und bindet ausser dem Antheil, den es vorher schon im Widerstreit mit dem mächtigen Drange der Reaction des Metalls gefesselt hielt, auf jeder Seite noch ein gewisses Quantum der im Beleg theils vorhandenen, theils neu hervorgerufenen Erregung mehr, welches um so grösser ist, je grösser die Intensität der Thätigkeit des Ganzen und die sogenannte Ladung ursprünglich ist. Unmittelbav nach diesem Momente binden sich alsdann, wenn die Schliessung aufgehoben, die entgegengesetzten Erregungen auf jeder Seite vollkommen und es findet scheinbar das entschiedenste Gleichgewicht Statt. Nach einiger Zeit aber vermag das Glas dem Drange der Reaction des Metalls mit derselben Energie der Thätigkeit, zu welcher es im Momente der Schliessung gereizt wurde, nicht ferner mehr das Gleichgewicht zu halten, es sinkt allmälig wieder auf einen geringeren Grad der Erregungsthätigkeit hinab und das innere Beleg reagirt 
aufs Neue mit positiv, das äussere mit negativ thätiger Erregung, nur, wie sich von selbst versteht, in viel schwächerem Grade, als nach der ursprünglichen Ladung. Diese abermalige eben so auch wohl noch nach einer zweiten und dritten Entladung, aber immer schwächer, wie eine von Neuem gebildete Ladung, wiederkehrende Reaction, die sehr unpassend mit gänzlicher Verkennung ihrer wahren Bedeutung der Rückstand der anfänglichen Ladung genannt zu werden pflegt, erscheint so, im vollkommensten und natürlichsten Zusammenhange mit dem Ganzen unserer Ansicht, als ein sehr wesentliches und schlechthin nothwendiges Moment der Phänomenologie, während sie rach den gewöhnlichen Vorstellungen, durchaus gegen die $\mathrm{Be}-$ ständigkeit der Erscheinung in der Erfahrung, nur als ein zufälliger, aller befriedigenden Nachweisung ermangelnder Umstand angesehen wird.

Wir haben mit der auf S. 308 . begonnenen Uebersicht der Grunderscheinungen im Galvanismus bis jetzt vornehmlich das Wesen der Verknüpfung zwischen der Elektricität und dem chemischen Processe in Erwägung gezogen. Wir wollen daher jetzt auch noch kürzlich den Magnetismus, als das dritte Hauptglied in dieser Gemeinschaft ins Auge zu fassen und so bestimmt als möglich zu charakterisiren trachten.

Der entschiedene Chemismus, welcher erst bei einem hinlänglichen Grade von Vollkommenheit in der Schliessung der galvanischen Kette eintritt, findet, so weit er sich als äusserliche That zeigt, immer nus in den Berührungsflächen der differenten Glieder der geschlossen Kette Statt. Betrachten wir, um indessen die Thätigkeit, welche nichts desto weniger in allen 
übrigen Punkten der Kette herrschend ist, desto lebendiger anzuschauen, nur zuvörderst den speciellen Fall, in welchem eine galvanische Batterie durch eine Wassersäule von einiger Länge geschlossen ist, so dass also das Wasser, dem der bessern Wirkung wegen ein kleiner Antheil irgend einer Säure oder eines Salzes beigemischt sey, in Berührung mit dem einen Extrem der Säule zu Oxygen und in Berührung mit dem andern zu Hydrogen wird und als solches hervortritt, während eben so jede einzelne Schicht der Flüssigkeit, welche sich in der Batterie zwischen zwei Metallplatten befindet, in der Berührung mit den Flächen der letzteren eine gleiche, sogenannte, Zersetzung erleidet. Nur in allen übrigen Punkten, ausser diesen gemeinschaftlichen Berührungsflächen, scheinen die Flüssigkeit und das Metall, dem äusserlichen Anblicke nach, völlig indifferent und unthätig zu seyn. Das sind sie nun freilich der innern Anschauung, auch wenn es kein Mittel einer weiteren Nachweisung gäbe, schon an und für sich schlechterdings anf keine Weise, weil die Thätigkeit der Flüssigkeit und des Metalls, wenn gleich nur zunächst in jenen Berührungsflächen äusserlich dargelegt, darum nicht minder eine Thätigkeit der ganzeu Flüssigkeit und des sämmtlichen MetalIs in der ganzen Batterie überhaupt seyn muss. Aber die lebendige Regung in jedem Punktekann durch das einfachste Mittel versichtbart werden.

Wir versetzen in das Innere der schliessenden Wassersänle, in der geraden Linie zwischer ihren beiden Extremen, irgend wo, einen Platindrath von belichiger Länge, jedoch um seine Lage bequem verändern zu können, noch beträchtlich kürzer als ein Drit- 
tel der ganzen Länge der Säule. Wir wissen und sehen es, dass alsdann augenblicklich an beiden freien Extremen des Drathes, wo wir ihn übrigens auch in jener Dimension anbringen mögen, dieselbe chemische Thätigkeit erfolgt, welche sich überall da in der Kette zeigt, wo nur ein metallisches Extrem und die Flüssigkeit in wechselseitige Berührung treten. Wenn wir das eine Extrem der Säule, an welchem sich das Oxygen entbindet, nämlich das in eine einzelne Kupferplatle ausgehende Extrem der Batterie, mit $a$, das andere, an welchem das Hydrogen auftritt, welches an der Batterie die in eine einzelne Zinkplatte ausgehende Endigung ist, mit $b$ bezeichnen und das Ende des Draths, welches nach $a$ hin gerichtet ist, durch $\alpha$, das nach $b$ hin gerichtete durch $\beta$ unterscheiden, so entbindet sich an $\alpha$ Hydrogen und an $\beta$ Oxygen. Wird der Drath aus einer Lage in eine andere versetzt, so dass fortwährend $\alpha$ gegen $a, \beta$ gegen $b$ gekehrt bleibt, aber $\alpha$ unmittelbar in die Stelle rückt, welche eben vorher $\beta$ einnahm, so wird auch in derselben Stelle der Flüssigkeit, an welcher vorher Oxygen erzeugt wurde, jetzt Hydrogen enthunden; oder wenn statt dessen $\beta$ in die vorher durch $\alpha$ behauptete Stelle versetzt wird, so entbindet sich in derselben Stelle der Flüssigkeit Oxygen, aus welcher unmittelbar zuvor das Hydrogen hervortrat. Wenn aber der Dralh umgekehrt wird, so dass $\alpha$ gegen $b$ und $\beta$ gegen $a$ gewandt wird, so erzeugt sich sogleich an $\alpha$ Oxygen und an $\beta$ Hydrogen, während so lange an jedem Extrem des Drathes das entgegengesetzte Product entbunden wurde. Versetzen wir noch ein Platin - oder Goldblech in die Flüssigkeit, so dass die eine seiner breiten Flächen nach $a$, die andere nach $b$ 
gekehrt ist, so entbindet sich an jener das Hydrogen, an dieser das Oxygen, an welcher Stelle in der Säule das Blech sich auch befinden und wie geringe, bis zum dünnsten Blattgolde hinab, seine Dicke auch seyn möge.

Diese ganze Phänomenologie zeigt auf das unverkennbarste, dass in jedem Punkte der Säule die polare Tendenz zum Chemismus, zur Oxydation und Desoxydation nach entgegengesetzten Seiten auf eine so lebendige Weise angeregt sey, dass ihr nur durch das Metall Gelegenheit und Bedingung dazu dargeboten werden darf, um sie sogleich in entschiedene That übergehen zu sehen. Dabei ist die Seite, nach welcher hin eine jede von beiden polaren Thätigkeiten erfolgt, auf das vollkommenste bestimmt. Wenn wir nämlich, ausser den vorhin durch $a$ und $b$ unterschiedenen Punkten, noch den mittleren Theil der Batterie mit $c$ und denjenigen der schliessenden Wassersäule mit $d$ bezeichnen, indem wir uns die Batterie und Säule etwa von gleicher Höhe, einander parallel und an den obern wie an den untern Extremen durch metallische Fortsätze verbunden vorstellen, so geht von jedem Punkte aus, so oft der Chemismus wirklich auf denselben eintritt, die Oxydation nach der einen Seite, gemäss der Richtung $c b d a$, die Desoxydation nach der entgegengesetzten $c$ a $d b$ vor sich. Welche Richtungen aber die diametral entgegengesetzten Tendenzen, vermöge welcher diese chemische Thätigkeit, so oft sie wirklich Statt findet, nąh jenen entgegengesetzten Seiten hin erfolgt, gegen die zum Kreise geschlossene Longitudinalaxe der ganzen Kette haben, darüber lässt sich aus demjenigen, was uns die obigen Erscheinungen darbie- 
ten, indem sie uns nur den auf getrennten Punkten bereits erfolgenden Chemismus, aber nicht diese Tendenzen selbst unmittelbar vor Augen legen, an und für sich auf keine Weise schon mit Sicherheit entscheiden. Wir sehen überall den Drath oder das Metall, welches wir in die Flüssigkeit versetzen, in jeder Lage, die wir ihm auch geben mögen, sich nach jenen entgegengesetzten Seiten hin in zwei Zonen der polaren Thätigkeiten und eine $\mathrm{zwischen}$ beiden liegende Indifferenzzone theilen. Da nun die Impulsion zu'diesen Thätigkeiten unwidersprechlich von jedem Punkte der Flüssigkeit ausgeht und das Metall also auch in jedem Punkte von ihr afficirt werden muss, da die Thätigkeit selbst nur im Conflict der gegenseitigen Anregung der Flüssigkeit und des Metalls erfolgt, von denen das letztere, seiner Natur gemäss, der Aufforderung zu einer in jedem Punkte hervortretenden Bipolarität mächtig widerstrebt und die entgegengesetzten Pole so weit auseinander als möglich nach den Extremen hindrängt, und da endlich die Gase nach ihrer Entbindung begreiflich nicht mehr der Richtung der Tendenz zu ihrer chemischen Production, sondern ganz, andern mechanischen Gesetzen in ihren Bewegungen folgen, so kann aus dem, was bei den obigen Erfolgen das Auge wahrnimmt, ohne weiteres keinesweges sogleich über die Richtung der unsichtbaren Tendenzen zu diesen Wirkungen geurtheilt werden. Man könnte allenfalls aus der Menge des entbundenen Gases einen Schluss zur Bestimmung jener Richtung ziehen und von derjenigen Lage des Metalls, bei welcher die grössesten Quantitäten Gas erscheinen, präsumiren, dass durch sie die Hauptfläche des Metalls jenen Impulsionsrichtungen gerade recht- 
winklig dargeboten würde, während in derjenigen Lage, mit welcher die kleinsten Quantitäten an Gas sich erzeugen, nach dieser Reflexion, die Hauptfläche des Metalls sich in jenen Richtungen selbst befinden oder mit ihnen parallel laufen würde; und hiernach müssten dem Augenschein zufolge diese Tendenzen eine gegen die Longitudinalaxe der Kette überall senkrechte oder beinahe senkrechte Richtung haben, weil an dem Drathe z. B. das meiste Gas offenbar dann, wenn er der Longitudinalaxe der Kette parallel, das mindeste aber dann entbunden wird, wenn er gegen diese Axe unter einem rechten Winkel gehalten wird.

Wir haben aber noch mehr Grund bereits a priori zu erwarten, dass, wenn auf irgend eine Weise diese Tendenzen an und für sich selbst unmittelbar versichtbart werden, sie unter einer mehr oder weniger stark geneigten Richtung gegen die Longitudinalaxe der geschlossenen Kette in die Erscheinung treten müssen, weil ihre wenn auch ursprünglich jener Axe parallel fallenden Thätigkeitsrichtungen durch die hemmende $\mathrm{Op}$ position der mit dem Contact der differenten Metalle gesetzten Tendenzen einerseits eine solche Energie und Schwungkraft, welche der Action der Kette erst das rechte Leben giebt, andererseits aber damit zugleich auch eine solche diagonale Abweichung von der Longitudinalaxe der Kette nothwendigerweise erhalten müssen. Die herrschende polare 'Tendenz der geschlossenen Kette ist diejenige, welche in der gegenseitigen Erregung zwischen Metall und Flüssigkeit erzeugt wird, die geradehin entgegengesetzte ist die im gegeuseitigen Contact der differenten Metalle geltend gemachte; beide steigern sich wechselweise, so aber, dass die erstere, 
welche die ursprünglich innerlich mächtigere ist, dadurch zur eigentlichen lebendigen Diagonalaction der Kette gefördert wird. Die auf den reellen Chemismus zwischen $\mid$ Metall und Flüssigkeit gerichtete Thätigkeit wird in jedem Moment durch den reagirenden, in der Contactelektricität der Metalle schon vor der Schliessung der Kette dargelegten Effect einestheils gehemmt; aber anderntheils erhält sie auch gerade durch diese Opposition ein so viel entschiedneres, beschleunigtes, progressives Uebergewicht, jedoch unter einer solchen Modification, mit welcher die Richtung ihrer Tendenz in jedem Punkte eine Diagonale wird. Wäre es möglich, dass in einem Momente in der ganzen Kette überall eine reelle Befriedigung der Tendenzen, zu welcher jeder Punkt in ihr angeregt ist, eintreten könnte, so würden wir sie in demselben Momente in Spirallinien, nach der einen Seite hin als Oxygen, nach der andern als Hydrogen auseinander, wirbeln sehen, Aber die chemische Thätigkeit erfolgt nur in der gegenseitigen Berührung des Metalls und der Flüssigkeit, an polarisch und diametral einander entgegengesetzten Stellen und ansser dem, wenn man die zufällig erzeugten, den gewöhnlichen mechanischen Gesetzen unterworfenen Bewegungen in der Kette ausnimmt, findet weiter durchaus keine Bewegung, am allerwenigsten diejenige irgend eines fabelhaften strömenden elektrischen, galvanischen, magnetischen etc. Fluidums in ihr Statt, sondern die herrschende Tendenz der Thätigkeit, zu welcher alle Punkte in der Kette ohne Ausnahme nach gleichem Maass und Gesetz organisch angeregt sind, ist einzig und allein nur das lebendig in ihr waltende Princip von solcher Art und Richtung, dass erst dann, 
wenn diese Tendenz in reelle That und Bewegung überall in allen Punkten auf einmal überginge, die letztere lediglich in solchen spiralförmigen Wirbeln erfolgen würde.

Das eben Gesagte muss seine Anwendung auf jede künstliche einfache oder zusammengesetzte, zweigliedrige oder dreigliedrige galvanische Kette finden; eine jede solche Kette hat, wie wir wissen, ihre Focalstellen, deren eine der Hauptsitz der ursprünglichen, herrschenden und progressiven, die andere Sitz der opponirenden, eben damit zum möglichst hohen Grade der Thütigkeit anregenden Tendenz ist. Aber die herrschende Thätigkeit muss eben deshalb, auch in solchen Ketten, in welchen sie auf keinem Punkte in reellen, entschiedenen Chemismus überzugehen vermag, sondern in denen sie eben nur überall lebendig gesteigerte Tendenz nach beiden polarisch entgegengesetzten Seiten hin bleibt, stets diagonal, gegen die Longitudinalaxe der Kette rechtwinklig oder beinahe rechtwinklig gerichtet seyn und so sehen wir sie denn in der That im Magnetismus der geschlossenen Kette unmittelbar verf sichtbart. Die magnetische Nord- und Südpolarität, welche die geschlossene galvanische Kette durch die bestimmte Art ihrer Einwirkung auf die gemeine Magnetnadel, nach diametral entgegengesetzten, diagonalen, - auf der Longitudinalaxe senkrecht erscheinenden Richtungen zeigt, ist nichts anderes als die Versichtbairung jener gleichgerichteten polaren Tendenzen der Oxydation und Desoxydation, zu welcher jeder Punkt der Kette lebendig angeregt ist, derselbigen Tendenzen, die, wenn durch das Experiment gehörig dafür gesorgt ist, in jeder dargebotenen Wechselberührung zwischen 
Metall und Flüssigkeit im Momente realisirt sind und die wir, bei unbefangen geöffnetem Blicke hier in der Natur eben so klar und, unzweideutig aus der That entnehmen, wie sich uns in der moralischen Welt die Gesinnungen aus den Handlungen offen und sicher zu erkennen geben.

Die magnetische Polarität der geschlossenen galvanischen Kette ist also auch dieselbe Tendenz zur chemisch polaren Thätigkeit, welche sich vor der Schliessung der Kette in der elektrischen Polarität derselben verkündigte. Beide, die Elektricität und der Magnetismus sind dem höheren Ziel, und Gehalt nach identisch: die Südpolarität der Magnetnadel ist, so wie die negative Elektricität, die Tendenz zur Selbstoxydation, die magnetische Nordpolarität eben so, wie die positive Elektricität, Tendenz zur Selbstdesoxydation; aber als relativ gesonderte Momente des Processes, der Erscheinung und dem bestimmten, wesentlichen Charakter nach sind sie schlechterdings von einander verschieden und können nimmermehr eine der andern substituirt oder aequivalent gemacht werden. Sie sind eins, aber sie sind durchaus nicht in dem widerstrebenden, von einer höheren Naturansicht ganz entfernt gehaltenen, Sinne der Ampèreschen Fiction einerlei. Der Magnetismus offenbart sich, wie die Elektricität, nur in den Phänomenen der Anziehung und Abstossung; aber das Wesen und der Charakter dieser Offenbarung ist ein ganz anderer geworden. Bei der Elektricitüt regen sich die beiden polaren Tendenzen von Aussen her in verschiedenen Individuen, jede besonders in jedem Gliede der Kette durch die des andern bestimmt und auf die chemische Synthesis beide hingerichtet. 
Da hingegen, wo der Magnetismus auftritt, ist alle Mal schon diese Synthesis erreicht, die äusserliche Sonderung ist bereits in einer zum Kreise geschlossenen Gemeinschaft der differenten Glieder überwunden und ein bestimmter, fester Mittelpunkt einer harmonisch in einander greifenden, in sich schrankep̣losen, selbstständigen, Thätigkeit gefunden. Vor der Schliessung der Kette sind ihre Glieder Individuen und als solche in der Tendenz zur Schliessung entgegengesetzt elektrisch erregt; nach der Schliessung sind sie nur Organe der höheren Individualität der Kette selber; die früheren Tendenzen regen sich alsdann nicht mehr auf individuelle Weise, nur ron Aussen her bestimmt, nur in diesem oder jenem Gliede gesondèrt, sondern sie erscheinen wahrhaft universell in jedem Punkte der Masse eines jeden Gliedes der Kette zugleich und allein nur der polaren Richtung, nicht dem Raume nach, gesondert; jeder einzelne Punkt der ganzen Kette will jetzt, gleich allen übrigen, nach den entgegengesetzten Seiten hin als ein oxydirtes und desoxydirtes aus sich hinaus treten, mit einer Thätigkeit, die in demselben Grade nicht mehr und nicht minder selbstständig zu seyn trachtet, als sie nur durch die Gesammtthätigkeit des Ganzen eingeleitet, bedingt und getragen wird. Dies ist der Charakter der magnetischen Polarität, welche von der elektrischen eben so himmelweit wie die Schwere vom Lichte verschieden ist, obgleich in einer höheren Ansicht auch diese nur relativ gesonderte Momente, dem innern Ziel der Naturthätigkeit nach aber wahrhaft eins sind.

Der Magnetisnıus kann dem Obigen zufolge eine in jedem Punkte ron Innen nach Aussen sich erstrek- 
kende, universelle Tendenz, oder, unserer früheren Bezeichnungsweise gemäss, eine auf den analytischen, das heisst den eigentlichen Effect des Chemismus, wie er sich immer nur unter dem Typus der Thätigkeit der geschlossenen Kette darstellt, hingerichtete Tendenz genannt werden, während wir den Elektrismus als eine von Aussen her angeregte, individuelle, auf den blossen synthetischen Effect des Chemismus hin gerichtete Tendenz bezeichinet haben. Die magnetische Erregung muss daher ferner in denjenigen Gliedern, welche für sich ausser Gemeinschaft mit der Kette ein Uebergewicht der Indifferenz und einer in allen Punkten gleichmässig widerstrebenden Reaction gegen die chemische Thätigkeit versichtbaren, also vorzüglich in den Metallen, mit der Action der Kette gerade am stärksten hervortreten, indem die mit der übrigen Masse der Kette gemeinsam angeregte Tendenz im Conflict mit ihrer ursprünglichen Reaction eben dadurch, so wie der Ton in einer harten Masse, um so energischer in ihnen ansprechen muss.

Schon bei der Elektricität sind die Wirkungen des Anziehens und Abstossens eigentlich niemals vereinzelt, sie sind es mehr scheinbar, als wirklich. Die entgegengesetzten elektrischen Erregungen sind zwar in den verschiedenen Individuen, von denen sie ausgehen, gesondert; aber eben damit ist zugleich das Gesetz geltend gemacht, dass ein positiv und ein negativ elektrisch. Erregtes sich nothwendig immer einander irgendwo gegenüber stehen und eben deshalb ist jede von einer Seite her erfolgende elektrische Anziehung zugleich auch mehr oder weniger eine Abstossung von einer ardern Seite her, und umgekehrt. Im Magnetismus der 
Kette aber sind dagegen diese entgegengesetzt polaren Wirkungen niemals gesondert; es gehört zur eigentlichsten Natur der magnetischen Erregung schlechthin und charakterisirt sehr bestimmt ihren Gegensatz zur Elektricität, dass sie als etwas von Innen nach Aussen sich Erstreckendes, immer nur in einem und demselben Individuum und niemals, wie $+E$ und $-E$, mit ihren beiden zusammengehörigen Polen in verschiedenen, gesonderten Individuen sich befinde. Jeder Punkt der Kette will nach der einen Seite der Oxydations- und zugleich nach der andern der Desoxydationsthätigkeit genügen, das heisst, er ist süd- und nordpolar-magnetisch zugleich, oder die nagnetische Süd - und Nordpolarität erstrecken sich über die ganze Kette und alleTheile derselben rings herum ohne alle Schranken, ohne alle einseitig hervortretende Hemmung und Prüponderanz, unter einer schlechthin feststehenden allgemein gültigen Norm, nach den bekannten Gesetzen der elektromagnetischen Circularpolarität. Daher sind alle in beweglichen Theilen der geschlossenen Kette durch magnetische Einwirkungen hervorgebrachte Bewegungen niemals die Folge einer blossen einseitigen Anziehung oder Abstossung allein, sondern unter allen Umständen sind sie immer durch beide Wirkungen zugleich und durch gleiche Antheile derselben am Erfolg hervorgebracht. Jede Bewegung der Art ist eine Rotation und eine in stehende Orientirung ausgehende Bewegung derselben Art ist nur das Resultat zweier oder mehrerer entgegengesetzter Rotationsimpulse zugleich, die, so lange die Bewegung dauert, noch ungleich sind, auf dem Punkte aber, wo der Stillstand eintritt, gleich werden und sich eufheben. So stellt sich z. B. der bewegliche elektro- 
magnetische Ring nicht etwa, weil er magnetische Pole hat und mit der einen Seite vom magnetischen Nordpol, mit der andern vom Südpol der Erde angezogen wird, in die Ost - Westebene, sondern allein deshalb, weil er in jeder andern Lage mit entgegengesetzten ungleicheu, in dieser aber mit entgegengesetzten gleichen und sich also aufhebenden Rotationsimpulsen durch den Erdmagnetismus sollicitirt wird.

Die ursprüngliche und eigentliche Form der magnetischen Polarität ist überall nur die der Circularpolarität. Die Elektricität ist geschäftig, wo ein Individuum dem andern gegenübersteht und das Streben zur Gewinnung der verlornen oder zur Bildung einer höheren Einheit, zur Schliessung der Kette in ihnen erwacht. Der Magnetismus bezeichnet dagegen die bereits geschlossene Kette; er deutet auf die Einheit einès höheren, in umfassenderer Sphäre bestehenden Einverständnisses der organischen Gesammtthätigkeit aller żu einem einzigen Individuum vereinigten Glieder und er tritt gerade da, wo die Stufe der Organisation des Individuums noch am niedrigsten und in denjenigen Organen, die vor der Gemeiuschaft mit den übrigen am indifferentesten erscheinen, am stärksten hervor. Daher offenbart sich auch in der grossen Kette des tellurisch kosmischen Processes der Magnetismus vorzugsweise, aber, wie bekannt, keinesweges ausschliesslich, nur in den sogenannten magnetischen Metallen, die, wie das Wasser in der Reihe der Flüssigkeiten durch seine chemische Zersetzbarkeit, so in der Metallreihe durch ihre hohe magnetische Erregbarkeit, den Indifferenzpunkt vermöge einer den Einwirkungen der Totalität nach allen Seiten hin auf das gleichmässigste begegnenden Reaclion 
behaupten. Dieser gemeine longitudinal-polare $\mathrm{Ma}^{\mathrm{a}}$ gnetismus ist so wie derjenige, welcher sich in den vom Schliessungsdrathe der elektromagnetischen Kette angezogenen Eisenfeilspänen regt, nur als eine partielle Differentialerregung zu betrachten, die allein durch den Connex mit einer grossen, umfassenden Erregung des ganzen Planetensystems getragen und erhalten wird, von welcher letzteren wir das Vorhandenseyn, auch wenn jene gemeinen Longitudinalmagnete gar nicht existirten, durch die gegenseitigen magnetischen Wirkungen von verschiedenen Ketten auf einander, oder von verschiedenen beweglichen Theilen einer und derselben Kette, nach der Analogie schon sehr entschieden würden anerkennen müssen. $\mathrm{Ob}$ der Erdmagnetismus selbst nur wieder eine solche partielle Differentialerregung der grossen, weitumfassenden, ganze Sonnensysteme durchdringenden magnetischen Erregung sey, oder ob die magnetischen Pole der Erde nur scheinbar seyen und die wahre Form ihres Magnetismus an und für sich schon eine eigentliche Circularpolarität bilde, wird vielleicht nicht mehr so lange unentschieden bleiben; aber es ist mehr als wahrscheinlich, dass beständige, unter dem Typus zweigliedriger galvanischer Ketten erfolgende Thätigkeiten zwischen den Gliedern des Planetensystems und einem sie alle gemeinsam umfangenden aetherischen Fluidum Statt finden und dass alle periodisch regelmässigen und regellosen Variationen der Meteorologie und des Erdmagnetismus, so lange dieser Beziehungspunkt keine Berücksichtigung. wird gefunden haben, fortwährend Räthsel und unauflösliche Probleme bleiben werden.

Magnetismus setzt also jedes Mal eine geschlossene 
galvanische Kette roraus; aber da die letztere eigentlich immer nur in einem unvollkommenen, niemals|in einem absoluten Grade der Vollkommenheit geschlossen ist, so ist sie jedes $\mathrm{Mal}$ auch mit einer permanenten elektrischen Erregung verbunden und es ist also überall, wo Magnetismus auftritt, auch Elektricität vorhanden, die aber im Experimente wenigstens für die Wahrnehmung gänzlich Null seyn kann. Umgekehrt ist mit jeder elektrischen Erregung auch eine geschlossene Kette, sey der Grad der Vollkommenheit der Schliessung auch noch so gering, bedingt, folglich auch Chemismus oder wenigstens die erhöhte Tendenz dazu im geschlossenen Kreise der Kette, das ist Magnetismus, damit verbunden, der aber ebenfalls hinter jeder Gränze der Wahrnehmbarkeit zurückgezogen seyn kann. Magnetismus und Elektrismus sind also, streng genommen, in der Wirklichkeit immer coexistirend, auch in allen den Fällen, in welchen nur einer von beiden in der Erscheinung entschieden ausgesprochen ist; der andere liegt alsdann nur ausserhalb der Schranken unserer Wahrnehmung. In einer absolut geschlossenen Kette würde nur Magnetismus ohne Elektricität und in einer absolut ungeschlossenen Kette nur Elektricität ohne Magnetismus herrschen; aber Schliessung und Oeffnung der Kette sind nur relativ, niemals absolut getrennt und dasselbe gilt daher auch von jenen beiden, den Chemismus der Kette begleitenden, Polarextremen desselben.

Das Wort Elektromagnetismus bezeichnet sehr zweckmässig eine solche magnetische Erregung, in welcher dieser Zusammenhang zwischen der Llektricität und dem Magnetismus durch die Erfahrung ausser Zweifel gesetzt ist, dadurch dass der letztere, nicht so 
fern er nur den vorzugsweise so genannten magnetischen Metallen in der Form der Longitudinalpolarität angehört, sondern überall, in welchen Substanzen es auch sey, unter Umständen, die zugleich elektrische Erregung bedingen, in der Form der Circularpolarität in die Erscheinung tritt. Dieses ist der wahre, von der ersten Einführung des Worles an bezweckte Sinn desselben, in welchem allein wir desselben, so oft es in der gegenwärtigen Schrift vorkommt, uns auch ausschliesslich nur bedient haben. Wo aber das Wort in der Bedeutung eines empirischen Einerleiseyns der Elektricität und des Magnetismus gebraucht wird, da herrscht nicht mehr der wahre Sprachgebrauch, sondern nur Missbrauch der Sprache und eine gegen den Sinn der letzteren wie gegen den der Naturerscheinungen auf gleiche Weise verstossende WiHkühr der Ansicht.

In den durch gemeine Elektricität eingeleiteten Ketten findet im Moment der entschiedensten Schliessung, wie die magnetische Erregung des Eisens zeigt, Magnetismus Statt; aber der Augenblick der Entladung ist zu kurz, um an einer Magnetnadel das Moment der Trägheit zu überwinden und sie abzulenken. Auch in einer längere Zeit hindurch unterhaltenen elektrischen Entladung, wie sie z. B. in derleitenden Verbindung zwischen Conductor und Reibzeug einer thätigen Elektrisirmaschine, oder in einer durch Spitzen oder Halbleiter bewirkten Schliessung einer elektrischen Batterie Statt findet, scheint der Mangel an hinlänglich geschwinder, continuirlicher, inteusiv kräftiger Erregung die wahre Ursache der ausbleibenden Abweichung der Magnetnadel unter dem Leitungsdrathe zu seyn; vielleicht gelingt sie aber noch unter angemessenen, noch zu versuchenden Vorkehrungen. 
Dass die Thätigkeit jeder natürlichen galvanischen Kette, also jeder chemische Process, jede mit oder ohne Flamme erfolgende Verbrennung u. s. w. von magnetischer Erregung begleitet sey, muss nach unsern Ansichten schon darum als nothwendig erscheinen, weil jede einzelne der unzähligen Partialketten, deren Ge-sammtthätigkeit den ganzen Process bildet, gleich jeder zweigliedrigen, mit zwei Focalstellen zusammenhängenden galvanischen Kette, nicht ohne Magnetismus gedacht werden kann. Warum aber dieser Magnetismus, selbst bei einer verhältnissmässig sehr hohen Intensität, nicht nothwendig wahrnehmbar seyn dürfe, das ist schon oben S. $275 \mathrm{ff}$. bei der besondern Betrachtung der natürlichen zweigliedrigen Kette bestimmt entwickelt worden und bedarf daher hier keiner besondern Auseinandersetzung mehr.

Nach der obigen, auf die drei Grundmomente der galvanischen Thätigkeit bezogenen, Durchführung unsers Princips, welches in der Action der künstlichen und vornehmlich der zweigliedrigen Kette zugleich den Typus der Thätigkeit der natürlichen Kette und des chemischen Processes überhaupt nachzuweisen trachtet, wollen wir dasselbe zugleich noch nach einigen andern sehr wesentlichen Richt.ungen weiter zu verfolgen suchen.

Wenn es gewiss ist, dass in der geschlossenen galvanischen Kette kein Glied als ein absolutes, sondern nur als ein immanentes Organ des ganzen Kreises und nur in Folge seiner Relation gegen jedes der übrigen Glieder wirksam zu seyn vermag, so ist also auch in einem jeden chemischen Processe die qualitative und quantitative Thätigkeit der in ihm wirksamen Glieder schlechthin gegenseitig und nur die Folge oder vielmehr 
die thätige Offenbarung ihrer wechselseitigen Relationen. Tritt statt irgend eines Gliedes der geschlossenen galvanischen Kette ein anderes, an quantitativer Thätigkeit ihm gleiches, aber qualitativ, und folglich auch in seiner Relation zu den übrigen Gliedern von ihm verschiedenes Glied in den geschlossenen Kreis ein, so ist auch die Intensität und der Grad der inneru Befriedigung des Processes in einem der veränderten Relation entsprechenden Maasse verändert und so oft dieser Grad, ungeachtet jener veränderten qualitativen Relation des Gliedes zu den übrigen, dennoch derselbe bleiben soll, so muss umgekehrt auch die quantitative Wirkung dieses Gliedes der veränderten Relation gemäss geändert werden. Es kann z. B. in einer Kette mit zwei Metallen, deren qualitative Relation unter sich und gegen die Flüssigkeit sehr gering ist, dennoch unter dem gehörigen quantitativen Verhältnisse im Unterschiede der wirkenden Berührungsflächen eine eben so grosse Intensität des Processes entwickelt werden, wie in einer andern, die aus differenteren, aber quantitativ gleichen, das heisst hier, mit gleicher Fläche wirkenden Metallen gebildet ist. Indem nun dasselbe von den Gliedern eines jeden chemischen Processes gelten muss, sofern sie nach quantitativen und qualitativen Bestimmungen zugleich diesen Process als Glieder einer geschlossenen galvanischen Kette bedingen, so ist damit das stöchiometrische Gesetz der chemischen Aequivalente in seiner Nothwendigkeit schon allgemein und auf eine solche Weise nachgewiesen, dass niemand, so weit die Bedeutung des Gegenstandes nur aus diesen ersten Grundlinien der Darstellung hervorgeht, in irgend einem einzelnen Falle das , bestimmte Verhältniss der $\mathrm{Ae}=$ 
quivalente: verschiedener Stoffe aus blossen elenden Würfelspielereien des Atomismus wird herleiten wollen. Die Zahlenwerthe der chemischen Aequivalente sind nichts anderes als die Exponenten der chemischen Relationen selbst, in Bezug auf den Grad der Befriedigung im synthetischen Effect des Chemismus und so gewiss die elektrische Erregung durch den Contact nichts anderes als die Tendenz zum synthetischen Effect des Chemismus ist, so gewiss müssen auch die elektrischen Relationen, wenn sie nicht am Elektrometer und Condensator, sondern aus der Wirkung der zweigliedrigen Kette beobachtet, nach der in dieser Schrift entwickelten Methode und im Geiste ihrer Conception als Exponenten in Reihen von Zahlenwerthen dargestellt werden, in einem festen und bestimmten Verhältnisse zu den Zahlenwerthen in den Reihen der chemischen Aequivalente stehen. In welchem? das ist eine Frage, über die freilich nach dem gegenwärtigen Zustande der Wissenschaft fürs erste noch nicht anders als durch Induction und nur in Folge vielfältiger, noch anzustellender Beobachtungen entschieden werden kann; aber wenn sie ein Mal beantwortet worden, so wird es nur der vollzogenen Bestimmung der elektrischen Relation irgend zweier Stoffe bedürfen, um daraus auch, unter gänzlicher Beseitigung aller anderweitigen empírischen Ermittelungen, die chemischen Aequivalente derselben Stoffe herleiten zu können.

Wenn es ferner gewiss ist, dass der Process einer jeden geschlossenen künstlichen galvanischen Kette mit einer Temperaturveränderung verbunden ist (die bis jetzt nur zufällig bei beträchtlicher hervortretenden Temperaturerhöhungen beobachtet ist, aber unter be- 
stimmten Bedingungen und namentlich bei einfachen zweigliedrigen Ketten auch wohl füglich in einer überwiegenden Erniedrigung der Temperatur bestehen kann, worüber bis jetzt freilich roch die entscheidenden, zur tieferen Begründung der Würmelehre unentbehrlichen Versuche mangeln), so muss auch die Action jeder natürlichen Kette und also überhaupt jeder chemische Erfolg, eben weil er nichts anderes ist, als ein Hergang unter dem 'Typus der Thätigkeit der künstlichen galvanischen Kette, von einer seiner Natur und Intensität entsprechenden Temperaturveränderung begleitet seyn und die Erhöhung oder Erniedrigung der Temperatur, welche während eines chemischen Processes hervortritt, hat schlechthin dieselbe Quelle und Bedeutung, welche der Veränderung in der'Temperatur während der Action einer geschlossenen künstlichen galvanischen Kette zum Grunde liegt. Wir müssen zuvörderst die Aetiologie der Wärmeerscheinungen an der künstlichen galvanischen Kette studiren, wenn wir die Wärme überhaupt unter allen übrigen Bedingungen, die ihre Entstehung, ihre Erhöhung oder Erniedrigung zur Folge haben, begreifen wollen. Von einem solchen Studium, welches in dieser Bestimmtheit des Gesichtspunktes, in dieser entschiedenen Richtung bis jetzt noch nicht da gewesen ist, werden wir, sobald man anfangen wird, es ernstlich zu betreiben, ohne Zweifel in Zukunft Aufschlüsse und tiefere Anschauungen über die innere Natur und über das qualitativ Gesetzmässige der Wärmeerscheinungen erhalten, wie sie uns so lange noch gänzlich gemangelt haben. Aber wie bedeutend auch die Erweiterung unsers Gesichtskreises von dieser Seite ausfallen mag, so werden wir doch auch schon jetzt we- 
nigstens die Grundzüge zu dem Umrisse der Idee der Wärmeerscheinungen überhaupt, unter welchen besondern Bedingungen sie sich übrigens anch zeige im Geiste einer höheren Naturansicht zu entwerfen vermögen.

Es ist auf den ersten flüchtigster Blick schon gewiss, dass die Wärme nicht ein charakteristisches Moment in der Action der galvanischen Kette sey, deren Kreis vielmehr in der Trias des Elektrismus, Chemismus und Magnetismus vollständig geschlossen ist, sondern die Wärme gehört einer grösseren, ungleich weiter verbreiteten Sphäre der Naturthätigkeit, die his zur höchsten Stufe thierischer Organisation hinaufreicht. Aber wo sie sich auch zeigen mag, von der galvanischen Kette an, im chemischen Process bis zum vollendetsten heseelten Individuum hinauf, überall ist sie eben an die Existenz eines Individuums, an einen selbstständig, organisch in sich abgeschlossenen Kreis

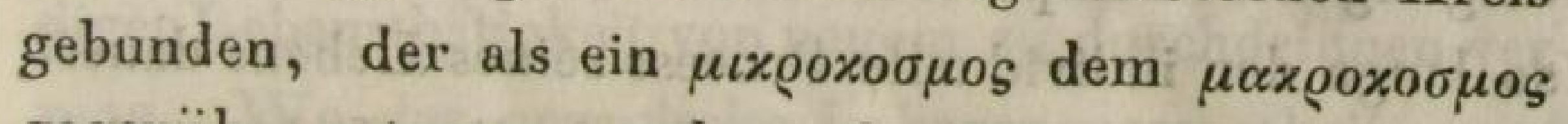
gegenüber getreten, und wie der Magnetismus im galvanischen Kreise die universelle Offenbarung des Conflicts zwischen der gemeinsam angeregten Tendenz und der ursprünglichen Reaction der einzelnen Glieder der individuellen Kette ist, so ist unverkennbar wieder die hervortretende Wärme und die eigenthümlicheTemperatur jedes einzelnen Individuums, sey dieses eine künstliche oder natürliche galvanische Kette, sey es irgend ein individuelles Glied aus irgend einem niedern oder höheren Reiche der Organisation, - nichts als der offenbarte Conflict zwischen der individuellen und der universellen, allen übrigen Individuen, wie dem ganzen Kreise des kosmischen Naturlebens gemeinsamen 
Thätigkeit. Was sich für sich zu einer mehr oder minder selbstständigen Sphäre des Daseyns zu schliessen und in sich zurück zu ziehen trachtet, tritt eben damit zugleich in einen unausweichlichen Kampf gegen die Ansprüche, welche die Totalität von Aussen her an das Individuum macht und mit denen sie, sey es unter dem relativen Uebergewicht der Reaction auf der Seite des Individuums oder der Totalität, jenes stets wieder seiner eigenthümlichen Sphäre zu entreissen und in den allgemeinen Ahgrund des universellen, unterschiedlosen Seyns zurück zu ziehen trachtet. Aber gerade dieser Widerstreit steigert die Functionen des Individuums, dass es mit erhöhter, eigenthümlich gespannter Thätigkeit, die sich als Wärme und Expansion offenbart, dem allgemeinen Feinde siegend entgegensteht und der eigenen erhöhten Temperatur und Expansion gegenüber in der Totalität rings herum Erniedrigung der Temperatur und Contraction hervorruft, so lange der individuelle Process seines Lebens dauert. Da wo die Intensität dieses individuellen Lebens nicht etwa nuv durch momentane Impulse gesteigert wird und ausserdem nur so eben hinreicht, sich gegen den reagirenden Drang der Totalität zu behaupten, da fällt jene Temperaturerniedrigung und Contraction in seiner unmittelbaren Nähe mit allen berührenden Massenpunkten der äussern Umgebung zusammen; da zeigt sich eben deshalb, aber nur relativ und mehr scheinbar als wirklich, dieses Individuum selbst kalt. Wo hingegen die Fülle der Lebenskraft in sich mächtig genug ist, noch über den unmittelbaren Raum des eigenen körperlichen Daseyns hinaus zu wirken und sich zu behaupten, da können jene Contractionen mit den zu- 
zehörigen Temperaturveränderungen bis auf unbestimmte Gränzen hinaus fallen, da werden alle Purkte der umgehenden Totalität selbst noch mehr oder weniger durch die expandirende Temperaturerhöhung, welche sie erleiden, in das individuelle Leben mit hineingezogen und da erscheint eben deshalb das Individuum selbst und mit ihm in engeren oder weiteren Gränzen seine ganze Umgebung durchgehends erwärmt und expandirt. Ueberall, wo die Wärme hervortritt, da hat sie nur diesen Ursprung und diese Bedeutung; sio ist die zuverlässige Verkündigerinn der gefundenen, wenn auch nur ephemerisch behaupteten Einheit eines individuellen Lebens, sie offenbart die Fülle der Selbstständigkeit, mit welcher das letztere nicht allein gegen die drohende Negation der Totalität reagirt, sondern mit der es nicht selten zugleich, indem es dieses thut, abermals neue Kreise organisch geschlossener Functionen sich selbst gegenüber anzuregen und zu selbstständiger Luebensthätigkeit von neuem zu durchdringen vermag. Wo der organische Lebensprocess theils noch ungesichert, theils, wenn auch von tieferen Wurzeln getragen, doch nur so eben gegen Andrang der allgemeinen Thätigkeit sich siegend zu behaupten vermag, $\mathrm{da}$ ist die individuelle Temperatur, wie in so vielen chemischen Processen, in den Pflanzen und den niedern Thierorganismen, bis in das Innerste des Individuums verhüllt und schon seine unmittelbarste Umgebung zeigt die Reaction der Totalität durchı Kälte oder Indifferenz der Temperatur, die nur durch grosse und gedrängte Massen von Individuen, wie z. B. durch ausgedehnte Waldungen, Heere schwärmender Insekten u. dergl. modificirt zu werden vermag. Auf den höheren und A a 
höchsten Stufen der Organisation wird dagegen in dem gemässigten, sich gleich bleibenden Grade der auch äusserlich in die Umgebung verbreiteten thierischen Wärme die stille, sicher unterhaltene Flamme eines Lebens versichtbart, das mit entschiedenem Uebergewichte den Sieg gegen die Reaction des allgemeinen Lebens errungen hat und denselben mit Klarheit und geregelter, gleichmässiger Kraft fortwährend behauptet. In dem Gebiete der sogenannten leblosen, anorganischen Natur erscheint die Wärme, durch den mehr oder minder mächtigen Drang der Gegenwirkung auf der Seite der Totalität und nach Maassgabe des Umfangs und der Intensität des angeregten und begonnenen Processes, bald in niedrigeren bald in höheren Graden; aber immer nur in dem organisch geschlossenen Kreise der galvanischen Kette, oder was dasselbe ist, im chemischen Processe. Niemals hat die Erscheinung der Wärme einen andern Ursprung und eine andere $\mathrm{Be}$ deutung, als in der sich offenbarenden Tendenz der Behauptung einer eigenthümlichen, gegen die allgemeine Naturthätigkeit tretenden individuellen Selbstständigkeit, sey es auch in den ersten, embryonischen Anfängen des sich gestaltenden Organismus, wo gerade durch momentane Impulse und bei dem Mangel an sicherę, geregelter Haltung die Temperatur in schnell vorübergehenden Erfolgen, wie z. B. im Verbrennungsprocesse, bis zu den höchsten Graden verzehrender Glut gereizt und gesteigert zu werden vermag. — So ist also einerseits durch das eigenthümliche Wesen der Wärme der chemische Process als ein organisch in sich geschlossener charakterisirt, während andererseits die Möglichkeit eines tieferen Verständuisses der Wärme 
zugleich wiedcrum daraus hervorgehen wird, dass der chemische Process, von dem durch unsere Untersuchung gewonnenen Standpunkte aus, als ein dem Process der galvanischen Kette identischer, nach gleichem Typus mit ilım vollzogener Erfolg erfasst und in $\mathrm{Be}$ trachtung gezogen wird $\star$ ).

Höchst umfassende Aufschlüsse aber sowohl über die Wärme wie über eine grosse $\mathrm{Zahl}$ anderer dem $\mathbf{G e -}$ biete der Physik, Chemie und Physiologie angehörender Erscheinungen haben wir zugleich von dem fortgesetzten Studium der grossen, durch Herrn Dr. S e e b e ck gemachten, Entdeckung des Thermomagnetismus zu erwarten. Unter allen ausgezeichneten Thatsachen, durch deren Auffindung die Naturwissenschaft in den neuern Zeiten bereichert worden ist, giebt es unsers Erachtens keine, die an Wichtigkeil und fruchtbarer Consequenz bedeutender und umfassender genannt zu werden verdiente, als diese. Der Thermomagnetismus hat uns ein Gebiet aufgeschlossen, von dem der Uebergang auf die Erscheinungen des Elektromagnetismus, wenn die letzteren nicht zufällig früher entdeckt waren, leicht

*) Steffens hat die Bedeutung der Wärme schon vor zwanzig Jahren mit einer Bestimmtheit ausgesprochen, welche die Tiefe und Sicherheit seiner innern Naturanschaung auf eine um so bewunderungswürdigere Weise darlegt, je mehr es zu der Zeit noch an den bestimmten Thatsachen fehlte, welche die Speculation gegenwärtig zu unterstützen vermögen. Er sagt in seinen Grundzügen der philosoph. Naturwissenschaft, S. 64. ausdrücklich: , ,B ei ein em jeden chemischen Processe entsteht nothwendig Temperaturveränderung, weil während der chemischen Action die differenten Körpereinen eige. nen, individuellen Kreis bilden, der durcheine eigenthümliche Temperatur bezeichnetwird."

$$
\text { A a } 2
$$


und gleichsam von selbst eröffnet worden wäre. Der entgegengesetzte Weg vom Elektromagnetismus zum Thermomagnetismus war dagegen keinesweges so indirect gefunden, während er zugleich, nachdem er ein Mal glücklich eingeschlagen worden, die Aussicht auf alle bereits durch die Entdeckung des Elektromagnetismus hervorgehobenen Punkte auf eine höchst wichtige und lehrreiche Weise erweitert und vervollständigt. Herr Dr. S e eb e ck wurde, wie wir gleich im Anfange seiner reichen Abhandlung (über die magnetische Polarisation der Metalle und Erze durch Temperaturdifferenz) erfahren, auf die Entdeckung besonders mit durch die Betrachtung geführt, nach welcher ihm, seinen eigenen Worten gemüss, aus mehreren Thatsachen es hervorzugehen schien, dass nicht sowohl die Action an dem Berührungspunkte der Metalle miteinander, als vielmehr die Ungleichheit der Actionen an den beiden Berührungspunkten der Metalle mit dem feuchten Leiter die magnetische Polarisation der ganzen geschlossenen Kette begründe. Und dies ist, wie man sieht, im Wesentlichen schon die Präsumtion eben derselben Thesis, die wir oben (S. $7^{8}$. unter N. 1.) bereits als ein Hauptresultat unserer eigenen Untersuchungen und als einen fest begründeten, integrirenden Fundamentalsatz unserer Theorie des Processes der galvanischen Kette ausgesprochen haben. Auf der andern Seite aber wird in unserer Theorie, unsern bisherigen Darlegungen gemäss, der vor der Schliessung der Kette in der Contactelektricität der. Metalle versichtbarte Effect zwar als ein untergeordnetes, die ursprüngliche Richtung des Processes zu dem erhöhten Grade der Thätigkeit bloss reizendes und steigerndes, aber eben damit doch keines- 
weges als ein nur zufälliges und entbehrliches, isondern vielmehr gleichfalls als ein wesentliches und zur $\mathbf{G e -}$ sammtaction der geschlossenen Kette schlechthin erforderliches Moment betrachtet. Denn wenn es einerseits ein durchaus beschränkter und höchst befangener Standpunkt ist, von dem aus lediglich die Contactelektricität der Metalle zum Princip der Thätigkeit der Kette gemacht wird, so würde es andererseits nicht minder mangelhaft und unzulässig seyn, weun man in der elektromagnetischen Kette nur die chemische Relation «wischen der Flüssigkeit und den Metallen und eben so in der thermomagnetischen Kette nur die Einwirkung der Wärme auf die Masse der Metalle als ausschliessliches Causalitätsprincip für die Gesammtaction während der Schliessung der Kette, ohne Berücksichtigung des sehr wesentlichen Antheils, den der mit der Contactelektricität der Metalle an und für sich zusammenhängende Effect daran hat und nothwendiger Weise daran haben muss, anerkennen wollte. Nur muss dieser Effect im Geiste unserer ganzen Ansicht als eine in der geschlossenen Kette zu grösserer Entwickelung gesteigerte und ausgebildete chemische Tendenz, nicht aberals eine und dieselbe vor und während der Schliessung der Kette unverändert bleibende, völlig leere und problematische Elektricitüt aufgefasst werden; denn wo dieses geschieht, da gehört freilich auch die Gedankenleerheit des gemeinen hypothetischen Gesichtskreises dazu, um allen lautsprechender Thatsachen, mit deren Kunde uns die neueste Zeit bereichert hat, gleichsam zum Trotz, die Erscheinungen an der geschlossenen galvanischen Kette noch fortwährend als eine circulirende Elektricität und diejenigen der thermomagnetischen eben so als eine 
solche durch die Wärme, gleichviel wie, woher und auf welche Weise im Kreise umher getriebene Elektricitüt zu stempeln.

elio Die Erscheinungen des Thermomagnetismus stehen, wie diese Ueberzeugung schon seit längerer Zeit ausgesprochen ist, mit unsern bisherigen in dieser Schrift

- entwickelten Ansichten über den Galvanismus überhaupt in vollkommenem Einklange. Allerdings, wie überall die wahre Aufgabe der Wissenschaft keine leichte ist, wie sie überall nur daranf hingewiesen ist, die Räthsel der Erscheinungen in der Wahrheit, nicht im Dunst der Hypothesen, aufzulösen und in den scheinbaren Verwirrungen das Gesetz und die Einheit dergestalt nachzuweisen, dass darin selbst die Nothwendigkeit jenes trügerischen Scheins auf eine bestimmte Weise erkannt wird, - allerdings ist es für den höheren und eigentlichen Standpunkt der Wissenschaft, auf dem die Thatsachen, so lange sie für sich gesondert da stehen, von gar keiner, und nur so fern sie auf ein gemeinsames Gesetz bezogen werden, von wahrhafter Bedeutung sind, eine die höchste Aufmerksamkeit in Anspruch nehmende Forderung, die Consequenz unserer Grundansicht in allen Classen der thermomagnetischen Erscheinungen zu bewähren; aber bis jetzt finden wir in dem ganzen von uns sorgfältig in Kenntniss -gezogenem Inbegriff dieser Erscheinungen nichts einzelnes, das unserer Theorie, die bereits vollstündig ausgebildet und deren Darlegung in der gegenwärtigen Schrift dem grössten Theil nach bereits abgedruckt war, ehe wir die genauere Bekauntschaft mit dem in der Seebeckschen Abhandlung enthaltenen Detail der Thatsachen zu machen Gelegenheit fanden, auf eine 
directe Weise widerspräche; das Ganze fügt sich im Gegentheil mit der Mehrzahl seiner Erscheinungen sehr harmonisch denselben Bestimmungen, die wir als wesentliche Gesichtspunkte für das Verstïndniss der [galvanischen Thätigkeit überhaupt kennen gelernt haben und bildet so zugleich, wenn uns noch ein Zweifel gegen die Richligkeit und Angemessenheit unserer Ansichten hätte übrig bleiben können, eine höchst genügende Bestätigung derselben.

Es kann natürlich nicht unsere Absicht seyn, diese Congruenz auf allen bis jetzt. bekannten Punkten der Phänomenologie des Thermomagnetismus am gegenwärtigen Orte umständlich zu demonstriren. Eine solche Nachweisung würde, ansserdem, dass sie von unserer Seite zur vollständigen Darlegung unserer Argumentation noch vielfältige experimentale Gegenuntersuchungen erheischte, deren Anstellung wir uns bis dahin noch auf keine Weise haben unterziehen können“ ein eigenes, die ganze gegenwärtige Schrift vielleicht noch an Volumen übertreffendes Buch bilden. Aber eine gewissenhafte Rechenschaft über jenen Zusammenhang der Grunderscheinungen des Thermomagnetismus mit den bisher für das Verständniss der elektromagnetischen und galvanischen Phänomene überhaupt von uns als wesentlich hervorgehobenen Gesichtspunkten wird dafür hier vollkommen an ihrer rechten Stelle seyn.

Die gewöhnliche einfache thermomagnetische Kette, wie wir ihre Darstellung dem tiefen und glücklichen Blicke des Herrn Seebeck zu verdanken haben, ist eine künstliche zweigliedrige Kette aus zwei differenten Metallen zusammengesetzt (auch in dem Falle, wenn 
ein und eben dasselbe Metall in verschiedenen Zustän den, z.B. im flüssigen und festen Zustande, gleich zwei ursprünglich differenten Gliedern die Kette bildet), und ihre Untersuchung ist daher in dem gegenwärtigen $\mathrm{Ab}$ schnitte für uns um so mehr an der Ordnung, da wir darin bereits künstliche zweigliedrige Ketten, die theils aus zwei differenten Flüssigkeiten, theils aus einer Füssigkeit und einem Metalle bestehen, in Betrachtung: gezogen haben. Allerdings können auch diese letzteren Ketten Erscheinungen zeigen, welche durch Temperaturdifferenz an beiden Berührungspunkten bedingt sind; aber dies wird immer nur zum Theil der Fall seyn, weil głeichzeilig mit diesen auch die von uns schon untersuchten, von jener Temperaturdifferenz unabhängigen, Wirkungen derselben Statt finden, Nach jenen beiden früher in Retrachtung gezogenen Combinationen ist nun die zweigliedrige, aus zwei differenten Metallen gebildete, Kette die nuch übrige und mit gleichem Rechte, wie jene, der näheren Prüfung sich darbietende Verbindung; aber alle jene Umstände, unter welchen bei den beiden ersten Kategorien eine galvanische Thätigkeit imerhalb des geschlossenen Kreises der künstlichen Kette erfolgte, erzeugen hier durchaus keine, wenigstens keine von unserer Wahrnehmung erreichbare Wirkung,

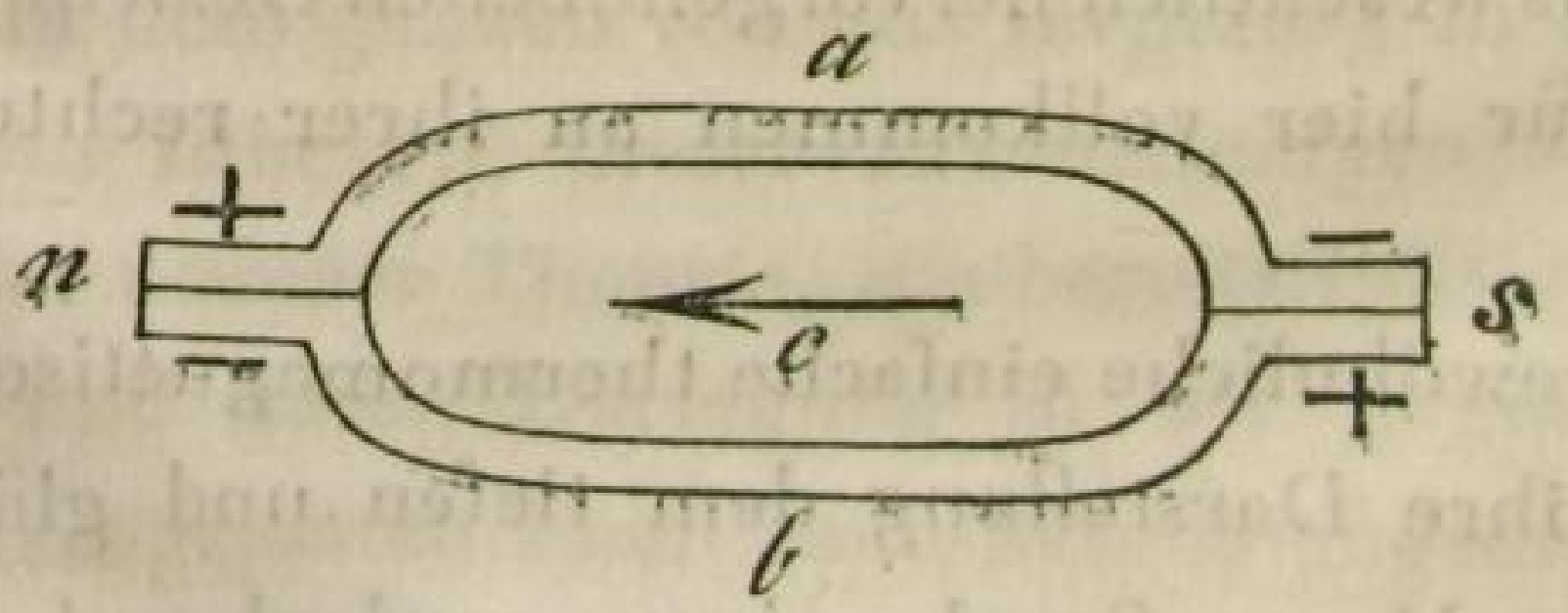

Wenn die Bogen $a$ und $b$ entweder zwei differente Flüssigkeiten sind, oder wenn der eine von ihnen ein Metall, der andere eine Flüsssigkeit ist, und beide sich 
an zwei Stellen, einer südlichen $s$ und einer nördlichen $n$, berühren, wodurch zunächst in $s$ der eine $a$ negativ, der andere $b$ positiv erregt werde, so hängt es, wie wir wissen, von dem Zustande der Erregung im zweiten Berührungspunkte $n \mathrm{ab}$, ob die Thätigkeit einer geschlossenen galvanischen Kette und mit ihr magnetische Erregung Statt finde oder nicht. Wird nämlich $a$ auch in $n$ ebenfalls und eben so stark negativ wie in $s$, desgleichen $b$ in $n$ wie in $s$ gleich stark positiv erregt, so findet durchaus keine Action Statt, es bleibt allein bei der überall gleichen elektrischen Spannung und die Kette ist nur der Form, nicht dem Wesen nach geschlossen. Wird hingegen in $n$ der Bogen $a$ positiv und $b$ negativ erregt, wie es in der Zeichnung angedeutet worden, danu ist, wie schwach auch vor der Schliessung auf dem einen oder andern Extrem diese Erregungen einzeln in der Form einer leisen, kaum wahrnehmbaren elektrischen Spannung versichtbart seyn mochten, durch ihre Wechselwirkung eine zu wirklichem Chemismus, oder wenigstens zu einer ungleich lebendigeren Tendenz desselben, gesteigerte Thätigkeit beider in der geschlossenen Kette vorhanden; die Oxydationsthätigkeit, oder wenigstens die erhöhte Tendenz zur Oxydation herrscht alsdann im Kreise unter einer die Axe der Kette beinahe rechtwinklig durchschneidenden diagonalen Neigung in der Richtung $s a n b$, die Desoxydationsthätigkeit eben so in der entgegengesetzten Richtung sbna und eine innerhalb des Kreises durch den Erdmagnetismus vorher orientirte Magnetnadel $c$ wird nach $\mathrm{O}$ sten abgelenkt.

Wenn aber auch der Bogen $a$ in $n$ eben so wie in $s$ negativ, und $b$ gleichfalls in $n$ wie in $s$ positiv erregt 
wird, doch so, dass die Intensitäl der Erregung bei beiden Bogen in dem einen Berührungspunkte, z. B. in $n$, schwächer als am andern Berührungspunkte $s$ ist; dann ist damit ebenfalls, wie wir oben gesehen haben, dieselbe Thätigkeit der geschlossenen Kette, nach demselben Typus, wie er eben vorher angegeben worden, bedingt. Von den beiden Focalstellen $s$ und $n$ bildet alsdann $s$ den Sitz der eigentlichen progressiven Thäligkeit, während $n$ nur durch Opposition jene ursprünglich von $s$ ausgehende Action um so lebhafter steigert, aber dabei zugleich durch das in $s$ wirksame Uebergewicht so beherrscht wird, dass, im Gegensatz der Thätigkeiten in $s$, der Bogen $a$ in $n$ entschieden posiliv, $b$ in $n$ entschieden negativ wirksam ist und dass folglich, wie gesagt, die polaren Richtungen des ganzen Processes und die Ablenkung der Nadel innerhalb des Kreises der Kette vollkommen eben so ausfällt, wie vorhin unter der Voraussetzung, nach welcher gleich von Anfang an ursprünglich die Erregung in $n$ derjenigen in $s$ entgegengesetzt angenommen wurde.

Wir wissen es, dass in der Regel nur auf diese Weise, bloss durch eine ursprüngliche, wenn auch noch so kleine Differenz der Erregung auf heiden Seiten, keinesweges durch eine wirkliche ursprüngliche entgegengesetzte Erregung, die Thätigkeit der künstlichen zweigliedrigen Ketten, die aus zwei Flüssigkeiten oder einem Metalle und einer Flüssigkeit gebildet sind, erzeugt werde und zwar ist dazu, weil die Erregung in der geschlossenen Kette zu einer so beträchtlichen Intensität erhöht wird, schon der geringste Unterschied der Errégung vollkommen hinreichend, der in der isolirten Beobachtung am empfindlichsten Elektrometer 
um so weniger mehr wahrnehmbar ist, da überhaupt Unterschiede der elektrischen Erregung schon beträchtlich seyn müssen, wenn sie nur durch kleine Vergrösserungen in der Divergenz unserer immer nur sehr unvollkommenen Elektrometer erkannt werden sollen. An zwei Stücken eines und desselben Metalls, deren Oberfläche qualitativ so wenig unterschieden seyn kann, dass die feinste Beobachtung die schwache im Contact bewirkte elektrische Erregung schlechterdings nicht mehr zu unterscheiden vermag, ist dennoch diese leise Differenz schon hinreichend, wenn beide Metalle auf der einen Seite unter sich, auf der andern mit einer Flüssigkeit in Contact treten und so mit dieser zur Kette geschlossen werden, eine durch die Einwirkung auf die Magnetnadel sehr vernehmliche Action zu bedingen. Ausser solchen zufälligen, qualitativen Verschiedenheiten der in Berührung gesetzten Extreme waren es, wie wir wissen, noch besonders theils dio Ungleichheit der Grösse der Berührungsflächen auf beiden Seiten, theils die Priorität der Berührung auf der einen Seite, welche schon auf beiden Extremen eine solche Differenz der polaren Erregung zu bewirken vermochten, in Folge deren die Bedingungen zu einer längere oder kürzere Zeit anhaltenden Action der Kette, nach unsern oben umständlich darüber dargelegten Ansichten, vollkommen gegeben waren.

Sind nun aber $a$ und $b$ zwei Bogen von verschiedenen Metallen, z. B. wenn a ein Bogen von Kupfer, $b$ von Zink ist, die sich zuvörderst in $s$ berühren, so dass $a$ negativ, $b$ positiv erregt wird, so ist, wenigstens innerhalb der bisherigen für diesen Fall schon ziemlich ausgedehnten Grünzen unserer Erfahrung;, weder eine 
qualitative Verschiedenheit der Oberflächen beider $\mathrm{Me}$ talle an den Extremen in n, die sonst bei der Dazwischenkunft einer Flüssigkeit schon Action bedingen würde, noch die Ungleichheit der Berührungsflächen an beiden Extremen in $s$ und $n$, noch der spätere Contact in $n$ vermögend, eine galvanische Thütigkeit auch nur in der Form der leisesten wahrnehmbaren magnetischen Erregung in den auf beiden Seiten in Berührung ge1retenen Metallen zu veranlassen. Die Metalle, ihrem Charakter getreu, die in einem Punkte der Masse empfangene Erregung auch alsbald gleichmässig durch die ganze Masse zu verbreiten, versichtbaren, wie überall, so hier besonders deutlich, dieselbe Unaufgeschlossenheit gegen die den Flüssigkeiten eigenthümliche polare Erregung, und nachdem die Berührung auch an dem zweiten Extrem in $n$ erfolgt ist, so ist unter allen oben genannten Umständen, so lange nur keine Temperaturdifferenz auf beiden Extremen Statt findet, der in $s$ negative Kupferbogen $a$ auch in $n$ eben so stark negativ und der in $s$ positive Zinkbogen $b$ auch in $n$ eben so stark positiv erregt. Es bedürfte zu einem wirklichen Effect der geschlossenen Kette, entweder in $s$ oder $n$ allein, nur der allermindesten Schwächung oder Verstürkung der schon bestehenden Erregung; aber alle jene Umstände, die sonst in zweigliedrigen Ketten, deren Glieder nicht beide zugleich Metalle sind, diese Wirkung herbeiführen, sind hier ohne Erfolg. Nur der belebende Hauch der Wärme, der die Materie zum organischen, selbstständigen L.eben erweckt, durchdringt auch hier die starre Gleichförmigkeit der metallischen Masse und ruft mit unwiderstehlicher Gewalt uf der Seite seiner Wirksamkeit eine Differenz der 
Erregung hervor, vermöge deren 'jedes Glied der Kette für den polaren Gegensatz lebendig aufgeschlossen und die ganze Kette dem gemäss in die durch den Magnetismus derselben offenbarte Thätigkeit versetzt wird.

Um uns, so weit es hier noch dem Raum und den übrigen Umständen nach angeht, eine möglichst deutliche Einsicht über die Art und Weise dieses Herganges zu verschaffen, müssen wir uns vor allem insbesondere das Folgende zuvörderst vergegenwürtigen. Wenn zwei Metalle bei der gewöhnlichen Temperatur oder innerhalb gewisser, durch die individuelle Natur der Metalle bestimmter, 'Temperaturgränzen durch gegenseitigen Contact sich erregen, so ist die Erregung jedes einzelnen von ihnen nicht progressiv, sondern regressiv; sie ist jedes Mal nur die Folge gegenseitiger Reaction. Wenn z.B., wie wir fortwährend annehmen, der eine metallische Bogen $a$ aus Kupfer, der andere $b$ aus Zink besteht, so ist $a$ das minder oxydable und ursprünglich positive, $b$ das oxydablere, zum Fortschritte in der Metamorphose, das heisst zur Oxydation in höherem Grade und dem gemäss ursprünglich negativ erregle Metall; indem aber durch den Contact ein retrogrades Streben zurEinheit der Masse in beiden erwacht, vermöge dessen jedes einzelne Metall das andere aus der universellen Richtung in die entgegengesetzte individuelle hineinzieht, so wird das ursprünglich positive $a$ negativ und das ursprünglich negative $b$ positiv. So wie ferner jede Flüssigkeit, nicht mehr so wie das Metall an eine einseitige Erregung vorzugsweise gebunden, sondern im Contact mit einem Metalle dasselbe vielmehr im progressiven Effect ursprünglich zu oxydiren und es dem gemäss zuvörderst negativ zu er- 
regen trachtet, obgleich dieser Effect, wie wir wissen, nicht überall zu Stande kommt, sondern vermöge der Reaction gewisser Metalle gegen gewisse Flüssigkeiten gerade durch den entgegengesetzten Erfolg verdrängt wird, so ist auch die belebende Wirkung der Wärme, gleichartig mit derjenigen der Flüssigkeit, ursprünglich immer darauf hingerichtet, den Gegenstand der Einwirkung von der Seite der finsteren regulinischen Stabilität und Indifferenz hinweg nach der entgegengesetzten Richtung in den lebendigen Fortschritt zum Licht, in die allgemeine Metamorphose des Lebens hineinzuziehen, ihn folglich, wenn sein Standpunkt noch so tief jenseit der untersten Stufen der chemischen Umbildung liegt, zu oxydiren und daher vor allem negativ zu erregen. Das bestätigt die längst bekannte Erfahrung, dass von zwei Stücken eines und desselben Metalls das erwärmtere gegen das minder erwärmte stets negatiy ist, wenn anders ein für die Wahrnelimung hinlänglicher Temperaturunterschied zwischen beiden Statt findet und so hat Herr Dr. See beck, wie wir aus einer vorläufigen Mittheilung in einer Anmerkung zu seiner oben angeführten Schrift ersehen, aus einer beträchtlichen Zahl von Versuchen das umfassende Factum constatirt gefunden, dass in der Regel jedes Metall, bis zu einem bestimmten Grade erhitzt, gegen irgend ein kaltes im Contact. mit ihm negativ, letzteres hingegen positiv erregt wird. Obgleich, wie aus allen früheren Punkten unserer Betrachtungen hinlänglich bekannt und geläufig seyn muss, von der einseitigen, bloss im einfachen Contact zweier heterogener Substanzen erfolgenden, Erregung nicht so gerade hin auf den $\mathrm{Zu}$ stand der Erregung der Substanzen un den beiden Fo- 
calstellen in der gegenseitigen, die Erfolge mannichfach modificirenden, Wirkung der Kette geschlossen werden darf, so sprechen die obigen Thatsachen werigstens entschieden so viel ans, als ohen behauptet worden ist, dass nämlich da, wo in einer Substanz, namentlich in einer metallischen, eine relative Erwärmung Statt finde, auch eine relative Richtung zum Oxydationseffect in ihr erregt werde, der zufolge das ursprïnglich positive jedes Mal minder positiv oder entschieden negativ, und das ursprünglich negative noch negativer werden müsste, wenn hier gleichfalls, so wie bei der Einwirkung der Flüssigkeiten auf Metalle, nicht noch Reactionserfolge möglich wären, die zum Theil wenigstens entgegengesetzte Tendenzen geltend zu machen vermöchten.

Wir haben, ehe uns über das Detail der thermomagnetischen Phänomene etwas Bestimmteres bekannt geworden war, nach den Ergebnissen von Versuchen, die nicht auf trüglichen elektrometrischen Beohachtungen beruhten, sondern unserer in der gegenwärtigen Schrift entwickelten Methode gemäss unternommen waren, die Thesis aufgestellt, dass die ganze Metallreihe in zwei Hälften zerfalle, von denen die Glieder der einen, welche wir die überwiegend reagirende Seite nennen können, eben einer solchen Reaction zufolge, gegen alle Flüssigkeiten in der Regel positiv auftreten, während die Glieder der andern Hälfte, die wir die überwiegend progressive S eite der Metallreihe nennen wollen, dem wahren und ursprünglichen Verhältnisse gemäss, allen Flüssigkeiten gegenüber in der Regel negativ erregt werden (S. oben S. 29. und S. $9^{5}$ ff.). Auf der überwiegend reagirenden Seite finden wir nun in der Gegend des einen äussern Extrems 
das Silber, in der Gegend des andern innern Extrerns dagegen den Wismuth; auf der überwiegend progressiven Seite der Metallreihe steht auf dem äussern Extrem wieder der Zink und in der Nähe des andern innern Extrems das Antimonium, und es ist schon sehr merkwürdig und durchaus nichts Zufälliges, dass die eben als Glieder der innern Extreme bezeichneten Metalle, Wismuth und Antimon, in der S e ebeckschen Reihe auf den äussern Extremen stehen, während die auf den äussersten Extremen stehenden Glieder, Silber und Zink, in der Seebeckschen Reihe mitten inne liegen.

Es wäre zu wünschen, dass uns neben der Seeb e c ks chen thermomagnetischen Reihe auch die genau nach dem Verhalten in der galvanischen Kette bestimmte elektrische Reihe derselbigen metallischen Individuen, auf deren Verhalten sich jene Reihe bezieht, zur Vergleichung vorläge. Wir sagen, die elektrische Reihe derselben metallischen Individuen, denn wir können uns durch so vielfältige frühere Erfahrungen und namentlich auch durch die Resultate in der Seebeckschen Reihe zu der Behauptung vollkommen berechtigt halten, dass nicht nur nicht die empirische, durch Gleichnamigkeit bezeichnete Einerleiheit, sondern dass auch selbot nicht ein Mal die angebliche, mit aller Sorgfalt und Geschicklichkeit dargestellte chemische Reinheit gleichnamiger Metallstücke als solche nothwendiger Weise ein gleiches Verhalten, eine gleiche Stelle derselben in der elektrischen oder in der thermomagnetischen Reihe bedinge. Man prüfe gleichnamige, mit allem Fleisse im höchsten Grade der Reinheit dargestellte Metallstücke, die verschiedenen Ur- 
sprungs sind, ebenfalls mit der höchsten Genapigkeit, und sie werden nicht selten an ganz verschiedenen Stel $\mathrm{T}$ len in einer Reihe anderer mit ihnen in Beziehung auf ihr elektrisches oder thermomagnetisches Verhalten zugleich geprüfter Metalle, begreiflich in Folge individueller Indifferenzen und Beimischungen, über, welcho alle chemische Technik nichts mehr vermag, zu stehen kommen. Wir müssen daher um so mebr, da es, wie gleich anfangs bemerkt, worden, nicht unsere Absicht seyn karn, hier schon alle Einzelheiten derErscheinungen in Vergleichung zu ziehen, uns nur auf eine summarische Rechenschaft von den Phänomenen des Thermomagnetismus beschränken, und wir richten dem gemäss unsere Aufmerksamkeit besonders auf jenen Hauptumstand, dass die Metalle auf den Extremen der elektrischen Spannungsreihe zu innern Gliedern, und die $\mathrm{Me}-$ talle auf den innern Extremen der reagirenden und progressiven Seite der Metallreihe zu äussern Gliedern der thermomagnetischen Reihe werden.

In den Metallen, welche Glieder der überwiegend reagirenden Seite bilden, offenbart sich dieser Charakter der Reaction, den sie im Conflict mit den Flüssigkeiten zeigen, auch in Beziehung auf die Wärme, Wenn ein solches Metall, von dieser reagirenden Seite, wie unser Kupferbogen $a$, mit einem Metalle von der andern progressiven Seite, wie mit unserm Zinkbogen $b$, an den Zwei verschiedenen Stellen $s$ und $n$ sich im Contact befindet, dass also das ursprünglich positive $a$ in $s$ wie in $n$ negativ, und das ursprünglich negative $\boldsymbol{b}$ in beiden Berührungspunkten gleich stark positiv erregt ist, und es tritt nun in dem südlichen Berührungspunkte $s$ eine Tenperaturerhöhung ein, so wird dadurch zunächst $b$ B b 
in $s$ an und fir sich unbedingt noch negativer, seine Tendenzz zur Oxydation wird hier noch grösser, als sie an und fur sich bereits ist, und es fragt sich nur, ob es jetzt auch in der Wechselwirkung mit $a$, eben deshalb, weil es schon wegen seiner ursprüuglichen Negativität. im Contact mit a positiv ist, wegen dieses neuen, durch đie Wärme gewormenen, Zuwachses an Negativität, noch unim so positiver gegen $a$ hervortreten, oder ob es nicht vielleicht im Gegentheil wieder minder positiv als vorher gegen dasselbe sich verhalten werde. Dass wenigstens in deu meisten Füllen eins von beiden Statt finden müsse, ist. gevwiss ; die Entscheidung hängt dabei theils von der absoluten Natur jedes einzelnen Metalles, theils von ilirer wechselseitigen Einwirkung auf einander ab; aber eben wegen dieses complicirten Durcheinandergreifens der Beziehungen kann der Effect in verschiedenen Fitlen, bei verschiedenen Metallen bald so, bald anders ausfallen, und mannichfaltige, mit scheinbaren Anomalien verknüpfte, Gestaltung gewinnen, so dass es fürs erste wohl noch eine Zeit lang schwer bleiben wird, bevor hinlängliche anderweitige Fundamentaluntersuchumgen nach den erforderlichen Richtungen hin za diesem Behufe angestellt sind, die Erfolge überall mit Sicherheit zu construiren.

Man begreift indess im Allgemeinen schon'sehv wohl, so weit wir den Gegenstand bis jetzt nur ins Auge gefasst haben, dass nach Verschiedenheit der Bedingungen durch die'Temperaturerhöhung in dem einen Beruihrungspunkte, hier in $s$, sehr leicht Erhöhung, oder Erniedrigung des frühern Erregungsgegensatzes der beiden Metalle, mit grösserer oder geringerer Intensität, in s erfolgen könne, womit dann, wie wir ein 
für allemal wissen, die Bedingungen zu einer durch magnetische Polarisation nach dieser oder jener Richtung stärker oder schwächer ausgesprochenén Thätigkeit der geschlossenen Kette, die jedoeh etwas ganz anderes ist, als der überall und nirgends rinnende courant électrique, wesentlich verknüpft sind. Es ist auch denkbar, dass sich in speciellen Fällen unter einem Zusammentreffeu besonders geeigneter Uinstände die sämmtlichen in einander verschlungénen Wirkungen und Gegenwirkungen wechselseitig so ergänzen und binden können, dass der anfärigliche Gegensatz im Contact auch nach der Temperaturerhöliung in gieicher Stärke wie vor derselben bleibt und mithin auch gar keine Action und magnetische Polarität Statt findet, wie wir, wenn dieses gleich, so weit unsere bestimmten Erfahrungen reichen, bei den simplen Metallen in den bisher angewandten Graden der Temperaturdiffereniz beider Berïhrungspunkte mirgends vorkommt, doch bereits deri umfassenden Forschungen des Herrin Seebeck die entschiedene Hinweisung auf Metallgemische zu verdanken haben, deren thermomagnetische Action in Verbindung mit bestimmten Metallen geradelin Null seyn muss.

Wenn in dem obigen Falle das 7 , weil es an und für sich durch die Erhöhung der Temperatur negativer geworden, gegen $a$ eben darum noch positiver wird, so kann dieses nicht beträchtlich seyn, weil seine universelle Tendenz zur Oxydation schon so stark ist, dass ein noch weiter getriebener Regress in der individuellen Thätigkeit gegen $a$ schon sehr beschränkt und gehemmt seyn muss. Wenn aber $b$ gegen $\boldsymbol{a}$ noch etwas mehr positiv wird, so muss $a$ auch gegen $b$ noch eben so viel

$\mathrm{B}$ b 2 


\section{8}

mehr negativ werden; aber $a$ wird nun zugleich durch die Erwärmung seinerseits ursprünglich ebenfalls mehr negativ oder minder positiv, folglich wird es eben daher in seinem individuellen Verhalten gegen $b$ anch wieder um so mehr positiv hervortreten, und es'ist eben daher klar, dass, wenn der durch die Würme gewonnene Zawachs an Negativität bei $b$ eben so gross wie bei $a$ wäre, dass alsdann eir jedes der beiden $\mathrm{Me}$ talle einerseits eben so viel mehr positiv als negativ werden, dass' also der Gegensatz zwischen beiden so wie vorher bleiben und gar keine Action erfolgen würde. Aber der durch die Wärme gewonnene Zuwachs an Negativität ist bei $a$, in Folge seiner oben erwälnten Reaction, in jedem Falle geringer als bei $b$, folglich wird das letzte Resultat dahin ausfallen, dass durch die Temperaturerhöhung in $s$ der Zink $b$ noch etwas mehr positiv und das Kupfer $a$ eben so noch etwas mehr negativ als vorher, also derselbe schon in der Contactelektricität vor der Temperaturveränderung iausgesprochene Gegensatz der Thätigkeit auf der Seite $\delta$ des würmern Berührungspunktes, noch etwas erhöht wird, wiewohl wegen der schon bis zu den Extremen der constanten Metallität ausgedehnten Steigerung des ursprünglichen Gegensatzes nur in einem sehr geringen Grade.

Mit diesem Uebergewichte der Erregung in $s$ ist nun auf die ein für allemal von uns erfasste Weise die Action der Kette entschieden. $a$, welches in $n$ ebenfalls negativi zulseyn strebt, wird durch jenes Uebergewicht gezwungen, sich dort positiv zu verhalten, und durch seine Opposition wird die negative Erregung in $s$, sa wie dadurch wieder diese positive in $n$ auf das leben- 
digste gesteigert. Eben so wird $\boldsymbol{b}$, wälirend seine positive Erregung in $s$ gesteigert ist, un so entschiedener in $n$ negativ wirksam, und Tendenz und Richtung der Thätigkeit sind von derselben Art, als wenn am Berührüngspunkte $n$ zwischen $a$ und $b$ irgend ein Leiter zweiter Klasse eingeschoben wäre, das heisst die Magnet-

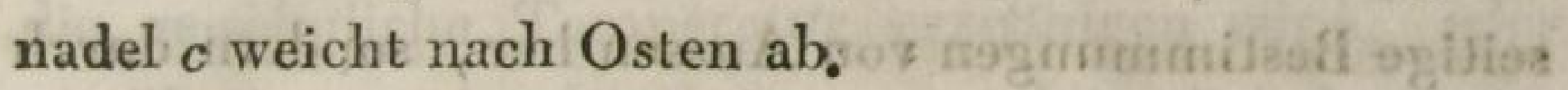

Gegen diese bis jetzt entwickelte Ansicht des Herganges möchten vornehmlich etwa zwei Argumente voin einigem Gewicht geltend gemacht werden, die jedoch bei unbefangener Prüfung in der That auf keine Weise geeignet scheinen, einen reellen $\mathrm{Z}_{w}$ weifel gegen die $\mathrm{Au}$ gemessenheit unserer Betrachtungsweise des Gegenstandes zurück zu lassen. Es könnte nämlich zuvörderst gesagt werden, dass die mit der erhöhten Temperatur verstärkte Erregung im gégenseitigen Contact der beiden Metalle am Berïhrungspunkte s, wodurch wir vornelhmlich die Action motivirt machten, auch als solche am Elektrometer wahrnehmbar seyn müsse. Aber dagegen ist die schon oben S. 378 ff. gemachte Bemerkung zu wiederholen, dass die Verstärkung der Erregung so gering seyn könne, dass sie keine entschiedene Ver-grösserung in der Divergenz des Elektrometers hervokzubringen vermöge, während sie vellkommen hinreicht, einen beträchtlichen Effekt in der geschlossenen galvanischen Kette zu erzengen. - Bedeutender könnte der zweite Einwurf scheinen, wenn man anfiihren möehte, dass die thermomagnetische Wirkung der beiden $\mathrm{Me}$ talle, die von uns als eine Folge der Verstärkung der ursprüngliehen Erregung auf dem erwärmtten Extrem angesehen wird, auch dann noch dieselbe bleibe, wenn das positive Metall, wie oben der Zink, für sich vorher 
bereits so stark erhitzt worđen, dass es gegen das andere Metall entschieden negativ, dieses dagegen positiv werden müsse. Dagegen ist indess sehr bestimmt zu erinnern, dass man keinen Augenblick übersehen dürfe, dass die Action der geschlossenen Kette, so wie die einer jeden andern galvanischen Kette, nicht durch einseitige Bestimmungen von Aussen her, sondern durch das wechselseitige, in sich abgeschlossene Durcheinandergreifen aller Funktionen von àllen Punkten aus bedingt sey, so dass von einseitigen, nur auf einen Berührungspunkt bezogenen Erregungseffecten ausserhalb der Kette nicht auch einseitige Schlüsse auf das Bedingende ihrer zunächst von zwei Berührungspunkten und sehr mannichfaltigen Conflicten ausgehenden Thätigkeit im geschlossenen Zustande gemacht werden mögen. Wenn der erhitzte Zink $b$ dem Kupfer $a$ in $s$ wie in $n$ bereits gleichmässig negativ entgegen tritt, dass mithin $\boldsymbol{a}$ in beiden Berührungspunkten gleich stark positiv erregt wird, so findet keine Temperaturdifferenz und keine Thätigkeit der Kette, also keine Ablenkung der Nadel Statt. Wird nun aber in $s$ eine noch höhere Temperatur als in $n$ bewirkt, so ist es ganz in der Ordnung, dass durch diese Temperaturdifferenz beider Berührungspunkte an dem heisseren $s$ das $b$, aus denselben Gründen, nach welchen es ausserdem mehr positiv wird, jetzt minder negativ und eben so $a$ minder positiv wird. Dadurch würde jetzt also ein Uebergewicht der Erregung in $n$ eintreten, dort würde $b$ entschieden negativ, $a$ entschieden positiv bleiben, während auf der Seite der blossen Opposition, vermöge der schwächern Erregung in $s$, das $b$ positir und $a$ negativ thätig seyn müsste, womit nur die Relativitüt der Focalstellen ge- 
ändert seyn, die Thätigkeitsrichtungen und die Ablenkung der Nadel aber noch völlig so wie, sonst ausfallen würde. $\mathrm{Ob}$ aber, wenn diese mit negativer Erregung verbundene Erhitzung des sonst positiven Metalls nur an einer Seite $s$ bewerkstelligt wird, während auf der andern Seite irgend wie durch künslliche Mittel die gewöhnliche Temperatur erzwungen wird, oder ob überhaupt durch sehr grosse, künstlich bewirkte Temperaturdifferenzen an beiden Berülhungspunkten nicht Erfolge, die den gewöhnlichen und bis jetzt grossentheils bekannten in Hinsicht der Thätigkeitsrichtungen gerade entgegengesetzt wären, Statt finden sollten, wie es gerade nach unserer Ansicht sehr wahrscheinlich und erklärbar seyn würde, darüber müssen wir noch erst die Ergebnisse bestimmter, zu diesem Beliufe besonders vorgenommener, Untersuchungen abwarteu. Denn offenbar sind die mannichfach in einander greifenden Wirkungen hier so complicirt, dass man das Ganze der Erscheinungen zwar sehr wohl auf allgemeine Bestimmungsgründe zurüekfuhren, aber über die bestimmte Art des Erfolgs in den meisten einzelnen Füllen für jetzt wenigstens nicht füglich anders als nur durch die Erfahrung Entscheidung zu exhalten vermag.

So wie nun Kupfer und Zink eine thermomagnetische Kelte bilden, auf dieselbe Weise findet die nämliche Action in der Regel zwischen jeden zwei Metallen Statt, von denen das eine, wie das Kupfer, der reagirenden, und das andere, so wie der Zink, der vorzugsweise progressir wirksamen Seite der Metallreile angehört, das heisst : wenn zwei solche, jn einem südlichen und nördlichen Punkte, $s$ und $n$, sich berïhrende Metalle am ersterı Berührungspunkte $s$ erwärmt werden 
und das gewöhnlich so genannte negative Metall $a$, nämlich dasjenige von der reagirenden Seite, so wie in der Figur auf S. 376 das obere ist, während das sogenannte positive $\boldsymbol{b}$, welches der progressiven Seite angehört, unten liegt,'so weicht die Magnetnadel $c$ nach Osten hin $\mathrm{ab}$, indem die in der gewöhnlichen Temperatur bestehende Polarität der gegenseitigen Thätigkeit beider Metalle in $s$ durch die Erwärmung erhöht und eben daher in $n$ zur entgegengesetzten wird. Dabei ist die Wirkung in der Regel um so stärker, je mehr Spielraum derselben, unserer obigen Nachweisung gemäss, durch grössere Entfernung beider Metalle von den äussern Extremen der Metallreihe nach den elektrisch chemischen Relationen verstattet ist; je näher diese Metalle den innern Extremen der beiden Hälften der Metallreihe stehen und beim Wismuth und Antimon, welche diese innern Extreme entweder selbst bilden oder donselben sehr nahe stehen, ist sie am stärksten.

Von diesen Bestimmungen scheinen nach den bisherigen Erfahrungen vorzüglich das Zinn und Blei eine Ausnahme zu machen, indem sie in der Seebeckschen Reihe schon über dem Silber stehen, während man, unserer Regel gemüss, sie noch unterhalb des Zinks, zwischen diesem und dem Eisen zu finden erwartet haben sollte. Aber diese beiden Metalle treten überhaupt auch noch in manchen andern Hinsichten unter bedeutenden Anomalien auf und gehören ohne Zweifel zu den beweglichsten in der elektrischen Spannungsreihe, da die kleinsten Beimischungen und zugleich eine grosse, nicht blos chemische, sondern auch mechanische, Veränderlichkeit des Zustandes ihrer Oberfläche auf 
'ihr Verhalten von besoriders grossem Einflusse zu seyn scheinen.

Wie dem aber auch seyn möge, unsere ganze Darstellung des Ursachlichen in der thermomagnetischen Action wird durch einen solchen Fall auf keine Weise aufgehoben, da sie vielmehr von der Art ist, dass dergleichen scheinbare Anomalien, die ausserdem völlig unverständlich seyn würden, nach ihr sehr wohl möglich und begreiflich erscheinen müssen, Unsere Erklärung fordert ihrer Natur nach keinesweges eine solche durchaus unabänderliche Regel eines festen und schlechthin bestimmten Verhältnisses zwischen der elektrischen und thermomagnetischen Reihe; sie zeigt zuvörderst nur, wie durch die partielle Temperaturerhöhung auch eine partielle Verstärkung oder Schwächung der in der Contactelektricität versichtbarten polaren Thätigkeit der Metalle und mit dieser, unserer ganzen Ansicht von der galvanischen Thätigkeit zufolge, auch die Action der thermomagnetischen Kette erfolgen müsse; während es gleich von Anfang an durch diese Nachweisung selbst bemerklich wird, wie gerade bei den mannichfach sich durchkreuzenden Eigenthümlichkeiten und Gegenwirkungen beider Metalle bald Erhöhung, bald Erniedrigung des ursprünglichen Gegensatzes der Thätigkeit, und so bald diese bald jene Richtung der Thätigkeiten in der geschlossenen Kette durch die parlielle Temperaturerhöhung eintreten könne. Es ist schon genug, und mehr als die gegebene Erklärung bedarf, dass ihr eine Norm des Verhaltens in einer Mehrzahl von Fällen entspreche, and wenn die Ausnahme, welche das Zinn und Blei von jener Regel zu machen scheint, reeil ist, so wird wahrscheinlich 
auch auf der reagirenden Seite der Metallreihe eine kleine Minderzahl von Gliedern gefunden werden, die ihrerseits ebenfalls eine solche Ausnahme machen, ohne dass wir dadurch irgend wie zur Aufgebung unserer Ansicht, wohl aber, was jedoch noch erst nach vielseitigen Untersuchungen möglich ist und dann gewiss auch geleistet werden wird, zur Nachweisung, woher jene Ausnahmen rühren, genöthigt wären.

So wie es nun Regel ist, dass bei zwei Metallen von verschiedenen Seiten der Metallreihe, an dem würmern Berührungspunkte der Gegensatz der Contactelektricität erhöht werde, so ist es Regel, dass bei zwei Metallen von einer und derselben Hälfte der Metallreihe, die also entweder beide der reagirenden, oder beide der progressiven Seite angehören, wie z. B. im ersten Falle Wismuth und Kupfer, im letzlern Antimon und Zirk, — dass bei diesen durch ein auf beiden Seiten Statt findendes Uebergewicht der Reaction in jenem, so wie der progressiven Thätigkeit in diesem Falle, der Gegensatz der in der Contactelektricität ausgesprochenen Thätigkeit am wärmern Berührungspunkte geschwächt und dadurch ein gleiches, aber in Hinsicht der Thätigkeitsrichtungen dem bisherigen entgegengesetztes thermomagnetisches Verhalten bewirkt werde. Wenn z. B. so wie in der Zeichnung auf S. 376 das obere nach der gewöhnlichen Bezeichnung sogenanute negative Metall $a$ Kupfer und das positive $b$ Wismuth ist, oder wenn $a$ Antimon und $b$ Zink ist, so wird durch die höhere Temperatur in $s$ der Gegensatz der Erregung geschwächt, er tritt dagegen am kältern Berührungspunkte $n$ stäker hervor und in $s$ wird damit $a$ entschieden positiv, $b$ negativ, während in $n$ das $a$ ne- 
gativ und $b$ positiv bleibt. Die Thätigkeitsrichtungen sind nun den früheren durch die Zeichen in der Figur angedeuteten gerade entgegengesetzt, sie sind jetzt von $\operatorname{der}$ Art, als wenn man nicht wie sonst bei $n$, sondern bei $s$ zwischen $a$ und $b$ irgend einen Leiter zweiter Classe eingeschaltet hätte und die $\mathrm{Nadel} c$, die sonst nach Osten hin abgelenkt wurde, weicht jetzt nach Westen hin ab. Dabei ist hier die Action in der Regel um so stärker, je näher die beiden Metalle den Extremen derselben Hälfte der Metallreihe stehen, zu welcher sie beide gehören; sie ist um so schwächer, je näher sie in derselben Hälfte nach der Mitte zu liegen.

Dieser und den vorhergehenden Bestimmungen gemäss müssen der thermomagnetischen Thätigkeit der Kette und der elektrischen Spannung der Metalle, aus welchen sie besteht, in Hinsicht der Stärke oder Schwäche, begreiflich bald die gleichen; bald die entgegengesetzten Prädicate zukommen, und wenn man sich die Metalle nach ihrer Folge in der elektrischen Spannungsreihe in einen Kreis geordnet vorstellt, so kann derselbe im Allgemeinen und in der Regel die Folge der Metalle nach ihrer thermomagnetischen Wirksamkeit nur darstellen, wenn man, statt der äussern Extreme der elektrischen Spannungsreihe, die beiden innern Extreme der reagirenden und progressiv thätigen Hälfte zu Anfangs - und Endgliedern der thermomagnetischen Metallreihe macht. Wenn z. B. die nachstehenden Metalle:

Silber, Kupfer, Kobalt, Wismuth, Antimon, Arsenik, Ag. Cu. Co. Bi. Sb. As. Eisen, Zink,

Fe. Zn. 


\section{6}

so wie sie hier stehen, zugleich von der Linken zur Rechten, wach der Contactelektricität, vom negativen zum positiven Extrem hin aufgeführt sind, und in einen Kreis nach der folgenden Figur geordnet werden, so stellen die Nummern an der äussern Seite der Peripherie des Kreises die Folge derselben Metalle in der elektrischen und die inwerhalb der Peripherio stehender Nummern ihre Ordnung in der thermomagnetischen Reihe dar:

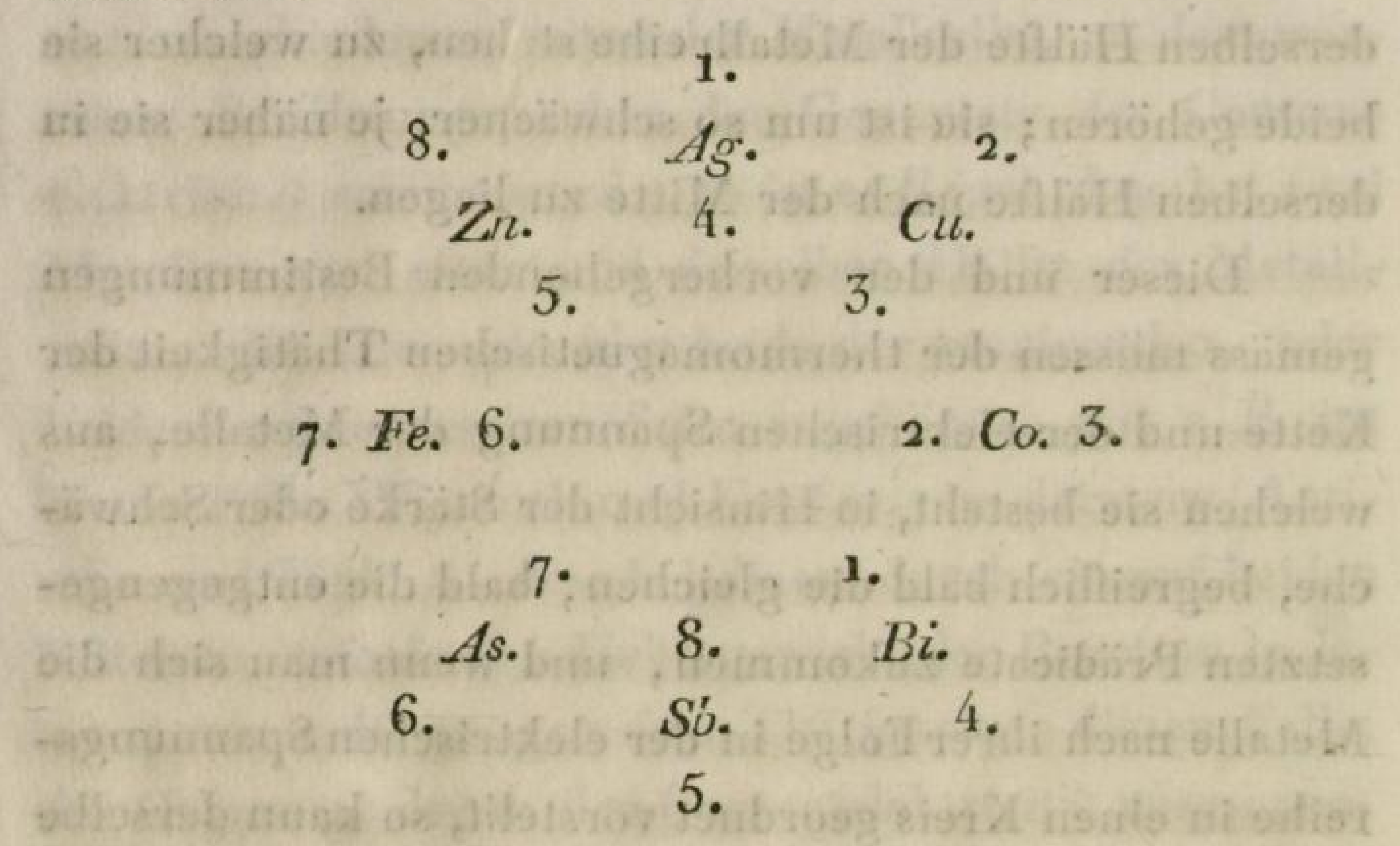

so dass in der letzteren Beziehung jedes vorhergehende Metall an der Stelle von $a$ in der obigen Zeichnung, in Verbindung mit irgend einem nachfolgenden an der Stelle von $b$, die Nadel $c$, durch eine Erhöhung der Temperatur im südlichen Berührungspunkte $s$, nach Osten hin ablenkt.

Aber wir müssen nochmals ausdrücklich bemerken, dass unsere Erklärung der Phänomene an und für sich besteht, ohne einer solchen Uebereinstimmung der Fortschreitung in der elektrischen und thermomagnetischen Metallreihe zu bedürfen. Die elektrische Reihe ist der Grundbedeutung nach die Reihe der chemischen 
Relationen dér Métalle und 'diese Relationen sind iwieder Funktionen von der ganzen Mannichfaltigkeit dev Cohäsionsformen, deren relative Maxima únd/Minima in verschiedenen Gliederń desselben Kreises liegen und die bald näch dieser, bald näch entgegengesetzter Richtunig fortschreiten und dürcheinandergreifen, so dass sie von viereinzelten Gesichtspunkten aus betrachtet, in Beziehung auf jede einźelne Cohäsionsform, die allemal nür eine Function aller fubrigen seyn kann, däuter fortschreitungen ohne scheinbare Regel unid Consequenz hilden müsseir. Daher kann auch die thermomagnetische Reihe weder mit der elektrischen, noch mit irgend einer andern Reihe, in welcher die Metalle nach irgend einer einzelnen Cohäsionsform geordnet sind, überein-f stimmen, oder in einer einfachen, schlechthin ohne Aus-nähme gültigen, festen Bezieliung stehen, obgleich wir die angegebene Combination im Grossën, mit Bezug auf die innern Extremé den beiden grossen géschiedenen Hälften der Metallreihe, für wesentlich und für eine unauslässliche Fundamentalbestimmung zux Würdigung der Phänomene anérkeunen zu müssen glauben,

Wir müssen uns auf die hier gegebenen Andeutungen über den Thermomagnetismus beschränken, da eines Theils der Raum nicht melir fernere Auseinandersetzung gestattet, theils der Gegenstand zu einer speciellern Construction noch bei weitem nicht die exforderliche Reife hat und sie wahrscheinlich auch noch längere Zeit lindurch micht, erhalten wird, [wenn, nicht mehrere Forscher in demselben Geiste und unter einem planmässigen Einverständnisse auf demselben Felde thätig sind. Wir dürfen indess, so viel Aufschlüsse auch noch aus fortgesetzten Untersuchungen za erwar- 
ten sind, durch welche auch unsere Ansicht noch mehr oder weniger modificirt zu werden vermöchte, bei der innigen Verbindung und Zusammenstimmung derselben mit den wesentlichsten Grundmomenten unserer unerschütterlich begründeten Theorie des Galvanismus, wenigstens die Ueberzeugung nähren, dass wir auch in diesem Gebiete der galvanischen Erscheinungen ein zuverlässiges und angemessenes Fundament betreten haben, auf dem künftig befriedigende Nachweisungen über die thermomagnetischen Phänomene bis in das specielle Detail der constanten Thatsachen hinein sich werden geben lassen, und durch welche zugleich unsere Befreundung mit der Natur in ihren bedeutungsvollsten Offenbarungen nach mannichfaltigen Richtungen hin erweitert und gedeihlicher gemacht werden wird.

Alle unsere bisherigen Betrachtungen über die Action der künstlichen und natürlichen galvanischen Kette haben uns die Natur, die gesetzliche Art und Weise der Entstehung, Anregung und Unterhaltung des Processes derselben kennen gelehrt, ohne dass ,wir bis jetzt noch auf das Produkt dieses Prncesses, wo ein solches zu Stande kommt und auf sein Verhältniss zur fortschreitenden Thätigkeit der Kette ganz bestimmte Rücksicht genommen haben. Wir haben die Bedingungen, unter welchen die Action erregt und in Gang gesetzt wird, auch als bleibende Bedingungen des Fortganges und Bestehens der Thäligkeit betrachtet, indem wir die sich erregenden, in wechselseitige Berührung getretenen Flächen der Glieder der Kette während der Dauer der Action als heständig differente und sich unaufhörlich in allen folgenden Momenten so wie in den frühern Momenten der Thätigkeit fortwährend 
erregende gesetzt, wenigstens auf ihre im Fortgange des Processes erfolgende Veränderung keine Rücksicht genommen haben. Da wo aber nicht allein die lebendig erhöhte Tendenz zum Chemismus, sondern der Chemismus selbst in der Kette Statt findet und als soleher das neutrale synthetische Product seiner Thätigkeit erzeugt, welches sich gerade an den Stellen des Contacts der differenten Flächen bildet und diese mehr oder weniger von einander zu sondern und somit auch die gegenseitige Erregung und die Bedingung zur ferneren Thätigkeit zu hemmen oder wenigstens zu modificiren vermag, ist zugleich die Berücksichtigung dieses Products und seines Einflusses auf den Fortgang der Action für die bestimmte Erkenntniss der 'Thätigkeit der Kette und des Chemismus überhaupt ron besonderer Wichtigkeit, und indem wir diesen Momente jetzt noch eine besondere aufmerksame Betrachtung $\mathrm{zu}$ widmen haben, kommen wir auf die bereits oben, S. $275 \mathrm{ff}$, angeregte Frage, über die bestimmte Art und Weise, nach welcher der eingeleitete Process der Kette, und zwar vornehmlich der der natürlichen, während der Bildung des neutralen chemischen Products unablässig bis zu seinem Ende fortschreitet, wieder zurück eine Frage, deren Beantwortung uns zugleich in das Gebiet der Krystallisationserscheinungen hineinführen, und damit, so wie die Krystallisation als die letzte Frucht des reinen Chemismus zu betrachten ist, auch den Schlussstein dieser dargelegten Theorie des Processes der galvanischen Kette bilden soll.

Ich sehe mich veranlasst, an die Spitze dieser Entwickelung noch eine bestimmte Beschreibung eines Fundamentalversuchs über die polare Thätigkeit des 
Leiters zweiter Classe in der galvanischen Kette $z \mathbf{u}$ stellen, um die ganze Darlegung, deren Verständniss die Kenntniss dieser Erscheinungen erheischt, so selbstständig als möglich zu machen und um den Zusammenhaug der Betrachtung in der Folge nicht durch eingeschobene Erläuterungen unterbrechen zu dürfen. Ein Theil von der zu diesem Fundamentalversuche gehörigen Phänomenologie ist bereits oben, gleich im Anfange des ersten Abschnittes vorgetragen worden, wo es daher auch nicht unzweckmässig gewesen seyn würde, sogleich schon den Gegenstand in dieser seiner ursprünglichen und charakteristischen Gestalt, unter welcher er sich zuerst dargeboten hat, hervorzuheben. Der Plan dieser Schrift hatte aber beim Entwurfe jenes Theils, welcher den ersten Abschnitt derselben bildete, noch nicht den Umfang, zu welchem er sich erst mit und während ihrer Fortsetzung von selbst erweiterte und jene Mittheilung, weil sie zum Verständnisse des zunächst Folgenden-nich̀t so unumgänglich nöthig war, unterblieb daher dort; sie wird dagegen jetzt, wo dieses Bedürfniss als ein wesentliches eintritt, um so mehr hier an ihrer Stelle seyn.

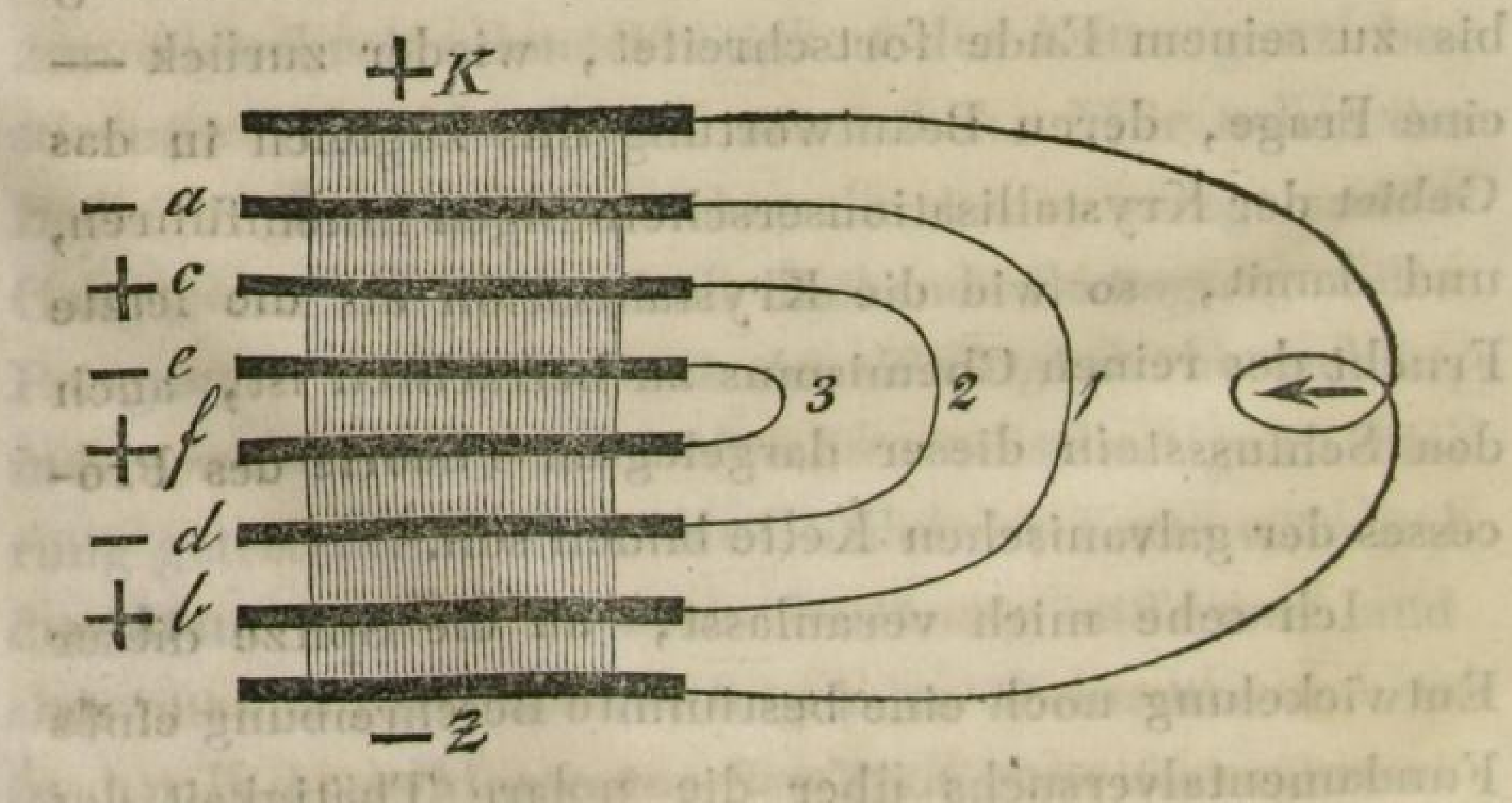


Man bildet eine einfache galvanische Kette, indem man zwischen ein Kupfer - und Zinkblech $k$ und $z$ von ungefähr 6 Zoll im Quadrat mehrere gleich grosse und gleich stark mit der Flüssigkeit (verdünnter Schwefelsäure) durchzogene Pappscheiben, etwa 7 Stück über einander legt. $Z$ wischen die Pappscheiben werden ferner eine entsprechende Zahl von Kupferblechen, bei 7 Scheiben höchstens 6 Bleche, $a, b, c, d, e, f$, von solcher Grösse eingeschaltet, dass sie mit trockenen Rändern überall über die Pappscheiben etwas hervorstehen und so geordnet, dass jedes Kupferblech von jedem benachbarten Bleche wenigstens durch eine feuchte Pappscheibe getrennt ist.

Man verbindet die Kupferbleche paarweise; wie es in der Zeichnung versichtbart ist, durch metallische Schliessungsdräthe; das äussere Paar $\boldsymbol{a}$ und $b$ durch den Drath 1, das 2te Paar $c$ und $d$ durch den Drath 2, das 3te Paar $e$ und $f$ durch den Drath 3 und schliesst das eigentliche Erregerpaar $k$ und $z$ durch den um die Magnetnadel geschlungenen Mutliplicator, so wird die Nadel eine zwar durch die Zwischenplatter geschwächte, aber dennoch völlig entschiedene, normale Ablenkung erleiden. Steht die Bussole, so wie es in der Zeichnung angegeben ist, im Süden der Kette und ist das mit dem Kupfer $k$ verbundene Extrem des Multiplicators über die Nadel von Norden nach Süden geführt, so dass der Drath unter ihr wieder von Süden nach Norden zum Zink $z$ der Kette zurückgeht, so ist die Ablenkung, der Regel gemäss, östlich.

Man kann nun schon nach dem Ganzen unserer bis dahin begründeten Theorie den Erregungszustand der eingeschalteten Kupferbleche, während die Kette so

C c 


\section{2}

geschlossen ist, mit Zuverlâssigkeit im Voraus bestimmen. Die äussere Kupferplatte $k$ ist positiv, die an sie gränzende flüssige Schicht in der Berührungsfläche mit ihr negativ. Auf der entgegengesetzten Seite in der Berührung mit $a$ ist daher eben diese Schicht positiv, und folglich das Blech $a$, nach $k$ hin, negativ. Wäre es nicht durch den Drath 1 mit $b$ zu einem Continuum verbunden, so würde es, so lange die Kette geschlossen ist, auf entgegengesetzten Seiten auch entgegengesetzt erregt und nach $z$ hin positiv seyn. Aber jetzt, da es mit $b$ eine und dieselbe erregte Metallmasse ausmacht, ist. es an und für sich als die eine Seite dieser Masse ganz negativ, und $b$, welches die andere nach $z$ hin gerichtete Seite bildet, ist dagegen durchgehends positiv erregt. Die flüssige Schicht zwischen $z$ und $b$ ist in der Berührung mit dem negativen $z$ positiv und in der Berührung mit dem positiven $b$ negativ, und wie $a$ und $b$ durch die Wirkuig von $k$ aus bestimmt werden, sind sie eben so auch durch die Wirkung von $z$ aus bestimmt, so und nicht anders, jenes negativ, dieses positiv erregt und thätig zu seyn.

Ganz so aber wie vermittelst der Haupterreger $k$ und $z$ eine jede von den zunächst angränzenden Armaturen $a$ und $b$, durch die polare Erregungsthätigkeit der flüssigen Zwischenlagen zu einer dem benachbarten Haupterreger entgegengesetzten Thätigkeit bestimmt wird, so wirken nun auch vermittelst der erregten Armaturen $a$ und $b$ die angränzenden Flüssigkeitsschichten mit polarer Erregungsthätigkeit nach den innern zu weiter fort, so dass wiederum das nächstfolgende Paar der Armaturen $c$ und $d$ dadurch zu einer solchen Erregung und Thätigkeit bestimmt wird, dass die dem ne- 
gativen $a$ benachbarte $c$ wieder positiv und die dem positiven $b$ benachbarte $d$ negativ wird, Und eben so wirken die an $c$ und $d$ gränzenden Flüssigkeitsschichten erregt und erregend weiter fort auf $e$ und $f$, dass jenes abermals zu negativer, dieses zu positiver Thätigkeit erregt und bestimmt wird.

Wenn die Hauptwirkung in $k$ und $z$ lebhaft und stark genug ist, eine hinlängliche Zahl solcher Zwischenketten zu durchdringen, so muss dieser Wechsel der Erregung durch eine angemessene Zahl solcher 'gehörig verbundener Armaturen sich hindurch erstrecken, und das Verhalten der Magnetnadel bestätigt die Realität der Thätigkeit, so wie wir sie eben als nothwendig erkannt haben, auf das befriedigendste. Verbindet man die Haupterreger $k$ und $z$ durch einen einfachen Drath und dagegen die Armaturen $a$ und $b$, nachdem der Verbindungsdrath I fortgenommen worden, durch den Multiplicator, so dass das Ende desselben, welches früher mit $k$ verbunden war, jetzt an $a$, und eben so das andere vorher mit $z$ verbundene jetzt an $b$ gelegt wird, so wird die Nadel, welche vorher durch $k$ und $z$ östlich abgelenkt wurde, jetzt durch $a$ und $b$ westlich'abgelenkt. Verbindet man nun aufs neue $a$ und $b$ durch den Drath 1 , und legt statt des Drathes 2 den Multiplicator in der nämlichen Ordnung der Extreme an $c$ und $d$, so also, dass das eine vorher mit $a$ verbundene Extrem jetzt an $c$, das andere von $b$ jetzt an $d$ gelegt ist, so ist die Ablenkung wieder östlich, und nachdem die Verbindung 2 wieder hergestellt worden, so ist, wenn $e$ und $f$ in der nämlichen Ordnung durch den Multiplicator verbunden worden, die Ablenkung der Nadel abermals der vorhergehenden entgegengesetzt, nämlich

C c 2 
westlich u. s. f. Dieser Wechisel ist, wenn gleich die Ablenkungen rom zweiten Paare der Armaturen an beträchtlich geringer und gegen die Mitte hin sehr schwach werden, dennoch vollkommen entschieden und höchst constant. Bei grossen und kräftig wirkenden Haupterregern kann man ilın wenigstens durch sechs Paare von Armaturen, die durch einzelne feuchte Pappscheiben getrennt sind, auf das bestimmteste verfolgen: Ior Die Kupferplatten in diesem Versuche geben als eben so viele Armaturen des flüssigen Leiters, indem sie durch den Multiplicator verbunden werden, die Art der, Erregung der Flüssigkeit an jeder mit einer einzelnen Armatur in Berührung begriffenen Durchschnittsfläche des flüssigen Leiters auf das bestimmteste zu erkennen, und da man so viel solcher Armaturen als man will, oder die vorhandenen in jeder andern beliebigen Entfernung an jeder Stelle der Flüssigkeit zwischen $k$ und $z$ anbringen kann, so ist durch das Experiment der Erregungszustand der Flüssigkeit deutlich ausgesprochen, so dass diese als aus unzählig viel Differenzialschichten zusammengesetzt angesehen werden kann, die wie die Durchgangslamellen eines Krystalls abwechselnd positive und negative Thätigkeit zu erkennen geben, oder, wodurch man der Natur der Sache in der Vorstellung noch näher tritt, jede einzelne der unzählig vielen Schichten, in die man auf solche Weise die Flüssigkeit zerfallen sieht, kann zugleich positiv und negativ, nur nach entgegengesetzten Richtungen hin, thätig gesetzt werden, nümlich nach $k$ hin negativ, nach $z$ hin positiv, eine Vorstellung, deren Angemessenheit sich unmittelbar noch durch das Experiment auf folgende Weise darthun lässt. 


\section{5}

Man nimmt die sämmtlichen Verbindungsdräthe: 3, 2,3 u. s. f. fort, verbindet die Haupterreger $k$ und $z$ durch einen besondern Drath und sodann etwa die $\mathrm{Ar}$ maturen $a$ und $f$ durch den Multiplicator, so wird sich $a$ negativ, $f$ positiv erregt zeigen. Hebt man darauf diese Verbindung zwischen $a$ und $f$ wieder auf, und verbindet dagegen $b$ und $f$ durch den Multiplicator, so, wird sich $b$ positiv, $f$ hingegen negativ erregt zeigen. Es wird also bei der ersten Verbindung durch die Armatur $f$ eine gegen $z$ hin positive Erregung versichtbart, während bei der zweiten Verbindung die nämliche Armatur $f$ an der nämlichen Stelle der Flüssigkeit nach der entgegengesetzten Richtung, nämlich nach $\boldsymbol{k}$ hin, eine negative Thätigkeit zu erkennen giebt.

Diese abwechselnd positiv und negativ erregten Schichten der Flüssigkeit bilden aber durchaus keine reelle, factische Sonderung der chemischen Factoren, sondern indem sie gleich von vorn herein nur als Differenzialschichten aufgefasst und indem jedes einzelne als negativ und positiv zugleich, nur nach entgegengeselzten Seiten hin, entgegengesezt erregt gedacht worden, eben so wie im Magneten ein und derselbe Punkt nach entgegengesetzten Richtungen nord- und südpolar zugleich gesetzt werden muss, so ist darin nur die Tendenz der Flüssigkeit manifestirt und ergriffen, in solche positive und negative Schichten, das heisst in solche aus ihren differenten chemischen Factoren bestehende Lamellen auf eine reelle und wahrhaft faktische Weise zu zerfallen. In der künstlichen galvanischen Kette wird diese Tendenz immer nur unmittelbar in den Berührungsflächen der Flüssigkeit mit den Metallen und ausserdem dennoch immer nur auf eine einseitige, sehr 
modificirte Weise erfüllt; unter andern Umständen aber, von denen weiter unten die Rede seyn wird, tritt sie auf eine ausserlich verwirklichte und wahrhaft faktische Weise durch die räumliche Masse der Flüssigkeit nach allen Dimensionen hervor, nämlich in der Krystallbildung. Es ist eine zu bestimmt dargebotene und durchaus nicht mehr zu verkennende Ansicht, dass die Blätter jedes einzelnen Durchganges im Krystall eben nur diese und keine andere Bedeutung haben; sie sind die von neuem differenzirten und in unzähligen Schichten abwechselnd wieder aus einander getretenen chemisch polaren Factoren, welche vor dem Auseinandertreten in engern und weitern, von der Flüssigkeit zu einem gemeinsamen indifferenzirten Gegensatze umfassten, Verbindungen gebunden und neutralisirt sind.

Solcher Verbindungen müssen in jeder krystallisirenden Flüssigkeit wenigstens drei enthalten seyn, nämlich das Oxygen und Hydrogen im Wasser, das Oxygen und das Radikal der Säure, z. B. Oxygen und Carbonium, und das Oxygen und Radikal der Base, z. B. Oxygen und Calcium. Indem nun eine jede der einzelnen Verbindungen an und für sich nach deniselben Richtungen wie die übrigen, welche mit ihr zugleich von der Flüssigkeit umfasst werden, in der Tendenz sich zu differenziren, begriffen, aber zugleich noch fortwährend durch jede der übrigen gebunden ist, so müssen alle auf einander, so wie mehrere über einander liegende Magnetnadeln, die nach einer gemeinsamen Richtung im Ganzen sollicitirt, aber zugleich auch mit verschiedener Intensität gegenseitig auf einander wirksam sind, sich wechselseitig mit den gleichnamigen Polen abstossen, und sonach alle zwar ge- 
meinsam, aber doch jede einzeln nach einer besondern, aus der Gesammtwirkung aller resultirenden, unter einem bestimmten Winkel gegen die übrigen gegebenen, Richtung sich zu differenziren und aus einander zu treten streben, und da, wo diese Tendenz in der That realisirt wird, nämlich im Krystall, müssen also immer mehr oder weniger, mindestens drei unter bestimmten Winkeln gegen einander geneigte Durchgänge der Blätter vorhanden seyn, deren jeder allein einer von den in der krystallisirenden Flüssigkeit enthaltenen Verbindungen entspricht und den reell gesonderten, chemisch polaren Gegensatz des basischen Factors dieser Verbindung gegen das Oxygen offenbart. Ein und derselbe Krystall wird hiernach folglich in jedem einzelnen Durchgange stets eine von denen der übrigen Durchgünge völlig verschiedene Base unter einer relativen Präponderanz derselben mit dem Oxygen darbieten; z. B. in einem Dúrchigange etwa abwechselnde Schichten von Hydrogen und Oxygen; in einem zweiten Wechselschichten von Kohle und Oxygen; in einem' dritten eben solche Wechselschichten von Kalk und Oxygen, u. s. f. Es ist längst entschieden, dass das Wesentliche in der Bildung des Krystalls durchaus unabhängig von demjeringen sey, was man allgemein die primitive Form oder den Kern des Krystalls zu nennen pflegt, und dass vielmehr seine wahre Gestalt in nichts Anderem beslehe oder durch nichts Anderes bedingt sey, als eben nur durch die Zaht der Blätterdurchgänge nnd ihre gegenseiligen Neigungswinkel zu einander. Die eben angegebenen Bestimmungen werden daher zunäclist als erste Ausgangspunkte von der Speculation zu beachten seyn, weIche über das Innere und bis da- 


\section{8}

hin noch völlig verborgen Gebliebene der Erscheinungen auf dem Gebiete der Krystallisation weitere Aufschlüsse zu finden bemüht ist; wir werden unten bald mit noch grösserer Entschiedenheit auf denselben Gegenstand wieder zurück kommen, nachdem wir über den wahren Hergang in der Erzeugung des chemischen Produkts durch die galvanische Thätigkeit, in Folge der Betrachtung, zu welcher wir uns jetzt wenden, das Nähere werden kennen gelernt haben.

Unter allen Phänomenen, welche die zusammen= gesetzte galvanische Kette darbietet, ist fast kein einziges geeigneter, die walıre Natur des Chemismus auf eine augenscheinlichere Weise zu offenbaren, als die sogenannten Durchgünge oder Durchführungen chemisch polarer Stoffe nach entgegengesetzten Seiten der Ket.te, wie wenn z. B. Schwefelsüure und Ammonium aus getreunten, mit den Extremen; der Kette verbundenen Gefässen durch communicirende nasse Streifen oder Mittelgefässe, jene vom negativen zum positiven, dieses rom positiven zum negativen $\mathrm{Pol}$ scheinbar, oder, wie man am häufigsten wähnt, wirklich durch einander hindurch geführt werden.

Die gewöhnliche Ansicht will die Reflexionen des gemeinen Bewusstseins, die gar nicht in die Wissenschaft hinein gehören, sondern vielmehr durch die letztere in ihrer Nichtigkeit erkannt werden müssen, beständig auch in der Wissenschaft geltend machen, und sie verkehrt in diesem Bestreben unaufhörlich die Beziehungen und stellt alles auf den Kopf, indem sie, statt die materiellen Differenzen und Bewegungen aus den innern dynamischen Veränderungen der Relationen herzuleiten, umgekehrt immer nur die innern absolut 
lebendigen, geistigen Qualitäten aus gemeinen, empirisch sinnlichen Bestimmungen und örtlichen Bewegungen deduciren und begreiflich machen will. So wird auch in diesem Falle die respective Umwandlung der sauern und alkalischen Flüssigkeit als das Resultat eines eigentlichen gegenseitigen Durchmarsches beider betrachtet, statt dass der Wahrheit nach die scheinbare locale Veränderung nur die Folge der rein innerlichen, dynamisehen Metamorphose ist, welche die beiden Stoffe als immanente Glieder der Kette durch den organischen Process, in welchen sie mit allen übrigen und unter einander in Wechselwirkung getreten sind, einzig und allein in sich selbst erlitten haben.

Wer dieses nicht zugestehen will, der mag sehen, wie er, in der Meinung, die sonstige Unbegreiflichkeit des Herganges durch die Annahme einer örtlichen Bewegung zu heben, der noch viel grösseren Unbegreiflichkeit ausweichen könne, dass die Süure nach dieser Annahme durch ein mit Lackmustinctur gefärbtes Mittelgefäss hindurch zu gehen vermag, ohne bekanntlich factisch in dieser auch nur eine Spur ihrer örtlichen Gegenwart durch die leiseste Rölhung hervorzubringen. Zwwar könnte gesagt werden, dass die Säure bei dem angeblichen Uebergange von einer Seite zur andern, in ihrer Thätigkeit als Säure zugleich so gebunden werde, dass zwischen ihr und der Lackmustinctur keine Reaction Statt finde; aber diese Entgegnung ist im Grunde schon ein Zugeständniss unserer Ansicht. Denn wenn dem Processe der Kette diese bindende Kraft eingeräumt wird, vermöge welcher er die Wirkung der Säure gänzlich aufhebt und vernichtet, so dass sie für das empfindlichste Reagens durchaus 
todt ist, warum soll er nicht auch die lösende Kraft besitzen, welche in den zuvor indifferent gewordenen Stoffen die entgegengesetzlen Relationen hervorzurufen und eine Metamorphose, deren Resultate wir in den organischen Processen der Natur in jedem Augenblicke tausendfältig gewahr werden können, vollständig durchzufuhren vermag. Die Ansicht theilweise anerkennen müssen und doch bei der völlig untergeordneten mechanischen Vorstellungsiveise stehen bleiben, heisst geradehin der höheren Erkenntniss widerstreben oder einen glinzlichen Mangel an Empfänglichkeit für dieselbe darlegen.

Die Flüssigkeiten bleiben in der geschlossenen Kette, so gut wie jedes andere Glied derselben, an einer und derselben Stelle; es findet keine andere örtliche mechanische Bewegung in derselben Statt, als nur eine solche, welche die Folge innerer Thätigkeiten und bereits vollzogener, rein dynamischer Transformationen ist, und wenn in der Sprache der höheren Physik ron einem Kreislaufe der Functionen, von einem Auseinandertrelen der chemischen Factoren u. s. w. die Rede ist, so haben diese Ausdrïcke, só wie alle, welche die Sprache zur Bezeichnuing der innern Anschauungen von sinnlichen Beziehungen zu erborgen genöthigt ist, nur eine schlechthin metaphorische Bedeutung.

Das innerhalb und ausserhalb der Kette auftretende Oxygen und Hydrogen sind nicht zivei vom Wasser absolut verschiedene, durch eine quantitative Dirention oder durch den quantitativen Zutritt irgend eines dritten Substrats erzengte Stoffe, sondern jeder von ihnen ist nichts als das in sich transformirte, nur durch qualitative Relation differenzirte Wasser selbst, 
und das letztere ist wiederum nichts als das Oxygen und Hydrogen selbst, nur unter der Indifferenz der durch jene dargestellten differenten Relationen. Ritter sagt bei der Betrachtung des bekannten v. Hauchschen Versuchs, den die Atomistik lïngst hätte beherzigen können und müssen, wenn sie überall nur ein Herz, oder dieses wenigstens nur auf der rechten Stelle hätte, "die Batterie (und wir setzen hinzu: der chemische Process überhaupt) giebt erst das Verhältniss, in welchem das Wasser aus Hydrogen und Oxygen bestehen soll, oder die Batterie macht diese Bestandtheile erst, oder noch besser: das Wasser be ste ht gar nicht aus Oxygen und Hydrogen und so viel von diesem und so viel von jenem, sondern das Wasser wird zu Oxygen und wird zu Hydrogen, und zu wie viel Oxygen und Hydrogen es werden soll, das kommt von dem Verhältnisse der umbildenden Potenzen selbst zu einander her." (Ritter's phys. chem. Abl. 2r Bd. S. 3 10 ff.) Das zum positiven $\mathrm{Pol}$ der Kette scheinbar hingezogene Oxygen ist nur das unmittelbar in der Nachbarschaft dieses Pols in Oxygen verwandelte ungetheilte Wasser und das zum negativen $\mathrm{Pol}$ scheinbar hingezogene $\mathrm{Hy-}$ drogen ist nichts als das in der unmittelbaren Nachbarschaft dieses Pols als Hydrogen auftretende, in sich schlechthin ungetheilte Wasser selbst.

Eben so aber ist auch das zum negativen $\mathrm{Pol}$ scheinbar übergeführte Alkali nur die in Alkali transformirte Süure und die zum positiven Pol scheinbar hingezogene Säure ist nur das in der unmittelbaren Nachbarschaft dieses Pols ortlich unbewegt gebliebene und allein innerlich zur Säure umgewandelte Alkali. Der ganze Hergang stellt einem Jeden, der Augen hat 
zu sehen; auf örtlich aus einander gehaltenen Stufen den vollständigen Kreislauf der Metamorphose sichtbar vor Augen, welchen in jedem chemischen Processe die Factoren beständig auch da vollführen, wo sie sonst in unmittelbarer Berührung mit einander ihre wechselnden Zustände auf geheimnissvolle Weise gegenseitig verhüllen. Während die Säure noch Säure, das Alkali noch Alkali ist, nimmt mit dem fortschreitenden Processe der geschlossenen Kette die Intensität ihrer gegenseitigen Relationen fortwährend ab. Die Säure in Verbindung mit dem negativen Pol der Batterie wird negativ erregt, indem die Endplatte am negativen Extrem der letztern nach innen zu negativ, nach aussen dagegen positiv ist; das Alkali auf der Seite des positiven Pols wird dagegen in gleicher Art positiv erregt; wo aber Säure und Alkali in mittelbarer oder unmittelbarer Berührung mit einander stehen, da ist die Süure positiv, das Alkali negativ, und von hier aus beginnt dem gemäss die Neutralisation beider, indem Säure und Alkali, unter diesen, ihrer ursprünglichen Wirksamkeit angemesserien, Erregungen sich begegnend, sich gegenseitig indifferenziren, die Säure in absteigender, das Alkali in aufsteigender Richtung. Die Säure wird so weit desoxydirt, das Alkali bis zu dem Punkte hinauf oxydirt, bis beide, auf gleicher Stufe stehend, eine und dieselbe gleichartige Flüssigkeit bilden. Dieses neutrale Product, von beiden Seiten erregt und erregend, nach beiden Seiten hin unter entgegengesetzten Thätigkeiten zurückwirkend, tritt gegen die noch differente Säure, wie vorhin das Alkali selbst, negativ, gegen dieses dagegen, wie vorhin die Säure selbst, positiv auf, und Säure und Alkali werden im Conflict mit diesem neu- 
tralen Produkt, so wie vorhin im Conflict mit sich selbst, im wogenden, durch kleinere und grössere Epochen pulsirenden Fortschritte des Processes der Kette immer weiter bis zu den Extremen hinauf neutralisirt, bis ein Moment der vollständigen Indifferenz eintritt, mit welchem jede einzelne Flüssigkeit ganz und gar in allen Punkten dasselbe ist, was eine neutrale aus der chemischen Synthesis beider gebildete Mischung darstellt.

Aber der fortschreitende Process der Batterie bleibt hierbei nicht stehen, sondern führt von diesem Moment an die Flüssigkeit noch weiter über den neutralen Zustand hinaus zu einer Differenz, die von neuem und zwar nun unter entgegengesetzten Relationen hervortritt. Das neutrale Product, in unmittelbarer Berührung mit dem negativen $\mathrm{Pol}$, fortwährend negativ durch ihn erregt, zur alkalischen 'Thätigkeit bestimmt, wird jetzt in der That dasselhe Alkali, welches vor der Neutralisation am positiven $\mathrm{Pol}$ sich befand, durch schlechthin innere, organische Umbildung, unter einer rein dynamischen Vertauschung der Relationen; und eben so tritt am positiven $\mathrm{Pol}$ die positiv erregte neutrale Flüssigkeit als dieselbe Süure auf, die sich vorher am negativen Pol befand, ohne dass diese Erfolge im Sinne der gemeinen, roh sirnlichen Betrachtungsweise eine unmittelbare gegenseitige Dislocation, einen blossen Quartierwechsel der beiden Flüssigkeiten bildeten, sondern die thätigen umbildenden Erregungen erstrekken sich vielmehr in entgegengesetzten Richtungen von denjenigen, nach welchen ein solcher Marsch Statt finden müsste, von den Extremen bis zur Mitte so lange unablüssig fort, bis mit der wieder hergestellten ur- 
sprünglichen Differenz die Metamorphose vollständig durchgeführt ist.

Vollkommen dasselbe, was hier die künstliche Kette zeigt, geschieht auch in der natürlichen, also in jedem chemischen Processe, bei welchem die Stoffe in unmittelbarer Vereinigung für sich allein die Kette bilden, während sie in der Batterie nur als untergeordnete Glieder im Organismus des Ganzen die diesem angemessene Umbildung auf gesonderten Stellen erleiden; aber der Erfolg und sein Product, wenn bei diesem Processe der natürlichen Kette Zeit und Umstände sich vereinigen, es vollständig darzustellen, sind alsdann auch durch die unmittelbare Einwirkung der Factoren auf einander und ihre selbstständige Thätigkeit auf eine eigenthümliche, bedeutungsvolle Weise modificirt.

Treten irgend zwei Factoren, die ihrer Natur nach an und für sich bereits chemisch auf einander einwirken, mit einander in Berührung, so beginnt der Process der geschlossenen Kette unter dem ein für allemal, von uns erkannten Typus, wie er insbesondere oben an der Figur auf S. 273 , in welcher $a$ ein Alkali oder überhaupt den basischen Factor, und $s$ eine Süure oder überhaupt den aciden Factor bezeichnet, auf symbolische Weise dargestellt worden. Als Repräsentanten der unzähligen Partialketten des Processes sind dort die geschlossenen Kreise $m \sigma n \alpha, r \sigma n \alpha, r \sigma v a$ angedeutet und $m$ und $r$ sind die Focalstellen für die progressive, und $n$ und $v$ dagegen die entsprechenden Focalstellen der reagirenden Thätigkeit dieser, die Gesammtwirksamkeit des chemischen Processes ausmachenden Partialketten. In $m$ und $r$ wird daher das neutrale Product des Processes erzeugt, indem dort das positiv erregte $s$ bis $z \mathbf{u}$ 
dem Grade desoxydirt und das negativ erregte $a$ bis zu dem Grade oxydirt wird, bis beide zu einer und derselben Stufe der homogenen Neutralität geführt sind und auf ihr festgehalten worden. So wie in $m$ und $r$ erzeugen sich mithin in unzähligen Stellen der gemeinsamen Berührungsflüche $g g$ eben so viel gesonderte Quanta neutraler Masse, im Gegensatze eben so unzähliger Quanta differenter Masse auf den reagirenden Focalstellen $n$ und $v$. In der künstlichen Kette, deren Polarität durch die Mehrzahl ihrer Elemente fest und unabänderlich bestimmt ist, schreitet die Action auf die ohen bereits angegebene Weise nach den einmal begonnenen Richtungen unaufhörlich fort, nur unter den nach grössern und kleinern Perioden wechselnden Pulsen in den Maximis und Minimis der progressiven und der reagirenden Thätigkeit des Processes. In der natürlichen Kette hingegen ist der Fortgang des Processes nicht füglich anders als unter einer beständigen Oscillation in dem Wechsel der progressiven und reagirenden Thätigkeit selbst denkbar, da die Action nicht, so wie es in der künstlichen Kette und namentlich in der Batterie geschieht, durch einen zusammengesetzten Organismus geregelt, durch Continuität der Flächenerregung zusammengehalten und nach bestimmten Seiten hin ausschliesslich gerichtet, sondern vielmehr nur durch die Erregung zahlloser discreter Punkte bestimmt und so lodernd oder fluthend bald nach jener, bald nach dieser Seite hin geworfen ist. An den reagirenden Focalstellen $n$ und $v$ ist das negativ erregte $s$ im Drange zur entgegengesetzten positiven, und das positiv erregte $a$ eben so im Drange zur entgegengesetzten negativen Erregung begriffen gewesen und dieser Drang hat ge- 
rade die progressive Thätigkeit in $m$ und $r$ so gefördert, dass dort die Erregung in chemische Thätigkeit übergegangen, deren nächstes Product die neutralen Quanta in $m$ und $r$ sind. Durch diese neutralen Quanta werden aber $s$ und $a$ in $m$ und $r$ von einander getrennt und die anfängliche Intensität der Erregung in $m$ und $r$ wird dadurch geschwächt. Zwar ist auch die ursprüngliche Erregung des $s$ gegen das neutrale Product gleichartig mit der gegen $a$, nämlich positiv und so umgekehrt, die des $a$ gegen eben das Product gleichartig mit der gegen $s$, nämlich negativ; aber der Drang der Erregung in $n$ und $v$ bei der unmittelbaren Berührung der Factoren $s$ und $a$ ist jetzt so viel mächtiger, dass er das Uebergewicht gewinnt und in allen Partialketten der Thätigkeit des Processes eine der anfänglichen gerade entgegengesetzte Richtung giebt. Das $s$, welches in $n$ und $v$ so lange negativ war und nur positiv zu werden strebte, wird dort jetzt in der That positiv, und das $a$, welches so lange in $n$ und $v$ positiv war und nur negativ thätig zu seyn strebte, wird dort eben so jetzt wirklich negativ. Dagegen wird das $s$ in $m$ und $r$, unter dem Drange gegen die neutralen Quanta der Masse positiv hervorzutreten, gezwungen, sich negativ zu verhalten, und eben so wird $a$, unter dem Drange, gegen dieselben Quanta negativ zu seyn, durch das Uebergewicht der Erregung in $n$ und $\boldsymbol{v}$ genöthigt, sich positiv gegen dieselben zu verhalten. Alle Focalstellen, welche'so lange nur der reagirenden Thätigkeit angehörten, 'sind also jetzt in progressiver Thätigkeit begriffen und diejenigen, welche bis dahin progressiv thätig waren, sind jetzt der Sitz der bloss reagirenden Thätigkeit. So wie bis dahin nur in den letzteren das neutrale Product der 
chemische Synthesis in unzähligen discreten Quantis erzeugt wurde, so geschieht es jetzt auch in jenen, bis abermals, aus denselben Gründen wie beim ersten Wechsel, der Erregungsdrang in $m$ und $r$ wieder das Uebergewicht über den Impuls in $n$ und $p$ erlangt und der Process aufs neue die entgegengesetzte ursprüngliche Thätigkeitsrichtung gewinnt, mit. welcher die ursprünglichen neutralen Quanta in $m$ und $r$ einen zweiten Zuwachs erhalten, nach dessen Ausbildung eben so, mit abermaliger Wendung der Richtungen wieder in $n$ und $v$ ein neuer Zuwachs der Neutralisation Statt findet. Und so schreitet unter dem Wechsel dieser Oscillationen der Process bis zum höchsten, durch das quantitative Verhältniss der Factoren und durch den Grad ihrer qualitativen Relation bestimmten, Punkt der Indifferenzirung beider fort, anfänglich in rascherer, später in langsamerer, allmählig mehr und mehr gedehnter, wogender Bewegung. Der Uebergang von einer Schwingung zur entgegengesetzten geschieht durch ein relatives Null und jenseit des letztern wird die nach der einen Richtung erschöpfte, erstorbene Action nach der entgegengesetzten Seite immer wieder zu neuer, frisch auflodernder Thätigkeit angefacht, bis der letzte schwache Puls der Neutralisation geschlagen hat und mit ihm nur noch an unzähligen Punkten der indifferent gewordenen Masse, nümlich an allen mit diesem letzten Pulse zusammengehörigen reagirenden Focalstellen, eine noch leisere Tendenz zu einer abermaligen Differenzirung, in welcher aus dem neutralen Product die differenten Factoren als solche wieder gesondert auf entgegengesetzten Seiten von Neuem hervorzugehen streben, gleich einem im Verborge-

D d 
nen unter der Asche glimmenden Funken, zurückbleibt.

Dieser Indifferenzirungsprocess ist also die sogenannte chemische Auflösung, der synthetische Effect des Chemismus; aber der ganze Erfolg ist durchaus nicht das, was die gewöhnliche Art zu sehen in ihm erkennt, er ist kein körperliches Aufgenommenwerden, kein materielles, äusserliches, gegenseitiges Durchdringen der Stoffe, bei welchem etwa der eine Factor nur in Millionen Partikelchen zerbröckelt, durch den ganzen Raum der Flüssigkeit des andern zerstreut und vertheilt würde, sondern die Durchdringung ist schlechterdings, einzig und allein nur eine innere, und die $\mathrm{Be}-$ deutung des Worts bei der Bezeichnung des chemischen Processes absolut metaphorisch; der Erfolg ist eine lebendige, rein dynamische Metamorphose, welche, so wie bei der Säure und dem Alkali in den einzelnen Gefüssen an den Extremen der galvanischen Säule, in absolut stetiger Continuität fortschreitet, ohne dass auch nur ein Atom des basischen wie des aciden Factors während des ganzen Herganges aus der Stelle bewegt werden dürfte, die es vom ersten Anfange des Processes an einnahm. Beide Theile erleiden in der dynamischen Thätigkeit der Metamorphose die Veränderung lediglich und ausschliesslich in sich selbst allein, beide sinken aus ihren differenten Relationen unaufhörlieh hinab, oder es steigt vielmehr der basische Factor so lange in sich hinauf, der acide Factor dagegen so weit in sich hinab, bis beide sich auf gleicher Stufe begegnen, und auf ihr das durchaus neutrale, in seiner absolut klaren Einheit und Homogeneïtät für den Mechanismus der blinden Atomistik ewig unerreichbare 
und unbegreifliche Product der sogenannten chemischen Synthesis bilden.

Mit diesem Punkte der Neutralisation oder Sättigung ist aber noch keinesweges die Durchbildung der Metamorphosé, welche die Stoffe erleiden, geschlossen, sondern, eben so wie unter den oben betrachteten Umständen an der Säule, nach der Indifferenzirung der Säure und des Alkali, die Metamorphose vollends erst durch die Umwandlung der Säure in Alkali und des Alkali in Säure realisirt wurde, so führt auch der Process der natürlichen galvanischen Kette seine Factoren durch alle Stufen der entgegengesetzten Relationen weiter hindurch, bis vollends der acide Factor zum basischen, der basische zum aciden geworden, und beide wiederum, so wie in der Säule, als völlig neu gebildetes, umgeschaffenes Product des Processes gesondert hervortreten. Aber dieses Product erscheint hier in der natürlichen Kette, während es einerseits die polare Sonderung der Factoren durch eine bis ins Unendliche fortzusetzende Theilbarkeit ausspricht, auf der andern Seite durch die selbstständige, in sich abgeschlossene Wechselthätigkeit der Stoffe in eine höhere Einheit aufgenommen, unter einer unendlich bedeutungsvolleren Gestalt als in der künstlich zusammengesetzten Säule, - es ist der Krystall.

Die Krystallisation ist nicht als das Resultat eines blossen Rückganges im Chemismus zu betrachten, sie hat eine noch höhere Bedeutung; sie ist jedes Mal zugleich die Genesis einer völlig neuen specifisch differenten Masse, und so oft sie unter besonderen Umständen scheinbar nur unter der Form der Bildung eines blossen Educts oder Praecipitats sich darstellt, ist. sie

$\mathrm{Dd} 2$ 
nichts desto weniger nicht als eine Reduction im buchstäblichen Sinne des Worts, sondern immer nur als eine durch den künstlich beschleunigten Kreislauf der Metamorphose plötzlich herbeigeführte und eben daher alsdann in der Regel auch nur verkümmert erscheinende Production zu betrachten. Jeder aus einer neutralen Verbindung, künstlich, oder scheinbar freiwillig, erzeugte Niederschlag, der Erfolg einer jeden sogenannten Scheidung oder Zersetzung ist als das Resultat einer solchen unvollkommenen, einseitigen Krystallisation anzusehen; denn in der neutralen Mischung ist das als Educt bezeichnete Quantum nicht mehr als solches enthalten, es ist bereits durch die begonnene Metamorphose ein anderes geworden, und indem es scheinbar als ein ausgeschiedenes hervortritt, ist es nur ein von Neuem erzengtes Product des weiter geführten Kreislaufs der Metamorphose.

Die galvanische Säule ist bereits ein künstlich zusammengesetzter Krystall, jedes Element in ihr ist eine Verbindung derselben Factoren, die sich in der nämlichen Ordnung in allen übrigen Elementen, oder in der Mehrzahl derselben wiederholen, und die Thätigkeit der Säule, ursprünglich angeregt durch den natürlichen chemischen Process, aber modificirt durch die Continuität der polaren Action der Metallfäehen und mächtig gemacht durch das Gesetz und die Zahl der Schichtungen, offenbart sich besonders darin, dass, wo in einem oder mehreren ihrer Elemente Mangel an Uebereinstimmung der Relationen seiner einzelnen Glieder mit dem überwiegenden Polaritätsgesetze des Ganzen gegeben ist, alsbald eine durch das relative Null der Indifferenz hindurch gehende Metamorphose eine dem 
Totalsysteme gemässe Reform beginnt und zu Stande bringt. Jedem einzelnen Elemente ist der Typus seiner Thätigkeit durch das bereits anticipirte Bildungsgesetz des Ganzen vorgeschrieben, und die Form des aus dieser Thätigkeit hervorgehenden Products ist eine endliche, gesonderte, weil die Form des Ganzen nur eine künstliche, relative, endliche und discrete ist. Daher ist zwar in der Säule die Tendenz zur Diremtion in jedem Punkte ihrer Masse vorhanden, aber sie wird nicht in jedem Punkte, sondern nur in jedem einzelnen Elemente und nur auf zwei entgegengesetzten Seiten des letzteren in der Berührungsfläche des Metalls und der Flüssigkeit realisirt; aus der neutralen, chemisch bipolaren Flüssigkeit tritt nur nach der negativen Seite hin der acide und nach der positiven der basische Factor als Repräsentant einer einzigen krystallinischen Durchgangsfläche und nicht öfter hervor. Bei dem chemischen Processe der natürlichen Kette ist dagegen der Entwickelung des Products durch keine äusserliche, künstlich aufgezwungene Gesetzmässigkeit vorgegriffen, die Tendenz zur Differenzirung der Masse wird, wenn anders nur zufällige Störungen beseitigt bleiben, successiv in jedem Punkte angeregt und realisirt und das krystallinische Product, dessen Form bei der künstlichen Säule auf eine endliche Weise anticipirt ist, geht hier erst von Innen als eine vollendete Einheit in lebendiger Mannichfaltigkeit unter einer Unendlichkeit von Differenzen mit unzähligen, nach mehrfachen Richtungen sich durchkreuzenden Durchgangsflächen aus dem Schoosse des Processes hervor.

Wenn auf S. $273 m$ und $r$ als die dem letzten Indifferenzirungspulse des Processes zugehörigen Focal. 
stellen der progressiven Thätigkeit gesetzt werden, so sind $n$ und $v$ die entsprechenden Focalstellen der reagireuden Thätigkeit, und indem mit der letzten Neutralisation in $m$ und $r$ die ganze Masse indifferenzirt ist, so bleibt in den unzähligen, durch $n$ und $v$ repräsentirten, Focalstellen doch noch die leise, unbefriedigte, wenn auch schlummernde, doch keinesweges getilgte Tendenz zurück, vermöge welcher nach der Seite von $s$ hin die Masse als Säure oder als acider Factor, im Gegensatze des letzten Indifferenzirungsmomentes des aciden Factors, und eben so nach der Seite von $a$ hin als Alkali oder als basischer Factor, im Gegensatze des letzten Indifferenzirungsmomentes des basischen Factors, wiederum hervorzutreten strebt.

Diese schlummernde Reaction erwacht früher oder später und macht sich nach einiger Zeit, wie die Reaction einer entladenen elektrischen Flasche, zumal durch zufällige Umstände begünstigt, an einer oder mehreren Stellen geltend. Mit dem Momente aber, in welchem es ihr gelingt, die Realisirung ihrer Tendenz in dem Hervortreten eines unendlich kleinen differenten Quantums des aciden und basischen Factors zu beginnen, ist dieser Act bereits als ein überwiegender mit progressiver Thätigkeit vorhanden; und der Krystallisirungsprocess nimmt einen sichern, mit jedem folgenden Momente immer entschiedener und ausgebreiteter werdenden, Gang an. Die Stellen, in welchen, wie z. B. etwa in $n$ und $v$, das erste Hervortreten der differenten Quanta Statt findet, sind zunächst Focalstellen der progressiven Thätigkeit und mit ihnen zu galvanischen Kreisen geschlossen, gehören nothwendiger Weise eben so viel Stellen, wie etwa $m$ und $r$, als Focalstellen 
einer Reaction zusammen, vermöge welcher nach $s$ hin, dem in $n$ und $v$ frei werdenden aciden Quantum gegenüber, die Tendenz des Freiwerdens eines basischen Quantums in $m$ und $r$, und eben so nach $a$ hin, dem in $n$ und $v$ frei werdenden basischen Quantum gegenüber, die Tendenz zum Freiwerden eines aciden Quantums in $m$ und $r$ sich geltend macht, aber eben damit das wirkliche Freiwerden eines aciden und basischen Quantums von unendlich kleinen Dimensionen in $n$ und $v$ befördert. Nach der vollendeten Realisirung dieses Freiwerdens wirft sich alsdann das Uebergewicht der'Thätigkeit nach $m$ und $r$; diese Stellen werden jetzt zu Focalstellen der progressiven 'Thätigkeit und rufen eben so, wie sie vorhin hervorgerufen wurden, jetzt wieder reagirende Tendenzen in $n$ und $v$ hervor, während sich in $m$ und $r$, so wie anfänglich in $n$ und $v$, ein basisches und acides Quantum von unendlich kleinen Dimensionen, nur jenen in $m$ und $r$ zuvor gebildeten entgegengesetzt gelagert, sondert und ausbildet. Und so schreitet dieser krystallisirende Process, ganz so wie vorhin der neutralisirende, dessen Supplementarseite er einzig und allein nur bildet, unablüssig weiter, von jenem bloss darin unterschieden, dass die frühere Tendenz der reagirenden Seite jetzt zur progressiven Thätigkeit, und die frühere progressive Thäligkeit jetzt zur reagirenden Tendenz geworden ist.

Es ist aber für das bestimmtere Verständniss des Krystallisirungsprocesses ausser dem bisherigen noch ein sehr wesentliches Moment der Beachtung dieses: dass in einem jeden frei werdenden aciden oder basischen Quantum aufs Neue eine untergeordnete Trennung polarer Factoren sich zu wiederholen vermag, die 
abermals in ihrem einen oder beiden secundüren Factoren ein Freiwerden und Auseinandertreten von Factoren des dritten untergeordneten Grades nach sich ziehen kann u. s. f., deren gesetzmässige Lagerung die mannichfaltigen Richtungen in den Durchgängen des Krystalls hervorbringt. Wir sind hier veranlasst, um dieses deutlicher zu machen, den Faden unserer obigen auf Seite 408 abgebrochenen Entwickelung wieder aufzunehmen. Es ist dort bereits bemerkt worden, dass eine jede krystallisirende neutrale Flüssigkeit wenigstens drei indifferente Verbindungen enthalten müsse, nämlich das Oxygen und Hydrogen des Wassers, das Oxygen und Radikal der Süure und das Oxygen und Radical der Base. Aber diese drei Verbindungen können nur dadurch eine neutrale Mischung bilden, dass zwei derselben, nachdem sie sich gegenseitig wie zwei einfache Factoren indifferenzirt haben, abermals als ein gemeinsamer Factor, als ein acides oder basisches der dritten Verbindung gegenüber treten und mit ihr von Neuem ein höheres neutrales Product darstellen. Dieses enthält also im weitern Umfange immer nur zwei Factoren, von denen der eine an und für sich wieder zwei untergeordnete Factoren in sich begreift, und jeder der beiden letzteren, so wie jener das Ganze neutralisirende Factor ist wieder aus den einfachen, als primitiv betrachteten, Factoren zusammengesetzt. Eben so stellt jede aus noch so viel Verbindungen zusammengesetzte neutrale Mischung im weitesten Umfange immer nur einen Dualismus indifferenter Factoren dar, von denen jeder einzelne oder wenigstens der eine derselben wieder einen Dualismus untergeordneter Factoren enthält, die jeder für sich abermals einen solchen Dualismus in 
sich begreifen können, und so fort bis zu den primitiven aciden und basischen Factoren hinab.

Wenn der chemische Process bis zum Neutralisationspunkte gelangt ist, so sind mithin alle jene Gegensätze in einen einzigen allumfassenden aufgenommen, der als der letzte in sich selbst indifferenzirt ist, und alle Gegensätze vom grössesten bis zum kleinsten werden sämmtlich und wie mit einem Schlage in den einzelnen Focalstellen wieder frei, in dem Maasse, in welchem der gemeinsame, allumfassende selbst wieder aus der Indifferenz hervortritt.

Dieses abermalige Hervortreten aus der Indifferenz aber bildet nach der oben gewonnenen Ansicht den Fortschritt der Metamorphose, die, wenn sie auch auf dem Punkte der Neutralisation eine Zeit lang in schwebender Ruhe verweilt hat, dennoch durch den leisesten Ausschlag auf irgend einer Seite aus dem Gleichgewichte gehoben und durch eine zweite Hälfte des begonnerien Kreislaufs wieder hindurch geführt wird. Die schwache Erregung zwischen der Flüssigkeit und den Wänden des Gefässes, oder irgend eines im Innern desselben befindlichen fremdartigen Körpers ist hinreichend, die schlummernde Tendenz zu wecken und eine Thätigkeit anzuregen, mit der sogleich alle Gegensätze erwachen und sich nach den, durch die gemeinsame Gegenthätigkeit aller bestimmten, Durchgangsrichtungen der krystallinischen Bildung, bis in das Innerste gesondert, in der höheren Einheit des Krystalls wiederum offenbaren. Da, wo die zufälligen Erregungen von Aussen her dem Entwickelungsdrange der Metamorphose nicht genügen, treibt der Process von Innen heraus soine Früchte, und 
auf der gemeinsamen, nach entgegengesetzten Seiten mit entgegengesetzter Erregung hervorgerufenen, Basis bildet sich der Zwillingskrystall. Identische oder'symmetrische Punkte jeder Zwillingskrystallisation entsprechen sich wie gleichzeitige Focalstellen der progressiven und reagirenden Thätigkeit des galvanischen Processes überhaupt. Die Neigungswinkel der Durchgangsebenen sind nach der oben S. 406 ff. entwickelten Combination durch die Intensität der chemisch polaren Gegensätze hedingt, diese hängt wiederum zusammen mit dem stöchiometrischen Verhältnisse der Aequivalente der chemischen Factoren, und letzteres ist, wie oben zu zeigen versucht ist, zugleich wieder irgend eine Function von den elektrischen Relationen der einzelnen Glieder der Verbindungen. So erhellt für jetzt wenigstens schon die Möglichkeit, dass aus diesen Momenten in einer zukünftigen Theorie der Krystallisation die bewunderungswürdige Gesetzlichkeit der Bildungen und die constante Beziehung auf gemeinsame Axen sich herleiten und nach ihrer innern Nothwendigkeit alleinlaus jenem einfachen Princip werde demonstriren lassen *).

*) Wie diese Ansichten mit den Erscheinungen der doppelten Strahlenbrechung zusammenhängen, hoffe ich noch an seinem Orte zu zeigen. Im übrigen verwahre ich mich auf das Bestimmteste gegen den etwanigen Vorwurf, dass die obige Deduction einen Atomismus involvire; denn daraus, dass der Process der Krystallisation durch die successive Bildung acider und basischer Quanta, die verschwindende Dimensionen haben und nach der Richtung der Durchgänge begränzt sind, fortschreitet, folgt nicht, dass der Krystall aus einer unzähligen Menge kleiner Primitivkrystalle bestehe, so wenig daraus, dass der Fortschritt einer Linie als eine Bewegung von Punkt zu Punkt Statt findet, hervorgeht, dass die Linie aus einer unbegränzten Anzahl von Punkten zusammengefügt sey. 
Da die Krystallbildung nur Fortsetzung des chemischen Processes ist, und der letztere, so wie der Process einer jeden Kette von magnetischer Erregung unaufhörlich begleitet ist, so muss folglich auch im Erzeugungskreise eines jeden Krystalls der Magnetismus walten; oder er muss vielmehr, unserer Ansicht gemäss, als das eigentlich richtende Element der Bildung angesehen werden. Die anziehende und abstossende Thätigkeit der polaren Tendenzen in den Gegensätzen der einzelnen Verbindungen, auf welcher die verschiedene gegenseitige Neigung der Durchgänge und somit die ganze Gestalt und Eigenthümlichkeit des Krystalls beruht, kann keine elektrische seyn, wie überhaupt die Elektricität im geschlossenen Kreise der Kette schweigt, soudern sie ist eine wahrhaft magnetische. Daher ha-

Diese sogenannten Primitivgestalten sind ja blosse abstracte Begriffe, nichts Reelles, Constituirendes; sie würden als bloss abgeleitete Erzengnisse der Reflexion viel besser Secundär - als Primitivgestalten genannt werden. Wie hat doch eine so grosse Zahl unserer Mineralogen, Chemiker und Physiker noch bei den untergeordneten Vorstellungen des Auslandes stehen bleiben können, nachdem nicht nur längst schon der Gesichtspunkt unserer Philosophie über alle jene atomistische Particularitäten hinausreicht, sondern nachdem auch W eifs, dieser Begründer eines consequenten Systems der Krystallographie, die einfach klare, von einseitigen Molecularvorstellungen gereinigte Grundanschauung des Krystalls schon länger als ein Decennium in aller Bestimmtheit gegeben hat. Die dynamische Ansicht der Krystallisation eben dieses würdigen Naturforschers kann, unter den Modificationen, welche die Zeit und eine tiefer gefasste Bedeutung der Kant'schen Dynamik gelehrt haben, als ein allgemein gültiges Prolegomenon zu jeder kūnftigen Theorie der Krystallgenesis, und folglich auch zu dem, was in dieser Hinsicht hier versucht worden, betrachtet werden, obgleich ich jene Entwürfe erst nach der vollständigen Ausbildung meiner speciellen Ansichten năher kennen gelernt und verglichen habe. 
ben auch, wie es bekannt ist, magnetische Einwirkungen von Aussen wenigstens Einfluss auf die Gruppirungen der Krystallisation im Ganzen, wenn gleich, so viel man bis jetzt weiss, auf die einzelnen Gestalten eben so wenig, so wenig, aus den bereits oben S. $275 \mathrm{ff}$. in Beziehung auf den chemischen Process überhaupt angegebenen Gründen, eine krystallisirende Flüssigkeit eine Ablenkung der Magnetnadel hervorzubringen vermag.

Wenn aber der Krystall als das Product 'des Processes fertig gebildet aus dem Kreise desselben hervorgeht, so stellt er in der zahllosen Menge über einander geschichteter differenter Lamellen eine ungeschlossene galvanische Säule oder eine Mannichfaltigkeit solcher Säulen dar unter einer zugleich höheren, vollendeteren Form von derjenigen, die beim Processe der künstlichen, zusammengesetzten galvanischen Kette in der Menge über einander geschichteter Elemente bereits anticipirt ist, und es ist gewiss, dass an hinlänglich empfindlichen Apparaten die Pole dieser natürlichen ungeschlossenen Säule an und für sich schon eine stete elektrische entgegengesetzte Erregung zeigen müssten, wie sie dieselbe unter dem die Thätigkeit 'erhöhenden Einfluss einer partialen Erwärmung häufig schon der gewöhnlichen Wahrnehmung versichtbaren.

Die tausendfältige elektrische Anziehung tausendfältig verflochtener, sich durchkreuzender Lamellen muss als Princip der Rigidität betrachtet werden. Die Genesis krystallinischer, specifisch differenter Masse stellt sich so zugleich als ein relatives Ziel der galvanischen Naturthätigkeit dar, und sofern die Mannichfaltigkeit der specifisch differenten Masse als die Sphäre eines 
durch Cohüsion bezeichneten Begrifís erfasst wird, so erscheinen die drei Momente der galvanischen Thätigkeit: Elektricität, Chemismus und Magnetismus als Functionen innerhalb des Gebietes einer solchen Cohäsionsthätigkeit, im höhern Sinne des Worts, wozu der unter deutschen, wie auch bei englischen Physikern der Idee und Thatsachen nach bereits früher begründete, von Arago kürzlich verwirklichte Versuch, in welchem der Magnetismus rotirender Körper nachgewiesen wird, einen neuen Beleg liefert.

Die galvanische Trias aber erscheint selbst wieder nur als ein einzelnes untergeordnetes Moment einer höheren, umfassenderen Trias in der allgemeinen $\mathrm{Na}$ turwirksamkeit überhaupt. Das Licht, die Materie und die Schwere sind einerseits die den Momenten der galvanischen Thätigkeit unverkennbar entsprechenden Momente einer universelleren Offenbarungssphäre, deren Centralpunkt die Genesis der Materie schlechthin ist, während andererseits die Irritabilität, die Reproduction und die Sensibilität die Grundmomente aller Erscheinungen im Gebiete der im engern Sinne ausschliesslich als organisch bezeichneten Naturthätigkeit ausmachen. In der Sphäre der einen Trias ist also Genesis der Masse schlechthin, in der der andern ist die Durchbildung der indifferenten Urmasse zur specifischen, individuellen Differenz das Ziel der Wirksamkeit, und in der letzten sehen wir mit den unendlich mannichfaltigen Zeugungs- und Erhaltungsprocessen organischer Individuen die höchste Stufe des Lebens im Kreise der sinnlich wahrnehmbaren Natur realisirt.

Aber jede einfache Trias ist zugleich Abbild und Vorbild der dreifachen, jede einzelne Erscheinung jeg- 
licher Sphäre verkündigt Ziel und Gesetz aller übrigen, und wir erkennen in dem Einzelnen das Ganze, und in dem Ganzen das Einzelne in dem Maasse, in welchem wir selbst, dem eigenen Ziele getreu, das innerste Leben reinigen und befreien, über die Willkühr, die Täuschung und Afterweisheit des gemeinen Bewusstseyns uns zu erheben trachten, und im tiefsten Grunde des Spiegels der sichtbaren Natur durch die hehre Unendlichkeit und Farbenpracht aller seiner Bilder hindurch, frommen Sinnes immer nur die Einheit des heiligen Flammenauges der göttlichen Allmacht und Liebe unaufhörlich suchen und anblicken, mit dessen ewigen, unwandelbaren Strahlen überall dasselbe Leben und dieselbigen Gesetze des Lebens ergossen und erhalten werden. 


\section{D r u ckfe hle r.}

Seite 35. Zeile 13.v.u. lies : o s cillirenden st. os cillirden - 56. - 6. l. verhält st. erhält

- 6o. - 13. v. u. l. nachzuweisen statt: nach-

$$
\mathrm{zu} \text { weissen }
$$

- 69. - 5. v. u. lies: elektromotorische statt: elektrometrische

- 73. - 9. 1. das st. als

- 119. - 7. 1. 105 st. 100

-135 . - 2. v. u. 1 . das st. da

- 140. - 2. 1. Es st. Er.

- 214. - 12. l. alkalische st. elektrische

- 243. - 12. v. u. l. er st. es

- 257. - 4. l. aller st. alle

- 3o6. - 1. l. wirken st. wirke

-326 . - 6. 1. also st. als

- 334. - 1. v. u. 1. logischen st. ogischen

- 340. - 2. 1. vermöchten st. vermöchte

- 580. Dem Anfange der letzten Zeile fehlt ein a

Unbedeutendere Abweichungen bedürfen keiner besonderen Anzeige. Der Verfasser bemerkt nur noch, dass es seiner Schreibart des Deutschen gemäss sei, das y dabei nicht anders, als nur in fremden Wörtern zu brauchen. Das durch den Corrector wieder aufgenommene $\mathrm{y}$ ist daher bei der letzten Revision anfänglich nur, weil es übersehen worden und später der Gleichmässigkeit wegen, im Buche stehen geblieben. 
STL Sächsische Landesbibliothek - 


\section{… Irov. 1983}

24. Oht. 1987

Dieser Band wurde 1997

durch Bestrahlung sterilisiert. Verfärbungen stellen

keine Gefahr dar.

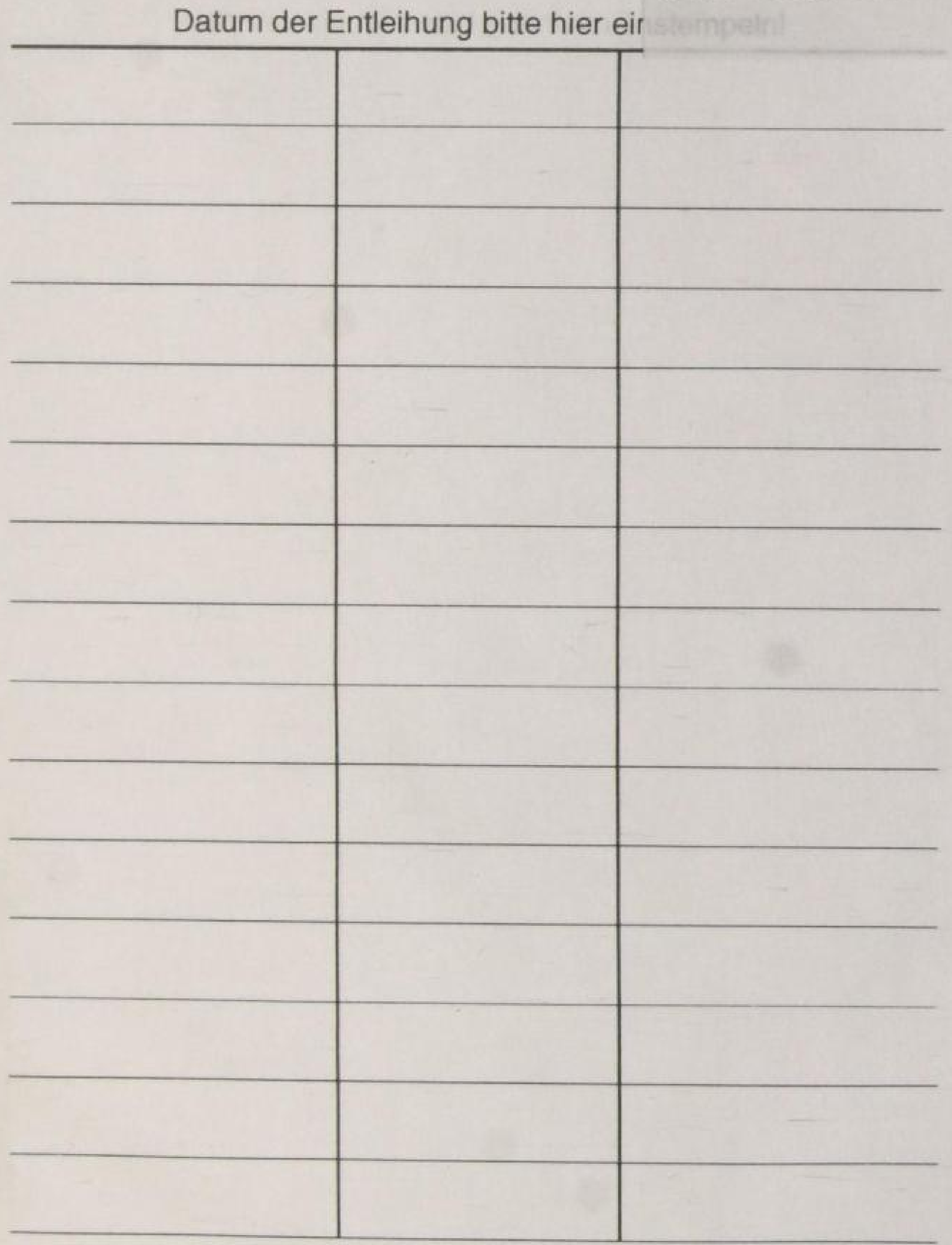

\section{Physica. $\log 5$.}

SL Sachsische Landesbibliothek U]

hitp://digital.slub-dresden.de/ppn338539239/465 


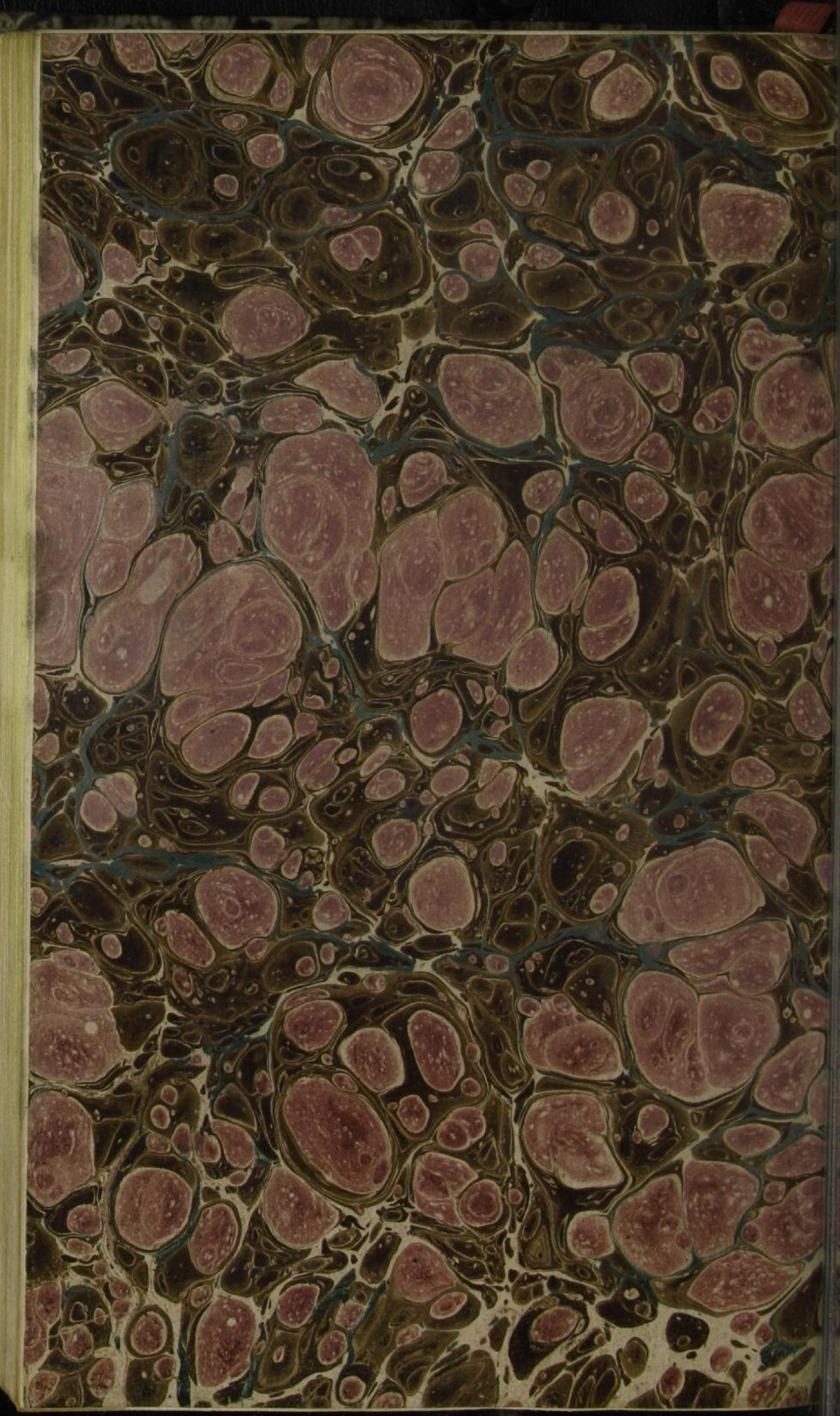

. 


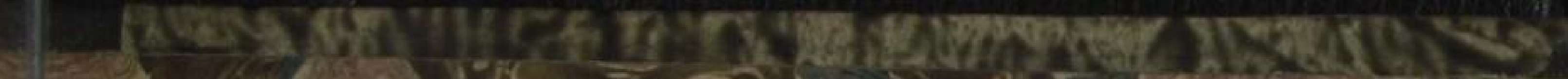
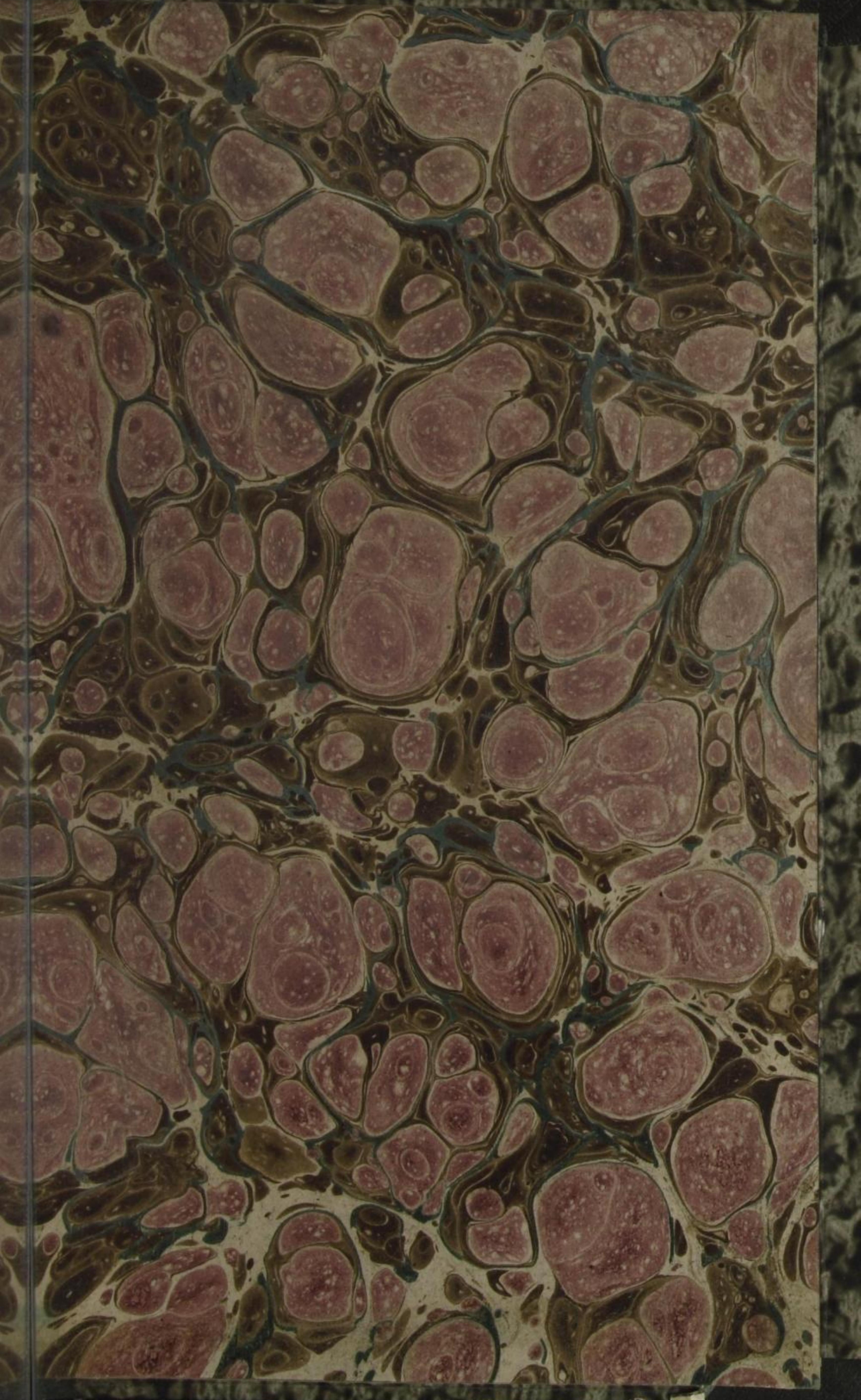


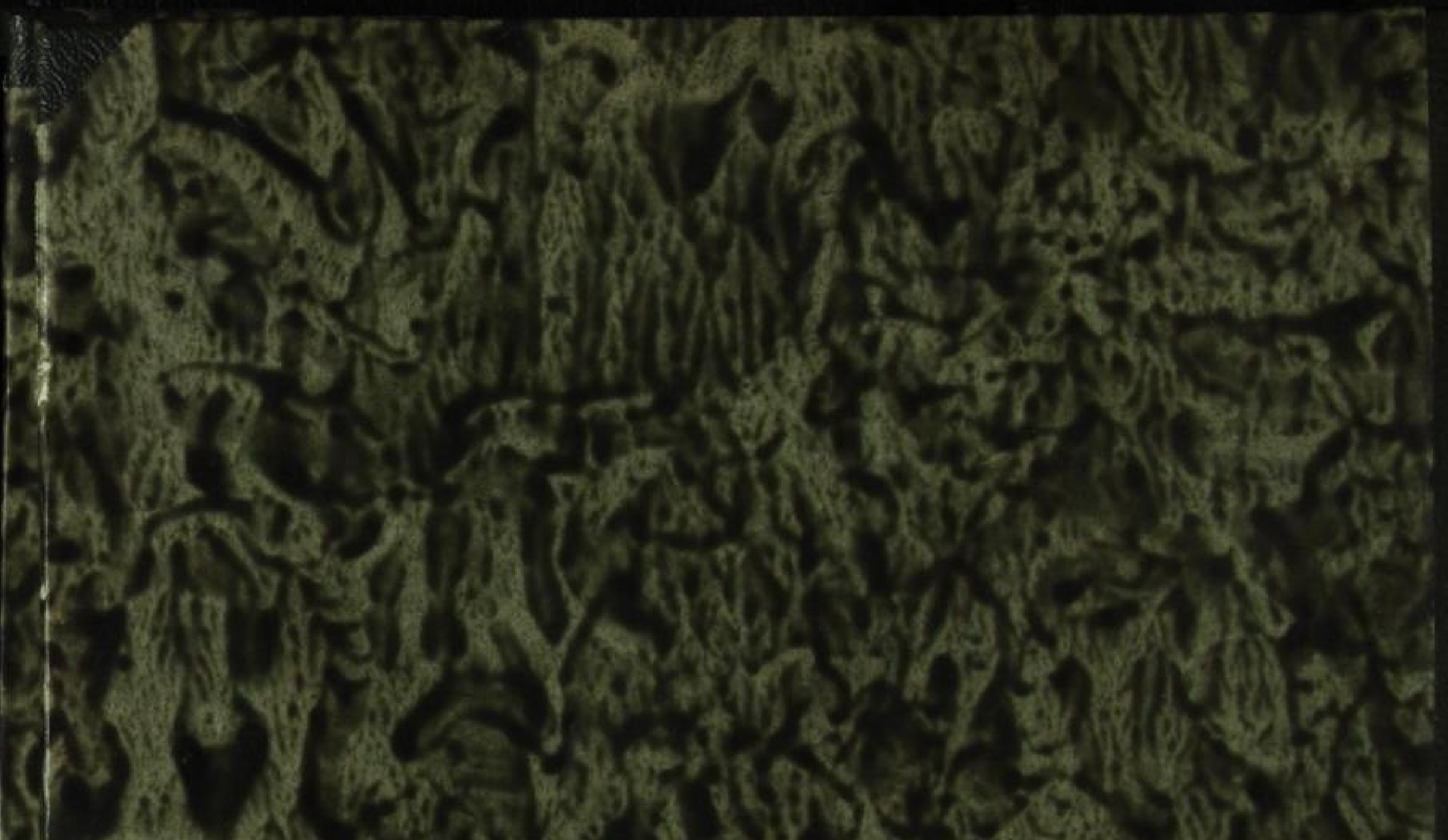

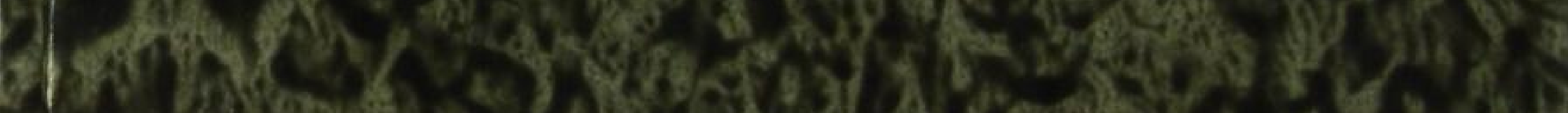

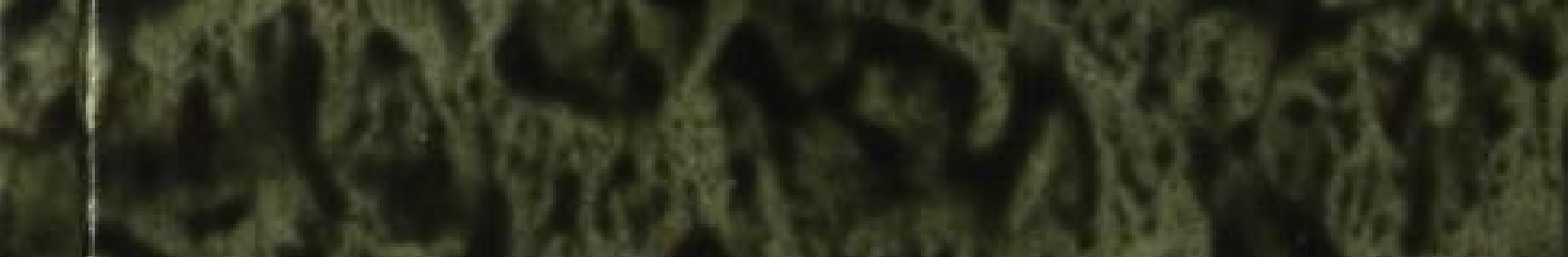

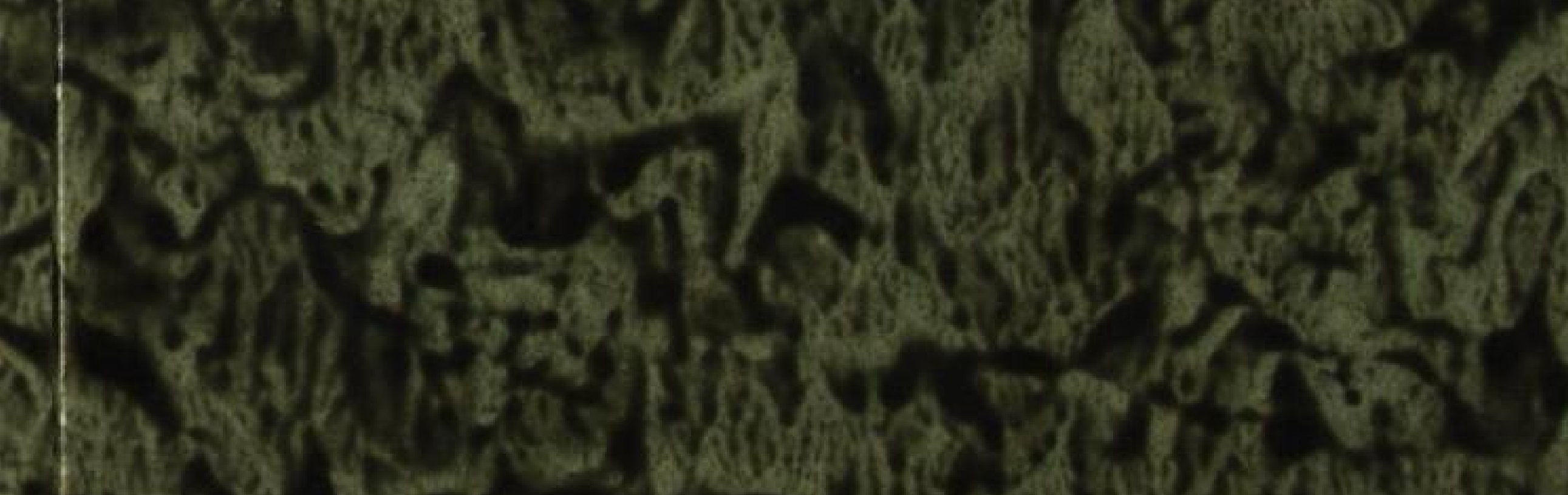

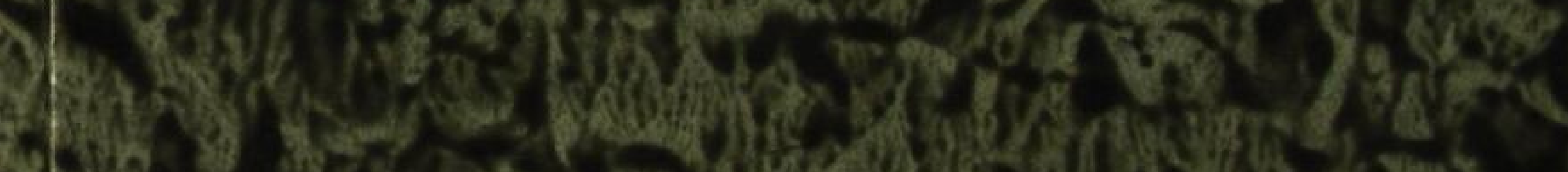

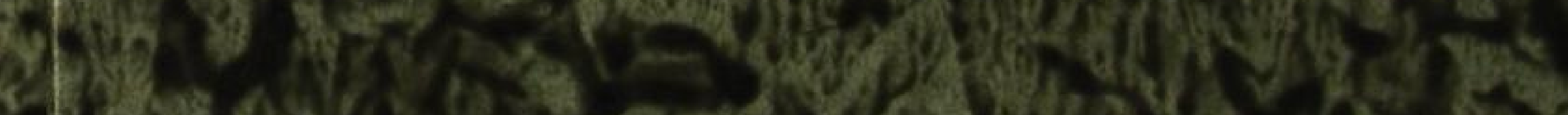
(1)

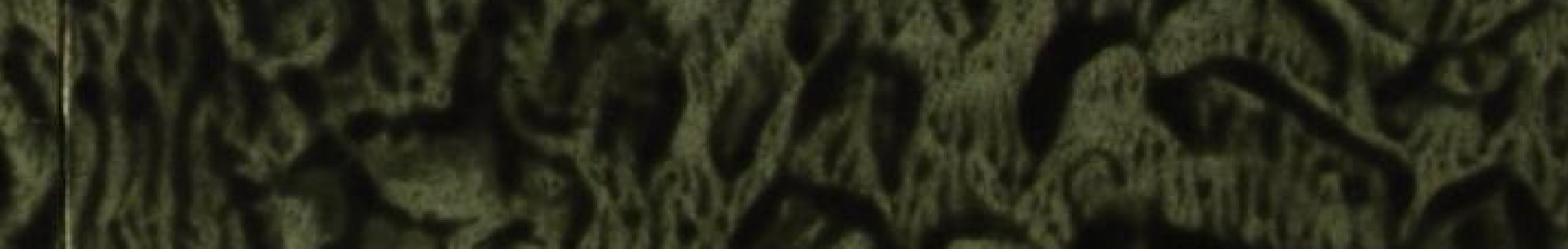

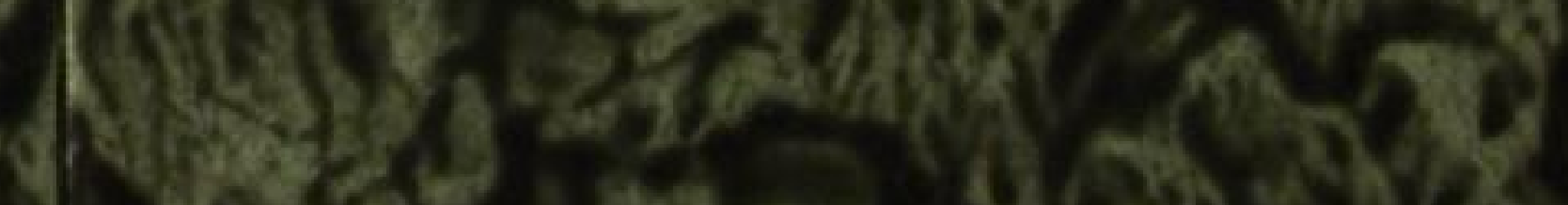

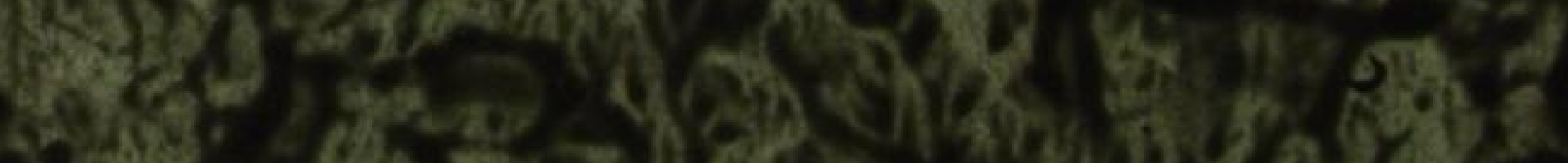
What a

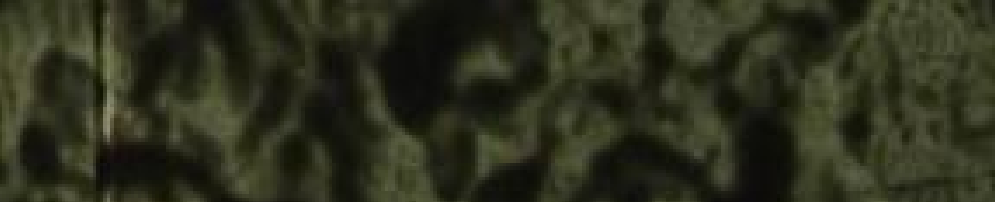
(W. f.

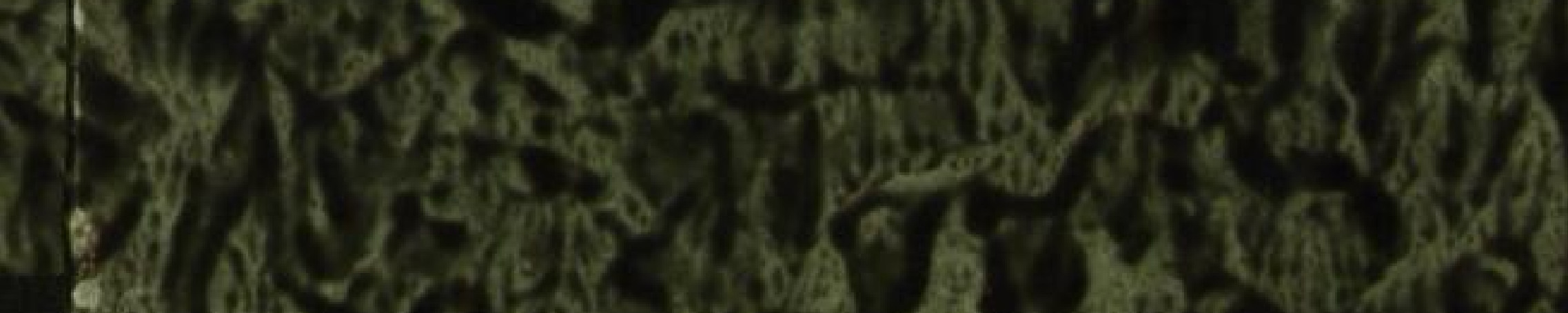

efing

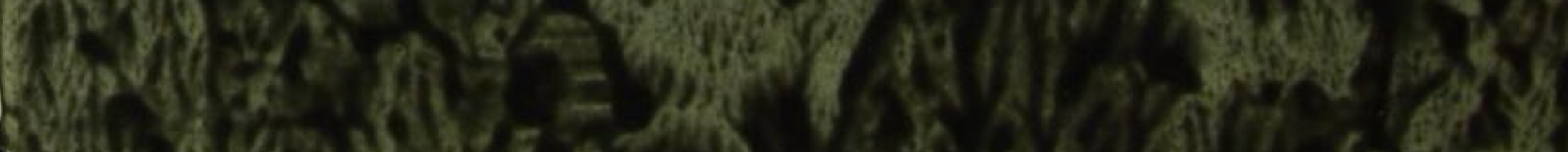

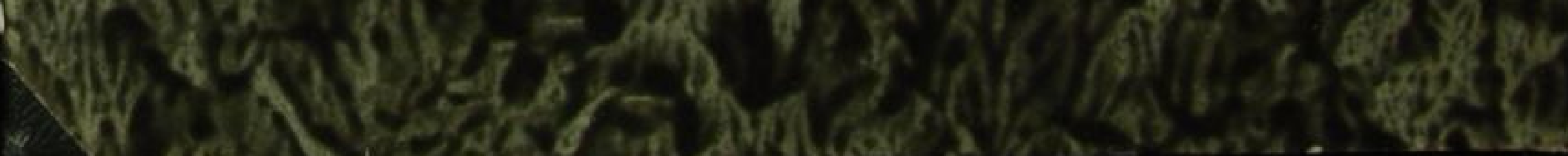

